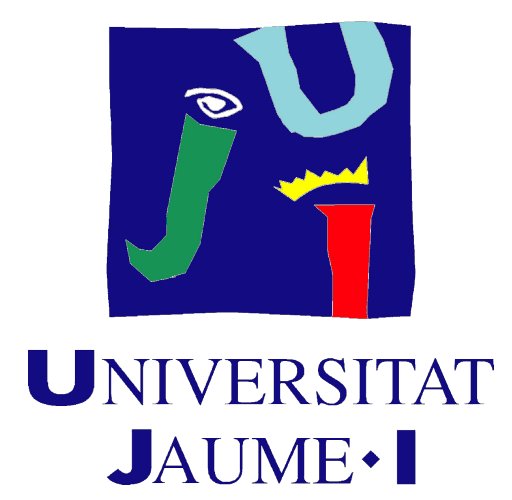

\title{
A Multimodal Approach to Metadiscourse as an
} Organizational Tool in Lectures

PhD dissertation presented by Edgar Bernad-Mechó

Supervised by:

Prof. Inmaculada Fortanet-Gómez

January, 2018 



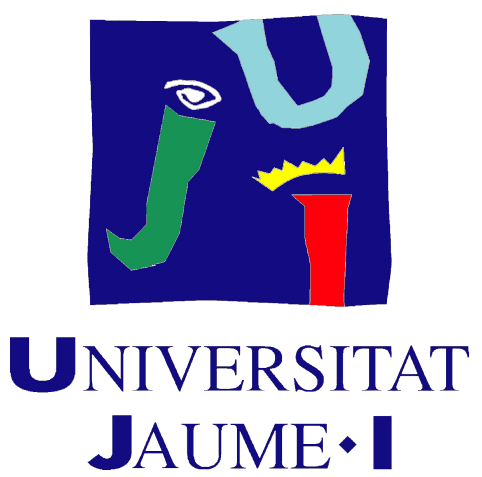

Programa de Doctorat en Llengües Aplicades, Literatura i Traducció

Escola de Doctorat de la Universitat Jaume I

\section{A MULTIMODAL APPROACH TO METADISCOURSE AS AN ORGANIZATIONAL TOOL IN LECTURES}

Memòria presentada per Edgar Bernad-Mechó per optar al grau de doctor per la Universitat Jaume I.

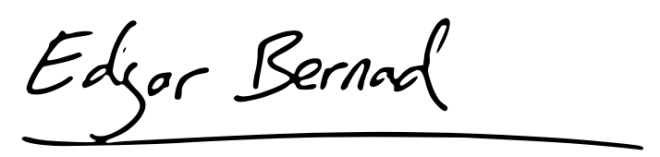

Edgar Bernad-Mechó

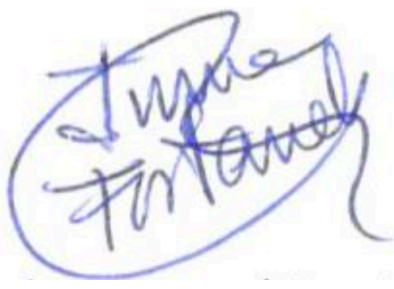

Dirigida per: Inmaculada Fortanet-Gómez 



\section{ACKNOWLEDGEMENT OF FUNDING}

My work in this thesis has been supported by Universitat Jaume I through a pre-doctoral scholarship (ref: PREDOC/2013/49). Furthermore, two research stays were conducted during the development of this study which contributed to establishing the methodological approach in my analysis. The first one, at the Multimodal Research Centre (Auckland University of Technology, New Zealand) was funded by Universitat Jaume I (ref: E-201612). The second one, at the Multimodal Analysis Group (Curtin University, Australia) was co-funded by Universitat Jaume I and BP Oil (ref: CON/288/133/2017 - Codi 16743). To these entities, I am ever grateful for their support. 



\section{ACKNOWLEDGEMENTS}

First and foremost, I would like to take this opportunity to express my immense gratitude to my supervisor, Prof. Inmaculada Fortanet-Gómez, for her wise guidance and valuable contributions that assisted me in each step to complete this thesis. Her constant encouragement at a personal level gave me the strength to walk this path to the end.

I am profoundly indebted to Prof. Sigrid Norris and Prof. Kay O'Halloran for allowing me to spend some time as an adjunct research fellow at their respective research centers and for their valuable academic input that shaped the methodological approach in this thesis.

I would also like to thank my colleagues in the GRAPE (Group for Research on Academic and Professional English) for sharing with me their expertise, knowledge and friendship, and for their words of encouragement.

Likewise, I would like to extend thanks to my family and friends for their utter support and understanding. They have served as a continuous reminder of the essential things in life outside academia.

Last but not least, I would like to show my appreciation to Andrea, who has borne with me with patience throughout the ups and downs of the writing process. 



\section{RESUMEN}

Esta tesis explora el uso del metadiscurso organizativo en clases universitarias desde una perspectiva multimodal. El metadiscurso organizativo es una herramienta que se emplea con frecuencia en clases universitarias para indicar el cauce que toma la clase, establecer conexiones entre los contenidos que están siendo desarrollados, y facilitar la comprensión de los estudiantes. Sin embargo, la mayoría de los análisis sobre metadiscurso se han llevado a cabo desde una perspectiva puramente lingüística. En esta tesis, sugiero que el metadiscurso organizativo se transmite a través de la combinación de múltiples modos en conjuntos multimodales (multimodal ensembles). Así pues, describiré el metadiscurso en tres niveles de análisis: cuantitativo, lingüístico y multimodal. En este sentido, mi estudio contribuye a expandir investigaciones previas sobre metadiscurso y ofrece una visión holística de sus usos en clases universitarias. Para terminar, sugiero que el uso del metadiscurso organizativo, tanto a nivel lingüístico como a nivel no verbal, está influenciado por el estilo de enseñanza elegido por los profesores (conversacional, retórico o de lectura).

El objetivo principal de este estudio es doble. Por un lado, este estudio intenta expandir el conocimiento sobre los géneros académicos hablados y para ello, examino el metadiscurso organizativo desde una perspectiva multimodal y teniendo en cuenta los estilos de enseñanza como variable clave que afecta al uso del mismo. En este sentido, estoy interesado en explorar no solo lo que se dice (metadiscurso verbal), sino también la manera en la que se dice, es decir, a través de una combinación de modos específica. Por otro lado, es mi intención validar la metodología utilizada en esta tesis y que se basa en una combinación de enfoques cuantitativos, lingüísticos y multimodales. En esta línea, la metodología multimodal ideada para esta tesis es especialmente novedosa, ya que combina conceptos y herramientas de tres marcos de análisis multimodal (Multimodal Social Semiotics, Multimodal Discourse Analysis, and Multimodal Interaction Analysis). 
Así pues, el estudio presentado en esta tesis está basado en las siguientes preguntas:

1. ¿Cómo se usa el metadiscurso organizativo desde un punto de vista cuantitativo en las clases universitarias?

2. ¿Cómo se expresa el metadiscurso organizativo verbalmente?

3. ¿Cómo se expresa el metadiscurso organizativo desde un punto de vista no verbal?

4. ¿Cómo contribuye el metadiscurso organizativo en el proceso de estructuración de las clases universitarias?

Esta tesis se divide en 9 capítulos. Los tres primeros capítulos describen algunas nociones sobre el análisis del discurso, el análisis de los géneros, la multimodalidad y el metadiscurso que definen el marco teórico para mi investigación. El capítulo 4 tiene en cuenta estos conceptos teóricos para diseñar una metodología para el estudio del metadiscurso organizativo en clases universitarias. A continuación, los capítulos del 5 al 8 describen y comentan los análisis realizados en esta tesis (un análisis cuantitativo, un análisis lingüístico, un análisis multimodal del uso de los recursos semióticos, y un análisis multimodal de cómo los profesores estructuran el discurso organizativo en secuencias de acciones). Finalmente, el capítulo 9 presenta algunas conclusiones, sugiere aplicaciones pedagógicas y reflexiona sobre las limitaciones del estudio a la vez que plantea posibilidades para próximas investigaciones.

Para contestar a las preguntas planteadas anteriormente, he recopilado un corpus de 6 cursos universitarios completos en el campo de las humanidades (dos por cada estilo de enseñanza), con un total de 152 clases. Este corpus se ha extraído del OpenCourseWare de la Yale University (un conjunto de materiales de diversos cursos universitarios disponibles en la red). Además, he definido dos sub-corpus: un corpus de 6 clases representativas (una por curso), y un corpus de 6 segmentos estructurales (structuring segments) (uno por curso), es decir, secciones con una alta frecuencia de elementos metadiscursivos. El corpus principal se ha utilizado en el análisis cuantitativo que da respuesta a la pregunta 1. El subcorpus de 6 clases representativas se ha utilizado para examinar el uso del metadiscurso desde un punto de vista lingüístico (pregunta 2) y siguiendo un enfoque desde Multimodal 
Interaction Analysis para examinar las estructuras en las secuencias de acciones llevadas a cabo por los profesores (pregunta 4). Por último, el sub-corpus de los segmentos estructurales ha sido anotado multimodalmente y analizado para descubrir cómo se expresa el metadiscurso desde una perspectiva no verbal (pregunta 3).

El análisis cuantitativo llevado a cabo para contestar a la primera pregunta demuestra que las categorías de previewing y reviewing son las más recurrentes en el uso de metadiscurso organizativo en clases universitarias. Además, el metadiscurso organizativo parece concentrarse al principio de las clases, y al principio y al final de los cursos. Adicionalmente, se pueden observar ciertas similitudes en el uso total del metadiscurso organizativo dentro de cada uno de los estilos de enseñanza. Finalmente, el análisis cuantitativo ha permitido limitar el alcance de los análisis de esta tesis al centrarse solamente en aquellos usos recurrentes y representativos del metadiscurso.

Respecto a la segunda pregunta, he identificado una serie de tipos y sub-tipos sintácticos que parecen repetirse en el uso del metadiscurso organizativo. Además, algunos componentes léxicos, como el uso de verbos de comunicación y mentales, aparecen en una alta frecuencia como elementos de entrada del metadiscurso. Aún así, las diferencias entre estilos de enseñanza son mínimas desde un punto de vista lingüístico y se limitan a una mayor frecuencia en el uso del pronombre 'we' en clases universitarias leídas.

Acerca de la tercera pregunta, el análisis multimodal de los recursos semióticos demuestra que, a parte del modo verbal, los gestos, la mirada, la postura, la proxémica y el paralenguaje se usan frecuentemente en los segmentos estructurales. Además, se puede observar que el metadiscurso (modo verbal) se combina con otros modos en conjuntos multimodales. Respecto a la influencia de los estilos de enseñanza, los resultados señalan a una cierta limitación en la disponibilidad de los recursos semióticos que parece estar relacionada con éstos. Por ejemplo, el uso de algunos modos como los gestos y la mirada parece estar limitado en aquellos profesores que dependen en una alta medida de sus notas (especialmente los profesores que leen sus clases). En esta línea, las diferencias a través de los estilos de enseñanza son evidentes y este análisis contribuye a definir a los estilos de enseñanza según los recursos semióticos utilizados. 
Finalmente, respecto a la cuarta pregunta, los resultados muestran como los profesores indican la organización de las sesiones en secuencias de acciones. En este sentido, se pueden encontrar claras diferencias en los estilos de enseñanza: los profesores de un estilo conversacional realizan acciones en las que se desarrolla contenido y que se funden en acciones organizativas que sirven como elementos separadores entre temas; los profesores de un estilo retórico organizan secuencias largas de acciones en las que se desarrolla contenido y que pueden ocasionalmente ser interrumpidas por acciones de organización; y los profesores de un estilo de lectura alternan acciones leídas con acciones espontáneas. Finalmente, el análisis de las secuencias de acciones realizadas por los profesores muestra dos roles principales en el uso del metadiscurso: un rol activo cuando el metadiscurso se utiliza en un primer plano para indicar la orientación de la clase, establecer conexiones, etc.; y un rol pasivo cuando el metadiscurso se usa en un plano medio y sirve para rellenar el modo verbal. 


\section{ABSTRACT}

This thesis explores the uses of organizational metadiscourse in lectures from a multimodal perspective. Organizational metadiscourse is a tool that is often employed in lectures to signal the directions of the lecture, to establish connections across the contents being developed, and to facilitate the comprehension of the students. However, most analyses of metadiscourse have been conducted only from a linguistic perspective. In this thesis, I argue that organizational metadiscourse is conveyed through the combination of multiple modes in multimodal ensembles. Thus, I look at metadiscourse in three different levels of analysis: a quantitative, a linguistic and a multimodal one. In this regard, my study contributes to expanding previous research on metadiscourse and offers a holistic view on its uses in lectures. Finally, I suggest that the use of organizational metadiscourse, both at a linguistic and at a non-verbal level, is influenced by the lecturing style chosen by the lecturers (conversational, rhetorical or reading styles).

The ultimate aim of this study is twofold. On the one hand, I intend to expand the knowledge of spoken academic genres by looking at organizational metadiscourse from a multimodal perspective while considering lecturing styles as a key variable that influences its use. In this sense, I am interested in exploring not only what is said (verbal metadiscourse), but also how it is said, i.e. through which particular combinations of modes. On the other hand, I aim to validate the methodology employed in this thesis that is based on the combination of quantitative, linguistic and multimodal approaches. In this line, the multimodal methodology devised in this thesis is particularly novel, as it combines concepts and tools from three multimodal frameworks (Multimodal Social Semiotics, Multimodal Discourse Analysis, and Multimodal Interaction Analysis).

Thus, the study presented in this thesis is based on the following research questions:

RQ 1. How is organizational metadiscourse used quantitatively in academic lectures?

RQ 2. How is organizational metadiscourse expressed verbally? 
RQ 3. How is organizational metadiscourse expressed non-verbally?

RQ 4. How does organizational metadiscourse contribute to the structuring process of the lectures?

This thesis is structured in 9 chapters. Chapters 1 to 3 discuss some notions on discourse analysis, genre analysis, multimodality and metadiscourse, which define the theoretical framework for my research. Next, Chapter 4 considers these theoretical concepts to devise a methodology for the study of organizational metadiscourse in lectures. Then, chapters 5 to 8 describe and discuss the various analyses conducted (a quantitative analysis, a linguistic analysis, a multimodal analysis of the use of semiotic resources, and a multimodal analysis of the process in which lecturers structure speech as sequences of actions). Finally, Chapter 9 provides some conclusions, suggests pedagogical applications, and reflects upon the limitations of the study while identifying possibilities for further research.

In order to answer the research questions presented above, I have compiled a corpus of 6 full courses in Humanities (two courses per lecturing style), which are made up of 152 lectures. These lectures have been extracted from Yale University's OpenCourseWare (a compilation of lectures and educational materials from various university courses that is available online). Two sub-corpora were then created: a corpus of six representative lectures (one per course), and a corpus of six structuring segments (one per course), i.e. sections with a high frequency of metadiscursive instances. The main corpus has served as the basis for a quantitative analysis to discuss RQ1. The sub-corpus of six representative lectures has been inspected from a linguistic perspective (RQ2) and using a Multimodal Interaction Analysis approach to look at the structuring sequences of actions performed by the lecturers (RQ4). Finally, the sub-corpus of six structuring segments has been multimodally annotated and analyzed to discern how metadiscourse is expressed from a non-verbal perspective (RQ3).

The quantitative study conducted to respond to my first research question has identified previewing and reviewing as the most recurrent categories of organizational metadiscourse in lectures. Moreover, organizational metadiscourse seems to be more frequent at the beginnings of the lectures and both at the beginnings and endings of the courses. In 
addition, some similarities arise within each of the lecturing styles in terms of the total amount of organizational metadiscourse employed in the lectures. This quantitative analysis has served to narrow down the scope of analysis by focusing on those recurrent and representative uses of metadiscourse.

Concerning my second research question, a series of syntactic types and subtypes have been identified as recurrent patterns in the use of organizational metadiscourse. Furthermore, some lexical choices, such as the use of communication and mental verbs, have also been spotted in a high frequency as being used to proclaim metadiscourse. Nevertheless, the differences across lecturing styles are minimal from a linguistic point of view and they come down to a higher frequency in the use of 'we' pronouns in reading style lectures.

Regarding my third research question, the multimodal analysis of semiotic resources reveals that, apart from the verbal mode, gestures, gaze, posture, proxemics and paralanguage are frequently used in structuring segments. Besides, metadiscourse has been found as co-occurring with several of these modes in multimodal ensembles. As for the influence of lecturing styles, the results point to a constraint of certain lecturing styles over the availability of these resources. For example, the use of some modes like gestures or gaze seems to be limited in lecturers who depend highly on their notes (especially, reading style lecturers). In this line, differences across lecturing styles are evident and this analysis contributes to defining lecturing styles in terms of the use of semiotic resources.

Finally, as for my fourth research question, the findings show how lecturers signal the organization of the lecture in sequences of actions. In this regard, key differences are found across lecturing styles: in conversational style lectures content-developing actions merge into organizational ones that serve as separating elements between topics; rhetorical style lectures are often organized in long sequences of content-developing actions that might occasionally be interrupted by organizational ones; and reading style lectures alternate reading and spontaneous actions. Finally, the exploration of the sequences of actions performed by the lecturers has revealed two main roles for metadiscourse: an active one when metadiscourse is used in the foreground to signal the direction of the lecture, 
establish connections, etc.; and a passive role when metadiscourse is used in the midground and serves as a verbal filler of the verbal mode. 


\section{TABLE OF CONTENTS}

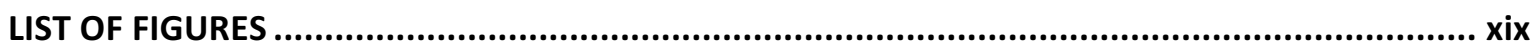

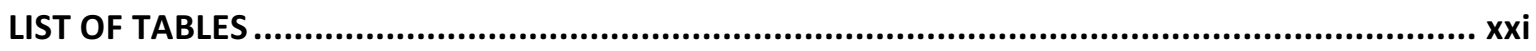

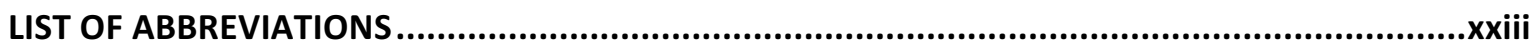

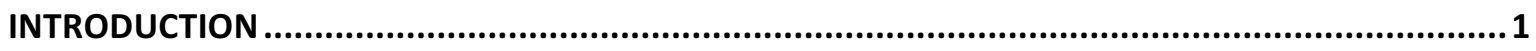

CHAPTER 1. DISCOURSE ANALYSIS AND THE GENRE OF THE LECTURE .....................................9

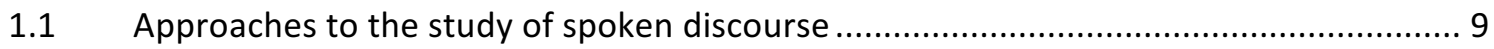

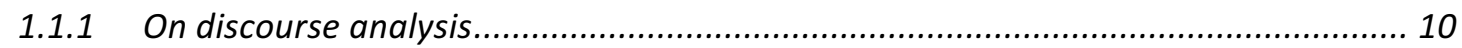

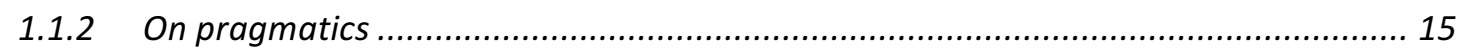

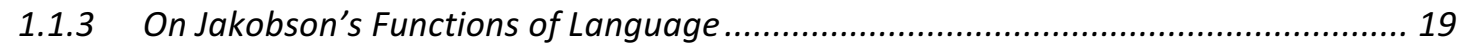

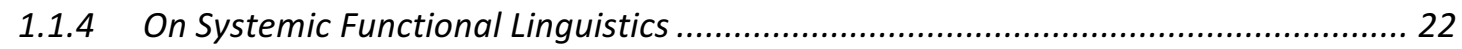

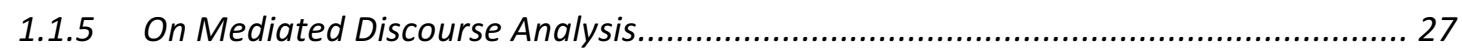

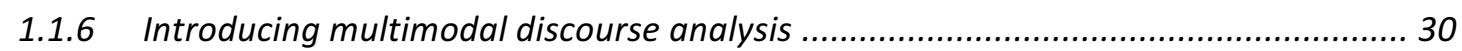

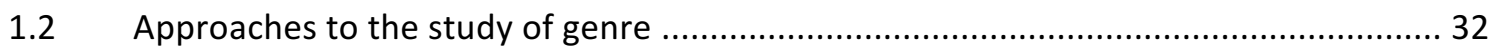

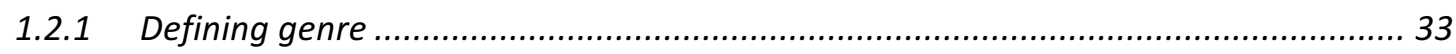

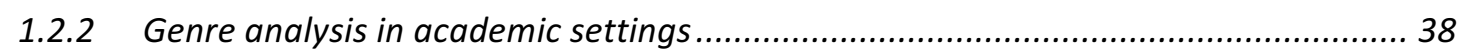

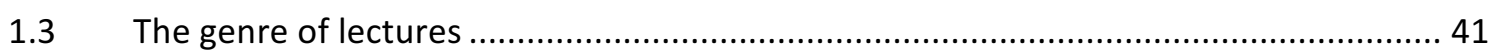

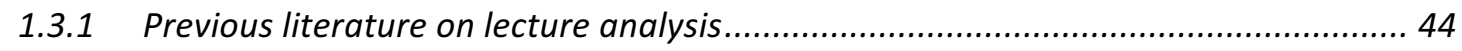

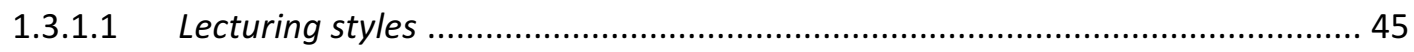

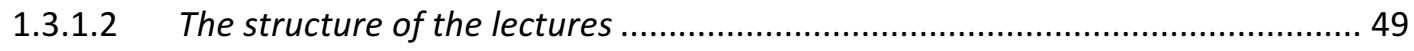

1.3.2 Multimodal studies on lectures ......................................................................... 58

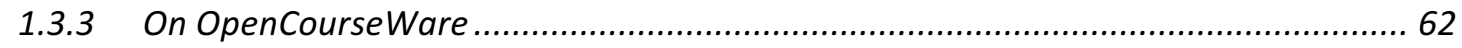

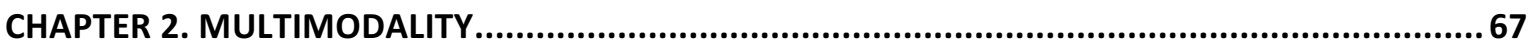

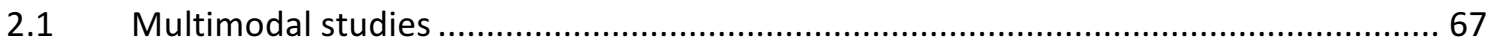

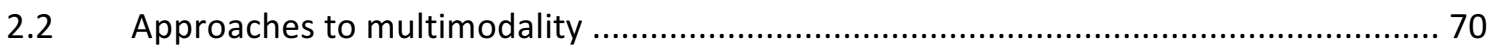

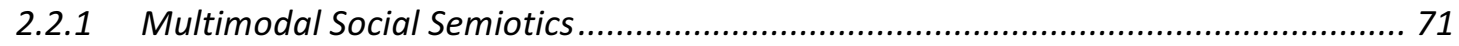

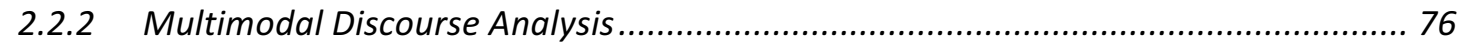

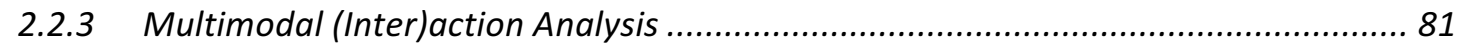

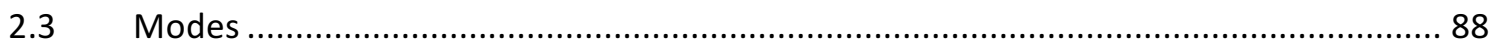

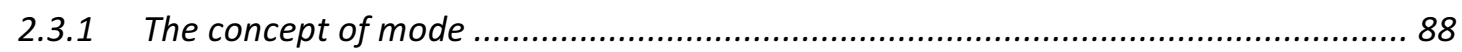


2.3.2 Previous research on modes 89

2.4 Multimodal transcription and multimodal annotation tools ................................ 105

2.4.1 On multimodal transcription .................................................................... 105

2.4.2 On multimodal annotation tools ............................................................. 108

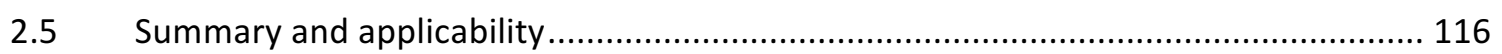

CHAPTER 3. METADISCOURSE.............................................................................. 119

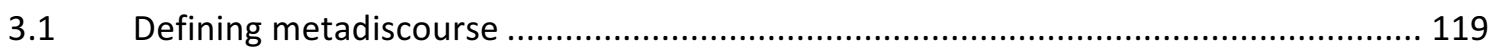

3.2 Approaches towards metadiscourse.............................................................. 125

3.2.1 Vande Kopple's model ................................................................... 125

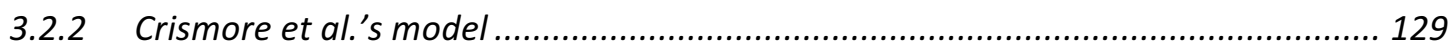

3.2.3 Hyland's model ................................................................................ 133

3.2.4 Ädel's model (The reflexive model) ........................................................ 137

3.3 Metadiscourse in spoken academic discourse ............................................ 152

3.3.1 A turn towards spoken language. Metadiscourse in lectures............................. 152

3.3.2 Metadiscourse and multimodality .................................................... 157

\section{CHAPTER 4. DRAWING FROM THEORY FOR A MULTIMODAL ANALYSIS OF ORGANIZATIONAL}

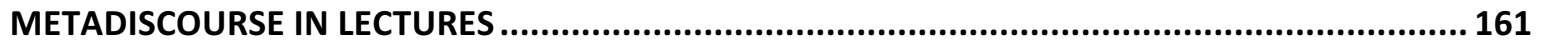

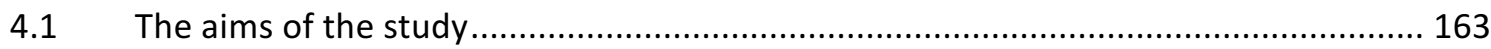

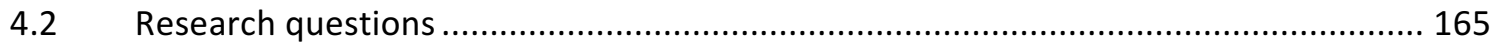

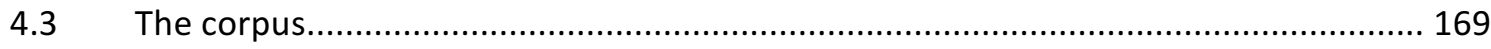

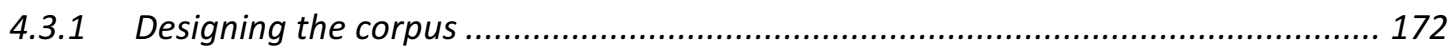

4.3.2 Description of the corpus ..................................................................... 178

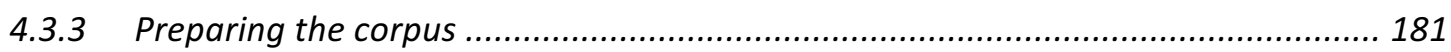

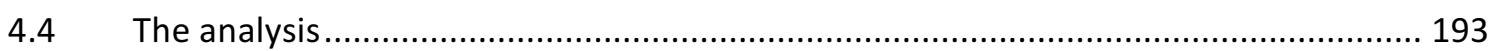

4.4.1 The quantitative analysis .................................................................. 193

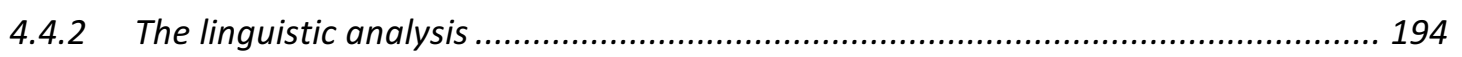

4.4.3 The analysis of the semiotic resources........................................................... 196

4.4.4 The analysis of structure and the role of organizational metadiscourse ................ 198

CHAPTER 5. ANALYSIS: A QUANTITATIVE STUDY ........................................................ 201

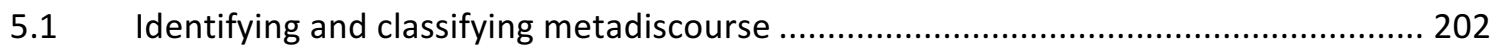

5.1.1 Issues in the identification of metadiscourse: what is and what is not metadiscourse 203

5.1.2 Issues in the identification of metadiscourse: overlapping categories - double

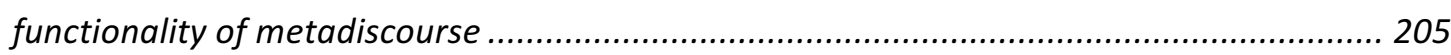


5.2 Quantitative use of organizational metadiscourse across disciplines 206

5.2.1 Overall use of organizational metadiscourse ..................................................... 206

5.2.2 The case of endophoric marking - A lecturer-dependent category ........................ 209

5.2.3 Comparing uses of organizational metadiscourse without endophoric markers .... 211

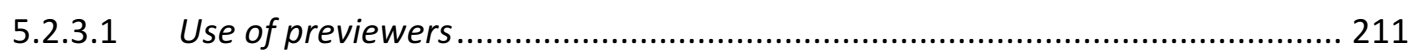

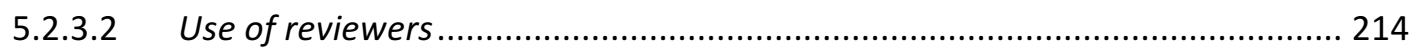

5.2.3.3 Previewers and reviewers in percentages ................................................. 216

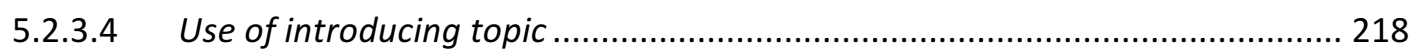

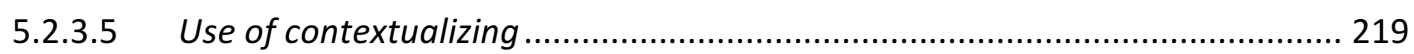

5.3 Distribution of organizational metadiscourse in the lectures and through the courses.... 220

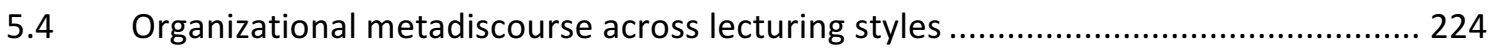

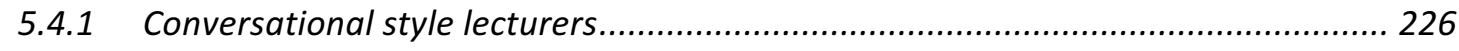

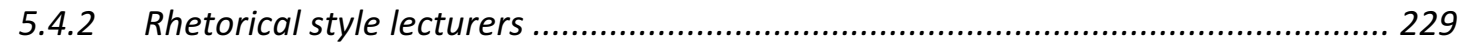

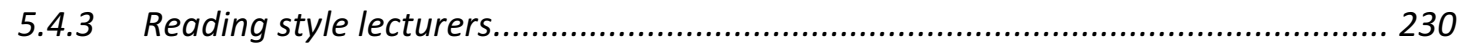

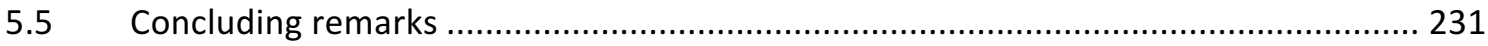

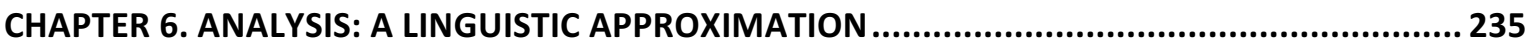

6.1 Syntactic structure in the use of organizational metadiscourse ................................... 236

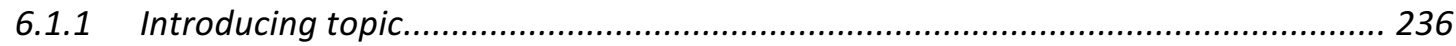

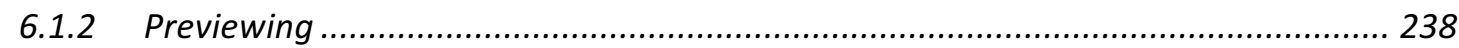

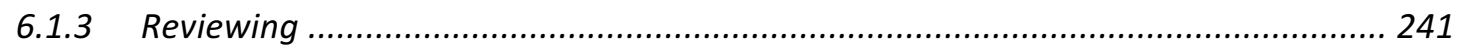

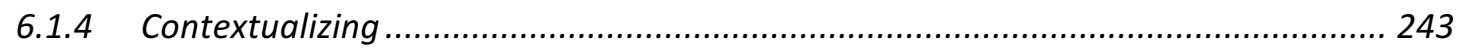

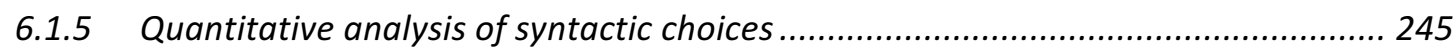

6.2 Lexical choices in the use of organizational metadiscourse ...................................... 246

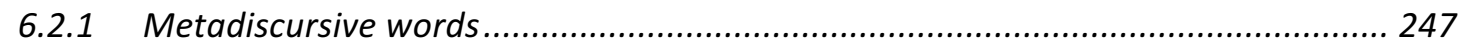

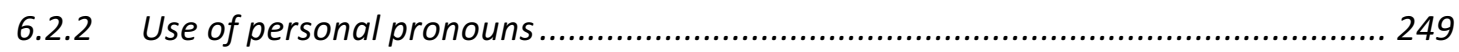

6.3 Linguistic expression of organizational metadiscourse across lecturing styles ........... 252

CHAPTER 7. MULTIMODAL ANALYSIS: EXAMINING SEMIOTIC RESOURCES..............................255

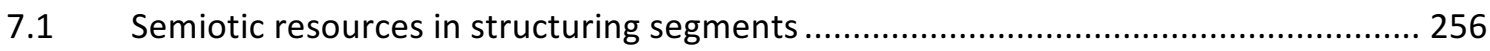

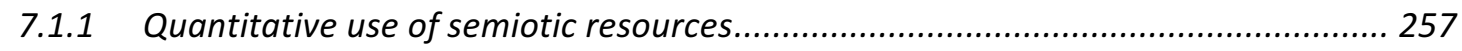

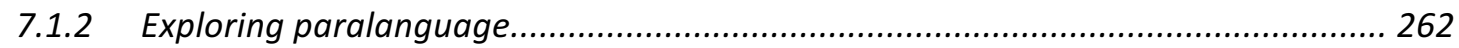

7.2 Combining semiotic resources in multimodal ensembles .......................................... 266

7.2.1 Multimodal ensembles in conversational style lectures .........................................2.267

7.2.2 Multimodal ensembles in rhetorical style lectures ............................................. 272 
7.2.3 Multimodal ensembles in reading style lectures .................................................. 276

7.2.4 Modal density as constrained by the lecturing styles .......................................... 280

CHAPTER 8. MULTIMODAL ANALYSIS: AN MIA APPROACH TO STRUCTURE.............................283

8.1 Addressing higher-level actions. On the structure of lectures.................................... 284

8.1.1 Prototypical structures in conversational style lectures ...................................... 285

8.1.2 Prototypical structures in rhetorical style lectures ............................................... 288

8.1.3 Prototypical structures in reading style lectures..................................................... 290

8.2 Examining the role of metadiscourse within sequences of actions ............................. 291

8.2.1 The role of metadiscourse in structuring segments .............................................. 292

8.2.1.1 Active role. Metadiscourse in the foreground …......................................... 293

8.2.1.2 Passive role. Metadiscourse in the midground ............................................. 298

8.2.2 The role of metadiscourse in spontaneous instances ............................................ 302

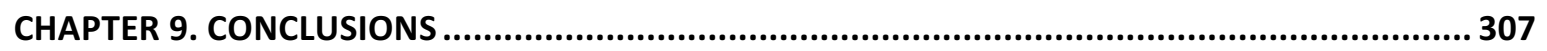

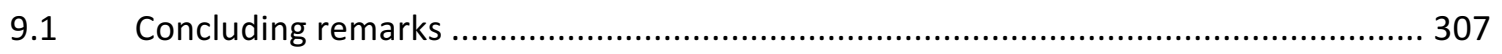

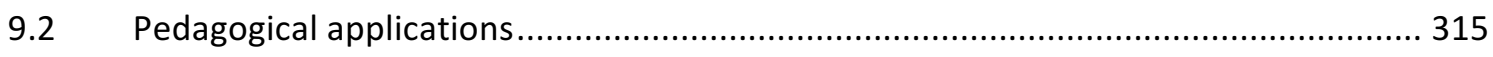

9.3 Limitations of the study and suggestions for further research ................................... 316

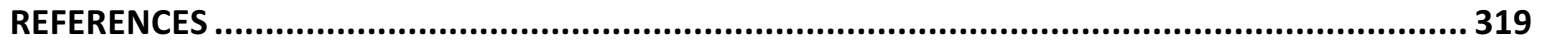

APPENDICES

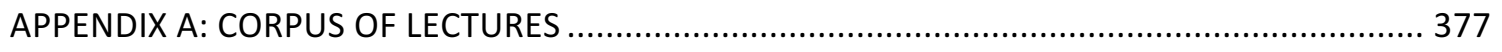

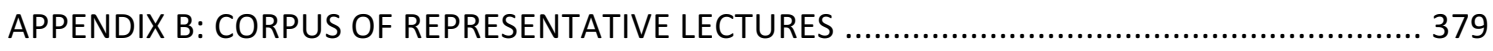

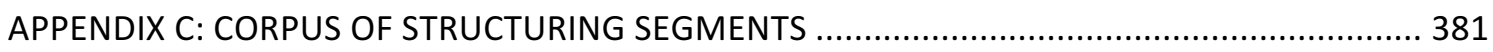




\section{LIST OF FIGURES}

Figure 1.1 Jakobson's factors involved in verbal communication (Jakobson, 1960, p. 353) ........................ 19

Figure 1.2 Jakobson's Functions of Language. Edited from Jakobson $(1960$, p. 357) ............................... 21

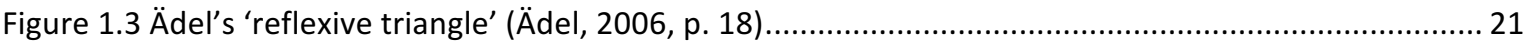

Figure 1.4 Stratification of language in SFL. Adapted from Halliday and Matthiessen (2014, p. 26) ............. 23

Figure 1.5 Classification of spoken academic genres according to their purpose. Adapted from Fortanet's

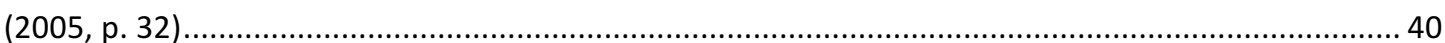

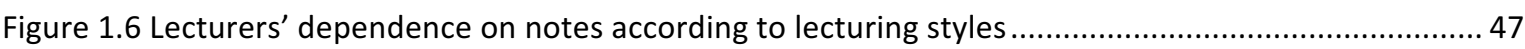

Figure 1.7 Thompson's (1994) functions and sub-functions in lecture introductions............................... 56

Figure 2.1Modal density foreground-background continuum of attention/awareness (Norris, 2004, p. 99 ) 84

Figure 2.2 Modal configuration for a moment when a lecturer is organizing their notes 87

Figure 2.3 a) Text-based multimodal transcription (Baldry \& Thibault, 2006, Appendix I, I); and b) Image-

based multimodal transcription (Norris, 2006, p. 405) .......................................................... 107

Figure 2.4 ELAN screenshot -extracted from Bernad-Mechó $(2015$, p. 63) ............................................ 110

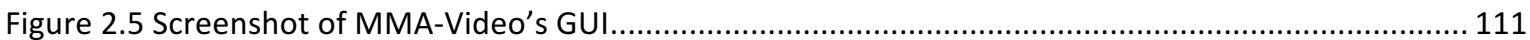

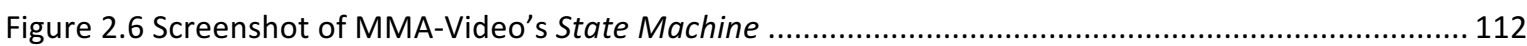

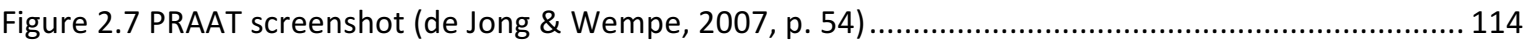

Figure 2.8 pYin analysis in Sonic Visualiser (Bernad-Mechó, 2017a, p. 52) .......................................... 115

Figure 4.1 Conventions for verbal transcription (adapted from various sources: Norris, 2004; Pirini, 2015;

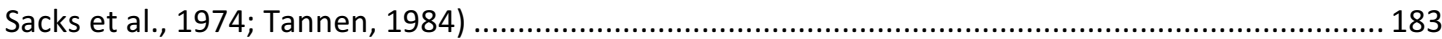

Figure 4.2 Example multimodal transcription -extracted from Bernad-Mechó (2017a) ........................... 185

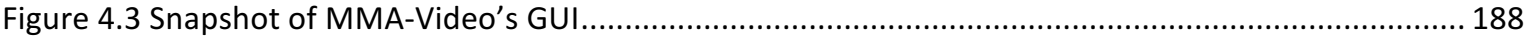

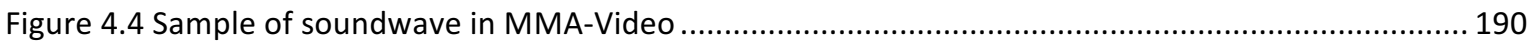

Figure 4.5 Framework for the multimodal annotation ............................................................................ 192

Figure 4.6 Analysis of multimodal ensembles using MMA-Video's General User Interface ....................... 197

Figure 5.1 Distribution of metadiscourse along C1: total amounts (a), previewing (b) and reviewing (c) .... 222

Figure 5.2 Average distribution of metadiscourse per minute in the lectures in C4..................................223

Figure 5.3 Distribution of metadiscourse per minute across lecture C2_L13 ......................................... 224

Figure 7.1 Use of intonation as an indicator of the separation of sections in C1..................................263

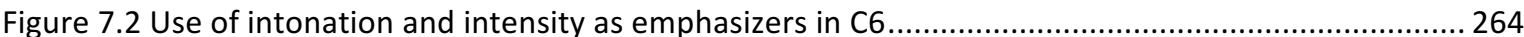


Figure 7.3 Ensemble 1 (Reviewing metadiscourse in C1) 269

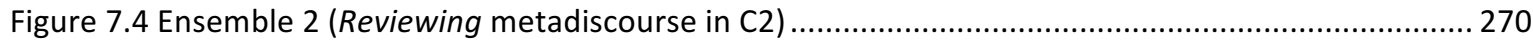

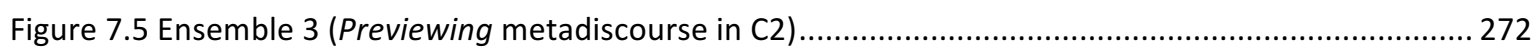

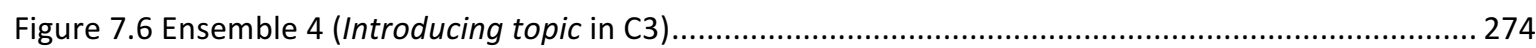

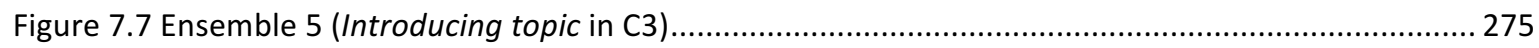

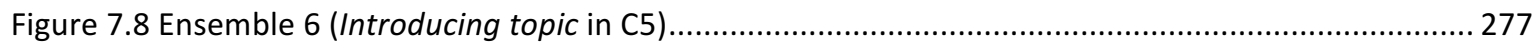

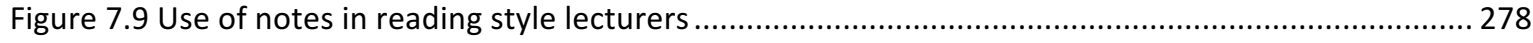

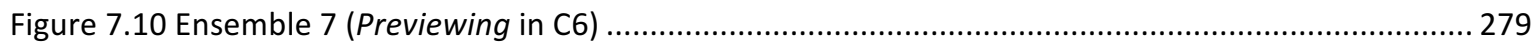

Figure 7.11 Modal density in the use of organizational metadiscourse across lecturing styles. Adapted from

Bernad-Mechó and Fortanet-Gómez (forthcoming). 282

Figure 8.1 Prototypical sequence of higher-level actions in conversational style lecturers ...................... 286

Figure 8.2 Prototypical sequence of higher-level actions in rhetorical style lecturers ...............................289

Figure 8.3 Prototypical sequence of higher-level actions in reading style lecturers..................................291

Figure 8.4 Succession of higher-level actions in a structuring segment in C3_L15 .................................... 295

Figure 8.5 Succession of higher-level actions across the foreground-background continuum................... 297

Figure 8.6 Succession of higher-level actions in a structuring segment in C4_L13 ................................. 299

Figure 8.7 Succession of higher-level actions across the foreground-background continuum.................... 301

Figure 8.8 Succession of higher-level actions in spontaneous metadiscourse in C6_L15 .......................... 303

Figure 8.9 Succession of higher-level actions across the foreground-background continuum................... 305 


\section{LIST OF TABLES}

Table 1.1 Phasal analysis -following Young (1994)- in the introduction to lecture C6_L15 (my corpus)....... 54

Table 2.1 Intonation in DI. Systems and choices (Brazil, 1997, p. vii) 102

Table 2.2 A comparison of the emphasis of approaches to multimodality Adapted from Jewitt (2014, p. 39)

Table 3.1 Vande Kopple's (1985) model of metadiscourse 126

Table 3.2 Crismore et al.'s (1993) model of metadiscourse 131

Table 3.3 Hyland's (2005) model of metadiscourse

Table 3.4 Ädel's (2006) model of metadiscourse

Table 3.5 Ädel's (2010) taxonomy of metadiscourse in academic English (spoken and written) 147

Table 4.1 Overview of the size of the main corpus 179

Table 4.2 Description of the sub-corpus of representative lectures 180

Table 4.3 Description of the sub-corpus of structuring segments

Table 5.1 Frequency of the use of metadiscourse across disciplines (raw and normalized frequencies) and total amounts of metadiscursive instances

Table 5.2 Instances of previewing metadiscourse across disciplines (raw and normalized frequencies) ..... 212

Table 5.3 Average types of previewing occurrences....

Table 5.4 Instances of reviewing metadiscourse across disciplines 214

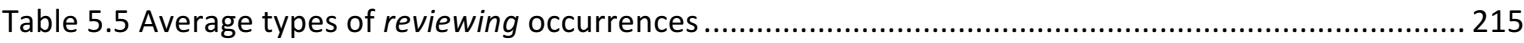

Table 5.6 Percentage in the use of metadiscourse over total use (excluding endophoric marking)............ 216

Table 5.7 Frequency of the use of topic managers across disciplines (raw and normalized frequencies) .... 218

Table 5.8 Frequency of the use of contextualizing metadiscourse across disciplines (raw and normalized frequencies)

Table 5.9 Total use of organizational metadiscourse excluding endophoric marking

Table 5.10 Comparison of the use of organizational metadiscourse in conversational style lecturers

Table 5.11 Comparison of the use of organizational metadiscourse in C1 and reading style lecturers..

Table 5.12 Comparison of the use of organizational metadiscourse in rhetorical style lecturers 229

Table 5.13 Comparison of the use of organizational metadiscourse in reading style lecturers 230

Table 6.1 Syntactic types and subtypes for introducing topic. 
Table 6.2 Syntactic types and subtypes for previewing 240

Table 6.3 Syntactic types and subtypes for reviewing .......

Table 6.4 Syntactic types and subtypes for contextualizing 244

Table 6.5 Number of instances and percentage of use of syntactic types and subtypes...

Table 6.6 Percentages of the use of personal pronouns across disciplines 250

Table 7.1 Quantitative use of semiotic resources in structuring segments (percentages over total duration of the fragment) 259

Table 7.2 Defining uses of semiotic resources across lecturing styles 266 


\section{LIST OF ABBREVIATIONS}

GRAPE: Group for Research on Academic and Professional English

SFL: Systemic Functional Linguistics

MSS: Multimodal Social Semiotics

MDA: Multimodal Discourse Analysis

SF-MDA: Systemic Functional - Multimodal Discourse Analysis

MIA: Multimodal (Inter)action Analysis

EAP: English for Academic Purposes

ESP: English for Specific Purposes

MIT: Massachusetts Institute of Technology

EFL: English as a Foreign Language

OCW: OpenCourseWare

MOOC: Massive Online Open Course

OCW-S: Social OpenCourseWare

MMA-Video: Multimodal Analysis-Video

DI: Discourse Intonation

FACS: Facial Action Coding System

DRS: Digital Replay System

ELAN: EUDICO Linguistic Annotator 
MPI: Max Planck Institute for Psycholinguistics

GUI: Graphical User Interface

pYin: Probabilistic YIN

MICASE: Michigan Corpus of Academic Spoken English 


\section{INTRODUCTION}

This thesis explores the use of organizational metadiscourse in lectures from a multimodal perspective, taking into account the linguistic and non-verbal elements that combine to convey organizational meaning. As I discuss in Chapter 3, metadiscourse is a linguistic category that is often used as an organizational device in lectures, which contributes to easing the comprehension of the audience by signaling the directions of the lecture, establishing connections within the lectures and throughout the courses, etc. However, metadiscourse has traditionally been looked at from a linguistic perspective in written genres. In this sense, previous research on metadiscourse in spoken academic genres is rather limited. Even more limited are the studies that look at metadiscourse as an element of communication that is conveyed through the combination of multiple modes. Against this background, I argue that organizational metadiscourse occurs as a verbal element taking part in a complex multimodal ensemble where several layers of meaning may be identified. Furthermore, when considering metadiscourse as an organizational element employed in lectures, I claim that the lecturing style chosen by a given lecturer constrains the ways in which such metadiscourse is conveyed.

As a junior lecturer, I commonly reflect about the strategies that I employ in my lectures in order to make the organizational and structural processes evident to the audience. In this sense, I believe that the learning process may be improved by clearly establishing connections among the distinct sections in the lectures and by signaling the directions towards which the explanation is addressed. In other words, an appropriate use of organizational metadiscourse seems to contribute to ease the comprehension of the students. Still, metadiscursive functions have traditionally been only explored from a linguistic perspective. In this regard, I argue that a larger all-inclusive analysis that considers not only linguistic traits, but also non-verbal and structural aspects of metadiscourse would contribute to expanding the knowledge of how metadiscourse works in academic genres. The motivation for this study is then twofold. On the one hand, I intend to look at metadiscourse as a multimodal element that is used in combination with several other 
modes capable of conveying meaning. It is precisely this combination of semiotic resources the main element that is capable of transmitting organizational meaning to the audience. On the other hand, the analysis of how metadiscourse works at all levels will provide valuable pedagogical results that might be applied to improving the lecturing practices in higher education. Furthermore, I intend to explore how distinct types of lecturers use metadiscourse differently and how this may affect the conveyance of meaning. As a final motivation, the results obtained in this study might contribute to overcoming the fears of junior lecturers when facing higher education lecturing for the first times.

The methodology employed in my research has been heavily influenced by two research internships that I conducted at the Multimodal Research Centre (Auckland University of Technology, New Zealand) and at the Multimodal Analysis Group (Curtin University, Australia), under the supervision of Prof. Sigrid Norris and Prof. Kay O'Halloran respectively. These researchers, as I detail in Chapter 2, have carried out pioneering research in the development of multimodal approaches to discourse, resulting in the creation of a series of theoretical and methodological tools for the multimodal analysis. In this regard, instead of choosing one method or the other, in this thesis, I have combined both methodologies -together with some concepts from Multimodal Social Semiotics- in order to obtain a wider perspective of the use of organizational metadiscourse.

Thus, the present thesis aims to explore the use of organizational metadiscourse beyond linguistic approaches and considering a multiplicity of modes in the meaning-making process. In order to do that, I look at how organizational metadiscourse is used in a corpus made up of six full university courses with a total amount of 152 lectures. In this study, I aim to discern how this type of metadiscursive instances are produced differently in distinct levels of analysis: a quantitative, a linguistic and a multimodal one. Besides, I intend to look into how the choices in the lecturing styles of the lecturers affect the use of organizational metadiscourse. Ultimately, this thesis suggests a novel combination of methodological frameworks to approach the study of metadiscourse holistically. The results outlined in this study may then be used for pedagogical applications or serve as the starting point of further research on metadiscourse. 
My study is guided by the following research questions:

RQ 1. How is organizational metadiscourse used quantitatively in academic lectures?

RQ 2. How is organizational metadiscourse expressed verbally?

RQ 3. How is organizational metadiscourse expressed non-verbally?

RQ 4. How does organizational metadiscourse contribute to the structuring process of the lectures?

The present thesis is structured in nine chapters. The first three chapters devise the theoretical framework that sets the ground for this study, including approaches to the study of spoken discourse (Chapter 1), multimodality (Chapter 2), and metadiscourse (Chapter 3). Next, Chapter 4 reviews the methodological approach employed in the analysis. Once the methodology has been described, the following four chapters include the empirical study: a quantitative study of metadiscourse (Chapter 5), a linguistic study (Chapter 6), a multimodal analysis of the semiotic resources used in lectures (Chapter 7), and a Multimodal (Inter)action approach to the structure of lectures (Chapter 8). Finally, Chapter 9 concludes this thesis by providing some concluding remarks, pedagogical applications, a reflection on the limitations of the study, and suggestions for further research.

Chapter 1 explores discourse analysis and genre analysis (with a special focus on the genre of the lecture) as the theoretical frameworks for the study of lectures. Section 1.1 in this chapter reviews some of the theoretical concepts that set the basis to understand the development of research in the study of metadiscourse and multimodality. Thus, the approaches towards discourse analysis -see, for instance, Paltridge (2005)- and pragmatics (Austin, 1962; Grice, 1975; Searle, 1969) make suitable tools to understand the linguistic aspects of the use of metadiscourse in lectures. Next, the review of Jakobson's functions of language (Jakobson, 1960) is necessary to understand the development of Ädel's (2006, 2010) reflexive model of metadiscourse described in Chapter 3. Besides, the study of Systemic Functional Linguistics (Halliday, 1985, 1994; Halliday \& Matthiessen, 2014) sheds light on the examination of the speakers' linguistic choices, and serves as the starting point 
of traditional approaches to metadiscourse (Crismore, Markkanen, \& Steffensen, 1993; Vande Kopple, 1985), as well as O'Halloran's (2004a, 2007) framework for multimodal studies (Multimodal Discourse Analysis). Finally, Section 1.1 concludes with a review of Mediated Discourse Analysis (Scollon, 1998, 2001; Scollon \& Scollon, 2004) and the multimodal analysis of discourse (Kress \& van Leeuwen, 2001; Norris, 2004; O'Halloran, 2004a), which serve as the theoretical basis for the development of the multimodal frameworks devised in Chapter 2. The second part of Chapter 1, Section 1.2, focuses on the notion of genre (Bhatia, 1993; Fortanet-Gómez, 2005; Swales, 1990) and explores genre analysis trends in academic settings. Finally, the last part of the chapter, Section 1.3, zooms in on the genre of lectures and reviews some of the previous literature on lecture analysis. A special focus is placed in this section on studies on lecturing styles (Dudley-Evans, 1994; Northedge \& McArthur, 2009), and the structure of the lectures (Thompson, 1994; Young, 1994). This section concludes with a short review of the most relevant studies in the analysis of lectures from a multimodal perspective, and a brief mention of OpenCourseWare, as the lectures utilized in this thesis have been extracted from Yale University's OpenCourseWare.

Chapter 2 pays attention to multimodality, and it is divided into five broad sections. In Section 2.1, I provide a general overview of the concept of multimodality and the different approaches that have tackled the issue from varied backgrounds. These approaches are looked at in detail in Section 2.2. In particular, I review Multimodal Social Semiotics (Kress, 2000; Kress \& van Leeuwen, 2001; van Leeuwen, 2005), Multimodal Discourse Analysis (O'Halloran, 2004a, 2007), and Multimodal (Inter)action Analysis (Norris, 2004, 2011). These models are reviewed in terms of the theoretical and methodological tools provided, while emphasizing the points in common and the divergences among them. This reflection sets the path for Section 2.3 in which I review the concept of mode as understood from the different frameworks towards multimodality, and I go through some of the previous literature in the study of the modes that are analyzed in this thesis. Specifically, I focus on the research conducted in the modes of gesture, gaze, head movement, posture, paralanguage, proxemics and facial expression. Next, Section 2.4 is devoted to two of the methodological issues commonly referred to when conducting multimodal analyses: the multimodal transcription, and the use of multimodal annotation tools. This section 
explores the conventions in the transcription of verbal and non-verbal data as well as some of the widely employed annotation tools, in particular, MMA-Video and Sonic Visualiser. Chapter 2 concludes with a summarizing section that focuses on the applicability of the concepts reviewed in this chapter to the study of metadiscourse in lectures.

Chapter 3 is devoted to metadiscourse and is organized in three main sections. Section 3.1 reviews the concept of metadiscourse by going through some of the definitions of the term. After reflecting upon the common ground in most definitions of metadiscourse, Section 3.2 describes some of the most influential models in the last decades: Vande Kopple's model (Vande Kopple, 1985), Crismore et al.'s model (Crismore et al., 1993), Hyland's model (Hyland, 2005), and Ädel's reflexive model (Ädel, 2006, 2010). Special emphasis is placed on the latter, as it is the model that will be used in order to identify and classify metadiscourse in this study. Finally, in Section 3.3, I conclude the chapter by reviewing a list of relevant studies of metadiscourse both in lectures and from a multimodal point of view.

After having reviewed the previous literature that sets the theoretical framework for this thesis, Chapter 4 outlines the methodology employed in the present study. In the first part of this chapter, I state the aims of the study and I elaborate the research questions that guide this study (sections 4.1 and 4.2 respectively). Next, in Section 4.3, I describe the main corpus of lectures employed for the quantitative analysis, and the sub-corpora of representative lectures employed in the linguistic and multimodal analyses. In this section, I also describe the process of assembling and preparing the corpus for the various analyses carried out. Finally, in Section 4.4, I describe the analyses carried out in this study by going through the processes conducted when exploring the data from the quantitative, linguistic and multimodal points of view.

Chapter 5 presents the results obtained by taking a look at the data from a quantitative perspective. In this chapter, I reflect upon some issues encountered when identifying and classifying the data (Section 5.1); I inspect the most recurrent types of organizational metadiscourse in Section 5.2; I establish common patterns in the distribution of metadiscourse both within the lectures and throughout the courses in Section 5.3; I 
compare the quantitative uses of metadiscourse across lecturing styles in Section 5.4; and I conclude the chapter in Section 5.5 by offering some concluding remarks on the findings obtained at a quantitative level.

The second chapter in the analytical part of the thesis, Chapter 6, focuses on the linguistic aspects of organizational metadiscourse. In this regard, in the first part of the chapter, Section 6.1, I look into the syntactic structures found in the metadiscursive uses explored across lecturing styles. Furthermore, I look at the recurrences in the syntactic structures from a quantitative point of view. The second part of the chapter is devoted to the exploration of the lexical choices that proclaim metadiscourse (Section 6.2). In particular, I look at recurrent metadiscursive words and the use of personal pronouns. Finally, In Section 6.3 , I conclude the chapter by looking at the most important similarities and differences spotted in the comparative study of lecturing styles.

Next, Chapter 7 is devoted to the multimodal analysis of the semiotic resources employed by the lecturers using Multimodal Social Semiotics and Multimodal Discourse Analysis. This chapter is divided into two main sections: in the first part, Section 7.1, I analyze how lecturers employ semiotic resources recurrently when conveying metadiscursive meaning. Then, in Section 7.2, I look into how these semiotic resources are used jointly to create multimodal ensembles; furthermore, I compare the creation of multimodal ensembles in the different lecturing styles considered for this study. Finally, I conclude the chapter by discussing how the modal density in the use of metadiscourse is constrained by the availability of choices in the lecturing styles.

The last analytical chapter in the present study is Chapter 8 . In this chapter, I outline a novel approach to the study of structures in lectures. In this sense, in Section 8.1, I describe how organizational fragments are structured as sequences of actions and how lecturers following distinct lecturing styles create different prototypical structures when organizing the lectures. Then, in Section 8.2, I look into the roles played by organizational metadiscourse; in particular, I compare active roles where metadiscourse is used as a signaling device that informs the audience about the directions and contents of the lecture, and passive roles in which metadiscourse is used as a verbal filler. 
Finally, in Chapter 9, I draw some general concluding remarks on the findings of this thesis. Moreover, I suggest some pedagogical applications, and I reflect upon the limitations encountered in this study while outlining lines of work for future research. 



\section{CHAPTER 1. DISCOURSE ANALYSIS AND THE GENRE OF THE LECTURE}

The present thesis provides a multimodal approach to the study of metadiscourse as an organizational tool for lecturers. This chapter, together with Chapter 2 -in which the notion of multimodality is explored in detail- and Chapter 3 -devoted to metadiscourse-, aims to discuss the main theoretical frameworks that lay the ground for the methodology applied in my investigation.

Chapter 1 is structured in three main sections. Section 1.1 discusses some approaches within the study of spoken discourse. After an introduction to discourse analysis and its evolution towards the study of spoken language, an exploration of pragmatics is provided. This section is followed by a general overview of two functional perspectives on language (Jakobson's functions of language and Halliday's Systemic Functional Linguistics), and a review of Mediated Discourse Analysis. Section 1.1 is finalized with a brief introduction to multimodal studies in discourse analysis. In Section 1.2, I look at the notion of genre and its relevance within the study of academic discourse. First, the concept of genre is defined. Next, an exploration of relevant studies within the tradition of genre analysis brings to the fore the impact of the field on investigations within academic settings with a particular emphasis on the studies on lectures. Finally, in Section 1.3, the focus turns to the concept of 'lecture'. From a genre perspective, I review previous research conducted on lectures, lecturing styles, the structure of lectures, and some studies integrating a multimodal perspective. Finally, I consider the recent trend in the compilation of lectures in OpenCourseWare.

\subsection{Approaches to the study of spoken discourse}

In order to understand the evolution of the study of discourse towards multimodality as a paradigm to explore spoken language in a holistic manner, I focus on the development of 
discourse analysis in Section 1.1.1 and I bring forward the notions of spoken language and multimodal discourse analysis. Section 1.1.2 is devoted to the study of pragmatics as an approach to discourse analysis where language is considered in relation to its context. Next, in sections 1.1.3 and 1.1.4 I explore two functional perspectives of language which contribute to the development of the study of both, multimodality and metadiscourse. On the one hand, in Section 1.1.3, I review Jakobson's view of the functions of language as a chief support for the theoretical basis in Ädel's $(2006,2010)$ model of metadiscourse, which is the one adopted in this thesis (see Chapter 3 for more information on metadiscourse). On the other hand, in 1.1.4, I explore the basic concepts in Halliday's Systemic Functional Linguistics, since they become instrumental in the development of most models of metadiscourse, and in Multimodal Social Semiotics and Multimodal Discourse Analysis (see Chapter 2 for further details on multimodality and approaches towards multimodality). Next, Section 1.1.5 describes Scollon's (2001) mediated discourse analysis, which serves as the basis for Multimodal (Inter)action Analysis, one of the multimodal approaches utilized in this study. Finally, Section 1.1 .6 serves as an introduction to an overall examination of multimodality (presented in Chapter 2).

\subsubsection{On discourse analysis}

Discourse analysis is an umbrella term to refer to a number of theoretical and methodological approaches with different backgrounds for which the analysis of language is a common factor (Burr, 1995). Thus, defining Discourse Analysis becomes an uneasy task, given the fact that the various approaches towards the analysis of discourse differ in their conceptualization of 'discourse', specific foci, and methodological frameworks. The studies on discourse analysis received special interest during the last quarter of the $20^{\text {th }}$ century (Schiffrin, Tannen, \& Hamilton, 2001; Widdowson, 1995) through the work of Chafe (1976, 1992, 1994); Givón (1979, 1983, 1990); Halliday (1973); etc. Nevertheless, the term 'Discourse Analysis' can be traced back to Harris (1952), who suggests a new method for the analysis of speech as opposed to descriptive linguistics. As he states, 
discourse analysis yields considerable information about the structure of a text or a type of text, and about the role that each element plays in such structure [...] how a discourse can be constructed to meet various specifications, [...] it also yields information about stretches of speech longer than one sentence (Harris, 1952, p. 30).

Harris's initial approach to discourse analysis is somehow centered on the analysis of texts from a grammar perspective. In other words, it offers a linguistic perspective towards the study of language. However, one idea can be extracted from this quotation which is recurrent in the literature on the matter: discourse analysis deals with fragments longer than one sentence. This view is consistent with the traditional understanding of the term 'discourse' as any text beyond the sentence (Chafe, 1992; Stubbs, 1983). The notion of 'discourse', however, can have a wider definition. Burr (1995, p. 32) argues that:

A discourse refers to a set of meanings, metaphors, representations, images, stories, statements and so on that in some way together produce a particular version of events. [...] there may be a variety of different discourses, each with a different story to tell about the object in question, a different way of representing it to the world.

From Burr's position, discourse transcends the realm of grammar to include a social aspect to it, which is constructed from different perspectives towards events. Gee and Handford $(2012$, p. 5) refer to this as "Discourses" with a big D which are "connected to views about and studies of different types of social groups". Thus, different viewpoints of the world can be shaped by means of different discourses (e.g. the discourse of politics, love, or racism). Out of this duality of approaches towards discourse, two perspectives arise within the studies in discourse analysis: one that is more textually-oriented and one that is more socially-oriented (Paltridge, 2005). Fairclough (2003) understands both approaches as complementary of each other. For the purposes of the present study, it is precisely the latter the one that becomes more relevant. The language in university lectures cannot be analyzed in isolation without taking into account the context in which it is placed or without considering the event as a social phenomenon. From my understanding, neglecting the context of lectures would hinder a complete appreciation of the genre. In this sense, language is understood as an integral part of the social context (Taylor, 2013). 
In order to exemplify how discourse analysis can focus on the text, on the social aspects or on both, Gee and Handford (2012) refer to Levinson's (2000) concepts of utterance-type meaning and utterance-token meaning. In other words, a given word can have a "meaning range", i.e. a set of possible meanings, but also "situated meanings", i.e. specific meanings determined by the context in which the word is used. Gee and Handford $(2012$, p. 1) exemplify this dichotomy by considering the example of the word 'cat' as used in "The world's big cats are all endangered". Here, 'cat' acquires a meaning beyond its meaning range and refers to felines like tigers and lions. Exploring situated meanings provides a wider scope for the analysis of language.

In an attempt to encapsulate most views in the analysis of language, Paltridge $(2005$, p. 2) provides an extensive definition of 'discourse analysis':

Discourse analysis focuses on knowledge about language beyond the word, clause, phrase and sentence that is needed for successful communication. It looks at patterns of language across texts and considers the relationship between language and the social and cultural contexts in which it is used. Discourse analysis also considers the ways that the use of language presents different views of the world and different understandings. It examines how the use of language is influenced by relationships between participants as well as the effects the use of language has upon social identities and relations. It also considers how views of the world, and identities, are constructed through the use of discourse. Discourse analysis examines both spoken and written texts.

Paltridge's definition provides a comprehensive inclusive description of the interests of discourse analysis. First, he describes discourse analysis as a tool to look at both, language beyond the sentence and the influence of its social context. In the second part of the definition, he refers to the concept of discourse in its broader interpretation as a constructor of "views of the world, and identities". Finally, Paltridge makes reference to the importance of considering both, spoken and written texts.

This last consideration is essential for the study of lectures, as they are inherently a spoken genre. Although the acknowledgement of orality as a relevant feature in the study of discourse is present from the very beginning in discourse analysis research, a rise in the number of approaches towards speech in general, and in academic settings in particular, 
only took place in the last decades -see Biber $(1986,1988)$, Fortanet-Gómez and Belles (2005), Jones (2016), or Pérez-Llantada and Ferguson (2006). In this regard, Paltridge (2005, pp. 14-19), based on Biber $(1986,1988)$, compares the spoken and written dimensions of discourse through eight ideas:

i) Grammatical intricacy and spoken discourse: Spoken discourse can be as grammatically complex as written discourse (Halliday, 1989).

ii) Lexical density in spoken and written discourse: Written discourse appears to show a higher lexical density.

iii) Nominalization in written and spoken discourse: Written texts offer a higher nominalization.

iv) Explicitness in spoken and written discourse: The explicitness of discourse seems to depend on the purpose of the text.

v) Contextualization in spoken and written discourse: The degree of contextualization of a text depends on the type of text (Tannen, 1982). While personal letters need a degree of shared context, academic lectures do not.

vi) The spontaneous nature of spoken discourse: Spoken discourse is organized differently from written discourse. It is commonly produced spontaneously and therefore, reformulation, interruptions, overlap, etc. can occur. Moreover, non-verbal language plays a role in the conveyance of meaning.

vii) Repetition, hesitation, and redundancy in spoken discourse: In general, spoken discourse shows a higher use of hesitation, pauses, fillers, etc. as "it is produced in real time".

viii) A continuum of differences between spoken and written discourse: The differences between spoken and written discourse can be placed on a continuum (McCarthy, 2001).

Paltridge's (2005) comparison of the spoken and written discourses reflects on Biber's (1988) conclusion: differences between spoken and written genres are not absolute and depend on the text. Expressed in a different way, each type of text (spoken or written) shares a set of features with similar texts that are intrinsic to that genre. Thus, Biber proves wrong some of the commonly held views on the characteristics of written and spoken discourses and refers to types of text, or, as I develop in Section 1.2, types of genre.

Two interesting notions can be extracted from points vi) and vii) in Paltridge's exploration of spoken and written discourse that are noteworthy for the purposes of this thesis. On the one hand, in point vi), Paltridge refers to the organization of spoken speech. Van Dijk's 
$(1977,1980)$ concept of macro-structure as a succession of episodes is one of the earliest references to the study of structure in discourse. Moreover, the organization of lectures is one of the topics that has received much attention from various researchers -see for instance Strodt-López (1991), Thompson (1994), or Young (1994). The study of the structure of lectures is one of the main areas of interest in my study. In Section 1.3.1.2 below, I offer an extensive review on previous approaches to the study of the structure in lectures. In addition, in Chapter 8, I explore the macro-structure of lectures from a multimodal perspective. The second notion that can be extracted from Paltridge's review is the reference in points vi) and vii) to the relevance of non-verbal language, fillers, and pauses, among others. In order to obtain a holistic view on the use of language, the study of spoken discourse needs to go beyond merely verbal aspects and also consider nonverbal features. This is the starting point of this thesis, in which a multimodal analysis is conducted with the aim of investigating in detail the uses of organizational metadiscourse in lectures. As I describe in Chapters 2 and 4, I draw on the theoretical and methodological tools proposed in various approaches towards multimodality in order to explore both the verbal and non-verbal features in the use of metadiscourse in lectures. In Norris's (2004, p. $x$ ) words: "people in interaction seldom communicate only through language". I detail throughout this thesis how language is just one mode within the set of modes that are present in spoken discourse and may or may not play a leading role in conversation (Kress, Jewitt, Ogborn, \& Tsatsarelis, 2001). A multimodal analysis allows for the exploration of all modes present in speech and the interaction among them, thus providing a rather complete image of the interactive process. In short, by considering the peculiarities of oral features, one step towards a holistic perspective of discourse is achieved. This view is expanded and complemented by the multimodal studies, which analyze traits beyond the verbal mode and which take into account not only what is said, but also how it is said (see Section 1.1.6 below).

A wide range of approaches towards the analysis of discourse can be found in the literature: Conversation Analysis (Sacks, Schegloff, \& Jefferson, 1974), Pragmatics (Austin, 1962; Brown \& Levinson, 1978; Grice, 1975; Searle, 1969, 1976), Critical Discourse Analysis (Fairclough, 2001; van Dijk, 1996), Systemic Functional Linguistics (Halliday, 1978, 1985), 
multimodal discourse analysis ${ }^{1}$ (Kress \& van Leeuwen, 1996, 2001, Norris, 2004, 2011, O'Halloran, 2004a, 2008, 2011), Ethnography (Harklau, 2005; Hymes, 1972), etc. Five approaches to discourse are particularly relevant for the present study. First, the study of pragmatics contributes to the description of how meaning is transmitted and related to the social context. Secondly, Systemic Functional Linguistics, Jakobson's Functions of Language and mediated discourse analysis are needed to understand the evolution of the models for the analysis of metadiscourse and the expansion of approaches towards multimodality. Finally, multimodal discourse analysis comprises the background to the use of methodological tools in this thesis. In the following sections, I briefly refer to these five approaches and describe their main foci.

\subsubsection{On pragmatics}

The view of language as it is being used as a tool "to do things in the world" (Johnstone, 2002, p. 3) and the importance of how users extract meaning from texts (Chimombo \& Roseberry, 1998) are some of the aims of discourse analysis. It is precisely the study of how language is interpreted the focus of attention of pragmatics (Green, 1989). In other words, pragmatics explores the connection between what is said and its communicative function (Cameron, 2001). These ideas are highlighted in Paltridge's (2005, p. 53) extensive definition of the aims of pragmatics:

\footnotetext{
Pragmatics is the study of meaning in relation to the context in which a person is speaking or writing. This includes social, situational and textual context. It also includes background knowledge context; that is, what people know about each other and about the world. Pragmatics assumes that when people communicate with each other they normally follow some kind of co-operative principle; that is, they have a shared understanding of how they should co-operate in their communications.
}

\footnotetext{
${ }^{1}$ In line with the terminology in previous literature, I will use multimodal discourse analysis (in lower-case letters) to refer to the compendium of approaches to the multimodal analysis of discourse, and Multimodal Discourse Analysis to O'Halloran's (2004a, 2008, 2011) approach towards multimodality.
} 
In the case of university lectures, lecturers need to adapt their speech to the context in which they are lecturing. They take into account the social, situational and textual context as well as the background knowledge shared by both, themselves and the students. In terms of content, this background knowledge can sometimes be brought to the fore by means of organizational metadiscourse. The use of organizational metadiscourse, in addition, can perform organizational functions like introducing a topic or connecting information in the lecture.

In the following paragraphs, I discuss three ideas that are recurrent in the study of pragmatics: speech acts, presuppositions, and the co-operative principle and the concept of implicatures.

The Speech Act Theory was first developed by Austin (1962) and Searle (1969) and postulates that language can be used to 'do' things, i.e. language is used to perform functions. This opposes to the traditional view of communication in which language is used for merely descriptive purposes. Having this idea in mind, Austin (1962) distinguishes three different types of acts that can be performed through language: the locutionary act, which refers to the literal meaning in the utterance of a statement; the illocutionary act, which looks at the speaker's intention in saying something, i.e. what speakers want to achieve with their statements; and the perlocutionary act, which describes the effect of a statement on the receiver. Furthermore, special interest is placed on the study of the illocutionary force (the intention of speakers as they perform utterances), as the literal content of what is said may not correspond with the intention of the speaker. The illocutionary force of a sentence is closely related to linguistic aspects. In van Valin and LaPolla's (1997, p. 41) words: "it refers to whether an utterance is an assertion, a question, a command or an expression of a wish". Still and all, the identification of such force cannot be conducted in isolation and the context is essential in determining it (Flowerdew, 1990). In relation to the idea of illocutionary force, two more concepts are introduced in the Speech Act Theory: direct and indirect speech acts. Direct speech acts refer to acts where the literal content of the utterance and the intention of the speaker coincide. On the other hand, indirect speech acts refer to instances where there is not a complete correspondence between what the speaker literally says and the illocutionary force of the sentence. For example, if a speaker 
says 'Can you open the door?', they are probably not asking whether the addressee is able to open the door or not; instead, the speaker is asking the addressee to open the door. Finally, indirect speech acts are most of the time cultural-specific and a difficult issue for second language learners (Paltridge, 2005). Within this framework, the study of the illocutionary force of lecturers as they organize their lectures is relevant in my study, as I aim to explore how lecturers develop structuring and organizational processes through the use of metadiscourse.

A second notion worth discussing within the field of pragmatics is the concept of presupposition. Paltridge (2005, p. 60) describes presuppositions as "the common ground that is assumed to exist between language users such as assumed knowledge of a situation and/or the world". In other words, speakers and listeners make assumptions about the background knowledge they share and adapt their speech accordingly. For example, to put it in a very simplified way, if a speaker utters the sentence "Sue stopped drinking", the addressee presupposes that Sue drank at some point (Kadmon, 2001, p. 10). Paltridge further distinguishes between conventional -also referred to as semantic (Frege, 1930/1980)- and pragmatic presuppositions. The former are less context-dependent than the latter. Conventional presuppositions, moreover, are commonly related to linguistic aspects. For example, the sentence "The king of Spain is tall" presupposes that there is a king in Spain. A pragmatic presupposition, on the other hand, "presupposes that its context is appropriate" (Keenan, 1971, p. 49). Potts $(2015$, p. 169) argues that

\footnotetext{
[p]ragmatic presuppositions include the preconditions for linguistic interaction (for example, the mutual public knowledge that we are speaking the same language), the norms of turn taking in dialogue, and more particularized information about conversational plans and goals.
}

Pragmatic presuppositions can become relevant in the study of lectures, as they can play a role in the organizational process of lecturers, who may make assumptions about the common knowledge shared with the audience.

The last aspect I would like to reflect upon is Grice's (1975) co-operative principle and the concept of implicatures. On occasions, speakers' literal utterances do not correspond with the intended meaning, for example, in irony. In order to explain the process through which 
a person discerns what another one intends to say, Grice describes a series of maxims that are assumed by the interlocutors. Grice $(1975$, p. 45$)$ refers to this process as the Cooperative Principle: "Make your conversational contribution such as is required, at the stage at which it occurs, by the accepted purpose or direction of the talk exchange in which you are engaged." In other words, in order for communication to occur effectively, the speaker should follow four maxims (Grice, 1975, pp. 45-46):

1) Maxim of quantity: - Make your contribution as informative as required (for the current purposes of the exchange).

- Do not make your contribution more informative than is required.

2) Maxim of quality: - Do not say what you believe to be false.

- Do not say that for which you lack adequate evidence.

3) Maxim of relation: - Be relevant.

4) Maxim of manner: - Avoid obscurity of expression.

- Avoid ambiguity.

- Be brief (avoid unnecessary prolixity).

- Be orderly.

Although listeners take for granted that these maxims are to be followed at all times, sometimes speakers flout them and they expect listeners to realize this, as they turn to their knowledge of the world. In such cases, the intended meaning of the speaker does not correspond with the literal content of their utterance. Therefore, implicatures are created as the listener makes sense of the meaning that is intended.

The study of speech acts shared expectations and common background between speakers and listeners, and the process through which meaning is deciphered may contribute to the study of the organizational processes in lectures. In this sense, Paltridge (2005, p. 62) comments on the importance of the speakers' use of metadiscourse for the interpretation of texts "as it shows both their attitude to what they are saying as well as their attitude to the audience of the text". Ädel (2006) also reflects upon this idea and refers to 'illocution 
markers' as explicit instances that comment on the speech act being performed (for example in 'to conclude...').

\subsubsection{On Jakobson's Functions of Language}

In this section and in the following one, I explore two functional approaches to language: Jakobson's Functions of Language and Halliday's Systemic Functional Linguistics. Although the application of Jakobson's functions is not a direct goal in this thesis, a brief review on his theory is necessary in order to understand the development of Ädel's $(2006,2010)$ model of metadiscourse that is used in my analysis (see Chapter 3 for more information on the different approaches towards metadiscourse).

In his seminal work Linguistics and Poetics, Jakobson (1960) builds over Bühler's (1933) trifunctional theory of language -where language can perform the emotive, conative and referential functions- and extends it to include the phatic, metalingual and poetic functions. Jakobson argues that each function of language is determined by the various factors involved in verbal communication. From a general perspective, he describes communication as the process in which an addresser sends a message to an addressee. This message occurs within a context and requires a code that is at least partially shared by both parts, and a contact or a channel through which communication occurs (see Figure 1.1).

\section{CONTEXT}

MESSAGE

ADDRESSER

CONTACT

\section{CODE}

Figure 1.1 Jakobson's factors involved in verbal communication (Jakobson, 1960, p. 353) 
Jakobson then distinguishes six functions of language that combine in language fragments usually carrying out more than one function at the same time, and may be organized hierarchically depending on which function is predominant in a given utterance. The six functions of language as described by Jakobson (1960, pp. 353-357) are:

1) Emotive function: It is focused on the addresser. It is used to express the speaker's attitude towards the content.

2) Poetic function: Its focus is "on the message for its own sake". It goes beyond the study of poetry and explores the intricacies of the message itself.

3) Conative function: It is oriented towards the addressee, and it is commonly found in the form or vocatives and imperatives.

4) Referential function: It is related to the context and helps in the contextualization of the message. It is mainly used to convey information.

5) Metalingual function: It is closely associated with the code. It is paramount "whenever the addresser and/or the addressee need to check up whether they use the same code".

6) Phatic function: Its focus is on the contact. It refers to the use of language "to establish, to prolong, or to discontinue communication, to check whether the channel works $[\ldots]$, to attract the attention of the interlocutor or to confirm his continued attention".

Jakobson's Functions of Language and their correspondences with the factors involved in conversation are represented in Figure 1.2. 
REFERENTIAL

(context)

EMOTIVE

(addresser)

\section{POETIC}

(message)

PHATIC

(contact)
CONATIVE

(addressee)

\section{METALINGUAL}

(code)

Figure 1.2 Jakobson's Functions of Language. Edited from Jakobson (1960, p. 357)

As I mentioned above, Jakobson's theory plays an important role in Ädel's (2006) development of her model of metadiscourse. Ädel argues that the metalingual, emotive and conative functions (metalinguistic, expressive and directive in Ädel's terms) are essential in metadiscourse and one or more of them may take a predominant role depending on the focus of the metadiscursive instance. In Ädel's reflexive model, metadiscourse can focus on the text (performing a metalinguistic function), the writer (performing an expressive function) or the reader (performing a directive function). This trifunctional description of metadiscourse is instantiated in what Ädel refers to as a 'reflexive triangle' as shown in Figure 1.3 (see Section 3.2.4 for an elaborate discussion on Ädel's model of metadiscourse).

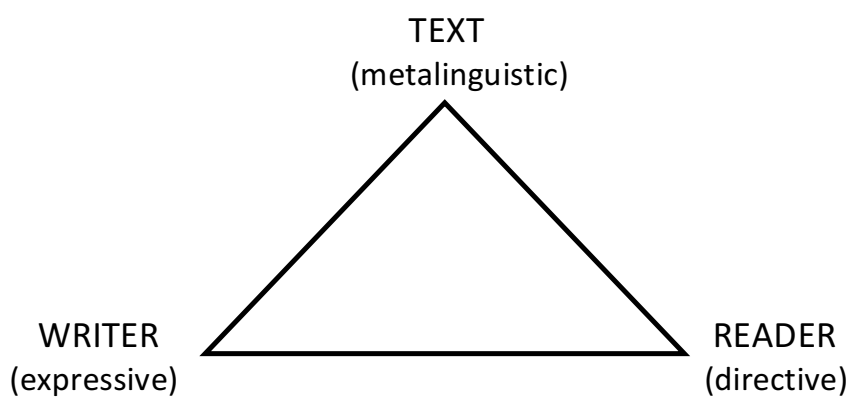

Figure 1.3 Ädel's 'reflexive triangle' (Ädel, 2006, p. 18) 


\subsubsection{On Systemic Functional Linguistics}

The second functional approach that I would like to review in this chapter is Halliday's $(1978,1985)$ Systemic Functional Linguistics (SFL). SFL is relevant for this thesis since it serves as the starting point of Multimodal Social Semiotics (Kress \& van Leeuwen, 2001) and Multimodal Discourse Analysis (O'Halloran, 2004a), as I develop in Chapter 2; and moreover, it becomes essential to comprehend the identification of metadiscourse as propositional material in some approaches, as I further discuss in Chapter 3 -see, for instance, Crismore et al. (1993), and Vande Kopple (1985).

SFL is a linguistic theory that explains the process of meaning-making in human communication as a progression of choices made by speakers. In other words, Halliday describes language as a social semiotic system of choices at different levels; speakers choose from a range of resources in each of the levels which are interrelated, thus conveying meaning (Halliday, 1985). In Halliday's (1994, p. 15) words, language is viewed "not as a set of structures but as a network of SYSTEMS, or interrelated sets of options for making meaning". The study of these choices provides an insight into how meaning is created at a linguistic level. Halliday and Matthiessen (2014) argue that language is organized in four basic strata: the semantic, lexicogrammar, phonology and phonetics. This description of language extends Halliday's previous one where phonology and phonetics are encompassed within the phonological stratum -see Halliday (1985). These strata, in turn, are structured in two planes: the content plane and the expression plane. The content plane includes the semantics and lexicogrammar strata and it is used to carry out interactions in the world. At the semantic level, "the interfacing part, experience and interpersonal relationships are transformed into meaning" which "is further transformed into wording" at the lexicogrammar level. The expression plane, on the other hand, includes the phonology and phonetics strata and it is used to produce speech. Phonetics express "the interfacing with the body's resources for speech and for hearing" while phonology is used in "the organization of speech sound into formal structures and systems" (Halliday \& Matthiessen, 2014, p. 25). Finally, the linguistic system is continuously 
influenced by the context, as represented in Figure 1.4 below. The choices in the content plane as well as the context in which these occur become of interest in this study, especially for the linguistic analysis carried out in Chapter 6.

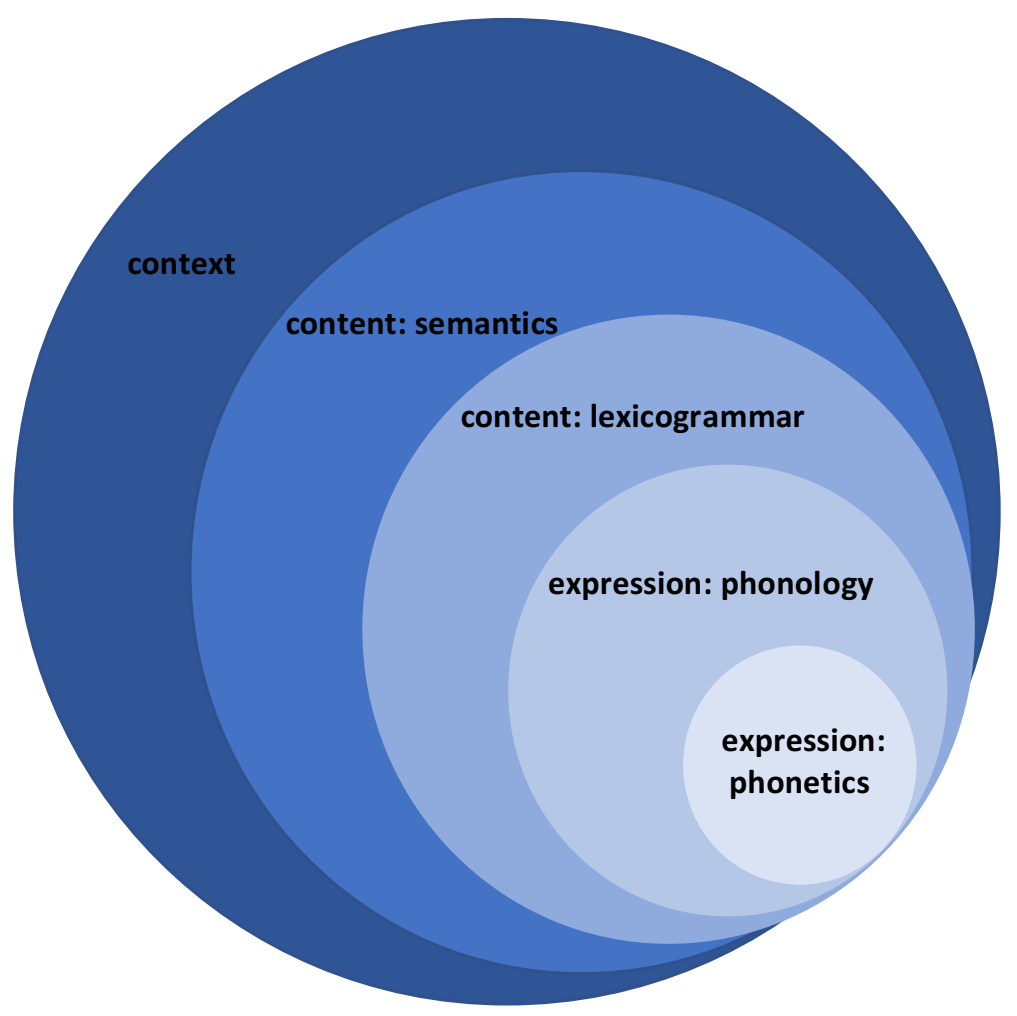

Figure 1.4 Stratification of language in SFL. Adapted from Halliday and Matthiessen (2014, p. 26)

SFL places particular interest in the use of language as part of social relations in a given context. In this sense, Halliday and Matthiessen (2014) distinguish three 'metafunctions' of language in social communication:

1) The ideational metafunction: it is present when language is used to construe human experience, i.e. to name things, create categories and sequences, or to represent concepts and actions.

2) The interpersonal function: it is present when language is used to enact personal relationships in the interaction with other people; in other words, when language is used in relation to the listener. 
3) The textual function: it facilitates communication as it contributes "to build up sequences of discourse, organizing the discursive flow, and creating cohesion and continuity as it moves along" (Halliday \& Matthiessen, 2014, p. 31).

These three metafunctions of language are used simultaneously in conversation, and it is through their interaction that meaning is created. Context is incorporated into the equation through the concepts of field, tenor, and mode, i.e. sets of variables from which the speakers can choose and which define the register of a text (Halliday, 1985). Schleppegrell (2012, p. 22) defines register as the "variation in linguistic choices with respect to context", and she adds that "drawing on different systems of language in different combinations realizes different registers, because the particular language choices [...] vary according to social and cultural context". This variation is realized through choices in field, tenor, and mode. Field refers to "what's going on in the situation"; tenor refers to "who is taking part in the situation"; and mode answers "what role is being played by language and other semiotic systems in the situation" (Halliday \& Matthiessen, 2014, p. 33). These values are in turn connected with the ideational, interpersonal and textual metafunctions respectively (Halliday, 1985).

The relation between organizational metadiscourse and the SFL metafunctions has been established in some models; however, this relation is controversial. Many studies have demonstrated the relation between interpersonal meaning and the expression of attitudes, engagement, evaluation, and graduation of assessments under the appraisal model (Martin, 2000a; Martin \& White, 2005; Querol-Julián, 2011a; Thompson \& Muntigl, 2008; Valeiras-Jurado, 2017). However, as I describe in Chapter 3 and in line with Ädel's (2006) arguments, I do not consider stance (or evaluation) as being metadiscourse, as no explicit reflection upon the use of language is present. However, the three metafunctions of language become relevant in the study organizational metadiscourse. As I develop in Chapter 3, early approaches towards metadiscourse -see Crismore et al. (1993) and Vande Kopple (1985)- identify metadiscourse with all language performing the interpersonal and textual functions; in other words, metadiscourse reflects all non-propositional material in a text. Ädel (2006), on the other hand, argues that the identification of metadiscourse with the interpersonal and textual functions is generally all too-inclusive and that metadiscourse 
requires the presence of a degree of reflexivity on the language. Ädel's approach is the one that I employ in the analysis of metadiscourse in this thesis.

Be that as it may, my focus in this thesis is on the use of organizational strategies in lectures. A review of how the textual metafunction works seems, therefore, appropriate for a verbal exploration of the organization of lectures, as it is the one used in organizational processes.

The concepts of theme and rheme (Halliday, 1985, 1994) are essential within the textual metafunction of language. Halliday (1994, p. 37) defines theme as the "point of departure; [...] that with which the clause is concerned" and which receives "special status" within the clause; he adds that "theme extends from the beginning of the clause and up to (and including) the first element that has a function in transitivity" (Halliday, 1994, p. 53). Rheme, on the other hand, is defined as "the remainder of the message" (Halliday, 1994, p. 52).

Themes can be simple or multiple: simple themes are commonly realized by the subject of the utterance, while in multiple themes a textual or interpersonal theme is placed before the theme that is realized by the subject, which Halliday calls 'topical theme'. In the sentences below (my own), 'the soldiers' is the theme in (1), 'the war' in (2) and 'in 1886' in (3). The remaining part of each of the sentences is the rheme. The content of the three examples is the same; however, in each of the utterances, the focus is placed on a different element, which is instantiated in the theme. In the case of (3), 'in 1886' is a textual theme that precedes 'the soldiers', which is the topical theme in a multiple theme sequence.

(1) The soldiers won the war in 1886.

(2) The war was won by the soldiers in 1886.

(3) In 1886, the soldiers won the war.

Although some researchers do not agree with Halliday's definitions -Berry $(1995,1996)$, for instance, claims that the theme does not need to end with the first ideational meaning; and some authors argue that the subject should be obligatory in the theme (Berry, 1995, 1996; Davies, 1997; Forey, 2002)-, it seems clear that the theme receives a special status and contributes to the understanding of the organization of the message. Moreover, the 
concepts of theme and rheme permit me to determine the choice that has been preferred by the speaker in the structuring process of a given utterance. In Forey's (2002, p. 52) terms, theme "is seen to contribute to the construal of a text's meanings, to the organization of the ideas in a text, and to a reader's interpretation of the message".

Another aspect of discourse that can be identified by studying the themes is whether the information that is being disclosed is new or, on the contrary, it has been introduced before. Halliday (1994) affirms that theme is commonly connected with given information, i.e. information that has been introduced before, and the rheme is connected with new information, which is not recoverable by the listener. Therefore, an exploration of the textual function, especially in instances such as introductions to the topic, previewing and reviewing fragments, might shed some light in a linguistic analysis of the data, as it allows for the exploration of both, the focus of the clause and the type of information provided (new vs. given).

The use of SFL in general, and the examination of the textual function, in particular, can provide a comprehensive insight into how meaning is conveyed and how discourse is organized. Nevertheless, few mentions are made of the capability of non-verbal semiotic modes to convey meaning in Halliday's theory. Halliday and Matthiessen (2014) refer to text as linguistic instantiations in a spoken or written form and acknowledge the contribution that SFL can make on the study of other semiotic resources beyond language. However, contributions to the study of non-verbal modes from a SFL perspective are provided by other researchers, for instance, in the work on gestures carried out by Muntigl (2004) and Hood (2011). Two of the most influential pioneering applications of SFL metafunctions to the study of non-verbal semiotic resources are Kress and van Leeuwen (1996), who offered a grammar of visual design, and O'Toole (1994), who uses SFL metafunctions in the study of meaning in sculpture, architecture and classical art. These two studies become the starting point for a new focus within the studies on discourse analysis: the multimodal analysis of discourse, and in particular the approaches of Multimodal Social Semiotics and Multimodal Discourse Analysis. Multimodal discourse analysis as a field within discourse studies is introduced in Section 1.1.6 in this Chapter and further expanded in Chapter 2. 


\subsubsection{On mediated discourse analysis}

As I stated above, two approaches towards multimodality are rooted in the theories of SFL (Multimodal Social Semiotics and Multimodal Discourse Analysis). However, there is a third multimodal methodology that I consider in my thesis whose origins are found in a different approach towards discourse analysis. As I discuss in the following section and in Chapter 2, Multimodal (Inter)action Analysis (Norris, 2004, 2011) is based on the theoretical underpinnings postulated in mediated discourse analysis (Scollon, 1998, 2001; Scollon \& Scollon, 2004). Therefore, in this section, I briefly review some of the concepts discussed in mediated discourse studies and which are adopted in the Multimodal (Inter)action Analysis approach used in this thesis.

Mediated discourse analysis is a theory of discourse developed by Scollon in the late 1990s and early 2000s (Scollon, 1998, 2001; Scollon \& Scollon, 2004). In his approach, Scollon (2001) suggests a series of theoretical and methodological tools to study discourse with a strong focus on the social context and the social actor. This researcher turns his attention to exploring discourse as part of the series of actions performed by speakers in their daily life. In Jones's (2014, p. 39) words, mediated discourse analysis attempts to shift "our focus away from discourse, and on to the actions people use discourse to take". Thus, the center of attention in Scollon's theory is the action. Scollon aims to examine the complexity of the sets of actions performed by people from a neutral point of view, without attaching a special status to any one action in particular. He argues that "mediated discourse analysis is a position which seeks to keep all this complexity [the complexity of human interaction] alive in our analyses without presupposing which actions and which discourses are the relevant ones in any particular case under study" (Scollon, 2001, p. 1). By doing this, Scollon looks at discourse as a series of actions within social interaction that may or may not be relevant depending on the purposes of the study. For example, in an informal meeting with a friend in a park, several actions can be analyzed: walking, laying on the grass, or staring at flowers, and also greeting a friend, talking about the family, planning a trip, and so on and so forth. The emphasis is no longer on the system (see SFL in the previous section) but 
on the social context and the speakers. This one principle is somehow transmitted into most multimodal approaches, where an initial equal status is assigned to all modes contributing to the conveyance of meaning. In this study, I deviate slightly from this idea. Although I agree with the fact that all modes are capable of equally contributing to the conveyance of meaning, the main focus of this thesis is the study of metadiscourse -a linguistic category. In this regard, the verbal mode is taken as the point of departure to conduct the studies in this thesis. Still and all, the focus on the speaker and the actions they perform is the approach that I take in the multimodal analysis of structure presented in Chapter 8. In this sense, I examine the sets of actions carried out by the speakers in order to determine the role that metadiscourse plays in those actions.

Scollon (2001, pp. 3-5) describes five concepts that are essential in the analysis of mediated discourse:

1) Mediated action. The mediated action is the unit of analysis in mediated discourse. This concept arises from Wertsch $(1994,1998)$ who, in turn, elaborates the concept from Vygotsky's $(1978,1986)$ notion of mediation. Mediated actions focus on social actors acting with or through mediational means (Wertsch, 1998). In other words, the focus of the study of mediated discourse analysis is the social actor as they interact with their environment.

2) Site of engagement. The site of engagement is the social space in which a mediated action occurs. It goes beyond the concept of 'context' as it is a "real-time window that is opened through an intersection of social practices and mediational means [...] that make that action the focal point of attention of the relevant participants". Jones (2014, p. 41) argues that "every action is unique" and influenced by particular people, cultural tools, etc. In this sense, the notion of site of engagement allows the analyst to consider all these aspects.

3) Mediational means. The concept of mediational means is key within the mediated discourse analysis theory. As described above, mediated actions are the result of the interaction between social actors and mediational means (Jones, 2014; Wertsch, 1998). Mediational means can be material objects in the world but also 
embodied means (like gestures or voice) and they carry "historical affordances and constraints". The idea of embodied mediational means will play an important role in the development of Multimodal (Inter)action Analysis.

4) Practice. Mediated actions, social practices, and mediational means interact at all times. The notion of practice relates to people's previous experiences in a given environment. In other words, social actors carry a history of experiences and interactions with the world that contextualizes their actions.

5) Nexus of practice. Scollon's last concept refers to "social practices in the plural". It studies how various practices are linked to each other to form a nexus. For example, the nexus of practice of 'university lecture' includes practices such as lecturing, note taking, or discursive practices.

Lastly, Norris and Jones (2005a) and Scollon (2005) consider one more category in relation to the social actor: Agency. This category reflects upon the intention of the social actor as discursive actions are constructed.

In short, mediated discourse analysis is based on the concept of mediated action and focuses on real actions occurring in a site of engagement, i.e. a real-time event considering all intricacies of a given action. Moreover, actions are mediated by mediational means that are attached to social structures and histories creating a nexus of practice (Scollon, 2001).

The principles suggested in mediated discourse analysis are adapted by Norris $(2004,2011)$ to develop a set of multimodal theoretical and methodological tools to study human communication in a holistic way. As I discuss in the following section and in Chapter 2, Multimodal (Inter)action Analysis uses the mediated action as the starting point for its analyses. The focus of Multimodal (Inter)action Analysis is thus the study of the social actors as they perform mediated actions in sites of engagement. By looking at the actions, the analyst is able to look at all modes from a neutral point of view and therefore discern which modes play an important role in a given action. Both the theory of mediated discourse analysis and the methodological tools provided by Multimodal (Inter)action Analysis (see sections 1.1.6 and 2.2.3) are paramount for the purposes of this thesis. In 
particular, the concepts of mediated action and mediational means are primary for a multimodal study of how lectures unfold and are structured. The concept of action, on the one hand, will allow me to explore the structure of lectures from an interactive point of view (see Section 8.1.1), as opposed to traditional structures of lectures extracted from their verbal contents (see Section 1.3.1.2 in this chapter for a discussion on previous studies on structure). In addition, Norris' (2004) development of the notions of higher-level and lower-level actions together with the concepts of modal density, foreground-background continuum and semantic/pragmatic means (see Section 2.2.3) are relevant to study the role of metadiscourse as an integrated part in the lecturers' sequences of actions (as shown in Section 8.1.2). Finally, the notion of mediational means is relevant for the exploration of the use the lecturers make of their notes. As I discuss in Section 1.3.1.1 below, the lectures in my study have been classified according to Dudley-Evans's (1994) lecturing styles. This categorization takes into account the degree of importance that the lecturers devote to their notes. Thus, by discussing the use of notes as a mediational means within the sets of actions performed by the lecturers, I am able to show how notes integrate into the process of lecturing and the role they perform in the structuring processes (see Section 8.2).

\subsubsection{Introducing multimodal discourse analysis}

As I stated in the introduction to this thesis, the present study aims to provide an extended analysis of how organizational metadiscourse is used to structure lectures at all levels. In order to achieve this aim, I conduct a series of multimodal studies on lectures. I ended Section 1.1.4 by showing how SFL does not contemplate the conveyance of meaning beyond the linguistic level. In this sense, multimodal discourse analysis was born from the principle that "language is inherently multimodal" (Fortanet-Gómez \& Crawford Camiciottoli, 2015, p. 2; Müller, 2009, p. 216); in other words, meaning is not conveyed through one means (or mode) only, but through a multiplicity of modes working together (Jewitt, 2009a; Kress \& van Leeuwen, 2001). Moreover, language is no longer central and 
becomes just one more mode that contributes to the conveyance of meaning. In Kress's (2012, p. 37) words,

[a] multimodal approach assumes that language, whether as speech or as writing, is one means among many available for representation and for making meaning. That assumes that the meanings revealed by forms of DA [Discourse Analysis] relying on an analysis of writing or speech are only ever 'partial' meanings. The meanings of the maker of a text as a whole reside in the meanings made jointly by all the modes in a text.

Thus, by conducting a multimodal analysis, a holistic view of human communication can be achieved (Norris, 2004), as the analyst takes into account not only the modes that play a role in communication but also how these interact to create meaning. Like discourse analysis, the concept of 'multimodal discourse analysis' is used here as an umbrella term. Jewitt (2014) distinguishes three main approaches towards multimodal analysis: Multimodal Social Semiotics (Hodge \& Kress, 1988; Kress \& van Leeuwen, 1996, 2001; van Leeuwen, 2005), Systemic Functional - Multimodal Discourse Analysis (O'Halloran, 2004a; O'Toole, 1994, 2011) ${ }^{2}$, and Multimodal (Inter)action Analysis (Norris, 2004; Norris \& Jones, 2005a; Scollon, 2001; Scollon \& Scollon, 2003). The first approach, Multimodal Social Semiotics (MSS) takes over Halliday's $(1978,1985)$ Social Semiotics and SFL theories in order to explore the process of meaning-making as a social activity that takes place in social environments (Kress, 2010). The second approach, Multimodal Discourse Analysis (MDA) is strongly based on Halliday's (1985) SFL and is concerned with the study of language as the result of a combination of semiotic resources; in particular, it aims at exploring models of semiotic resources, how they interact to convey meaning and how meaning can change through a resemioticization process (ledema, 2001, 2003; O'Halloran, 2011). Finally, the third approach, Multimodal (Inter)action Analysis (MIA), is grounded on Scollon's (2001) theory of mediated discourse analysis that I discussed in Section 1.1.5, and is organized around the concept of 'mediated action'. Its focus is on how social actors interact in a situated context. Jewitt (2014) argues that each approach differs from the other in their foci of study; thus, SSM shows an interest on the sign-maker as they interact in a social context, MDA focuses on the semiotic resources as systems of choices, and MIA's main

\footnotetext{
${ }^{2}$ For simplification purposes, and in line with Jewitt's terms, I will refer to 'Systemic Functional - Multimodal Discourse Analysis' simply as 'Multimodal Discourse Analysis'.
} 
interest lays on the social actor as they interact in a situated context (see Section 2.2 for more information on these approaches towards multimodality).

I side with Jewitt's (2014) view that distinct approaches towards multimodality are not mutually exclusive. As I discuss above, each approach has a different focus and explores distinct qualities in communication. In this sense, choosing one approach over the other in any one study will depend on the objectives of such study. In the present thesis, I combine MDA and MIA as I aim to look at both, the semiotic systems as sets of choices for the lecturers, and the lecturers themselves as social actors constantly organizing their discourse. On the one hand, an MDA will allow me to explore what semiotic resources are used in the organization of lectures through the use of metadiscourse and how they combine to convey meaning. And on the other hand, an MIA approach will be useful to explore the multimodal structures created in the organization of lectures as well as the role of metadiscourse within such structures. Finally, I will also make use of concepts from MSS such as the concepts of mode and semiotic resources. A comprehensive discussion on the approaches towards multimodality, the modes that will be considered in this study as well as the software employed for its analyses are presented in Chapter 2.

\subsection{Approaches to the study of genre}

In the previous section, I have reviewed the most relevant theoretical notions that are needed to contextualize the multimodal analysis of organizational metadiscourse in lectures. In this section, I briefly explore the concept of genre and its relevance to the study of discourse in academic settings and from a multimodal point of view. In this sense, the present section serves as an introduction to Section 1.3, in which I explore in detail the genre of lectures and previous research in the field. Thus, this section unfolds as follows: in Section 1.2.1, I review some influential definitions of genre as well as approaches towards the study of oral genres. Next, in Section 1.2.2 I focus on the concept of genre as 
it is applied to the study of academic discourse and I outline some relevant studies and taxonomies within the study of academic genres.

\subsubsection{Defining genre}

The study of genres, or genre analysis, has received a growing interest in the last decades with a particular focus on the exploration of the structure and communicative purposes in academic and professional discourses (Bhatia, 1991, 1993, 2001, 2002, 2004; FortanetGómez, 2005; Freedman \& Medway, 1994; Räisänen, 1999; Swales, 1990, 1996, 2004). The notion of genre, however, is a complex one and has been redefined from various perspectives. One of the earliest definitions of genre is provided by Martin (1984, p. 25) who defines a genre as "a staged, goal-oriented, purposeful activity in which speakers engage as members of our culture". Martin's definition is somehow simplistic but it includes some of the basic defining traits of the concept of genre: it is shared by a number of speakers with a common purpose and it is understood within a culture. Bakhtin (1986, p. 60), agrees with Martin on the ideas of participants and shared goals as common entities in genres and adds one of the earliest references to shared linguistic and structural elements:

All the diverse areas of human activity involve the use of language. [...] Language is realized in the form of individual concrete utterances (oral and written) by participants in the various areas of human activity. These utterances reflect the specific conditions and goals of each area not only through phraseological, and grammatical resources of the language, but above all through their compositional structure. [...] these aspects [...] are equally determined by the specific nature of the particular sphere or communication. [...] These we may call speech genres.

Some years later, Kress $(1989$, p. 19) described genres with a marked social point of view as genres have "specific forms and meanings, deriving from and encoding the functions, purposes and meanings of the social occasions". Similarly, in Kress $(1989$, p. 10), genre is defined as "the effects of the action of individual social agents acting both within the 
bounds of their history and the constraints of particular contexts, and with a knowledge of existing generic types". The view of genre as attached to a social group seems to be coherent in most definitions of the term. Kress also introduces the notion of 'constraint', which refers to the fact that genres are limited by given contexts which serve as boundaries among them. I further elaborate on the notion of 'constraint' in the following pages when tackling Bhatia's (1993) definition of genre.

Although these definitions fairly describe the basic elements defining a genre, Swales (1990, p. 58), in a more concise manner, provides one of the most recurrently cited definitions of 'genre':

\begin{abstract}
A genre comprises a class of communicative events, the members of which share some set of communicative purposes. These purposes are recognized by the expert members of the parent discourse community and thereby constitute the rationale for the genre. This rationale shapes the schematic structure of the discourse and influences and constrains choice of content and style. [...] In addition to purpose, exemplars of a genre exhibit various patterns of similarity in terms of structure, style, content and intended audience.
\end{abstract}

Swales, like Martin and Bakhtin, describes genres as communicative events shared by a group of people (the "discourse community") and with a common goal (the "communicative purpose"). Moreover, he refers to common structures, content, and style as shared elements within the members of a discourse community. The concepts of 'discourse community' and 'communicative purpose' are for Swales essential features within a genre.

On the one hand, Swales (1990, pp. 471-473) describes a discourse community as sharing six essential features:

1) it "has a broadly agreed set of common public goals";

2) it "has mechanisms of intercommunication among its members";

3) it "uses its participatory mechanisms primarily to provide information and feedback; 
4) it "utilizes and hence possesses one or more genres in the communicative furtherance of its aims";

5) "in addition to owning genres, a discourse community has acquired some specific lexis"; and

6) it "has a threshold level of members with a suitable degree of relevant content and discoursal expertise".

Some examples of discourse communities are the academia, the politics, or even Twitter. The members of these communities share goals, can communicate with each other and have specific genres with a specific lexis that is acknowledged to different degrees by each of the members.

On the other hand, in this definition, Swales describes 'communicative purpose' as one of the defining traits of genres. Swales argues that the communicative purpose (or "common set of goals") of a discourse community becomes the gluing element in the community over the rest of discoursal characteristics. He states that the "[c]ommunicative purpose is both a privileged criterion and one that operates to keep the scope of a genre [...] narrowly focused on comparable rhetorical action" (Swales, 1990, p. 58). In other words, the communicative purpose is the central element delimiting the borders of the genre. This idea, however, is not always clear-cut. Askehave (1999), for example, argues that although communicative purposes can indeed determine genres, texts rarely perform one single function and thus, determining a genre based on its communicative function seems to provide an uncomplete outcome. This proposal is further adapted by Askehave and Swales (2001) and Swales (2004) who accept the idea that although communicative purposes remain important within a given genre, they cannot be per se defining traits and argue that it is only through the results of a context-driven analysis that one could confirm the communicative purpose of a text.

Swales's definition has been further expanded and completed by many researchers Bhatia, (1993), Freedman and Medway (1994), or Yates and Orlikowski (1992), just to name 
a few. The most complete one seems to be Bhatia's (1993, p. 13), who expands on Swales's definition and refers to genre as

\begin{abstract}
a recognizable communicative event characterized by a set of communicative purpose(s) identified and mutually understood by the members of the professional or academic community in which it regularly occurs. Most often it is highly structured and conventionalized with constraints on allowable contributions in terms of their intent, positioning, form and functional value. These constraints, however, are often exploited by the expert members of the discourse community to achieve private intentions within the framework of socially recognized purpose(s).
\end{abstract}

One of the most relevant additions in Bhatia's definition is the inclusion of a reference to the professional and academic discourse communities. In this sense, as I discuss in section 1.2.2 below, genre analysis has received special attention within the fields of English for Academic and Professional Purposes -see, for instance, Brett (1994) or Dudley-Evans (1986, 1987) for approaches towards English for Academic Purposes (EAP), and Paltridge (2013) for a review of English for Specific Purposes (ESP) studies. Bhatia also refers to genres as "highly structured" events. The study of recurrent macro-structures in genres is one of the aims of genre analysis -see for instance Young (1994). In the present study, I aim to explore the macro-structure of lectures from a multimodal perspective, looking into how lecturers create sequences of actions that serve as structuring elements in the lecture.

Another defining trait highlighted in Bhatia's description of genre is the notion of 'constraints' -see also Kress (1989). Genres show a series of constraints that establish their boundaries. Constraints delimit what is acceptable and what is not within a given genre. As Bhatia (1993, p. 14) states, "this is one of the main reasons why most of us are able to distinguish a personal letter from a business letter, an advertisement from a promotional letter or a newspaper editorial from a news report". Finally, the last addition in Bhatia's definition is the reference to the expert members in a discourse community and their connection to the genre constraints. He argues that specialists in a genre can make use of the genre's constraints for their own purposes; for example, when an expert journalist transmits their own biased views in an unnoticed manner. All in all, Bhatia seems to offer an applied version of Swales's definition of genre that reflects upon the use of genres by their users as they bend the constraints intrinsic to each genre. Furthermore, Bhatia refers 
to some of the analytical issues posed by genre analysis as he describes the importance of professional and academic genres and the study of structures. Bhatia's view of genre, where the academic discourse and the importance of structures are foregrounded, seems to fit the purposes of my study as it could help unfold some of the intricacies in the structuring process of academic lectures.

The study of genres is commonly referred to as 'genre analysis' and is defined as "the study of how language is used within a particular context" (Hyland, 1992, p. 15). Fang (2012) extends the scope of the field as she argues that genre analysis provides an inside into the construction processes of genres. This view seems to reinforce the idea that the study of structuring mechanisms is an important issue within the study of genres. The approaches and different foci, however, are varied. Three main schools can be identified within the field of genre analysis: the New Rhetoric School (Bazerman, 1988; Freedman \& Medway, 1994; Miller, 1984; Yates \& Orlikowski, 1992) whose focus is on social and contextual issues (Hyon, 1996) and investigates native speakers of English in advanced education; the Swalesian or ESP School (Bhatia, 1993; Dudley-Evans, 1986, 1987, 1994; Johns, 1997; Swales, 1990), which is interested in the analysis of academic and professional settings emphasizing the focus on non-native speakers in tertiary education and the descriptions of structural and grammatical features; and the Australian or Sydney School (Martin, 2000b, 2006; Martin \& Rose, 2005), which makes use of Hallidayan SFL to explore grammar, lexicon and discourse structures on genres, particularly in native speakers in primary and secondary schools. In the present study, I side with the Swalesian approach towards genre analysis. As I illustrate in Section 1.2.3 below and in the analyses in Chapter 5, the approach I follow is influenced by studies on the structure of lectures -see for instance Young (1994)and analyses on lecturing styles -for example, Dudley-Evans (1994). 


\subsubsection{Genre analysis in academic settings}

In the previous section, I have outlined how genre analysis has traditionally placed its focus on the study of ESP, i.e. English in professional settings, and EAP, i.e., English in academic settings, particularly in the case of the Swalesian School. It is precisely the exploration of an academic genre, the lecture, the main aim of this thesis. In this section, I briefly go through previous literature in the study of academic discourse with a particular emphasis on oral academic genres and I show how these studies are relevant for the purposes of my study.

The study of academic genres has been prolific throughout the last decades, at first with a focus on written genres, and more recently with a shift towards the study of spoken genres. Although the focus of my study is exclusively on the study of lectures, it seems fair to acknowledge some of the main studies exploring written discourse. Researchers exploring written discourse have analyzed, for example, different sections in research articles (Bhatia, 1993; Kanoksilapatham, 2005; Ozturk, 2007; Paltridge, 1997; Swales, 1981, 1983, 1984, 1990), textbooks (Myers, 1992), or PhD dissertations (Bunton, 2002; Hyland, 2004b; Kwan, 2006). Moreover, the study of variations across disciplines and languages has also been the focus of some researchers -see, for example, Árvay and Tankó (2004), FortanetGómez, Posteguillo, Palmer, and Coll (1998), Hirano (2009), Holmes (1997), Hyland (2000), or Samraj (2002).

Although much research has been conducted in the analysis of written genres, I aim to explore a spoken genre: lectures. In this respect, research conducted in spoken genres can be categorized as focusing on two broad fields of study that have received most attention in the last years: conference presentations and lectures. The former have been studied, for example, comparing their structure with research articles (Rowley-Jolivet \& CarterThomas, 2005); with a focus on narrative discourse and the language of presentations (Ruiz-Garrido \& Fortanet-Gómez, 2008; Thompson, 2002); and focusing on various parts such as the introductions (Hood \& Forey, 2005), and the discussion sections (Querol-Julián \& Fortanet-Gómez, 2012). The study of lectures, on the other hand, has focused on the 
study of rhetorical structures (Young, 1994) with a focus on different parts like the introductions (Lee, 2009; Palmer Silveira, 2004; Thompson, 1994), and the conclusions (Cheng, 2012); the study of lecturing styles (Dudley-Evans, 1994; Goffman, 1981), the use of lexico-grammatical features (Biber, Conrad, \& Cortés, 2004; Fortanet-Gómez, 2004a; Giménez, 2000; Lee, 2009); the use of questions to enhance students' participation (Morell, 2007); or the use of asides (Strodt-López, 1991), to name a few. A more extensive review on some of these studies is provided under Section 1.3 and its subsections.

Spoken academic genres can be classified in different manners. Giménez (2000, p. 42, my translation), for example, classifies spoken academic genres according to the aims of the genre and the degree of interaction between speakers and listeners. According to her, spoken academic genres are classified as:

a) Expository genres: the talk (at a conference), the paper presentation, the poster presentation, the presentation, etc.

b) Interactive genres: the interview, the speech, the workshop, the negotiation, the academic meeting, the department meeting, etc.

c) Teaching genres: the tutorial, the seminar and the lecture.

Morell (2002), however, suggests that some objectives in this classification can overlap. For example, she argues that the lecture (as understood in her study) can have more than one objective as it can present material (expository genre), it can include interaction (interactive genre) and it is also used to teach students (teaching genre). Moreover, Fortanet-Gómez (2005) argues that the association of the degree of interaction between speakers and listeners together with that of the purpose of genres in Giménez's categories is confusing. She then presents a new classification solely based on the purpose of the genre without taking into account the degree of interaction between speakers and listeners. Fortanet-Gómez describes three main types of spoken academic genres: classroom genres, research genres, and institutional genres (see Figure 1.5). Classroom genres, on the one hand, refer to those genres that can be encountered in tuition processes and which are relevant for students and teachers (lecture, seminar, tutorial interview, 
students' presentations and oral exams). A second category, research genres, encompasses genres that are related to the research process. This category is subdivided into conference genres, i.e. those genres that are related to the process of giving talks in conferences, (plenary lecture, paper presentation, poster presentation, workshop and research meeting); and other research genres, which include genres that take place at the university (PhD thesis defenses, Master's thesis presentations and research projects). Finally, Fortanet-Gómez creates a third category, labelled 'institutional genres' where she encompasses those activities that cannot be directly linked to the classroom or to research purposes (academic year opening lectures, commencement addresses, Honoris Causa speeches, prize acceptance speeches, Presidents' or Rectors' addresses to the faculty, and memorial services for recently departed professors).

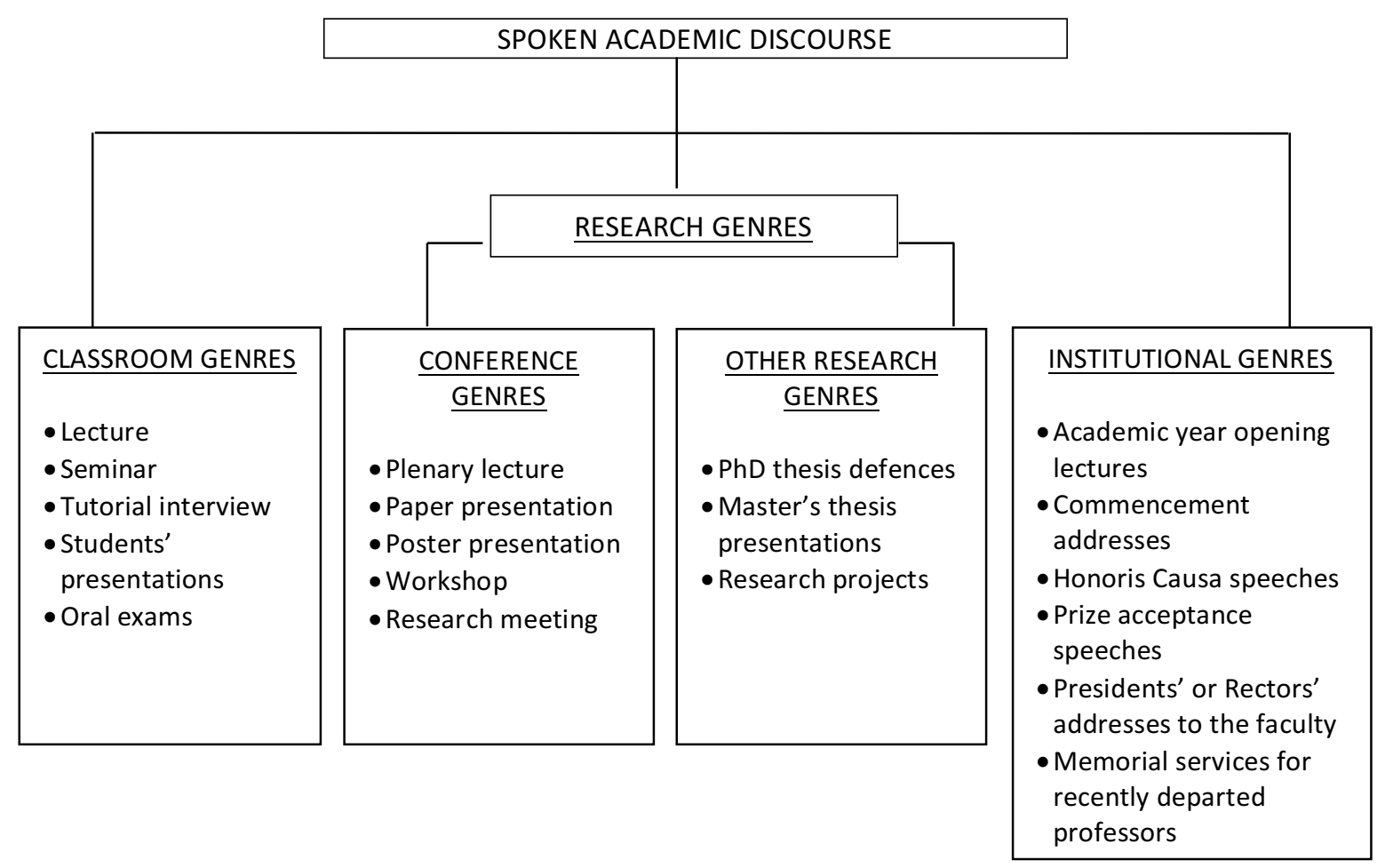

Figure 1.5 Classification of spoken academic genres according to their purpose. Adapted from Fortanet-

$$
\text { Gómez's (2005, p. 32) }
$$

Fortanet-Gómez offers a comprehensive description of spoken academic genres. Lectures are described as an element in the tuition process that becomes relevant for both teachers and students. I would add that lectures become essential in the learning process in higher 
education, "the central ritual of the culture of learning" (Benson, 1994, p. 181). In Flowerdew's (1994, p. 1) terms, "the lecture remains the central instructional activity".

\subsection{The genre of lectures}

The main focus of this thesis is on academic lectures. Lectures, as I stated above, are considered one of the central genres in the learning process in higher education; it is the academic genre par excellence (Varó Alcaraz, 2000). Bligh (2000) defines lectures as oral presentations in which a particular topic is developed. He explains that lectures appeared in the first universities as a tool to share information with large audiences at a time when books were rare. Even though higher education institutions evolved along the centuries, lectures are still present and central in teaching.

The concept of lecture as employed in this thesis is a complex one that requires clarification. Lectures constitute a classroom genre (Fortanet-Gómez, 2005) in which a lecturer delivers new information to students in a lecture room, about a specific topic, and generally through spoken interaction (Malavska, 2016). Lecturers, in turn, possess a degree of expertise on the given topic and are involved in the lecture providing the audience with information as well as opinions (Chafe, 1982; Malavska, 2016; Thompson, 1994). Furthermore, Malavska (2016) argues that lectures are characterized by having a speech plan (Bakhtin, 1986) that may be more or less followed with a degree of improvisation. In this sense, I argue that the extent to which improvisation plays an important role in lectures is determined by the lecturing style of the lecturer (see Section 1.3.1.1 below). In addition, lectures are an example of genre mixing (Helal, 2013), as lectures often combine speech with written texts like PowerPoint presentations, or the use of new technologies and software. Finally, Malavska (2016) argues that lectures have intertextual features as draw from previous texts that are referred to during the lecture (Crawford Camiciottoli, 2007).

The lectures considered for this thesis commonly consist of 40-minute to one-hour 
sessions $^{3}$ that are organized into courses, i.e. successions of lectures (roughly 20 to 25 ) that develop one broad subject matter -for example "The American Revolution" or "History of Epidemics".

Having said that, "lectures are not homogeneous" (Fortanet-Gómez \& Belles, 2005, p. 162). A basic distinction may be established between two main types of lectures: monological (or non-interactive) and interactive lectures. In this sense, Waggoner (1984) suggests that new interactive methods are changing the traditional lecturing landscape. Interactive lectures have been studied from genre analysis perspectives. Morell (2004), for example, compares the discourse in interactive and in non-interactive lectures in terms of textual and interpersonal discursive strategies showing a greater amount of these elements in interactive lectures.

On the contrary, the use of traditional lectures in today's universities has received some criticism: DiPiro (2009), for example, argues that passive lectures are not acceptable in pharmaceutical education, as successful practice in pharmacy cannot be acquired passively. In this line, Twigg (1999, p. 14) claims that lectures are "notoriously ineffective in engaging students".

To this complex scene a new element has been increasingly introduced in the last decade: online lectures -see, for instance, Schultze-Mosgau, Zielinski, and Lochne (2004), or Williams, Birch, and Hancock (2012). Kini (2011) argues that this new type of lecture is the result of policies to engage students at a low cost. Still and all, different outcomes are achieved when comparing traditional and online lectures. This is shown by Rabe-Hemp, Woollen, and Humiston (2009), who carry out a comparative analysis and demonstrate that online attendants were more reflective and involved in discussions and devoted more time to prepare the course. Traditional students, in turn, seemed to be more collaborative with their classmates.

Be that as it may, the study here presented is based on traditional non-interactive (monological) lectures as defined by Waugh and Waugh (1999, pp. 35-36):

\footnotetext{
${ }^{3}$ The term session is often used in this thesis as a synonym of lecture in order to avoid repetition.
} 


\begin{abstract}
A lecture is a teaching method where the lecturer talks, acts, persuades, cajoles; in fact, has perfect freedom to do whatever is desired, except to ask students to answer questions. The students do not discuss in the lecture the information conveyed, or question the lecturer verbally. If we think about teaching as a spectrum of techniques, at the one end we may have the pure Socratic method where the teacher only asks questions, and only the students give answers. At the other end of the spectrum, we have the straight lecture with no active or verbal participation by students at all. Within the spectrum, we have various other forms of modified lectures, tutorials and seminars. It is the extreme end of the spectrum, the straight lecture with no active student verbal participation at all, that we are discussing here.
\end{abstract}

As I expand in Chapter 4, even though the lectures in this thesis have been extracted from an online platform, they consist of traditional face-to-face sessions that were recorded and uploaded online with no editing process to adapt them as part of an OpenCourseWare. Traditional lectures are considered by many researchers as a valid method for teaching. Carlson (2005) shows how lecture-based approaches have obtained higher ratings by students when compared to problem-based learning. Similarly, van der Merwe, van Zyl, Nel, and Joubert (2014) suggest differences in the perception of traditional lectures by both, lecturers and students; while the former mostly agree with the statement that traditional lectures are outdated (54.7\%), only $39.8 \%$ of the students think so. In terms of motivational techniques, Hodgson (2005) studies the importance of lecturer enthusiasm as a tool to promote deep learning. Jones (2007) agrees with Hodgson and suggests that lecturers' engagement with the students can be achieved through empathy and emotional connection. Finally, Crawford Camiciottoli $(2007$, p. 3), in her study on business lectures, provides a series of arguments favoring traditional lectures:

from the practical and tactical points of view, lectures do offer some advantages [...] With classes of a hundred or more students, which is unfortunately often the reality of today's academic world, lectures are basically the only feasible teaching method. They lend themselves well to course pre-planning with detailed syllabuses to structure content, allowing teachers to cover material efficiently and adequately. At the same time, lectures can help students to streamline learning since they can take in content much more quickly than if they had to find it for themselves. Moreover, once a lecture has been prepared, it can be rather easily updated and re-used. 
In fact, she claims that (traditional) "lectures in universities are probably here to stay". In the following sections, I further explore the genre of lectures. In Section 1.3.1 and its subsections, I review some previous literature that is relevant for the present thesis, namely research on lecturing styles and the structure of lectures. Next, in Section 1.3.2, I examine the onset of studies on lectures from a multimodal point of view, and finally, in Section 1.3.3, I briefly refer to recent studies carried out on OpenCourseWare.

\subsubsection{Previous literature on lecture analysis}

As I have referred to in sections 1.2.2 and 1.3, research on academic lectures is extensive. Much of the focus within lecture analysis research has been placed on lecture comprehension -see, for instance, Buck (2001), Flowerdew (1994), Lebauer (1984), Lynch (1994), or Richards (1983)-, or the interpersonal factors influencing the learning process see Flowerdew and Miller (1992), MacDonald, Badger, and White (2000), Rounds (1987), or Thompson (1992). In addition, numerous studies have also been conducted with the aim of exploring lexico-grammatical features in the discourse of lectures -for instance, Biber et al. (2004), Biber, Johansson, Leech, Conrad, and Finnegan (1999), Fortanet-Gómez (2004a, 2004b), or Giménez (2000).

These studies, however, focus, on the one hand, on the learning process of the students and the way knowledge is acquired, and on the other hand, on linguistic aspects of the discourse. In my thesis, I turn to the role of lecturers as structurers and organizers of content in order to facilitate learning. Although I depart from a linguistic examination of metadiscourse as an element present in structuring sections, I look at lecturers as social actors who convey meaning through a multiplicity of modes and who structure lectures not only linguistically, but also through the use of several semiotic resources and as sequences of mediated actions. In this sense, two aspects seem to play an important role in how lectures are developed in previous genre analysis literature: the lecturing style of the 
lecturers and the types of macro-structural patterns they develop. These two aspects are discussed in the subsequent sections.

\subsubsection{Lecturing styles}

The lecturing style refers to the ways in which lecturers transmit their knowledge and it can be categorized following various parameters like formality or linguistic structures (Morell, 2002). The interest in the examination of lecturing styles (in 'traditional' lectures) can be traced back to the 1970s. Morrison (1974) distinguishes between formal lectures, which are closer to spoken prose and are delivered in a formal register, and informal lectures, which contain an elevated amount of informational content that is not necessarily delivered in a highly formal register. Although Morrison's classification serves as a broad categorization of lectures according to their formality, it offers little insight into the specific features of lectures. In this sense, Goffman (1981) presents a classification of lecturing styles based on the degree of interaction with the students. He distinguishes three modes of lectures: memorization, aloud reading and fresh talk. Memorization and aloud reading are very similar with the difference that in memorization sessions lecturers do not read their lectures but have memorized them instead. Fresh talk lectures, on the other hand, refer to sessions in which utterances are formulated one after the other in response to the current situation in the classroom. In other words, lectures are delivered in a rather conversational manner with the assistance of notes. Goffman (1981, p. 172), however, states that "fresh talk itself is something of an illusion of itself, never being as fresh as it seems". Goffman's classification is somehow more complete than Morrison's; still, the differences between memorization and aloud reading are not clearly described, and fresh talk lectures seem to be restricted in terms of how spontaneous they are. In this sense, Dudley-Evans and Johns (1981) and Dudley-Evans (1994) present a classification of lecturing styles that seems to be partially based on the degree of the use of notes in the lectures. Thus, they identify three lecturing styles: 
a) Reading style: It comprises lectures "in which lecturers either read the lecture or deliver it as if they were reading it" (Dudley-Evans, 1994, p. 148). In terms of phonological characteristics, Dudley-Evans and Johns (1981, p. 34) describe it as "characterized by short tone groups, and narrowness of intonational range" with a predominant falling tone.

b) Conversational style: It refers to those lectures "in which lecturers deliver the lecture from notes and in a relatively informal style with a certain amount of interaction with students" (Dudley-Evans, 1994, p. 148). Tone groups are here longer and move from high to low. Moreover, tempo may increase while intensity decreases at the end of a low key sentence. In other words, lecturers speed their pace and decrease the volume at the end of utterances.

c) Rhetorical style: It encompasses sessions "in which lecturers give a performance with jokes and digressions" (Dudley-Evans, 1994, p. 148). This lecturing style offers the widest intonational range. Asides and digressions are present and may be marked by key and tempo shifts.

Dudley-Evans and Johns's (1981) classification, though over 35 years old, seems to be generally accepted by researchers and has not been modified so far. In fact, this classification has proven to be useful, for instance, in the study of lexical phases in lectures (DeCarrico \& Nattinger, 1988); in the exploration of engagement through a multimodal study of semiotic resources constrained by lecturing styles (Bernad-Mechó \& FortanetGómez, forthcoming); or in a multimodal analysis of interaction (Crawford Camiciottoli, 2016). Dudley-Evans and Johns's (1981) description of lecturing styles offers, in my view, a more accurate representation of traditional lectures that describes lecturers in terms of how static lectures are. While reading style lectures seem to offer little room for improvisation, conversational and rhetorical style lectures can include a degree of spontaneity, particularly common in the latter. In this sense, the extent to which lecturers can show improvisation appears to be determined by the use of notes. Still and all, the reference to the use of notes is not made explicit in Dudley-Evans and Johns's (1981) description of rhetorical style lecturers. For the purposes of this study, I categorize lecturers 
in Dudley-Evans and Johns's terms by taking into account the interaction of lecturers as they resort to their notes. Therefore, reading style lecturers read through their notes most of the time -although some spontaneous commentaries can be found-; conversational style lecturers follow their notes most of the time but do not read through them; and rhetorical style lecturers rarely employ notes (see Figure 1.6).

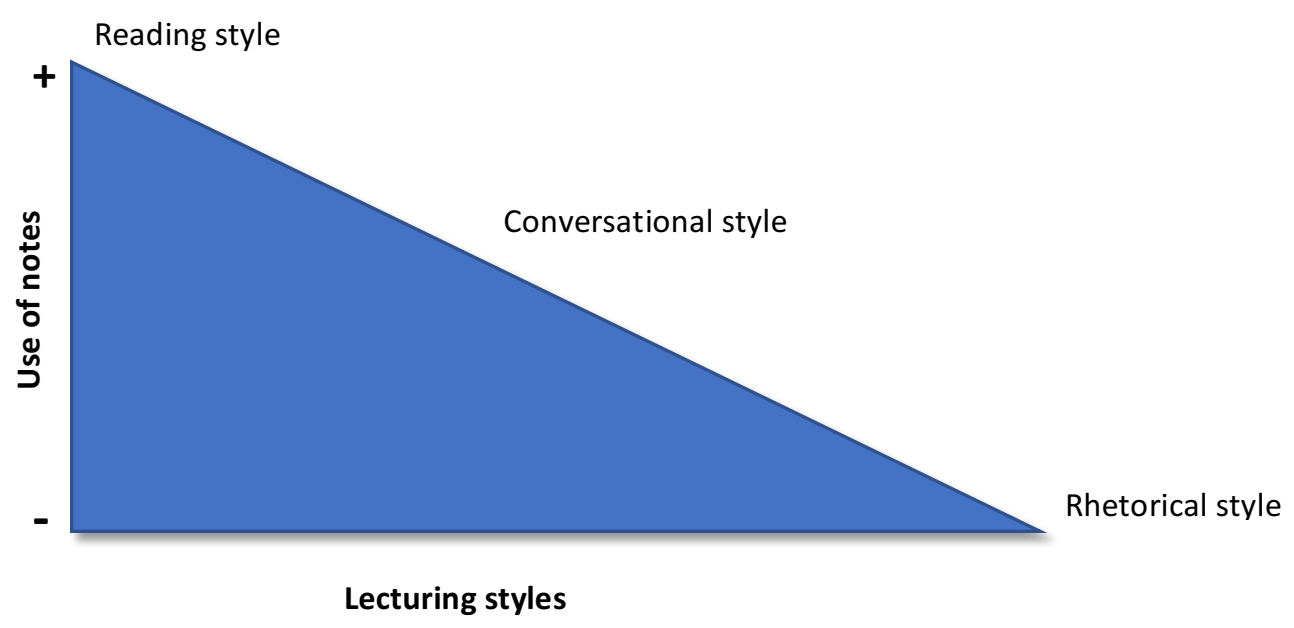

Figure 1.6 Lecturers' dependence on notes according to lecturing styles

Finally, lecturing processes, i.e. the ways in which lectures are approached by the lecturers, have been examined in relation to the roles attributed to the lecturers and the students. Northedge and McArthur (2009, p. 110) identify four basic roles:

a) Apprentice-scholar model: This model "foregrounds learning how to function as a member of the discipline community, through researching debating, publishing" and so on. In this model, lecturers guide students by suggesting readings that foster their critical thinking. Fortanet-Gómez (2013) suggests that this approach seems more appropriate for upper undergraduate and PhD studies.

b) Lecture-centered model: It "foregrounds the knowledge produced by the discipline community: how it can be assembled, organized, encapsulated and presented". In other words, the focus is on the content. In this approach, students may or may not have a passive role and "learn through listening to exposition of the subject matter" (Fortanet-Gómez, 2013, p. 160). This model coincides with Waugh and Waugh's 
(1999) description of lectures (see Section 1.3) and with the approach to lectures taken in the present study. As described above, these types of lectures can be useful, for instance, in contexts with a large number of students or when a great amount of content needs to be covered in a short period of time. This system is particularly common in undergraduate studies.

c) Radical student-centeredness: This approach "foregrounds development of self, realignment of values, coping with acquiring an identity as a member of a knowledge community". In this approach, students are in charge of their own learning process. Lecturers serve as facilitators in this learning process and as support for the students. Possibly, this approach is appropriate for workshops or classrooms with few students.

d) Constructivism: This model "foregrounds the processes of cognitive reorganization and development entailed in making sense within an unfamiliar field or knowledge". In this approach, lecturers are involved in an active process with students and provide opportunities to stimulate the students' minds through problem solving, reflection or debating (Fortanet-Gómez, 2013). Constructivism seems appropriate at all levels of higher education.

The description proposed by Northedge and McArthur (2009) defines lectures in terms of the involvement of the lecturers and the students in the active process of learning. Northedge and McArthur argue that these models can be combined in the teaching practice depending on the specific aims of the session. The description of approaches to lectures here described serves to define the type of lectures explored in this thesis in relation to the involvement of the lecturers and the students. Thus, in the present study, I am concerned with lecture-centered lectures. In particular, I examine reading, conversational and rhetorical lecture-centered lectures. These lectures are characterized by being delivered by lecturers that provide high amounts of content information and students that have no interaction in the lecture and learn by listening to the contents. This particular approach to lecturing requires the delivery of large sets of content in a short period of time (usually 40 minutes to 1 hour). Moreover, the students' learning process 
takes place both in the listening process and after the lecture during the revision of the notes that have been taken. It seems necessary, then, for the information to be organized and structured in a comprehensible manner that facilitates the knowledge transmission. It is precisely the study of how this organization takes place the main purpose of my thesis.

\subsubsection{The structure of the lectures}

As I discussed in Section 1.2.1, one of the aims of genre analysis theory is the exploration of the structures of genres -see Bakhtin (1986), Bhatia (1993), or Swales's (1990) definitions of genre. This is no exception in the genre of lectures, where the structuring and organizational mechanisms become essential in the listening comprehension process (Flowerdew \& Tauroza, 1995; Fortanet-Gómez \& Belles, 2005; Strodt-López, 1991; Thompson, 1994; Young, 1994), and to engage the active learning of students (Race, 1993). The importance of structuring processes of lectures is also recognized by Chaudron and Richards (1986) and DeCarrico and Nattinger (1988) who bring to the fore the relevance in the comprehension process of explicit verbal signals reflecting on the structure of the lectures. These signals, as I discuss in Chapter 3, can take place in the form of metadiscourse -see Ädel (2006) and Hyland (2005)-, which is one of the elements that I will explore in detail in my study. Organizational metadiscourse is particularly useful to establish connections among chunks of information across the course. In this sense, Revell and Wainwright $(2009$, p. 214) refer to the structure of the lecture as one of the highlighted aspects to achieve excellence in lectures. In their study, students identified as one of the features in 'unmissable' lectures "a clear structure which enabled [them] to identify key points and make integrative links with other areas of the course". In short, the structuring process of lectures seems to be "a complex and multi-faceted phenomenon" (Thompson, 2003, p. 6).

Some pioneering research into the structure of lectures was conducted in the late 1970s and early 1980s. Bligh $(1972,2000)$, for example, outlines the basic contents of a lecture as 
including three main sections, an introduction, a body and a conclusion, that are developed differently depending on the subject matter (hierarchically, as a chain of events, etc.). This traditional view of lectures as divided into three states does not seem to be outdated and is supported and encouraged by other researchers. Race (2001) and similarly Chan (2015) argue that lectures should be organized in a beginning, that lets the students know what the lecture is going to be about; a middle, where the main content is explained; and an end, where the lecturer reminds the students of the contents that have just been unfolded. Although this perspective towards the structure of lectures may be useful during the lecturers' preparation of sessions, it seems rather simplistic from a discourse analysis point of view. In this sense, studies within genre analysis explore the structure of lectures as sequences of sub-elements that carry out distinct functions.

One of the examples of an extensive investigation on the structure of lectures is Cook (1975). This researcher regards lectures as made up of series of expositions which are similar to what he describes as pedagogical phases determined by the teaching content of the lecture. Expositions, in turn, are made up of episodes, which consist of strands of speech with specific functions. Cook identifies four types of episodes: expectation, focal, developmental and closing episodes. Moreover, he refers to twelve types of moves occurring in the lectures: focusing, concluding, describing, asserting, summarizing, relating, recommending, listing, justifying, qualifying, contrasting and explaining. Although the identification of moves in Cook's description of the structures of lectures seems to explore a wide range of functions, it lacks an extensive description of their individual characteristics and how they succeed one another. In addition, and even though some organizational metadiscoursal categories are identified (focusing, concluding, summarizing, relating, listing), other categories that play an important role in the organization of lectures -like introducing a topic or outlining the contents- seem to be missing.

Another commonly cited work in the study of the structure of lectures is Young (1994). In her paper, Young examines the macro-structures of lectures in terms of phases and describes some of the micro-features that characterize these phases. Following a SFL approach, she explores seven lectures in order to find out recurrent patterns in their 
structures. In order to carry out this analysis, Young uses Gregory's (1983) concept of phase. She describes phases as:

strands of discourse that recur discontinuously throughout a particular language event and, taken together, structure that event. These strands recur and are interspersed with others resulting in an interweaving of threads as the discourse progresses (Young, 1994, p. 165).

Thus, Young describes lectures as sequences of intertwined phases rather than as a structure with three broad sections. Through the use of phases, Young is able to explain recurrent patterns in selected instances in the text and go beyond traditional descriptions of lectures. In Young's (1994, pp. 164-165) words,

[w]ith phasal analysis we can configure different patterns, different threads of a discourse. Phasal analysis seems to reveal a more accurate configuration of the discourse structure of university lectures than alternatives which characterize lectures in terms of a beginning, or introduction, a middle or body, and a conclusion [instead] there are many beginnings, many middles and many ends.

These phases, in turn, can be identified according to the semantic and syntactic choices made by the speaker. Thus, a phasal analysis allows for a fine-grained linguistic analysis of how lecturers carry out different activities throughout their lectures. Young (1994, pp. 166168) distinguishes six types of structuring phases. Out of these, three are labeled as metadiscoursal phases (Discourse structuring phase, Conclusion, and Evaluation) and are used to comment on content, and the other three (Interaction, Theory or Content and Examples) are used to develop the content. These phases are:

a) Discourse structuring phase: "addressors indicate the direction that they will take in the lecture". In other words, the lecturer indicates or signals what information will be delivered next.

b) Conclusion: "lecturers summarize points they have made throughout the discourse".

c) Evaluation: "the lecturer reinforces each of the other strands by evaluating information which is about to be, or has already transmitted". In these phases, lecturers make evaluative comments on the content (to emphasize, criticize, etc.). 
d) Interaction: this section includes comments that refer to "the extent to which these lecturers maintain contact with their audience in order both to reduce the distance between themselves and their listeners and to ensure that what has been taught is in fact understood". This phase is focused on the audience and may include comments such as questions to check the proper understanding of the content.

e) Theory or Content: it is during these phases that the main content of the discourse is delivered. These are used "to reflect the lecturer's purpose, which is to transmit theoretical information".

f) Examples: "the speakers illustrate theoretical concepts through concrete examples familiar to students in the audience. In other words, the lecturer exemplifies some of the theoretical notions.

Young offers a complete and systematic methodology to examine the structure of lectures in detail. Nevertheless, in my view, Young's model does not fit completely into the analysis I conduct in this thesis. First, Young follows SFL to create her model of phasal analysis. In this sense, she seems to consider all non-propositional material as metadiscoursal phases. Thus, evaluative comments are identified as metadiscoursal under the phase evaluation. As I described in Section 1.1.4 and throughout Chapter 3, and following Ädel (2006), the identification of metadiscourse with all non-propositional material seems too inclusive and therefore, I do not consider evaluation as metadiscourse. Second, the phases interaction and examples, which encompass instances of interaction with the audience and introductions of examples, are considered in most models of metadiscourse as metadiscursive material -see Ädel $(2006,2010)$ or Hyland (2005). In Young's view, these categories are not metadiscoursal. Third, some common metadiscursive categories like the reviewing of previous information or the contextualization of the lecture (see Chapter 3 for a full explanation on these categories) do not seem to be explicitly considered in Young's model; therefore, it is not clear if such references can be categorized as discourse structuring phases or as concluding ones. Finally, the fine-grained analysis offered in Young (1994) may sometimes be impractical when trying to obtain a general overview of how a given lecture is organized. In other words, although Young provides a realistic account of 
macro-structural features for lectures, she does not examine whether phases constitute any organizational sections at an upper level.

With the aim of simplifying the analysis in this thesis, I have introduced the term structuring segment in my study. Focusing on the use of organizational metadiscourse, structuring segments refer to sections in the lecture where there is a higher presence of this type of metadiscourse. By using this concept, I can identify relevant sections in the lecture where organizational processes take place. Structuring segments are commonly found in the introductions of the lectures, although they can also be encountered throughout the lecture, especially in instances where the lecturer moves from one topic to another. These segments, in turn, are made up by successions of phases; mainly discourse structuring phases, but also other metadiscoursal and content phases.

The concept of structuring segment is essential for the development of the multimodal explorations in this thesis, as it is the unit of analysis employed in these analyses. By way of example, I describe in Table 1.1 a structuring segment in the introduction to the lecture in lecture C6_L15 (my corpus) and show how metadiscoursal phases are succeeded and interspersed with content ones. For practical reasons, I have considered reviewing sections within the phase concluding, although this is not clearly made explicit in Young (1994). During the introduction to this lecture, the lecturer reviews some concepts dealt with in previous sessions and outlines the contents of the present one; these actions are characterized by an ample use of organizational metadiscourse. However, the lecturer intersperses the organization of the lecture with short fragments where theory is discussed. In a phasal analysis, this is shown as series of metadiscoursal phases interrupted by content ones.

All in all, by looking at structuring segments rather than at individual structuring phases, a more general view of how the organization of lectures occurs can be obtained. By considering structuring segments as organizational fragments, I explore how the structuring process is signaled in terms of use of semiotic resources (see Chapter 7), and as a series of actions carried out by the speakers (see Chapter 8 ). 


\begin{tabular}{|c|c|c|}
\hline TIMESTAMP & TEXT & PHASE \\
\hline 00:01:15 & $\begin{array}{l}\text { I want to return briefly to "desengaño," because there may be some } \\
\text { confusion caused by "disillusionment", the English word used to translate } \\
\text { the term, which is an approximation as all translations are. }\end{array}$ & $\begin{array}{l}\text { Discourse } \\
\text { structuring }\end{array}$ \\
\hline 00:24:04 & $\begin{array}{l}\text { "Disillusionment" can mean in English "disenchantment" and } \\
\text { "disappointment," words that have a very negative connotation whereas, } \\
\text { "desengaño" does not quite have that connotation. At worst, it could mean } \\
\text { "resignation", meaning, I was resigned to find out that such-and-such a } \\
\text { person was not as good as I thought him or her to be. }\end{array}$ & Content \\
\hline $00: 52: 29$ & $\begin{array}{l}\text { Remember the quote from Otis Green that I read you, in which } \\
\text { "desengaño" was thought of as the summum bonum, the ultimate good } \\
\text { desired by the stoic wise man. }\end{array}$ & Conclusion \\
\hline 01:12:10 & $\begin{array}{l}\text { Baroque desengaño is a positive condition at which the individual arrives } \\
\text { after having shed the scales from his eyes }\end{array}$ & Content \\
\hline 01:22:08 & - remember?- & Conclusion \\
\hline 01:24:00 & $\begin{array}{l}\text { and learned of the deceitfulness of appearances of the mystifying allure of } \\
\text { all that he has taken as being valuable. Everything that shines is not gold, is } \\
\text { what the individual learns, having gone through the process of engaño, that } \\
\text { is deceit and desengaño, }\end{array}$ & Content \\
\hline 01:46:15 & to put it in the simplest of terms. & Evaluation \\
\hline 01:50:19 & $\begin{array}{l}\text { What I suggested, moreover is that the plot of the Quixote and that of some } \\
\text { of these stories embedded in it in this Part II go through a similar unfolding } \\
\text { from engaño to desengaño. }\end{array}$ & Conclusion \\
\hline 02:10:22 & $\begin{array}{l}\text { We will be following this development in the episodes that we will be } \\
\text { dealing with during the rest of the semester, some of which are the } \\
\text { culminating episodes in the entire book, not only of the second part, but } \\
\text { the entire Quixote. }\end{array}$ & $\begin{array}{l}\text { Discourse } \\
\text { structuring }\end{array}$ \\
\hline 02:29:10 & $\begin{array}{l}\text { But let us first turn our attention today to two critics whose essays you are } \\
\text { reading this week in the Casebook, }\end{array}$ & $\begin{array}{l}\text { Discourse } \\
\text { structuring }\end{array}$ \\
\hline $02: 40: 23$ & $\begin{array}{l}\text { and this is sort of the highlight, or the high point, I should say, of the } \\
\text { Casebook, these two essays by Auerbach and Spitzer. }\end{array}$ & Evaluation \\
\hline 02:55:15 & $\begin{array}{l}\text { Now, we already saw Auerbach's main thesis in Mimesis, his famous book, } \\
\text { and that that thesis is about the Christian mixture of the sublime and the } \\
\text { low style in the New Testament, and how this led to the emergence and } \\
\text { development of realism and eventually to the novel and to a book like the } \\
\text { Quixote. }\end{array}$ & Conclusion \\
\hline
\end{tabular}

Table 1.1 Phasal analysis -following Young (1994)- in the introduction to lecture C6_L15 (my corpus)

As I have discussed above, the introductions of the lectures are sections where the lecturer may establish connections with previous lectures, outline the contents of the class ${ }^{4}$ and organize the message. In short, introductions seem to play an important role in the development of lectures. According to Thompson (1994, pp. 174-175), “lecture introductions are significant because they offer an opportunity for the lecturer to establish an interpretative framework for the audience to use as they listen to the rest of the lecture". In this sense, the structure of the introductions to the lectures has received

${ }^{4}$ The term class is used throughout this thesis as a synonym of lecture to avoid repetition. 
attention by many researchers. In her study, Thompson (1994) applies Swales's (1990) genre analysis to the examination of eighteen lecture introductions. She spots two main rhetorical functions carried out in the introductions: the function of setting up the lecture framework, which is found in all the introductions in her corpus, and in which the lecturer aims to provide the audience with information and guidance for the lecture; and the function of putting the topic in context, in which the lecturer situates the audience in the appropriate context to understand the topic. Furthermore, Thompson (1994) identifies several sub-functions (see Figure 1.7). Thus, the function of setting up the framework may include the sub-functions of announcing the topic; indicating the scope of the topic, i.e. how much about the topic will be said; outlining the structure of the lecture; and/or presenting the aims of the lecture. On the other hand, when putting the topic in context, the lecturers can show the importance of the topic, i.e. they can provide evaluative comments that reflect on the significance of the topic; relate new to given, in other words, appeal to the shared knowledge with the audience; and/or refer to earlier lectures. She further describes how several sequences of these sub-functions are arranged in the lectures. However, Thompson's (1994) analysis of functions in the introductions of the lectures focuses on the roles of individual strands of text rather than on their contents. Moreover, unlike Young (1994), this researcher does not consider the presence of content fragments interspersed with structural ones.

The structure of lecture introductions has also been examined in terms of the size of the audience (Lee, 2009). Lee suggests that the size of the class has an impact on the structure and lexico-grammatical features of the introductions. To conduct his study, Lee explores five small-size classes (12 to 24 students) and five large-size classes (100-250 students). He identifies that the same rhetorical moves are present in both corpora (warming up, setting up the lecture framework and putting the topic in context); however, lecturers in larger classes tend to offer reminders of class-related issues and refer to the main topic repeatedly and to upcoming lectures, while lecturers in smaller lectures tend to make more digressions and establish teacher-learner rapport. In this regard, the dataset compiled for the present study is centered on the lecturer and does not take into account the number of students enrolled in the courses. Therefore, I do not consider this variable in my study. 
However, given the fact that the lecturers perform lecture-centered sessions with very little interaction, it could be argued that these courses are designed for large audiences.

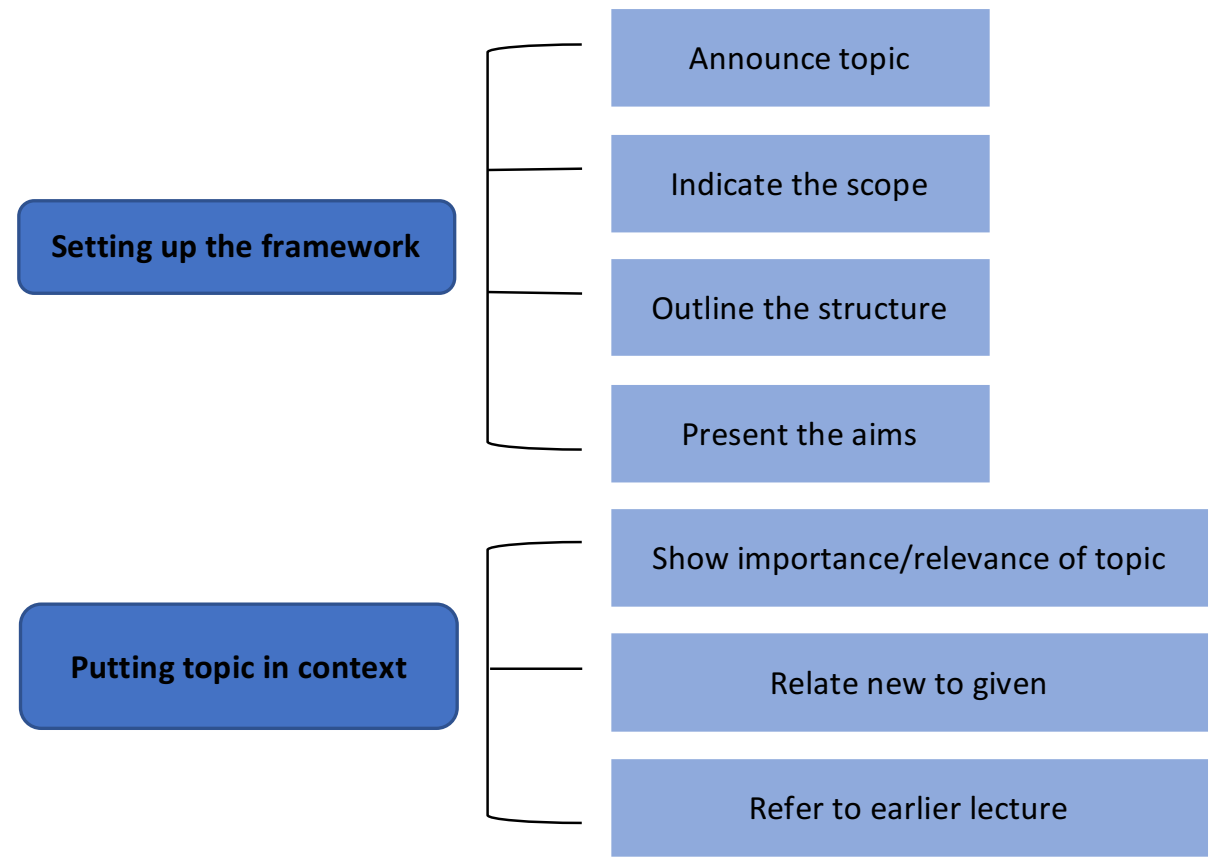

Figure 1.7 Thompson's (1994) functions and sub-functions in lecture introductions.

Finally, another element within lecture introductions that has been approached in detail is the introduction of topics. The introduction of a topic gives the audience information regarding the main topic of discussion and related concepts, as well as the purpose of the lecture (Palmer Silveira, 2004), and therefore, it contributes to easing the comprehension of the session. These introductions are generally found within discourse structuring phases where "the lecturer explicitly involves the students in the unfolding of the information, thereby ensuring that the audience is aware of the nature of the activity in which they are both engaged" (Young, 1990, p. 85). In this sense, Palmer Silveira (2002) argues that lecturers should aim at organizing the contents in an easy-to-follow manner and clearly state the purposes and the topics of the lectures. In a corpus-driven study, Palmer Silveira (2004) examines the ways in which topics are introduced in thirty lectures. He identifies the following trends: 
a) explicitly introducing the topic followed by an occasional outline of the lecture;

b) explicitly introducing the topic by using some references to previously acquired knowledge;

c) introducing the topic through an example; and

d) introducing the topic through the use of a humorous remark.

According to Palmer Silveira, types a) and b) are the most commonly occurring while types c) and d) are uncommon. Types a) and b) seem particularly interesting in the present study. Explicit introduction to topics might be performed through the use of metadiscourse (Ädel, $2006,2010)$ as one of the resources that lecturers could turn to. In this sense, the examination of metadiscourse (see Chapter 3) may be of interest in order to delve into Palmer Silveira's results.

All in all, the study of the structure of lectures -and the examination of lecture introductions in particular- is of recurring interest for many researchers. Still, all previous research outlined in this section is based on linguistic accounts of discourse. In this regard, the study of how lectures are structured multimodally and how metadiscourse is conveyed both verbally and non-verbally has traditionally been neglected. In this thesis, I intend to go beyond a linguistic exploration of the structure of lectures and I analyze how metadiscourse is conveyed through a multiplicity of modes and how structures are carried out in terms of multimodal mediated actions (Norris, 2004). From this perspective, I explore in Chapter 7 the use of a range of semiotic resources co-occurring with metadiscursive instances in structuring segments. This analysis describes how organizational metadiscourse is conveyed as a combination of modes to guide the audience through the lectures. Moreover, I argue that traditional explorations on the structure of lectures only offer a perspective on the linguistic contents and do not consider the lecturer as a real social actor performing the action of lecturing. In this sense, a multimodal exploration of how lecturers perform different sequences of actions to signal the development of the lecture may provide a further insight into the exploration of structure. This is the focus of Chapter 8 , in which I examine how structuring segments offer different prototypical 
structures in the different lecturing styles, possibly conditioned by a constraint in the use of semiotic resources intrinsically attached to the lecturing style.

\subsubsection{Multimodal studies on lectures}

With the rise of multimodal approaches in the last two decades (see Chapter 2), an interest has been developed by many researchers into the study of lectures beyond a linguistic perspective. Some of these studies consider non-verbal embodied modes to convey meaning -for instance, Bernad-Mechó (2017a), Bernad-Mechó and Fortanet-Gómez (2017, forthcoming), Crawford Camiciottoli (2016), and Thesen (2016)-, the use of visuals (Bruti, 2015; Gunel, Hand, \& Gunduz, 2006), the use of the board (Fox \& Artemeva, 2013), or multimedia learning (Tan, O’Halloran, \& Wignell, 2016). Fortanet-Gómez and Crawford Camiciottoli (2015) argue that multimodal research in the classroom can be looked at from two points of view: by either focusing on the communication process between teachers and students and how this process can be mediated through teaching materials, or by teaching multimodal skills to raise awareness about multimodal texts -see for instance O'Halloran, Tan, and E (2017). In my thesis, I focus on the former, and in particular, on how lecturers convey organizational meaning. In other words, I intend to explore how lecturers communicate the organization of their lectures, with a particular interest in how nonverbal modes contribute to this conveyance of meaning. Although many multimodal studies have been conducted with a focus on lectures, few of them particularly concentrate on lecturers and their communicative process through a multiplicity of modes.

Fortanet-Gómez and Ruiz-Madrid (2014) explore the multimodal extent of questions in guest lectures to facilitate comprehension in the classroom in non-native speakers of English. In order to do so, these researchers compare two lecturers, a native speaker of English and a non-native speaker. In the case of the native speaker, Fortanet-Gómez and Ruiz-Madrid show the interactive function of questions from a multimodal point of view with the particular function of checking comprehension. This seems to be influenced by the 
fact that the students and the lecturer do not share the same common cultural and linguistic background. Moreover, they identify the use of 'okay?' and clusters of questions as elements to call the audience's attention. In the case of the non-native English-speaking lecturer, Fortanet-Gómez and Ruiz-Madrid describe how this lecturer adapts her speech to the students by slowing down the pace of her interaction and using comprehension checks co-occurring with deictic gestures and gaze towards the audience.

Another researcher who has carried out multimodal studies with a focus on lecturers is Crawford Camiciottoli. For instance, in Crawford Camiciottoli (2015), this author analyzes five Humanities lectures with a focus on how explanations are carried out. Using ELAN (Wittenburg, Brugman, Russel, Klassmann, \& Sloetjes, 2006) -see Section 2.4.2-, she explores the co-occurrence of prosodic stress, gaze, and gestures with verbal explanations. At a linguistic level, Crawford Camiciottoli concludes that Humanities lecturers seem to resort to complex explanatory strategies over simpler ones like exemplification, which seems to be common in other disciplines (Crawford Camiciottoli, 2007). The multimodal analysis carried out in this study reveals how explanations commonly co-occur with gaze towards the audience as well as gestures and prosodic emphasis. In this sense, Crawford Camiciottoli argues that this particular combination of modes in explanatory sections reinforces comprehension and carries out the function of engaging the audience in the learning process. In a more recent study (Crawford Camiciottoli, 2016), this researcher goes on to study interactional devices between lecturers and students and how this interaction enhances comprehension. She identifies expected linguistic elements like questions, imperatives and comprehension checks as well as a degree of informality shown through phrasal verbs and idioms. Regarding the use of non-verbal elements, Crawford Camiciottoli shows how non-verbal elements are integrated into the speech to reinforce interactional sections.

These three studies seem to have a common underlying objective, namely the exploration of strategies that contribute to easing the students' comprehension of lectures. Indeed, the multimodal study of lectures raises awareness of the importance of the non-verbal modes in communication. Furthermore, a pedagogical application can be extracted from multimodal research on lectures as the results from these studies may be used in teaching 
training projects. Still and all, to the best of my knowledge, only a few studies have considered the structure of lectures from a multimodal point of view (Bernad-Mechó \& Fortanet-Gómez, forthcoming). McKeachie and Svinicki (2013) and Nilson (2016) argue that the organizational and structuring process of lectures is one of the crucial issues that new lecturers need to face in their first experiences in higher education. In this sense, a multimodal approach towards the structure of lectures would reveal interesting facts about how lectures are organized and how this organization is signaled to the students. Similarly, lecturing styles have not been considered in multimodal studies. In this regard, and even though the use of non-verbal modes varies from person to person and is influenced by personal and social traits (Galloway, 1972), I argue that the lecturing style of a lecturer is a variable that needs to be taken into account when exploring how lectures are structured and how meaning is conveyed multimodally. These aspects have been considered in a series of preliminary studies using the corpus compiled for this thesis:

In Bernad-Mechó and Fortanet-Gómez (2017), we compare the multimodal use of previewing and reviewing metadiscourse in two lectures (one in English and one in Spanish). At a quantitative level, the lecturer using English as a medium of instruction (a conversational style lecturer) used considerably more previewing metadiscourse than the lecturer teaching in Spanish (a rhetorical style lecturer). The use of reviewing metadiscourse, on the other hand, was very similar. From a multimodal point of view, both lecturers appear to accompany spontaneous metadiscursive instances with deictic gestures, gaze towards the audience and a parenthetical intonation characterized by a shorter syllabic duration and a lower volume. In this paper, we argue that the quantitative differences in the use of metadiscourse seem to be related to the lecturing style of the lecturers rather than to the use of one language or another. Thus, the conversational style lecturer would use more metadiscursive devices than the rhetorical one. These results coincide with those in a more recent study (Bernad-Mechó \& Fortanet-Gómez, forthcoming) where we offer quantitative results showing that rhetorical style lecturers employ fewer metadiscursive strategies than conversational or reading style lecturers. In addition, in this study, we examine how lecturers engage students through the use of various semiotic resources during organizational sections. We argue that the semiotic repertoire available to each lecturer is determined by their lecturing styles. By comparing 
the multimodal ensembles performed by 6 lecturers, we show examples of how a rhetorical style lecturer, for instance, makes use of gestures employing both hands, directs his gaze towards the audience, performs posture shifts and uses intonation to give emphasis; a conversational style lecturer alternates her gaze between her notes and the audience, performs gestures with one hand, and combines an eyebrow raising and a rising intonation to provide emphasis; and finally, a reading style lecturer simply uses intonation and facial expression to emphasize organizational sections.

Lastly, in Bernad-Mechó (2017a), I turn to the structuring process of the lectures and I explore how topics are introduced in a History lecture by a conversational style lecturer. By using an MIA approach (Norris, 2004, 2011) (see Section 2.2.3), I describe the sequences of actions performed by the lecturer and the attention devoted to the verbal use of organizational metadiscourse to introduce topics. The results seem to indicate that metadiscourse is used as a transitional element employed by the lecturer to move from one content phase to another. Furthermore, the modal density of these metadiscursive fragments, i.e. the level of attention received, is low. In this sense, introducing topic metadiscourse commonly receives medium attention by the lecturer. Two functions for introducing topic metadiscourse can be identified in this lecture: to signal the direction of the lecture, as expected, but also as a verbal filler while the lecturer organizes his notes. Finally, the multimodal analysis showed that the use of notes as a mediational means seems to play a relevant role for this lecturer. Indeed, two types of actions can be established in this lecture: those that are note-driven and those that are spontaneous.

These preliminary studies shed some new light on the possibilities provided by conducting multimodal analyses focused on the structuring devices of the lecturers that consider lecturing styles as a variable. In the present thesis, I follow these exploratory studies and expand on them. Through a wider exploration of the semiotic resources employed during organizational sections in the lectures (see Chapter 7) and the sequences of actions with varying modal densities performed by the lecturers (see Chapter 8), I provide an overview of the lecture structuring process by means of organizational metadiscourse across lecturing styles. 


\subsubsection{On OpenCourseWare}

Although the aim of this study is not to explore online teaching practices or virtual courses, a word on OpenCourseWare seems relevant, given the fact that the corpus here utilized is extracted from an online compendium of lectures. OpenCourseWare (OCW) constitute online collections of course lectures and lecture materials which are made available to the general public for free. This movement became influential when the Massachusetts Institute of Technology (MIT) decided to make available the core academic materials used in their lectures (syllabi, lecture notes, assignments, and exams) online in the early 2000s (D'Oliveira, Carson, James, \& Lazarus, 2010). OCW has expanded ever since, with hundreds of universities around the world publishing not only materials, but also recorded lectures, and with well-established universities like UC Berkeley and Yale University, together with MIT, as examples of the main promoters (Yang \& Sun, 2013). Most of these OCW are organized under the Open Education Consortium (former OCW Consortium) ${ }^{5}$, an entity that encompasses educational institutions and organizations around the globe with the aim to promote and advance openness in education. Ultimately, the main aim of OCW is to contribute to removing barriers to access education (Smith, 2009; UNESCO \& Commonwealth of Learning, 2015).

The exploration of OCW and their materials has become a field of research within applied linguistics in the recent years with many different foci. O'Rourke, Main, and Cooper (2014), for example, investigate the student perceptions of online interactive versus traditional lectures. They argue that although there is room for much improvement, students were enthusiastic about online lectures. Fukuhara (2008), on the one hand, and Edmundo Tovar and Nelson Piedra (2013) on the other, reflect upon the current status of OCW in Japan and in the world respectively. From a more applied perspective, Sun and Yang (2012) look into the ways in which, proficiency, lecture comprehension, and vocabulary acquisition are enhanced when viewing OCW lectures. They show how proficiency and better content

\footnotetext{
${ }^{5}$ www.oeconsortium.org Last accessed January $8^{\text {th }} 2018$.
} 
comprehension affect positively the process of acquisition of vocabulary. Moreover, they suggest that OCW lectures can be beneficial for the process of learning English. In a more recent study, Yang and Sun (2013), examine how OCW lectures can contribute to the process of vocabulary acquisition of English as a Foreign Language (EFL). Their results show that EFL learners benefited from viewing OCW lectures and gained vocabulary. Moreover, Yang and Sun (2013) also argue that learners were able to learn vocabulary associated with non-verbal elaboration more efficiently, i.e. those words accompanied by a non-verbal input. Finally, as I discuss above, Crawford Camiciottoli $(2015,2016)$ analyzes explanatory and interactive sections in OCW lectures respectively and explores how lecturers convey meaning through a combination of modes.

It is important to remark that OCW differ from Massive Open Online Courses (MOOCs). While the former consist of collections of materials that can be freely accessed and used as the individual desires, the latter are designed as courses with a structure and a number of assignments to be carried out by all enrolled participants and commonly offer certificates of completion at the end. In the case of the MOOCs, the activities and resources are generally accessible during a limited period of time. Moreover, MOOCs encourage interaction among peers through peer-reviewed activities (Martín-Monje, Bárcena, \& Read, 2014). In this regard, Edmundo Tovar and Nelson Piedra (2013) argue that OCW are evolving into social OCW (or OCW-S). In this new type of OCW, students can also obtain certifications at the end of the course, include platforms allowing large-scale feedback, and tools and strategies based on the Social Web principles. One of the main differences between OCW-S and traditional MOOCs is that OCW-S would still be based on large OCW materials that could be accessed at all times. The lectures analyzed in this thesis are selected from Yale University $\mathrm{OCW}^{6}$. They are traditional face-to-face lectures that have been recorded, compiled and published online for free access. In other words, these lectures are not intended for an online audience or as part of a virtual course, but rather they are traditional lectures occurring at Yale University. In Bernad-Mechó (2015b, forthcoming) I carry out a three-phase analysis of the macro-structure of Open Yale Courses' homepage following Villanueva, Luzón, and Ruiz-Madrid's (2008) model, which

\footnotetext{
${ }^{6}$ www.oyc.yale.edu Last accessed January $8^{\text {th }} 2018$.
} 
consists of a description of the general structure, the organization and hypertextual links, and the interactive elements of the platform where the lectures are located in order to understand the generic changes involved in the digital transformation of the genre of OCW. Next, I look into the organizational metadiscourse employed in two video-lectures as these linguistic resources seem to reveal underlying traits of the genre. All in all, I argue that Yale OCW website and their video-lectures do not follow most conventions present in digital genres nor do they use metadiscourse accordingly. The analysis of the organizational metadiscourse in both the website and the video-lectures demonstrates that the online environment is not considered by the lecturers and that there is no interaction with the users. In short, OCW seem to be hybrid genres that replicate the existing genre of lectures in their natural evolution towards MOOCs, Webinars, or OCW-S. As Shepherd and Watters (1998, pp. 98-99) put it "when a genre existing in a non-computer medium migrates to a computer environment, it tends to be faithfully replicated and, initially at least, not to exploit the capabilities of its new medium".

In conclusion, OCW is an interesting field for study that is still largely unexplored. Further examinations on this new genre would possibly shed light on how genres in the digital world emerge and evolve. However compelling that may be, such an endeavor lies beyond the scope of the present study.

In this chapter, I have reviewed a series of theoretical approaches that contextualize the present study and that contribute to the creation of a methodological framework for a multimodal analysis of lectures. In particular, I have explored the notions of discourse analysis and various paradigms within the discourse analysis tradition (pragmatics, SFL, mediated discourse analysis and multimodal discourse analysis), which, together with the study of Jakobson's Functions of Language, contribute to the understanding of the development of metadiscourse models and multimodal approaches. Next, I have looked into the concepts of genre and genre analysis and, particularly, that of the genre of the lecture and the relevance of lecturing styles and the structure of lectures. In this sense, I have emphasized the growing importance of multimodal studies to fully understand oral 
lectures. Finally, I have added a brief note on OCW as an emerging genre with ample possibilities. The next chapter expands on Section 1.1.6 and is devoted to multimodality as one of the main contributions of this thesis. 



\section{CHAPTER 2. MULTIMODALITY}

One of the innovative aspects of this thesis is the use of multimodal methodologies which provide a wider account of human communication. Multimodal studies go beyond traditional monomodal analyses (for instance, a linguistic examination of metadiscourse) and try to encompass all relevant aspects that play a role in communication (language, but also gestures, gaze, head movements, posture, intonation, proxemics, layout, visuals, etc.).

This chapter is concerned with multimodality and its application to the study of human communication and discourse analysis studies. In the first part, i.e. Section 2.1, I introduce the concept of multimodality, its relevance, and its development in recent years. In Section 2.2, I first look at the three main approaches towards multimodality: Multimodal Social Semiotics, Multimodal Discourse Analysis, and Multimodal (Inter)action Analysis. Moreover, and I examine a series of studies where these approaches have been applied. This examination prompts Section 2.3, where I review the concept of mode that I will use in this study. In addition, I introduce and examine a series of modes that will be taken into account in the analyses carried out in this thesis, namely those of gesture, gaze, head movement, posture, paralanguage, proxemics and facial expression. Next, in Section 2.4, I briefly refer to the process of multimodal transcription and look at software applications for video and audio analysis. Finally, in Section 2.5, I conclude the chapter by reflecting upon the use of multimodal methodologies in the genre of academic lectures and the specific use of multimodality that I will implement in this thesis.

\subsection{Multimodal studies}

As I introduced in Section 1.1.6, multimodality and multimodal methodologies have acquired an increasing importance in the last two decades. Multimodality starts from the premise that "language is inherently multimodal" (Fortanet-Gómez \& Crawford 
Camiciottoli, 2015, p. 2; Müller, 2009, p. 216), and thus, messages are not conveyed through one mode only, but rather through the combination of a series of modes (speech, gesture, facial expression, writing, color, music, PowerPoint slides, etc.) that contribute to the conveyance of meaning (Jewitt, 2009b; Kress \& van Leeuwen, 2001) (see Section 2.3.1 for a comprehensive explanation on the concept of mode). Kress and van Leeuwen (2001, p. 20) define multimodality as "the use of several semiotic modes in the design of a semiotic product or event, together with the particular way in which these modes are combined". Even though communication is and has always been multimodal (Kress \& van Leeuwen, 1996), the expansion of multimodal approaches did not take place until the early 2000s with the publication of Kress and van Leeuwen's Multimodal Discourse (Kress \& van Leeuwen, 2001), heavily influenced by previous works as Hodge and Kress (1988), Kress and van Leeuwen (1996) and van Leeuwen (1999). In Jewitt's words, "there is an increasing interest among academics, professionals and students in the role of image, gesture, gaze and posture, and the use of space in representation and communication -in other words, multimodality" (Jewitt, 2009b, p. 1).

Multimodal methodologies have been applied in a wide variety of disciplines such as painting, architecture and sculpture (O'Toole, 1994, 2011), advertising, websites and visual art (Adami, 2015; Bezemer \& Kress, 2014; Domingo, 2014; Domingo et al., 2015; Knox, 2009; Kress \& van Leeuwen, 1996; Tan, 2009, 2010), film studies (Bateman \& Schmidt, 2012; ledema, 2004; O’Halloran, 2004b; Tseng, 2008; Tseng \& Bateman, 2010), music (Callaghan \& McDonald, 2002; van Leeuwen, 1999; West, 2009), or spatial semiotics (Pang, 2004; Ravelli \& Stenglin, 2008; Stenglin, 2009, 2011). Nevertheless, and despite being applied in this wide variety of disciplines, multimodality has developed its greatest significance within the field of applied linguistics with special emphasis on the research on EAP (Bernad-Mechó, 2015a; Bernad-Mechó \& Fortanet-Gómez, 2017, forthcoming; Crawford Camiciottoli, 2015, 2016; Crawford Camiciottoli \& Fortanet-Gómez, 2015; Fortanet-Gómez \& Ruiz-Madrid, 2014, 2016, Jewitt, 2008a, 2008b, 2009b, 2011; Kress et al. 2001; Kress et al., 2004; Morell, 2013, 2015; Norte Fernández-Pacheco, 2016a, 2016b; O’Halloran, 2005; O’Halloran, Tan, \& Smith, 2016; Querol-Julián, 2010, 2011a, 2011b; Querol-Julián \& Fortanet-Gómez, 2012; Ruiz-Madrid \& Fortanet-Gómez, 2016, just to name a few). 
This expansion in multimodal analyses has been possible mainly thanks to the parallel development of new technologies. Technologies, on the one hand, have expanded the possibilities for multimodal communication. Ventola, Charles, and Kaltenbacher, (2004) argue that the arrival of new media forced analysts to investigate these new semiotic combinations. On the other hand, technologies have equally provided researchers with tools for multimodal analysis. Thus, as a result of the development of new technologies, it is now possible to record and store large amounts of multimodal data that can be systematically annotated and analyzed. On top of that, the emergence of several multimodal annotation tools (Rohlfing et al., 2006) has allowed for a deeper study and understanding of multimodality.

Multimodality is ultimately concerned with how meaning is made and remade and how various semiotic resources contribute to communication. The greatest turning point of multimodality is its detachment from traditional linguistic analyses in which only the written or spoken language modes are considered. In this sense, multimodality takes all modes into account at the same initial level of importance providing a new lens for the study of communication. Jewitt (2013), for example, affirms that language (as a mode) is part of a multimodal ensemble; it is, therefore, just one more element within a complex set of modes that contributes to a greater or lesser extent to the creation of meaning. Moreover, Jewitt declares that each mode realizes a different communicative work within the multimodal ensemble and that these roles are formed and reshaped by culture, society, and history. Consequently, the choice of studying one mode over another becomes of great importance. In this sense, Jewitt claims that meaning is conveyed in each instance through a particular selection and configuration of modes; it is the particular combination of modes what interests most analysts of multimodality.

Although these ideas seem to be consistent in most multimodal studies, there are, however, three more or less distinguishable approaches to multimodality with their overlaps and differences. These approaches are based on social semiotics (Hodge \& Kress, 1988; van Leeuwen, 2005), on SFL (Halliday, 1985, 1994; Halliday \& Matthiessen, 2014), and on mediated discourse analysis (Scollon, 2001; Scollon \& Scollon, 2003) -see sections 1.1.4 and 1.1.5 for a theoretical development of SFL and mediated discourse analysis 
respectively. In the following section, I examine these approaches with a critical eye and having in mind the purposes of this thesis. In addition, I review some studies where these methods have been applied. Lastly, I also take a look at some less known trends in multimodal studies.

\subsection{Approaches to multimodality}

As I mentioned in the previous section, there are three clearly distinguishable directions towards multimodal studies. For the purposes of clarification and in order to be consistent throughout this dissertation, I will refer to these models as Multimodal Social Semiotics (Hodge \& Kress, 1988; Kress \& van Leeuwen, 1996, 2001; van Leeuwen, 2005), Multimodal Discourse Analysis (Baldry, 2004; Baldry \& Thibault, 2006; O'Halloran, 2004a, 2005, O'Toole, 2004, 2011) (also known as Systemic Functional - Multimodal Discourse Analysis), and Multimodal (Inter)action Analysis (Norris, 2004; Norris \& Jones, 2005a; Scollon, 2001; Scollon \& Scollon, 2003). These models are described in sections 2.2.1, 2.2.2 and 2.2.3 respectively.

The three main approaches to multimodality differ in their underlying theories, the degree of importance placed on the context and the interrelationship among modes, and the degree of attention that the sign-maker receives (Jewitt, 2014). Despite their differences in focus, these approaches are not necessarily mutually exclusive. In fact, boundaries between approaches are not always clear-cut and they can be remade and contested (Jewitt, 2014). Having this idea in mind, the selection of one method over another will be advantageous when answering distinct research questions. In other words, depending on the interests and the purposes of the investigation, one approach or another will be more appropriate. This is the case of the present dissertation, in which I make use of combined multimodal methodologies in order to obtain a full account of the use of organizational metadiscourse in lectures. As I detail in Chapter 4, in order to carry out a full examination of how metadiscourse is used, I account for the use of metadiscourse from a linguistic and 
a multimodal point of view. Within the multimodal analyses, I use a Multimodal Discourse Analysis approach as well as some concepts from Multimodal Social Semiotics that will allow for an in-depth examination of the modes as they are being used in lectures and the interrelation among them when conveying metadiscourse. Moreover, I use a Multimodal (Inter)action Analysis approach in order to study the differences in the role of metadiscourse within the set of actions carried out by the speakers. In the lines below, I briefly discuss the three main currents within multimodal approaches.

\subsubsection{Multimodal Social Semiotics}

Multimodal Social Semiotics (MSS) -mainly developed by Kress (2003, 2010), Kress et al. $(2001,2004)$, Kress and van Leeuwen $(1996,2001)$, and van Leeuwen $(1999,2005)$ - is based on Halliday's (1973) Systemic Functional Linguistics (SFL) and in particular on Social Semiotics (Halliday, 1978), which is further expanded in Hodge and Kress (1988) and in Kress and van Leeuwen (2001). Thibault (1991) defines the focus of Social Semiotics when studying meaning-making practices as being not only verbal, but also visual or aural (i.e. meaning in all its forms). For Thibault, the aim of Social Semiotics is that of developing analytical tools to explain how meaning is made in a social context. In short, Social Semiotics' main interest is meaning in all its forms, which occurs in social environments and social interactions (Kress, 2010). On this account, semiotics and multimodality seem to have traditionally been "inseparable academic companions" (Stöckl, 2014, p. 274). When inserting the term multimodality in Social Semiotics, van Leeuwen (2012, p. 549) describes multimodality as the study of "the integrated use of different communicative resources". In an earlier definition, Kress and van Leeuwen (2001, p. 20) talk about multimodality as "the use of several semiotic modes in the design of a semiotic product or event". Two main notions arise from these definitions: the study of distinct modal resources (or semiotic resources) in the creation of meaning, and the significance of the social context where this creation occurs. Therefore, the emphasis on the sign-maker and the semiotic choices they make in a given context is what interests the most in MSS (Jewitt, 2014). In other words, 
MSS is interested in how writers/speakers make meaning through the use of a multiplicity of modes in a social world.

I have mentioned the great influence of SFL in the birth of multimodality. One of the transparent examples of this influence is Kress and van Leeuwen (1996). In their seminal work Reading Images: The Visual Grammar of Display, and similarly to O'Toole's (1994) adaptation of Halliday's (1985) theory of the metafunctions of language to the analysis of visual art, Kress and van Leeuwen adjust SFL concepts to their own work on images combined with writing. Kress and van Leeuwen report how resources are used in meaning making in order to represent things about the world (representational meaning), represent things about authors and addressees (interactive meaning) and provide cohesion (compositional meaning). These three meaning functions correspond to Halliday's (1985) ideational, interpersonal and textual metafunctions of language. Furthermore, this early work in multimodal studies is complemented by Kress and van Leeuwen's (2001) Multimodal Discourse: The Modes and Media of Contemporary Communication, where these researchers aim to unveil the complexity of multimodal communication while moving "towards a view of multimodality in which common semiotic principles operate in and across different modes [...] to create a theory of semiotics appropriate to contemporary semiotic practice" (Kress \& van Leeuwen, 2001, p. 2).

From this moment onwards, two different perspectives appear to prevail in the set of studies on multimodality until the appearance of Multimodal (Inter)action Analysis in 2004 (Norris, 2004) -see Section 2.2.3 below. The first of these approaches is the one I am discussing here-MSS-, which seems to detach at this point from a pure SFL grammatical approach, despite its initial Hallidayan influence, and places more importance on the social and contextual aspects of semiotics. On the other hand, the second approach -Multimodal Discourse Analysis (MDA)-, appeals for the development of a Systemic Functional Grammar in multimodality (see Section 2.2 .2 below).

Thus, MSS's aim is to explore the principles and ideas conveyed through the combination of a series of modes and its social impact. Adami $(2017$, p.455) summarizes the main purposes of MSS: 
Social semiotics conceives of sign-making as the expression of social processes; through a fine-grained qualitative analysis of usually small samples of texts, social semiotics is interested in unveiling ideologies, social values, power roles, and identities as expressed in texts, together with how individuals actively maintain, reinforce, contest and challenge them through their sign-making choices.

In order to conduct MSS studies, there are a series of concepts that have proven to be analytically useful and contribute to the development of this approach. In the following lines, I will describe the concepts of mode (in MSS), semiotic resource, meaning potential/modal affordance, and multimodal ensemble.

Mode (in MSS)

The concept of mode is probably one of the key elements within all multimodal studies. Most MSS analyses begin with a detailed analysis of the modes present in a given object of analysis. Nevertheless, it is not understood equally in all three approaches towards multimodality. Kress and van Leeuwen (2001) describe modes as semiotic systems with rules and regularities. Later, Kress elaborates on the definition of mode, stressing its social aspect when used in meaning making:

Mode is a socially shaped and culturally given semiotic resource for making meaning. Image, writing, layout, music, gesture, speech, moving image, soundtrack and 3D objects are examples of modes used in representation and communication. Phenomena and objects which are the product of social work have meaning in their cultural environments: furniture, clothing, food, 'have' meaning, due to their social making, the purposes of their making and the regularity of their use in social life (Kress, 2010, p. 79).

In this sense, it is necessary to take context into account in order to properly understand the implications of the use of one mode over another, i.e. MSS highlights the relevance of the social aspect of communication. Finally, one last characteristic in modes is that they are created and subject to change through social processes (Jewitt, 2013). In this sense, ledema $(2001,2003)$ introduces the idea of resemiotization as a tool to analyze how meaning making changes in different contexts and practices. 


\section{Semiotic resource}

In order to completely understand the concept of mode, one has to review another relevant concept for the study of multimodality: semiotic resource. Semiotic resources are the connection between representational resources and the use people give them (Kress \& van Leeuwen, 2001). Van Leeuwen further defines a semiotic resource while drawing attention to how semiotic resources are used:

\footnotetext{
Semiotic resources are the actions, materials and artifacts we use for communicative purposes, whether produced physiologically - for example, with our vocal apparatus, the muscles we use to make facial expressions and gestures - or technologically - for example, with pen and ink, or computer hardware and software - together with the ways in which these resources can be organized. Semiotic resources have a meaning potential, based on their past uses, and a set of affordances based on their possible uses, and these will be actualized in concrete social contexts where their use is subject to some form of semiotic regime (van Leeuwen, 2005, p. 285).
}

Here, van Leeuwen refers to the meaning potential of semiotic resources as being subordinate to a semiotic regime that is able to reshape them depending on the preference of their users. This idea leads the way to the following concepts: meaning potential/modal affordance.

\section{Meaning potential/Modal affordance}

Meaning potential and modal affordance are two concepts that are used interchangeably by multimodal analysts most of the time. The term affordance originates in the work of Gibson $(1977,1979)$ and Norman $(1988)$ and is taken up by Kress (1993) who refers to modal affordance as what is possible to be expressed with a mode. Kress argues that affordance connects the material, the cultural and the social-historical uses of modes. Van Leeuwen $(2005,2010$, for instance), in turn, favors the use of the term meaning potential to refer to the material and cultural elements of modes. On the whole, meaning potential and modal affordance allude to the capability of modes to create meaning while accentuating the importance of cultural aspects. In a subsequent reference, Kress argues 
that "modes offer different potentials for making meaning" and "these have a fundamental effect on choices of mode in specific instances of communication" (Kress, 2014, p. 61). He then exemplifies how the mode of writing turns to resources like words, clauses, sentences, font, size, bolding, spacing, punctuation marks, and layout. Subsequently, he brings to the fore the issue that these resources have different forms in different cultures, thus emphasizing the importance of specifying context and social environment in MSS studies. In a nutshell, "meanings are socially made, socially agreed and consequently socially and culturally specific" (Kress, 2010, p. 88).

\section{Multimodal ensemble}

The last concept I will turn to within this section is multimodal ensemble. As aforementioned, all communications are multimodal and therefore, meaning is conveyed through a multiplicity of modes. Having said that, it is important to remark that all modes combine in order to represent a message's meaning in a given situation (Kress et al., 2004, 2001) creating what is called a multimodal ensemble. Later (Kress, 2010), Kress refines the concept by distinguishing between multimodal orchestrations and ensembles. Orchestrations refer to the process in which different modes are assembled and organized together, while ensemble is the semiotic result of such orchestration. Jewitt (2013, p. 256) expands the notion of multimodal ensemble and defines it as "a material outcome or trace of the social context, available modes and modal affordances, the technology available and the agency of an individual". All in all, the study of how different modes contribute to the creation of meaning as well as how this interrelationship itself works in the meaning making process is paramount in an MSS analysis. Against this background, and following Lanham (2001), the question of which modes are more appropriate in a designated context needs to be taken into consideration. In this sense, the analysis of the multimodal ensemble might contribute to answering that question. 
As I outlined in Section 2.1, MSS has had many recent applications in a wide range of disciplines. A number of studies have been conducted with the aim of examining the meaning potential of technology for students and teachers, (Archer \& Newfield, 2014; Davidsen \& Vanderlinde, 2014; Flewitt, Messer, \& Kucirkova, 2014). In children's literacy studies, for instance, Mavers (2014) examines the role of image in the multimodal ensemble of children's drawing from a social semiotic lens. Within the realm of technology and media, Burn (2014) explores the combination of sign-systems in film and machinima (the use of computer graphics engines to develop cinematic animations), and van Leeuwen (2014) emphasizes the importance of social context for the proper understanding of social practices through examples on the use of color in film, video and digital media. In the study of specific modes, Bezemer (2014b), for example, investigates the semiotic potential and affordances of gesture as well as gesture-speech relations in professional health-care surgery activities; and Bezemer and Kress (2008) look into the design of textbooks and the affordances of the modes utilized in them.

In short, MMS allows for an in-depth exploration of how meaning is made in a given social situation as well as the meaning potentials and relationships of given semiotic resources. In Kress's words, "Social Semiotics is able to say something about the function of each of the modes in this multimodal text; about the relation of these modes to each other; and about the main entities in this text" (Kress, 2010, p. 59). In this thesis, I make use of the concepts of mode, semiotic resources, modal affordance and multimodal ensemble in order to describe how metadiscourse is used in academic lectures. In particular, I will explore which semiotic resources are used and what is the interrelation among the different modes employed by lecturers.

\subsubsection{Multimodal Discourse Analysis}

Multimodal Discourse Analysis (MDA), also known as Systemic Functional - Multimodal Discourse Analysis (SF-MDA), is based on Halliday's (1985) Systemic Functional Grammar 
and O'Toole's (1994) work on displayed art, paintings, architecture, and sculpture. It has mainly been developed, among others, by Baldry (2000, 2004), Baldry and Thibault (2006), O'Halloran (2004a, 2005, 2007, 2011), O'Toole (1994, 2004, 2011), Tan (2009) and Unsworth (2006). Regarding its main concerns and research lines, the emphasis in MDA studies is mainly placed on the systems as sets of choices approaching discourse at the micro-textual level (Jewitt, 2014).

O'Halloran (2011, p. 120) describes MDA as "an emerging paradigm in discourse studies which extends the study of language per se to the study of language in combination with other resources, such as images, scientific symbolism, gesture, action, music and sound". Initially, this definition could apply to any multimodal methodology; however, two worthdiscussing ideas stand out. Firstly, O'Halloran narrows down the scope of MDA to the study of 'discourse'. Jewitt (2014) effectuates a reflection on the wide use of the word 'discourse' and its different meanings, and proposes Kress and van Leeuwen's (2001, p. 4) interpretation: "Discourses are socially constructed knowledges of (some aspect of reality) [...] developed in specific social contexts". Jewitt's statement brings up the question as to what can be considered 'discourse' and what cannot. Settling this issue is outside the scope of this thesis, but for practical reasons, I will stick to Kress and van Leeuwen's definition of 'discourse' throughout this study. The second debatable thought in O'Halloran's definition is the view of MDA as "extending" the study of language. In a sense, it looks as though language is prioritized over the rest of modes, in a way; or at least, language is the point of departure which is then combined with the rest of the modes. This will also be the approach taken in the analytical study of semiotic resources in this thesis. In this analysis, I depart from a linguistic exploration of metadiscourse and expand the study towards the rest of modes and their combinations. After all, spoken language is the fundamental source for transmitting content in academic lectures (Fortanet-Gómez \& Crawford Camiciottoli, 2015); therefore, quantitative and linguistic analyses will be conducted over the content of the lectures before moving on to multimodal studies (see Chapters 5, 6 and 7). Having said that, it is important to remark that this does not mean that I consider speech -or any other mode- more important than the rest of semiotic resources. However, metadiscourse is a linguistic category that is transmitted verbally; therefore, it seems sensible to approach this category from a verbal perspective first. 
As I mentioned above, the main focus of MDA is that of studying the system, i.e. sets of semiotic resources and their regularities. The forerunner of this approach is O'Toole with one of MDA's most influential works in his book The Language of Displayed Art (O'Toole, 1994). In this book, the author develops a framework for the study of displayed art that could be extrapolated to other analyses. In particular, O'Toole looks into specific paintings, architectural designs and sculptures in order to develop a bottom-up grammatical approach that opposes to the top-down procedure interested in ideology and general principles that can be found in Kress and van Leeuwen (1996) (O'Halloran, 2011). O'Toole's (1994) work is highly influenced by Halliday's (1985) functional grammar and the metafunctions of language. In O'Toole's (1994) terminology, Halliday's functions are referred to as representational (ideational), modal (interpersonal), and compositional (textual). The representational function is used to express information about the real world; the modal function is made up of resources employed by the author to catch the audience's interest; and the compositional function helps create cohesion among the different elements in the exhibitions. In order to further examine displayed art, O'Toole creates a hierarchy of ranks following Halliday (1973) which encompasses from higher to lower rank: work, episode, figure and member, the lowest rank. O'Toole then classifies meaning resources like gaze, stylization, action, parts of the body or parallelism into these ranks, and in turn, into the three metafunctions of displayed art. By creating this exhaustive stratification of meaning and semiotic resources, $\mathrm{O}^{\prime}$ Toole is able to come up with a detailed 'grammatical' framework for the analysis of exhibitions.

Hence, MDA analyses start from a detailed comprehensive examination of short parts of 'texts' (meaning any source that is capable of conveying meaning) with the aim of developing theories and frameworks that explain how semiotic resources work. Some other challenges for MDA include the study of social settings (as in van Leeuwen, 2008), and the processes of resemiotization (as in ledema, 2001, 2003) and intersemiosis (as in Jewitt, 2009a) (O'Halloran, 2011). Furthermore, in a previous paper, O'Halloran also refers to "developing analytical approaches for SF-MDA through the use of information technology and software applications" as one of the goals of MDA (O'Halloran, 2008, p. 445). Regarding this last issue, O'Halloran, Podlasov, Chua, and E (2012) developed the interactive software Multimodal Analysis - Video (MMA-Video) for fine-grained 
multimodal analyses at the Multimodal Analysis Lab in Singapore. An extended list of software applications for the study of multimodal analysis is provided in Section 2.4 below.

Apart from the differences in focus between MSS and MDA, minor discrepancies in the use of terminology in both approaches can also be found. In this sense, O'Halloran (2011), for example, offers some clarification on the use of common terms in multimodal studies. She proposes the term semiotic resource (referring to language, gesture, image, music, etc.) as a synonym of mode. In general terms, however, there seems to be a distinction between the concepts of mode and semiotic resource in MDA approaches. In this sense, Jewitt (2014) describes semiotic resources in MDA as systems of meaning like language, mathematical symbolism or images, and then, modes are realized through these resources. Thus, "language can be realized through written text (a visual mode) and spoken language (an oral mode)" where language is a semiotic resource and written texts and speech (spoken language) are modes (Jewitt, 2014, p. 23). In this thesis I side with O'Halloran's (2011) initial interpretation of the term semiotic resource. Accordingly, as I detail in Section 2.3.1, I employ the terms mode and semiotic resource interchangeably to refer to the various elements that are capable of conveying meaning in communication.

In addition to the reflection on the concepts of mode and semiotic resources, O'Halloran (2011, p. 121) introduces the notions of sensory modalities, multimodal phenomena, and medium:

semiotic resource is used to describe the resources (or modes) (e.g. language, image, music, gesture and architecture) which integrate across sensory modalities (e.g. visual, auditory, tactile, olfactory, gustatory, kinesthetic) in multimodal texts, discourses and events, collectively called multimodal phenomena. [...] The medium is the means through which the multimodal phenomena materialise (e.g. newspaper, television, computer or material object and event).

As a last remark into MDA's theory, it is worth noting that O'Halloran (2011, p. 124) proposes three theoretical and analytical issues to be considered in MDA. 
a) Modeling semiotic resources which are fundamentally different to language.

b) Modeling and analyzing inter-semiotic expansions of meaning as semiotic choices integrate in multimodal phenomena.

c) Modeling and analyzing the resemiotization of multimodal phenomena as social practices unfold.

I will not examine each of these proposals in detail here, but a series of guidelines for the study of multimodality from an MDA approach can be extracted from them. The recurrence of the term modeling when describing the aims of MDA seems to refer to the creation of grammatical systems that successfully catalog semiotic resources, in particular, those different to language. In other words, the common ground in all three statements is that of creating models (or frameworks) for the study of semiotic events. However, only in the last issue is a social entity considered. In this sense, a higher emphasis on the system rather than on the context can be inferred. Lastly, the presence of the individual as a sign-maker appears to be obviated. In a fabricated study, Jewitt (2014) hypothesizes on what the aims of MDA would be when tackling a corpus of textbooks and other learning materials. She suggests that MDA would be interested in "the semiotic potential available [...] mapping the choices available and those which are taken" and also in "making an inventory of the system, the resources, principles and rules, the levels and ranks within systems according to a stratal model" (Jewitt, 2014, p. 35). Accordingly, the sign-maker as well as the addressee seem to receive little attention in MDA studies.

As in MSS, there are many researchers who have opted for an MDA model of analysis. By way of illustration, the functional approach taken by O'Toole (1994) has been applied to many other studies in order to explore grammatical systems. O'Halloran, for example, aims at unveiling the intricacies of mathematical discourse (O'Halloran, 1998, 2005) or the visual imagery and soundtrack in films (O'Halloran, 2004b). Similarly, O'Toole (2004) applies his own framework for the analysis of displayed art (O'Toole, 1994) to explore the architecture of Jørn Utzon's Sydney Opera House, and Alias (2004) studies the semiotic makeup of Orchard Road and the Marriott Hotel in Singapore. With the aim of developing technological methods in the study of multimodality, a remarkable example is Baldry (2004), who investigates the use of computer software for the analysis of films and 
videotexts. Some more recent works include Stenglin's (2014) investigation into space and communication in exhibitions or Knox's (2014) examination of online newspapers.

On the whole, MDA can be considered a bottom-up Systemic Functional approach to multimodality whose main interest is the study of semiotic systems and their rules. Precise analyses can be carried out in order to disclose the complexities of multimodal semiotic resources. In this section, I have examined the basics of MDA from its early development by O'Toole to more recent applications.

\subsubsection{Multimodal (Inter)action Analysis}

Multimodal (Inter)action Analysis (MIA) -mainly developed in Norris (2004, 2011)- is a more interactional approach towards multimodality where the focus is on the actions carried out by the social actor. MIA places a special interest in the examination of context and situated interaction (Jewitt, 2009b). As Jewitt (2014, p. 33) puts it, "the work of the actor is, therefore, everything". Thus, the social actor becomes central in MIA analyses, and this approach aims at figuring out the intricacies of interactions and how social actors behave in specific instances (Norris, 2004). MIA offers a set of methodological tools and concepts for the analysis of multimodal data. Below, I describe some of the most relevant concepts.

MIA is mainly grounded in Scollon's work on mediated discourse and the concept of mediated action (Norris \& Jones, 2005b; Scollon, 1998, 2001; Scollon \& Scollon, 2003; Wertsch, 1998) -see Section 1.1.5 for an elaborate description of mediated discourse analysis-, and also in interactional sociolinguistics and anthropology (Goffman, 1959, 1963, 1974; Gumperz, 1982; Tannen, 1984), and multimodal analysis (Kress \& van Leeuwen, 1996, 2001; van Leeuwen, 1999). As I described in Section 1.1.5, the concept of mediated action is in turn based on Vygotsky's $(1978,1986)$ notion of mediation, further developed by Wertsch (Wertsch, 1991, 1998; Wertsch, Tulviste, \& Hagstrom, 1993). Scollon's (1998) paradigm confronts traditional linguistics by suggesting that social actions are the 
organizing principle of human communication where language is simply a part of these social actions (Norris, 2015b). The mediated action becomes the unit of analysis in MIA and refers to a social actor acting through or with mediational means (Scollon, 1998). By using the idea of mediated action, the actor, the actions and the mediational means are all considered in the analysis:

\begin{abstract}
[w] hen using the mediated action as our unit of analysis, the action can neither be analyzed without analyzing the social actor(s) who is(are) performing the action, nor can it be analyzed without the mediational means that the social actor(s) draws on when performing the action (Norris, 2014, p. 89).
\end{abstract}

Types of actions: lower-level, higher-level, and frozen actions

As I stated above, the unit of analysis in MIA studies is the mediated action. Actions are usually characterized by having more or less clear-cut beginnings and ends. Norris (2004) distinguishes three types of actions: lower-level actions, higher-level actions, and frozen actions. Out of these, higher-level actions are especially relevant for this study.

In order to understand higher-level actions and how they work, the concept of lower-level action needs to be reviewed. A lower-level action is defined as "the smallest interactional meaning unit" (Norris, 2004, p. 11). For example, a posture change, a gesture or an utterance are lower-level actions. They are demarcated by a beginning and by an end. Higher-level actions consist of chains of lower-level actions bracketed by an opening and a closing (Norris, 2004). For example, a conversation about the weather would be a higherlevel action formed by a series of lower-level actions including many utterances, gestures, gaze shifts, and so on and so forth. These higher-level actions, in turn, can often be subdivided into smaller higher-level actions or embedded within other higher-level actions. This is what Norris calls scales of actions (Norris, 2017). Thus, the higher-level action of talking about the weather might be divided into smaller actions like discussing temperature and discussing the latest heavy rains; and it could be embedded within a hypothetical supra higher-level action of meeting with friends. The last type of action identified by Norris is frozen actions. Frozen actions are defined as "higher-level actions which were performed 
by an individual or a group of people at an earlier time than the real-time moment of the interaction that is being analyzed [...] frozen in the material objects" (Norris, 2004, p. 13). In other words, frozen actions would entail the processes and sets of actions that made a certain object be where it is. For example, a cup of coffee on a table is made up of the higher-level actions of making a mug, making coffee, serving coffee, etc. Frozen actions usually show characteristics of the social actors that use them; for instance, a playlist might provide an insight into a social actor's tastes in music. Norris and Makboon (2015), for example, offer a series of examples demonstrating how frozen actions reveal aspects of the social actors' identity. Nevertheless, the concept still needs some polishing; the boundaries of what is and what is not a frozen action are not definite. A group of mountains, for instance, is not a manmade object, and therefore there is not a group of higher-level actions that led to the creation of those mountains. To my knowledge, the theory does not limit the scope of what could be considered a frozen action. Still and all, the concepts of lower-level, and especially, higher-level actions are central in the present study in order to identify the role of metadiscourse within the speaker's organization of actions (see Chapter 8).

Other central concepts in MIA are those of levels of attention and foreground-background continuum, modal density, semantic/pragmatic means and modal configurations.

Levels of attention and foreground-background continuum

Social actors producing higher-level actions may conduct several of them at the same time at different levels of attention/awareness. For instance, while a social actor is talking about the weather they may also be taking care of their children and thinking about dinner at the same time. The foreground-background continuum (Norris, 2004) enables the representation of different levels of attention/awareness in a three-staged graph demonstrating the higher-level actions occurring in the foreground, midground and background (see Figure 2.1). Several higher-level actions can occur simultaneously in the midground (receiving a certain degree of attention) or in the background (with the social actors barely being aware of the action); however, only one higher-level action can be 
foregrounded at the same time. Going back to the previous example, the social actor can only be completely focused on either talking about the weather, taking care of children, or thinking about dinner, i.e. the action in the foreground. The other two actions, albeit simultaneous, will receive less attention by the social actor and will, therefore, be represented in the midground or background. Thus, foregrounded higher-level actions are focused on higher-level actions, i.e. the social actor is highly aware of them and devotes most of their attention/awareness to its fulfillment.

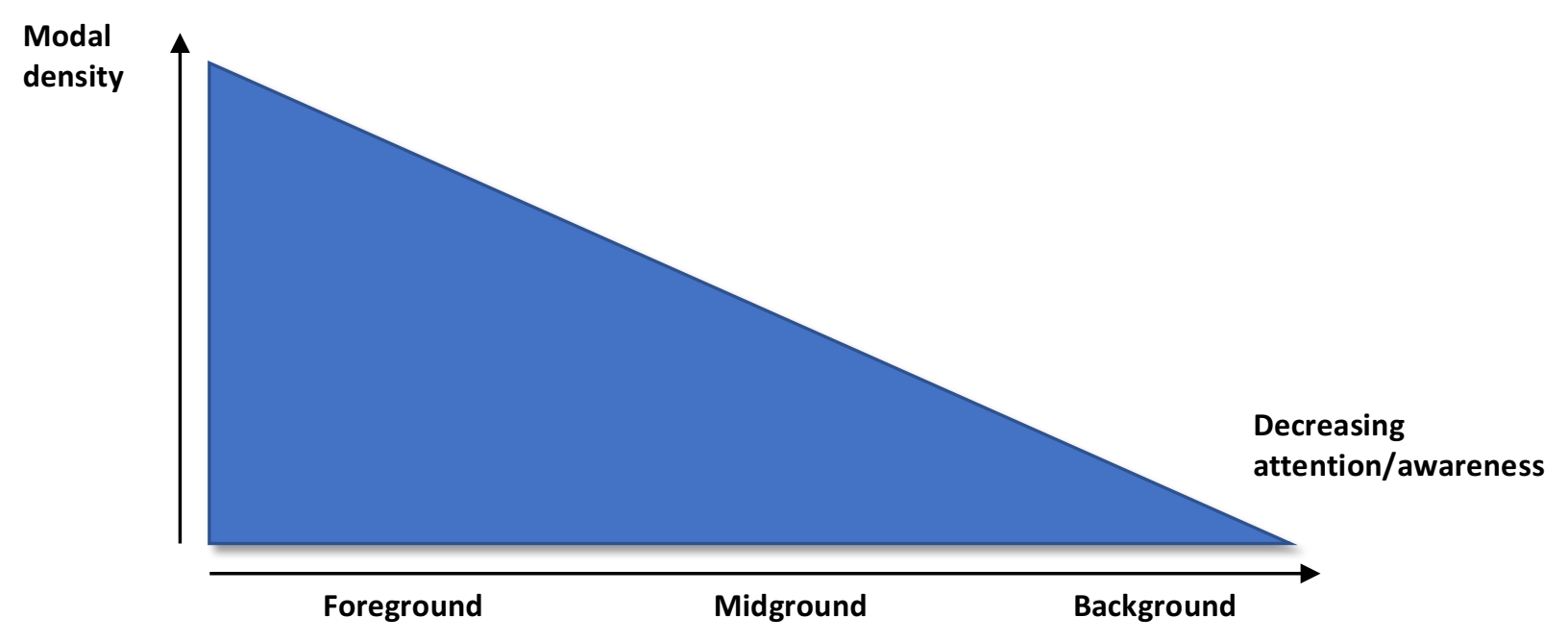

Figure 2.1 Modal density foreground-background continuum of attention/awareness (Norris, 2004, p. 99)

\section{Modal density}

The levels of attention/awareness of the social actor towards a higher-level action are determined by their modal density (Norris, 2004). The concept of modal density arises from the concept of a mode. Norris (2013, p. 156) defines mode as "a system of mediated action with regularities" and so, modes are acquired by the users as they interact through lowerlevel actions in the world. Nevertheless, modes are for Norris theoretical constructs that assist the researcher in their analyses. According to this researcher, modes help to dissect communication as a whole into smaller distinguishable aspects. This definition of mode is somewhat different from Kress's (2014), Kress and van Leeuwen's (2001) and O'Halloran's (2011) in the idea that modes do not exist per se, but are only analytical tools. As claimed 
by Norris, the regularities of the modes are sometimes closer to the social actor and sometimes closer to the mediational means, but modes do not occur without the social actor (Norris, 2013). In the case of this thesis, however, as I stated in the previous section, the concept of mode is used complementary to that of semiotic resources, following O’Halloran (2011).

A higher-level action is more modally dense when the action is produced with higher modal complexity (many modes devoted to carrying out the action), or when it is produced with a higher modal intensity (a given mode or modes take a more intense role in the performance of the action). In other words, if a social actor is, for instance, performing the higher-level action of talking about the weather while their posture and gaze are turned towards their interlocutor and their gestures are related to the conversation, the action is modally complex, as most modes are devoted to the performance of the action. However, if the social actor is engaged in talking about the weather but suddenly turns their head to a kid and says "stop doing that", then the higher-level action of taking care of children becomes modally dense after receiving high modal complexity (most modes are still devoted to the action of talking about the weather but the modes of gaze and spoken language play a more intense role). In this case, the higher-level action of taking care of children becomes foregrounded in the foreground-background continuum.

\section{Semantic/pragmatic means}

Higher-level actions are produced with different levels of attention/awareness all the time, being foregrounded, midgrounded or backgrounded constantly. Shifts when foregrounding higher-level actions are frequently indicated by semantic/pragmatic means (Norris, 2004). Semantic/pragmatic means are pronounced lower-level actions (e.g. a gesture, a head movement, laughter) that indicate a shift in the level of attention that a social actor devotes to particular higher-level actions. They carry out two functions: a semantic function, as they structure the social actor's interaction organizing foregrounded higher-level actions; and a pragmatic function, as they can communicate the social actor's shift to the interlocutors. Semantic/pragmatic means are useful in this thesis in order to identify shifts in attention, 
and therefore, the presence of new higher-level actions that show the lecturers' structuring of their presentations (see analysis in Chapter 8).

\section{Modal configurations}

The last concept I will be using in this thesis is that of modal configurations. Norris defines modal configurations as "the hierarchical configuration of lower-level actions (or their chains) in relation to other lower-level actions (or their chains) within a higher-level action" (Norris, 2015a, p. 6). Modal configurations can be applied to heuristically analyze a given instant within a higher-level action. They show the lower-level actions being performed at an exact moment and the importance given to these by the social actor in the construction of the action. Figure 2.2 shows a fabricated example of the organization of notes by a lecturer during a class. The figure represents each of the modes occurring in the higherlevel action of organizing the notes as circles. The size of the circles aims to provide a visual representation of the importance of each mode within the higher-level action. Thus, the modes of object handling and gaze play an important part in the action; the modes posture, proxemics, and gesture play a lower role; and the modes of speech, head movement, and paralanguage are not so important.

Modal configurations, in a way, can be understood as multimodal ensembles, i.e. descriptions of the combinations of modes co-occurring in a given instance. However, modal configurations add a structural element to this representation: modal configurations categorize modes according to their importance (or attention received) within the set of modes being analyzed. Although the identification of importance in the use of modes contributes to the analysis of levels of attention to any one specific action, it may be sometimes a subjective task. In this regard, I will favor the concept of multimodal ensemble throughout this thesis and I will use modal configurations for the exploration of higherlevel actions in Chapter 8. 


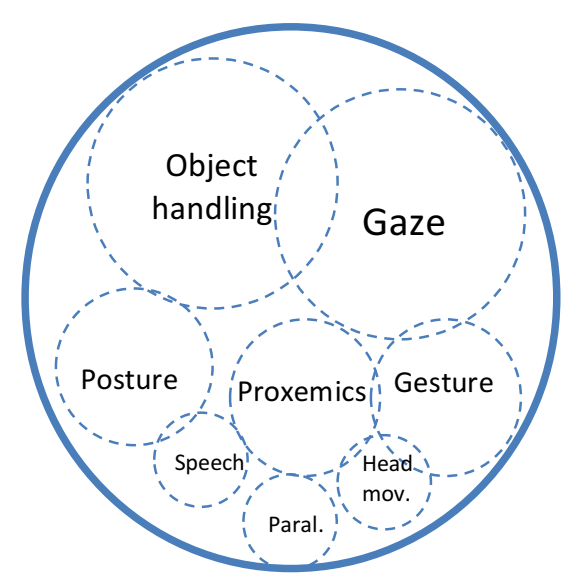

Figure 2.2 Modal configuration for a moment when a lecturer is organizing their notes

MIA has recently been applied in a variety of studies. Pirini has used this methodology in numerous occasions to explore shared attention/awareness in high school tutoring sessions (Pirini, 2014), to analyze business coaching through the concept of modal density (Pirini, 2013), or to develop the notions of agency and intersubjectivity in tutoring sessions (Pirini, 2015) among others. Within the field of education, Norte Fernández-Pacheco (2016b) has recently used the concept of higher-level action to structure a series of vodcasts with the aim of analyzing which multimodal ensembles are more beneficial for students' comprehension. In translation studies, Krystallidou (2014) uses MIA and the concept of foreground-background continuum of attention/awareness to look into gaze and posture when teaching how to translate between patients and doctors. Finally, I have also used MIA elsewhere (Bernad-Mechó, 2017a) in order to examine how topics are introduced through the use of introducing topic metadiscourse (Ädel, 2010) in a History lecture.

All in all, MIA allows for an in-depth exploration of human communication holistically and with a particular emphasis on the individual. MIA involves a more interactional approach in which the action becomes central for the analysis. In the present study, an MIA approach is utilized in Chapter 8 to provide a further insight into the complex process of lecture structuring by focusing on the actions carried out by the lecturers. By scrutinizing these actions, I intend to figure out the role played by organizational metadiscourse within the whole set of actions present in the dataset. 
MSS, MDA and MIA are the most widely utilized approaches towards multimodality; however, it is worth mentioning that there are a number of researchers whose work in the study of multimodality seems to translate into a development of new trends in multimodal methods. Some of these new trends include an approach towards multimodality from the perspective of Cognitive Linguistics (Forceville \& Urios-Aparisi, 2009; Müller \& Cienki, 2009; Urios-Aparisi, 2009; Yu, 2009; Yus, 2009); a combination of Critical Discourse Analysis and multimodality (Machin, 2004, 2014; Machin \& Mayr, 2012; van Leeuwen, 2008, 2013); and multimodal analyses from a Conversational Analysis perspective (Belhiah, 2009; Deppermann, 2013; Schmitt, 2007). These new developments demonstrate that multimodality is currently receiving much attention from researchers in various fields within Linguistics and is constantly expanding its boundaries.

\subsection{Modes}

After having discussed the current paradigms in the study of multimodality, in Section 2.3.1, I set out to reflect upon the concept of mode as understood by the different approaches previously described. Moreover, I aim to provide a description of worth noting research in the study of gesture, gaze, head movement, posture, paralanguage, proxemics and facial expression in Section 2.3.2.

\subsubsection{The concept of mode}

In Section 2.2 above, I have explored how different approaches to multimodality define the concept of mode. MSS understands mode as the outcome of a process of cultural shaping of a material which displays a series of regularities inferred from how people use them (Jewitt, 2009a). Expressed in a different way, modes are socially and culturally shaped semiotic resources with the purpose of making meaning (gesture, image, speech, etc.) 
(Kress, 2010). Therefore, in MSS modes' meaning depends ultimately on the social and cultural values attached to them. 'Semiotic resources', in turn, refer to the materials we use to communicate (vocal apparatus, pen, computer hardware, etc.) (van Leeuwen, 2005). In MDA, however, semiotic resources are considered systems of meaning (like language, mathematical symbolism or images) that are instantiated into modes (written text, spoken language, etc.) (Jewitt, 2009a). Thus, MDA adopts a more grammatical approach where semiotic resources are systems with regularities -like languages-, and modes are systems in use. In a subsequent definition (O'Halloran, 2011), however, mode and semiotic resources are presented as interchangeable concepts. As I stated in Section 2.2.2, it is precisely O'Halloran's (2011) description of mode the one employed in this thesis, as it simplifies the analyses. By considering modes and semiotic resources as synonyms, both concepts refer to the use of systems with regularities. In other words, one less level of specification is placed on whether the systems are being referred to as theoretical notions or as entities being used. Finally, MIA decides on a more radical alternative; in MIA modes are merely theoretical constructs that help the multimodal analyst (Norris, 2013). The focus of MIA is on the action, rather than on how meaning is conveyed. That being the case, modes become part of the action as systems of representation that mediate it (Norris, 2004). However, modes do not occur per se without the individual (Norris, 2013). In this sense, Chapter 8 in this thesis employs an MIA approach to study of the role of metadiscourse within the set of actions carried out by the lecturer. However, in an effort to simplify the study, the concepts of mode and semiotic resources are also presented as equivalents in this analysis.

\subsubsection{Previous research on modes}

In the following lines, I consider some of the distinctive developments conducted in the study of various modes that will assist in my analyses of lectures. Tan et al. (2016), following Hyland (2009), Jewitt (2008a) and Lim, O'Halloran and Podlasov (2012), argue that some of the semiotic resources being used in traditional face-to-face lectures are speech, gaze, 
gesture and use of space (proxemics). Another semiotic resource considered in the study of lectures is paralanguage. Crawford Camiciottoli $(2015,2016)$, for example, considers the use of speech, gaze and gestures in her analyses of lectures and also reflects upon the use of prosody (paralanguage), especially when used to stress certain lexical items. Moreover, in a previous study (Bernad-Mechó, 2017a) I analyze the pitch lines in a lecturer's speech to discern whether intonation indicates that an utterance is finished or it is being continued. Finally, in Bernad-Mechó and Fortanet-Gómez (forthcoming), we explore the semiotic resources employed by lecturers during the use of organizational metadiscourse when engaging the audience in the discourse. Apart from the aforementioned resources, we also identify head movement and facial expression (particularly eyebrow raising and frowning) as two semiotic choices that the lecturers may resort to in order to provide emphasis and engage the audience into the speech. Thus, the modes of verbal speech, gesture, gaze, head movement, posture, paralanguage, proxemics and facial expression seem to be present in different degrees of importance among the choices made by the lecturers when conveying meaning. Consequently, these are the modes that will be considered in the multimodal analyses in the present study.

\section{Gesture}

The growth of multimodal studies took place at the end of the 1990s and early 2000s, but studies in non-verbal communication may be traced back to the 1940 s. Gesture is probably one of the most explored modes, (Bavelas, Chovil, Coates, \& Roe, 1995; Bavelas, Chovil, Lawrie, \& Wade, 1992; Efron, 1941; Ekman \& Friesen, 1969; Freedman, 1972; Freedman \& Hoffman, 1967; Goldin-Meadow, 2003; Kendon, 1967, 1978, 1980, 1987, 1988, 2004; McNeill, 1985, 1992, 2000, 2005; McNeill \& Levy, 1982). The New Oxford American Dictionary defines gesture as "a movement of part of the body, especially a hand or head, to express an idea or meaning". Two ideas are extracted from this definition: gestures can be performed not only with hands, but also with other parts of the body, and they express meaning, i.e. they have semiotic connotations. Although gestures can be performed with various parts of the body, in this thesis I identify 'gestures' with Norris's (2004) 'hand-arm 
gestures'. As for movements of other parts of the body like head movements or body posture, those will be referred to in those terms and are explored in detail further below in this section.

As I mentioned above, research on gestures is extensive and thorough. Ekman and Friesen's (1969) early taxonomy of gestures, influenced by Efron (1941), puts forward a categorization of general non-verbal behavior into emblems, which are composed of translatable non-verbal actions; illustrators, which encapsulate what is being said in speech; affect displays, which express emotions; regulators, which maintain the nature of speaking and listening; and adaptors, which are used to "satisfy self bodily needs [...] perform bodily actions [...] manage emotions or to develop or maintain prototypic interpersonal contacts" (Ekman \& Friesen, 1969, p. 84). Still and all, Ekman and Friesen's taxonomy is too broad for a fine-grained analysis of gestures.

A turning point in gesture theory is Kendon and McNeill's work. Inspired by Kendon (1988), McNeill (1992) publishes a continuum of gestures which he refers to as Kendon's continuum in his honor. In this depiction of gestures, McNeill distinguishes between gesticulation (or gestures) which constitute hand-arm movements that go together with speech; languagelike gestures, which include gestures that are grammatically inserted into speech, filling gaps or substituting words, for instance; pantomime, where hands are used to represent objects or actions through miming; emblems, which are culturally dependent and their meaning is generally understood by the intended addressees (for instance the OK sign or the thumbs up sign); and finally, sign languages, which are full means of grammaticalized communication with a rich lexicon that is shared by a community of users. Out of this classification, the present study focuses on gesticulation (which I will refer to simply as 'gestures' from now on), as these are the gestures occurring spontaneously in normal speech.

McNeill (1992) then further expands the category of gestures and identifies four basic types: iconic, metaphoric, deictic and beats. Therefore, gestures are iconic when they express pictorial content and there is a relationship with the content of the speech; metaphoric when the gestures express pictorial content but they represent abstract ideas 
or notions; deictic when they point to concrete or abstract entities; and beats, which are repeated gestures that seem to mark the rhythm, as Norris (2004, p. 29) puts it, "as if the performer is beating musical time in quick succession".

Apart from classifying types of gestures, McNeill also explores how gestures co-occur and synchronize with speech. Once more, following Kendon (1972, 1980), McNeill (1992, p. 83) describes gestures as having three phases:

1. Preparation (optional), in which the limb moves away from its rest position to a position in gesture space where the stroke begins [...]

2. Stroke (obligatory) is the peak of effort in the gesture. It is in this phase that the meaning of the gesture is expressed. [...]

3. Retraction (optional) is the return of the hand to a rest position

McNeill, building on Kita (1990) also identifies two sub-phases: the pre-stroke hold, which is the position at the end of the preparation, and the post-stroke hold, which is a holding position after the stroke has been performed. Moreover, it is worth noting that while the stroke is always present in all gestures, phases 1 and 3 are optional and some gestures like beats consist of only two phases. With the aim of exploring synchrony, McNeill further offers the concepts of Gesture-Units which are defined as the time in between limb rests and which are made of one or more Gesture-Phrases consisting, in turn, of one or more phases. With these concepts in mind, McNeill then identifies three rules that describe how gestures and speech interact, and in particular, the synchrony between the two modes: phonological synchrony rule where the stroke precedes or ends at the phonological peak of the syllable (Kendon, 1980); semantic synchrony rule when both speech and gesture coincide in meaning and time; and pragmatic synchrony rule, which occurs when gestures and speech offer the same pragmatic function.

Finally, one last aspect that is worth turning to when analyzing gestures is their function. Bavelas et al. (1992, 1995), for instance, put forward a number of functions that beats (what they refer to as interactive gestures) can perform. These types of gestures are used to help the addressee follow the conversation and they can be used to mark the delivery of the information, to cite the other's contribution, to seek a response, and/or to turn 
coordination in the conversation. This is worthy of attention, as these gestures would be performing, in a way, the same functions that are expected in metadiscourse (see Section 3.1), which are those of helping the listener and organizing the discourse. Similarly, Kendon (2004) also distinguishes functions in gestures. According to him, gestures can perform a referential function when they aim to represent content from speech; an interpersonal function when they regulate the organization of the speech; and a pragmatic function when gestures refer to the move or speech act that is occurring, when they help to interpret speech or when they insert 'punctuation' in speech. Moreover, gestures may be performed with an emphatic function. Calbris (2008), for example, examines the co-expression of speech and gestures and suggests that gestures being performed with both hands may emphasize the verbal message.

There are some other taxonomies of gestures (Efron, 1941; Ekman \& Friesen, 1969; Freedman \& Hoffman, 1967). Nevertheless, in the present work I will make use of McNeill's (1992) as it offers a detailed account of hand-arm gestures and seems to be widely accepted in multimodal analyses -see Fortanet-Gómez and Ruiz-Madrid (2015, 2016), Norris (2004), Querol-Julián (2011a) or Querol-Julián and Fortanet-Gómez (2012), just to name a few. Moreover, as I detail in Section 4.3.3, I perform a multimodal annotation of hand-arm movements that cannot be regarded as gestures (like scratching or handling notes) and I indicate whether gestures are performed with a single hand or with both hands. By looking at these aspects, I may discern what type of gestures are more predominant, whether these are given any particular emphasis (single-handed vs. twohanded gestures), and whether there is a particular use of non-gesture movements (for example, if the handling of notes plays an important role for a given lecturer). As for the functions of gestures, following previous multimodal examinations of lectures (BernadMechó, 2015a, 2017a, Bernad-Mechó \& Fortanet-Gómez, 2017, forthcoming), I classify gestures according to their type (McNeill, 1992). However, during the analyses, I will occasionally refer to the functions of specific gestures as described by Kendon (2004).

From a perspective of multimodal analysis, the studies on gesture are abundant. Examples within academic genres include, for instance, Querol-Julián and Fortanet-Gómez (2012), who explore evaluation in discussion sessions in conference presentations and what 
gestures (and other modes) say about the speakers. Moreover, with a focus on lectures, I have detailed in Section 1.3.2 how Crawford Camiciottoli $(2015,2016)$ explores the elaboration of explanations and the interaction in lectures respectively, and how speech co-occurs with gestures (and other non-verbal resources) to convey meaning. Similarly, I also described under Section 1.3.2 previous research (Bernad-Mechó, 2015a; BernadMechó \& Fortanet-Gómez, 2017, forthcoming) in which gestures in lectures are examined as part of the multimodal ensembles employed to convey metadiscursive functions.

Gaze

Another mode that has received much attention from researchers in the second half of the $20^{\text {th }}$ century is gaze (Argyle \& Cook, 1976; Argyle, Ingham, Alkema, \& McCallin, 1973; Duncan \& Niederehe, 1974; Field, 1981; Geoffrey, 1981; Goffman, 1963; Goodwin, 1979, 1981, 1984; Heath, 1984; Kendon, 1967, 1990a; Kimble \& Olszewski, 1980; Nichols \& Champness, 1971; Psathas, 1990; Strongman \& Champness, 1969). Gaze refers to the direction people look at in interactions. Norris (2004, p. 36) defines gaze as "the organization, direction and intensity of looking".

Kendon's (1967) is one of the earliest approaches to gaze. In his paper, Kendon finds out that addressees gaze at the speaker more than the other way around. Speakers, in turn, tend to move from a position where they look away at the beginning of utterances to a position where they look at the addressee towards the end, thus revealing some sort of turn-taking behavior. Moreover, Kendon also observes that speakers tend to look away when they reach high emotional levels. Therefore, gaze seems to indicate changes in the speaker's attitudes towards communication. Another researcher who places attention on gaze is Goodwin (1981), who describes a sequential structuring of gaze. Norris (2004), however, points out that gaze might alternate between organized structures (for instance, when having a conversation) and arbitrary ones (a walk through a forest). Therefore, Norris suggests that gaze can be placed in a continuum that oscillates between structured and arbitrary sequences of gaze. Finally, she also draws attention to the fact that gaze might be culturally shaped and patterns of use might differ in different cultures. An additional 
controversial issue in Goodwin's (1981) text is the idea that gaze is subordinated to language. This notion confronts most points of departure in multimodal analyses where all modes are considered at the same level and are capable of meaning-making per se. In this sense, Norris (2004, p. 37) claims that "gaze may play a superordinate role when people are simultaneously engaged in other activities while conversing". Consequently, according to Norris, gaze can have both roles, a role when gaze is subordinated to language and a superordinate role when gaze receives a higher importance and is able to communicate perse.

The study of functions, although not as extended as in gestures, has also been conducted in gaze. Argyle et al. (1973) explore the functions of gaze in social interaction. They conclude that gaze may be used to seek information, to signal interpersonal attitudes and accompany speech, as a cue for intimacy, to avoid undue intimacy, and to avoid excess input of information.

Most of the studies on gaze have been conducted from a Conversational Analysis point of view. Nevertheless, some examples of multimodal studies can also be found. Krystallidou (2014), as I mentioned in Section 2.2.3, explores the importance of gaze and body posture when training future patient-doctor translators. Moreover, a number of studies have been conducted using eye-tracking methodologies in multimodal research, especially in the study of graphics and newspapers (Holsanova, 2010, 2014; Holsanova, Holmberg, \& Holmqvist, 2009). In addition, gaze is also considered as an element influencing the multimodal ensembles created by lecturers in some of the studies described in Section 1.3.2 (Crawford Camiciottoli, 2015, 2016). Finally, Tan, Smith and O'Halloran (2015) have identified gaze as playing an important role in the meaning-making process to engage online audiences. Thus, engagement seems to be achieved by looking directly at the camera. Similarly, engagement is tackled in Bernad-Mechó and Fortanet-Gómez (forthcoming) where gaze is identified as an element fostering engagement in metadiscursive instances in face-to-face lectures.

In the present thesis, I look at gaze in two terms: as a mark of rhythm and structure in the line of the studies presented by Goodwin (1981) and Norris (2004); and as an indicator of 
the focus of the lecturers (either on the audience or on the notes). In this sense, as I describe in Section 4.3.3, the multimodal annotation of gaze describes its direction (towards the audience, the notes, the board, and so on). As I argue in Bernad-Mechó (2017a), gaze is one of the elements that displays the focus of the attention of the lecturer. Changes in attention, in turn, provide an insight into how sections succeed one another in lectures.

\section{Head movement}

Head movement is another mode that has been widely studied in recent decades (Altorfer et al., 2000; Dittmann, 1972; Duncan, 1972; Hadar, Steiner, Grand, \& Rose, 1983, 1984a, 1984b, Kendon, 1972, 1990b, 2002; Maynard, 1987; McClave, 2000; Norris, 2004). When exploring head movements, the analyst is focused on the position and the changes in direction of the head. Altorfer et al. (2000) differentiate three main types of movement: rotational (when shaking the head), lateral (when tilting the head to one side or the other), and sagittal (when nodding). Norris (2004) refers to these as simple head movements and adds the category of complex head movements to refer to those movements that include two or more patterns. This researcher further distinguishes between conventional or iconic movements that have clear verbal counterparts (like nodding or shaking the head in Western societies meaning yes and no respectively) and novel head movements that do not have verbal counterparts. Novel head movements may consist, in turn, of deictic movements that, like gestures, can be divided into three stages (preparation, stroke, and retraction) and which are used to point to something or someone; and head beats (or tosses) which consist of only two positions (up/down or back/forth) and which are used to strengthen the message. According to Norris, the more movements the stronger the message. In this regard, Hadar et al. (1983, 1984a, 1984b) identify that head movements mainly co-occur during speech sections and stop or slow down during pauses.

Similarly, Kendon (2002) studies the uses of head shakes and proposes intensifying as one of the functions that can be carried out by head movements when occurring together with speech. The strengthening -or intensifying-function is not the only one that may be carried 
out by head movements. McClave (2000) demonstrates through the microanalysis of conversations in American native speakers of English, that head movements co-occurring with speech seem to follow specific patterns and may carry semantic, discourse and interactive functions. For example, she finds out that lateral movements come about together with speech when the latter expresses inclusivity, uncertainty, and intensification. Furthermore, this author argues that speakers change head positions when starting direct quotes and these movements are deictic during narrations, as speakers try to locate an abstract referent in space. Finally, McClave brings up the main limitation of these types of studies: head movements -like all other modes- are many times culturally dependent, and different societies might use different types of movements; therefore, cross-cultural studies are needed. An example of a cross-cultural analysis on head movements is Maynard (1987), who conducted a study with Japanese speakers and determined that head nods are performed to establish the boundaries of clauses, fill transition phases in turn-taking conversations and establish emphasis. Head nods, moreover, seemed to be far more frequent in Japanese speakers than in American speakers.

In the present study, I side with Norris's taxonomy of head movements as it seems to offer a complete description of the types of head movements. Moreover, Norris classifies head movements depending on whether these have verbal counterparts or not, or whether they are used to point or to mark the rhythm (in the case of those movements with no verbal counterpart). This particular description makes it easy to establish the connections between speech and head movements. Moreover, by sharing part of the terminology employed by McNeill (1992) in the description of the types of gestures (iconic, deictic and beats), the description of head movements becomes more comprehensible.

\section{Posture}

One of the first accounts on the study of posture is provided by Scheflen (1964), who investigates the significance of posture in communication systems and asserts that body positions "demarcate the components of individual behavior that each person contributes to the group activities, indicate how the individual contributions are related to each other, 
and define the steps and order in the interaction" (1964, p. 316). In a more straightforward definition, Norris (2004, p. 24) refers to posture as "the ways that participants position their bodies in a given interaction". She further explains that body posture is performed not only by the limbs, but also by the torso and the influence of the head. Besides, Norris distinguishes two aspects to focus on when analyzing posture: the form of the body position and the postural direction; and in particular, how these relate to the actions performed by the participants. This latter idea constitutes a remarkable aspect in Norris's view of posture. Norris argues that the position of a given social actor is intrinsically related to the actions that they are conducting. From this perspective, I demonstrate elsewhere (Bernad-Mechó, 2017a) how body posture reveals the focus of attention of a conversational-style lecturer, whether on the audience or the notes he is using, and how these changes in posture structure the underlying chain of higher-level actions performed by the lecturer. In other words, body postures may serve as indicators of different foci of attention.

The studies on postures have also examined the meaning of specific positions. Machotka (1965), for example, investigates how open and closed positions are perceived, and reaches the conclusion that open-armed postures are judged positively, while closed-armed postures portray cold, shy and passive attitudes. Regarding attitudes, posture may also convey a series of emotional states (Ekman, 1965; Ekman \& Friesen, 1967). In this regard, Lhommet and Marsella (2015) explore how basic human emotions like anger, joy, sadness, surprise, pride, fear, disgust and boredom are frequently associated to given body posture configurations.

Finally, body postures may indicate engagement. In this regard, Anderson (1999) considers the engagement of face-to-face postures (as opposed to disengagement situations). This is corroborated in Bernad-Mechó and Fortanet-Gómez (forthcoming), where posture is seen as an element employed by rhetorical style lecturers to engage the audience in the structuring process of the lecture.

The analysis of posture in the present study is limited to the description of the posture adopted by the lecturers. In the multimodal micro-analyses, the examination of the posture 
provides information on the foci of attention of the lectures as they deliver metadiscursive instances.

\section{Paralanguage (and spoken language)}

Spoken language is the mode that has received most attention in the last decades. In particular, the study of spoken language in academic settings has drawn the attention of many researchers (Csomay, 2007; Deroey \& Taverniers, 2011; Fortanet-Gómez \& Belles, 2005; Pérez-Llantada \& Ferguson, 2006). For a more extensive explanation on spoken academic lectures as a genre, see Section 1.3.

Nevertheless, there are many aspects that can be analyzed within spoken language. For the purposes of this thesis, and in an attempt to clarify the terminology, I separate spoken language and paralanguage as two different entities (even though one cannot exist without the other). In this sense, I will use spoken language or speech to refer to the main source of content in the communications that I look at, i.e. what is uttered. On the other hand, as defined by the Collins English Dictionary (Complete \& Unabridged 2012 Digital Edition), paralanguage will refer to "nonverbal elements in speech, such as intonation, that may affect the meaning of an utterance", i.e. how content is uttered.

The study of paralanguage -also referred to as paralinguistic or extralinguistic- has also been considered by many researchers (Archer \& Akert, 1977; Crystal, 1969, 1975; Crystal \& Quirk, 1964; Laver, 1980; Poyatos, 2002; Richmond \& McCroskey, 2000; Roach, Stibbard, Osborne, Arnfield, \& Setter, 1998; Trager, 1958). One of the most recurrent descriptions of paralinguistic material in previous literature in multimodality is Poyatos's (2002). In this description, Poyatos establishes three categories within paralinguistic elements: qualities, which include pitch, tempo, syllabic duration, rhythm, loudness and timbre, among others; qualifiers, like breathing, laryngeal, pharyngeal, velopharyngeal, esophageal, lingual, mandibular, labial, articulatory and articulatory-tension control; and differentiators, which include sounds like laughing, crying or sobbing. 
Particularly interesting for the purpose of this thesis is what Poyatos describes as qualities, i.e. intensity, loudness, syllabic duration/speed, and so on. These qualities of voice, specifically, have also been referred to as prosody (Roach et al., 1998) and are key in studying how speakers transmit the message. In multimodal studies, Querol-Julián and Fortanet-Gómez (2012) and Querol-Julián (2011a, 2011b) study-among other aspects- the contribution of loudness, syllabic duration, and laughter in Question-Answer sections in conference presentations. Furthermore, paralanguage has also been studied as an intensifier of verbal messages producing prosodic stress (Crawford Camiciottoli, 2015, 2016) and as an element to engage the audience (Bernad-Mechó \& Fortanet-Gómez, forthcoming).

One of the items that has received much attention within prosody and whose functions have been outlined by many scholars is intonation (Bolinger, 1986; Brazil, 1984, 1997; Brazil, Coulthard, \& Johns, 1980; Cauldwell, 2002, 2013; Chun, 2002; Crystal, 1969, 1975; Cutler, 1983; Dalton \& Seidlhofer, 1994; Halliday, 1985; Halliday \& Greaves, 2008; O'Connor \& Arnold, 1973; Wells, 2006). Intonation refers to the variations in pitch when speaking, i.e. to the rise and fall processes of the voice. Dalton and Seidlhofer $(1994$, p. 176) add that these variations in pitch are able "to convey different kinds of meaning in discourse". Thus, intonation may contribute to the conveyance of meaning, and therefore, the study of intonation within a multimodal analysis appears to shed light on how meaning is made through variances in speech production. In a study on the ways in which topics are introduced in lectures (Bernad-Mechó, 2017a), I demonstrate how intonation and syllabic duration indicate whether an utterance belongs to one higher-level action or another.

An approach that has often been acknowledged within the studies of intonation is the one proposed by Brazil et al. (1980), Brazil, $(1984,1997)$ and Cauldwell $(2002,2013)$. These researchers undertake intonation from a rather communicative perspective and develop a framework known as Discourse Intonation (DI). DI studies pitch sequences which are made up of tone units. Tone units, in turn, include one or two prominent syllables, i.e. syllables that stand out over the rest because of their volume or duration. In DI, these prominent syllables are referred to as onset, the first prominent syllable, and tonic syllable, the second prominent syllable. Thus, syllables can be described as prominent or non-prominent. At 
this point, it is relevant to remark that the use of pitch sequences as the unit of analysis (Brazil, 1997), however, contrasts with the unit of analysis employed in MIA. Norris (2004), following Chafe (1994), favors the use of intonation units separated by the inhaling of air.

Brazil (1997) further explores tone units and describes five tones the speakers can choose from when uttering sentences: rise-fall, fall, level, rise, and fall-rise. The relationship between the choice of tone and the content of speech has to do with the disclosure of new or shared information. According to Brazil, rise-fall and fall tones are used to reveal new information, while fall-rise and rise tones suggest that the information given is shared with the audience. Finally, level tone is used when the speaker focuses on the exact words that are being transmitted.

Furthermore, another system described by Brazil (1997) is key. Key refers to the choice in pitch for the onset syllable of the tone unit and it can be low, mid, or high. The pitch in one onset syllable is compared with the pitch of the previous prominent syllable and a relationship in meaning can be extrapolated. Low keys show an equating relation with the previous material, i.e. they indicate that the new content is equitable to the content that has already been released. Mid keys, in turn, transmit the idea of adding information to the material that has previously been released. Lastly, high keys indicate a denial of expectations with the previous material, i.e. they contrast and express disagreement.

The last system explored in DI is termination. Termination describes the choice in pitch for the tonic syllable in relation to the previous prominent syllable. Termination, like key, can be low, mid or high, and each of these can be interpreted in a different manner. Low terminations indicate that communication has ended. Moreover, mid terminations are used when speakers expect listeners to agree or have a passive position. Finally, high terminations usually imply the presence of the listener, from whom a response is expected, for example, in questions; and they can also indicate surprise. Table 2.1 summarizes the systems proposed in $\mathrm{DI}$ as well as the range of possibilities from which speakers can choose. 


\begin{tabular}{l|l|l} 
System & Choices & Number \\
\hline Prominence & prominent/non-prominent syllables & 2 \\
\hline Tone & rise-fall, fall, level, rise, rise-fall & 5 \\
\hline Key & high, mid, low & 3 \\
\hline Termination & high, mid, low & 3 \\
\hline
\end{tabular}

Table 2.1 Intonation in DI. Systems and choices (Brazil, 1997, p. vii)

Following previous multimodal studies (Bernad-Mechó, 2015a, 2017a, Crawford Camiciottoli, 2015, 2016, Querol-Julián, 2011a, 2011b; Querol-Julián \& Fortanet-Gómez, 2012) three main aspects will be considered in the study of paralanguage in this thesis: syllabic duration, loudness, and pitch. In particular, I describe whether the syllabic duration is shorter (the speaker speaks faster) or longer (the speaker speaks slower); and whether the lecturer speaks louder (for emphasis) or quieter. Regarding pitch, as I describe in Section 4.3.3, I make use of a simplified version of Brazil's (1997) system of choices.

Still and all, and as a concluding remark, it is important to emphasize the cultural dependence of these approaches. The language that is being studied in most of the literature on intonation is English (mostly in American or British contexts), and the extrapolation of notions from these contexts to other languages or cultures cannot be assumed.

\section{Proxemics}

Proxemics is commonly referred to as "the ways in which individuals arrange and utilize their space" (Norris, 2004, p. 19). In the case of the present study, the use of the classroom space made by the lecturers. One of the earliest accounts of the use of space is Hall's (1959, 1966). For example, in Hall (1966), this researcher examines the distances between speakers and distinguishes four spaces: the intimate space, which indicates a close relationship and comfort between individuals and is associated to actions like whispering or hugging; the personal space, which is present among family members or close friends; the social space, used with acquaintances or people unknown for the speaker; and the public space, used in public speaking situations like lectures or presentations. 
Another interesting aspect to take into account when analyzing proxemics is the relation established between the use of space and the actions performed by the actors. In this regard, Hall (1966) maintains that the perception of space is closely related to the actions being performed, and therefore, proxemics is dynamic. Regarding the relation between the use of space and the speakers Norris (2004, p. 20) argues that

\footnotetext{
proxemic behavior is tightly integrated with the higher-level actions that are being performed [and] proxemic behavior is not arbitrary in a given situation among specific individuals, and gives insight into the kind of social interaction that is going on.
}

Having this idea in mind, the position of the lecturers in the lecture halls may give an insight into the foci of attention of such lecturers. For example, if a lecturer moves from the lectern towards the board, the use of space indicates that the focus of attention of the lecturer has changed from lecturing to using the board. Similarly, if a lecturer moves from the lectern towards the students, this seems to indicate a higher level of attention on the audience.

In a more recent paper, Lim et al. (2012) study the positions of teachers in the classroom as realized in combination with other semiotic resources. They describe how the position maintained by the teachers is related to the pedagogical process. In this sense, Lim et al. argue that different spaces in the classroom are associated with specific meanings and particular discourse practices. Another example of the study of proxemics in multimodal communication is Mead (2016) who, among other non-verbal modes, examines the proxemics in face-to-face human-robot interactions with the aim to adjust the robot's behavior to maximize its ability to recognize social signs.

In the present work, I focus on open speaking situations in which the distance maintained between the lecturer and the audience rarely varies. However, as I detail in Chapter 7, different lecturers choose different positions within the classroom to deliver their lectures. These distinct uses of space, in turn, may indicate how "close" to the audience the lecturers are. Moreover, as I describe above, the study of proxemics may indicate the higher-level actions that are being foregrounded by the lecturers. In this sense, as I detail in Section 4.3.3, the annotation of proxemics is performed by describing the positions of the lecturers in the classroom. 


\section{Facial expression}

The study of facial expression has its roots within the fields of psychology, psychiatry, and sociology (Ekman, 1972, 1985, 2007; Ekman et al., 1987; Ekman \& Friesen, 1969, 1978). In this sense, facial expression has traditionally been studied as an indicator of emotions. Ekman (1972), for instance, describes six primary facial expressions (happiness, sadness, anger, fear, surprise, and disgust) and claims that these emotional expressions are universal. A relevant contribution to the study of facial expression is what Ekman and Friesen (1978) refer to as Facial Action Coding System (FACS), a tool for measuring facial expressions that has further been adapted for automated recognition systems -see, for instance, Ryan et al. (2009). An interesting fact about FACS is the classification of expressions as occurring in three distinct areas in the face: the lower face (cheeks, nose, and mouth), the eyes and eyelids, and the brows and forehead.

The analyses of facial expressions within multimodal studies in academic genres are widespread. In a study on conference presentations, for example, Fernández Polo (2014) describes the use of smile as a softening element employed by presenters when citing someone from the audience. Another example is Zhang (2015), who performs an extensive analysis on the expression of disagreement by plenary speakers and concludes that facial expression, posture, and gestures are salient elements indicating difference of opinions. In a more specific fashion, the study of eyebrows has received attention by many researchers; brows have been identified as elements for emphasis, punctuation, to underline and animate speech and to pose questions (Birdwhistell, 1979; Eibl-Eibesfeldt, 1972; Hwang \& Matsumoto, 2016). Finally, as I describe in Section 3.3.2, Hübler (2007) describes the use of lip adaptors as separating elements between topics in speech.

For the purposes of this thesis, I will only consider those expressions performed with the lower face and the brows and forehead area. In this sense, the expressions with the eyes and eyelids will be studied under the analysis of gaze. Given the nature of the data here analyzed (academic lectures), little emotional expression is expected. Instead, the main focus of the study of facial expression in the multimodal analyses here performed will be 
on the emphasizing uses of eyebrows and the use of lower face elements as possible topical boundaries.

\subsection{Multimodal transcription and multimodal annotation tools}

In this section, I focus on two aspects that need to be taken into account when conducting multimodal analyses. First, in Section 2.4.1, I briefly explore the types of transcriptions (verbal and multimodal) employed when representing audiovisual data. Then, in Section 2.4.2, I review some well-known software applications for the multimodal annotation of data.

\subsubsection{On multimodal transcription}

One of the steps to be taken into account by the multimodal analyst is the process for the transcription of video and audio data (Baldry \& Thibault, 2006; Bezemer, 2014a; Flewitt, Hampel, Hauck, \& Lancaster, 2014; Mavers, 2012; Norris, 2004). The main issue lies in the fact that "multimodal transcripts entail numerous transcripts of any one interaction" (Norris, 2004, p. 65), i.e. a transcription of each of the modes that are being considered. As a result, a multimodal transcription should combine all modes so that it helps the researcher to obtain a global scope of the multimodal ensemble. Bezemer (2014a) suggests five steps in the process of multimodal transcriptions: selecting a methodological framework, establishing the purpose of the transcript, designing the transcript, reading the transcript and extracting conclusions. Out of these, establishing the purpose of the transcript stands out as paramount in order to optimize the transcription so it exemplifies the point that is being made. By way of illustration, if an analyst is trying to show how gestures are performed at a given point, a transcription of the intonation might be irrelevant. Furthermore, the analyst should consider aspects such as the readability of the 
transcription and the appropriateness of the transcription system. In this regard, attention has also been brought to how transcriptions are presented. Flewitt et al. (2014) compile a number of types of transcriptions carried out by different multimodal researchers whose foci vary from one another. There seem to be two broad types of transcriptions: those which are text-based, with few images, and which describe in writing what is coming about for each of the modes being analyzed -see Figure 2.3 a) (Baldry \& Thibault, 2006, Appendix I, I)-; and those which are image-based with few or no descriptions at all within the transcription -see Figure 2.3 b) (Norris, 2006, p. 405).

In the present study, I will provide two main types of transcriptions: verbal and multimodal transcriptions. On the one hand, verbal transcriptions will consist of representations of the spoken language mode. These transcriptions will provide content information related to the lecture, as well as some indications showing pauses, hesitations or overlaps among other aspects. They are meant to lay out initial details of what is going on in the lecture in terms of content and are helpful in linguistic analyses. Multimodal transcriptions, on the other hand, are meant to represent what is going on in a given interaction, not only in the use of spoken language, but also in the use of various semiotic modes that contribute to the conveyance of meaning. As I stated before, the aim of this thesis is to focus on the modes of gesture, gaze, head movement, posture, paralanguage, proxemics and facial expression. In order to describe how these modes interact, I use image-based transcriptions selecting particular screenshots that aim to accurately represent the complexity of the multimodal ensembles (see Section 4.3.3 for a full description of the transcriptions conducted in this thesis). 

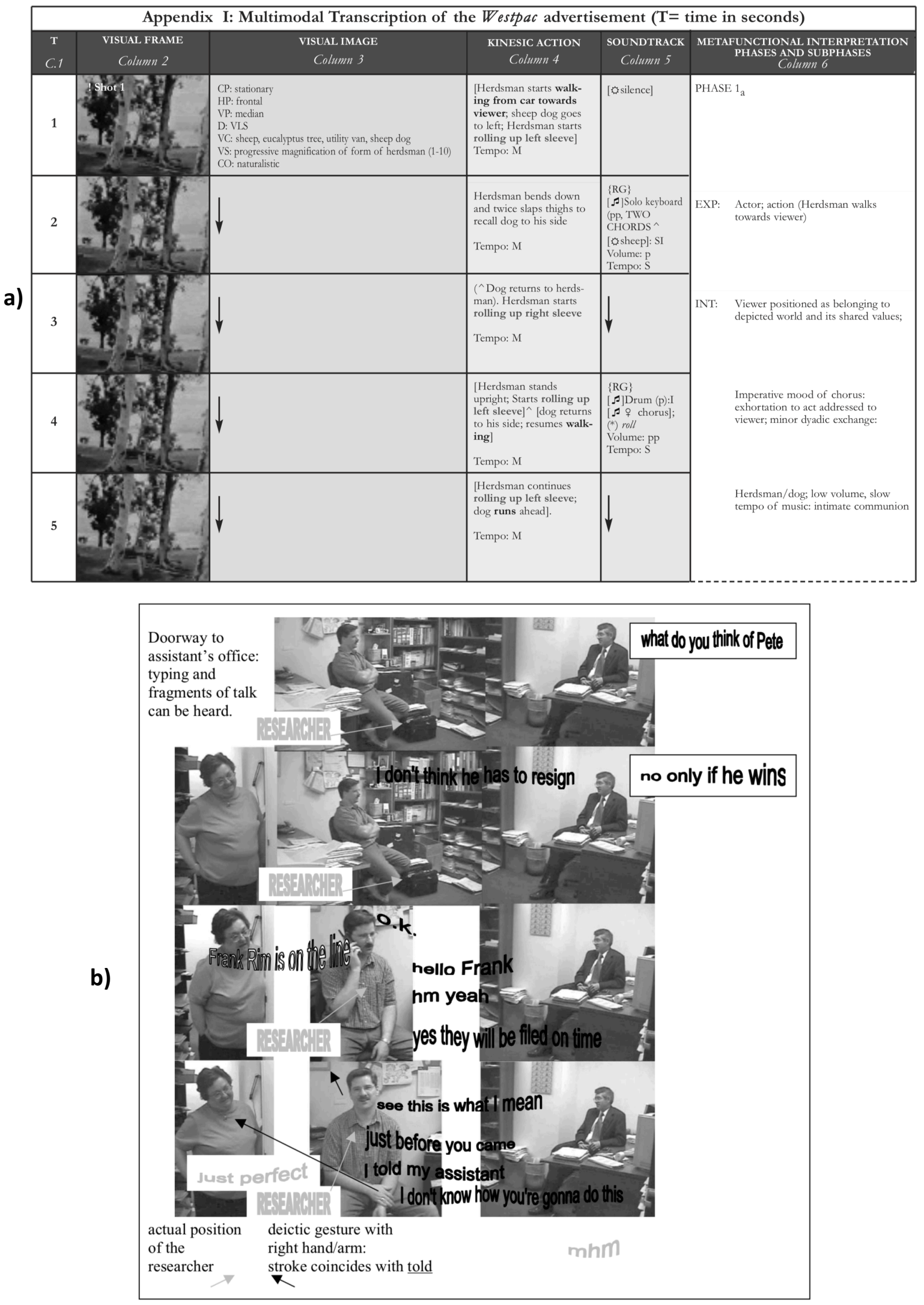

Figure 2.3 a) Text-based multimodal transcription (Baldry \& Thibault, 2006, Appendix I, I); and b) Imagebased multimodal transcription (Norris, 2006, p. 405) 


\subsubsection{On multimodal annotation tools}

After having explored the basic elements to be considered in multimodal transcriptions, in this section I look at a number of software applications for the analysis of multimodal video and audio. Multimodal analyses require the dissection of communication into several modes that work together simultaneously. In order to obtain comprehensible representations of these interweaving modes, some software applications can be employed. Rohlfing et al. (2006) compile an extensive review and compare various tools for multimodal analysis. In particular, they review traditional media and text editors on the one hand, and tools for video and audio annotation on the other (Anvil, ELAN, EXMARaLDA, TASX, and MacVisTA). These are not the only multimodal annotation tools that exist: other relevant tools that can be used for multimodal annotation are DRS (Digital Replay System) (French et al., 2006) a concordancer initially developed for ethnographic studies; and Multimodal Analysis-Video (MMA-Video) (O'Halloran et al., 2012), especially designed for multimodal analysis and the software that is used in this thesis. Out of all these options, ELAN and MMA-Video seem to be recurrently referred to in the study of multimodality (Bernad-Mechó, 2015a; Norte Fernández-Pacheco, 2016b; O’Halloran et al., 2012; QuerolJulián, 2011a; Tan et al., 2015, 2016).

\section{ELAN}

ELAN (EUDICO Linguistic Annotator) (Sloetjes \& Wittenburg, 2008; Wittenburg et al., 2006) is a free open source tool developed by the Max Planck Institute for Psycholinguistics (MPI) and designed for the annotation of video and audio data. It can be downloaded from The Language Archive section in MPI's website ${ }^{7}$. ELAN allows for the creation of synchronized multilayer annotations. This type of annotation works like a musical score for several instruments where every one layer (or tier) represents a mode. Thus, the user can create a

\footnotetext{
${ }^{7}$ http://tla.mpi.nl/tools/tla-tools/elan/ Last accessed January $8^{\text {th }} 2018$.
} 
series of tracks and then annotate relevant information for each of the modes that are being analyzed. These tiers, in turn, can be structured hierarchically one within the other.

An interesting feature offered by ELAN is the possibility of compiling linguistic types and controlled vocabularies. The purpose of these tools is that of creating lists of possible choices that can be quickly attached to a specific mode in a particular instance of the clip so that the process of annotating becomes methodically systematized. Thus, each tier can be annotated following a given linguistic type created by the user (for example, gestures or paralinguistic features). Linguistic types, in turn, are governed by controlled vocabularies, i.e. lists of choices that are encompassed within each linguistic type (for instance, palm up or palm down in the case of the linguistic type gestures, or pause and syllabic duration shorter for paralinguistic features). The creation of controlled vocabularies is timeconsuming at the beginning of the annotation, but once they have been created, this process expedites and vocabularies only need to be edited when a new type of mode is found on the data. Finally, a template file of the linguistic types and controlled vocabularies can be extracted so that they can be used in the annotation of other projects.

Additionally, ELAN, like Anvil, is also capable of showing waveforms. Furthermore, ELAN can load up to four video files. Nevertheless, pitch contours cannot be shown in ELAN and the use of other software is needed. In this sense, files from PRAAT (see its description in the paragraphs below) can be imported. At a technical level, ELAN is Java-based and runs well on bpth Windows and OSX. Some problems have been reported in the use of Linux, though (Rohlfing et al., 2006). Installation is straightforward and various guides for new users are offered at the website.

Figure 2.4 shows a screenshot of ELAN. The video being analyzed is on the upper left side of the screen. This part of the screen can be detached and shown in bigger size in an additional monitor. On the upper right side, there is a menu with the media controls (grid, text, subtitles, lexicon, audio recognizer, video recognizer, metadata, and controls) where various functions can be conducted. The lower side of the screen is devoted to the waveform and the tiers with its respective annotations. The lower left side of the screen 
shows the names of the tiers created in ELAN and their structure, including a display of the waveform, and a series of annotations that have already been performed.

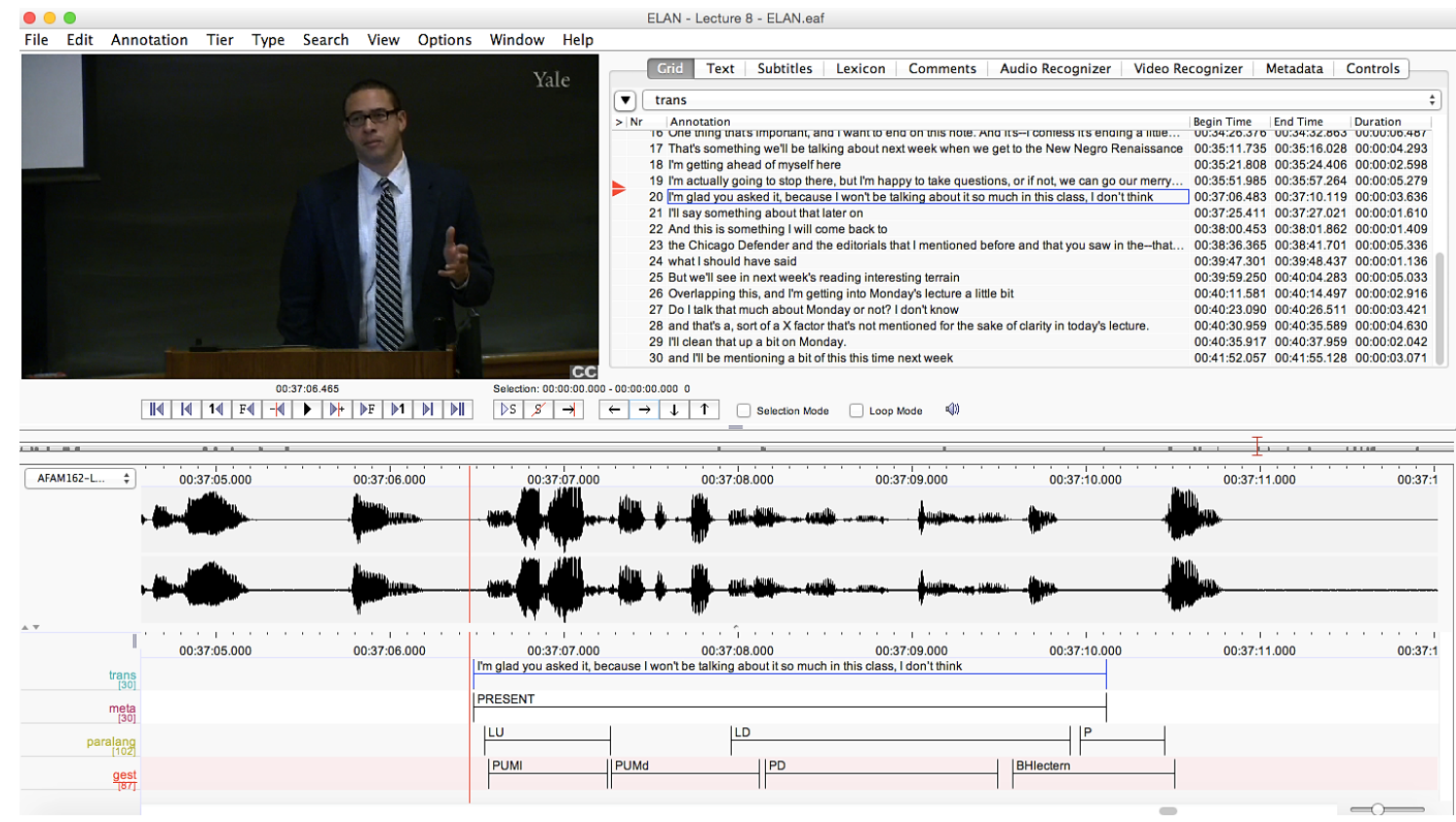

Figure 2.4 ELAN screenshot -extracted from Bernad-Mechó (2015a, p. 63)

\section{MMA-Video}

Another recurrent tool for multimodal annotation is Multimodal Analysis-Video (MMAVideo) developed by Kay O'Halloran and her colleagues at the Multimodal Analysis Company (O'Halloran et al., 2012). Unlike ELAN, however, MMA-Video is not free open source software and needs to be purchased from the company's website ${ }^{8}$. Like ELAN, a series of synchronized and hierarchically organized strips (or tiers) can be created for the analysis of modes. The strips are created in the Graphical User Interface (GUI), i.e. the main interface of the software. This interface is shown in Figure 2.5 below and consists of several parts. First, on the upper left side, there is a video box that can be detached and expanded. Next to it, there is a box for the verbal transcriptions. On the upper right side, there is a set of three boxes from which the analyst can select system choices. Finally, under the upper

\footnotetext{
${ }^{8}$ http://multimodal-analysis.com/products/multimodal-analysis-video/ Last accessed January $8^{\text {th }} 2018$.
} 
section, there are a series of strips including a film strip, sound strip (waveform), a dialog strip, and a list of customizable strips for multimodal annotations.

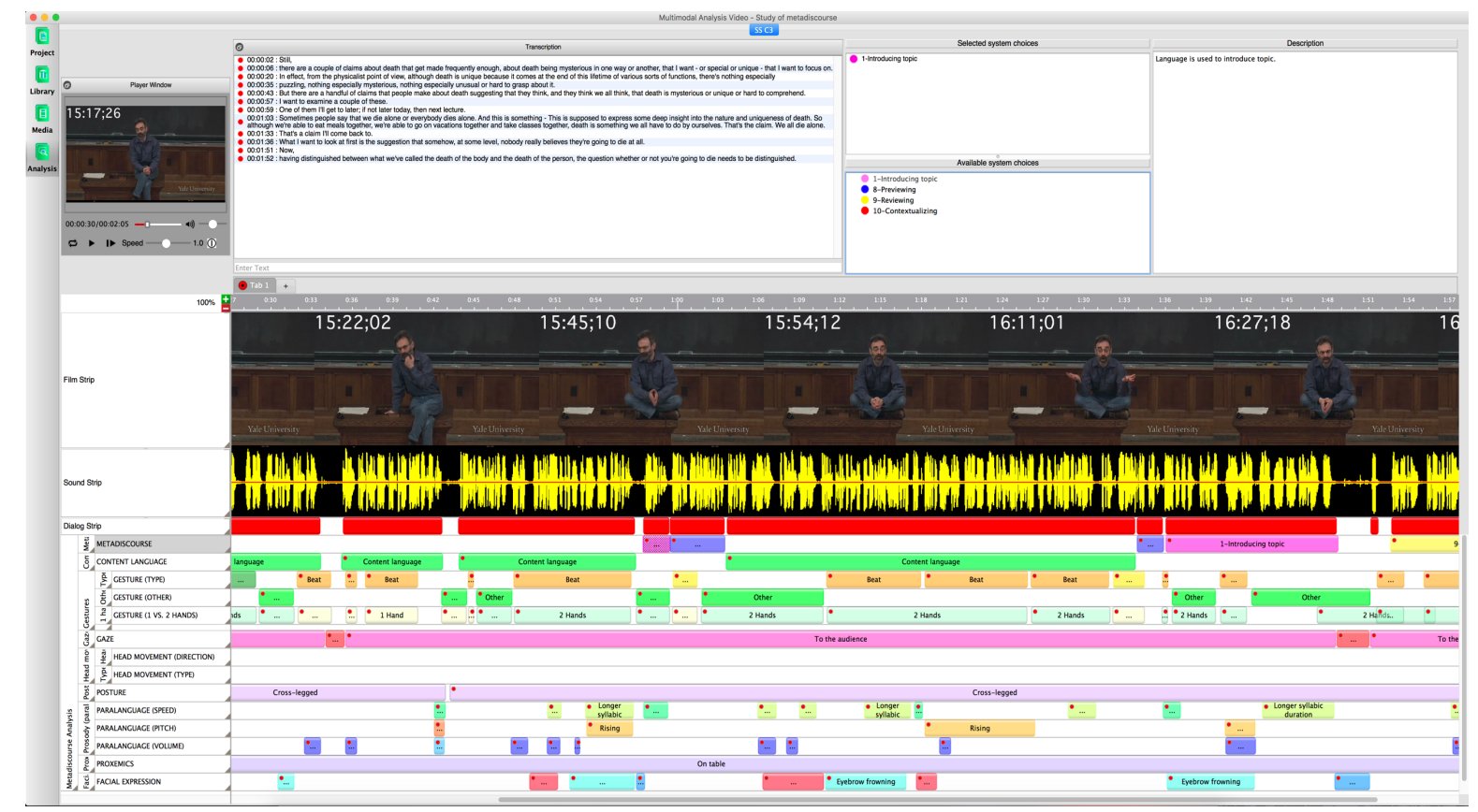

Figure 2.5 Screenshot of MMA-Video's GUI

Like ELAN, MMA-Video offers the possibility of configuring a framework for analysis in which a hierarchy of system choices can be established. For instance, a category entitled gestures can be created with the system choices iconic, metaphoric, deictic and beatfollowing McNeill (1992), and so on and so forth (see Section 4.3.3 for a full description of the framework employed for the analyses in this thesis). In any case, the interface presented in MMA-Video makes this process more user-friendly if compared with ELAN. Anyhow, the greatest innovation in MMA-Video when compared to other applications is the State Machine. The State Machine is a representation system that displays the percentages of occurrence of particular modes and combinations of modes as well as the unfolding of such combinations as the video clip progresses. In short, the State Machine provides quantitative data on the use of semiotic resources in a given file. Figure 2.6 shows an example of the State Machine in which occurrences of metadiscourse and gestures are compared. The circular nodes on the left [1] represent all possible combinations of metadiscourse and types of gesture (e.g. introducing topic, introducing topic and beat, introducing topic and metaphoric gesture, introducing topic and deictic gesture, and so on 
and so forth), and the percentage of time in which such a combination occurs. The arrows between nodes [2] describe the transitions between combinations of choices. Finally, the box on the right [3] displays the particular combination that is taking place in the selected frame. In this particular case, Figure 2.6 shows that the combination of introducing topic metadiscourse accompanied by a beat gesture occurs in $10.71 \%$ of the total duration of the clip.

Finally, at a technical level, MMA-Video works smoothly both in Windows and OSX. Overall, MMA-Video has proven to be a complete tool with an intuitive friendly-user interface that facilitates the learning process. Furthermore, the application includes an extensive manual for the user.

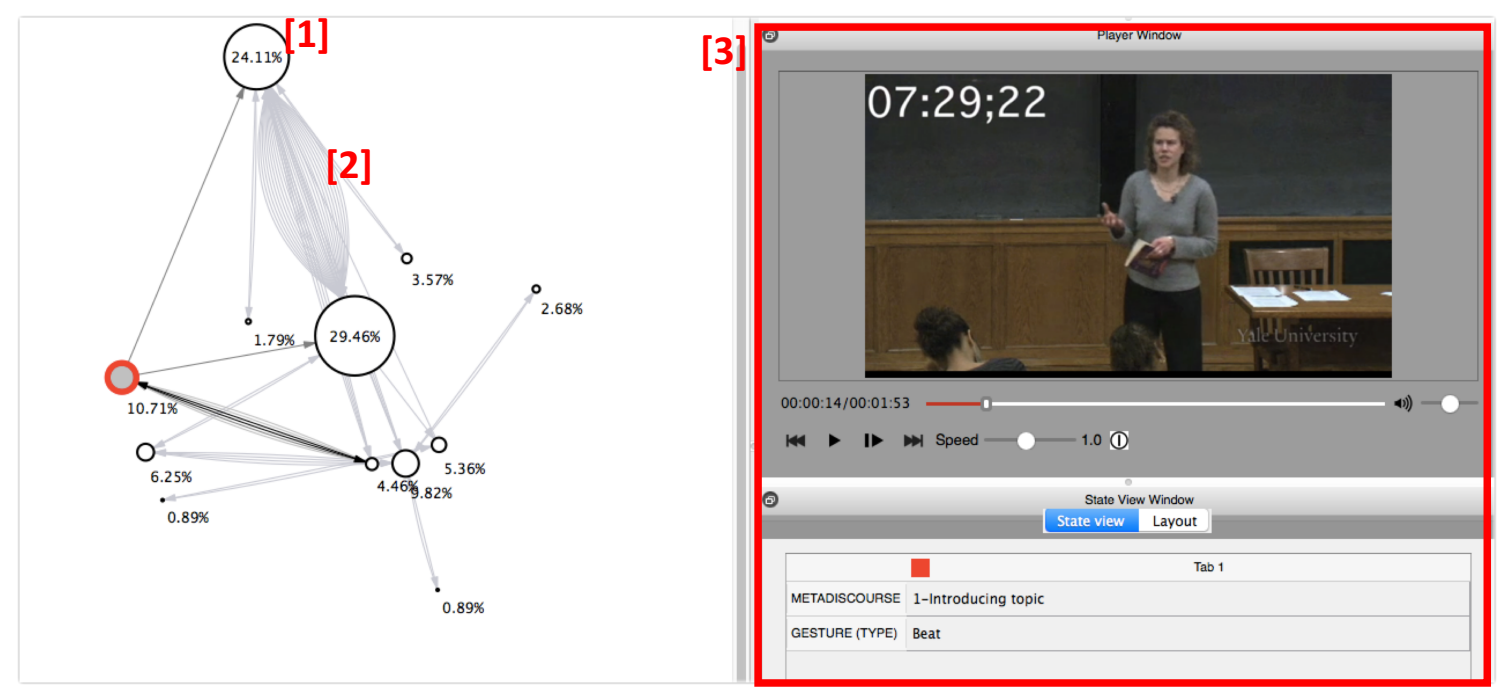

Figure 2.6 Screenshot of MMA-Video's State Machine

All in all, both applications (as well as some of the other previously mentioned tools) are very similar and offer homologous functionalities. As Rohlfing et al. (2006, p. 122) put it:

[t]he goal [...] here was not to decide which tool is the best. There is no single best one. In our comparison, it became apparent that tools are only a means to an end. Taking advantage of technology, analysis is supported by tools that have been designed against the background of specific theoretical assumptions.

Notwithstanding that all these applications allow for the synchronized analysis of various modes, I will utilize MMA-Video to conduct multimodal annotations in this thesis. The fact 
that this application has been purposely developed and optimized for multimodal analyses and especially, the fact that MMA-Video is able to provide quantitative data on the use of semiotic resources have been paramount when choosing this software. After having used ELAN in previous studies (Bernad-Mechó, 2015a; Bernad-Mechó \& Fortanet-Gómez, 2017), I argue that MMA-Video's user-friendly interface as well as the easy process for the creation of frameworks of analysis complete an all-round tool that will make the process of annotating simpler and more efficient.

The study and annotation of audio, however, has not received proper attention in multimodal annotation tools. While most of them enable the display of a basic waveform, a thorough analysis of these is not possible. As a possible solution, there are some tools to examine audio in detail. In the following lines, I will briefly refer to PRAAT (Boersma, 2001; Boersma \& Weenink, 2017) and Sonic Visualiser (Cannam, Landone, \& Sandler, 2010).

PRAAT

Although PRAAT is not employed in the analyses in this thesis, it remains one of the recurrent tools employed by multimodalists and it is worth discussing here. PRAAT (Boersma, 2001; Boersma \& Weenink, 2017) is a free open-source computer program developed by Boersma and Weenik at the Institute of Phonetics Sciences of the University of Amsterdam. It can be downloaded from PRAAT's webpage ${ }^{9}$. PRAAT is used to analyze speech and allows for an extensive examination of prosodic features. In particular, PRAAT creates spectral analyses, pitch analyses, formant analyses and intensity analyses, among others. Moreover, annotations can be created and then exported to multimodal annotation tools like ELAN or Anvil. Despite its usefulness, the learning curve of PRAAT is rather steep and it requires some time to get used to its functionalities. Furthermore, the length of the sound that is being analyzed in a given file is limited. Figure 2.7 shows a screenshot of PRAAT extracted from de Jong and Wempe (2007, p. 54). The first pane, in the upper part of the screen, is a standard waveform of the file; right under the waveform

\footnotetext{
${ }^{9}$ http://www.praat.org Last accessed January $8^{\text {th }} 2018$.
} 
there is a second pane which includes the main analyses being performed (in this case, a pitch analysis and an intensity analysis); the rest of the tiers are created by the researcher in order to annotate the file.

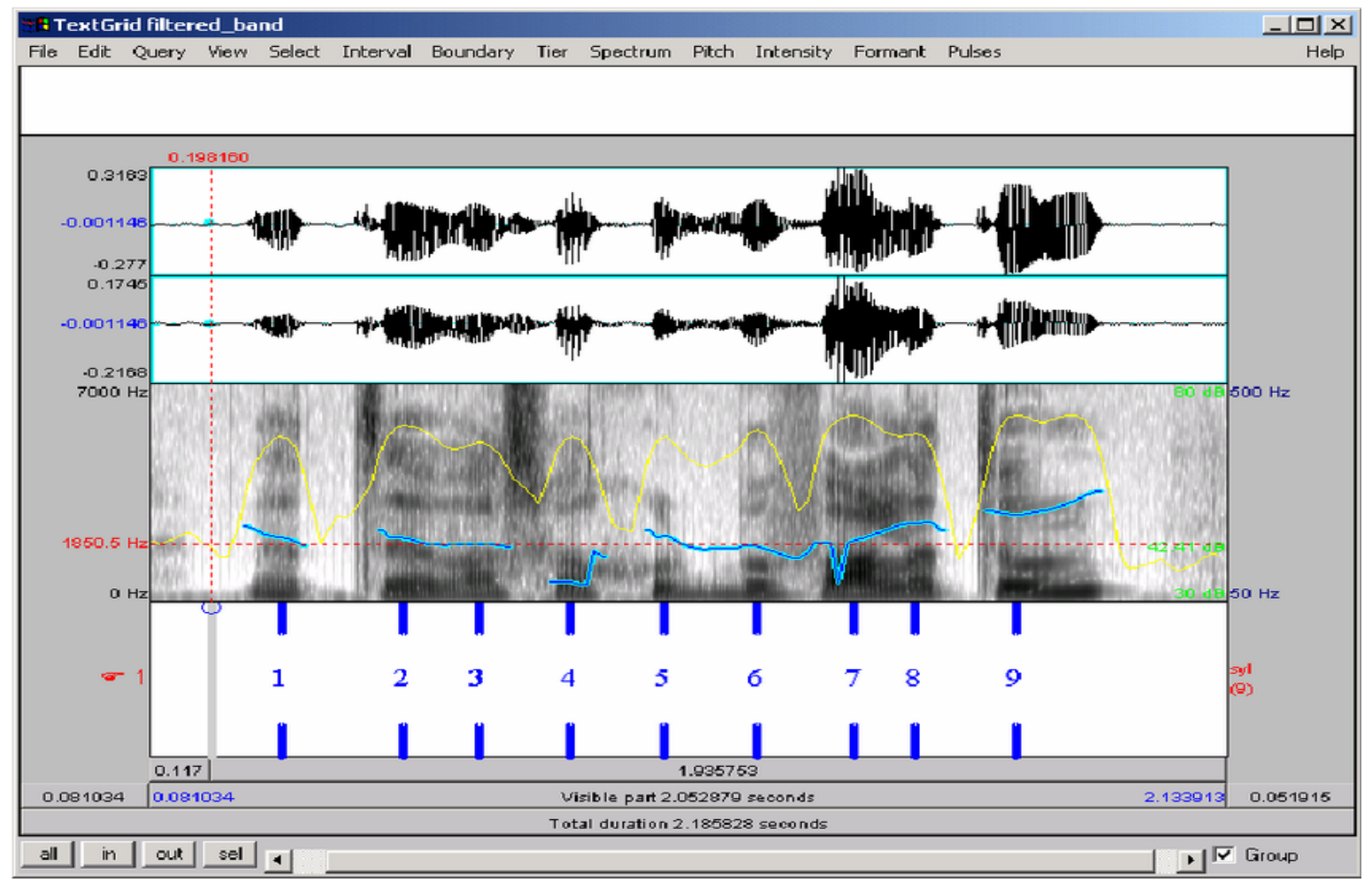

Figure 2.7 PRAAT screenshot (de Jong \& Wempe, 2007, p. 54)

\section{Sonic Visualiser}

Sonic Visualiser (Cannam, Landone, \& Sandler, 2010) is a tool designed at the Centre for Digital Music at Queen Mary, University of London for viewing and analyzing music audio files. It can be downloaded for free at their official website ${ }^{10}$. Although designed for musicologists at first, it also allows for in-depth analyses of speech. As with PRAAT, Sonic Visualiser shows basic waveforms, analysis tiers and can add a number of annotated tiers. Annotations in Sonic Visualiser, however, consist of labeled time points and defined sections. In this sense, PRAAT seems to offer a wider range of possibilities for free annotations. That being said, one of the most useful contributions of Sonic Visualiser is the

\footnotetext{
10 http://sonicvisualiser.org
} 
option of extending the basic features of the software through the use of Vamp plugins. Vamp plugins are systems for audio processing that can extract information from audio files. For example, in the study of intonation, the Probabilistic YIN (pYin) plugin (Mauch et al., 2015; Mauch \& Dixon, 2014) -a modification of the YIN algorithm (de Cheveigné \& Kawahara, 2002)- can provide an accurate estimation of the pitch track of monophonic audio files. This pitch track can then easily be exported to image or .pdf formats with Sonic Visualiser. Figure 2.8 displays a representation of the intonation of a fragment as performed with pYin and displayed in Sonic Visualiser. Finally, the user-friendly interface of Sonic Visualiser makes the learning process uncomplicated. These last arguments justify the use of Sonic Visualiser and pYin for prosodic analyses in this thesis.

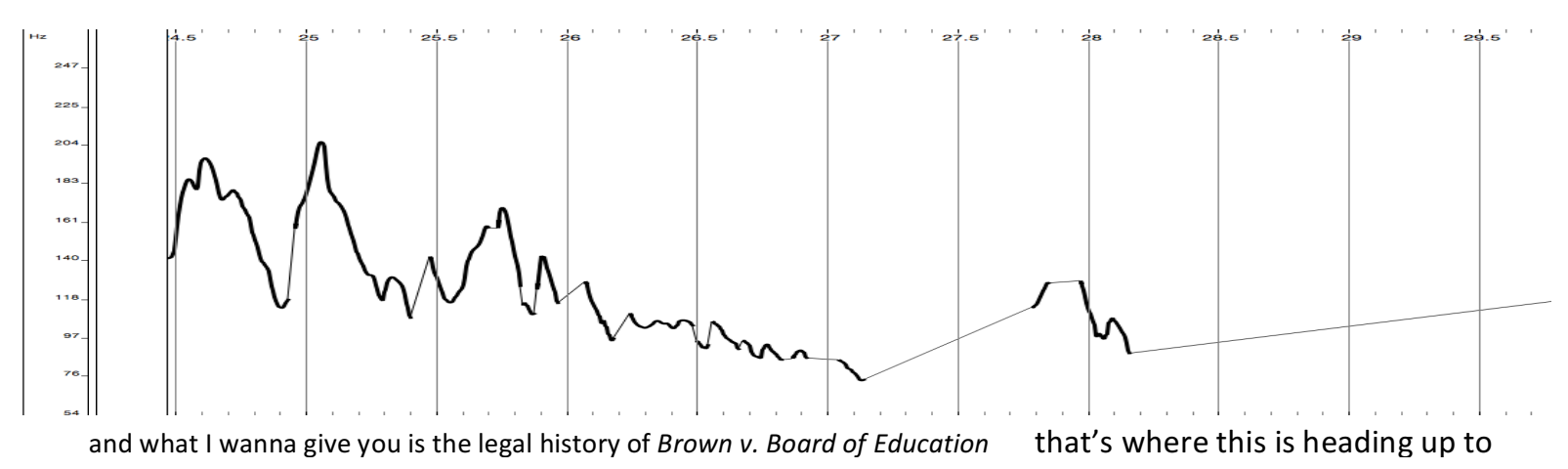

Figure 2.8 pYin analysis in Sonic Visualiser (Bernad-Mechó, 2017a, p. 52)

In this section, I have reviewed some of the most commonly used tools for multimodal annotation of video (ELAN and MMA-Video) and audio (PRAAT and Sonic Visualiser) and presented examples of their usefulness and drawbacks. Moreover, I have shown how MMA-Video and Sonic Visualiser will be advantageous for the analyses conducted in this thesis. 


\subsection{Summary and applicability}

In Chapter 2, I have reviewed the main methodological approaches to multimodality: MSS, MDA and MIA. All multimodal studies share the idea that all communication is multimodal and language is just one more mode within a complex multimodal ensemble. However, different approaches to multimodality provide distinct foci of attention. In this sense, Jewitt (2014) summarizes the differences in each approach in a table showing the emphasis placed on the context, the system of communication and the individual who communicates (see Table 2.2).

\begin{tabular}{|l|lll|}
\hline Approach & $\begin{array}{l}\text { Emphasis on the context } \\
\text { Emphasis on the system }\end{array}$ & $\begin{array}{l}\text { Emphasis on the } \\
\text { individual }\end{array}$ \\
\hline $\begin{array}{l}\text { Multimodal Social } \\
\text { Semiotics [MSS] }\end{array}$ & $\begin{array}{l}\text { Medium-high: interest } \\
\text { on the moment of the } \\
\text { sign-making process }\end{array}$ & $\begin{array}{l}\text { Medium: as resources } \\
\text { with regularities }\end{array}$ & $\begin{array}{l}\text { High: importance of } \\
\text { the sign-maker }\end{array}$ \\
\hline $\begin{array}{l}\text { Multimodal Discourse } \\
\text { Analysis (MDA) }\end{array}$ & $\begin{array}{l}\text { Medium-high: meaning } \\
\text { is contextual }\end{array}$ & $\begin{array}{l}\text { High: study of systems as } \\
\text { sets of choices with levels } \\
\text { and organizational } \\
\text { principles }\end{array}$ & Low \\
\hline $\begin{array}{l}\text { Multimodal } \\
\text { (Inter)action Analysis } \\
\text { (MIA) }\end{array}$ & $\begin{array}{l}\text { High: interest in the } \\
\text { moment of the } \\
\text { interaction }\end{array}$ & $\begin{array}{l}\text { Low } \\
\text { Migh: the social actor }\end{array}$ \\
\hline
\end{tabular}

Table 2.1 A comparison of the emphasis of various approaches to multimodality. Adapted from Jewitt

(2014, p. 39)

These approaches to multimodality are not mutually exclusive and the choice of one over the other will be determined by the research questions. As I explain in Chapter 4 , I intend to conduct a full analysis on how organizational metadiscourse is used in academic lectures. Therefore, for the purposes of this thesis, I utilize concepts from all three approaches. Both MSS and MDA will allow me to explore how meaning is conveyed, how systems work and what combinations occur when conveying meaning. MIA, on the other hand, will be particularly useful to shed light on how individuals interact; this interaction, in turn, will reveal structures of higher-level actions that will help to determine what role organizational metadiscourse plays within the set of actions performed by the lecturers. 
Furthermore, I have explored both, how the notion of mode is defined in the different approaches, and some previous research on the non-verbal modes that I will be focusing on in this study, i.e. gesture, gaze, head movement, posture, paralanguage, proxemics and facial expression. The choice of these particular modes describes an emphasis on the lecturers themselves. In this sense, this thesis concentrates on how lecturers transmit their message through the (embodied) resources they have at hand.

The last section of Chapter 2 reflects upon two issues in multimodal investigations: how transcriptions are made and some tools for multimodal annotation. Regarding the former, the purpose of the transcription will determine its type. Generally, image-based transcriptions will be used in this thesis showing shifts in gestures, gaze, posture, and other non-verbal elements; transcriptions of pitch lines and other prosodic features will also be included when analyzing paralanguage. Finally, in-writing explanations might be added when further clarification is needed. As for the second issue, the tools for multimodal annotation, I have described and compared a range of tools for the creation of multimodal corpora. In the studies of semiotic resources conducted in this thesis, I will make use of MMA-Video for video annotations and Sonic Visualiser together with the Vamp plugin pYin for the study of paralanguage. Both applications provide user-friendly interfaces and display a comprehensible representation of the synchronic interaction of modes in communication. Furthermore, MMA-Video provides quantitative data on the percentages of use of specific combinations of modes.

The following chapter deals with metadiscourse. Particularly, I review the definition of metadiscourse and explore its most influential models. Furthermore, I look into some of the previous research conducted in academic settings, and particularly, from a multimodal perspective. 



\section{CHAPTER 3. METADISCOURSE}

This thesis describes the use of metadiscourse, and more specifically, how organizational metadiscourse is employed in spoken academic lectures. This description, as stated in the previous chapter, is approached from a multimodal discourse analysis perspective, thus considering linguistic, paralinguistic and non-verbal features to convey meaning, as well as the co-occurrence and interaction among this ensemble of elements. In the process of carrying out this study, I intend to shed some light on the field of spoken academic discourse, where very few studies have been conducted from a multimodal point of view.

This chapter concludes the theoretical part of the thesis and is devoted to an overview on metadiscourse, its main trends and taxonomies, as well as a review of some existing works on metadiscourse in spoken academic discourse. First, in Section 3.1, I look at the concept of metadiscourse and compile a series of definitions in an attempt to narrow them down to a working description of the term. This leads the way to Section 3.2 where I review the main frameworks and taxonomies for the study of metadiscourse. Finally, Section 3.3 revisits some of the current trends in metadiscourse in spoken academic language and includes an examination of an assembly of relevant studies on metadiscourse in university lectures. This section also explores the multimodal analysis of metadiscourse in spoken academic discourse. In this regard, I go through some of the very few studies that have approached metadiscourse from a multimodal perspective where non-verbal semiotic resources have been taken into account.

\subsection{Defining metadiscourse}

Metadiscourse is probably one of the fields within language studies that has received most attention by scholars in the recent decades. It has been studied from many different perspectives: discourse analysis, linguistics, applied linguistics, pragmatics, rhetoric, and 
second-language theory and pedagogy (Vande Kopple, 2012); and in many different languages (Hyland, 2005). Aguilar (2008) offers an extensive compilation of a series of studies on metadiscourse from a contrastive rhetoric and genre analysis perspective (Connor, 1996; Dafouz Milne, 2003; Dahl, 2004; Fuentes-Olivera, Velasco-Sacristan, Arribas-Bano, \& Samaniego-Fernandez, 2001; Heino, Tervonen, \& Tommola, 2002; Le, 2004; Longo, 1994; Moreno, 1997), from the perspective of interaction (Fortanet-Gómez, 2004a; Hyland, 2001a, 2002a, 2005; Thompson, 2001; Thompson \& Thetela, 1995), from a native vs. non-native speaker point of view (Ädel, 2006; Aguilar \& Arnó, 2002; Chaudron, 1982; Chaudron \& Richards, 1986; Cheng \& Steffensen, 1996; Chiang \& Dunkel, 1992; Crawford Camiciottoli, 2003; Fung \& Carter, 2007; Granger \& Tyson, 1996; Haas \& Flowers, 1988; Hinkel, 2002; Hsu, 2006; Intaraprawat \& Steffensen, 1995; Meyer, Brandt, \& Bluth, 1980; O’Malley, Chamot, \& Cüpper, 1989; Tyler, 1992; Watts, 1989), or from a perspective of genre (Biber, 2006; Mauranen, 2002; Swales, 2001).

However, and despite not being a new field, the term metadiscourse has not always been referred to as such, but in numerous ways instead; e.g. metatalk (Schiffrin, 1980), metalanguage (Jakobson, 1998; Simpson, 1988), text reflexivity (Mauranen, 1993b), or metatext (Bäcklund, 1998; Bunton, 1999; Dahl, 2004; Johanna, 1994; Mauranen, 1993a; Valero-Garcés, 1996). Other examples of this variety of names for metadiscourse can be found in Ädel's (2006, pp. 215-218) glossary of terms relating to "reflexivity in language", or in Sinclair (2005), who questions the appropriateness of the use of the term metadiscourse. What is more, many of these authors have developed their own models for metadiscourse, leading to a greater controversy of the concept. Therefore, and in spite of the amount of research conducted within the field, metadiscourse still remains a fuzzy category which is not equally defined by all experts. It is important, then, to revisit the most influential definitions and models of metadiscourse with the aim to look for similarities and extract a valid working description of metadiscourse for this thesis.

One of the earliest works on metadiscourse is Vande Kopple's (1985). Vande Kopple took over the works of Williams (1981) and Lautamatti (1978) and expanded them, generating what could be considered one of the first full accounts on the topic. He briefly defines metadiscourse as "discourse about discourse or communication about communication" 
(1985, p. 83). Vande Kopple's model will be later explained in Section 3.2.1, but it is worth mentioning at this point that he distinguishes between at least two levels of language: language carrying propositional content -ideational meaning in Halliday's (1985) SFL-, and metadiscourse, which can convey interpersonal or textual meanings, thus adopting a functional approach. With these concepts in mind, he further defines metadiscourse as linguistic material that does not add propositional meaning to the content but signals the presence of the writer. In this sense, he argues that "[o]n [...] the level of metadiscourse, we do not add propositional material but help our readers organize, classify, interpret, evaluate and react to such material" (Vande Kopple, 1985, p. 83).

The identification with Halliday's SFL theory is recurrent in many models for metadiscourse and it is also one of the controversial points where some scholars disagree, as I will further develop in the section below. Having said that, what I consider relevant in this definition is one of the first references to metadiscourse as a tool to organize language, which is the type of metadiscourse this thesis is devoted to.

Vande Kopple's brief definition of metadiscourse is supplemented by Crismore et al.'s $(1993$, p.40). For them, metadiscourse is

\footnotetext{
linguistic material in texts, written or spoken, which does not add anything to the propositional content but that is intended to help the listener or reader organize, interpret and evaluate the information given.
}

This definition is also influenced by Halliday's functions of language, as Crismore et al. define metadiscourse by contrasting it to language without a metadiscursive function (propositional language). The reference to the use of metadiscourse as an organizational tool of language is also present in this definition.

Another author worth reviewing in the study of metadiscourse is Hyland. Hyland is one of the essential references when talking about metadiscourse, since he has devoted a great part of his career to its study and to establish a strong model of metadiscourse, as I will briefly discuss in Section 3.2.3. Crismore et al.'s idea of metadiscourse as a tool to organize text is also held by Hyland: "the way writers intrude into their texts to organize their arguments and represent themselves, their readers, their attitudes. This is largely 
accomplished through non-propositional material or metadiscourse" (Hyland, 1999c, p. 5); and "the linguistic resources used to organize a discourse or the writer's stance towards either its content or the reader" (Hyland, 2000, p. 109). Hyland \& Tse (2004) complement these quotations by stating three key principles of metadiscourse with a clear functional interpretation:

1. Metadiscourse is distinct from propositional aspects of discourse;

2. metadiscourse refers to aspects of the text that embody writer-reader interactions; and

3. metadiscourse refers only to relations which are internal to the discourse.

In a later work, however, the references to the organization of language and the clear functional perspective are left aside in Hyland's approach as he defines metadiscourse as

the cover term for the self-reflective expressions used to negotiate interactional meanings in a text, assisting the writer (or speaker) to express a viewpoint and engage with readers as members of a particular community (Hyland, 2005, p. 37).

One of the similarities common to all these authors is the identification of metadiscourse with non-propositional language. In the case of Crismore et al. (1993) and Vande Kopple (1985), moreover, it is also evident the categorization of metadiscourse from a functional perspective within Hallidayan linguistics, identifying Halliday's (1985) three metafunctions of language and underlining of the non-propositionality of metadiscourse. However, this idea is not commonly shared by all experts and there is a number of researchers who are not satisfied with the traditional identification of metadiscourse with non-propositional content and who argue against these models -see Ädel (2006), Mao (1993), Mauranen (1993b) or Toumi (2009), for example. The new models are frequently referred to as the non-integrative approach (to metadiscourse) or, in Ädel's (2013) terms, reflexive approach. Reflexivity in language or text reflexivity is a term first used to refer to metadiscourse by Mauranen (1993b) which is borrowed from Lyons (1977), who talks about the ability of languages to refer to themselves. However, it is Ädel (2006) who develops a full extensive reflexive model of metadiscourse. This model is not based on Halliday's ideas but relies on 
Jakobson's $(1972,1998)$ theory and the metalinguistic function of language (see Section 1.1.3). I will further discuss this model, together with a detailed taxonomy, in Section 3.2.4. Within the reflexive paradigm, Mao (1993, p. 265) defines metadiscourse as "various kinds of linguistic tokens that an author employs in her text to guide or direct her reader as to how to understand her, her text, and her stance toward it". In the same line, for Ädel (2006) metadiscourse is

text about the evolving text, or the writer's explicit commentary on her own ongoing discourse. It displays an awareness of the current text or its language use per se and of the current writer and reader qua writer and reader (Ädel, 2006, p. 20).

In addition, according to Ädel, metadiscourse can be used to guide the readers, interact and maintain a relationship with them, and influence them. She distinguishes two main types of metadiscourse, namely those of metatext (impersonal metadiscourse) and writerreader interaction (personal metadiscourse), which cover references to the text itself, to the writer, and to the reader of the current text. In a more general definition (Ädel, 2013, p. 3663), she describes metadiscourse as "a specific type of reflexivity in language" where a particular awareness of the discourse as discourse is present. This awareness is reached through the inclusion in the text of elements which help organize the discourse, highlight the main message, show appropriateness or connect with the audience, for instance.

With the aim to integrate the ideas of each and every one of these definitions, a series of common ideas can be listed:

a) Metadiscourse is frequently recognized as a tool employed by writers/speakers to show awareness of the discourse. The prefix meta, from the Greek, can be translated as "beyond" or "after". In a sense, the prefix is present in nearly all terms used to refer to metadiscourse and the idea of metadiscourse as a realization of language "beyond discourse" is consistent with most definitions.

b) Metadiscourse will be strictly non-propositional, or not, depending on the approach adopted (integrative/non-integrative). This constitutes one of the most controversial aspects among scholars. For a further development of this point, see Section 3.2 and its subsections. 
c) Metadiscourse is a fuzzy category, since the identification of elements as metadiscursive materials is not always clear-cut (Ädel, 2006). In the same line, Crismore (1989) also refers to the fuzziness of metadiscourse when she claims that theories of metadiscourse have to account for fuzzy categories. As Crismore et al. (1993, p. 54) put it: "[m]etadiscourse is an admittedly messy but very important part of language use".

d) Metadiscourse can be used to carry out an abundant set of actions, e.g., help readers make sense of the discourse, organize ideas, assist the writer, and (in some approaches) evaluate and express stance, just to name a few. For example, FuentesOlivera et al.(2001) and Amiryousefi and Eslami-Rasekh (2010) talk about the important role of metadiscourse in organizing the discourse, engaging the audience and signaling the writer's or speaker's attitude. In any case, these actions bring the attention to the discourse and are most of the times intended to help communication, which brings up the next point:

e) Because of the many resources employed in the use of metadiscourse, it becomes crucial for achieving successful communication (Ädel, 2013). Some other authors also deliberate about the significance of metadiscourse within language. Toumi (2009), for example, refers to the considerable importance of metadiscourse in academic genres, as I will further develop in Section 3.3.

The analysis of how academic discourse is organized is precisely one of the major interests in this thesis. In this regard, the references towards metadiscourse functioning as an organizer of discourse are present in many of the aforementioned definitions. Therefore, it can be affirmed that organizing metadiscourse is one of the pivotal and common varieties of metadiscourse that will be present, in one way or another, in all models and taxonomies of metadiscourse, as I expand on in the following sections. After looking through and considering the previously described definitions, I would conclude that metadiscourse is made up of language that is essential for the speaker (or writer) in order to facilitate interaction with the audience, structure and/or show stance (depending on the approach adopted) while showing awareness of the discourse. 


\subsection{Approaches towards metadiscourse}

The intricacy of the very many approaches towards metadiscourse, as I commented in the previous section, has led to the elaboration of distinct theoretical and methodological frameworks for its analysis. Even though all these models share some attributes, they also show discrepancies and incompatibility among themselves. In this section, I will look into the most relevant models of metadiscourse and taxonomies that are frequently cited in literature on metadiscourse. Having these ideas in mind, I will briefly examine the models developed by Vande Kopple (1985), Crismore et al. (1993), and Hyland (2005) in sections 3.2.1, 3.2.2 and 3.2.3 respectively. Finally, I will extensively explore Ädel's (2006, 2010) model of metadiscourse in Section 3.2.4, which will be the one adopted for the present study.

\subsubsection{Vande Kopple's model}

As I indicated before, Vande Kopple was one of the first researchers to develop a full account of metadiscourse -see Vande Kopple $(1985,2002)$. There had been a number of researchers before him that had worked with metadiscourse -the most relevant are probably Crismore (1982) and Schiffrin (1980)-, but he is the first to encompass his model within Hallidayan linguistics, where metadiscourse performs the interpersonal and textual functions (as opposed to ideational meaning or propositional content). According to Vande Kopple, metadiscourse is used to express interpersonal meaning when employed by writers to express personal opinions, evaluate and show attitude towards ideational material, indicate expectations about the reader's response, or show the role they are choosing in the communicative situation. On the other hand, metadiscourse seems to indicate textual meaning when writers relate ideational data within a text (Vande Kopple, 2002). An interesting reflection at this point is the fact that Vande Kopple refers to the users of language as 'readers' and 'writers'; terms which restrict the scope of metadiscourse to 
written discourse. I will argue in Section 3.3 that it was only in the last decades that spoken academic language began to receive greater attention from researchers, especially those dealing with metadiscourse.

In Vande Kopple (1985), metadiscourse is classified into seven kinds: text connectives, code glosses, illocution markers, validity markers, narrators, attitude markers and commentary. This classification could be divided, using Halliday's terms, into textual and interpersonal metadiscourse. Text connectives, code glosses, validity markers and narrators would constitute textual metadiscourse, as they contribute to the creation and organization of the text. Illocution markers, attitude markers, and commentary, on the other hand, might be considered as interpersonal metadiscourse, given their role as mediators between writer and reader. Table 3.1 summarizes the seven kinds of metadiscourse described by Vande Kopple together with their functions and some instances as examples.

\begin{tabular}{|l|l|}
\hline Type of metadiscourse & $\begin{array}{l}\text { Function and examples } \\
\text { Text connectives }\end{array}$ \\
\hline $\begin{array}{l}\text { Organize texts and guide readers: sequencers, logical or temporal connectives, } \\
\text { reminders, announcements and topicalizers. E.g.: first; next; therefore; } \\
\text { however, as for; in regard to. }\end{array}$ \\
\hline Code glosses \\
$\begin{array}{l}\text { Help readers understand and interpret meaning properly. E.g.: that is; in other } \\
\text { words. }\end{array}$ \\
\hline Illocution markers & $\begin{array}{l}\text { Make explicit to the readers those speech acts performed by the writer. E.g.: } \\
\text { I promise to; to summarize. }\end{array}$ \\
\hline Validity markers & $\begin{array}{l}\text { Express the probability of truth of a given statement and the commitment of } \\
\text { the reader: hedges, emphatics, and attributors. E.g.: might; to some extent; } \\
\text { indeed. }\end{array}$ \\
\hline Narrators & $\begin{array}{l}\text { Express the origin of a statement (who said or wrote something). E.g.: John } \\
\text { said that; according to... }\end{array}$ \\
\hline Attitude markers & $\begin{array}{l}\text { Express the writer's attitude or stance towards the propositional material. } \\
\text { E.g.: unbelievably; I find it awkward that... }\end{array}$ \\
\hline Commentary & $\begin{array}{l}\text { Address the readers directly. E.g.: you will not like this; you will probably find } \\
\text { the materials too basic. }\end{array}$ \\
\hline
\end{tabular}

Table 3.1 Vande Kopple's (1985) model of metadiscourse

Text connectives organize texts while helping readers go through them. They may be used to indicate sequences (first; next); to indicate logical or temporal relationship (however; therefore); to remind about material presented earlier (as we saw in the previous section); to refer to material on the verge of presenting (what I want to do now is talk about that); or to reintroduce information or connect new information to information already presented through topicalizers (as for; in regard to). 
Code glosses are used to help readers understand and interpret meaning properly. They may appear in a text in the form of definitions, explanations, reformulation or clarification of terms (that is; in other words). As Vande Kopple (1985, p. 84) notes, they “do not expand the propositional content of the text but help readers understand and interpret it".

Interestingly, and unlike other approaches, Vande Kopple's does not consider exemplification as part of code glosses. Instead, examples are part of illocution markers, which are elements used to make explicit to the readers those speech acts performed by the writer. Therefore, examples are considered discourse actions together with summing up, making claims, hypothesizing, and many others (for example; I promise to; to summarize; I maintain that).

Validity markers are used to express the probability of truth of a given statement and the commitment of the reader. They incorporate hedges (may; might; to some extent), emphatics (indeed; obviously; evidently), and attributors (according to...). In the case of the latter, there is a reference to authorities and the validity and veracity of the statement become the reader's decision.

Another kind of metadiscourse is narrators. Narrators are very similar to validity markers functioning as attributors in that they refer to a third person. For Vande Kopple, the only difference lies in the fact that narrators are used to letting the readers know who said or wrote something, i.e. the origin of the information (John said that...).

The next kind of metadiscourse in Vande Kopple's list is attitude markers. These are used to express the writer's attitude or stance towards the propositional material (unbelievably; I find it awkward that...). It is interesting to notice again the understanding of metadiscourse as opposed to propositional content.

Lastly, Vande Kopple refers to a kind of metadiscourse he labeled as commentary. Commentary metadiscourse consists of language used to address the readers directly. The writer can comment on their state of mind or opinion, foresee expectations, recommend, or build up their relationship (You will not like this; you will probably find the materials too 
basic; you should have read it already; dear friends). Essentially, commentary includes any fragment where the reader can be distinctly identified.

An interesting fact mentioned in Vande Kopple (1985) that I will further elaborate on when I discuss Ädel's taxonomy in Section 3.2.4 is the idea that a metadiscursive word or phrase may be considered within more than one category. Vande Kopple argues that expressions such as to conclude this section could be encompassed within both, text connectives and illocution markers and that the text is the reference to establish which category is more prominent. Indeed, the notion of what I call double functionality will become a key element in the process of identification of metadiscourse, as I describe in Section 5.1.2. Vande Kopple will revisit this taxonomy later on Vande Kopple (2002) and will apply some minor changes. One category disappears when validity markers and narrators merge into what he refers to as epistemology markers. Moreover, new sub-divisions are included.

Vande Kopple's model meant a first full account of metadiscursive language. His pioneering categorization influenced many subsequent works, both in the theoretical and the practical fields. Nevertheless, this model is not as developed as more recent ones. One of the main constraints of this model, as I will argue when developing Ädel's model, has to do with the non-propositionality of metadiscourse, which is the point in which many researchers disagree. Additionally, as I mentioned before, the limitation of the analysis of metadiscourse to written discourse makes the entire approach very limited for the purposes of this thesis, that is based on spoken lectures. Finally, regarding the treatment of organizational metadiscourse, references to the organization of the discourse can only be encountered within text connectives. In this sense, a further development of this category and its sub-categories is still needed in order to successfully identify all intricacies at play in the organization of discourse. 


\subsubsection{Crismore et al.'s model}

As argued above, following classifications were inspired by Vande Kopple's seven kinds of metadiscourse in the theoretical ground. One of the most important reappraisals of this model is shown in the work by Crismore et al. (1993), who took over Vande Kopple's taxonomy and developed it in what would become one of the first cross-cultural studies on metadiscourse. In their study, these researchers account for the use of metadiscourse in a contrastive study of texts written by American and Finnish students in English and Finnish respectively. Their study points to a series of differences in the use of metadiscourse presumably attributed to culture and gender.

Their greatest contribution, however, was probably the taxonomy for metadiscourse that they developed. Crismore et al. (1993) define metadiscourse as all non-propositional language, even including punctuation and typographical marks as metadiscursive items that can signal a series of reflections upon discourse. In this sense, Crismore et al. establish what could only be hinted in Vande Kopple (1985), i.e. a comprehensible separation of two main types of metadiscourse: textual and interpersonal, thus relating their taxonomy to Halliday's (1985) theory of the functions of language.

After explicitly stating that they modified Vande Kopple's (1985) theory of metadiscourse, Crismore et al. go over their improvements: they discard the categories of narrators and temporal connectives, rename the category of text connectives into textual makers, and shift code glosses, announcements and illocution markers to a new category called interpretive makers. They also separate validity markers into hedges, certainty markers and attributors (into which they now include narrators). Attitude markers and commentary are kept as they were. All in all, there are two points I would like to make here. First, I believe it is worth remarking the distribution selected by these researchers. As I mentioned before, there is a clear identification of Crismore et al.'s broad metadiscourse categories (textual and interpersonal) with Halliday's theory, but it is also interesting to comment on the creation of two sub-categories within textual metadiscourse, textual markers, and interpretive markers, depending on whether metadiscourse is used to organize texts or 
help readers interpret them. And second, I would add a note on the fact that Crismore et al. did not include a temporal connectives subcategory. As they put it "we are interested in metadiscourse that helps readers understand how the text is connected rather than in how events outside the text are related to each other temporally" (Crismore et al., 1993, p. 46). Therefore, they downplay the importance of organizational metadiscourse in their taxonomy by including this type of references within textual or interpretive markers. Crismore et al. refer to this as the multifunctionality of metadiscourse. In this regard, they realized that what they could consider metadiscourse could also work as propositional content depending on the context. In a sense, this is an idea that Hyland (2005) will develop in his model and that I expand in Section 3.2.3 below. Finally, I should note here that this concept is not related to what I call double functionality of metadiscourse, in which a piece a metadiscourse can be encompassed within more than one metadiscursive category.

To put it in a nutshell, Crismore et al. (1993) distinguish seven types of metadiscourse (textual markers, interpretive markers, hedges, certainty markers, attributors, attitude markers and commentary) within two general categories (textual and interpersonal metadiscourse). Table 3.2 illustrates these types of metadiscourse and their sub-categories with examples.

The first type of metadiscourse in Crismore et al.'s (1993) taxonomy is textual markers. This category is subdivided into four different groups, namely, those of logical connectives, sequencers, reminders, and topicalizers. Their main function is that of structuring the text. Logical connectives are used to join two main clauses and so, help the reader interpret the text; they include coordinating conjunctions (and; but), and conjunctive adverbs (moreover; consequently). Sequencers arrange the text in a logical sequence; they include words like first, second, third, and also typographical marks like 1. or 2., which are used to organize points. Reminders, as in Vande Kopple (1985), refer to previously mentioned text and include words and expressions like as I mentioned in the previous section or we discussed earlier. Finally, topicalizers, for its part, encompass phrases used to introduce a new topic, such as regarding the economy, but also words like now or well that might be also used to propose a new theme. 


\begin{tabular}{|c|c|}
\hline Type of metadiscourse & Function and examples \\
\hline \multicolumn{2}{|c|}{ TEXTUAL METADISCOURSE } \\
\hline \multicolumn{2}{|l|}{ Textual markers } \\
\hline Logical connectives & $\begin{array}{l}\text { Join two main clauses and help the reader interpret. E.g.: and; moreover; } \\
\text { consequently. }\end{array}$ \\
\hline Sequencers & Arrange the text in a logical sequence. E.g.: first; second. \\
\hline Reminders & $\begin{array}{l}\text { Refer to previously mentioned text. E.g.: as I mentioned in the previous } \\
\text { section... }\end{array}$ \\
\hline Topicalizers & Introduce a new topic. E.g.: regarding the economy... \\
\hline \multicolumn{2}{|l|}{ Interpretive markers } \\
\hline Code glosses & Explain the text. E.g.: namely; by this I mean. \\
\hline Illocution markers & $\begin{array}{l}\text { Refer to the speech act being performed by the writer. E.g.: I claim that...; } \\
\text { I insist on... }\end{array}$ \\
\hline Announcements & Preview information. E.g.: As I will discuss in the following section... \\
\hline \multicolumn{2}{|c|}{ INTERPERSONAL METADISCOURSE } \\
\hline Hedges & Show uncertainty. E.g.: may; might; I guess. \\
\hline Certainty markers & $\begin{array}{l}\text { Express full commitment to the statement. E.g.: definitely; there is no doubt } \\
\text { that... }\end{array}$ \\
\hline Attributors & Point to the source of information. E.g.: according to Newton... \\
\hline Attitude markers & Show the writers attitude towards a statement. E.g.: I hope; fortunately. \\
\hline Commentary & Refers to the reader. E.g.: you should think about that. \\
\hline
\end{tabular}

Table 3.2 Crismore et al.'s (1993) model of metadiscourse

Another type of metadiscourse in Crismore et al.'s taxonomy is interpretive markers. This category includes code glosses, illocution markers and announcements as subsections and its main role is to help readers interpret the text. Code glosses, on the one hand, consist of explanations of the text (namely; by this I mean; for example). Illocution markers refer to the speech act the writer is carrying out and provide it with a name; for instance, I claim that or I insist on. The last subcategory of interpretive markers is announcements. Crismore et al. do not devote much space to discuss this section, but it would include previewing material of a future discourse (as I will discuss in the following section; we will examine the data in Chapter 5).

These two types of metadiscourse constitute what Crismore et al. refer to as textual metadiscourse. The following five types are part of the interpersonal metadiscourse.

Hedges show the absence of allegiance or uncertainty of the writer towards the validity of a statement, i.e. they are used when the writer does not want to make clear their position on a given issue. Some examples are modal verbs (may; might; could; would; should, among 
others) or expressions such as I think or I guess. This lack of certainty can also be expressed with adverbs like perhaps or maybe.

On the other hand, certainty markers refer to the commitment of writers with a statement, but from a different perspective: authors fully commit to the validity of the assertion. This category might include words and expressions like definitely, there is no doubt that, or indubitably.

The next type of metadiscourse is attributors. These are used to point to the source of the information. This type of metadiscourse was already present in Vande Kopple's (1985), with the difference that Crismore et al. also include Vande Kopple's narrators within this category. After all, both categories are used to refer to the source of information with the only distinction of the authority of the source. Therefore, attributors in this taxonomy include expressions such as according to Newton and Sarah states that.

Attitude markers emphasize the propositional content. This type of metadiscourse should not be mixed up with certainty markers. While certainty markers show commitment, attitude markers merely show the writers attitude towards a statement, the style, or even themselves, and not necessarily in a positive manner. Some examples of attitude markers could be: I hope; hopefully; or fortunately. Interestingly, Crismore et al. decide not to include adjectives, even though these might convey writer's attitude, and consider them propositional material.

Finally, the last type of metadiscourse in Crismore et al.'s taxonomy is commentary. Commentary, as in Vande Kopple's (1985) model, includes references to the reader to comment on their probable views or on their relationship (you might think that is not correct; you should think about that). Crismore et al.'s greatest development in this category is the inclusion of six devices to construct commentary: direct address to the reader, use of imperatives, real questions, rhetorical questions, tag questions and asides or comments to the reader that interrupt the propositional content.

Crismore et al.'s model became a powerful redefinition and expansion of Vande Kopple's work. However, this does not mean it is a complete model as there are several gaps that 
need to be filled. Apart from the identification of metadiscourse with all non-propositional material (an idea that I will argue against when expanding Ädel's model in Section 3.2.4), it is worth discussing the treatment of organizational metadiscourse in this model. This type of metadiscourse, which this thesis aims to explore, is visibly expanded if we compare it with Vande Kopple's model. In this sense, text connectives (textual markers in Crismore et al.'s), are developed and subdivided into four demarked categories. Nevertheless, this is still a primitive taxonomy with maybe too few subcategories, given the many distinct possible occurrences of organizational metadiscourse in a particular text. Besides, announcements are not developed at all and are clearly separated from reminders. With this idea in mind, Aguilar (2008) wonders why reminders and announcements are seen as so different in Crismore et al.'s model. These are two items which, to my understanding, should work together; when everything is taken into consideration, both subcategories point to different parts of the discourse, one forwards and the other one backwards.

\subsubsection{Hyland's model}

The third model of metadiscourse that I intend to review is Hyland's (2005) -previously schematized in Hyland and Tse (2004). Hyland's has probably been the most influential model in the last decade and has been extensively used by researchers studying metadiscourse. Some of the most recent studies using Hyland's model include, for instance, Anwardeen, Luyee, Gabriel, and Kalajahi, (2013), Khedri, Heng, and Ebrahimi, (2013), Abdi, Rizi, and Tavakoli, (2010), Cao and Hu, (2014), Fu, (2012), Heng and Tan, (2010), Lee and Casal, (2014), and Lee and Subtirelu, (2015), just to name a few. Hyland (2005) starts describing his model of metadiscourse by stating three key principles about metadiscourse that I mentioned before when discussing Hyland's definitions of metadiscourse in Section 3.1. He claims that "metadiscourse is distinct from propositional aspects of discourse", "metadiscourse expresses writer-reader interactions", and "metadiscourse distinguishes external and internal relations" (Hyland, 2005, pp. 38-48). Before, moving into Hyland's taxonomy of metadiscourse it is worth inspecting these three points. 
The first assertion has to do with the propositionality (or rather non-propositionality) of metadiscourse. Just like in Vande Kopple and Crismore et al.'s models, the propositionality of language plays an important role in Hyland's model. In his words, "a propositional/content distinction is required for exploring metadiscourse" (Hyland, 2005, p. 39). Nevertheless, Hyland rejects the identification of propositionality with Halliday's (1985) functions of language and a full functional approach, and does not associate metadiscourse to all non-propositional material in a text. Therefore, he proposes to use Sinclair's (1981) theory of planes of discourse, where metadiscourse would be integrated into the process of communication, as it would participate in both planes, the interactive and the autonomous one. I will not go into further detail at this point, as I will argue that the mere identification of metadiscourse with non-propositional data is fundamentally inaccurate in the following section. The second idea introduced by Hyland aims to discard the previous division of metadiscourse into textual and interpersonal categories. As he mentioned in a previous work (Hyland \& Tse, 2004), he considers all metadiscourse to be interpersonal, as it is based on the relationship between reader and writer. Consequently, he suggests adapting Thompson and Thetela's (1995) distinction between interactive and interactional resources. The last argument has to do with the functions of textual items. According to Hyland (2005), a word or phrase can convey either propositional or interpersonal meaning depending on the context. This is an idea also shared by Crismore et al. For Hyland, it is necessary to distinguish these uses; he calls them internal and external references respectively, and only internal references are considered metadiscourse.

Therefore, Hyland establishes two broad categories of metadiscourse, with several subcategories. On the one hand, interactive metadiscourse, which includes metadiscourse that would make the writer's awareness of the audience explicit in order to adjust to their knowledge, interests and needs in order to guide the reader through the discourse; and on the other hand, interactional metadiscourse, which is used to show stance and bring in the reader. Interactive metadiscourse includes transition markers, frame markers, endophoric markers, evidentials and code glosses. Interactional resources, in turn, include hedges, boosters, attitude markers, self mention, and engagement markers. I will briefly summarize Hyland's views on each of these categories. 
Transition markers are largely made up of conjunctions and adverbials and help the readers understand the text by describing the relations between sentences. They can express addition (and; moreover; what is more), comparison (in the same way; likewise; however; but) or consequence (thus; consequently; as a result; in any case).

Another kind of interactive metadiscourse is frame markers. These structure arguments in the text. They can add relations (first; next; finally; $a$.; b.), label text stages (to conclude; to introduce the topic), signal discourse goals (I intend to; my purpose here is) and point to topic shifts (now; let us talk now about). It is interesting to mention that Hyland, just like Crismore et al. (1993), also considers now and well as topic shifters.

Endophoric markers are used to refer to other parts of the text. These refer to previously mentioned information, details that have not been dealt with yet, or even tables and figures (in Chapter 4; as I stated before; Table 10). This type of metadiscourse helps organize the text and guides readers through the content.

Hyland picks up Thomas and Hawes's (1994) work to include a further kind of metadiscourse: evidentials. These are used to refer to other sources and "establish an authorial command on the subject" (Hyland, 2005, p. 51). In other words, they designate the source of the information (according to; James states that).

Finally, the last item within interactive metadiscourse is code glosses. These comment on previous material to help readers understand what was meant. They include rephrasing, explanations, etc. Some examples could be for example; in other words; or for instance.

The first type of metadiscourse within interactional metadiscourse is hedges. This is a category also used in Crismore et al.'s model and it includes words or phrases to emphasize the lack of commitment of the writer (may; could; it is possible that).

What was referred to as certainty markers in Crismore et al.'s model is now present in Hyland's under the label of boosters. These express the certainty of the writer towards a statement (definitely; indeed; I am positive that), and emphasize the message. 
Attitude markers express the writer's attitude towards a proposition. However, Hyland emphasizes that in this category, writers convey affective attitude rather than epistemic attitude. Attitude markers encompass attitude verbs (/ agree; I enjoy), sentence adverbs (fortunately; sadly) and adjectives (awful; outstanding). Unlike Crismore et al., Hyland does include adjectives as part of metadiscourse.

Drawing from an earlier work (Hyland, 2001b), Hyland decides to include self mention as one of the types of metadiscourse in his taxonomy. This type of metadiscourse incorporates mentions to the author or authors $(l ;$ we; our; my). This could be interpreted as a valuable tool in quantitative analyses to establish the degree of presence of the author in a text.

Finally, the last category in Hyland's taxonomy is engagement markers. These are references to the readers that can be compared to Vande Kopple's or Crismore et al.'s commentary. Engagement markers is a quite well-developed category in Hyland's model. For him, these markers are used to adequately meet the reader's expectations (you; you may notice) and to rhetorically positioning the audience, (you should; consider this). Table 3.3 below summarizes Hyland's model.

All in all, Hyland's (2005) model represents one of the most accomplished accounts for metadiscourse to the date; he thoroughly expanded the number of categories and their description in an interpersonal (reader-writer) oriented approach, rejecting thus a textualinterpersonal division. By adopting this method, he puts some distance between his model and previous functional-oriented models. In his work, Hyland goes beyond a mere classification of metadiscourse and investigates how it relates to rhetoric, genre, culture, and community (Hyland, 2005). As I mentioned at the beginning of this section, Hyland's taxonomy has been and still is extensively used by many researchers, especially in studies focused on academic language. Nevertheless, and even though Hyland is one of the first researchers to acknowledge spoken discourse in a definition of metadiscourse (see Section 3.1), the majority of his works before the publishing of his taxonomy as well as his model of metadiscourse are based on a written discourse tradition (see for instance Hyland, 1994, 1996a, 1996b, 1998, 1999a, 1999b, 2000, 2001a, 2001b, 2002b, or 2004a). Hyland and Tse (2004) is also an example of this. Moreover, a clear position towards the distinction 
between propositional and non-propositional material when analyzing metadiscourse along with a method for the identification of metadiscursive instances is lacking in Hyland's model. In this sense, Ädel (2006, 2010), as I discuss below, addresses all of these issues, providing what is, in my view, a more complete model of metadiscourse for the purposes of this thesis, i.e. the analysis of how spoken lectures are organized in terms of metadiscourse. Particularly, Ädel develops an extensive taxonomy on organizational (and other types of) metadiscourse in spoken academic lectures.

\begin{tabular}{|c|c|}
\hline Type of metadiscourse & Function and examples \\
\hline \multicolumn{2}{|c|}{ INTERACTIVE METADISCOURSE } \\
\hline Transition markers & $\begin{array}{l}\text { Describe the relations between sentences: addition, comparison, and } \\
\text { consequence. E.g.: in the same way; consequently. }\end{array}$ \\
\hline Frame markers & $\begin{array}{l}\text { Structure arguments: add relations, label text stages, signal discourse goals } \\
\text { and point to topic shifts. E.g.: to conclude; my purpose here is...; } \\
\text { let us talk now about; first. }\end{array}$ \\
\hline Endophoric markers & $\begin{array}{l}\text { Refer to other parts of the text. E.g.: as I will develop in the second part...; } \\
\text { Table } 10 .\end{array}$ \\
\hline Evidentials & $\begin{array}{l}\text { Designate the source of the information. E.g.: according to...; James states } \\
\text { that... }\end{array}$ \\
\hline Code glosses & $\begin{array}{l}\text { Help readers understand through rephrasing, explanations, etc. E.g.: in } \\
\text { other words; for instance. }\end{array}$ \\
\hline \multicolumn{2}{|c|}{ INTERACTIONAL METADISCOURSE } \\
\hline Hedges & $\begin{array}{l}\text { Show lack of commitment towards a statement. E.g.: it is possible that...; } \\
\text { may; could. }\end{array}$ \\
\hline Boosters & Show certainty towards a statement. E.g.: indeed; I am positive that... \\
\hline Attitude markers & $\begin{array}{l}\text { Show the writer's affective attitude towards a statement. E.g.: I agree; } \\
\text { sadly; awful. }\end{array}$ \\
\hline Self mention & Incorporates mentions to the author(s). E.g.: l; we; our; my. \\
\hline Engagement markers & Refer to the reader. E.g.: you; you should consider this. \\
\hline
\end{tabular}

Table 3.3 Hyland's (2005) model of metadiscourse

\subsection{4 Ädel's model (The reflexive model)}

There are indeed great differences in the approaches towards metadiscourse that I have examined previously. On the one hand, Vande Kopple (1985) and Crismore et al. (1993) 
foster a definite division between textual and interpersonal metadiscourse, following Halliday's (1985) theory. On the other hand, Hyland (2005) adopts an approach based on semantic and pragmatic terms where metadiscourse becomes exclusively interpersonal by considering and adapting the discourse towards the reader. Still and all, as I have alluded to when developing these three models, these approaches share one main trend, which is the identification of metadiscourse, to a greater or lesser extent, with non-propositional language. In this respect, Ädel (2006) reveals the existence of two main general trends towards metadiscourse: what she refers to as the broad (or integrative/interactive) and the narrow (or non-integrative/reflexive) approaches. The first two models that I have reviewed are considered as integrative (or interactive), in that they include both interpersonal and textual functions, whereas non-integrative models -or reflexive, as Ädel (2010) prefers to call them- refer only to the textual function of discourse. Hyland's model, where metadiscourse is said to be only interpersonal, would also be encompassed within the interactive models according to Ädel, since one of the main features of reflexive approaches is that they do not include stance (or validity markers, hedges, attitude markers, etc.), nor some types of connectives as forms of metadiscourse. Instead, reflexive approaches focus on how texts are organized, excluding interpersonal arguments (Ädel, 2006). This might seem, in a sense, rather suitable for the purposes of this dissertation. Ädel argues that one of the main problems of interactive approaches is that they are "too all-inclusive" (Ädel, 2006, p. 171) and quotes Markkanen, Steffensen and Crismore (1993, p. 143) who claim that metadiscourse "covers such a wide area of language use that it requires subclassification; saying that some item in a text is metadiscourse does not say much". Similarly, Crismore et al. (1993) also refer to the wide range of inclusion of metadiscourse by arguing that the richness of metadiscourse made them limit their study to more explicit instances. Some of the most influential works carried out from a reflexive approach are, for instance, Bäcklund (1998), Bunton (1999), Dahl (2004), Mao (1993), Mauranen (1993b) Schiffrin (1980), and Valero-Garcés (1996). However, reflexive approaches are also open to criticism. Ädel (2006) acknowledges this and comments on the fuzziness of what is and what is not metadiscourse and how categories such as addressing the reader in the reflexive approach by Mauranen (1993b) become difficult to justify without considering the writer-reader relationship. These are aspects that Ädel will try to 
overcome by prioritizing Jakobson's (1998) -although first published in Jakobson (1960)theory of the six functions of language (see Section 1.1.3).

Another aspect emphasized in Ädel's works (Ädel, 2005, 2006, 2010, 2013), and also related to the establishment of Jakobson's theory as her starting point, is the criticism of the traditional identification of metadiscourse with propositional material. Ädel builds up most of her model from the notion that the distinction between propositional and nonpropositional material to identify metadiscourse is inaccurate. In Ädel (2005), she argues that the interactive or broader approach originates as an attempt to encompass all nonpropositional material within the term metadiscourse. However, this idea is solely based on the identification of propositional versus non-propositional material in Hallidayan terms. In order to contradict this notion, Ädel (2006) goes back to Halliday's (1994, p. 70) definition of proposition that states that

[w] hen language is used to exchange information, the clause takes on the form of a PROPOSITION. It becomes something that can be affirmed or denied, and also doubted, contradicted, insisted on, accepted with reservation, qualified, tempered, regretted and so on.

Then, Ädel shows a series of examples showing that propositional material can indeed become metadiscourse and vice versa:

\footnotetext{
A statement like I have discussed $X$ and $Y$ in Chapter 4 [which is a metadiscursive instance] must be propositional according to the common use of the term (for example, we could easily check the veracity of the statement by looking at the discussions in Chapter 4) and, therefore, not metadiscursive (Ädel, 2006, p. 210).
}

In this example, Ädel is referring to the "truth-conditional criterion"; in other words, all propositional material, following Halliday's definition, can be tested in terms of true, false, or be doubted, and not as a trait of discourse. Ädel also uses arguments in Mao (1993), Mauranen (1993b) and Schiffrin (1980) to support her claims. Schiffrin (1980), for instance, talks about meta-talk as being used for informational and referential purposes as well as for evaluative purposes. In the same line, Mauranen (1993b, p. 147) states that 
[m]etadiscoursal elements have content, convey information, and they can occasionally be more important for the communication than the subject matter. What distinguishes them from the rest of the text is that they refer to the text or the writing process, while the rest refers to anything but the text or the writing of it.

On the whole, Ädel proposes to disregard the association of metadiscourse with all nonpropositional material, acknowledging that most of the times it will be distinct to the subject matter. Instead, she offers a model of metadiscourse based on its linguistic functions.

Ädel establishes three main advantages of using Jakobson's $(1960,1972,1998)$ theory of the six functions of language:
a) the 'proposition' problem is avoided [...]
b) Including the writer and reader makes the concept less decontextualized [...]
c) reflexivity is appropriately emphasized (Ädel, 2006, p. 13).

As discussed in Section 1.1.3, Ädel uses three out of Jakobson's six functions (the metalinguistic, the expressive and the directive), and she identifies each of them with a specific focus within discourse (the text/code, the reader, and the writer respectively). One of these functions will be more dominant over the other two in each metadiscursive instance; although, as I further discuss below, some metadiscursive fragments can be encompassed within more than one category. Ädel develops two slightly different taxonomies of metadiscourse (Ädel, 2006, 2010) that I explore in this section. The main difference between these models has to do with the origin of the data in the corpora explored by Ädel. In the first model (Ädel, 2006), Ädel employs three corpora of written essays in English. In the second model (Ädel, 2010), this researcher reconsiders the initial taxonomy and includes a spoken perspective to it. In this sense, she explores 130 written essays and 30 spoken academic lectures. In the present thesis, I make use of Ädel's (2010) taxonomy, as it seems more appropriate for the study of spoken lectures. In the following lines, I review Ädel's (2006) first model.

Ädel (2006) refers to four possible configurations of metadiscourse depending on their function on the text: text-oriented metadiscourse, writer-oriented metadiscourse, reader- 
oriented metadiscourse and participant-oriented metadiscourse (a combination of writer and reader-oriented metadiscourse).

Inspired to some extent by the works of Kuo, (1998) and Vassileva (1998) on the functions of "I" and "we" and Mauranen's (1993b) study on text-reflexivity, Ädel establishes two broad categories of metadiscourse: metatext and writer-reader interaction. Metatext refers to the text and how it is organized. Writers can use metatext to comment on how they refer to the text as organizers and language users. This category is divided into fourteen different sub-categories: ten personal categories (defining, saying, introducing topic, focusing, concluding, exemplifying, reminding, adding, arguing, and contextualizing), and four impersonal categories (phorics, references to the text/code, code glosses, and discourse labels). Writer-reader interaction, on the other hand, is subdivided into six distinct types of metadiscourse: anticipating the reader's reaction, clarifying, aligning perspectives, imagining scenarios, hypothesizing about the reader and appealing to the reader. Table 3.4 condenses all these types of metadiscourse with their functions and examples.

Within the personal metadiscourse in metatext, defining has to do with the introduction of new terms in the discourse. In a sense, it is a type of metadiscourse that aims to explicate and comment on how to interpret terminology. Some examples could be Let's take a look at the definition of...; or What do you mean by...?

Saying is a type of metadiscourse that involves verbs like say, speak, tell, write, or ask, i.e. verba dicendi (what I am saying here is...; I should mention that...). Both, defining and saying are types of metadiscourse that are related to the code. The following types of metadiscourse have to do with the text and how texts are structured.

The first kind of metadiscourse introduced in this section by Ädel is introducing the topic. As implied by its label, this type of metadiscourse is used to explicitly introduce a topic, stating what the text is going to deal with (in this essay I will try to discuss...; I want to talk about...). It is interesting that Ädel mentions that introducing the topic instances are always a "preview". I will show at the end of this section a series of examples that illustrate how these two functions are so closely interrelated. 


\begin{tabular}{|c|c|}
\hline Type of metadiscourse & Function and examples \\
\hline \multicolumn{2}{|l|}{ METATEXT } \\
\hline \multicolumn{2}{|c|}{ Personal Metadiscoruse } \\
\hline Defining & $\begin{array}{l}\text { Introduces new terms in the discourse. E.g.: let's take a look at the definition } \\
\text { of... }\end{array}$ \\
\hline Saying & $\begin{array}{l}\text { Involves verbs like say, speak, tell, write, or ask. E.g.: what I am saying here } \\
\text { is... }\end{array}$ \\
\hline Introducing topic & Starts a new topic. E.g.: I want to talk about... \\
\hline Focusing & Delimits a previously introduced topic. E.g.: I will not discuss that. \\
\hline Concluding & $\begin{array}{l}\text { Concludes a previously introduced topic. E.g.: to conclude; I will summarize } \\
\text { what I have mentioned before.. }\end{array}$ \\
\hline Exemplifying & Explicitly introduces an example. E.g.: let me show you some examples. \\
\hline Reminding & $\begin{array}{l}\text { Points to previously introduced information. E.g.: as I have mentioned } \\
\text { before... }\end{array}$ \\
\hline Adding & $\begin{array}{l}\text { Explicitly adds information to a previously introduced topic. E.g.: let me add } \\
\text { another idea. }\end{array}$ \\
\hline Arguing & $\begin{array}{l}\text { Stresses the argumentative discourse. E.g.: I argue that the concept is used } \\
\text { incorrectly. }\end{array}$ \\
\hline Contextualizing & $\begin{array}{l}\text { Refers to the process of writing itself. E.g.: I have chosen this slide because...; } \\
\text { due to space limitations... }\end{array}$ \\
\hline \multicolumn{2}{|c|}{ Impersonal metadiscourse } \\
\hline Phorics & $\begin{array}{l}\text { Refer to connections within the text: previewing material, references to } \\
\text { previous material, enumerators, adverbs like here and now, and other } \\
\text { structuring devices. E.g.: as we will discuss in the following section... }\end{array}$ \\
\hline $\begin{array}{l}\text { References to the } \\
\text { text/code }\end{array}$ & $\begin{array}{l}\text { Refer to the whole text or parts of it. E.g.: this thesis aims to describe the use } \\
\text { of metadiscourse. }\end{array}$ \\
\hline Code Glosses & $\begin{array}{l}\text { Comment on elements of the text to facilitate comprehension. E.g.: namely; } \\
\text { I mean. }\end{array}$ \\
\hline Discourse labels & $\begin{array}{l}\text { Name discourse acts in the text. E.g.: I aim to describe...; I will answer that } \\
\text { shortly. }\end{array}$ \\
\hline \multicolumn{2}{|c|}{ WRITER-READER INTERACTION } \\
\hline \multicolumn{2}{|c|}{ Personal metadiscourse } \\
\hline $\begin{array}{l}\text { Anticipating the } \\
\text { reader's reaction }\end{array}$ & $\begin{array}{l}\text { Tries to foresee the reader's intention or opinion. E.g.: I know you might not } \\
\text { believe me. }\end{array}$ \\
\hline Clarifying & $\begin{array}{l}\text { Makes meaning explicit to foster correct understanding. E.g.: I want you to } \\
\text { perfectly understand what I am saying. }\end{array}$ \\
\hline Aligning perspectives & $\begin{array}{l}\text { Attribute the reader with the writer's ideas (mainly through the use of an } \\
\text { inclusive 'we'). E.g.: we can say that... }\end{array}$ \\
\hline Imagining scenarios & Transmits ideas through the use of vivid experiences. E.g.: consider this fact. \\
\hline $\begin{array}{l}\text { Hypothesizing about } \\
\text { the reader }\end{array}$ & $\begin{array}{l}\text { Employs a series of strategies in order to evaluate the background } \\
\text { knowledge of the reader, thus showing their inclusion within the text. E.g.: } \\
\text { you have likely read about it. }\end{array}$ \\
\hline $\begin{array}{l}\text { Appealing to the } \\
\text { reader }\end{array}$ & $\begin{array}{l}\text { Refers to the reader, clearly having them in mind in the text. E.g.: I would } \\
\text { recommend you to watch the film. }\end{array}$ \\
\hline
\end{tabular}

Table 3.4 Ädel's (2006) model of metadiscourse 
Focusing is used to delimit a previously introduced topic, marking what is going to be the focus within a topic. Some examples are I will not discuss that; our focus in this Chapter will be...

Next, Ädel describes concluding; which is used to conclude a previously introduced topic by using expressions like to conclude, I would like to state that...; or I will summarize what I have mentioned before.

Exemplifying is used to explicitly introduce an example (let me show you some examples; if we use this as an example...).

Reminding is used to point to previously mentioned information (as I have mentioned before...; we have seen how it works).

Adding is used to explicitly add information to a previously introduced topic or argument. Some examples might be: I would like to add that...; let me add another idea.

The next metadiscursive item in Ädel's model is arguing. In Ädel's words arguing "stresses the argumentative discourse act being performed in addition to the simple expression of an opinion or viewpoint" (Ädel, 2006, p. 71). Some of the verbs employed in this category are argue, claim, assert, or support. (I argue that the concept is used incorrectly; I claim that the use of metadiscourse is essential to discourse).

Finally, the last type of metadiscourse within personal metatext is contextualizing. Contextualizing includes references to the process of writing itself (due to space limitations...; I could elaborate more on the topic; I have chosen this slide because...). Interestingly, Ädel includes examples from Luukka (1994) like I'll move this slide a little bit; or these differences can be seen in picture 1. This is what Luukka refers to as contextual metadiscourse, and will become an independent category in Ädel's (2010) taxonomy as I will discuss below.

Ädel (2006) also explores the use and functions of impersonal metadiscourse and she examines four further categories that could be encompassed within metatext: phorics, references to the text/code, code glosses, and discourse labels. 
Phorics refer to connections within the text. They help organize and structure the discourse. They include previewing material (as we will discuss in the following section...), references to previous material (as we discussed in Chapter 1...), enumerators (first; second), adverbs like here and now, and other structuring devices. Phorics are, in essence, one of the most important types of metadiscourse for the purposes of this thesis, as they arrange and give cohesion to the discourse. However, some more development is needed in this category. Ädel (2010), as I discuss below, will develop this section into a more elaborate taxonomy.

Again, following Mauranen (1993b), Ädel establishes the category of references to the text/code in order to explicate metadiscursive fragments that refer to either the whole text or parts of it (as we can see in Chapter 1...; this thesis aims to describe the use of metadiscourse).

Code glosses are brought onto this taxonomy from Vande Kopple's (1985) model and comment on the elements of the text in order to facilitate comprehension. Some examples could be i.e.; namely; I mean.

Finally, discourse labels refer to the discourse acts employed in the text. Their function is to label or name them (I aim to describe...; I will answer that shortly).

So far, Ädel's (2006) categories represent a considerable expansion compared to previous approaches. It is one of Ädel's aims to elucidate possible ambiguities and produce a methodology to identify metadiscourse. The following six types of metadiscourse belong to the writer-reader interaction category and are focused on the participant.

Based on Crismore (1989), Ädel brings along the category of anticipating the reader's reaction, which is for both researchers one of the chief categories of metadiscourse, especially for considerate or persuasive writers. Some examples might include you must be very surprised; or I know you might not believe me...

Clarifying, similarly, is also used to accommodate discourse in a way that it is made clear for the audience in an aim of the writer for being understood ( $/$ want you to perfectly understand what I am saying, so I will emphasize that...). 
Aligning perspectives is a type of metadiscourse that has to do with attributing the reader with the writer's ideas or perspectives. One of the most common ways to create this type of alignment is, according to Ädel, through the use of an inclusive 'we' (we can say that...; we can extract several ideas from this excerpt).

A further type of metadiscourse is imagining scenarios. The purpose of imagining scenarios is to transmit ideas through the use of vivid experiences. For instance: imagine you are the president of the US in 1945; consider this fact...

When hypothesizing about the reader, the writer employs a series of strategies in order to evaluate the background knowledge of the reader, thus showing their inclusion within the text. Some examples could be: I'm sure you know about what happened; you have likely read about it.

Finally, the last type of metadiscourse discussed within writer-reader interaction is appealing to the reader. This category includes references to the reader that show a clear adaptation of the text having the reader in mind such as I hope the reader agrees; or I would recommend you to watch the film.

All in all, Ädel's (2006) model represents an expansion of the categorization of metadiscourse as well as the establishment of an innovative approach where criteria are delimited when identifying and classifying metadiscourse. In this regard, one of Ädel's main aims, as I will develop further below, is that of establishing a set of criteria for the identification of metadiscourse in an attempt of structuring what could otherwise be considered a fuzzy category. This model has been broadly used by researchers seeking a more meticulous system of metadiscourse -see for instance Pérez-Llantada (2010), Salas (2015), Salas Valdebenito (2015), or Toumi (2009). Nevertheless, some disparity arises when dealing with the elements that may be considered as metadiscourse. In this regard, there is a diversity of opinions on whether categories like stance or participation should be included within a taxonomy of metadiscourse. In Ädel's (2006, p. 179) words, including stance "makes the concept of metadiscourse overly broad and inclusive, and leads us too far of the realm of explicit reflexive language". While Aguilar (2008) dislikes the idea of excluding important elements like hedging, Salas (2015) argues that by delimiting the scope 
of metadiscourse, Ädel contributes to the clarification of the term. Furthermore, some authors like Querol-Julián and Fortanet-Gómez (2012) or Querol-Julián (2011b) favor the use of terms like evaluation for their studies on stance thus identifying it as a separate category. For a further development of the differences between evaluation and metadiscourse go to Ädel (2005). On top of that, I argue that there are two unresolved issues in Ädel's (2006) model. First, as in previous models, Ädel's (2006) approach focuses on written language while spoken genres are neglected. The second issue has to do with the treatment of organizational metadiscourse: while introducing topic, focusing, concluding, reminding, adding and contextualizing are included within metatext, and therefore personal metadiscourse, phorics is separated and included within impersonal metadiscourse. I argue that all these elements contribute to the organization and cohesion of the text, yet they are not closely presented. In a sense, organizational elements are dispersed among the different subcategories of metadiscourse and many times lack a proper definition. Moreover, an explicit previewing category including metadiscourse used to refer to information to be disclosed at a future point in the discourse is missing, as it seems to be included within the introducing topic or the phorics categories. These two issues will be solved in Ädel (2010).

Ädel's (2010) article examines 30 spoken academic lectures and 130 essays, thus partly shifting her focus onto spoken genres. She also presents a prolonged re-examination of her taxonomy in Ädel (2006). The greatest change has to do with the identification of two broad categories of metadiscourse: metatext, which is divided into metalinguistic comments, discourse organization and speech act labels, and audience interaction, consisting of references to the audience. Table 3.5 shows a detailed subclassification of these items. 


\begin{tabular}{|c|c|}
\hline Type of metadiscourse & Function and examples \\
\hline \multicolumn{2}{|l|}{ METATEXT } \\
\hline \multicolumn{2}{|l|}{ Metalinguistic comment } \\
\hline Repairing & Corrects a previous statement. E.g.: I'm sorry; that's not correct. \\
\hline Reformulating & $\begin{array}{l}\text { Provides an alternative statement in order to increase understanding. E.g.: } \\
\text { Let me put it in other words... }\end{array}$ \\
\hline $\begin{array}{l}\text { Commenting on } \\
\text { linguistic form/meaning }\end{array}$ & $\begin{array}{l}\text { Refers to the linguistic form, election of terms and meaning. E.g.: I'm not } \\
\text { sure how to say this, but... }\end{array}$ \\
\hline Clarifying & $\begin{array}{l}\text { Makes meaning explicit to foster correct understanding. E.g.: Now, I'm not } \\
\text { saying that is the case, what I mean is that... }\end{array}$ \\
\hline Managing terminology & Defines or explain terms. E.g.: let's consider what metadiscourse means. \\
\hline \multicolumn{2}{|l|}{ Discourse organization } \\
\hline Introducing topic & Starts a new topic. E.g.: today, I want to talk about the Revolution. \\
\hline Delimiting topic & $\begin{array}{l}\text { Restricts a topic or focuses attention. E.g.: we won't go into that in this } \\
\text { class. }\end{array}$ \\
\hline Adding to topic & $\begin{array}{l}\text { Adds information to a topic. E.g.: let me add to that that it was not until } \\
1785 . .\end{array}$ \\
\hline Concluding topic & $\begin{array}{l}\text { Finalizes or summarizes a topic. E.g.: now, we've seen how Americans } \\
\text { became independent and how... }\end{array}$ \\
\hline Marking asides & Initiates or finalizes an aside. E.g.: I want to set an aside here... \\
\hline Enumerating & $\begin{array}{l}\text { Structures the discourse in an orderly fashion. E.g.: there are two aspects } \\
\text { you should know about [...] first... [...] and second... }\end{array}$ \\
\hline Endophoric marking & $\begin{array}{l}\text { Connects elements like tables, handouts, slides, etc. E.g.: please look at } \\
\text { the page } 373 \text { of your book. }\end{array}$ \\
\hline Previewing & $\begin{array}{l}\text { Refers to information that will be disclosed at any point in the future. E.g.: } \\
\text { we'll talk about that in our class next week. }\end{array}$ \\
\hline Reviewing & $\begin{array}{l}\text { Refers to information that was disclosed at any point in the past. E.g.: last } \\
\text { lecture I talked about... }\end{array}$ \\
\hline Contextualizing & $\begin{array}{l}\text { Comments on the organization or planning of the discourse. E.g.: I believe I } \\
\text { still have a couple of minutes to talk about this. }\end{array}$ \\
\hline \multicolumn{2}{|l|}{ Speech act labels } \\
\hline Arguing & $\begin{array}{l}\text { Expresses the action of arguing. E.g.: I will argue that they did not plan it } \\
\text { like that. }\end{array}$ \\
\hline Exemplifying & Explicitly provides examples. E.g.: let me give you an example of that. \\
\hline $\begin{array}{l}\text { Other speech act } \\
\text { labeling }\end{array}$ & Name discourse acts. E.g.: I want to remind you that... \\
\hline \multicolumn{2}{|l|}{ AUDIENCE INTERACTION } \\
\hline \multicolumn{2}{|c|}{ References to the audience } \\
\hline $\begin{array}{l}\text { Managing } \\
\text { comprehension/channel }\end{array}$ & Checks the communication channel. E.g.: can you hear me back there? \\
\hline $\begin{array}{l}\text { Managing audience } \\
\text { discipline }\end{array}$ & $\begin{array}{l}\text { Instructs or reprimands the audience. E.g.: may I have your attention, } \\
\text { please? }\end{array}$ \\
\hline $\begin{array}{l}\text { Anticipating the } \\
\text { audience's response }\end{array}$ & $\begin{array}{l}\text { Tries to envisage the audience's reactions and opinions. E.g.: you'll } \\
\text { probably think that I am wrong... }\end{array}$ \\
\hline Managing the message & $\begin{array}{l}\text { Refers to the audience to emphasize the core message. E.g.: what I want } \\
\text { you to think about is how all these elements... }\end{array}$ \\
\hline Imagining scenarios & $\begin{array}{l}\text { Transmits ideas through the use of vivid experiences. E.g.: now, imagine } \\
\text { you have to do that. }\end{array}$ \\
\hline
\end{tabular}

Table 3.5 Ädel's (2010) taxonomy of metadiscourse in academic English (spoken and written) 
If we compare both taxonomies, there are many changes. The category of metalinguistic comments encompasses previous types of metadiscourse like clarifying, defining (managing terminology) and adds repairing, commenting on linguistic form/meaning and reformulating. It is also interesting to remark how terminology changes from a writtendiscourse-oriented perspective into a more inclusive standpoint that allows for the incorporation of spoken genres (writer-reader interaction vs. audience interaction, or anticipating the reader's response vs. anticipating the audience's response among many other examples).

Then, a new category entitled discourse organization is included and compiles all those previous elements that were dispersed in Ädel (2006) that help organize discourse (introducing topic, focusing -delimiting topic-, adding, concluding, reminding -reviewingand contextualizing), but also marking asides, enumerating, endophoric marking and most importantly, previewing. In a sense, this category includes metadiscourse related with the management of topics and phorics (substituting the previous categories of phorics and references to the text/code and agglutinating all of these types under a common organizing function). This group is particularly relevant for my study, as I intend to describe how lectures are structured. That being the case, there are four new categories of discourse organization that are worth detailing. Marking asides metadiscourse is used to begin or end a diversion within a given topic ( want to set an aside here...; let me talk just for a second about an anecdote; let's go back to the main topic). Enumerating is part of phorics management and is used to structure different parts of a topic; for instance, I will describe two ideas: first, [...] and then [...]. Endophoric marking is possibly one of the most irregular categories in terms of presence. Ädel describes it as connections with elements that do not clearly exist in the past or future within the discourse, for example when referring to tables or external elements. An illustration could be if you take a look at the handout. In any case, the number of endophoric marking instances in a given lecture will ultimately depend on the lecturer and the possible external materials (like slides, books, or handouts) that they might use. Finally, one of the most relevant additions is previewing. Previewing elements are one of the most common metadiscursive devices when organizing lectures (BernadMechó \& Fortanet-Gómez, 2017). They are used to point forward in the discourse to information that is still to be revealed. Some examples could include as I will develop in a 
minute; we'll talk about that on Wednesday's lecture; or we'll see how history is represented throughout the semester.

Following with the general categorization, a further broad inclusion is the category of speech act labels, which encompasses previous types of metadiscourse like arguing, exemplifying and other speech act labeling (discourse labels).

Finally, the category references to the audience includes metadiscursive types that are singularly relevant in the case of spoken language: managing comprehension/channel, managing audience discipline, anticipating the audience's response, imagining scenarios and managing the message. These categories seem to substitute the previous hypothesizing about the reader, aligning perspectives or appealing to the reader categories in Ädel's (2006) model.

Apart from describing metadiscursive functions in a well-regulated manner, Ädel's (2010) reappraisal of her initial taxonomy encompasses two aspects that utterly relate to the purposes of this thesis: it widely develops the category of discourse organization proposing a distinct attitude towards the description of how discourse is organized; and it is partly based on spoken material, as a corpus-based analysis is conducted on university lectures, which is the genre that I focus on.

Additionally, as I mentioned before, one of the aspects that becomes relevant in Ädel's model is her concern to establish a series of features to properly identify metadiscourse. Metadiscourse is a fuzzy category and it is often difficult for the analyst to discern whether a fragment can be considered as metadiscourse or not, or to accurately categorize instances. In this sense, Ädel (2006) proposes five features to identify metadiscourse. First, metadiscourse should be explicit -also in Mauranen (1993b)-; i.e., there should be an evident presence of the text, the writer or the reader through wording. In other words, there needs to be a degree of reflection upon language for metadiscourse to occur. This excludes previous approaches where typographical elements were also considered as metadiscourse. A second item has to do with the world of discourse; for Ädel, metadiscursive instances will be discourse-internal (as opposed to discourse-external), i.e. metadiscourse will only encompass references within a given text, where a certain degree 
of reflexivity is present. In this sense, metadiscourse can be used to organize both, the discourse itself and other non-related or external events. For instance, if a lecturer is reading a fragment from a novel where metadiscursive elements are being used, those elements cannot be identified as metadiscourse, as they belong to an external discourse. In a case like this, only the metadiscourse referent to the current discourse (the process of lecturing) will be taken into account. This sets the path for Ädel's third feature: current text. For references to external discourses, Ädel uses Mauranen's (1993b) notion of current text; thus, metadiscourse refers to the current text, rather than to other texts, in which metadiscursive fragments are seen as intertextuality. This idea will play an important role when analyzing some of the lectures within the corpus of this thesis, especially in those literature-related sessions where a high use of metadiscourse referring to external materials and stories can be found. In any case, and for the purposes of my analysis, I will only take into account metadiscourse that clearly refers and shows reflexivity on the discourse produced by the speakers. The last two features described by Ädel are writer qua writer and reader qua reader. These features are very similar to the world of discourse feature with the only difference that they refer to the writers and readers. For instance, it is interesting to distinguish whether personal pronouns like $I$, we, or you, refer to either the writer, the reader, both, or none of them.

Still and all, the thought of proper identification of metadiscursive categories, and therefore a solution to the fuzziness of this field of language, is still an unresolved issue among metadiscourse analysts. Fa-gen (2012), for instance, argues that the identification of metadiscursive instances is often determined by a matter of degree; i.e. it is necessary to resolve to what extent a fragment could be encompassed as a metadiscursive figure or another and which role is more relevant, which will eventually become a decision made by the analyst. As I describe in Section 5.1.2, in the present study, a series of instances were initially identified as belonging to two possible metadiscursive categories.

There are two last points that I would like to make regarding the identification of metadiscourse. As I briefly discussed above, there are instances of metadiscourse that may be encompassed within more than one category. From now on, I will refer to this phenomenon as double functionality of metadiscourse. If we take for instance an 
expression like "today we will talk about the American Revolution", it might a priori be considered introducing topic; however, and depending on the context and its pragmatic function, it could also be considered as previewing. In cases like this, my resolution will be to attempt to identify the category which the instance belongs to by considering the frame of reference where the expression is found and also by seeking the pragmatic intention of the lecturers. The second thought has to do with the identification of adverbs like now and well as topic shifters or concluding remarks. This is an idea mentioned in Ädel (2006), Crismore et al. (1993), and Hyland (2005). Even though these types of adverbs might indeed indicate a shift in the discourse, i.e., they could perform a pragmatic action, I believe that they do not contain enough reflexivity over the discourse per se and therefore, they will not be included as part of my analysis.

This dissertation borrows Ädel's (2006) model as developed in Ädel's (2010) taxonomy for its analyses. By limiting the scope of metadiscourse to reflexive approaches (as opposed to an identification of metadiscourse with all non-propositional material) and setting a number of criteria for the identification of metadiscursive material, metadiscourse becomes less of a fuzzy category thus leading to more accurate studies. Ädel's (2010) taxonomy particularly fits the purposes of this thesis as it recognizes the singularities of spoken academic English while perspicuously extending the knowledge on discourse organization metadiscourse.

The four models of metadiscourse described in the foregoing lines show an evolution from interactive perspectives to a more concise reflexive model and from succinct taxonomies to broad corpus-based ones. These were not the only models of metadiscourse, but they are, to my understanding, the most influential and relevant ones to comprehend the evolution of studies on metadiscourse. 


\subsection{Metadiscourse in spoken academic discourse}

In this section, I review some of the studies conducted on metadiscourse in spoken academic genres. In this sense, in Section 3.3.1, I look at some recent studies of metadiscourse in spoken genres, with a particular interest in the developments in the genre of lectures. Finally, in Section 3.3.2, I go through a small number of papers exploring metadiscourse from a multimodal perspective.

\subsubsection{A turn towards spoken language. Metadiscourse in lectures}

As I have outlined throughout this chapter, most studies on metadiscourse have been carried out from the perspective of written discourse. The study of metadiscourse is especially relevant within academic discourse (Hyland, 2005, 2010) and it is this field that has compiled most research on this topic. Many studies have traditionally been, and are still conducted from monolingual or cross-linguistic perspectives to describe metadiscourse in research articles (Abdi, 2011; Abdi et al., 2010; Afros \& Schryer, 2009; Blagojevic, 2004; Bondi, 2010; Bruce, 2009; Cao \& Hu, 2014; Dahl, 2004; Duszak \& Lewkowicz, 2008; Fløttum, Kinn, \& Dahl, 2006; Hu \& Cao, 2015; Hyland, 1998, 1999a, 1999b, 2001a, 2001b, 2005; Hyland \& Tse, 2005; Keshavarz \& Kheirich, 2011; Khedri et al., 2013; Mar Dueñas, 2003, 2007, 2011, Mauranen, 1993a, 1993b; Moreno, 1997; Murillo, 2012; Myers, 1989; PérezLlantada, 2007, 2010, Pisanski Peterlin, 2008, 2010; Salas, 2015; Salas Valdebenito, 2015; Toumi, 2009; Vassileva, 2000; Yakhontova, 2006), undergraduate and postgraduate academic writing (Ädel, 2006; Anwardeen et al., 2013; Burneikaitè, 2008; Crismore et al., 1993; Hyland, 2004a, 2010; Hyland \& Tse, 2004; Lee \& Casal, 2014; Letsoela, 2013; Mirshamsi \& Allami, 2013; Noble, 2010; Nursyuhada et al., 2014; Swales, 1990; Tan, 2012), persuasive essays (Heng \& Tan, 2010), textbooks (Freddi, 2005; Hyland, 1994, 1999c, 2005; Ifantidou, 2005; Poppi, 2004), etc. 
Be that as it may, spoken academic discourse and the analyses of university lectures have become more and more relevant for researchers in recent years (Csomay, 2007; Deroey \& Taverniers, 2012; Pérez-Llantada \& Ferguson, 2006). Querol-Julián (2011a) argues that the increase of analyses on spoken academic discourse might be triggered by the compilation of spoken corpora like MICASE (Michigan Corpus of Academic Spoken English), and also many others -see Querol-Julián (2011a, pp. 118-136) for a full account on spoken corpora. Analyses of metadiscourse in conversation can be found as early as the 70s and 80 s (Keller, 1979; Schiffrin, 1980). However, most of the studies on spoken academic discourse were developed in the early 2000s. Two great branches can be identified in metadiscourse approaches: studies on research discourse such as conference presentations (Dubois, 1981; Heino et al., 2002; McKinlay \& Potter, 1987; Querol-Julián, 2011b; Querol-Julián \& Fortanet-Gómez, 2012; Wulff, Swales, \& Keller, 2009) and studies on lectures (Ädel, 2010; Bellés-Fortuño, 2006; Biber, 2006; Bondi, 2005; Bu, 2014; Crawford Camiciottoli, 2004, 2007; Dafouz Milne \& Núñez Perucha, 2010; Deroey, 2012; Deroey \& Taverniers, 2011; Fortanet-Gómez, 2004a; Fung \& Carter, 2007; Lee \& Subtirelu, 2015; Lin, 2010; Mauranen, 2001, 2002; Nesi \& Basturkmen, 2006; Pérez-Llantada \& Ferguson, 2006; Poos \& Simpson, 2002; Schleef, 2008; Simpson, 2006; Swales, 2001; Swales \& Burke, 2003; Thompson, 2003). Furthermore, these studies have been conducted with distinct aims in mind (comparisons of hedges, discourse markers or lexical bundles, for instance; or description of genres). I would like to highlight some of the aforementioned investigations on metadiscourse in lectures that put their foci on how lectures are organized. Much has been said about how lectures are organized from a lexico-grammatical point of view and about lecture structural patterns -see Young (1994), for example, in Section 1.3.1.2-, but I am interested in the role of metadiscourse and how it contributes to the structuring of lectures.

Crawford Camiciottoli (2004) compares the use of interactive discourse structuring elements in guest lectures for non-native speakers (English as L1 and L2) and classroom lectures for mostly native speakers (English as L1). She looks at how native and non-native speakers in guest or classroom lectures moderate the use of structuring devices. She particularly focuses on macro-markers (Chaudron \& Richards, 1986), most of which could be considered organizational metadiscourse in Ädel's (2010) taxonomy. Her results show 
that there is a higher use of structuring patterns in the non-native guest lecturers. She suggests that this might be rooted in the identification of the lecturers as non-native speakers themselves and their understanding of the students' difficulties. Native speaker guest lecturers, in turn, seem to be less concerned with language issues and use less structuring devices. She concludes that the type of lecture, i.e. guest lectures and classroom lectures, does not have an effect on the discourse structuring material. Crawford Camiciottoli's work, however, compares many variables and leaves out, as she points out, aspects such as references to visuals or English varieties, which she thinks might influence in the use of structuring references.

Another example is Lee and Subtirelu (2015), who make use of Hyland's (2005) model to examine the metadiscourse employed by native speakers of English in content university lectures for native speakers and in EAP lessons for non-native speakers. In an exhaustive corpus-driven analysis, they conclude that the use of metadiscourse depends on the context and content of teaching and learning. They demonstrate that metadiscourse is more frequent in EAP lessons for non-native speakers where lecturers might feel the need to accommodate their language to students who are still learning it. In part, these findings seem to coincide with those in Crawford Camiciottoli (2004) mentioned above, as Crawford Camiciottoli also identifies a higher presence of metadiscursive devices when lecturers interacted with non-native speakers. On the other hand, and referring to the organization of discourse, lecturers in content university classes focus more on framing the discourse to set up classrooms tasks with twice as much use of frame markers than in EAP lessons. Transitions are more common in these lectures and contribute to maintaining coherence and cohesion. Endophoric markers, however, were more present in EAP lessons with references to different pages in course textbooks.

Nesi and Basturkmen (2006) approach the organization of lectures from a corpus linguistics point of view. Based on Biber et al. (2004) and Halliday and Hasan's (1976) approaches to lexical bundles, Nesi and Basturkmen conduct a descriptive quantitative study of 160 monologic lectures. When referring to discourse organizers they list a series of examples of common lexical bundles used to signal the introduction of topics. These types of bundles include expressions as different as "I want you to go through this diagram", "that's a little 
bit of a sideway sideline", or "and finally in this sort of hierarchy...". They conclude that four-word lexical bundles play a relevant role in discourse signaling in lectures and emphasize a need for the teaching of these bundles to non-native speakers. The identification of lexical bundles contributes to a description of how lectures are organized linguistically. Moreover, they can be easily identified in massive corpora-driven analyses. Nevertheless, these researchers do not go further into the different functions carried out by these bundles (introducing topic, changing topic, marking asides, etc.) following a comprehensive study of metadiscourse.

Finally, from a methodological point of view, Dafouz Milne and Núñez Perucha (2010) contribute to the development of a taxonomy for the analysis of metadiscourse in lectures. Taking as a basis Young's (1994) theory of phasal categories present in lectures, they revise and develop her taxonomy. While Young considered evaluation as part of metadiscoursal phases, Dafouz Milne and Núñez Perucha do not. Furthermore, following Hyland (2005), they include interaction (a non-metadiscoursal category in Young's theory) as metadiscourse together with discourse structuring and conclusion. Additionally, they subdivide each of these phases (discourse structuring, interaction, and conclusion) in a series of types of metadiscourse that could perform each of these functions. Special relevance is given to the phase of discourse structuring which is divided into openers, sequencers, topicalizers, prospective markers and retrospective markers. Even though Dafouz Milne and Núñez Perucha's taxonomy provides a useful tool for the metadiscourse analyst, especially when referring to discourse organization, it is less extensive than Ädel's (2010). Dafouz Milne and Núñez Perucha, for example, consider conclusion phases as separate from discourse structuring phases. Ädel, on the other hand, includes concluding topic within discourse organization, which seems more logical as these conclusions indicate the end of a topic and therefore contribute to the structuring of the discourse. Dafouz Milne and Núñez Perucha (2010) apply their taxonomy to the study of metadiscourse in lectures in Spanish (L1) and English (L2). They compare six lectures by three native speakers of Spanish teaching the same class in Spanish and in English. Their results, although based on a very limited dataset, show a higher presence of metadiscursive devices when teaching in their L1 with a high occurrence of topicalizers. These results contradict the ones obtained in Bernad-Mechó and Fortanet-Gómez (2017) where topic management fragments are 
rather low. This might be due to the fact that different approaches to what can be considered one type of metadiscourse or another are being used. While Dafouz Milne and Núñez Perucha include rhetorical questions like "What is the main characteristic of the service conditions for pistons?" and structures such as "we have" as topicalizers, these instances would be part of audience interaction rather than discourse organization in Bernad-Mechó and Fortanet-Gómez (2017). Dafouz Milne and Núñez Perucha conclude that there is a similar use in the types of metadiscourse to structure the lecturers' classes across languages. Some differences are encountered in the degree of explicitness, though; there is less variety of metadiscourse and a lower level of specificity in English and a higher presence of conclusion markers in Spanish. All in all, Dafouz Milne and Núñez Perucha's, like any other model of metadiscourse, was created in a specific context and for a specific purpose. In this sense, different models naturally lead to different results.

Crawford Camiciottoli (2004), Dafouz Milne and Núñez Perucha (2010) and Lee and Subtirelu (2015) all compare to a greater or lesser extent the use of metadiscourse between native and non-native speakers and throughout disciplines. Nevertheless, to my knowledge, few studies compare metadiscourse across different types of lecturers (Bernad-Mechó \& Fortanet-Gómez, forthcoming). I believe different lecturing styles require different preparation processes and therefore, varying uses of metadiscourse are expected. Moreover, an exhaustive study of metadiscourse from a reflexive approach is needed in order to fully disclose the intricacies of organizational metadiscourse in lectures. On top of that, the aim of this thesis is to go beyond words and investigate how lecturers structure their classes from a multimodal point of view, i.e. taking into account linguistic, paralinguistic and non-verbal aspects as well as the interrelation among them when conveying meaning. This methodology will allow for a broader interpretation into the actual process of lecture structuring. 


\subsubsection{Metadiscourse and multimodality}

As I argued at the beginning of this chapter in Section 3.1, metadiscourse has been studied from a wide variety of perspectives. Nevertheless, while studies on metadiscourse in lectures are abundant, very few of these studies are conducted from a multimodal perspective, i.e. going beyond a linguistic approach into an examination of non-verbal material.

Within the studies on spoken academic research, Querol-Julián (2010, 2011a, 2011b) and Querol-Julián and Fortanet-Gómez (2012) examine evaluation in discussion sessions of conference presentations. An interesting aspect of their work is the extensive use of ELAN (see Section 2.4.2). They conduct a multimodal discourse analysis in order to take a look at how paralanguage, gestures, facial expression, gaze and head movements play a role in conveying evaluative meaning. Other relevant studies in conference presentations are Morell $(2013,2015)$ where multimodal analyses are carried out to determine effectiveness; Ruiz-Garrido's (2015) study on intensifying adverbs and the non-verbal resources employed by presenters to reinforce them, or Diani's (2015) study on the use of PowerPoint slides by speakers in international applied linguistic conferences.

When it comes to the study of lectures there is also an important set of studies from a multimodal point of view (see Section 1.3.2 for a full development of the multimodal studies in lectures). However, out of these studies, only Bernad-Mechó (2015a, 2017a) and Bernad-Mechó and Fortanet-Gómez (2017, forthcoming) are particularly concerned about metadiscourse (once again, see Section 1.3.2 for a description of these studies). To my knowledge, very few studies deal with metadiscourse in lectures from a multimodal perspective. Even more difficult is to find studies that approach the organization of lectures from a multimodal point of view.

One of the examples in which non-verbal aspects are considered in the study of metadiscourse is Thompson (2003). This researcher conducts a study where she compares the use of text-structuring metadiscourse in six authentic undergraduate university 
lectures and five EAP published listening materials. The groundbreaking aspect of this article is the fact that Thompson also analyzes intonation as a resource to structure lectures. She uses Yule's (1980) theory of phonological paragraphs, which claims that phonological paragraphs are related to the topic and can be identified by their boundaries. These boundaries consist of a high pitch on the first stressed syllable and the lowest pitch in the last tone unit. The final part of these paragraphs can also be signaled by lowering the volume, slowing down the speech pace or by a longer pause. The use of phonological paragraphs becomes relevant for the listener and their correct understanding of the topic (Brown \& Yule, 1983; Tench, 1996; Wichman, 2000). As for the study of metadiscourse, Thompson employs Crismore et al.'s (1993) model. After text-structuring metadiscourse and phonological paragraphs are identified, Thompson reaches a series of conclusions. On the one hand, from a linguistic point of view, she spots three levels in the organization of metadiscourse: global structuring markers (for instance, to organize the lecture), topic structuring markers, and sub-topic structuring markers. The amount of metadiscourse is higher in the EAP talks than it is in the lectures, but Thompson relates this to the fact that they are not authentic spontaneous material, and therefore, a higher preparation and use of metadiscourse is expected. When analyzing the intonation of phonological paragraphs, Thompson identifies longer paragraphs in authentic lectures. This suggests that EAP talks have been divided into smaller parts and consequently, information is more condensed. Most importantly, Thompson compares the use of metadiscourse and phonological paragraphs. The results show that $39.6 \%$ of phonological paragraphs in authentic lectures include text-structuring metadiscourse in their beginning. However, a 75\% coincidence of intonation features and metadiscourse in authentic lectures is described when identifying smaller phonological sections within a phonological paragraph indicated by a low termination in the previous segment, a decrease in volume and/or speed, and/or a pause. Finally, she briefly refers to the fact that lecturers might use notes to structure their discourse. It is important to remember that one of the purposes of this thesis is to compare how lecturers structure their classes depending on their lecturing styles, which seem to be determined by the use of notes. I would like to finish this section by quoting Thompson (2003, p. 19): 
This is not to argue that text-structuring metadiscourse and phonological paragraphing are the only important variables [...] Rost (2002, p. 234) emphasizes the difficulty of deciding which of many different variables (speed of delivery, accent, use of text-structure metadiscourse etc.) have the greatest influence over lecture comprehension. Undoubtedly, for example, visual information (slides, OHTs, video clips etc.) can play a crucial role in signaling the organization of a lecture (Charles \& Ventola, 2002; King, 1994).

Thompson's article represents one of the initial insights into metadiscourse from a multimodal point of view. Nevertheless, there is a need for further analyses on metadiscourse from a multimodal perspective. In a sense, Thompson's article is just the tip of the iceberg' and a full multimodal analysis is needed to entirely disclose how lectures are actually organized.

In the examples described above, several researchers have taken a look at metadiscourse as it occurs with non-verbal resources. However, in all cases, metadiscourse seems to arise from a main verbal feature that is accompanied by non-verbal features. In this sense, it seems that some metadiscursive functions like topic shifts may be indicated through nonverbal cues even when no verbal metadiscourse is present. In other words, the function of indicating a change in topic can be performed through non-verbal language as demonstrated in Bernad-Mechó and Fortanet-Gómez (forthcoming). These non-verbal transitions could be explicated within the theory of metapragmatics (Bates, 1976; Bublitz \& Hübler, 2007; Caffi, 1984, 2006; Lucy, 1993; Silverstein, 1976, 1993). Metapragmatics takes an interest in the reflexive use of pragmatics, i.e. how language is employed to reflect upon pragmatics. Within this paradigm, for instance, Hübler (2007) explores the relation between non-verbal modes and topic from a metapragmatic point of view. This researcher looks into how transitions in content seem to be marked by the use of pauses and the presence of lip adaptors functioning as structuring signals. Thus, Hübler concludes that non-verbal features may serve structuring functions in communication. This contribution, however, cannot be interpreted from a traditional theory of metadiscourse as no reflection upon the discourse is produced. In other words, for metadiscourse to occur a condition needs to be met: "the writer's explicit commentary on her own ongoing discourse" (Ädel, 2010 , p. 20). In this example, non-verbal elements can be understood as performing a pragmatic act and can be encompassed within the domain of metapragmatics. 
In this Chapter, I have reviewed the most common definitions of metadiscourse as well as the most utilized models (Vande Kopple, 1985; Crismore et al., 1993; Hyland, 2005; and Ädel, 2006, 2010) in order to display the evolution in the study of metadiscourse form basic limited approaches to fully developed ones. I have also explained the advantages of using Ädel's reflexive model and why her taxonomy fits the purposes of this thesis. Finally, in Section 3.3, I have reviewed relevant studies on organizational metadiscourse and on metadiscourse from a multimodal point of view. The following chapter takes into account the theoretical review presented in the first three chapters in order to develop a method for the analyses in this thesis. 


\section{CHAPTER 4. DRAWING FROM THEORY FOR A MULTIMODAL ANALYSIS OF ORGANIZATIONAL METADISCOURSE IN LECTURES}

In this chapter, I consider the theoretical notions discussed in chapters 1, 2, and 3 in the fields of discourse analysis, genre analysis, multimodality, and metadiscourse, in order to devise a methodology to describe the use of organizational metadiscourse at all levels.

Having this idea in mind, in the present study I draw on the principles of discourse analysis and pragmatics (see sections 1.1.1 and 1.1.2) to discuss the metadiscursive functions of organizational metadiscourse and the context in which it occurs. Besides, the study of Jakobson's functions of language (Section 1.1.3) and Halliday's SFL (Section 1.1.4) is necessary to understand the development of the distinct models of metadiscourse, and, in the case of SFL, it also helps to explain the development of MSS and MDA, and contributes to the linguistic study of metadiscourse. As for MIA, its roots are discussed in mediated discourse analysis (Section 1.1.5). Finally, the study of lectures is contextualized within the approaches to the study of genre (sections 1.2 and 1.3). It is important to remark here, that the focus of the present study is on traditional lecture-centered non-interactive lectures, and special emphasis is placed on the lecturing styles and the ways in which lectures are structured.

On the multimodal plane in this thesis, several approaches towards multimodality have been reviewed: MSS (Section 2.2.1), MDA (Section 2.2.2), and MIA (Section 2.2.3). As I states in the introduction and throughout Chapter 2, in this thesis, I combine concepts and methodological tools from these three approaches in order to obtain a wider perspective of the use of organizational metadiscourse. In particular, I draw on MSS and MDA to explore use of semiotic resources employed by lecturers and their particular combinations when conveying organizational metadiscourse. This analysis is conducted by taking into account the modes described in Section 2.3 (speech, gesture, gaze, head movement, posture, paralanguage, proxemics, and facial expression), and by adapting the findings in previous research creating a framework for analysis (see Section 4.3.3 below). Finally, I employ the 
methodological tools provided in MIA to explore the structures of actions performed by the lecturers when organizing discourse.

As for the study of organizational metadiscourse, I have described throughout Chapter 3 some of the most influential models (Vande Kopple's, Crismore et al.'s, Hyland's and Ädel's). For the analyses in the present thesis, Ädel's (2010) taxonomy of metadiscourse is the most appropriate, as it is the only one that is -partially-created considering lectures and it thoroughly describes organizational metadiscourse. In this sense, this thesis validates and expands on Ädel's model.

Against this background, in the first section of this chapter, Section 4.1, I state the general aims of my study and in Section 4.2 I explore the research questions that will guide my analyses. These initial inquiries lead the way to the description of the corpus collected for this thesis in Section 4.3. Here, the process of obtaining, editing and assembling the data is detailed. First, I discuss the criteria considered for the compilation of the data; then, I move on to describe the main corpus and its sub-corpora on which both, the linguistic and multimodal analyses have been carried out; and finally, I look at the process of annotating the multimodal dataset. Lastly, in Section 4.4, I thoroughly illustrate the types of analyses implemented in this thesis. First, I describe the process carried out in the quantitative study of the use of organizational metadiscourse. This description is followed by an exploration of the methodological framework employed to explore the linguistic aspects of organizational metadiscourse in lectures and the non-verbal semiotic resources employed. The last part of the chapter is devoted to detailing how the analysis of the multimodal structures of organizational sections has been conducted and how the role of organizational metadiscourse is contemplated within the set of sequences of actions carried out by lecturers. 


\subsection{The aims of the study}

This dissertation aims to shed new light on the current research on spoken academic discourse by employing a multimodal approach to the study of metadiscourse and its role in the organizational process of lectures. In short, the purpose of this thesis is to take a look, from a multimodal perspective, at the use of metadiscourse and how it is being used to organize lectures. As I described in Section 3.3.2, multimodal approaches to the study of metadiscourse are scarce, and so are the studies in which the lecturers' discourse is examined as a combination of modes. In Section 1.3.2, moreover, I argued that while some aspects dealing with the multimodal nature of the lectures have received attention in recent years (e.g. the use of visuals, the use of the board, or multimodal literacy), very few studies have explored the multimodal communication of lecturers -see Bernad-Mechó (2015a, 2017a), Bernad-Mechó and Fortanet-Gómez (2017, forthcoming), or Crawford Camiciottoli $(2015,2016)$ as representative examples. Multimodal analyses towards oral genres seem to offer a more inclusive picture of the elements playing a role in the communicative process. In this sense, the study here presented goes beyond most traditional studies of metadiscourse where only linguistic features are considered and explores non-linguistic layers of meaning in order to understand how these are combined in the communicative process. Therefore, and as I describe in Section 4.4, I create a methodological framework made up of a combination of linguistic and multimodal approaches to discuss how meaning is constructed at all levels.

At this point, it is worth mentioning that the departing point of the analysis of this thesis is the exploration of a linguistic category, i.e. organizational metadiscourse. As I elaborated in Section 3.1, metadiscourse is referred to as one of the organizational devices through which lecturers signal the direction of the lectures, thus easing comprehension and guiding the students in their learning process. Therefore, in order to explore how lectures are organized and how this organization is transmitted to the audience, I focus on those sections of the lectures where organizational metadiscourse is present. An initial linguistic approach to examine metadiscourse at quantitative and qualitative levels seems 
appropriate in order to understand the use of organizational metadiscourse in the classroom. This, however, does not mean that I somehow prioritize the linguistic mode over non-verbal modes. Instead, the linguistic expressions of metadiscourse are identified in order to single out relevant segments in the lectures where organization occurs. Considering this, I assume that organizational metadiscourse is employed by lecturers through the use of an elaborate compendium of modes, which should initially receive equal attention. In other words, I expect most linguistic instances of organizational metadiscourse to be accompanied by a multiplicity of modes that hold semiotic weight per se and which contribute to the conveyance of meaning. Having said that, it is important to remark that it is not my objective to conduct a thorough analysis of all modes participating in the multimodal ensemble, which would be a task way beyond the scope of this thesis. Instead, as I describe in Section 4.4, I focus on those semiotic resources that are most relevant to explore how metadiscourse is conveyed.

Furthermore, I argue that the organization of lectures seems to be closely related to the ways in which discourse -and actions- are organized. Although, as I described in Section 1.3.1.2, the study of the structure of the lectures has received much attention by genre analysts -see, for instance, Young (1994) or Thompson (1994)-, to my knowledge, there is no study that considers the structure of lectures as sequences of actions performed by a lecturer. That is to say, the structure of lectures has traditionally been explored by looking at the verbal transcriptions of the lecturer's speech. In this study, I suggest that by considering the sequences of actions performed by the lecturers in organizational sections, a further insight into the role that metadiscourse plays in those actions can be obtained. To that end, the multimodal examination of organizational metadiscourse is complemented at a supra level with a close look at the structure of organizational sections in the lecture. By utilizing a multimodal approach, this inspection provides an insight into the role played by metadiscourse and the attention that it receives from the lecturers.

Finally, I claim that one of the variables that influences the lecturers' choices in the use of metadiscourse (both linguistic and non-verbal) is that of the lecturing style. Initial studies of the corpus employed for this thesis -see Bernad-Mechó (2015a, 2017a, 2017b) and Bernad-Mechó and Fortanet-Gómez (2017, forthcoming)- reveal significant differences in 
the quantitative use of organizational metadiscourse and the semiotic resources employed to its conveyance that seem to be related, to an extent, to the lecturing styles of the lecturers. Bearing this in mind, I set out to investigate how different lecturing styles constrain or determine the use of organizational metadiscourse.

Thus, in order to fulfill these aims, I present four main analyses: a detailed quantitative exploration of 152 lectures to account for the usage of organizational metadiscourse in terms of quantity; a subsequent linguistic exploration of the use of metadiscourse in a subcorpus of six representative lectures; a multimodal exploration of the use of semiotic resources in a dataset extracted from the aforementioned sub-corpus; and a multimodal review of the structures of organizational sections in which metadiscourse is used employing the sub-corpus of representative lectures. The ultimate practical aim of the present study is to use the outcomes of these analyses to help improve the lecturers' discourse and the students' comprehension of lectures. At the same time, I propose to raise awareness of the need to consider not only linguistic aspects, but also non-verbal features in academic discourse.

\subsection{Research questions}

In order to fulfill the aims presented above and provide a deeper level of concretion to the main objectives of the study, I suggest the following research questions and sub-questions to guide my analyses:

\begin{tabular}{|l|l|}
\hline RQ 1 & $\begin{array}{l}\text { How is organizational metadiscourse used quantitatively in academic } \\
\text { lectures? }\end{array}$ \\
\hline RQ 1.1 & What are the most common types of organizational metadiscourse in academic lectures? \\
\hline RQ 1.2 & $\begin{array}{l}\text { Where within the lectures and throughout the course does organizational metadiscourse } \\
\text { occur? }\end{array}$ \\
\hline RQ 1.3 & $\begin{array}{l}\text { Are there any similarities or differences in the quantitative use of organizational } \\
\text { metadiscourse across lecturing styles? }\end{array}$ \\
\hline
\end{tabular}




\begin{tabular}{|l|l|}
\hline RQ 2 & How is organizational metadiscourse expressed verbally? \\
\hline RQ 2.1 & $\begin{array}{l}\text { What are the recurrent syntactic and semantic structures in the use of the most common } \\
\text { types of organizational metadiscourse? }\end{array}$ \\
\hline RQ 2.2 & $\begin{array}{l}\text { Are there any similarities or differences in the verbal use of organizational metadiscourse } \\
\text { across lecturing styles? }\end{array}$ \\
\hline
\end{tabular}

\begin{tabular}{|l|l|}
\hline RQ 3 & How is organizational metadiscourse expressed non-verbally? \\
\hline RQ 3.1 & $\begin{array}{l}\text { What are the recurrent semiotic resources lecturers turn to in the use of metadiscursive } \\
\text { instances? }\end{array}$ \\
\hline RQ 3.2 & How do these semiotic resources combine in multimodal ensembles? \\
\hline RQ 3.3 & $\begin{array}{l}\text { Are there any similarities or differences in the non-verbal use of organizational } \\
\text { metadiscourse across lecturing styles? }\end{array}$ \\
\hline
\end{tabular}

\begin{tabular}{|l|l|}
\hline RQ 4 & $\begin{array}{l}\text { How does organizational metadiscourse contribute to the structuring } \\
\text { process of the lectures? }\end{array}$ \\
\hline RQ 4.1 & $\begin{array}{l}\text { What sequences of actions do lecturers perform during the organizational sections of the } \\
\text { lectures? }\end{array}$ \\
\hline RQ 4.2 & $\begin{array}{l}\text { What is the role of organizational metadiscourse in the lecturer's multimodal organization of } \\
\text { lectures? }\end{array}$ \\
\hline RQ 4.3 & $\begin{array}{l}\text { Are there any similarities or differences in the multimodal organization of lectures across } \\
\text { lecturing styles? }\end{array}$ \\
\hline
\end{tabular}

Following these research questions, I organize the analyses carried out in this thesis in two broad sections. On the one hand, the first part of the study aims to offer a description of the use of organizational metadiscourse at different levels (quantitatively, linguistically and multimodally). These analyses are conducted in order to answer research questions 1, 2 and 3. On the other hand, the second part of the study looks into how organizational metadiscourse is used in the structuring process of the lectures.

Having this idea in mind, the RQ1 aims to provide an initial overview of the use of organizational metadiscourse in lectures. In order to answer this question, I conduct a quantitative study to identify and classify all metadiscursive instances along six full courses in social sciences. The results will show the most common types of organizational metadiscourse in academic lectures (RQ 1.1). Moreover, I explore where organizational metadiscourse is commonly concentrated in the lectures and throughout the course with a focus on bundles of organizational metadiscourse. I will subsequently refer to these bundles as structuring segments (see Section 1.3.1.2 for more information on this concept). 
In this way, I aim to expose the parts of the lectures where organizational metadiscourse is more common as well as the distribution of metadiscursive elements throughout the course (RQ 1.2). Finally, these findings are compared taking into account the different lecturing styles (RQ 1.3). Several results are expected: as initial explorations of the data anticipate (Bernad-Mechó, 2017b; Bernad-Mechó \& Fortanet-Gómez, 2017, forthcoming), differences in the quantitative use of organizational metadiscourse are found across lecturing styles. In this regard, conversational style lecturers appear to employ the most organizational metadiscursive instances while rhetorical style lecturers use the least. Moreover, a higher use of phorics management metadiscourse to give cohesion to the lecture is expected; in particular, those of endophoric marking, previewing, and reviewing metadiscourse (Bernad-Mechó \& Fortanet-Gómez, 2017). Finally, a higher use of previewing devices is expected in the initial sessions of the courses, and a higher use of reviewing metadiscourse in the last sessions. It seems logical that lecturers devote the first lectures of the course to explain to the audience what the course is going to be about and to outline the main topics that will be dealt with. These introductory elements to the course might be carried out through the use of previewing metadiscourse. Likewise, lecturers might devote the last lectures of the course to summarize the main contents and therefore, reviewing metadiscourse is expected. Similarly, a higher presence of metadiscursive devices could be encountered during the introductions to the lectures, where a series of connections with the previous sessions and an outline of the contents of the present one are expected. If these assumptions are confirmed, the answer to this question will shed new light on the relevance of lecturing styles when examining organizational metadiscourse in lectures. Moreover, this question aims to limit the scope of the analyses carried out in this thesis. By discerning which types of metadiscourse are the most relevant and spotting the sections in the lectures in which organizational metadiscourse occurs with a higher frequency (structuring segments), I restrict both the linguistic and multimodal analyses to those relevant (general) uses of organizational metadiscourse. As I describe in Section 4.3, multimodal analyses entail arduous time-consuming annotating tasks; consequently, the choice of the fragments of the lecture to be analyzed need to be as specific and representative as possible. 
RQ2 looks at the linguistic data from a qualitative point of view. This question aims to explore the linguistic intricacies appearing in the use of organizational metadiscourse across lecturing styles. Particularly, I intend to account for any relevant similarities and differences in the construction of metadiscursive instances from a lexico-grammatical perspective, taking into account how metadiscourse is created syntactically and semantically (RQ 2.1). As I mentioned before, differences in the multimodal use of organizational metadiscourse across lecturing styles are expected (Bernad-Mechó \& Fortanet-Gómez, forthcoming); the answer to RQ 2.2 will confirm whether these differences are also present at a linguistic level.

RQ3 takes as a starting point the premise that all communication is "inherently multimodal" (Fortanet-Gómez \& Crawford Camiciottoli, 2015, p. 2; Müller, 2009, p. 216). This question addresses the multimodal conveyance of organizational metadiscourse. Initially, I focus on the recurrent semiotic resources employed in the conveyance of metadiscourse (RQ 3.1). Furthermore, I aim to explore what particular combinations of semiotic resources are brought together during structuring segments in order to discern how metadiscourse is expressed non-verbally ( $R Q$ 3.2). In this context, I further intend to find out whether lecturing styles constrain the availability of semiotic resources (RQ 3.3). As I discussed above, in Bernad-Mechó and Fortanet-Gómez (forthcoming), we argue that lecturers following different lecturing styles resort to distinct semiotic resources when trying to engage the audience in the lecture. The paper shows how the modal density in the multimodal ensembles seems to decrease as the influence of written notes becomes more obvious for the lecturers. Thus, the modal density in the use of organizational metadiscourse decreases from rhetorical to conversational styles and from conversational to reading styles. In the present thesis, I aim to confirm these results in a larger scale study. To answer this question, I perform a fine-grained multimodal analysis of the modes employed in structuring segments.

Finally, RQ4 completes the present study by examining the structure of lectures from a multimodal perspective. This research question aims to provide insights into the structuring process of lectures from an innovative perspective, i.e. by considering the lectures as successions of interactive actions performed by the lecturers (RQ 4.1). The 
ultimate purpose of this question is to discern the role of organizational metadiscourse within the sequences of actions (RQ 4.2). An MIA approach towards the analysis of structure will allow the identification of sequences of higher-level actions occurring simultaneously in the lectures. These actions, in turn, can be attached to a degree of attention/awareness indicated by the modal density of each action. Consequently, a certain degree of importance can be assigned to the actions in which organizational metadiscourse is verbalized. Thus, these actions occur in either the foreground, the midground or the background in the foreground-background continuum. A specific role of metadiscursive actions may be then hinted at by considering the attention/awareness received by the given action (see Section 2.2.3 for an extensive review of MIA approaches). In a preliminary study (Bernad-Mechó, 2017a), I demonstrate the complexity of the structures in the introductions of topics in a conversational style lecturer and how verbal introducing topic metadiscourse is commonly used as a midgrounded action. In other words, the action in which introducing topic is verbalized receives less attention than other simultaneous actions (like the actions of organizing notes or developing content). RQ4 is meant to expand this study to examine the differences across lecturing styles (RQ 4.3) and taking into account not only introducing topic metadiscourse, but also other relevant categories like previewing and reviewing. Eventually, the answer to this question will test the validity of a new methodology for the study of organizational metadiscourse and the structuring processes of lectures.

\subsection{The corpus}

In this section, I explore the corpus that has been compiled to conduct the present study. After a brief introduction on Yale University's OCW -the source from which I have extracted the lectures being analyzed in this thesis-, I describe the series of features that were taken into account for the compilation of the corpus in Section 4.3.1. In this regard, the courses for the analysis were not randomly selected; instead, they were picked following a series of standards to be met. By applying selected restrictions to the corpus, I aim to create a 
dataset as homogeneous as possible for a valid comparison. The explanation of the process of designing the corpus is followed by a full description of the corpus and its sub-corpora in Section 4.3.2. Finally, some notes on the process of compilation and preparation of the corpus are given in Section 4.3.3.

The lectures selected for this study have all been extracted from the OCW offered at Yale University's website ${ }^{11}$. Yale University offers online access to 42 full university courses covering a large range of fields of study, including Humanities, Social and Natural Sciences. Yale University's OCW is not designed for online courses, but consists of a compilation of face-to-face traditional lectures that were recorded at Yale University between years 2006 and 2011 and then uploaded to the website to make them accessible to the public. In this respect, no apparent difference can be established between a self-recorded lecture and the online lectures provided in Yale University's OCW.

I argue that the benefits of using lectures extracted from an OCW over self-recorded lectures are diverse. On the one hand, OCW commonly offer real lectures that have been recorded professionally considering technical aspects like the type and position of the cameras, the lighting, and the sound recording. Furthermore, the raw videos are edited to synchronize video and audio and to improve their quality. In this respect, the outcome is usually a recorded lecture of the highest quality that can be used in multimodal analyses. On an ethical frame, and with a focus on the corpus utilized in this thesis, Yale University's OCW is, as of 2018, licensed under a Creative Commons Attribution-Noncommercial-Share Alike 3.0 license ${ }^{12}$. This means that the lectures included in their OCW can be shared and adapted as long as appropriate credit is given, it is not done with commercial purposes and the final result is shared with the same license as the original. In a way, working with Creative Commons licensed materials facilitates the access to readily usable lectures. Finally, the variety of lectures available in online OCW is abundant and general datasets can be compiled within a degree of specification.

\footnotetext{
${ }^{11}$ http://oyc.yale.edu/ Last accessed January $8^{\text {th }} 2018$.

12 https://creativecommons.org/licenses/by-nc-sa/3.0/us/ Last accessed January $8^{\text {th }} 2018$.
} 
On the contrary, amateur self-recorded events allow for the creation of very specific tailormade datasets. However, some problems may arise during the collection of the data. First, the process of preparing, recording, transcribing, editing and adapting the video data is time-consuming and requires a degree of expertise. Bearing this in mind, the analyst often needs to deal with technical issues arising from the recording process such as a bad quality of image or sound that makes the analysis more difficult and the validity of the video data compromised -see Jewitt (2012) for a reflection upon the conditions and decisions to be taken into account during the recording process for multimodal studies. Moreover, the access to volunteering lecturers who agree to be recorded and analyzed may be limited. All in all, the obstacles in the process of compiling self-recorded lectures make it difficult to obtain large corpora for quantitative studies. In the present thesis, I aim to obtain an insight on the use of organizational metadiscourse as it is normally used in lectures. The use of OCW materials which are illustrative of real face-to-face lectures seems suitable for the objectives sought here.

Yale University's OCW offers not only high-quality uncut videos of the lectures, but also MP3 files with the audio recorded during the sessions, accurate linguistic transcriptions, and any visual materials employed during the lectures as well as handouts and proposed assignments. The fast availability of the video and audio data as well as the linguistic transcriptions of the lectures is a key element to facilitate the compilation of the corpus. As Yale University states:

Open Yale Courses provide free and open access to a selection of introductory courses taught by distinguished teachers and scholars at Yale University. The aim of the project is to expand access to educational materials for all who wish to learn.

- All lectures were recorded in the Yale College classroom and are available in video, audio, and text transcript formats (Yale University, 2018).

In order to carry out the objectives of this study, I have compiled a self-assembled corpus made up of six full university courses in Humanities with a total of 152 lectures. Moreover, a sub-corpus of 6 representative lectures (one for each course) has been extracted to conduct the linguistic analysis and the analysis of the structure of the sequences of actions performed by the lecturers. Finally, a sub-corpus of six structuring segments (see Section 
1.3.1.2) has been selected from the sub-corpus of representative lectures in order to perform the fine-grained multimodal analysis of semiotic resources.

\subsubsection{Designing the corpus}

In this section, I outline the factors considered for the compilation of the main corpus and its sub-corpora. As I stated above, the present study is based on a corpus consisting of six full courses and a total amount of 152 lectures in Humanities. The decision to choose Humanities lectures was not arbitrary. As Crawford Camiciottoli (2015) argues, most multimodal research on lectures has focused on hard sciences -see, for instance, Artemeva and Fox (2011), Fox and Artemeva (2013), O'Halloran (1998, 2003, 2008), or Weinberg, Fukawa-Connelly, and Wiesner (2013). In this sense, very few studies focus on the study of Social Sciences and Humanities -Bernad-Mechó and Fortanet-Gómez (2017), or Crawford Camiciottoli $(2015,2016)$, for example- and further explorations on these fields would entail valuable contributions in the process of discerning the intricacies of the multimodal discourse of lecturers. Moreover, and as I detail in this section, in order to carry out a comparison of the use of organizational metadiscourse, the corpus needs to be as homogeneous as possible. This was limited by the available courses at hand and the quality of the material. In addition, I am interested in traditional non-interactive lectures where the lecture is focused on the audience. This seems to be more common in Humanities since more theoretical content is expected than in Sciences - where lecturers might interact more with the audience to clarify issues or use various resources like visual presentations or the board. Finally, the last reason for selecting disciplines within Humanities is a personal one; as I mentioned in the introduction to this thesis, being a junior lecturer in Linguistics myself and coming from a background in soft sciences, I find Humanities more comprehensible and closer to my own experience as a lecturer. Having these ideas in mind, I decided to select disciplines that were as close as possible. 
Still and all, the selection of these specific courses within Humanities was not random either. The design of the corpus was planned according to the objectives of this thesis. In this sense, this thesis does not attempt to make a contrastive study of different disciplines; instead, I seek to account for the general use of organizational metadiscourse in the structuring processes of the lectures from a multimodal point of view. In particular, I set out to examine the organizational differences across lecturing styles. In order to accurately compare these elements, the corpus requires a certain degree of resemblance. That being the case, I established a set of parameters that I tried to neutralize during the selection of the courses from Yale University's OCW so that the differences between lectures and between lecturers were as minimal as possible. In particular, I considered the following aspects: the amount of interaction between lecturers and students, the duration of the lectures, and the number of lectures in a course. Furthermore, I selected two courses being taught in each of the lecturing styles considered in this thesis (conversational, rhetorical and reading styles). From a technical perspective, and bearing in mind the fact that multimodal analyses require high-quality video and audio data, I also considered the type of camera shot. Thus, a preliminary viewing of the 42 courses provided at Yale University's OCW was carried out to select the most suitable courses for the analysis. As I said, in this thesis I intend to focus on lectures within Humanities; therefore, all Sciences courses (9 out of 42) were directly discarded.

One of the first factors that I considered was the amount of interaction between lecturers and students. As I described in sections 1.3 and 1.3.1.1, my focus is on lecture-centered sessions where interaction from the students is rare. The phases in the macro-structure of lectures with a certain degree of lecturer-student interaction may differ considerably from those in a lecture with limited or no students' interventions. Using Young's (1994) terms, interactions occur in interaction phases, which are uncommon in the lectures that I intend to analyze. In an effort to reduce the differences across the lectures selected for the corpus, I decided to omit those courses where the interaction lecturer-students was frequent.

Secondly, the duration of the lectures was taken into account for the creation of the corpus. The duration of lectures in Yale University's courses ranges from 40 to 75 minutes. A longer duration of lectures might entail an impractical size for the corpus, making it more difficult 
to analyze. In the compilation of the corpus, I tried to avoid selecting lectures of very different durations as they might include a different amount of organizational metadiscourse that might jeopardize the validity of the research. For instance, a 75-minute lecture could include more topics (and therefore more introducing topic metadiscourse) than a 40-minute one. Although this should not be an issue in the quantitative analysis as instances of metadiscourse are normalized (see Section 4.4 for a description of the analytical processes in this thesis), it could still offer unreliable results in the study of the structure. The average duration of the lectures in the courses selected for this thesis ranges from 45 to 55 minutes with some exceptions in which lectures can offer runtimes as short as 38 minutes or as long as 61 minutes.

Similarly, a further aspect to examine was the number of classes within a course. Most courses in Yale's repertoire consist of 24 to 26 lectures. However, there are some courses where the average number of sessions ranges from 35 to 38 . The number of lectures might not be exceedingly relevant to explain the use of organizational metadiscourse from a multimodal point of view, yet it is a relevant factor to be considered when analyzing its structure and distribution. A selection of courses with a high variation in the number of lectures would make a comparison difficult and inaccurate. 24 to 26 lectures is the common number of sessions in the courses selected, as I discarded courses with a higher number of lectures.

The lecturing style of the lecturers (see Section 1.3.1.1) rounds up the picture of the compilation of the corpus. In order to compare how lecturing styles influence in the verbal and non-verbal uses of organizational metadiscourse and in the structuring processes in the lectures, I decided to choose two conversational style, two rhetorical style and two reading style lecturers according to the definitions by Dudley-Evans (1994). Although lecturers cannot always be categorized completely within one style or another -for instance, some reading style lecturers may also offer spontaneous comments as a conversational style lecturer might do, or a rhetorical style lecturer could occasionally turn to their notes to verify details-, I selected the lecturers in terms of how much they would resort to their notes. Thus, conversational style lecturers employ their notes mostly all throughout the lectures but do not commonly read them; rhetorical style lecturers rarely 
use any notes; and reading style lecturers read through their notes during most of the lecture.

As I hinted in Section 4.2 and I further develop in Section 4.4 below, the analyses carried out in this study are organized into four blocks: a quantitative analysis conducted on the main corpus; a linguistic analysis performed on a sub-corpus of six representative lectures; a multimodal analysis of the semiotic resources employed in the lectures that has been carried out on a sub-corpus of six structuring segments extracted from the representative lectures; and a multimodal analysis of the structure of the actions in the lectures for which the corpus of representative lectures has been used. In this regard, although the quantitative and linguistic analyses just required a linguistic transcription of the lectures that allowed for the exploration of the types and distributions of organizational metadiscourse, the multimodal analyses entailed a close examination of video and audio data in order to account for the use of non-verbal modes. Accordingly, a number of technical issues needed to be taken into consideration during the selection of lectures, regarding the quality of video and audio. Thus, from a technical point of view, I examined the quality of video and audio and the type of camera shot used for the recording of the lectures. Every course in Yale University's OCW has been shot with a single camera pointed to the lecturer in an angle that varies depending on the disposition of the classroom (for example, at the back of the classroom, in the first rows, or from a side). Occasionally, cameras may be directed to a visual presentation or to the board, especially when the lecturer is using these resources. In the interest of obtaining valid data for the multimodal analyses, the type of shot and framing of the lecturers was paramount. A too general shot would be inadequate when carrying out a multimodal analysis of gestures, head movements or gaze, for example, as these might be unnoticeable from the distance. Likewise, a too close framing could leave out some hand-arm gestures being performed out of the screen. Although these elements cannot always be controlled, lectures in which the lecturer is recurrently recorded from either a long shot or a close-up position were ruled out. On that account, the preferential choice of lectures was those filmed from a medium shot or a close full shot where at least the upper part of the body could be clearly seen and all movements were recognizable. In this regard, the quality of the video is of great importance. Yale University's OCW lectures are offered in DVD quality (640x360 pixels); 
although this display resolution is far from more modern formats (HD, Full HD or $4 K$ ), it is enough to distinguish all movements. The last technical aspect to be considered was the quality of the audio. In the interest of conducting a proper analysis of audio features (paralanguage), voices need to be clear with no background noises. In Yale's lectures, all lecturers used microphones positioned close to the voice source, so the quality of the audio is excellent. Finally, one of the factors that facilitated both the quantitative and linguistic analyses is the fact that verbal transcriptions are available for download at the website. Although these transcriptions will need to be adapted to conduct the multimodal analyses (see Section 4.3.3) they have proven to be useful in the identification of organizational metadiscourse.

By considering all these aspects, I attempted to minimize the differences from one course to the other to create a unified corpus. However, despite the efforts to create a homogeneous corpus, there may be factors that are difficult to be accounted for; for example, individual, cultural and social traits that may influence both the use of verbal and non-verbal resources and the ways in which lectures are delivered. In this sense, idiosyncratic traits seem to be present at all times. Thus, lecturers within their respective lecturing styles might show their own particular individual features. In this line, Galloway (1972) argues that non-verbal cues are highly individual and are influenced by series of personal traits as a result of the complexity of human communication. Isolating and neutralizing these aspects might require, for instance, an ethnographic study where the data is discussed with the lecturers. Such an approach, however, is beyond the reach of the present study. Still and all, it is important to remark that the present study aims to provide a general overview of the use of organizational metadiscourse rather than specific generalizations.

Having these features in mind, the courses that were selected for this study and which were complied with the aforementioned parameters were: Course 1 - "African American History, from Emancipation to the Present"; Course 2 - "The American Revolution"; Course 3 "Death" (a Philosophy course); Course 4 - "The American Novel since 1945"; Course 5 "Epidemics in Western Society since 1600"; and Course 6 - "Cervantes' Don Quixote". These are described in Section 4.3.2. Out of these, Courses 1 and 2 are taught by 
conversational style lecturers, Courses 3 and 4 by rhetorical style lecturers, and Courses 5 and 6 by reading style lecturers.

Following the compilation of the main corpus, a sub-corpus of six representative lectures was extracted from the main dataset (see Section 4.3.2 below). This sub-corpus served as the main data on which the linguistic and one of the multimodal analyses were carried out. After carrying out a quantitative study of the uses of organizational metadiscourse (see Chapter 5), and based on the results obtained, I selected a representative lecture from each of the courses. Two main criteria were considered in the selection of the representative lectures. On the one hand, I discarded lectures occurring either at the beginning or at the end of the courses, as these generally contain a higher amount of organizational metadiscourse -for instance, when lecturers broadly outline the contents of the course in initial sessions or when they summarize some of the main points towards the end of the course. In this regard, I opted for lectures occurring in the middle of the course (sessions 10 to 15 ) that showed an average amount of organizational metadiscourse (see Section 5.3). On the other hand, I took into account the distribution of organizational metadiscourse across the lectures. As I mentioned in Section 1.3.1.2, I am interested in fragments in the lectures where several instances of organizational metadiscourse occur in a short period of time, and which I refer to as structuring segments. These segments often occur in the introductions to the lectures, although they can also be found all throughout the sessions, especially in transitional instances between broad content-related sections. Furthermore, I also account for the presence of organizational metadiscourse in spontaneous utterances, i.e. organizational metadiscourse encountered in isolation outside structuring segments. In this sense, representative lectures were selected in which an average number of both structuring segments and spontaneous metadiscourse were present. These factors were considered individually for each course in order to select the most appropriate lecture in each of them.

Finally, one further level of specification was needed in the multimodal analyses. As I detail in Section 4.4, two multimodal analyses have been conducted in this thesis: an MDA examination of the use of semiotic resources in the conveyance of organizational metadiscourse, and an MIA approach towards the study of the multimodal structure of 
lectures and the role played by metadiscourse as an element within the actions performed by the lecturers. Although the latter is performed on the full representative lectures and explained through examples extracted from any part of the sessions, the former requires extra planning. In other words, the MIA approach aims to explore the prototypical sequences of actions carried out by different lecturers during structuring segments and spontaneous metadiscourse. In this regard, as I explain in Section 4.4.4, all metadiscursive instances in representative lectures have been examined so that prototypical structures and modal choices could be identified. For the MDA analysis (see Section 4.4.3), however, a multimodal annotation software application (MMA-Video) was used for the identification of verbal and non-verbal cues conveying meaning in organizational instances. Consequently, short specific video-clips needed to be selected and imported into the software for analysis. Thus, a sub-corpus of six structuring segments was selected out of the six representative lectures.

In short, three levels of specification were considered in this thesis: a broad corpus made of 152 lectures that served as the basis for the quantitative analysis; a sub-corpus of 6 representative lectures on which the linguistic analysis and the analysis of the structure and the role of organizational metadiscourse were performed; and a smaller multimodal dataset made up of six short video-clips for a fine-grained analysis of the semiotic resources employed. In the following section, I describe the composition of each of these levels.

\subsubsection{Description of the corpus}

The departing point of the analyses in this thesis has been the quantitative exploration of the whole corpus. This initial exploration has served as a tool to narrow down the scope of the thesis focusing on those relevant uses of organizational metadiscourse in representative lectures. Two sub-corpora have been further created from this broad corpus. The first one contains a representative lecture from each of the six courses compiled for this thesis. The linguistic analyses and the analysis of the structure of the 
lectures have been conducted using this dataset. Finally, one short video-clip (a structuring segment) has been selected from each of these six representative lectures in order to explore the multimodal use of semiotic resources. The transcriptions of all the lectures utilized in this thesis, as well as the full video clips of the six representative lectures and the six structuring segments can be found in Appendices $A, B$, and $C$ respectively.

\section{The main corpus}

The main corpus comprises 152 lectures divided into 6 courses in Humanities extracted from Yale University's OCW and adding up to 994.171 words and 122 hours, 27 minutes and 37 seconds. Two of the lectures -lecture 26 in Course 4 and lecture 26 in Course 5were discarded since they were devoted to discussing possible doubts in preparation for the final exams. The format of these two lectures contrasts with that in the rest of the lectures where contents are disclosed in an expositive manner and so, their inclusion might compromise the validity of the results. Table 4.1 below provides an overview of the size of the corpus in terms of words and duration of the clips.

\begin{tabular}{|c|c|c|c|c|c|}
\hline & $\begin{array}{l}\text { Number } \\
\text { of texts }\end{array}$ & $\begin{array}{l}\text { Number of } \\
\text { words }\end{array}$ & $\begin{array}{c}\text { Total } \\
\text { duration }\end{array}$ & $\begin{array}{l}\text { Average text } \\
\text { length }\end{array}$ & $\begin{array}{l}\text { Average } \\
\text { duration }\end{array}$ \\
\hline $\begin{array}{l}\text { Course } 1 \text { (African- } \\
\text { American History) } \\
\end{array}$ & 25 & 159990 & $19 \mathrm{~h} 30^{\prime} 46^{\prime \prime}$ & 6400 & $46^{\prime} 50^{\prime \prime}$ \\
\hline $\begin{array}{l}\text { Course } 2 \text { (The American } \\
\text { Revolution) }\end{array}$ & 25 & 190017 & $18 \mathrm{~h} 25^{\prime} 30^{\prime \prime}$ & 7601 & $44^{\prime} 13^{\prime \prime}$ \\
\hline $\begin{array}{l}\text { Course } 3 \text { (Philosophy: } \\
\text { death) }\end{array}$ & 26 & 174775 & $20 h 45^{\prime} 12^{\prime \prime}$ & 6722 & $47^{\prime} 53^{\prime \prime}$ \\
\hline $\begin{array}{l}\text { Course } 4 \text { (The American } \\
\text { Novel) }\end{array}$ & $25^{*}$ & 157428 & $19 h 56^{\prime} 11^{\prime \prime}$ & 6297 & $47^{\prime} 51^{\prime \prime}$ \\
\hline $\begin{array}{l}\text { Course } 5 \text { (History of } \\
\text { Epidemics) }\end{array}$ & $25^{*}$ & 136654 & $20 h 2^{\prime} 28^{\prime \prime}$ & 5466 & $48^{\prime} 6^{\prime \prime}$ \\
\hline $\begin{array}{l}\text { Course } 6 \text { (Spanish } \\
\text { Literature: Don Quixote) }\end{array}$ & 24 & 175307 & $23 \mathrm{~h} 47^{\prime} 30^{\prime \prime}$ & 7304 & $59^{\prime} 29^{\prime \prime}$ \\
\hline
\end{tabular}

Table 4.1 Overview of the size of the main corpus

\footnotetext{
* Courses 4 and 5 are actually made up of 26 lectures. Nevertheless, as explained above, lecture 26 in both courses is devoted to debating doubts for the written exam. This type of lecture differs considerably from the expositive structure of the rest of the dataset and therefore has not been included in the analyses.
} 


\section{Sub-corpus of six representative lectures}

Out of this corpus, and after a first examination of the use of organizational metadiscourse (see Chapter 5), six representative lectures were selected. As I explained in the previous section, these lectures have served as the basis for the linguistic analysis of metadiscourse (see Chapter 6) and for the multimodal analysis of the structure of the lectures (see Chapter 8). Consequently, the choice of representative lectures was made having several considerations in mind. The lectures were selected from the middle of the course to ensure an average amount of organizational metadiscourse, and the distribution of metadiscourse within the lectures was examined in order to select those lectures with a representative number of structuring segments. Table 4.2 describes the lectures selected for the creation of the sub-corpus.

\begin{tabular}{|c|c|c|}
\hline Code & Number of words & Duration \\
\hline C1_L13 & 6996 & $19 \mathrm{~h} 30^{\prime} 46^{\prime \prime}$ \\
\hline C2_L13 & 8280 & $18 \mathrm{~h} \mathrm{25^{ \prime } 3 0 ^ { \prime \prime }}$ \\
\hline C3_L15 & 5943 & $20 \mathrm{~h} 45^{\prime} 12^{\prime \prime}$ \\
\hline C4_L13 & 6208 & $19 \mathrm{~h} \mathrm{56^{ \prime } 1 1 ^ { \prime \prime }}$ \\
\hline C5_L15 & 4913 & $20 \mathrm{~h} \mathrm{2} 28^{\prime \prime}$ \\
\hline C6_L15 & 7530 & $23 \mathrm{~h} \mathrm{47^{ \prime } 3 0 ^ { \prime \prime }}$ \\
\hline
\end{tabular}

Table 4.2 Description of the sub-corpus of representative lectures

\section{Sub-corpus of six structuring segments}

Finally, the multimodal analysis of the semiotic resources employed in the use of organizational metadiscourse has been carried out on a collection of short video-clips extracted from the sub-corpus described in Table 4.2. One clip was selected from each lecture. The clips were chosen considering those fragments containing abundant organizational metadiscourse; in other words, structuring segments were identified and one of them was selected in each of the lectures. The introductions to the lectures were prioritized when selecting the fragments for the multimodal analysis; however, the introductions in courses 3 and 4 are way too short, and therefore, structuring segments within the lecture were selected. Furthermore, the introduction to the lecture in Course 1 
does not take place right at the beginning of the lecture, but some minutes afterwards, as the lecturer spends the first moments of the session reading and commenting on a fragment from a diary. All segments in this sub-corpus were selected taking into account the first metadiscursive instance in the fragment as the starting point, and the end of the last metadiscursive utterance marking the completion of the segment. Logically, these segments show distinct runtimes; however, this will not be considered in the analysis of the semiotic resources as the data will be provided in percentages over the total duration of the clip (see Section 4.4.3 for further explanations on this type of analysis). By carrying out a fine-grained analysis of the use of semiotic resources in these clips, I aim to show the possible similarities and differences across lecturing styles in the non-verbal use of modes accompanying organizational metadiscourse. Table 4.3 below describes the video-clips selected for the multimodal analyses.

\begin{tabular}{|c|c|c|c|c|}
\hline Lecture & Code & Number of words & Duration & Extracted from \\
\hline C1_L13 & SS_C1 & 377 & ${\text { 2' } 48^{\prime \prime}}^{\prime \prime}$ & 06:52:18 to 09:40:12 \\
\hline C2_L13 & SS_C2 & 564 & 3' 39" $^{\prime \prime}$ & 00:01:00 to 03:39:23 \\
\hline C3_L15 & SS_C3 & 260 & $2^{\prime}$ 5" & 14:47:29 to 16:52:29 \\
\hline C4_L13 & SS_C4 & 235 & 1' 53" $^{\prime \prime}$ & 07:16:01 to 09:09:01 \\
\hline C5_L15 & SS_C5 & 239 & $2^{\prime} 13^{\prime \prime}$ & 00:01:00 to 02:14:00 \\
\hline C6_L15 & SS_C6 & 362 & 3' 24" & 00:01:00 to 03:24:29 \\
\hline
\end{tabular}

Table 4.3 Description of the sub-corpus of structuring segments

\subsubsection{Preparing the corpus}

The process of preparing the corpus was divided into three stages: the compilation of videos and transcriptions; the editing of the video files and transcriptions; and the multimodal annotation of the sub-corpus of structuring segments for the analysis of the semiotic resources. As I detailed at the beginning of Section 4.3, Yale's OCW offers highquality video files and transcriptions of the lectures for download, which highly facilitates the process of compilation of data. 


\section{Compiling videos and transcriptions}

The first step in the preparation of the corpus was to download all 152 videos of the lectures together with their verbal transcriptions from Open Yale Courses website. The verbal transcriptions of these lectures served as the basis to carry out the quantitative analysis.

\section{Editing the videos and the transcriptions}

With the quantitative data, the sub-corpus of six representative lectures was created and the editing process began: the quality of the videos was improved in terms of brightness and color correction, the audio files were cleaned for any background noises, and timestamps were added to facilitate the representation of video screenshots in this thesis. The correction of brightness and color and the addition of timestamps were carried out using Adobe Premiere Pro, a software application for video editing. Although in general terms the quality of the video files in Yale University's OCW is high, the video image in some of the lectures selected was slightly dark, which might have made it more complicated to conduct fine-grained multimodal analyses. Moreover, the use of timestamps is a common tradition in multimodal analyses (see for instance Norris, 2004) that helps the analyst and the reader situate a fragment within the broader event and have a notion of the amount of time separating two or more video stills. Finally, Adobe Premiere Pro was also used to separate the six short video clips from the representative lectures that were employed in the sub-corpus of structuring segments for the analysis of semiotic resources.

The audio correction, in turn, was carried out using Adobe Audition, software for the edition of audio files. Like the video files, the audio provided by Yale University's OCW meets the standards of quality for multimodal analyses. Still and all, the files were cleaned for possible background noises and hisses and the vocal frequencies were enhanced for a clearer understanding of the voice of the lecturers. The editing process of audio improved the quality of the voice. This improvement becomes particularly relevant for the analysis 
of pitch using Sonic Visualiser (see Sections 2.4 and 4.4.3); a higher quality in the clarity of the voice means more reliable results in the analysis of pitch.

At this point, the linguistic transcriptions of the selected lectures were reviewed for accuracy and modified to fit the conventions for verbal transcriptions in multimodal analyses. In order to conduct these transcriptions, I followed Norris (2004) and Pirini (2015) and used conventions from a series of sources (Sacks et al., 1974; Tannen, 1984). The conventions I employed in this thesis are summarized in Figure 4.1.

- Time within the lecture is indicated in the form of $\mathrm{mm}$ :ss:ff (minutes, seconds, frame). It indicates the beginning of the utterance.

- Punctuation is used to reflect basic intonation, not grammar.

- $\quad$ CAPITAL LETTERS are used for emphasis.

- Numbers in parentheses $(x)$ are used to indicate the length of a pause in seconds.

- $\quad$ Latched utterances are marked with diagonal brackets. E.g.:

Speaker 1: that was about to happen

in 1966

Figure 4.1 Conventions for verbal transcription (adapted from various sources: Norris, 2004; Pirini, 2015; Sacks et al., 1974; Tannen, 1984)

An example of a verbal transcription is shown in Example 1 below. In this example, time is indicated to contextualize the fragment within the lecture, the numbers in parentheses indicate pauses and are shown in seconds, a latched utterance is indicated with a diagonal bracket and capital letters have been used to show the emphasis in the voice.

1) 02:29:05 So but let us (.5)

02:30:15 first turn our attention today (1)

02:33:00 erm...

02:33:29 to um...

02:34:27 erm...

02:35:00 two critics (.5), whose essays (.5), you are reading this week in the

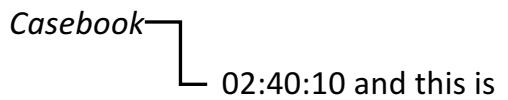

$02: 41: 19$ this is sort of the erm...

02:43:20 the erm... (1.5)

02:45:18 the HIGHLIGHT or the high point I should say of the Casebook these two essays (.5), by Auerbach and Spitzer (3.5) 
When multimodal transcriptions were needed, a series of steps were followed to accurately represent live interactions on paper. First, relevant screenshots were brought together in image strips. These screenshots show instances where a change in posture or gaze has occurred, a gesture is being performed, etc. Furthermore, a timestamp was included on the top left corner of the image in the form of mm:ss:ff (minutes, seconds, frames) and images were numbered in order of occurrence on the bottom left corner. Finally, a verbal transcription was occasionally added under the images in order to place the action within the content of the lecture. This type of transcription favors the study of specific modes as they occur in interaction, and therefore, the timing between one image and the other is not constant. Norris (2004) suggests that the screenshots should be taken at prominent instances in modes; thus, in the case of a deictic gesture, for example, three screenshots -at least-, would describe the whole action: screenshots of the preparation, stroke and retraction phases. Additionally, arrows or other symbols can be added to clarify the movement. In the case of two-position gestures (beats), gaze and posture shifts and head movements, two images would probably describe the action accurately. Nevertheless, one of the issues in this type of transcriptions arises from the fact that image strips become too all-inclusive and therefore, less readable. Consequently, choices on which screenshots are representative had to be made so that actions like gestures or posture shifts could be represented using only a few screenshots. Lastly, intonation was added to the transcription when relevant. In order to illustrate intonation, I detached from Norris's (2004) system for representing pitch variations -see Norris (2004, pp. 75-78). In Norris's words,

we visualize the rising and lowering of intonation by transcribing utterances as curves; pitch by size and boldness of letters; pauses by spaces between letters or utterances; and overlap by closeness/touching of utterances.

Although this system is able to represent audio features into writing in a more or less readable fashion, it is often based on the perception of the researcher and might not accurately represent changes in intonation. As a result, I show intonation as a pitch line with a verbal transcription added below -see Bernad-Mechó (2017a), for example. In order to extract the pitch line, I utilized the software Sonic Visualizer (Cannam et al., 2010) and 
the plug-in pYin (Mauch et al., 2015; Mauch \& Dixon, 2014) (see Sections 2.4 and 4.4 .3 below for further information). An extract of a multimodal transcription can be seen in Figure 4.2. In this excerpt, a change in gaze and a metaphoric gesture are described together with a peak in high tone in the pitch line. This type of multimodal transcription offers a full visual description of specific gestures, gaze shifts, intonation, and other nonverbal material.

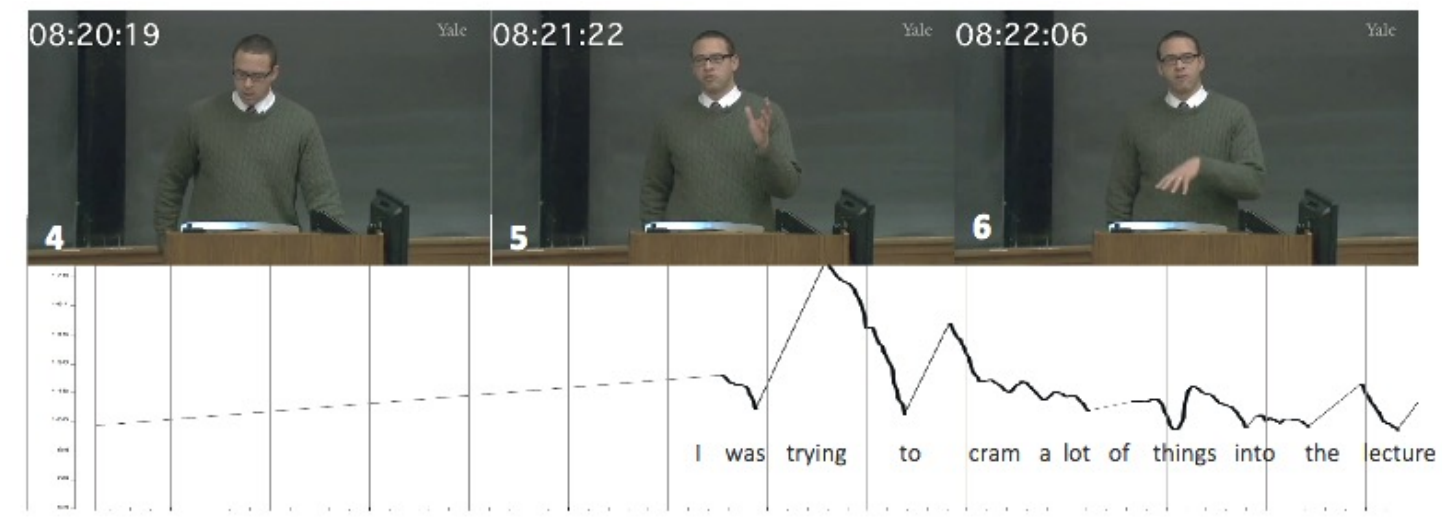

Figure 4.2 Example multimodal transcription -extracted from Bernad-Mechó (2017a)

\section{The multimodal annotation}

The last step in the preparation of the corpus was the multimodal annotation of the subcorpus of six structuring segments described in Section 4.3.2 and Table 4.3 above. The ultimate aim of the multimodal annotation is to discern how lecturers exploit the semiotic resources available to them and which particular combinations of modes are more common. As I detailed in Section 2.3.2, I focus on a series of modes for the analysis of the semiotic resources employed by the lecturers; namely, I look at the use of gestures, gaze, head movement, posture, paralanguage, proxemics and facial expression. Moreover, in the multimodal annotation, I also examine the verbal mode, i.e. the "words" verbalized by the lecturers. Halliday and Hasan (1985, p. 4) refer to communication, context and culture "as a set of semiotic systems, a set of systems of meaning, all of which interrelate". In order to conduct the multimodal annotation, a framework of analysis including the possible choices in each of the semiotic systems had to be created. The software MMA-Video offers the possibility of designing an ad hoc framework of analysis. 
As detailed in Section 2.4.2, in order to annotate the use of semiotic resources using MMAVideo, a set of strips was created in the Graphical User Interface (GUI) (see Figure 4.3). This interface is made up of four broad sections: a video window where the clips can be played [1]; a box for verbal transcriptions [2]; a set of three boxes where system choices can be singled out [3], i.e., the analyst can describe each of the semiotic resources which have been selected by the lecturer; and a list of strips where choices are annotated in time [4]. Three strips are provided by default by the software, the film strip [a], that displays snapshots extracted from the video clip; the sound strip [b], which displays a waveform of the audio in the clip; and the dialog strip [c] where the verbal transcription can be inserted and which is displayed in box [2]. The rest of the strips are created manually with the aim of annotating all relevant semiotic resources employed in the lecture fragments.

The first two strips have to do with the use of speech; in particular, I annotate the use of organizational metadiscourse [d] and that of content language [e]. By comparing these two aspects I intend to obtain data about the percentage of speech devoted to discuss the direction of the lecture, to establish connections with other parts of the lectures or the courses, to introduce topics, etc., in short, the percentage of speech where lecturers employ organizational metadiscourse, as opposed to the parts of speech where normal content-based information is provided. Within the strip metadiscourse, in turn, I offer a set of choices following Ädel's (2010) taxonomy of metadiscourse: introducing topic, delimiting topic, adding to topic, concluding topic, marking asides, enumerating, endophoric marking, previewing, reviewing, and contextualizing.

The next strips are devoted to annotating the gestures performed by the lecturers. Drawing on the work of McNeill (1992), in gesture (type) [f], I indicate the type of gesture performed by the lecturers: iconic, metaphoric, deictic, or beat. The type of gestures may be an indicator of the relevance of the gestures. Thus, beats are commonly used to accompany the speech, provide rhythm, and may emphasize certain instances during communication. On the other hand, other types of gestures like iconic and metaphoric gestures are meant to have a direct relation with the contents of speech, and deictic gestures are used to point at concrete or abstract entities. Two more strips are created in MMA-Video for the description of hand-arm movements. In the strip gesture (other) [g], I annotate any 
movements performed by the lecturers with their hands and arms which cannot be regarded as gestures. These include, for example, scratching, or touching one's clothing, but also handling notes, holding a book or using a computer. Finally, in gesture (1 vs. 2 hands) [h], I describe whether gestures are performed using only one hand or both hands. As detailed in Section 2.3.2, Calbris (2008) suggests that gestures may sometimes be performed with both hands for emphasis. By annotating whether lecturers use one or both hands, I aim to spot sections that have been emphasized by the lecturers.

In gaze [i], a list of system choices is provided: gaze towards notes, gaze towards the book, gaze towards audience, other. As discussed in Section 2.3.2, gaze has been proven to play an important role in social interaction (Argyle et al., 1973). Tan et al. (2015) indicate that gaze contributes to the meaning-making process by contributing to the engagement of an online audience when speakers look directly at the camera. Similarly, in Bernad-Mechó and Fortanet-Gómez (forthcoming), we identify gaze as one of the semiotic resources employed by lecturers to engage the audience in the organizational process of lectures. Therefore, in the multimodal annotation of gaze, I expect to discern which lecturers focus more on the audience and which ones focus on the written materials they use in class.

The strips head movement (direction) [j] and head movement (type) [k], are designed to describe the use of head movements by lecturers. In these strips, I do not aim to annotate those head movements coinciding with the direction of the gaze (for example, when a lecturer gazes down at their notes they also move their head in accordance with their gaze, or when they look at the audience, their head is also facing the audience). Instead, here I register those head movements that do not correspond to gaze shifts. Following Norris (2004), I annotate those head movements that are iconic, i.e. those head movements that have a verbal counterpart (for example, yes/no signaling), and novel head movements that do not have a verbal equivalent. The latter, in turn, may also be classified into deictic movements which point to concrete or abstract entities, and beat movements, that consist of two-stroke movements marking the rhythm or emphasizing certain fragments. 


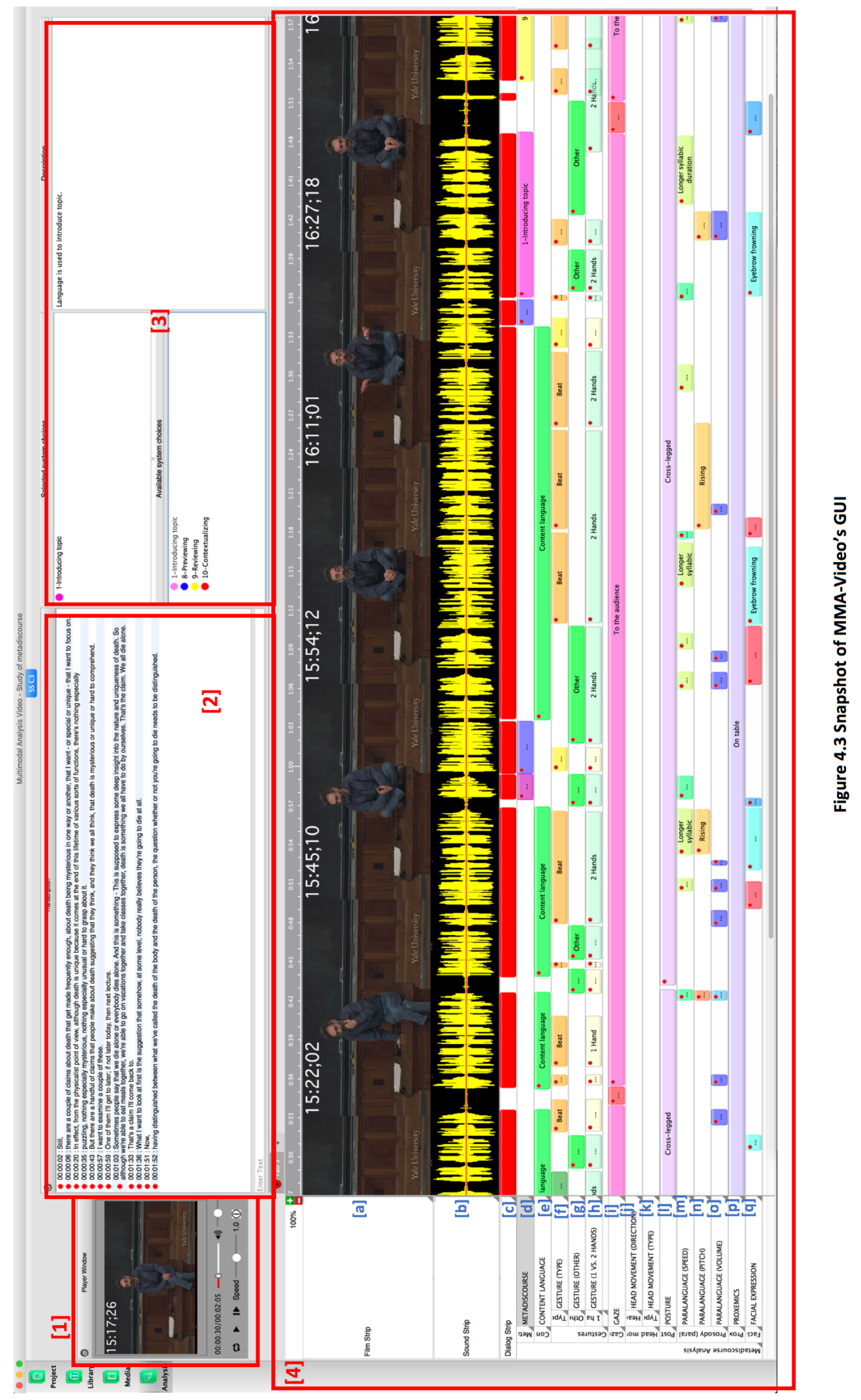


The next strip, posture [I], logs the ways in which the lecturers position their bodies during the lectures. The particular position adopted by a given lecturer may provide information about the elements on which the lecturer is focusing. For example, in Bernad-Mechó (2017a), I describe how the posture adopted by the lecturer reveals his focus of attention, varying from a focus on the notes to a focus on the audience. In the multimodal analysis of the short video clips, I aim to obtain quantitative data that sheds light on how the lecturers change their foci of attention as they deliver they lectures. In this regard, the strip posture provides a description of the body postures performed by the lecturers. Among the postures identified in the dataset, there are two broad categories: standing and sitting on a table. These categories, in turn, can be further specified in several sub-types. Within the former, lecturers can have an upright position or a position towards the lectern/table. Within the latter-only present in Course 3-, the lecturer can be cross-legged or have their legs in a stretched position. The feature of swaying is also included within posture when the lecturers perform a swaying movement that seems to mark the rhythm of the communication -see Bernad-Mechó (2017a).

The annotation of prosody is carried out in the strips paralanguage (speed) [m], paralanguage (pitch) [n], and paralanguage (volume) [o]. Some paralinguistic features like a parenthetical intonation can be found in spontaneous metadiscourse (Bernad-Mechó, 2015a). These metadiscursive instances are characterized by a decrease in the volume and an increase in the speed of the utterance. In these cases, metadiscourse commonly interrupts the flow of the main utterance and is included as an apposition to the main content. Similarly, in Bernad-Mechó (2017a), I describe how the pitch line of the utterances may indicate whether a given sentence belongs to one higher-level action or another. In this sense, pitch may serve as an indicator of the finiteness of a clause. Following previous multimodal studies (Bernad-Mechó, 2015a; Querol-Julián, 2011a, 2011b; Querol-Julián \& Fortanet-Gómez, 2012) I describe two choices within the strip paralanguage (speed): syllabic duration shorter when the lecturer speaks faster, and syllabic duration longer when the lecturer speaks slower. Also following these studies, in paralanguage (volume), I describe the loudness of the voice, i.e. whether the lecturer speaks louder (for emphasis) or quieter. Finally, in paralanguage (pitch) I offer a simplified version of Brazil's (1997) 
model with the choices of rising, falling and level intonations. One aspect, however, needs to be highlighted in the study of paralanguage. Unlike 'visual' modes such as gestures, gaze, or posture, where shifts and positions are clearly identifiable, the manual analysis of sound features remains somehow subjective. An initial examination of the volume can be carried out by observing the soundwave. The soundwaves visually display silences and changes in intensity (see Figure 4.4) although no exact data is provided. Thus, although an initial annotation of paralinguistic features can be carried out with MMA-Video, I make use of Sonic Visualiser and the plug-in pYin to obtain reliable data describing pitch and intensity variations (see Section 2.4.2 for a full description of the software). The analysis of speed, in any case, needs to be done manually by dividing the number of syllables between the time employed.

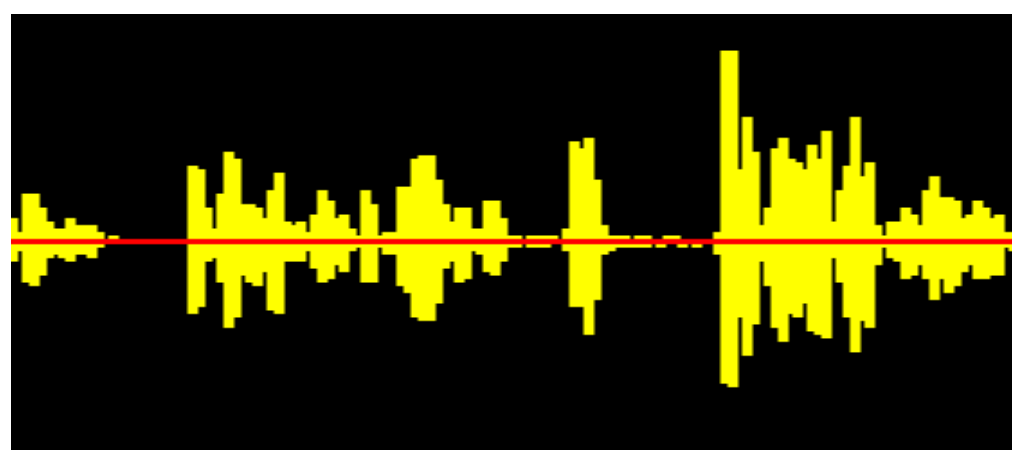

Figure 4.4 Sample of soundwave in MMA-Video

The following strip, proxemics [p], describes the use of the classroom space made by the lecturers. As discussed in Section 2.3.2, the use of space may provide clues as to what higher-level actions are being performed. Six choices have been described in this strip: lectern, when the lecturer stands behind the lectern; table, when the lecturer stands by the table; on the table when the lecturer is sitting on the table; to the board when the lecturer turns to the board; in front of the audience, when the lecturer is standing in front of the audience; moving in front of the audience, when the lecturer moves back and forth or from side to side in front of the audience.

Finally, the last strip in the multimodal analysis is devoted to the study of facial expression [q]. In this strip, I annotate all elements displaying facial expression like eyebrow raising, frowning, laughter and smile, and also actions like swallowing and lip licking. Apart from 
the fact that facial expressions are indicators of emotions (for instance, grief, sadness, happiness, anger, fear, or disgust), they also become relevant in the conveyance of content meaning in conversation (Ekman, 1972). Thus, brows may be used with an emphatic function (Birdwhistell, 1979; Eibl-Eibesfeldt, 1972; Hwang \& Matsumoto, 2016). Lip adaptors, on the other hand, have been identified as possible topical boundaries (Hübler, 2007). In the multimodal analysis here presented, the study of the combination of facial expressions with other modes might expand these findings.

As I describe in Section 4.4.3, the combination of semiotic resources in multimodal ensembles contributes the most to the description of the multimodal use of organizational metadiscourse in lectures. A full description of the framework employed in the annotation process is shown in Figure 4.5 below. Once the corpus had been compiled, the sub-corpora of representative lectures and structuring segments selected, the video and audio files edited, cut and transcribed, and the short clips annotated, the corpus was ready for its analysis. 


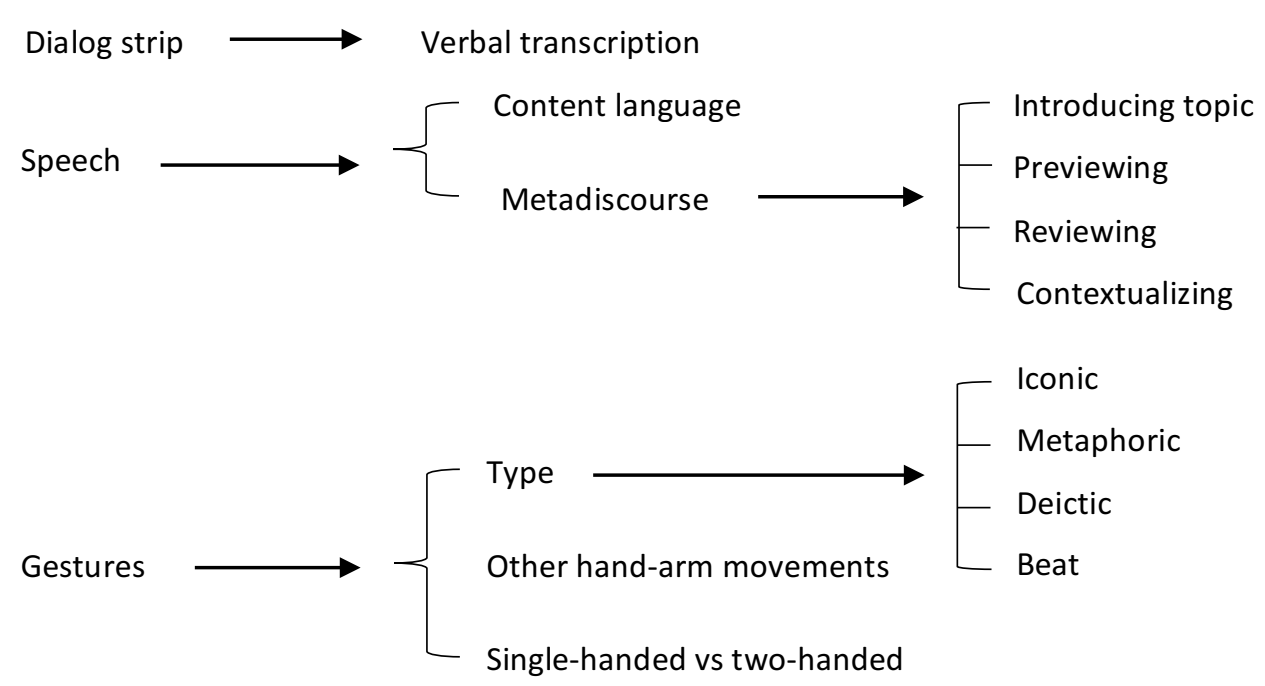

Gaze

Towards notes/Towards audience/Towards book/...

Head

movement
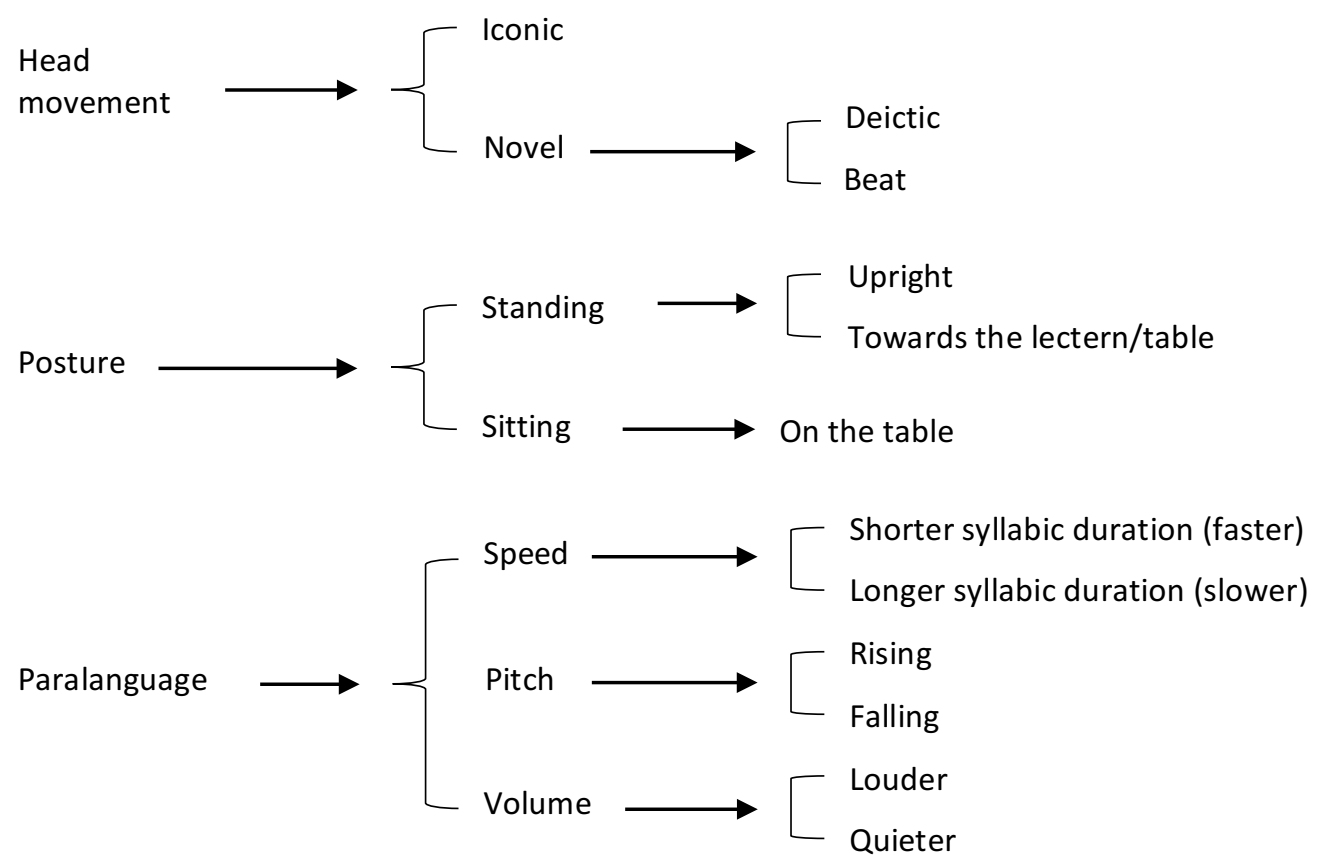

Proxemics Lectern/Table/On table/To board/In front of the audience/Swaying/...

Facial expression

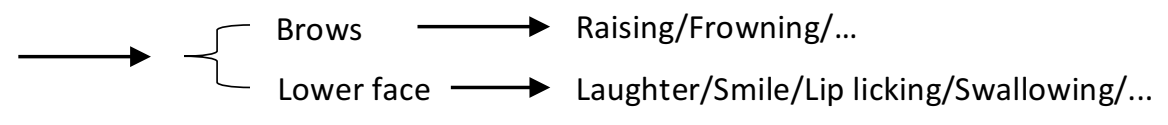




\subsection{The analysis}

In the present thesis, I make use of combined methods to provide a full description of the use of organizational metadiscourse in lectures. In particular, I carry out four analyses: a quantitative analysis, a linguistic analysis and two multimodal analyses (an exploration of the use of semiotic resources from an MSS/MDA perspective, and an analysis of the structures and role of organizational metadiscourse following an MIA approach). While both the quantitative and linguistic analyses can be performed independently, it is uncommon to encounter a combination of two different multimodal approaches in the same study. In this respect, I side with Jewitt's (2014) view that different approaches to multimodality may be useful to answer distinct questions. In other words, depending on the purpose of the study, the analyst may find that one approach is more suitable for a specific purpose than another. In the case of this thesis, as I outlined throughout Chapter 2, I make use of the concepts and technological tools employed in MSS (Kress, 2000, 2010, Kress \& van Leeuwen, 1996, 2001) and MDA (O'Halloran, 2004a, 2007) to explore which semiotic resources and combinations of modes are common for each lecturer. Moreover, I make use of the theoretical and methodological tools in MIA (Norris, 2004, 2011, 2016, 2017) to explore the structures of the lectures as a succession of actions and thus, discern the role played by verbal organizational metadiscourse within such structures. The combination of these four analyses will allow me to answer the research questions posed in Section 4.2 and therefore obtain a broad overview of the use of organizational metadiscourse in lectures at all levels.

\subsubsection{The quantitative analysis}

Through the quantitative exploration of the data, I intended to answer RQ1. In particular, I described the use and distribution of organizational metadiscourse in the lectures and courses and I considered any similarities and differences across lecturing styles. Moreover, 
the quantitative analysis performed a practical function: by analyzing which are the most common types of metadiscourse and how these are organized in the lectures and in the courses, I narrowed down the scope of this thesis to focus on only those common metadiscursive occurrences.

The first step in the quantitative analysis was to conduct a manual examination of the transcriptions of the corpus to spot and classify all instances of organizational metadiscourse instances. This process was carried out in all 152 lectures and organizational metadiscourse was identified and classified following Ädel's (2010) taxonomy of metadiscourse (see Section 3.2.4). Although computer-based corpus analyses of organizational metadiscourse are possible -see for instance Hasselgård (2016)-, a manual analysis, albeit more time-consuming, provides a more specific and reliable identification of metadiscourse. Once all metadiscursive instances were identified and classified, I explored the results for relevant aspects and analyzed the distribution of organizational metadiscourse within the lectures and throughout the courses. The distribution of organizational metadiscourse was carried out by comparing the number of instances in each session throughout the course and by counting the average number of instances per minute to discern the ways in which metadiscourse is distributed within the classes. In this sense, I was interested in discerning where in the lectures and in the courses metadiscourse is present. In other words, this examination allowed me to zoom in on the relevant sections in the data where metadiscourse is representatively used. Finally, I compared the quantitative results across lecturing styles in order to account for relevant similarities and differences within each of the groups.

\subsubsection{The linguistic analysis}

The linguistic analysis was designed to answer RQ2. Through this analysis, I intend to explore the linguistic features that characterize the use of organizational metadiscourse in lectures. In particular, I discuss the specific choices of lexical items, grammatical structures, 
and stylistic resources, and how these are differently employed across lecturing styles. The identification of distinct recurrent lexical and grammatical patterns in the use of metadiscourse will shed some light on the description of the use of metadiscourse in lectures, and it will emphasize a variable that has not been considered before, i.e. lecturing styles.

At this point, it is important to remark that the study presented in this thesis is a multimodal one. In other words, I describe the use of organizational metadiscourse as a combination of modes performed by a lecturer. As a linguist, my natural tendency would be to focus on the linguistic aspects of the use of metadiscourse. In fact, Fortanet-Gómez and Crawford Camiciottoli (2015) state that most content is transmitted through the verbal mode in academic lectures. This is the main reason why I decided to start my analysis of metadiscourse by first looking at the verbal elements. However, hierarchies of modes cannot be assumed in multimodal analyses; that is to say, language (the verbal mode) is just one more item within a multimodal ensemble where modes are combined to convey meaning. Still and all, as I described in Section 3.4, some organizational functions generally attributed to metadiscourse can be performed non-verbally; for example, in Bernad-Mechó and Fortanet-Gómez (forthcoming), we describe how the use of silence together with a change in posture is used to indicate a change in topic. However, although the functions of metadiscourse seem to be found in non-verbal expressions, I consider metadiscourse as a linguistic item. Thus, in order for metadiscourse to occur, there has to be a verbal reflection on the use of language. These instances can-and do- occur together with a multiplicity of modes that can integrate, contradict, emphasize, etc. the original meaning in different degrees of importance. In this regard, non-verbal expressions carrying out metadiscursive functions cannot be considered metadiscourse, but can find an explanation in metapragmatics (see Section 3.3). 


\subsubsection{The analysis of the semiotic resources}

In the analysis of semiotic resources, I employed notions from MSS (Kress, 2000, 2010, Kress \& van Leeuwen, 1996, 2001) and MDA (O'Halloran, 2004a, 2007) to explore how metadiscourse is conveyed at all levels (see sections 2.2.1 and 2.2.2 resectively). In order to carry out the analysis, I turned to the multimodally annotated sub-corpus of six structuring segments (see Section 4.3.2). This analysis aims to answer RQ3; in particular, I intend to discern which specific semiotic choices are preferred by the lecturers following different lecturing styles, as well as the ways in which these semiotic resources interact with each other in multimodal ensembles to convey meaning and engage the audience.

The study of semiotic resources was conducted in two phases: a quantitative analysis of the use of semiotic resources and a study of the transitions between combinations of modes using the State Machine provided in the software (see Section 2.4.2 for a full description of MMA-Video); and an exploration of the co-occurrences of modes using the GUI in MMA-Video.

In the first part of the analysis, the State Machine was used to obtain quantitative data on the use of semiotic resources (see Figure 2.5 in Section 2.4.2 for a full explanation of how the State Machine works). Thus, by analyzing the different possible combinations of modes with the State Machine, quantitative data could be obtained for both individual uses of semiotic resources and the most common co-occurrences (multimodal ensembles).

In the second part of the analysis, I analyzed what particular combinations of modes are chosen when structuring the class (sections with a high concentration of organizational metadiscourse). For example, Figure 4.6 shows a snapshot of the modes co-occurring in a previewing instance. In this fragment, the lecturer is previewing some of the information that she is going to introduce in the lecture. She does so by verbally introducing the information [1], performing metaphoric, iconic and beat gestures [2] with both hands in the first two and a single hand for the beats [3], maintaining her gaze towards the audience [4] and her posture upright [5], slowing down the pace of the speech at the end of the 
utterance [6] and raising the intensity [7], moving from left to right in front of the audience [8] and performing an eyebrow raising for emphasis [9]. The use of MMA-Video's GUI allowed for the exploration and description of all modes occurring synchronously by means of the comparison of sequences in different stages of the clips.

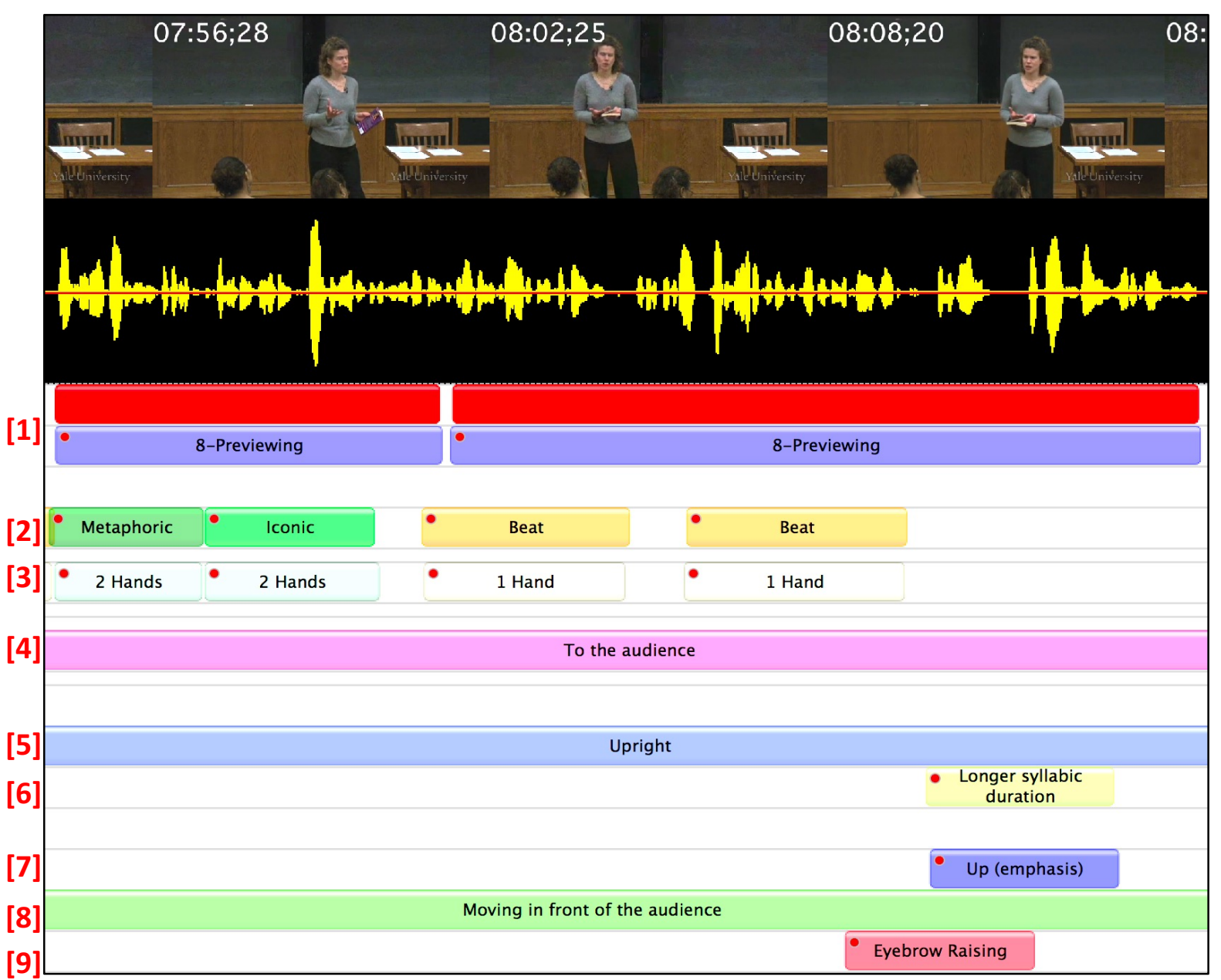

Figure 4.6 Analysis of multimodal ensembles using MMA-Video's General User Interface

All in all, the microanalysis of the semiotic resources using MMA-Video offers a comprehensive review on the use of organizational metadiscourse both from a quantitative and a qualitative perspective. To put it in other words, the analysis provides quantitative data that displays which modes and combinations of modes are more frequent and it allows for the comparison of specific fragments in the dataset. 


\subsubsection{The analysis of structure and the role of organizational metadiscourse}

The last analysis that I performed was formulated to answer RQ4. In this analysis, I intend to determine the extent of the contribution of organizational metadiscourse in the processes in which the lecturers make the structure of the lecture explicit. To do so, I made use of the theoretical and methodological notions proposed in MIA (Norris, 2004, 2011, 2016,2017 ) (see Section 2.2.3 for a full review of MIA). As in the linguistic analysis described in Section 4.4.2, the sub-corpus of six representative lectures was used for the analysis of the structure. This section was organized into two broad processes: the description of prototypical higher-level actions for each lecturing style, and the analysis of the roles played by organizational metadiscourse as part of the sequences of higher-level actions performed by the lecturers.

On the one hand, I looked at the prototypical structures of higher-level actions performed by the lecturers. This approach looks at the structure of lectures from a completely novel perspective. As I have mentioned on numerous occasions throughout this dissertation, all communication is multimodal. It seems then logical that I look at the structure of lectures beyond a linguistic perspective and adopting a holistic view. In this part of the study, I analyzed the sequences of higher-level actions performed whenever organizational metadiscourse was used throughout the six representative lectures of the corpus. This analysis was carried out manually in a series of steps following the methodology devised by Norris (2004): first, the video clips of the lectures, and in particular the sections where organizational metadiscourse occurs, were viewed multiple times. Second, the distinct higher-level actions co-occurring in the interaction were identified by carrying out a multimodal analysis that attaches the use of particular modes to specific actions. Simply put, semiotic resources can be identified as being used within given actions. For instance, if gaze is directed towards a set of notes, it can be attached to the action of handling notes. Similarly, if a lecturer is verbally developing the contents of the lecture while handling the notes, it may be concluded that the verbal mode is devoted to performing the action of developing content. Finally, an analysis of the modal density of each action was conducted, 
which permitted me to attach a degree of attention/awareness to each of the actions. By describing the higher-level actions performed by lecturers in metadiscursive instances, and in structuring segments in particular, a set of recurrent patterns could be established. Then, a prototypical higher-level action was described as a set of possible choices from which the lecturers may choose.

The analysis of the structures of higher-level actions was complemented by the second part of this study: an examination of the role of organizational metadiscourse. As I mentioned above, once the higher-level actions have been identified, a level of attention/awareness can be assigned to each of them judging from the modal density received by the action. Thus, actions can be performed in the foreground (high modal density), in the midground (medium modal density), or in the background (low modal density). Depending on the attention devoted to the higher-level actions where organizational metadiscourse is introduced, the role of metadiscourse may be interpreted.

In short, by conducting these analyses, I described the structures of higher-level actions in the different sections where organizational metadiscourse is used. Moreover, I described the role played by metadiscourse within the sets of actions and account for any features that are intrinsic to the lecturing styles of the lectures.

In this chapter, I have drawn on the theoretical underpinnings established in the previous chapters to design the methodology to be followed in the present study. I have reviewed the aims of the thesis and proposed four research questions to guide the study. Then, I have described the process of compilation and preparation of the corpus and its subcorpora, and finally, I have recounted the four analyses that will be conducted in this thesis. The subsequent chapters (chapters 5 to 8 ) are devoted to an account of the results of the study and their respective discussions. Chapter 5 entails the quantitative analysis of organizational metadiscourse. 



\section{CHAPTER 5. ANALYSIS: A QUANTITATIVE STUDY}

In the foregoing chapters I have contextualized the present thesis within the studies of spoken discourse analysis and academic genres, and in particular, as part the recent tradition in multimodal analyses. Moreover, I have sketched the most influential models of metadiscourse and some of the previous literature considering metadiscourse in spoken lectures and from a multimodal perspective. Besides, in Chapter 4 I have described both the main corpus and its sub-corpora, and the methodology employed for the present investigation. Finally, I have proposed a series of research questions. The following chapters (Chapters 5 to 8) discuss those research questions: Chapter 5 addresses RQ1 and is focused on the quantitative aspects in the use of organizational metadiscourse in academic lectures; Chapter 6, in turn, looks at RQ2 and illustrates the verbal and linguistic features present in metadiscourse; next, Chapter 7 is devoted to the exploration of RQ3 and zooms in on how metadiscourse is expressed through a multiplicity of modes; and finally, Chapter 8 provides an answer to RQ4 and investigates the structure of lectures as sequences of actions and the role of metadiscourse within these sequences. In all chapters, moreover, a special focus is placed on how metadiscourse is used differently across lecturing styles.

Thus, in the present chapter, I aim to discuss RQ1 and its sub-questions:

\begin{tabular}{|l|l|}
\hline RQ 1 & $\begin{array}{l}\text { How is organizational metadiscourse used quantitatively in academic } \\
\text { lectures? }\end{array}$ \\
\hline RQ 1.1 & What are the most common types of organizational metadiscourse in academic lectures? \\
\hline RQ 1.2 & $\begin{array}{l}\text { Where within the lectures and throughout the course does organizational metadiscourse } \\
\text { occur? }\end{array}$ \\
\hline RQ 1.3 & $\begin{array}{l}\text { Are there any similarities or differences in the quantitative use of organizational } \\
\text { metadiscourse across lecturing styles? }\end{array}$ \\
\hline
\end{tabular}

In order to answer these questions, I make use of the main corpus of 152 lectures. Specifically, I examine the quantitative use of the most common types of organizational metadiscourse for each of the courses analyzed, I explore the distribution of metadiscourse throughout the courses and within the lectures, and I compare the results across lecturing styles. 
In short, I set out to investigate how organizational metadiscourse is used from a quantitative perspective. A quantitative exploration of the data will allow a limitation of the scope of the study, as it will provide further information about which types of metadiscourse are commonly encountered and which ones seem to be less relevant in terms of quantity. This analysis will also determine which sections within the lectures show a higher presence of metadiscourse. Multimodal analyses are laborious tasks where finegrained explorations of the data are needed; by specifying the recurrent uses of metadiscourse I will be able to focus the analysis on representative instances.

In the following lines, I introduce five broad sections that structure the quantitative analysis of the corpus. In the first section in the chapter, Section 5.1, I reflect on the use of Ädel's (2010) taxonomy of metadiscourse for the present thesis and some of the issues that I have encountered. This sets the path for Section 5.2, in which I answer RQ 1.1. In particular, I conduct a first approach to the total number of metadiscursive instances found in the dataset and I review the concept of endophoric marking and its role in the lectures. Moreover, I review the uses of previewing, reviewing, introducing topic and contextualizing metadiscourse throughout the disciplines studied in this thesis. Then, in Section 5.3, I focus on RQ 1.2 and I move on to explore where organizational metadiscourse occurs within the lectures and within the whole set of the course. The following section, Section 5.4 answers RQ 1.3 by providing a further analysis of the data presenting significant similarities and differences in the use of organizational metadiscourse across lecturing styles. Finally, in Section 5.5, I briefly summarize the results of the present quantitative analysis.

\subsection{Identifying and classifying metadiscourse}

In this section, I briefly consider two methodological aspects that arose during the identification process of metadiscursive instances in the corpus. Specifically, I comment on two issues that need to be considered when classifying metadiscourse. First, I reflect on what can be considered metadiscourse and what cannot in Section 5.1.1. Then, in Section 
5.1.2, I discuss the concept of double functionality of metadiscourse, that is to say, the fact that a metadiscursive instance may be encompassed as performing more than one metadiscursive function. Ultimately, this section aims to make an argument in favor of manual analyses of metadiscourse over computerized ones.

\subsubsection{Issues in the identification of metadiscourse: what is and what is not metadiscourse}

As mentioned in the methodology section, the first step in the analysis is the application of Ädel's (2010) taxonomy of metadiscourse in academic English in order to manually classify all snippets of organizational metadiscourse along the dataset (see Section 3.2.4). Examples 2 to 11 show metadiscursive instances extracted from the corpus which are illustrative of the functions established in Ädel (2010).

2) Introducing Topic: Today I plan on discussing some critical aspects of the Montgomery bus boycott and the integration of Central High School in Little Rock (C1_L14)

3) Delimiting Topic: I'm going to talk about colonial attempts before the $1760 \mathrm{~s}$ [...] and there were only three of them that I'm going to talk about (C2_L4)

4) Adding to Topic: And I should add here [...] sometimes I know I'm saying Federal Convention and sometimes I'm saying Constitutional Convention, and they're two ways of referring to the same thing (C2_L23)

5) Concluding Topic: So before I just leave the subject of immortality, let me conclude with some words of wisdom from a former Miss USA contestant (C3_L20)

6) Marking Asides: I just want to stop there for a minute. Haze sees the car [...] (C4_L3)

7) Enumerating: [...] and I want to concentrate on three aspects in particular. The first part would be [...] The second, and much more dramatic story, is the impact [...] The third task for the morning is to come [...] (C5_L7)

8) Endophoric Marking: Now actually, if you look up on the website [...] the University of Oklahoma Law School is named for Ada Sipuel now (C1_L13) 
9) Previewing: So much, for the time being, for the episode of Montesinos' cave, to which we will probably have to allude a number of times in succeeding lectures (C6_L17)

10) Reviewing: Last time, I distinguished between two ways in which thinking about the facts about the nature of death could influence our behavior (C3_L22)

11) Contextualizing: Now, on Wednesday, in the very short time I will have, I'll talk about [...] (C4_L15)

Once the data were collected, a manual examination was conducted on the main corpus (152 lectures) in order to identify metadiscursive instances. A manual examination of the dataset becomes essential in order to obtain accurate accounts of the use of metadiscourse. Every instance is identified after a process of reflection upon the function of the metadiscursive fragment in the lecture. In this process, it is particularly important to separate metadiscourse from intertextual expressions. As discussed in Section 3.2.4, Ädel (2006) identifies metadiscourse as being explicit and self-reflexive. Furthermore, metadiscourse needs to refer to the current text, and references to other texts would fall into the realm of intertextuality. This dichotomy is illustrated in examples 12 and 13 below.

12) It says in Webster's - Remember what I said about language and dialect? A language is a dialect with an army [...] (C6_L2)

13) [...] the business about Queen Madasima and the surgeon having an affair - remember that psychotic version that he had in his mind about the deflowering of Luscinda. (C6_L8)

Both instances seem to refer to a previous situation; however, example 12 comments on something the lecturer said about languages and dialects during the lecture while example 13 alludes to a passage within Don Quixote that the students are expected to have read. Thus, Example 12 constitutes a reviewing metadiscursive fragment, while, on the other hand, Example 13 is an instance of intertextuality and is not classified as metadiscourse. Therefore, a close manual examination of the context seems necessary in order to discern the instances that can be included in the data. 


\subsubsection{Issues in the identification of metadiscourse: overlapping categories - double functionality of metadiscourse}

One further advantage of a manual examination of the dataset is that it has led to the identification of what I referred to in Chapter 3 as double functionality of metadiscourse. In other words, there might be a certain overlap in categories when classifying metadiscourse and consequently, a metadiscursive fragment might a priori be considered as performing more than one function. This overlap in categories is also identified by Hasselgård (2016), who claims that Ädel's (2010) framework offers some degree of overlapping, especially between the categories previewing and reviewing on the one hand, and endophoric marking on the other. In the data here analyzed, I have found further instances of overlapping between introducing topic and previewing categories. Examples 14 and 15 are prototypical examples which show this type of overlapping.

14) This morning we'll take up one of the themes [...] and one of those is the development of various public health strategies (C5_L11)

15) This morning I want to talk about a fourth approach to public health, and this was what's called commonly the sanitary movement (C5_L11)

Example 14 takes place right at the beginning of the class. If taken into account in isolation, this example could be classified as either an introducing topic or a previewing fragment. However, some moments later in the class, the lecturer produces the utterance in Example 15. Here, the lecturer properly introduces the topic that is being dealt with, i.e. the sanitary movement. Therefore, a final decision is made on these two excerpts and Example 14 is classified as performing a previewing function while Example 15 shows an introducing topic function. In a sense, and when looking at these fragments in a decontextualized manner, miscategorizations could occur. This reinforces the argument, as stated above, that a manual examination of metadiscursive fragments in their context is advisable in order to obtain accurate results.

All things considered, it can be argued that although Ädel's taxonomy establishes straightforward descriptions of metadiscursive categories in academic settings, boundaries 
between functions are not always clear-cut. The overlapping cases found in the dataset for this study confirm Hasselgård's (2016) claim. Nevertheless, further examinations of Ädel's taxonomy might provide a more specific division of metadiscursive functions with less blurry boundaries. In this sense, a subdivision of categories previewing and reviewing is provided under sections 5.2.3.1 and 5.2.3.2 below. These subordinated categories provide a further level of specification to a detailed analysis of phorics.

\subsection{Quantitative use of organizational metadiscourse across disciplines}

In this section, I present an account of the results of the classification of organizational metadiscursive fragments found along the six courses analyzed. This section aims to discuss RQ 1.1:

\begin{tabular}{l|l} 
RQ 1.1 & What are the most common types of organizational metadiscourse in academic lectures?
\end{tabular}

To answer this question, I first look at the data as a whole in Section 5.2.1. Then, I review the category of endophoric marking and the role it plays in the dataset in Section 5.2.2. Lastly, in Section 5.2.3, I analyze the uses of previewing, reviewing, introducing topic and contextualizing as the most common types of organizational metadiscourse.

\subsubsection{Overall use of organizational metadiscourse}

Although efforts were made in order to obtain a homogeneous comparable corpus, the length of the lectures vary slightly from one lecturer to another and proportionate figures are needed in order to accurately contrast data. Therefore, tables in this chapter show both the total number of metadiscursive instances found in a specific category $(\mathrm{N})$ as well as normalized frequencies per 10,000 words $(/ 10,000 \mathrm{w})$. Additionally, it is worth remembering that following Dudley-Evans (1994), courses 1 (African-American History) 
and 2 (The American Revolution) have been classified as conversational style, as lecturers in these courses make a fair use of class notes without reading through them and with a certain focus on the audience; courses 3 (Philosophy: Death) and 4 (The American Novel) are taught by rhetorical style lecturers who rarely employ notes in their lectures; and courses 5 (History of Epidemics) and 6 (Spanish Literature: Don Quixote) are encompassed within a reading style tradition where lecturers read through their notes for most of the time. Hereafter, and for practical reasons, I will refer to these courses as C1, C2, C3, C4, C5, and $\mathrm{C6}$.

Table 5.1 shows the number of organizational metadiscursive fragments found in each of the courses and for each of the types of metadiscourse in Ädel's (2010) taxonomy. After the first inspection of these results, it can be concluded that the most common types of organizational metadiscourse at a general level, i.e. when looking at the aggregate, are reviewing (16.5 instances every 10,000 words), previewing (14.5 instances) and endophoric marking (12.6). Moreover, the categories of introducing topic (5.7) and contextualizing (3.9) also seem to receive a certain degree of importance in academic lectures. Finally, delimiting topic (2), enumerating (1), marking asides (0.7), adding to topic (0.6) and concluding topic (0.5) are inconsequential with rare occurrences within the whole use of organizational metadiscourse. This demonstrates that the use of phorics, i.e. how lecturers establish connections among various parts of the discourse, is paramount in academic lectures. Nevertheless, the general trend of the most common types of metadiscourse extracted from the aggregate is not representative a priori of each of the courses. Thus, for example, the category of previewing (14.5 instances in the aggregate) is more present in C2 (21.7 instances per 10,000 words) and C5 (17.3 instances). Similarly, reviewing (16.5 instances in the aggregate) seems to be even more important in C6 (23.1 instances per 10,000 words). In the same way, the category contextualizing (3.9) plays a more important position in conversational style lecturers: C1 shows 5.5 instances and C2 7.6, in contrast to the total aggregate of 3.9. Still and all, the most salient differences in the use of organizational metadiscourse are found in the use of endophoric markers, which I discuss in the following section. 


\begin{tabular}{|c|c|c|c|c|c|c|c|c|c|c|c|}
\hline 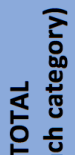 & $\begin{array}{l}3 \\
0 \\
0 \\
0 \\
0\end{array}$ & $\hat{i n}$ & $N$ & : & นُ & $\hat{o}$ & $\Rightarrow$ & 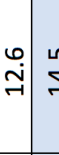 & 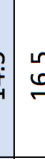 & $\stackrel{9}{m}$ & $\stackrel{\infty}{n}$ \\
\hline$\stackrel{\Xi}{\stackrel{\Xi}{ \pm}}$ & $z$ & : & 号 & 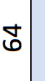 & นิก & $\stackrel{m}{\sim}$ & مَ| & 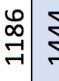 & 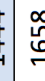 & ৪্ & $\hat{\tilde{n}}$ \\
\hline \multirow[t]{2}{*}{8} & $\begin{array}{l}3 \\
0 \\
0 \\
0 \\
1\end{array}$ & in & $\overrightarrow{\mathrm{i}}$ & ¿ & 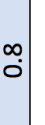 & ¿̊. & ؛ُ & $\begin{array}{l}m \\
\stackrel{m}{a}\end{array}$ & $\approx$ & i & 䓟 \\
\hline & $z$ & ณ & จ & $\wedge$ & $\vec{~}$ & $\wedge$ & a & 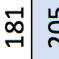 & $\vec{s}$ & ని & 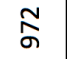 \\
\hline \multirow[t]{2}{*}{ ชิ } & $\begin{array}{l}3 \\
0 \\
0 \\
0 \\
0\end{array}$ & $\begin{array}{l}\infty \\
\dot{\varphi} \\
\dot{0}\end{array}$ & $\stackrel{n}{\rightarrow}$ & 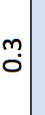 & นุ. & 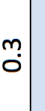 & $\begin{array}{l}\overbrace{-} \\
\sim\end{array}$ & $\begin{array}{c}m \\
\stackrel{9}{\mathrm{~g}}\end{array}$ & & $\stackrel{\circ}{i}$ & $\begin{array}{l}0 \\
\dot{G}\end{array}$ \\
\hline & $z$ & m & $\vec{N}$ & $\nabla$ & $\wedge$ & $\nabla$ & $\approx$ & 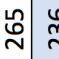 & $\stackrel{\wp}{\circ}$ & $\stackrel{n}{m}$ & $\begin{array}{c}\infty \\
\infty \\
\infty\end{array}$ \\
\hline \multirow[t]{2}{*}{ S } & $\begin{array}{l}3 \\
\text { ò } \\
0 \\
0\end{array}$ & นُ & $\stackrel{\searrow}{\mathrm{i}}$ & : & :- & $\hat{o}$ & $\Rightarrow$ & \begin{tabular}{c}
$\infty$ \\
$\substack{\infty \\
\hdashline}$ \\
\end{tabular} & & $\stackrel{0}{m}$ & $\stackrel{t}{\overleftarrow{6}}$ \\
\hline & $z$ & 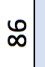 & $\hat{m}$ & 익 & N & $\Rightarrow$ & $\stackrel{0}{\circ}$ & ְ̊f & $\%$ & in & $\begin{array}{l}\vec{b} \\
\stackrel{-}{-}\end{array}$ \\
\hline \multirow[t]{2}{*}{3} & $\begin{array}{l}3 \\
0 \\
0 \\
0 \\
1\end{array}$ & $\stackrel{\leftrightarrow}{\dot{m}}$ & 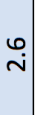 & ¿. & ১. & : & $\vec{i}$ & هి & $\begin{array}{l}c \\
\mathfrak{c}\end{array}$ & $\stackrel{\circ}{i}$ & 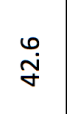 \\
\hline & $z$ & 8 & $\mathscr{f}$ & $\wedge$ & $\wedge$ & 이 & ค & in & $\stackrel{5}{5}$ & $\mathscr{q}$ & $\stackrel{\text { そq }}{\sim}$ \\
\hline \multirow[t]{2}{*}{$\widetilde{\tau}$} & $\begin{array}{l}3 \\
0 \\
0 \\
0 \\
1\end{array}$ & $\hat{\text { iे }}$ & $\underset{\mathrm{i}}{\mathrm{m}}$ & ๑) & $\begin{array}{l}0 \\
\circ\end{array}$ & \begin{tabular}{ll}
\multirow{r}{*}{} &
\end{tabular} & $\underset{i}{\stackrel{m}{i}}$ & 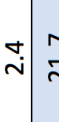 & & $\stackrel{\circ}{\sim}$ & $\begin{array}{l}\text { స̃ } \\
\text { - }\end{array}$ \\
\hline & $z$ & 吕 & $\stackrel{n}{*}$ & $\hat{~}$ & $\approx$ & $\approx$ & $\stackrel{\tilde{N}}{*}$ & $\mathscr{f}$ & & $\stackrel{\text { q }}{\sim}$ & 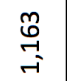 \\
\hline \multirow[t]{3}{*}{ J } & 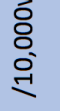 & 宓 & $\stackrel{\leftrightarrow}{\mathrm{N}}$ & \begin{tabular}{c}
\multirow{7}{*}{} \\
-
\end{tabular} & 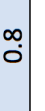 & 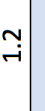 & í. & $\approx=$ & & นn & $\stackrel{7}{n}$ \\
\hline & $z$ & :े & 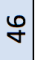 & ๑ & $m$ & శ. & $\Rightarrow$ & ఫొ & $\stackrel{4}{\overbrace{}}$ & $\infty$ & जे \\
\hline & & 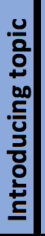 & 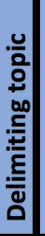 & 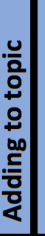 & 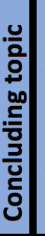 & 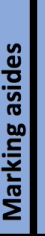 & 总 & 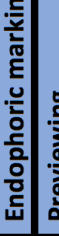 & & 昱 & 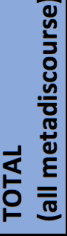 \\
\hline
\end{tabular}




\subsubsection{The case of endophoric marking - A lecturer-dependent category}

The use of endophoric markers is abnormally distinct throughout the courses in the dataset with occurrences ranging from 2.4 instances per 10,000 words in C2 to 28.8 in C4. Ädel (2010) defines the category of endophoric markers as being

used to point to a specific location in the discourse; it refers to cases in which it is not clear or relevant whether what is referred to occurs before or after the current point [...], as for example when the audience is instructed to look at a table, or turn to a specific point in a handout (Ädel, 2010, p. 86).

The identification of endophoric markers in written texts appears to offer clear-cut distinctions (for instance in if we look at Figure 8 or as we can see in example 8). As Ädel points out, endophoric markers refer to parts of the discourse where a logic of previewing or reviewing information does not apply. Thus, endophoric marking instances include references to tables, figures, etc. The use of this metadiscursive category in spoken lectures, however, seems to be more complex and questions as to what can be considered an endophoric marker and what cannot arise. In the identification process during the manual examination conducted for this study, a degree of reflexivity upon the use of language was sought in order to discern metadiscursive instances from the rest of the text. In the case of endophoric markers, explicit mentions to slides, handouts or even books were considered as long as the lecturer would distinctly indicate such a reference (see Example 16).

16) There is a more complicated version that I just want to show you on 96,97 (referring to page numbers). (C4_L15)

The number of endophoric markers that can be found in a given course shows signs of being related to the use of external materials by the lecturers. A course where the lecturer constantly refers to slides or handouts, for example, would be likely to include more endophoric markers than a course where those references do not occur very often. In the dataset here analyzed, the use of endophoric markers does not seem to depend on disciplines or lecturing styles and varies from lecturer to lecturer. 
On the one hand, when examining this category in similar disciplines no relation is encountered. By way of illustration, within the field of History, the lecturer in C2 makes little use of endophoric markers (only 2.4 instances per 10,000 words) whereas the lecturer in C5 offers many more references (19.3) being the most common type of organizational metadiscourse in this course. Comparably, in Literature, while the lecturer in C4 makes an elevated use of endophoric markers (28.8 instances per 10,000, which represents more than twice the amount of the second most common type of organizational metadiscourse in this course), the lecturer in C6 uses considerably fewer markers (10.3). Alternatively, these cases are explained as the lecturer in $\mathrm{C} 5$ makes use of a great number of slides (as opposed to the lecturer in $\mathrm{C} 3$ ), and the lecturer in $\mathrm{C} 4$ provides numerous references to other texts (as opposed to the lecturer in C6).

On the other hand, when considering lecturing styles, the use of endophoric markers also appears to be unrelated: C3 and C4, for example, are both taught by rhetorical style lecturers but make very different uses of endophoric markers (2.9/10,000w and 28.8/10,000w respectively).

All in all, the use of endophoric markers appears to be lecturer-specific and no evident connection is established with either disciplines or lecturing styles. In contrast, as described in Section 3.2.4, the presence of this type of metadiscourse in lectures is associated with the use of external sources and materials during lecturing. In order to obtain a more genuine comparison of the use of organizational metadiscourse across lecturing styles, I have decided to omit this category for the purposes of this study. Being lecturer specific, endophoric markers do not show any information about the use of metadiscourse in different lecturing styles, and moreover, they distort the total results in the use of organizational metadiscourse. 


\subsubsection{Comparing uses of organizational metadiscourse without endophoric markers}

If endophoric markers are not considered, then, the most common types of organizational metadiscourse are previewing and reviewing. In this section, I investigate how these metadiscursive elements are used from two perspectives: by exploring the quantitative results across disciplines, and in terms of percentage, where I describe the importance of these types of metadiscourse when compared to the rest of organizational metadiscourse in each of the courses. Thus, I first focus on the quantitative uses of previewers and reviewers in sections 5.2.3.1 and 5.2.3.2; and then, I look into the percentages of these types of metadiscourse within the overall use of metadiscourse in Section 5.2.3.3. Finally, in sections 5.2.3.4 and 5.2.3.5, I briefly turn my attention to the categories introducing topic and contextualizing respectively. Although in a lower frequency, introducing topic and contextualizing also seem to be recurrently employed by most lecturers.

\subsubsection{Use of previewers}

In general terms, and considering normalized figures, the use of previewing is rather homogeneous in most courses. Thus, C1, C3, C4 and C6 show very little variations in the number of previewers utilized ranging from 11.5 to 12.5 instances per 10,000 words (see Table 5.2). C2 and C5, on the other hand, show a more elevated frequency (21.7 and 17.3 occurrences per 10,000 words respectively). This difference in C2 and C5 seems to be motivated by the presence of longer introductions to the lectures in which the lecturers provide a thorough outline of the lecture, which contains an ample number of previewing fragment, thus increasing the total number of previewing occurrences. 


\begin{tabular}{|c|c|c|c|c|c|c|c|c|c|c|c|c|}
\hline & \multicolumn{2}{|r|}{ C1 } & \multicolumn{2}{|r|}{ C2 } & \multicolumn{2}{|r|}{ C3 } & \multicolumn{2}{|r|}{ C4 } & \multicolumn{2}{|r|}{ C5 } & \multicolumn{2}{|r|}{ C6 } \\
\hline & $\mathrm{N}$ & $/ 10,000 \mathrm{w}$ & $\mathrm{N}$ & $/ 10,000 \mathrm{w}$ & $\mathrm{N}$ & $/ 10,000 \mathrm{w}$ & $\mathrm{N}$ & $/ 10,000 \mathrm{w}$ & $\mathrm{N}$ & $/ 10,000 w$ & $\mathrm{~N}$ & $/ 10,000 \mathrm{w}$ \\
\hline Previewing & 192 & 12 & 413 & 21.7 & 201 & 11.5 & 197 & 12.5 & 236 & 17.3 & 205 & 11.7 \\
\hline
\end{tabular}

Table 5.2 Instances of previewing metadiscourse across disciplines (raw and normalized frequencies)

Lecturers seem to use previewers with two broad functions: in order to introduce material that is going to be brought up within the lecture in question (Example 17), and in order to present information that will be dealt with in future lectures (Example 18). Moreover, previewers may also be employed to refer to moments in the future where the time reference is not clear-cut (Example 19). In other words, previewers are used to establish connections with either the same lecture or with a future one, and either specifying a moment in time where such connection occurs or not.

17) I will announce at the end of the class which book it will be. (C4_L16)

18) So that's what I want to talk about next time, which is the movement from the era of consumption to the era of tuberculosis (C5_L18)

19) But in 2003 major difficulties overtook the campaign - and we'll come back to those - and now the campaign is a decade behind schedule [...] (C5_L24)

Taking these distinct uses of previewing into account, I suggest a distinction of three main types of previewers for academic lectures: present lecture previewers, future lecture previewers, and non-connected previewers.

On the one hand, present lecture previewers may be used to provide an outline of the lecture or to introduce future parts of the lecture, i.e. the lecturer connects the present content with a moment that will occur in the near future within the same lecture. By using present lecture previewers, lecturers provide guidance and make the development and organization of the class explicit for the students. Future lecture previewers, on the other hand, are used to connect the present lecture with future lectures in the course. A higher presence of this type of previewers may be expected in the last part of the lectures where the lecturer connects the present class with the following one. These previewers are used to foster cohesion throughout the course. Finally, the last type of previewers, i.e. nonconnected previewers, are used to introduce information that has not been disclosed yet, 
and for which it is not specified where this information will be included in the set of the course. Referents are not specified in non-connected previewers probably as they are unimportant or not relevant for the correct comprehension of the contents. Table 5.3 below shows normalized frequencies of these types of previewing instances -with references to present lecture, future lecture or no specified references- utilized by the lecturers in the dataset.

\begin{tabular}{|l|c|c|c|c|c|c|}
\cline { 2 - 8 } \multicolumn{1}{c|}{} & C1 & C2 & C3 & C4 & C5 & C6 \\
\cline { 2 - 8 } & $/ 10,000 \mathrm{~W}$ & $/ 10,000 \mathrm{~W}$ & $/ 10,000 \mathrm{~W}$ & $/ 10,000 \mathrm{w}$ & $/ 10,000 \mathrm{~W}$ & $/ 10,000 \mathrm{~W}$ \\
\hline Present lecture & 3.5 & 11.1 & 5.5 & 6.4 & 6.7 & 2.3 \\
\hline Future lecture & 6.6 & 5.9 & 2.9 & 3.2 & 6.7 & 3.1 \\
\hline Non-connected & 1.9 & 4.7 & 3.1 & 2.9 & 3.9 & 6.3 \\
\hline
\end{tabular}

Table 5.3 Average types of previewing occurrences

When looking at the types of previewers, some similarities arise in general terms for C3 and C4 (rhetorical style lecturers). Furthermore, the use of future lecture previewers is also similar for C1 and C2 (conversational style lecturers). No significant differences are observed in the dataset except for the elevated number of references to the present lecture in C2. As I mentioned before, this can be explained as the lecturer in this course performs longer introductions to the lecture in which the contents that are about to be dealt with are outlined (see Example 20, found at the beginning of lecture C2_L11, as a representative example of this type of previewer).

20) And part of what we're going to be looking at today in this lecture is that obviously this Declaration was more than just a piece of paper produced by a bunch of guys in one room [...] (C2_L11)

Finally, another interesting piece of data in Table 5.3 is the slightly higher number of future lecture previewers in History courses $(\mathrm{C} 1, \mathrm{C} 2$, and $\mathrm{C} 5)$. Thus, History disciplines in the dataset seem to provide more connections between present and future lectures when compared to the rest of fields of study. This might be due to the nature of the discipline, where events are traditionally accounted in a linear fashion and, therefore, references to future events in such line can be expected. 


\subsubsection{Use of reviewers}

A second relevant category in the organization of lectures is reviewers. The use of reviewers is very similar in courses C1 to C5 with recorded instances ranging from 14.1 to 18.4 (see Table 5.4) and with the exception of C6, where the use of reviewers is slightly higher (23.1 instances per 10,000 words). The case of C6 may be explained in terms of style, i.e. as an individual trait of the speaker. In this sense, lecturer in C6 may occasionally interrupt the main reading flow in his lectures in order to make spontaneous comments. During these spontaneous sections, the lecturer frequently contextualizes the present account of events with previous information developed earlier in the lecture or in the course. Furthermore, the fact that C6 only deals with one topic (that of Cervantes's Don Quixote) may also contribute to the presence of more reviewers as connections with previous parts of the discussion on the novel can be established recurrently throughout the course.

\begin{tabular}{|c|c|c|c|c|c|c|c|c|c|c|c|c|}
\hline & \multicolumn{2}{|r|}{ C1 } & \multicolumn{2}{|r|}{ C2 } & \multicolumn{2}{|r|}{ C3 } & \multicolumn{2}{|r|}{ C4 } & \multicolumn{2}{|r|}{ C5 } & \multicolumn{2}{|r|}{ C6 } \\
\hline & N & $/ 10,000 \mathrm{w}$ & $\mathrm{N}$ & $/ 10,000 \mathrm{w}$ & $\mathrm{N}$ & $/ 10,000 \mathrm{w}$ & $\mathrm{N}$ & $/ 10,000 \mathrm{w}$ & N & $/ 10,000 \mathrm{w}$ & $\mathrm{N}$ & $/ 10,000 \mathrm{w}$ \\
\hline Reviewing & 225 & 14.1 & 350 & 18.4 & 290 & 16.6 & 192 & 12.2 & 196 & 14.3 & 405 & 23.1 \\
\hline
\end{tabular}

Table 5.4 Instances of reviewing metadiscourse across disciplines

As with previewers, a three-leveled distinction can be established for reviewers. They can refer to the present lecture or to lectures in the past, and these references, in turn, can be explicit or not. Examples 21, 22 and 23 show instances of references to the present lecture, past lecture and a moment in past which is not specified respectively.

21) And with the body view, when I started arguing a few moments ago that the best version of the body view was the brain view [...] (C3_L11)

22) And as you'll recall from my lecture on Monday as I was wrapping it up, weeks before the Democratic National Convention convenes [...] (C1_L17)

23) But, as I said, the war effort complicated his task, and he turned to people who'd retired (C5_L20)

In general terms, present lecture reviewers are used to recapitulate the information that has been dealt with during a given lecture. When used with this function, they are 
commonly present at the end of the lecture and serve as concluding remarks. Additionally, they can also be used to connect one topic with the next one. In this case, they are found all throughout the lecture. Secondly, past lecture reviewers connect the present class with previous moments throughout the course and contribute to the cohesion of the course. Like present lecture reviewers, past lecture reviewers are used with a variety of functions: they can be used to connect the present lecture with the immediately previous one, or to connect the present lecture with other previous moments throughout the course. Thus, past lecture reviewers are common at the beginning of some lectures, as the lecturer connects the last part of the previous lecture with the present one; and also at any point during the lecture when there is a connection with introduced information along the course. Finally, non-connected reviewers are found anywhere in the lectures and connect new information with introduced information where the specification of the referent is not clear or not needed in the context of speech. Table 5.5 below shows normalized figures of the distribution of these three types of reviewers across the different disciplines.

\begin{tabular}{|l|c|c|c|c|c|c|}
\cline { 2 - 7 } \multicolumn{1}{c|}{} & C1 & C2 & C3 & C4 & C5 & C6 \\
\cline { 2 - 7 } & $/ 10,000 \mathrm{w}$ & $/ 10,000 \mathrm{w}$ & $/ 10,000 \mathrm{~W}$ & $/ 10,000 \mathrm{w}$ & $/ 10,000 \mathrm{w}$ & $/ 10,000 \mathrm{~W}$ \\
\hline Present lecture & 2.3 & 2.8 & 2.7 & 1.3 & 0.6 & 0.9 \\
\hline Past lecture & 5.9 & 9 & 4.8 & 5 & 1.7 & 4.5 \\
\hline Non-connected & 5.7 & 6 & 9 & 5.9 & 12 & 17.7 \\
\hline
\end{tabular}

Table 5.5 Average types of reviewing occurrences

In general terms, some similarities may be found in the use of reviewers. Present lecture reviewers, for example, are generally low, indicating that summaries or reflections upon the present lecture are infrequent. This is particularly relevant in C5 and C6 (reading style lecturers) where this type of reviewers is almost non-existent. In the use of past lecture reviewers, an element stands out in Table 5.5: a higher presence of these reviewers in C2, probably as a result of the long introductions to the lectures performed by this lecturer, who contextualizes the contents of the present lecture by also referring to previous sessions. Finally, some similarities are found within non-connected reviewers, especially in conversational style lecturers ( $\mathrm{C} 1$ and $\mathrm{C} 2$ ) and in reading style lecturers ( $\mathrm{C} 5$ and $\mathrm{C} 6$ ). In the case of the latter, this type of reviewers is quite common. This seems to be a feature of the lecturing style of the lecturers, i.e. a reading style. I explained above how the lecturer in C6 
would use reviewers mainly as appositions where the natural flow of reading sections is interrupted by spontaneous comments. As I demonstrate in Chapter 8, a further MIA approach on reading style lecturers will suggest the importance of reading sections over commentary in these courses. Given the fact that a considerable number of non-connected reviewers in $\mathrm{C} 5$ and $\mathrm{C} 6$ occur during apposition fragments, i.e. spontaneous commentaries on the contents being read, I argue that the structure of the lectures and the course is not obvious for the lecturers. Therefore, even though these lecturers are able to create connections with previously dealt material, the reference as to when that material was dealt with is not clear-cut, and is, consequently, omitted. In other words, the focus of these lecturers when using reviewers is on the information that is being reviewed rather than the moment in time when the information was reviewed.

\subsubsection{Previewers and reviewers in percentages}

Further insight into the use of these categories is achieved when exploring the percentage of previewers and reviewers in comparison with the total aggregate of organizational metadiscourse in each of the disciplines. Table 5.6 below shows the percentage of usage of each category over the total use of organizational metadiscourse within each course. The category of endophoric markers, as explained above, has been removed in order to obtain more realistic results.

\begin{tabular}{|l|c|c|c|c|c|c|}
\cline { 2 - 7 } & \multicolumn{1}{c|}{ C1 } & C2 & C3 & C4 & C5 & C6 \\
\cline { 2 - 8 } & $\%$ & $\%$ & $\%$ & $\%$ & $\%$ & $\%$ \\
\hline Introducing topic & 15.1 & 9.7 & 9.9 & 14.1 & 15 & 12 \\
\hline Delimiting topic & 6.4 & 2.2 & 6.7 & 6.2 & 3.4 & 2.5 \\
\hline Adding to topic & 2.6 & 1.5 & 1 & 1.6 & 0.6 & 0.9 \\
\hline Concluding topic & 1.8 & 1.1 & 1.1 & 0.3 & 1.2 & 1.8 \\
\hline Marking asides & 2.6 & 2 & 1.4 & 1.8 & 0.6 & 0.9 \\
\hline Enumerating & 1.5 & 2.2 & 2.7 & 2.6 & 3.6 & 1.1 \\
\hline Previewing & $\mathbf{2 6 . 6}$ & $\mathbf{3 7}$ & $\mathbf{2 8 . 9}$ & $\mathbf{3 2 . 4}$ & $\mathbf{3 8 . 2}$ & $\mathbf{2 5 . 9}$ \\
\hline Reviewing & $\mathbf{3 1 . 2}$ & $\mathbf{3 1 . 3}$ & $\mathbf{4 1 . 7}$ & $\mathbf{3 1 . 6}$ & $\mathbf{3 1 . 7}$ & $\mathbf{5 1 . 2}$ \\
\hline Contextualizing & 12.2 & 13 & 6.6 & 9.4 & 5.7 & 3.7 \\
\hline TOTAL & 100 & 100 & 100 & 100 & 100 & 100 \\
\hline
\end{tabular}

Table 5.6 Percentage in the use of metadiscourse over total use (excluding endophoric marking) 
The percentages of the presence of these categories over the total use of organizational metadiscourse are, generally, quite homogeneous across the dataset. In this regard, very similar results are found in the use of reviewers in C1 and C2 (conversational style lecturers) and in the use of previewers in C3 and C4 (rhetorical style lecturers). Moreover, slight stylistic differences may be found, for example, in the higher percentage of previewers in C2 and C5. As I discussed in Section 5.2.3.1, the lecturers in these courses perform long introductory sections to their lectures and therefore make use of numerous previewing instances when outlining the contents of the class.

However, an interesting fact is encountered in the data: C3 and C6 distinctly favor the use of reviewers over previewers. These differences can be explained differently for each of the cases: by looking at the structure of $\mathrm{C} 3$, which is rather irregular and seems to determine the need for extra connections; and in terms of the nature of $C 6$, which only deals with one broad topic all throughout the course. In the case of $\mathrm{C} 3$, the higher presence of reviewers can be explained by looking at the structure followed by the lecturer through the course (see Appendix A for the transcriptions of the six courses here analyzed). The philosophical questions discussed in C3 may be distributed through more than one lecture (extending from 1 up to 5 sessions). Logically, when a topic is extended through more than one lecture, reviewing sections need to be present in order to contextualize the class within the right topic. In the case of $\mathrm{C} 6$, this course presents almost twice as many reviewers as previewers (51.2\% and $25.9 \%$ respectively). The explanation for this imbalance seems to lie in the nature of the course itself. Given that this course is centered on the study of only one novel, connections to previously introduced materials across lectures are more frequent all throughout the course.

All in all, the exploration of the percentages of use of previewing and reviewing over the total use of organizational metadiscourse provides an insight into the importance that these categories are given. Although no clear-cut distinctions are observed (either across disciplines or across lecturing styles), the study of percentages allows for the identification of individual traits in the use of metadiscourse. 


\subsubsection{Use of introducing topic}

While previewing and reviewing are by far the most common metadiscursive functions in the dataset (amounting from $57.8 \%$ to $77.1 \%$ of all organizational metadiscourse employed by lecturers), introducing topic seems to stand out over the rest of topic managers in all courses. Introducing topic is the most commonly used metadiscursive category within topic management metadiscourse (introducing topic, delimiting topic, adding to topic, concluding topic, and marking asides). The rest of topic managers present a rather inconsequential use within the total amount of organizational metadiscourse in the dataset. As stated in Section 1.3.1.2, introducing the topic is one of the key elements within a lecture as it involves the students and provides them with information regarding the main topic and concepts, as well as the purpose of the lecture (Palmer Silveira, 2004; Young, 1994). Table 5.7 shows total amounts and normalized frequencies in the use of topic managers across disciplines in the dataset being analyzed.

\begin{tabular}{|c|c|c|c|c|c|c|c|c|c|c|c|c|}
\hline & \multicolumn{2}{|r|}{ C1 } & \multicolumn{2}{|r|}{$\mathrm{C} 2$} & \multicolumn{2}{|r|}{ C3 } & \multicolumn{2}{|r|}{ C4 } & \multicolumn{2}{|r|}{ C5 } & \multicolumn{2}{|r|}{ C6 } \\
\hline & $\mathrm{N}$ & $/ 10,000 w$ & N & $/ 10,000 w$ & $\mathrm{~N}$ & $/ 10,000 w$ & $\mathrm{~N}$ & $/ 10,000 w$ & N & $/ 10,000 w$ & $\mathrm{~N}$ & $/ 10,000 w$ \\
\hline Introducing & 109 & 6.8 & 108 & 5.7 & 69 & 3.9 & 86 & 5.5 & 93 & 6.8 & 95 & 5.4 \\
\hline Delimiting & 46 & 2.9 & 25 & 1.3 & 46 & 2.6 & 37 & 2.4 & 21 & 1.5 & 20 & 1.1 \\
\hline Adding & 19 & 1.2 & 17 & 0.9 & 7 & 0.4 & 10 & 0.6 & 4 & 0.3 & 7 & 0.4 \\
\hline Concluding & 13 & 0.8 & 12 & 0.6 & 7 & 0.4 & 2 & 0.1 & 7 & 0.5 & 14 & 0.8 \\
\hline Mark. aside & 19 & 1.2 & 22 & 1.2 & 10 & 0.6 & 11 & 0.7 & 4 & 0.3 & 7 & 0.4 \\
\hline
\end{tabular}

Table 5.7 Frequency of the use of topic managers across disciplines (raw and normalized frequencies)

Introducing topic is distributed rather homogeneously across disciplines (variation of \pm 2.9 instances per 10,000 words). In this sense, no differences can be claimed in terms of the use of this category by different lecturing styles. However, it is interesting to note that a slightly higher occurrence is found in History courses (C1, C2 and C5). As I suggested in Section 5.2.3.1 in this chapter, History courses seem to be topicalized by default, i.e. they are structured in a list of topics in succession (commonly, in one-topic-one-lecture relations). Each lecture, in turn, may be subdivided into subtopics which can also be introduced through the use of introducing topic metadiscourse. See, for instance, Examples 24 to 26 , which introduce the main topic of the lecture-smallpox-and some of its subtopics 
-smallpox as a disease, the symptoms of smallpox, etc. In brief, the thorough distribution of topics and subtopics in History courses as compared to other disciplines seems to be the reason behind the slight difference in the amount of introducing topic metadiscourse in some courses.

24) I want to turn to the next topic, which marks a new unit in our course. [...] Now l'd like to look, for comparative purposes at a very different high-impact disease; and this time and next we'll be dealing with smallpox. (C5_L6)

25) Let's begin with smallpox as a disease. (C5_L6)

26) Now, I'm going to give some attention [...] to the symptoms of smallpox. (C5_L6)

\subsubsection{Use of contextualizing}

The second category that seems to play an important role for some lecturers and that I will take into account in this section is the use of contextualization. This type of organizational metadiscourse is used to refer to the conditions of the lecture and to comment on the act of lecturing. Table 5.8 contains total occurrences of contextualizing metadiscourse in the dataset as well as normalized figures.

\begin{tabular}{|c|c|c|c|c|c|c|c|c|c|c|c|c|}
\cline { 2 - 13 } & \multicolumn{2}{c|}{ C1 } & \multicolumn{2}{c|}{ C2 } & \multicolumn{2}{c|}{ C3 } & \multicolumn{2}{c|}{ C4 } & \multicolumn{2}{c|}{ C5 } & \multicolumn{2}{c|}{ C6 } \\
\cline { 2 - 14 } & $\mathrm{N}$ & $/ 10,000 \mathrm{w}$ & $\mathrm{N}$ & $/ 10,000 \mathrm{w}$ & $\mathrm{N}$ & $/ 10,000 \mathrm{w}$ & $\mathrm{N}$ & $/ 10,000 \mathrm{w}$ & $\mathrm{N}$ & $/ 10,000 \mathrm{w}$ & $\mathrm{N}$ & $/ 10,000 \mathrm{w}$ \\
\hline Context. & 88 & 5.5 & 145 & 7.6 & 46 & 2.6 & 57 & 3.6 & 35 & 2.6 & 29 & 1.7 \\
\hline
\end{tabular}

Table 5.8 Frequency of the use of contextualizing metadiscourse across disciplines (raw and normalized frequencies)

Contextualizing is a trivial category for $\mathrm{C} 3$ to $\mathrm{C} 6$ (rhetorical and reading style lecturers) if compared with the rest of categories of organizational metadiscourse. However, contextualizing shows a higher occurrence in conversational style lectures (C1 and C2), and it is the third most common type of metadiscourse in C2. Therefore, this higher presence of contextualizing seems to be related to conversational style lecturers. These lecturers might adapt their lecturing 'as they go'; the structure of their lectures does not seem to be 
as rigid as in reading style lecturers, where lectures are being read, nor as irregular as in rhetorical style lecturers. Then, conversational style lecturers may modify the structure of their lectures when necessary in order to fit their initial purposes. Examples 27 and 28 show how these modifications in the lectures occur and how they are made explicit through contextualizing commentaries. The use of contextualizing in other courses is far less reflective and most of the times merely refers to the position of the current speech within the lecture or to the time that is left in the lecture, i.e. situated time references, as well as short commentaries on the lecturing process (Examples 29 and 30).

27) I'm trying to compress some information so we can really be ready to catch next week right where we should be. (C1_L17)

28) So that was going to be today's lecture. That was my plan. But when I started thinking about the lecture and thinking about just preparing it and tweaking it, and again I had last thought about it back in December [...] and I decided at the absolute last minute I wasn't going to give that lecture - at literally the absolute last minute. (C2_L15)

29) And I'm running rapidly out of time, buy just say that there were, I would argue, not just immediate drama [...] (C5_L10)

30) Okay. I'd like to begin. Welcome back. (C4_L17)

\subsection{Distribution of organizational metadiscourse in the lectures and through the courses}

This section aims to provide an overview of the distribution of metadiscourse in the corpus. In other words, in the following lines, I intend to explain where organizational metadiscourse is commonly concentrated in the lectures and throughout the courses. In this sense, I intend to answer $R Q$ 1.2: 
In order to respond this question, I compare the number of instances in each session throughout the course and the distribution of instances per minute within each lecture.

In terms of the overall distribution of organizational metadiscourse, all lecturers show rather homogeneous amounts of metadiscourse distributed throughout the course. However, they all coincide in presenting high peaks of metadiscursive occurrences at the beginning and at the end of the courses. This seems to be the result of a higher presence of previewers during the first sessions of the course, and a high number of reviewers in the last sessions. It seems coherent that the lecturers may use more previewing metadiscourse in the first lectures of the course, as these sessions serve as a broad outline of the contents that will be examined in the rest of the course. Likewise, the use of reviewing metadiscourse at the end of the course seems to be consistent with summaries and recapitulating sections in the last sessions of the course. In Figure 5.1 below, a) represents the total amount of organizational metadiscourse throughout C1. The amounts of metadiscourse in a) are quite steady throughout the course showing ranges varying from 20 to 30 instances per lecture and up to 40 instances in some peak lectures. However, the first and the last lecture in the course show a remarkably high frequency of metadiscourse around 50 instances. This can be explicated by considering b) and c). On the one hand, b) describes the use of previewing instances throughout the course. These instances show their highest peak in the first lecture and descend as the course progresses. On the contrary, c) shows the distribution of reviewing metadiscourse throughout the course. These instances are significantly high in the last lecture of the course. This pattern is repeated for all courses under analysis.

As for the distribution of organizational metadiscourse within the lectures, all lecturers show an elevated use of organizational metadiscourse at the beginning of the lecture coinciding with the introductions to the lectures. As I described in Section 1.3.1.2, the introductions to the lectures are important sections in which the lecturers may introduce the topics, establish connections with previous sessions and outline the contents in an effort to facilitate the comprehension of the students by guiding them through the communication process. In this regard, the introductions to the lectures appear to be sections with abundant organizational metadiscourse. Figure 5.2 shows the average 
distribution of metadiscourse in the lectures in C4. Most metadiscursive expressions concentrate in the first 10 minutes of the session with occasional peaks distributed evenly through the lecture.
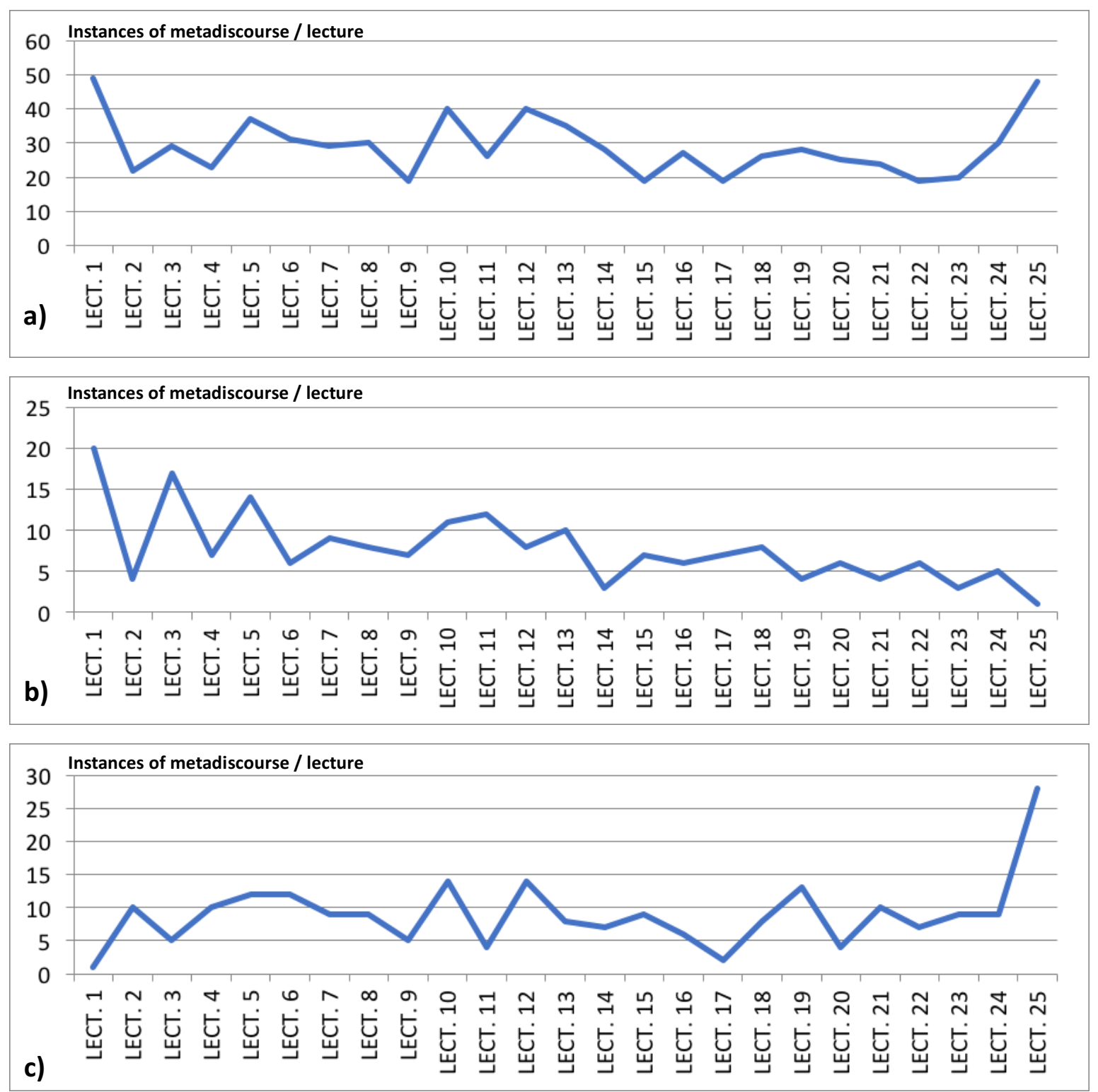

Figure 5.1 Distribution of metadiscourse along C1: total amounts (a), previewing (b) and reviewing (c) 


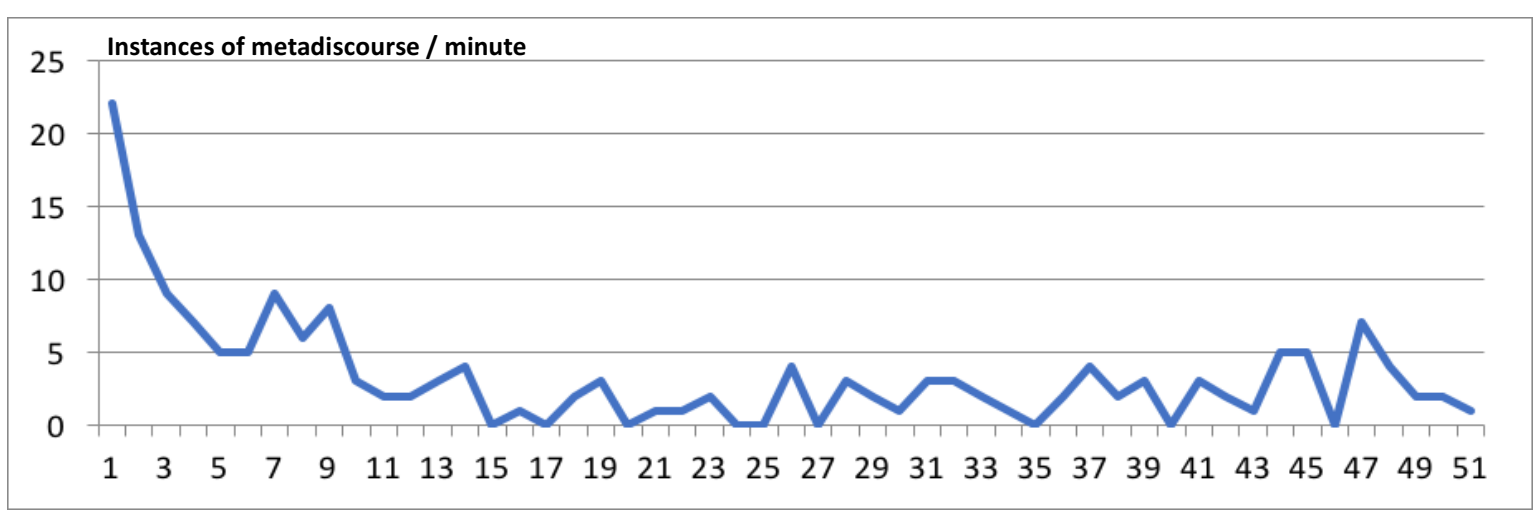

Figure 5.2 Average distribution of metadiscourse per minute in the lectures in C4

When taking a look at the distribution of metadiscourse in a single lecture, it is common to find distributions as the one presented in Figure 5.3 below. This figure corresponds to lecture C2_L13 (one of the lectures selected as representative for the sub-corpus of six lectures). In this lecture, most metadiscourse is concentrated in the first seven minutes. However, peaks of metadiscourse are found between the minutes 16 and 20 and between minutes 42 and 45 . These peaks may be found in most lectures in the corpus and correspond to what I refer to as structuring segments. These segments represent parts of the lecture with a high concentration of metadiscourse that may serve either as an introduction to a lecture, an introduction of a topic, or a separating segment between two broad sections in the lecture. Structuring segments will become particularly relevant in Chapter 7, where I zoom in onto these fragments to describe how organizational metadiscourse is performed at a non-verbal level. Finally, Figure 5.3 shows some independent instances of metadiscourse distributed through the session. These correspond to what I have called spontaneous metadiscourse. Spontaneous metadiscourse consists of individual metadiscursive fragments that are usually performed in a spontaneous manner and that may briefly interrupt the flow of the lecturing on content.

All in all, the analysis of the distribution of organizational metadiscourse throughout the courses and within the lectures becomes useful for narrowing down the scope of the linguistic and multimodal analyses performed in this thesis. Thus, in order to select representative lectures in a course, initial and final lectures need to be discarded. Having this idea in mind, a lecture from the middle of the course with no abnormal peaks of metadiscourse seems like a sensible representative option. Moreover, when examining the 
metadiscourse within the selected session, the lecture should present a high concentration of organizational metadiscourse at the beginning of the class, and contain both structuring segments and spontaneous metadiscourse.

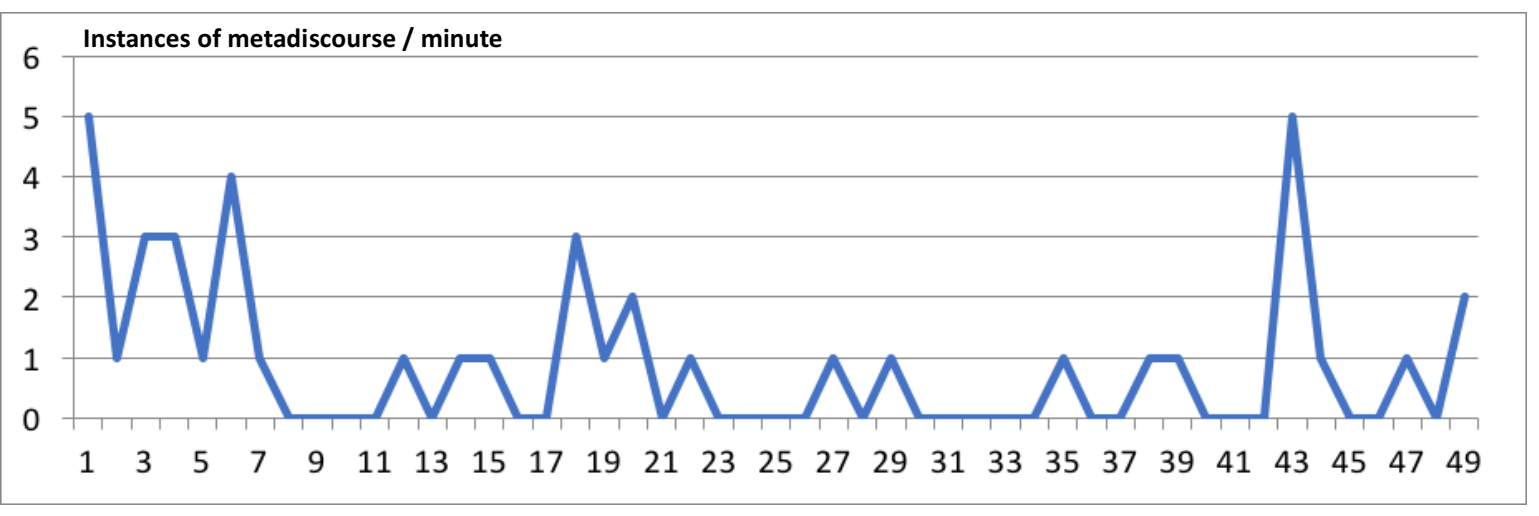

Figure 5.3 Distribution of metadiscourse per minute across lecture C2_L13

\subsection{Organizational metadiscourse across lecturing styles}

As shown in the analyses throughout Section 5.2, organizational metadiscourse may show similar uses within specific lecturing styles. Thus, in this section, I reflect upon how lecturing styles may have an impact on the use of metadiscourse. Having this idea in mind, I set out to answer $R Q$ 1.3:

\begin{tabular}{l|l} 
RQ 1.3 & Are there any similarities or differences in the quantitative use of organizational
\end{tabular} metadiscourse across lecturing styles?

In Chapter 3, I argued that organizational metadiscourse is a key element in the structuring of lectures and it is used to guide the audience through the contents. In this regard, I claim that the use of organizational metadiscourse might be dependent on the lecturing structure selected by the lecturers. In other words, I argue that organizational metadiscourse is closely connected to the ways in which lecturers plan and develop their sessions, i.e. to their lecturing styles. Consequently, lectures in which an irregular spontaneous structure is followed (for instance, those taught by rhetorical style lecturers) 
might contain fewer connections, and therefore, less metadiscursive fragments than a carefully prepared class where notes are used to help the lecturer in the organization of their speech (for example in conversational style lecturers).

The exploration of the percentages in the use of organizational metadiscourse has shown that the distribution of metadiscourse across disciplines within the same lecturing style is not completely homogeneous (see Section 5.2.3.3). Nonetheless, similarities within lecturing styles do arise. To exemplify this, Table 5.9 presents the total amount of metadiscursive instances (raw and normalized figures) in each of the disciplines of the dataset, once endophoric markers have been removed.

\begin{tabular}{|c|c|c|c|c|c|c|c|c|c|c|c|c|}
\hline & \multicolumn{2}{|c|}{ C1 } & \multicolumn{2}{|c|}{ C2 } & \multicolumn{2}{|c|}{ C3 } & \multicolumn{2}{|c|}{ C4 } & \multicolumn{2}{|c|}{ C5 } & \multicolumn{2}{|r|}{ C6 } \\
\hline & N & $/ 10,000 \mathrm{w}$ & N & $/ 10,000 \mathrm{w}$ & N & $/ 10,000 \mathrm{w}$ & N & $/ 10,000 \mathrm{w}$ & N & $/ 10,000 \mathrm{w}$ & N & $/ 10,000 \mathrm{w}$ \\
\hline TOTAL & 722 & 45.1 & 1,117 & 58.8 & 695 & 38.8 & 608 & 38.6 & 618 & 45.2 & 791 & 45.1 \\
\hline
\end{tabular}

Table 5.9 Total use of organizational metadiscourse excluding endophoric marking

Table 5.9 shows similarities in the general use of organizational metadiscourse within lecturing styles. These distinct quantitative uses of metadiscourse are particularly evident in rhetorical and reading style courses. Thus, C3 and C4 (taught by rhetorical style lecturers), for instance, present a similar total use of organizational metadiscourse (with a mere \pm 0.2 variation in the number of metadiscursive instances per 10,000 words). Rhetorical style lecturers seem to use less organizational metadiscourse than the other two styles. I argue that rhetorical style lecturers do not follow strict structures when lecturing and are not so self-aware of the organization of the lecture. Therefore, they make less use of signposting devices.

Likewise, C5 and C6 (by reading style lecturers) also show a rather similar use $( \pm 0.1$ instances). These lecturers follow a highly prepared text where connections and organization are expected. Moreover, they may add extra spontaneous metadiscursive fragments. This is reflected in a higher use of organizational metadiscourse.

The use of organizational metadiscourse in C1 and C2 (conversational style lecturers), however, is dissimilar $( \pm 13.7)$. In fact, the total number of organizational metadiscourse instances in $\mathrm{C} 1$ is very similar to that in reading style courses $( \pm 0.1)$. Conversational style 
lecturers are expected to use notes as a structuring guide and constantly reflect upon such structure, with extra spontaneous comments signaling a structure that is continually present for them. However, the quantitative results on the total amounts of organizational metadiscourse for conversational style lecturers are not conclusive and do not show a clear trend. In this sense, no broad generalizations can be extracted from these results and an analysis with a larger number of courses is necessary to corroborate these preliminary findings.

With the aim of further exploring the similarities and differences in the use of organizational metadiscourse across lecturing styles, comparisons of pairs of courses are needed. In sections 5.4.1, 5.4.2, and 5.4.3, I juxtapose the use of organizational metadiscourse in three main matching sets of courses: within conversational style courses, within rhetorical style courses, and within reading style courses. Furthermore, when examining conversational style lecturers in Section 5.4.1, I compare the use of metadiscourse between C1 (conversational style) and C5 and C6 (reading style courses), since they show a similar total use of organizational metadiscourse. Only those categories that have been identified as relevant in Section 5.2 (introducing topic, previewing, reviewing and contextualizing) are compared. By limiting the comparison to only those categories that are more recurrent, I aim to avoid unreliable data obtained from categories with very few instances.

\subsubsection{Conversational style lecturers}

Table 5.10 compares the use of introducing topic, previewing, reviewing and contextualizing in $\mathrm{C} 1$ and $\mathrm{C} 2$. This set of courses, unlike rhetorical and reading style courses, show differences in the total amount of organizational metadiscourse employed (45.1 and 58.8 instances per 10,000 words). However, when comparing the individual uses of each category, some similarities arise. Similar uses are found in introducing topic metadiscourse and in contextualizing. The use of contextualizing is particularly interesting in conversational style lecturers, as this type of metadiscourse seems to be more frequent in 
these lectures than it is in rhetorical and reading style lectures. This seems to be the result of a higher presence of the lecturers' voices in the lecture as they comment on the progression of the session. In conversational style courses, contextualizing is commonly used to refer to the timing of the session -for instance, to discuss whether there is enough time to tackle a particular topic-; to apologize-for example, when unfolding information in an unclear manner-; or to comment on the structural development of the lecture (see Section 6.1.4 for a further qualitative analysis on this category).

\begin{tabular}{|l|c|c|c|c|}
\cline { 2 - 5 } \multicolumn{1}{c|}{} & \multicolumn{2}{c|}{ C1 } & \multicolumn{2}{c|}{ C2 } \\
\cline { 2 - 5 } & $N$ & $/ 10,000 \mathrm{~W}$ & $\mathrm{~N}$ & $/ 10,000 \mathrm{~W}$ \\
\hline Introducing topic & 109 & 6.8 & 108 & 5.7 \\
\hline Previewing & 192 & 12 & 413 & 21.7 \\
\hline Reviewing & 225 & 14.1 & 350 & 18.4 \\
\hline Contextualizing & 88 & 5.5 & 145 & 7.6 \\
\hline
\end{tabular}

Table 5.10 Comparison of the use of organizational metadiscourse in conversational style lecturers

Nevertheless, the greatest significances occur in reviewing and particularly in previewing. For the latter category, C2 shows almost twice as much previewing occurrences as $\mathrm{C} 1$. The lecturer in C2, as mentioned in Section 5.2.3 and its subsections when describing both reviewers and previewers, devotes the first part of most lectures to establish long connections with previous lectures through the use of past lecture reviewers and to carefully outline the contents of the present lectures by using present lecture previewers. These initial sections in $\mathrm{C} 2$ do increase the amount of metadiscursive phorics managers in the aggregate. In a nutshell, this inconsistency seems to be the result of an individual trait of the lecturer in $\mathrm{C} 2$ and may explain the higher amount of organizational metadiscourse when compared to the other conversational style course.

Still and all, C1 still shows a use of metadiscourse which is similar to that of reading style courses. I argue elsewhere (Bernad-Mechó, 2017a) that this particular lecturer appears to be at a crossroads between conversational and reading styles: although he does his best in order not to read his notes, he is dependent on them and they become a strong structuring device in his lectures. Therefore, a comparison between $\mathrm{C} 1$, and C5 and C6 (reading style) 
might shed some light on the similarities and differences encountered among these courses at a quantitative level.

Table 5.11 compares the results obtained for $\mathrm{C} 1$ with those of reading style courses ( $\mathrm{C} 5$ and C6). No significant differences are shown in introducing topic since this is a category that shows very subtle changes from one course to the other. Furthermore, C1 shows similar uses of previewing metadiscourse with $\mathrm{C} 6$ and reviewing metadiscourse with $\mathrm{C} 5$. However, significant differences are also encountered when comparing $\mathrm{C} 1$ to reading style courses: the use of previewing in C5 is significantly higher (12 vs. 17.3 instances per 10,000 words) and reviewing metadiscourse is more common in C6 (14.1 vs. 23.1 instances). Finally, the main difference that distinguishes $\mathrm{C} 1$ from reading style courses is the use of contextualizing (5.5 instances in C1 vs. 2.6 and 1.7 in C5 and C6 respectively). As I discussed above, the use of contextualizing is particularly relevant in conversational style courses where lecturers reflect and comment upon the act of lecturing.

\begin{tabular}{|l|c|c|c|c|c|c|}
\hline \multicolumn{2}{c}{} & \multicolumn{2}{c|}{ C1 } & \multicolumn{2}{c|}{ C5 } & \multicolumn{2}{c|}{ C6 } \\
\cline { 2 - 7 } & $\mathrm{N}$ & $/ 10,000 \mathrm{~W}$ & $\mathrm{~N}$ & $/ 10,000 \mathrm{~W}$ & $\mathrm{~N}$ & $/ 10,000 \mathrm{~W}$ \\
\hline Introducing topic & 109 & 6.8 & 93 & 6.8 & 95 & 5.4 \\
\hline Previewing & 192 & 12 & 236 & 17.3 & 205 & 11.7 \\
\hline Reviewing & 225 & 14.1 & 196 & 14.3 & 405 & 23.1 \\
\hline Contextualizing & 88 & 5.5 & 35 & 2.6 & 29 & 1.7 \\
\hline
\end{tabular}

Table 5.11 Comparison of the use of organizational metadiscourse in C1 and reading style lecturers

Everything considered, the study of conversational style courses highlights the fact that the lecturer in $\mathrm{C} 1$ does share features with both the lecturer in C2 (conversational style) and the lecturers in $\mathrm{C5}$ and C6 (reading style). To be precise, the use of introducing topic and contextualizing is shared with $\mathrm{C} 2$; the use of previewing is similar in C1 and C6; and the use of reviewing is common for $\mathrm{C} 1$ and $\mathrm{C} 5$. These results, together with the fact that the total amount of organizational metadiscourse between $\mathrm{C} 1$ and reading style courses is very similar (see Section 5.4), suggest that the lecturer in C1 might be somewhere in between a conversational and a reading style. 


\subsubsection{Rhetorical style lecturers}

Rhetorical style lecturers seem to be prone to a higher degree of irregularity in the structures of the lectures, which implies less planning, and therefore, less organizational metadiscourse. Table 5.12 below compares the use of the most relevant organizational metadiscursive functions in rhetorical style courses and demonstrates similarities and differences in the use of organizational metadiscourse in C3 and C4.

\begin{tabular}{|l|c|c|c|c|}
\cline { 2 - 5 } & \multicolumn{2}{c|}{ C3 } & \multicolumn{2}{c|}{ C4 } \\
\cline { 2 - 5 } & $\mathrm{N}$ & $/ 10,000 \mathrm{~W}$ & $\mathrm{~N}$ & $/ 10,000 \mathrm{~W}$ \\
\hline Introducing topic & 69 & 3.9 & 86 & 5.5 \\
\hline Previewing & 201 & 11.5 & 197 & 12.5 \\
\hline Reviewing & 290 & 16.6 & 192 & 12.2 \\
\hline Contextualizing & 46 & 2.6 & 57 & 3.6 \\
\hline
\end{tabular}

Table 5.12 Comparison of the use of organizational metadiscourse in rhetorical style lecturers

The analysis of specific categories in rhetorical style lecturers reinforces the similarities found at a general level. In this regard, C3 and C4 show similar uses of introducing topic, previewing, and contextualizing. A slight difference, however, is found in the use of reviewers: C3 shows a higher use of reviewers than C4 (16.6 vs. 12.2 instances per 10,000 words). This can be explained by comparing the distribution of topics throughout the lectures in the course (see Appendix A to explore the transcriptions of these courses). In Section 5.2.3.3, I have shown how reviewers are, in terms of percentage, a relevant function in C3. This may be the result of the fact that topics in C3 are commonly expanded through more than two lectures (and up to five). In the case of C4, on the contrary, topics are often developed in just two lectures (and up to three). Thus, reviewing instances are relevant in C3 as connections within a given topic are extended through many lectures in order to establish cohesion. Consequently, the distribution of topics throughout both rhetorical style courses comes about differently: topics in C3 are extended to up to five lectures, which results in a higher presence of reviewers in this course. 
However, the only difference encountered within rhetorical style courses seems to have its grounds on a structuring element rather than an individual trait. Overall, rhetorical style lecturers often present more spontaneous, irregular structures where thoughts succeed each other and little reflection is given to make such organization explicit for the audience -see Chapter 8 for a description of how lecturers structure their sessions-, which results in a lower total use of organizational metadiscourse.

\subsubsection{Reading style lecturers}

The last pair of courses that I will compare in this section is C5 and C6 (reading style courses). Table 5.13 shows a comparison between these two courses. If compared to rhetorical style lecturers, reading style lecturers make a slightly higher use of organizational metadiscourse in general terms. Two main conclusions can be extracted from this comparison: similarities are present in the use of introducing topic and contextualizing in both courses and relevant differences are found in the use of previewing and reviewing.

Like rhetorical style courses, reading style courses show similarities in the total amount of organizational metadiscourse employed. Moreover, the use of both introducing topic and contextualizing does not show any significant differences, which contributes to the definition of the reading style.

\begin{tabular}{|l|c|c|c|c|}
\hline \multicolumn{2}{c|}{} & \multicolumn{2}{c|}{ C5 } & \multicolumn{2}{c|}{ C6 } \\
\cline { 2 - 5 } & $N$ & $/ 10,000 \mathrm{~W}$ & $\mathrm{~N}$ & $/ 10,000 \mathrm{~W}$ \\
\hline & & & & \\
\hline Introducing topic & 93 & 6.8 & 95 & 5.4 \\
\hline Previewing & 236 & 17.3 & 205 & 11.7 \\
\hline Reviewing & 196 & 14.3 & 405 & 23.1 \\
\hline Contextualizing & 35 & 2.6 & 29 & 1.7 \\
\hline
\end{tabular}

Table 5.13 Comparison of the use of organizational metadiscourse in reading style lecturers

On the contrary, although the amount of phorics management metadiscourse resulting from the total number of reviewing and previewing instances is similar (31.6 instances per 
10,000 words for $\mathrm{C} 5$ and 34.8 for (6), these functions show significant variations across both courses. First, C5 contains a more frequent use of previewers than C6. Second, C6 shows an unusually high use of reviewers. As I have already argued in this chapter, these two differences appear to result from stylistic decisions and structure constrains. In the case of the higher use of previewers, the lecturer in C5 occasionally includes longer outlines of the contents of the present lecture at the beginning of his speech. When turning to C6, the elevated use of reviewers in this course can be explained through a structural interpretation, since this course is centered on one broad topic only: Don Quixote. Therefore, connections with previous moments in the topic constantly occur all throughout the course, thus showing a higher use of reviewers.

\subsection{Concluding remarks}

In this chapter, I have provided a first exploration of the dataset from a quantitative perspective. A quantitative study on the amounts of organizational metadiscourse encountered across disciplines brings to the fore some relevant aspects of both the methodology employed for the analysis and how organizational metadiscourse is used differently by distinct lectures.

On a methodological reflection, I have discussed that one of the advantages derived from a manual examination of the data is the possibility of correctly distinguishing between metadiscursive fragments and intertextual material during the process of identification of metadiscourse. As for the use of Ädel's (2010) taxonomy, I have shown how a degree of overlap in functions may occur frequently, between previewing and introducing topic. Furthermore, I suggest a subdivision in the categories of previewing and reviewing. Thus, the former category would be divided into present lecture previewers, future lecture previewers, and non-connected previewers; and the latter, on the other hand, would be divided into present lecture reviewers, past lecture reviewers and non-connected reviewers. 
Most importantly, the quantitative analysis here presented limits the scope of the present study. In this sense, I have provided an answer to RQ1.1. The analysis of the dataset establishes that the most common types of organizational metadiscourse are previewing, reviewing and endophoric marking. However, the presence of the latter seems to be merely dependent on the use of external materials -like slides, handouts or books-, rather than on lecturing styles or disciplines, and therefore, varies from lecturer to lecturer. Consequently, and with the aim of obtaining comparable quantitative results, this category has been omitted. In addition, the categories of introducing topic and contextualizing also show a notable number of instances in the dataset and seem to exert a degree of influence in describing how lecturers organize their lectures.

In order to answer RQ1.2, I have examined how metadiscourse is distributed within the lectures and throughout the courses. The results show a higher presence of organizational metadiscourse at the beginning of the sessions, coinciding with the introductions to the lectures. Moreover, metadiscourse may be found both in structuring segments, which are sections of the discourse with a high concentration of metadiscursive expressions and which occasionally serve as transitions between topics and in spontaneous isolated instances. Throughout the courses, higher amounts of metadiscourse have been found in the first and last sessions.

Finally, when considering the use of organizational metadiscourse across lecturing styles in RQ1.3, relevant similarities do arise. The total amount of organizational metadiscourse used among rhetorical style courses, on the one hand, and among reading style courses, on the other, is very similar for each of the groups. In the case of conversational style courses, however, $\mathrm{C} 1$ presents an aggregate which is similar to that of reading style courses. Besides, a close comparison of the data has reinforced the similarities that are intrinsic to each lecturing style and pointed out some differences within courses taught in the same lecturing style. In general terms, similar uses of organizational metadiscourse are found within each lecturing style, which seems to point to a possible relation between lecturing styles and use of metadiscourse. The differences found, on the other hand, may be attributed to individual stylistic reasons or constraints in the structure of the discipline; for example, in the case of the lecturer in $\mathrm{C} 2$ who performs longer introductions to the lectures 
and therefore uses more previewing metadiscourse, or the case of C6 where abundant reviewing instances are employed as the course is organized around one single topic (Don Quixote).

Still and all, lecturing styles cannot be defined solely in terms of how lecturers utilize organizational metadiscourse and the data obtained in this quantitative analysis is not enough to put on display the intricacies of the use of organizational metadiscourse across lecturing styles. On that account, further explorations at a linguistic and a multimodal level are needed in order to shed more light on the matter.

All in all, Chapter 5 has tackled RQ1 by examining the quantitative aspects of the use of organizational metadiscourse. In the following chapter, I further explore the verbal use of organizational metadiscourse in lectures. From a linguistic point of view, I provide an account of the linguistic aspects that are recurrent in the use of organizational metadiscourse as well as any similarities and differences across lecturing styles. 



\section{CHAPTER 6. ANALYSIS: A LINGUISTIC APPROXIMATION}

After having explored the quantitative aspects of the use of organizational metadiscourse in lectures, in this chapter, I briefly zoom in on the linguistic traits that can be identified in this type of metadiscourse. In this regard, this chapter aims to provide an answer to RQ2 and its sub-questions:

\begin{tabular}{|l|l|}
\hline RQ 2 & How is organizational metadiscourse expressed verbally? \\
\hline RQ 2.1 & $\begin{array}{l}\text { What are the recurrent syntactic and semantic structures in the use of the most common } \\
\text { types of organizational metadiscourse? }\end{array}$ \\
\hline RQ 2.2 & $\begin{array}{l}\text { Are there any similarities or differences in the verbal use of organizational metadiscourse } \\
\text { across lecturing styles? }\end{array}$ \\
\hline
\end{tabular}

Particularly, in this chapter, I examine the linguistic aspects of organizational metadiscourse before moving on to a multimodal analysis and examine how metadiscourse is co-expressed through a variety of modes. In order to provide an answer to the questions proposed, I explore choices of lexical items, grammatical structures, and stylistic resources, as well as how these elements are encountered across lecturing styles. Thus, the analysis is organized as follows: in sections 6.1 and 6.2, I focus on RQ 2.1. In these sections, I describe the common syntactic structures encountered in the dataset in the use of the different types of organizational metadiscourse (Section 6.1), and the lexical elements like words and expressions that are used to proclaim metadiscourse, as well as the use of personal pronouns (Section 6.2). Finally, Section 6.3 is aimed to provide an answer to RQ 2.2 by examining these results as a whole and describing the differences in the linguistic uses of metadiscourse across lecturing styles.

In the foregoing chapter, I have restricted the scope of the corpus to four main types of metadiscourse that are most common in the data: introducing topic, previewing, reviewing, and contextualizing. Moreover, I have shown how the lectures in the middle of the course are prone to having an average amount of metadiscourse, not influenced by elevated amounts of previewing or reviewing. Therefore, as I described in Chapter 4, this analysis is based on the six representative lectures extracted from the main corpus (see Section 4.4.2). 


\subsection{Syntactic structure in the use of organizational metadiscourse}

In this section, I propose to answer RQ 2.1:

RQ 2.1

What are the recurrent syntactic and semantic structures in the use of the most common types of organizational metadiscourse?

Specifically, I describe the recurrent syntactic structures encountered in the dataset for each of the metadiscursive types considered: introducing topic (Section 6.1.1), previewing (Section 6.1.2), reviewing (Section 6.1.3), and contextualizing (Section 6.1.4). In other words, I describe and exemplify the different types of structures found in the corpus. The results described below show how different choices in the use of syntactic structures may, for example, attach more relevance to a piece of information or another. Finally, in Section 6.1 .5$, I briefly refer to the quantitative data obtained in the analysis of syntactic structures.

\subsubsection{Introducing topic}

Introducing topic is the third most recurrent type of metadiscourse -after reviewing and previewing-found in the sub-corpus of six lectures employed in this part of the analysis. Four distinct syntactic structures can be found with different foci (Types A, B, C, and D) and two subtypes are established for Type A structures (see Table 6.1). Type A introductions are the most common ones and are characterized by signaling the direction of the lecture using a personal form (either I, we, or you) and a verb that is used to indicate the volition of the lecturer to introduce a new topic or to make the new topic explicit for the audience. The differences between Types A-I and A-II have to do with the choice of the lecturer to foreground either the action of introducing the new topic or the new topic per se. Thus, in the examples presented in Table 6.1, the lecturer in Example 31 chooses to start his utterance by signaling the shift from one topic to the other ("we move on to..."), while the lecturer in Example 32 first presents the new topic ("there are a couple of claims about 
death that get made frequently enough") and then makes explicit that this will be the next topic in the lecture by saying "that I want to focus on". By using the second strategy, the lecturer gives more importance to the new topic itself instead of emphasizing the fact that there is a structuring shift in the lecture and that a new topic is being introduced. As discussed in Section 1.1.4, the choice of the theme, i.e. the point of departure of an utterance that receives a special status by the speaker, offers some information about the message. In this regard, themes are frequently connected to new information and become the most important part of the utterance. Having said that, this type of metadiscourse where the topic is thematized is very rare and is only found in three instances across the dataset of representative lectures.

\begin{tabular}{|c|c|c|c|}
\hline \multicolumn{2}{|c|}{ Syntactic Type } & \multirow[b]{2}{*}{$\begin{array}{l}\text { Description } \\
\text { Explicit signaling of the direction of the } \\
\text { lecture through expressions of volition } \\
\text { in a present tense (e.g. "I want to..."), } \\
\text { direction (e.g. "we move on to..."), or } \\
\text { use of verbs to describe the future (e.g. } \\
\text { "we will talk about..."). These } \\
\text { introductions follow a S+V+O structure } \\
\text { that can be slightly altered. }\end{array}$} & Example \\
\hline Type A & Subtype A-I & & $\begin{array}{l}\text { 31) Saying so, we move on to the } \\
\text { episode of the lions, which is } \\
\text { reminiscent of that of the galley } \\
\text { slaves in Part I. (C6_L15) }\end{array}$ \\
\hline & $\begin{array}{l}\text { Subtype A-II } \\
\text { (rare) }\end{array}$ & $\begin{array}{l}\text { Like Type A-I, these introductions } \\
\text { explicitly signal the direction of the } \\
\text { lecture, with the singularity that the } \\
\text { main topic is introduced before the } \\
\text { volition is expressed. }\end{array}$ & $\begin{array}{l}\text { 32) Still, there are a couple of claims } \\
\text { about death that get made } \\
\text { frequently enough [...] that । } \\
\text { want to focus on. (C3_L15) }\end{array}$ \\
\hline \multicolumn{2}{|l|}{ Type B } & $\begin{array}{l}\text { Explicit description of the contents of } \\
\text { the lecture. The subject is the lecture or } \\
\text { refers to it. Use of attributive } \\
\text { structures. }\end{array}$ & $\begin{array}{l}\text { 33) So much of today's lecture is } \\
\text { context, for much of the, for } \\
\text { going across the } 1940 \text { s up to } \\
\text { Brown v. Board [...] (C1_L13) }\end{array}$ \\
\hline \multicolumn{2}{|l|}{ Type C } & $\begin{array}{l}\text { Asking for permission. Use of formulae } \\
\text { "let me/us + Verb" or similar to } \\
\text { introduce the topic }\end{array}$ & $\begin{array}{l}\text { 34) So now let's turn to the } \\
\text { Continental Congress and how } \\
\text { they organized a war. (C2_L13) }\end{array}$ \\
\hline \multicolumn{2}{|c|}{ Type D (rare) } & $\begin{array}{l}\text { Indirect introduction of the topic. Use } \\
\text { of "there is/are" clauses or omission of } \\
\text { any of the previous formulae. }\end{array}$ & $\begin{array}{l}\text { 35) So, there is a deeper, even } \\
\text { darker side, I would suggest, to } \\
\text { the generation of sympathy in } \\
\text { Morrison's novels. (C4_L13) }\end{array}$ \\
\hline
\end{tabular}

Table 6.1 Syntactic types and subtypes for introducing topic

Type B structures differ from Types A in that there is no personal subject; instead, the subject is commonly the lecture itself or the topic. Thus, in these instances, the lecturers describe what the lecture is about or what topic is going to be dealt with in class by using attributive structures. In Example 36 below, for instance, the lecturer in C5 introduces a new topic by describing the topic. "one of the topics, or themes" becomes the subject and 
is connected with its referent (intellectual history) by using the attributive verb "to be". These instances, although more uncommon than Types A, seem to offer a clear reflection on the introduction of a new topic as they make a direct comment on the lecture (or topic) as a subject.

36) In our class, one of the topics, or themes [...] is intellectual history. (C5_L15)

Type $C$ introductions are characterized by using the formulae let me or let's (or similar expressions) followed by a verb to introduce the topic. Essentially, this type of introductions differs from the other in that the lecturers ask for permission and, as I describe in Section 6.2, make the audience a participant of the interaction by including them in the speech, either as the entity to which the lecturer asks for permission (let me) or as part of a group (let us) (see Example 34 in Table 6.1).

Finally, Type D introductions encompass rare instances in which the topic is introduced without the use of a verb either through there is/there are clauses (see Example 35 in Table 6.1) or by omitting the agent and the verbs common in Type A introductions (see Example 37 below). In these introductions, the degree of metadiscursive reflection is lower as there is no explicit commentary with a presence of the lecturer; still and all, the message can be understood and the function of introducing a topic achieved.

37) Now, very quickly, a few words about Earl Warren himself because it's actually fascinating. (C1_L13)

\subsubsection{Previewing}

In the case of previewing metadiscourse, two main types of syntactic structures have been identified (Types A and B), with three and two subtypes respectively (see Table 6.2). Type A structures, on the one hand, are personal clauses formed by a personal subject $(I$, we, and occasionally you), a verb in a future tense that describes an action that will take place later in time and that is used to preview the disclosure of new information, and an optional adverbial that may be placed at the beginning or at the end of the sentence. In this regard, 
Type A-I previewers include the subject, verb and the contents that are being previewed (commonly in the form of an object), but they do not incorporate an adverbial clause (see Example 39 in Table 6.2). Thus, Type A-I structures correspond to non-connected previewers in the expanded version of Ädel's (2010) taxonomy that I provided in Section 5.2. Type A-II structures include an adverbial clause that specifies the moment in time in which the information or the action that is being previewed is expected to occur (present and future lecture previewers) (see Example 40 in Table 6.2). The only difference between Types A-II and A-III is the relevance that is attached to the adverbial clause. While in the former the adverbial is placed at the end of the sentence, in the latter the adverbial is foregrounded and placed at the beginning (see Example 41 in Table 6.2). Once again, the thematization of the adverbial seems to attach more importance to the moment when the information that is being previewed is going to be fully disclosed. In this type of structures, the adverbials are often very specific. Compare, for instance, "in a couple of weeks" (Subtype A-II) and "over the course of today's lecture and really Monday's lecture" (Subtype A-III).

On the other hand, Type B previewers encompass impersonal clauses where a description of the contents that are being previewed is offered. The subject is commonly an impersonal one (e.g. "one of the questions"), or a topic that will be reintroduced at a later stage (see Example 38 below). In Example 38, for instance, the subject of the metadiscursive instance is "it", which refers to the fact that "there were real life experiences behind people's theoretical ideas". In this case, the metadiscursive utterance describes the contents that will be explained at some point in the future ("towards the end of the course"). Alternatively, there is/there are clauses may also be used to introduce this type of previewers. Type B-I structures seem to stand closer to content sections in the lecture as they do not commonly interrupt the flow of the lecture to preview information, but rather comment on a topic that is being explored by suggesting where else in the course will this matter be considered (see Example 41 in Table 6.2). This is shown in the use of adverbs like "again". Like in Type A structures, the differences between Subtypes B-I and B-II have to do with the position of the adverbial clause specifying the moment in time where the action will occur. In the latter, adverbials are foregrounded and become more specific (see 
Example 43 in Table 6.2). Finally, no instances of Type B structures are found in the dataset where the adverbial clauses are not used.

38) It'll come up again towards the end of the course, but basically there were real life experiences behind people's theoretical ideas. (C2_L13)

\begin{tabular}{|c|c|c|c|c|}
\hline \multicolumn{2}{|c|}{ Syntactic Type } & \multirow[b]{2}{*}{$\begin{array}{l}\text { Description } \\
\text { This type of structure includes a } \\
\text { personal subject (commonly I or we, but } \\
\text { also you), and a verb in a future tense } \\
\text { that describes an action in which new } \\
\text { information will be disclosed. The } \\
\text { reference in time where such action will } \\
\text { take place is not specified. }\end{array}$} & \multicolumn{2}{|c|}{ Example } \\
\hline \multirow[t]{3}{*}{ Type A } & Subtype A-I & & & $\begin{array}{l}\text { And I'm going to argue that } \\
\text { tropical medicine, and } \\
\text { particularly in this formative } \\
\text { early period before the First } \\
\text { World War, was clearly } \\
\text { socially constructed. (C5_L15) }\end{array}$ \\
\hline & Subtype A-II & $\begin{array}{l}\text { The most common type. Functions like } \\
\text { Subtype A-I, but the reference in time is } \\
\text { made explicit through the use of an } \\
\text { adverbial. }\end{array}$ & & $\begin{array}{l}\text { The plasmodium that causes } \\
\text { it, as we'll see in a couple of } \\
\text { weeks, lives in a closed cycle, } \\
\text { and never exists free in the } \\
\text { environment. (C5_L15) }\end{array}$ \\
\hline & Subtype A-III & $\begin{array}{l}\text { Functions like Subtype A-II, except that } \\
\text { the adverbial clause is brought to the } \\
\text { front of the sentence. }\end{array}$ & & $\begin{array}{l}\text { And over the course of today's } \\
\text { lecture and really Monday's } \\
\text { lecture, we're going to start } \\
\text { canvassing the ways in which } \\
\text { this period of, of incredible } \\
\text { instability in the United States } \\
\text { was made, was felt on many } \\
\text { different levels, in different } \\
\text { ways. (C1 L13) }\end{array}$ \\
\hline \multirow[t]{2}{*}{ Type B } & Subtype B-I & $\begin{array}{l}\text { Explicit description of the contents that } \\
\text { are being previewed. The subject is an } \\
\text { impersonal one that refers to the } \\
\text { contents that are being introduced (or } \\
\text { use of "there is/are" clauses). Use of } \\
\text { future tense verbs. They include an } \\
\text { adverbial to specify the moment in time } \\
\text { where the action will occur. }\end{array}$ & & $\begin{array}{l}\text { There is a rather eccentric } \\
\text { American general who will } \\
\text { come up again in the course. } \\
\text { (C2_L13) }\end{array}$ \\
\hline & $\begin{array}{l}\text { Subtype B-II } \\
\text { (rare) }\end{array}$ & $\begin{array}{l}\text { Like Subtype B-I, this type of structure is } \\
\text { an impersonal one in which a } \\
\text { description is provided. In this subtype, } \\
\text { the adverbial is brought to the front of } \\
\text { the sentence. }\end{array}$ & 43) & $\begin{array}{l}\text { On Thursday will be the } \\
\text { midterm here. (C2_L13) }\end{array}$ \\
\hline
\end{tabular}

Table 6.2 Syntactic types and subtypes for previewing 


\subsubsection{Reviewing}

Reviewers are the most common metadiscursive instances found in this dataset. Four main syntactic structures have been identified, Types A, B, C, and D (see Table 6.3). Moreover, three subtypes have been identified for Type A structures and two subtypes in the case of Type D structures. Subtype A-I reviewers introduce information that has been previously mentioned or explained by using a personal clause. Sentences within this type include a personal subject (commonly I or we, but also you), and a verb in the past tense (see Example 45 in Table 6.3), although as shown in Example 44 below, present perfect continuous forms may also be used. Additionally, the referent of information that is being reviewed often has the form of an object. In this subtype, time references that locate the information throughout the lecture or in past events are not included. Thus, Subtype A-I reviewers are composed of non-connected reviewers. References in time in the form of adverbial clauses are included in Subtypes A-II and A-III (present and past lecture reviewers) with one main distinction: adverbial clauses are brought to the beginning of the metadiscursive instances in Subtype A-III (see Examples 46 and 47 in Table 6.3).

44) I've been talking about the tension between the symbolic and the real. (C1_L13)

Unlike previewing instances, no impersonal descriptions that connect the metadiscursive instance with the referent are found for reviewers. Instead, three uncommon types complete the syntactic description of reviewers in the dataset. Type B reviewers is a rare structure that is only found on one occasion throughout the lectures that have been analyzed. As shown in Example 48 in Table 6.3, the lecturer in C3 introduces a reviewing metadiscourse fragment by employing a non-finite clause using a having + past participle form ("having distinguished between what we've called the death of the body and the death of the person"). Moreover, no adverbial clause is used to specify the moment in time where the information was delivered. In this fragment, the lecturer introduces a reviewing fragment in a subordinate sentence that triggers the main sentence intended in this example ("the question whether or not you're going to die needs to be distinguished"). It seems that the main aim of the lecturer in this fragment is not that of reviewing some 
information but rather that of introducing a new topic ("the question whether or not you're going to die"). However, the reviewing of information does occur in the subordinate sentence.

\begin{tabular}{|c|c|c|c|}
\hline \multicolumn{2}{|c|}{ Syntactic Type } & \multirow[b]{2}{*}{$\begin{array}{l}\text { Description } \\
\text { This type of structure includes a } \\
\text { personal subject (commonly I or we, } \\
\text { but also you), and a verb, commonly } \\
\text { in a past tense but occasionally in a } \\
\text { present perfect form, that is used to } \\
\text { refer to the disclosure of information } \\
\text { in the past. The reference in time } \\
\text { where such action took place is not } \\
\text { specified. }\end{array}$} & Example \\
\hline Type A & Subtype A-I & & $\begin{array}{l}\text { 45) Now, we already saw } \\
\text { Auerbach's main thesis in } \\
\text { Mimesis, his famous book, and } \\
\text { that that thesis is about the } \\
\text { Christian mixture of the } \\
\text { sublime and the low style in the } \\
\text { New Testament [...] (C6_L15) }\end{array}$ \\
\hline & Subtype A-II & $\begin{array}{l}\text { Functions like Subtype A-I, but the } \\
\text { reference in time is made explicit } \\
\text { through the use of an adverbial } \\
\text { clause. }\end{array}$ & $\begin{array}{l}\text { 46) Now, I ended the last lecture } \\
\text { before midterm talking about } \\
\text { A. Philip Randolph's March on } \\
\text { Washington Movement [...] } \\
\text { (C1_L13) }\end{array}$ \\
\hline & Subtype A-III & $\begin{array}{l}\text { Functions like Subtype A-II, except } \\
\text { that the adverbial clause is brought } \\
\text { to the front of the sentence. }\end{array}$ & $\begin{array}{l}\text { 47) Now, at the start, } \\
\text { distinguished two claims } \\
\text { people might have in mind } \\
\text { when they say, "Nobody } \\
\text { believes they're going to die". } \\
\text { (C3_L15) }\end{array}$ \\
\hline \multicolumn{2}{|c|}{ Type B (rare) } & $\begin{array}{l}\text { It is a rare type in which the referent } \\
\text { of the reviewing metadiscourse is } \\
\text { introduced through a non-finite } \\
\text { clause in the form of having + past } \\
\text { participle. }\end{array}$ & $\begin{array}{l}\text { 48) Now, having distinguished } \\
\text { between what we've called the } \\
\text { death of the body and the } \\
\text { death of the person, the } \\
\text { question whether or not you're } \\
\text { going to die needs to be } \\
\text { distinguished. (C3_L15) }\end{array}$ \\
\hline \multicolumn{2}{|c|}{ Type C (rare) } & $\begin{array}{l}\text { The lecturer uses a rhetorical } \\
\text { question to refer to a moment in the } \\
\text { past. }\end{array}$ & $\begin{array}{l}\text { 49) But didn't I start off by saying I } \\
\text { was going to grant the person } \\
\text { who is making this argument } \\
\text { that in order to believe } \\
\text { something, you've got to be } \\
\text { able to picture it? (C3_L15) }\end{array}$ \\
\hline \multirow[t]{2}{*}{$\begin{array}{l}\text { Type D } \\
\text { (rare) }\end{array}$} & Subtype D-I & $\begin{array}{l}\text { The lecturer establishes a connection } \\
\text { with previous information by using } \\
\text { the imperative "remember" followed } \\
\text { by a description of the reviewed } \\
\text { fragment in the form of a direct } \\
\text { object. }\end{array}$ & $\begin{array}{l}\text { 50) Remember that divide I was } \\
\text { describing in the 1960s' } \\
\text { political world. (C4_L13) }\end{array}$ \\
\hline & Subtype D-II & $\begin{array}{l}\text { Like Subtype D-I, the lecturer makes } \\
\text { use of the imperative "remember" } \\
\text { but completes the fragment with a } \\
\text { past action narrated in first person } \\
\text { singular. }\end{array}$ & $\begin{array}{l}\text { 51) Remember, I ended my lecture } \\
\text { on Pynchon by arguing that } \\
\text { sentiment remained important } \\
\text { in Pynchon's work. (C4_L13) }\end{array}$ \\
\hline
\end{tabular}

Table 6.3 Syntactic types and subtypes for reviewing 
Similarly, only one instance has been found for Type C structures. In Example 49 (Table 6.3), the lecturer in C3 uses a rhetorical question to refer to a moment in the past and therefore reviews some information that he delivered at the beginning of the lecture.

Finally, Type D structures are characterized by the use of the imperative "remember" addressing the audience. The imperative form may be followed by a description of an event in the form of a direct object (Subtype D-I) or a past action narrated in first person singular (Subtype D-II) -see Examples 50 and 51 in Table 6.3 respectively. In both types of syntactic structures, the connection with the audience seems more evident as there is an expressed appeal to them with the use of the imperative. In the case of Subtype D-II, the degree of explicit reflection upon language seems higher as there is a full account of a previous action that is described by the lecturer in the first person.

\subsubsection{Contextualizing}

Contextualizing is the least common metadiscursive type of the four types being analyzed in the dataset. It is only found in C1 (six instances), C2 (three instances) and C5 (one instance). Still, as shown in Table 6.4, three distinct types of structures are found (Types A, $B$ and C) and three subtypes have been identified for Type A structures. In Type A contextualizing metadiscourse the lecturer makes use of various syntactic strategies to describe and explain the decisions made by the lecturer during the development of the lecture. Present and future tenses are used in this type of structures and three subtypes may be distinguished: Subtype A-I, which is the most common one and in which the personal pronouns I and we are employed followed by descriptive verbs; subtype A-II, in which a let's + verb structure is preferred; and subtype A-III, in which "the lecture" is used as a subject. These three subtypes are used with the common aim of describing aspects relevant to the development of the lecture that offer valuable information for the audience as to how the lecture progresses (see Examples 52, 53, and 54 in Table 6.4). 


\begin{tabular}{|l|l|l|l|}
\hline \multicolumn{2}{|l|}{ Syntactic Type } & Description & Example \\
\hline Type A & Subtype A-I & $\begin{array}{l}\text { The lecturer uses present and future } \\
\text { tenses to describe and explain their } \\
\text { decisions regarding the development of } \\
\text { the lecture. Use of pronouns I and we, } \\
\text { followed by descriptive verbs. }\end{array}$ & $\begin{array}{l}\text { 52) I will stop there because we } \\
\text { are out of time. (C2_L13) }\end{array}$ \\
\cline { 2 - 5 } & $\begin{array}{l}\text { Subtype A-II } \\
\text { (rare) }\end{array}$ & $\begin{array}{l}\text { Differs from Sub-type A-I in that "let's + } \\
\text { verb" structures are used to describe the } \\
\text { decisions made by the lecturers. }\end{array}$ & $\begin{array}{l}\text { 53) Okay, well let's begin. } \\
\text { (C5_L15) }\end{array}$ \\
\cline { 2 - 5 } & $\begin{array}{l}\text { Subtype A-III } \\
\text { (rare) }\end{array}$ & $\begin{array}{l}\text { The subject of the description made by } \\
\text { the lecturer is not a personal one (I, we), } \\
\text { but “the lecture". }\end{array}$ & $\begin{array}{l}\text { 54) So today [...] the lecture is } \\
\text { titled Organizing a War. } \\
\text { (C2_L13) }\end{array}$ \\
\hline Type B & $\begin{array}{l}\text { The lecturer uses past or present perfect } \\
\text { tenses to justify actions that occurred in } \\
\text { the class. These expressions are } \\
\text { commonly performed in an apologetic } \\
\text { manner. }\end{array}$ & $\begin{array}{l}\text { 55) [...] I should have said that } \\
\text { first. (C1_L13) }\end{array}$ \\
\hline Type C (rare) & $\begin{array}{l}\text { The lecturer uses future tenses to justify } \\
\text { and explain the processes the lecturer is } \\
\text { following in the class. }\end{array}$ & $\begin{array}{l}\text { 56) Now, I'm going to move } \\
\text { away from these } \\
\text { two } \\
\text { groups rather } \\
\text { (C1_L13) }\end{array}$ \\
\hline
\end{tabular}

Table 6.4 Syntactic types and subtypes for contextualizing

In Type B structures, on the other hand, the lecturers use past tenses in an apologetic tone that aim at justifying actions that occurred in the past (see Example 55 in Table 6.4). Thus, the lecturer makes an open reflection about something that happened in the past and that should not have occurred. In Example 57 below, for instance, the lecturer in C1 apologizes for having lost track of the contents of the lecture and then indicates the end of the reflection and picks up the contents again by saying "there we go".

57) Excuse me, I've lost track for a second. There we go. (C1_L13)

Finally, Type C contextualizing structures have only been found in one instance across the dataset. In this type, the lecturer makes use of a future tense to explain and justify the process that he is going to follow in the lecture. In Example 56 in Table 6.4, the lecturer lets the audience know that the following explanations will occur faster than usual. 


\subsubsection{Quantitative analysis of syntactic choices}

Table 6.5 describes the number of instances and the percentage of use of each syntactic type within each of the metadiscursive categories here analyzed for each of the courses. Few representative differences are encountered in the choices of syntactic types made by the lecturers. In introducing topic metadiscourse, the most common type is A-I, i.e. personal $\mathrm{S}+\mathrm{V}+\mathrm{O}$ structures where the lecturer expresses the direction of the lecture. In the case of previewing, the most common type across lecturing styles is Subtype A-II, in which lecturers use structures with personal subjects (mainly I and we) and in which the referent in time is specified through adverbial clauses. Slight differences are shown in rhetorical and reading style lecturers who also show a relevant use of Subtype $A-I$, in which the referent in time is not specified. In the case of reviewers, Type A subjects are the common choice for all lecturers except for the one in C4. Subtype A-I, i.e. personal structures connecting with past events where the time references are not specified, is particularly common for reading style lecturers. As discussed in Section 5.3.1.2, the presence of non-connected reviewers is higher in these types of lecturers and this is reflected in the linguistic use of the metadiscursive expressions. In the case of $\mathrm{C} 4$, only two reviewing fragments have been identified in the representative lecture. Therefore, although both instances are encompassed within a Type D structure, no firm conclusions can be established. Likewise, very few instances of contextualizing metadiscourse have been identified. However, C1 seems to show a preference in structures in which the lecturer refers to past events in an apologetic manner (Type B), while Type A choices (Subtypes A-I and A-II respectively), in which descriptions of the lecturing process are provided, are common in C2 and C5. Still and all, no conclusions can be reached for this type of metadiscourse as the sample is too small. 


\begin{tabular}{|c|c|c|c|c|c|c|c|c|c|c|c|c|c|c|}
\hline & & & \multicolumn{2}{|c|}{ C1 } & \multicolumn{2}{|c|}{ C2 } & \multicolumn{2}{|r|}{ C3 } & \multicolumn{2}{|r|}{ C4 } & \multicolumn{2}{|r|}{ C5 } & \multicolumn{2}{|c|}{ C6 } \\
\hline & & & $\mathrm{N}$ & $\%$ & $\mathrm{~N}$ & $\%$ & $\mathrm{~N}$ & $\%$ & $\mathrm{~N}$ & $\%$ & $\mathrm{~N}$ & $\%$ & $\mathrm{~N}$ & $\%$ \\
\hline \multirow{5}{*}{$\begin{array}{c}\text { Introd. } \\
\text { topic }\end{array}$} & \multirow[t]{2}{*}{ Type A } & $A-1$ & 2 & 33.33 & 2 & 40 & 3 & 42.86 & 2 & 66.67 & 2 & 66.67 & 4 & 80 \\
\hline & & A-II & - & - & 1 & 20 & 1 & 14.29 & - & - & - & - & - & - \\
\hline & \multicolumn{2}{|l|}{ Type B } & 1 & 16.67 & 1 & 20 & - & - & - & - & 1 & 33.33 & - & - \\
\hline & \multicolumn{2}{|l|}{ Type C } & 2 & 33.33 & 1 & 20 & 2 & 28.57 & - & - & - & - & 1 & 20 \\
\hline & \multicolumn{2}{|l|}{ Type D } & 1 & 16.67 & - & - & 1 & 14.29 & 1 & 33.33 & - & - & - & - \\
\hline \multirow[t]{5}{*}{ Preview. } & \multirow[t]{3}{*}{ Type A } & A-I & 1 & 14.29 & 2 & 11.76 & 1 & 33.33 & 2 & 33.33 & 3 & 37.5 & 1 & 20 \\
\hline & & A-II & 5 & 71.43 & 10 & 58.82 & 2 & 66.67 & 3 & 50 & 4 & 50 & 4 & 80 \\
\hline & & A-III & 1 & 14.29 & 2 & 11.76 & - & - & - & - & 1 & 12.5 & - & - \\
\hline & \multirow[t]{2}{*}{ Type B } & B-I & - & - & 2 & 11.76 & - & - & 1 & 16.68 & - & - & - & - \\
\hline & & B-II & - & - & 1 & 5.88 & - & - & - & - & - & - & - & - \\
\hline \multirow[t]{7}{*}{ Review. } & \multirow[t]{3}{*}{ Type A } & $\mathrm{A}-\mathrm{I}$ & 6 & 66.67 & 5 & 35.71 & - & - & - & - & 6 & 85.71 & 8 & 80 \\
\hline & & A-II & 3 & 33.33 & 7 & 50 & 4 & 44.44 & - & - & 1 & 14.29 & 1 & 10 \\
\hline & & $A-I I I$ & - & - & 2 & 14.29 & 3 & 33.33 & - & - & - & - & - & - \\
\hline & \multicolumn{2}{|l|}{ Tyре B } & - & - & - & - & 1 & 11.11 & - & - & - & - & - & - \\
\hline & \multicolumn{2}{|l|}{ Type C } & - & - & - & - & 1 & 11.11 & - & - & - & - & - & - \\
\hline & \multirow[t]{2}{*}{ Type D } & D-I & - & - & - & - & - & - & 1 & 50 & - & - & 1 & 10 \\
\hline & & D-II & - & - & - & - & - & - & 1 & 50 & - & - & - & - \\
\hline \multirow[t]{5}{*}{ Context. } & \multirow[t]{3}{*}{ Type A } & $A-1$ & 2 & 28.57 & 2 & 66.67 & - & - & - & - & - & - & - & - \\
\hline & & $A-I I$ & - & - & - & - & - & - & - & - & 1 & 100 & - & - \\
\hline & & A-III & - & - & 1 & 33.33 & - & - & - & - & - & - & - & - \\
\hline & \multicolumn{2}{|l|}{ Type B } & 4 & 57.14 & - & - & - & - & - & - & - & - & - & - \\
\hline & \multicolumn{2}{|l|}{ Type C } & 1 & 14.29 & - & - & - & - & - & - & - & - & - & - \\
\hline
\end{tabular}

Table 6.5 Number of instances and percentage of use of syntactic types and subtypes

\subsection{Lexical choices in the use of organizational metadiscourse}

After having discussed the different types of syntactic structures that are recurrent in the use of organizational metadiscourse, in this section, I complete the answer to RQ 2.1 by zooming in onto a lexical level and examining the choice of words made by the lecturers in these metadiscursive instances. Thus, in Section 6.2.1, I reflect upon the words that are employed to proclaim metadiscourse, i.e. metadiscursive words. By examining these words, I look into the semantic choices made by the lecturers and how these differ for each course. Then, in Section 6.2.2, I explore the use of personal pronouns in metadiscourse. 


\subsubsection{Metadiscursive words}

The analysis of the words employed in metadiscursive instances reveals a series of trends in terms of the use of verbs and adverbs, particularly in introducing topic, previewing and reviewing metadiscursive types. The types of verbs are commonly shared in these types of metadiscourse with specific variations, especially in the verb tenses. As for the use of adverbs, these seem to be intrinsic to the specific metadiscursive category, although there might be some overlapping across categories that may result in a higher complexity when identifying metadiscursive functions in a text. Contextualizing metadiscourse, on the other hand, seems to work quite differently and lecturers make use of a varied lexicon in these instances.

Thus, the use of verbs in the metadiscursive instances analyzed is quite similar in introducing topic, previewing and reviewing metadiscourse. Following Biber et al.'s (1999) classification of verbs in semantic domains, some conclusions may be reached: communication and mental verbs are recurrently employed to proclaim metadiscourse. The former category includes verbs that involve communication activities like say, talk, speak, show, express, suggest, mention, quote, canvass, explain, describe, argue or discuss (see Example 58), and the latter provides a wider range of verbs that describe human experiences including cognitive verbs like focus (see Example 59), emotional expressions of volition like want (see Example 60), verbs of perception like see, distinguish and look at (see Example 61), and verbs of receipt of communication like read and hear (see Example 62). Furthermore, activity verbs expressing movement are also recurrent in these types of metadiscourse. Some examples are move on, go back, come back, turn to, go and return (see Example 63). Finally, in a less frequent occurrence, aspectual verbs like start, begin and end are also encountered in the data (see Example 64).

58) I've been talking about the tension between the symbolic and the real. (C1_L13)

59) [...] let's focus on my death as a person. (C3_L15)

60) I want to return briefly to 'desengaño' [...] (C6_L15)

61) We've been looking at some of the realities of the Continental Army. (C2_L13) 
62) [...] one of the principal organizers was a man named Bayard Rustin, someone we'll hear more about in the next couple of weeks. (C1_L13)

63) The two people were in Italy -and we'll be coming back to this in a couple of weeks, when we resume classes [...] (C5_L15)

64) Remember, I ended my lecture on Pynchon by arguing that sentiment remained important in Pynchon's work. (C4_L15)

The combination of verbs in lexical bundles is quite common in the organization of the discourse. This seems to be in line with the results shown by Nesi and Basturkmen (2006) who identify four-word bundles as recurrent devices in discourse signaling (see Section 3.3.1). As for the use of verbs in contextualizing metadiscourse, apparently, there are no evident trends. Contextualizing metadiscourse is used for various purposes: to comment on something that has occurred during the lecture, to apologize for various reasons, to make comments about how much time is left in the lecture, etc. In this regard, the verbs found in the dataset are heterogeneous as each instance is employed with a specific aim in mind.

The limited number of instances identified in these six representative lectures makes it impossible to claim that one expression or another can be assigned to a specific lecturing style. However, some trends in the use of verbal tenses seem to arise from this study for introducing topic, previewing and reviewing metadiscourse. In general terms, three main trends can be identified: both, present and future tenses are employed in the conveyance of introducing topic metadiscourse; future tenses are used in previewing fragments; and past tenses in reviewing instances. From this fact arises one of the issues encountered in the process of identification of organizational metadiscourse in the corpus: overlapping categories (see Section 5.1.2). The use of future tense verbs in previewing metadiscourse (either through the use of the auxiliary verb will or by means of to be + going to + verb formulae) may be very similar to the uses of future tenses in introducing topic metadiscourse. Thus, the distinction between introducing topic and previewing metadiscourse may pose problems to the analyst, especially when these instances are found in the introductions of the lectures where introductions of topics merge with 
previewing sections. In these cases, a close analysis of the context is needed to classify an instance within one category or another.

A second aspect that is worth commenting on, especially when discussing previewing and reviewing instances, is that of adverbs and adverbial clauses. As I detailed in sections 5.2.3.1 and 5.2.3.2, previewing metadiscourse may refer to information in the present lecture, in a future lecture, or it may not provide a connection with the referred information. Similarly, reviewing metadiscourse may refer to the present lecture, to a past lecture or to neither. In the cases in which references are provided, these are indicated by means of adverbial clauses. Thus, some of the adverbial clauses encountered in previewing metadiscourse in the representative lectures are: on Monday's lecture, on Monday/Thursday, in the next couple of weeks, at the end of the lecture, when we talk about..., in a moment, the next time, later today, after spring break, etc. Likewise, reviewing metadiscourse may be signaled by means of adverbial clauses like last time, previously, the last lecture, just, on this past Thursday, before, early in the course, at the start, etc. Although adverbial clauses are essential in many previewing and reviewing instances, they may also be present in introducing topic metadiscourse. In this case, they commonly refer to the most immediate present: today, at the moment, for now, first, this morning, etc. In this sense, the examination of these adverbial clauses may help distinguish introducing topic and previewing metadiscourse.

\subsubsection{Use of personal pronouns}

Another aspect of the linguistic analysis of organizational metadiscourse that I would like to point out is the use of personal pronouns. The use of pronouns has been identified as playing an important role in metadiscursive functions (Fortanet-Gómez, 2004a). In Ädel's (2006, p. 107) words, "the more deictic expressions are used in a text" (including pronouns such as $I$, we and you), "the more likely it seems that the text will be generally more metadiscursive". The choice of one pronoun over another may reflect an inclusion or 
exclusion of the audience in the process of guiding the students through the lecture. Three personal pronouns have been found in the dataset: $I$, we and you. Moreover, in the study of pronouns I have examined the bundles 'let me' and 'let us/let's', since these expressions also provide information about the inclusiveness of the audience in the speech.

A quantitative analysis of the occurrences of these pronouns in organizational metadiscourse is described in Table 6.6. The data in this table refer to the percentages over the total amount of metadiscursive instances for each of the lectures. It is important to remark that this table includes strategies used to introduce metadiscursive expressions in which personal pronouns are not employed -for instance, when choosing Type B structures that resort to descriptions of the topics/lectures or there is/there are structures. These strategies are contemplated under the label 'Other' in the table.

\begin{tabular}{|l|c|c|c|c|c|c|}
\cline { 2 - 7 } \multicolumn{1}{c|}{} & C1 & C2 & C3 & C4 & C5 & C6 \\
\hline I (or let me) & $67 \%$ & $55 \%$ & $53 \%$ & $78 \%$ & $26 \%$ & $36 \%$ \\
\hline We (or let's) & $17 \%$ & $30 \%$ & $47 \%$ & $11 \%$ & $68 \%$ & $64 \%$ \\
\hline You & $5 \%$ & $5 \%$ & - & - & - & - \\
\hline Other & $11 \%$ & $10 \%$ & - & $11 \%$ & $6 \%$ & - \\
\hline
\end{tabular}

Table 6.6 Percentages of the use of personal pronouns across disciplines

The results show that the use of $I$ is preferred over the rest of the options in $C 1$ and $C 2$ (conversational style lecturers) and C3 and C4 (rhetorical style lecturers). This preference is emphasized even more in the cases of $\mathrm{C} 1$ and $\mathrm{C} 4$. The use of $I$ has been identified as having growing preference in lectures (Hyland, 2001b). In fact, the proper use of we forms in conversational and rhetorical style lecturers is very limited and seems to be linked to perception verbs like 'see' and 'look at' (see Example 65). On the contrary, $l$ is preferred in the instances in which lecturers are describing the contents that they will develop in the lecture or those that were discussed in previous sessions (Example 66). These instances are many times linked to communication verbs like 'say', 'talk' or 'mention' and volition verbs like 'want'. Finally, the inclusion of the audience in the speech for these types of lecturers is mainly achieved by means of 'let us/let's' constructions (see Example 67). 
65) And as we saw really early on in the course, the colonies tended to come together for purposes of selfdefense when necessary [...] (C2_L13)

66) [...] but for now I'm going to talk about regionalism. (C2_L13)

67) But let's, at least, try to focus on the second question. (C3_L15)

On the other hand, we is the main choice for reading style lecturers (lecturers in $\mathrm{C} 5$ and C6). We forms are more inclusive and bring the students into the discourse, fostering engagement in metadiscursive sections (Young, 1994). This seems to be the case in the data here analyzed. In Example 68, for instance, the lecturer in C5 is introducing the lecture and uses the pronoun we to include the audience so that they take part in the unfolding process of the topics. The higher presence of we in reading style lecturers, moreover, could be the result of choosing the majestic we, which could be a common trend in traditional lectures. These results coincide with those in Fortanet-Gómez's (2004a) study of the use of we in which this pronoun is identified as an inclusive resource in the process of guiding throughout the speech event. Interestingly, the use of we by the lecturer in C5 is rejected in favor of I pronouns when making strong claims. This is shown in Example 69. In this example, this lecturer previews one of the arguments that he is going to develop in the class. In this case, he appears to use the pronoun I emphasizing his claim as he will be the one developing the argument.

68) Well, this morning we'll be considering that. (C5_L15)

69) And I'm going to argue that tropical medicine [...] was clearly socially constructed. (C5_L15)

Finally, the use of you is rarely found in the dataset and it is only present in C1 and C2 (conversational style) with one instance in each lecture (see Example 70). You forms appeal directly to the audience, however they seem to be rare in the organizational metadiscourse considered for this thesis.

70) And as you'll remember from going back to the First World War [...] (C1_L13)

After having examined the lexical choices in terms of metadiscursive words and the use of pronouns, in the following section, I consider both syntactic and semantic aspects as a whole and reflect upon the similarities and differences in the linguistic use of metadiscourse across lecturing styles. 


\subsection{Linguistic expression of organizational metadiscourse across lecturing styles}

This section aims to provide an answer to RQ 2.2:

RQ 2.2 1 Are there any similarities or differences in the verbal use of organizational metadiscourse across lecturing styles?

From a syntactic perspective, the dataset shows distinct types of structures arising from introducing topic, previewing, reviewing and contextualizing metadiscourse (see development in Section 6.1). However, in general terms, the choice of structures is rather homogeneous and the differences across lecturing styles are minimal. In this regard, only two aspects seem to stand out in the data. On the one hand, both rhetorical and reading style lectures show a slightly higher presence of Subtype A-I previewers, which include personal previewers in which the time referent (adverbial clause) is not specified. In other words, the use of non-connected previewers is slightly higher in rhetorical and reading style lecturers than it is in conversational style lectures. This seems to indicate a higher effort to specify time referents in conversational style lectures. Similarly, non-connected reviewers (Subtype A-I reviewers) are remarkably relevant in reading style lectures $(85.71 \%$ of the total number of reviewers in C5, and $80 \%$ in C6). As discussed in Section 6.1, these results are consistent with those presented at a quantitative level in Chapter 5 which may be related to the fact that metadiscourse occurs many times as a spontaneous comment on the speech with little reflection upon the structure of the lecture. However, in general terms, the number of metadiscursive instances encountered in the sub-corpus of representative lectures is not large enough to make broad generalizations.

In terms of lexical choices, two aspects have been analyzed: the use of common words in the use of organizational metadiscourse, and the use of personal pronouns. The study of common words aims to zoom in on the words that are recurrently employed to proclaim metadiscourse in lectures. In this sense, two categories of words seem relevant in the creation of metadiscourse: verbs and adverbs. In general terms, differences are found between introducing topic, previewing and reviewing on the one hand, and contextualizing 
on the other. While the former categories show a recurrent use of verbs and adverbs, no adverbs are found in contextualizing and the verbs in this category do not show any similar features with those in the other categories. The use of verbs and adverbs in introducing topic, previewing and reviewing, in turn, varies from category to category: previewing metadiscourse often employs verbs in future tenses and adverbs referring to either the present lecture or to a future one; reviewing metadiscourse employs verbs in past tenses and adverbs referring to either the present lecture or to a past one; and introducing topic metadiscourse uses verbs both in present and in future tenses, and commonly uses adverbs referring to the present lecture. Although the study of metadiscursive words shows trends in the lexical choices across types of metadiscourse, no relevant differences arise from the comparison of these uses in lecturing styles.

Finally, regarding the use of personal pronouns, conversational and rhetorical style lecturers seem to prefer the use of I over we or you, especially co-occurring with volition and perception verbs. On the other hand, reading style lecturers favor the use of an inclusive we, and $I$ has been found to be used in sentences where the presence of the lecturer needs to be distinguished, for instance, when the lecturers refer to their own arguments. The pronoun you is rarely used and has only been identified in conversational style lecturers.

In conclusion, few differences emerged in the linguistic uses of organizational metadiscourse across lecturing styles. In the cases where slight differences have been found, no strong conclusions may be posed as the number of occurrences analyzed is limited. In this sense, a broad linguistic annotation of a larger corpus followed by an automated corpus analysis might shed more light on the differences in the use of organizational metadiscourse at a syntactic and a lexical level.

In this chapter, I have provided an overall view of the ways in which organizational metadiscourse is used in academic lectures. I have described the syntactic and lexical aspects that are recurrent in the dataset, and I have looked at how metadiscourse is used linguistically across lecturing styles. In the following chapter, I take a deeper look into the 
use of organizational metadiscourse and I explore how lecturers use metadiscourse beyond words. In other words, I conduct a multimodal analysis to look at the use of non-verbal semiotic resources that co-occur with the linguistic verbalizations of metadiscourse. 


\section{CHAPTER 7. MULTIMODAL ANALYSIS: EXAMINING SEMIOTIC RESOURCES}

In the previous chapters, I have examined the use of organizational metadiscourse in lectures from a quantitative and a linguistic perspective. These analyses have contributed to narrowing down the scope of this thesis and to providing a general overview of the use of metadiscourse across lecturing styles. Having said that, the main contribution of this thesis to previous studies on metadiscourse is the use of multimodal methodologies to explore how metadiscourse is used as a combination of various modes -verbal and nonverbal, both embodied and disembodied-, to convey meaning. In this regard, the present chapter aims to answer RQ3 and its sub-questions:

\begin{tabular}{|l|l|}
\hline RQ 3 & How is organizational metadiscourse expressed non-verbally? \\
\hline RQ 3.1 & $\begin{array}{l}\text { What are the recurrent semiotic resources lecturers turn to in the use of metadiscursive } \\
\text { instances? }\end{array}$ \\
\hline RQ 3.2 & How do these semiotic resources combine in multimodal ensembles? \\
\hline RQ 3.3 & $\begin{array}{l}\text { Are there any similarities or differences in the non-verbal use of organizational } \\
\text { metadiscourse across lecturing styles? }\end{array}$ \\
\hline
\end{tabular}

In short, this chapter aims to describe the use of metadiscourse from a multimodal point of view, exploring the elements taking part in conversation and the ways in which they combine. As I discussed in Section 4.4.3, in order to analyze the use of semiotic resources as they are employed together with organizational metadiscourse in lectures, I employ the corpus of six structuring segments (see Section 4.3.2). Structuring segments are fragments of the lecture where the lecturers organize their speech by letting the audience know about the topics that are being introduced, by connecting information with previously explored contents or by outlining the contents of the lecture, for instance. These segments contain abundant metadiscursive instances, mainly those of introducing topic, previewing and reviewing. By employing concepts and tools from MSS (Kress, 2000, 2010, Kress \& van Leeuwen, 1996, 2001) and MDA (O'Halloran, 2004a, 2007, 2008, 2011; O'Toole, 2011), I annotated the clips using the software MMA-Video and considering the modes of speech, gesture, gaze, head movement, posture, paralanguage, proxemics and facial expression. The annotations were then closely examined and run through the State Machine provided by the software MMA-Video in order to obtain quantitative data on the use of semiotic 
resources. Moreover, the audio files were processed using the software Sonic Visualiser together with the plug-in pYin in order to examine paralinguistic features (see sections 2.4.2 and 4.4.3 for an elaborated review of the software employed and the processes carried out in this chapter).

In the next sections, I explore the results obtained in this analysis. In Section 7.1, I focus on RQ 3.1 and I describe the quantitative use of semiotic resources employed by lecturers in organizational sections by considering the quantitative data provided by the State Machine in MMA-Video. Moreover, I highlight those similarities and differences that seem to be intrinsic to lecturing styles. Next, in Section 7.2, I focus on RQ 3.2 and take a further look into the data. In this section, I compare how semiotic resources combine and co-occur to create multimodal ensembles. Finally, I look into the ways in which the choice of a lecturing style over another constrains the availability of semiotic resources at hand. The influence of the lecturing style as a variable seems to be more evident when multimodally exploring the data. In this sense, RQ 3.3, whose interest is in the comparison of lecturing styles, will be included in both Section 7.1 and 7.2.

\subsection{Semiotic resources in structuring segments}

In order to understand how lecturers make use of semiotic resources, I investigate their multimodal discourse and zoom in on the particular use of the modes speech, gesture, gaze, head movement, posture, paralanguage, proxemics, and facial expression, and how these modes combine to convey meaning. In this regard, this section is mainly concerned with RQ 3.1:

RQ 3.1

What are the recurrent semiotic resources lecturers turn to in the use of metadiscursive instances?

In order to answer this question, in Section 7.1.1 I provide quantitative data on the use of recurrent semiotic resources in structuring segments. These results are complemented by Section 7.1.2, in which I discuss the use of paralinguistic devices and show a series of 
examples extracted from the analysis using Sonic Vlsualiser. These sections demonstrate how gestures, gaze, posture, proxemics and paralanguage are regularly employed as semiotic resources in the use of organizational metadiscourse. Furthermore, along the present study, I argue that lecturing styles affect the use of organizational metadiscourse both at a linguistic and at a non-verbal level. Thus, throughout this section, I will refer to how the use of semiotic resources shows similarities and differences in relation to the lecturing styles. In other words, I will try to answer RQ 3.3 as far as the use of semiotic resources is concerned:

RQ 3.3 Are there any similarities or differences in the non-verbal use of organizational metadiscourse across lecturing styles?

Although individual traits may exert an influence on the choices made by each lecturer (Galloway, 1972), I focus on those elements that contribute to defining lecturing styles in terms of semiotic resources. In this sense, the exploration of RQ 3.3 in the following sections demonstrates a series of similar uses of semiotic resources that seem intrinsic to each lecturing style.

\subsubsection{Quantitative use of semiotic resources}

Table 7.1 below describes the results obtained when exploring each of the semiotic resources employed by each of the lecturers individually. The figures are shown in terms of percentages; thus, for example, the figure 23.21 in Gestures $>$ Gesture type > Beat for the lecturer in $\mathrm{C} 1$ indicates that this lecturer performs beats during a $23.21 \%$ of the time of the clip, and so on and so forth. The sets of system choices analyzed correspond to those in the analytical framework described in Section 4.3.3. The use of paralanguage is not included in this table as no objective quantitative data could be obtained using MMAVideo. Instead, this semiotic resource will be explored in detail in Section 7.1.2. As I explained in Section 4.4.3 and at the beginning of this chapter, the analysis of the semiotic resources here presented has been carried out by examining six short clips where lecturers are performing what I refer to as structuring segments. 
As stated above, the recurrent semiotic resources that seem to play an important role in the conveyance of metadiscourse are gestures, gaze, posture, proxemics, and paralanguage. Still and all, it seems appropriate to review all modes analyzed for this analysis. An interesting element within the mode of speech, for instance, is the use of pauses. The percentage of silence describes the amount of time in which lecturers do not use the mode of speech. In general terms, pauses seem to be more frequent in reading style lecturers (15.04\% in C5 and $21.08 \%$ in C6). Pauses are commonly employed by lecturers to look at their notes in preparation for the following bit of lecture (in conversational and reading style lecturers) or to mentally organize thoughts before going on with the lecture (in rhetorical style lecturers). In this sense, it is interesting to remark that $\mathrm{C} 1$ shows the highest amount of silence (24.40\%), which seems to indicate that this lecturer depends highly on the notes. This assumption coincides with previous results (Bernad-Mechó, 2017a) suggesting that this particular lecturer seems to assimilate features from reading style lecturers. Finally, although silences in rhetorical style lecturers are not common, these lecturers seem to perform longer pauses when changing ideas. I argue that these pauses are the result of a process of self-organization of thoughts in which lecturers move from one idea into the other. Having few verbal metadiscursive markers in their speech, these pauses help to mark the distinction between ideas. However, this assumption would need an analysis of a larger corpus to be confirmed. 


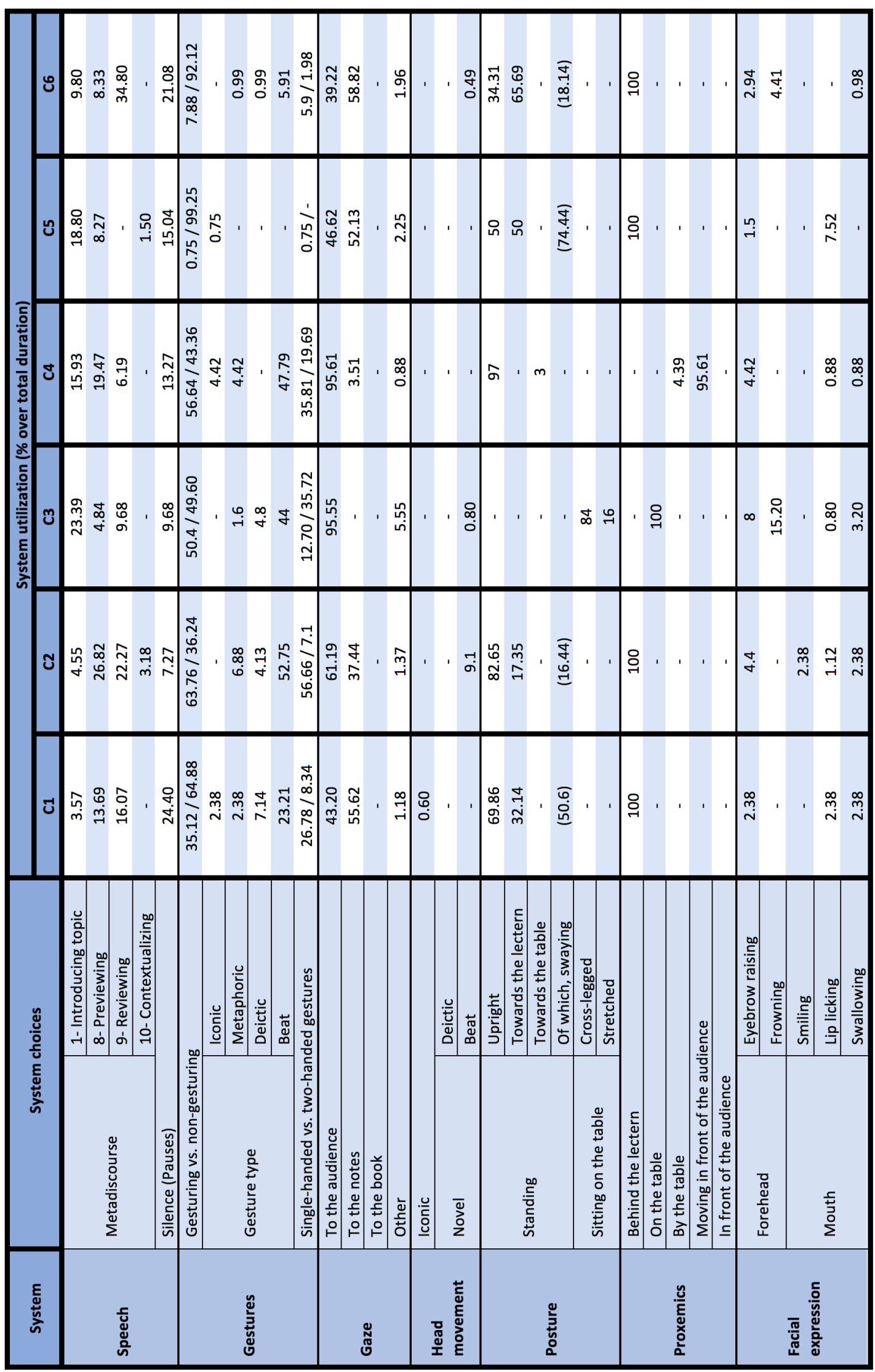

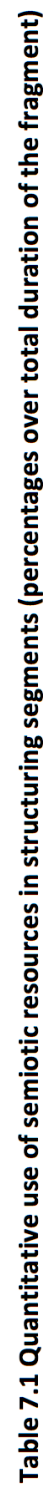


As for gestures, these are one of the most common semiotic resources utilized during speaking. In the present analysis, I have looked at the number of gestures employed during the clips, the types of gestures and whether gestures are performed with a single hand or with both hands. On the whole, beats are the most common type of gestures throughout the data. These gestures lack semantic content (Andric \& Small, 2012), often accompany speech and are used to mark the rhythm of the interaction or to emphasize certain parts of the discourse (Leonard \& Cummins, 2011). As for the rest of types, the use of metaphoric and deictic gestures also receives a degree of attention. In the case of the latter, deictic gestures are often accompanied by previewing and reviewing instances, as these gestures are used to point to the references in time to which the metadiscursive fragments refer (see Ensemble 2 in Section 7.2.1 for an example of the use of a deictic gesture). When looking at the lecturing styles, two main trends seem to arise: on the one hand, conversational and rhetorical style lecturers make a fair use of gestures (ranging from $35.12 \%$ to $63.76 \%$ ); on the other hand, reading style lecturers show the lowest figures in terms of gesture use $(0.75 \%$ for $\mathrm{C} 5$ and $7.88 \%$ for $\mathrm{C} 6)$. As reading style lecturers, the use of gestures is limited; these lecturers mostly focus on their notes and their hands are mainly placed either on the notes or on the lectern. In this line, gestures seem to be more common in spontaneously-driven comments that drag these lecturers off their notes into a more conversational style. Finally, the use of two-handed gestures is higher in rhetorical style lecturers and seems to show more expressiveness. In the case of conversational and reading style lecturers, single-handed gestures are preferred, probably due to the constraints exerted by the notes that are being held with at least one hand throughout the lecturing process.

In the case of gaze, this semiotic resource appears to be an indicator of the foci of the lecturers (whether they are focused on their notes or on the audience) and serves as an engager tool to bring the audience into the lecturing process. This is particularly relevant when signaling the direction and organization of the lecture through organizational metadiscourse (Bernad-Mechó \& Fortanet-Gómez, forthcoming). Thus, the more lecturers depend on notes, the more they turn their gaze towards them. On the one hand, when lecturers produce spontaneous comments their gaze is mostly directed towards the audience as they are providing information that has not been planned for and is not in their 
notes. In the dataset, differences across lecturing styles are easily identified in the use of gaze in structuring segments. On the other hand, rhetorical style lecturers gaze at the audience during almost all throughout the fragments. In contrast, reading style lecturers, look both at the audience, and particularly towards the notes $(52.13 \%$ in $\mathrm{C} 5$ and $58.82 \%$ in C6). Reading sections in these lecturers are interspersed with quick glances to the audience, especially at the end of utterances and in line with Kendon's (1967) results discussed under Section 2.3.2. Moreover, when reading style lecturers produce spontaneous comments, their gaze is mostly directed towards the audience. Finally, conversational style lecturers also share their gaze between the audience and the notes. However, the amount of time directed to the notes is dissimilar in these lecturers (55.62\% in C1 and $37.44 \%$ in C2). In line with the use of silence, this seems to indicate a higher relevance of notes for the lecturer in $\mathrm{C} 1$. In this regard, this lecturer makes constant pauses to check his notes before introducing new information.

The analysis of head movement reveals the fact that its use is rather limited if compared to other semiotic resources. In fact, only the lecturer in C2 seems to make a frequent use of this semiotic resource as she produces head beats during $9.1 \%$ of the time. This seems to be an individual trait of this lecturer as no other relevant uses have been found in the data. According to Norris (2004), the more head movements, the stronger the message is. Thus, the head movements identified in C2 might serve as intensifiers of the message.

As for posture, the ways in which lecturers position their bodies provide input on how the lecturers relate to their audience and their environment. Differences across lecturing styles in the use of posture are evident. On the one hand, rhetorical style lecturers show "alternative" strategies to lecturing position, as opposed to the traditional behind-thelectern style. Particularly, the lecturer in C3 sits on his table during his lectures, and the lecturer in C4 stands in front of the audience. In both cases, their postures face the audience at all times, thus engaging the audience in their discourse. The rest of the lecturers, both conversational and reading style lecturers, stand behind their lecterns and alternate an upright position facing the audience and a leaned position towards the lectern that indicates that the focus is on the notes. The use of upright positions is more frequent in conversational style lecturers $(69.86 \%$ for $\mathrm{C} 1$ and $82.65 \%$ for $\mathrm{C} 2)$ than in reading style 
lecturers who lean towards the lectern more frequently (50\% in C5 and 65.69\% in C6). Finally, a slight swaying movement has been identified in both conversational and reading style lecturers, which may be used as a rhythm marker to accompany speech.

When looking at proxemics and the use the lecturers make of the classroom spaces two trends can be easily identified. On the one hand, conversational and reading style lecturers make little use of the classroom space. Basically, these lecturers stand behind the podium and, as I have stated when describing the use of gaze and posture, they alternate facing the audience and their notes. Rhetorical style lectures, on the other hand, stand closer to the audience, which fosters the audience's engagement in the lecture.

Lastly, the use of facial expression as a semiotic resource is generally limited and does not seem to be directly related to the lecturing style of the lecturers. Instead, it appears to be an individual trait that varies from person to person.

Representations of the most common uses of semiotic resources across lecturing styles may be found in sections 7.2.1, 7.2.2, and 7.2.3.

\subsubsection{Exploring paralanguage}

In order to complete the study on recurrent semiotic resources, I explore the use of paralanguage in this section. As I detailed in Section 4.3.3, a quantification of paralinguistic resources employed by lecturers using MMA-Video is a tricky task as the software does not perform a sound analysis on the audio file and, therefore, all annotations would need to be manual on the subjective impression of the analyst. Consequently, no quantitative data is provided on the use of paralinguistic devices. Instead, an analysis of the pitch lines and intensity has been carried out using the software Sonic Visualiser and its plug-in pYin (see Section 2.4.2). The results provide various insights on the use of paralanguage in structuring segments: as an indicator of whether a section has finished or not and as an emphasizer. 
Firstly, in line with the results shown in Bernad-Mechó (2017a), intonation may indicate the level of completion of an utterance or a section; in other words, whether a part of speech has come to an end or is expected to be continued. In the example described in Figure 7.1 below, the lecturer in $\mathrm{C} 1$ is providing an enumeration in which he reviews the topics that he discussed in the previous lecture. After having listed the topics that were considered in the previous class, the lecturer introduces the new topic that will be developed through the first part of the lecture. The topics being reviewed -“A. Philip Randolph's March on Washington Movement, Randolph's bluff with FDR, FDR's issuing of Executive Order 8802, and the creation of the FEPC"-, are all pronounced in a rising pitch intonation except for the last one ("the creation of the FEPC") that is pronounced in a falling pitch intonation. The intonation at the end of each element in the list is circled in red. In this sense, the rising pitch intonation in an enumeration in English commonly indicates that the list is not over yet, while the falling intonation in an enumeration seems to mark the end of the list. From this perspective, the use of a paralinguistic device (intonation) serves in this example as a signal to indicate students where the separation between one section and the other occurs.

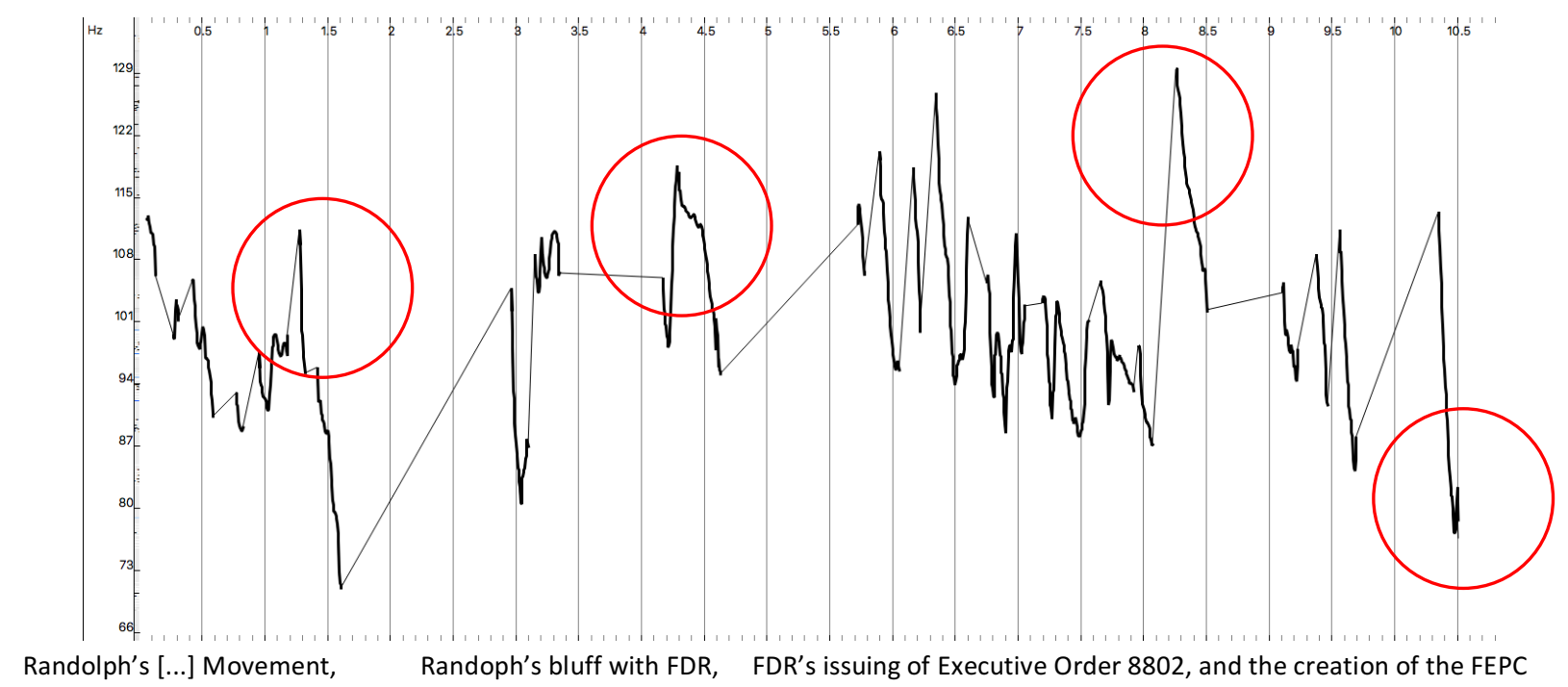

Figure 7.1 Use of intonation as an indicator of the separation of sections in C1

Secondly, pitch and volume may also be used as emphasizers. The use of paralinguistic devices to reinforce certain parts of the speech is common to all lecturers in the dataset. However, these uses are more marked in rhetorical and reading style lecturers. For the 
former, the use of paralinguistic devices for emphasis seems to be a result of the tendency of these lecturers to connect with the audience (for instance, through the use of twohanded gestures, gaze, posture, and proxemics, as detailed in the previous section). In the case of reading style lecturers, however, the paralinguistic emphasis seems to become one of the few semiotic resources that is available to them. In other words, as these lecturers' focus needs to be on the notes, they can only engage with the audience in a limited manner. In this regard, intonation and intensity serve not only as emphasizers, but also as engagers and as tools to break the monotony in reading sections. In Figure 7.2, the lecturer in $\mathrm{C} 6$ breaks his monotonous intonation during the explanation of the contents of two papers to emphasize the utterance "that thesis is about the Christian mixture of the sublime". He does so by employing high pitch and intensity in the syllables of the main content words in the utterance, i.e. "THEsis", "CHRIStian", "MIXture" and "sublime". The peaks in intensity are circled in red.

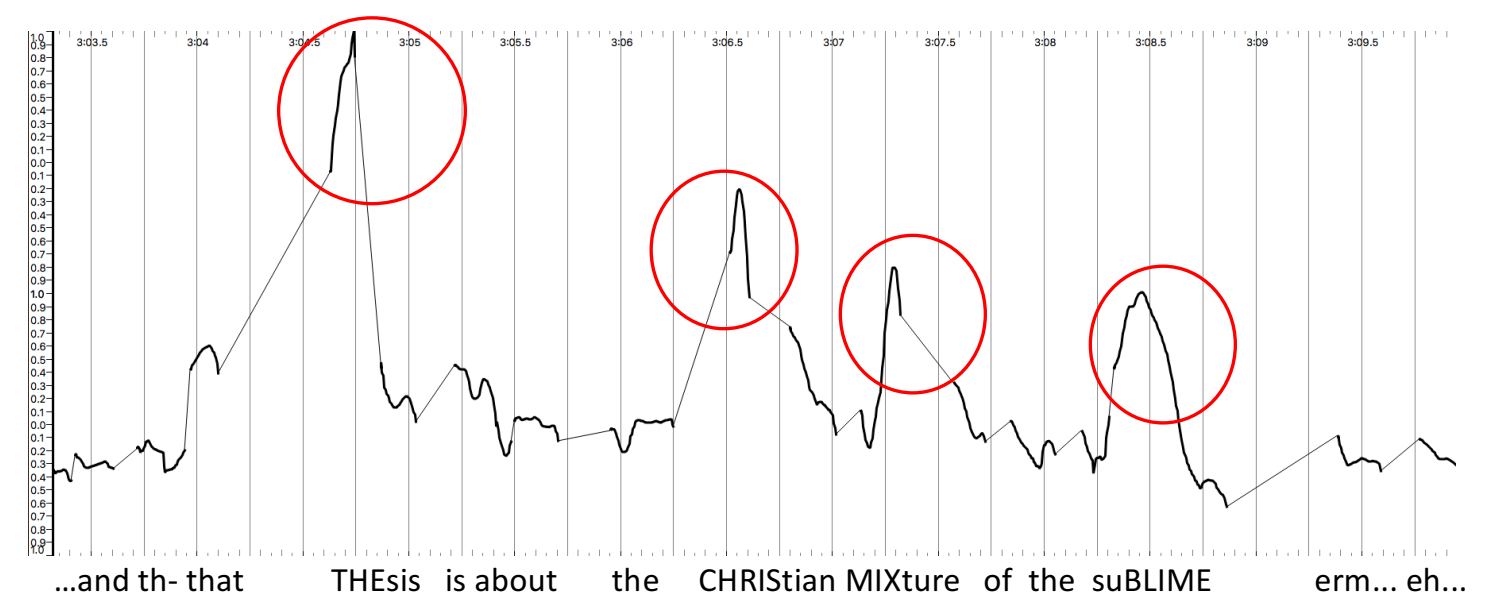

Figure 7.2 Use of intonation and intensity as emphasizers in $\mathrm{C6}$

In conclusion, paralinguistic resources can be used to indicate the degree of completion of utterances and separate long stretches of speech and to provide emphasis. Moreover, paralinguistic devices as emphasizers are particularly relevant in both rhetorical and reading style lecturers. This fact seems to be the result of two different motives. On the one hand, rhetorical style lecturers are the ones who employ more semiotic resources to engage the audience (Bernad-Mechó \& Fortanet-Gómez, forthcoming). In this sense, intonation is just one more element to stress certain parts of the text. Reading style 
lecturers, on the other hand, may use intonation as one of the few semiotic resources they have at hand. In section 7.3.4 below, I further examine this point as I reflect upon the availability of semiotic resources that seems to be attached to each lecturing style.

All in all, the analysis shown in the previous section and throughout the present one points to recurrent uses of specific semiotic resources that seem to describe a common ground for each lecturing style and which are summarized in Table 7.2. These common features may be understood in terms of the relation with the audience, i.e. the degree of engagement that they achieve, and the relation with the notes, i.e. the attention paid to the notes. Thus, conversational style lecturers convey organizational meaning by combining metadiscursive instances with abundant single-handed gestures, gaze positions that alternate from the notes to the audience, an upright position behind the lectern and a slight rhythmic swaying. Rhetorical style lecturers, in turn, also use abundant gestures (with high percentages for two-handed gestures), turn their gaze exclusively towards the audience and make a use of their body postures and space that bring them closer to the audience. Moreover, they may use paralinguistic devices for emphasis. Finally, reading style lecturers are characterized by using recurrent silences, very few gestures, being closer to their notes -which is shown in the use of gaze and posture towards the lectern-, and using intonation and intensity for emphasis. Still and all, some stylistic differences have been identified in the analysis within lecturing styles. The most representative example is that of C1. As indicated in Section 5.4.1, this lecturer seems to share traits with reading style lecturers. This may be the result of the higher degree of importance devoted to the notes. Being constrained by the use of notes, some of the resources employed by this lecturer are limited, thus showing similarities with reading style lecturers (see Section 7.3.4 for a discussion on how lecturing styles constrain modal density). In this regard, lecturing styles seem to offer fuzzy boundaries and individual lecturers may be positioned on a continuum that alternates a focus on the notes on the one hand and a focus on the audience on the other. 


\begin{tabular}{|l|l|l|l|}
\hline & \multicolumn{1}{c|}{ Conversational style } & \multicolumn{1}{c|}{ Rhetorical style } & \multicolumn{1}{c|}{ Reading style } \\
\hline Speech & No relevant similarities & No relevant similarities & $\begin{array}{l}\text { Significant use of } \\
\text { silences }\end{array}$ \\
\hline Gestures & Elevated use of gestures & $\begin{array}{l}\text { Elevated use of gestures. } \\
\text { Presence of two-handed } \\
\text { gestures }\end{array}$ & $\begin{array}{l}\text { Very few gestures } \\
\text { Gaze }\end{array}$ \\
\cline { 1 - 4 } & $\begin{array}{l}\text { Towards the audience and } \\
\text { the notes }\end{array}$ & Towards the audience & $\begin{array}{l}\text { Mainly towards the } \\
\text { notes, but also towards } \\
\text { the audience }\end{array}$ \\
\hline Head movements & No relevant similarities & No relevant similarities & No relevant similarities \\
\hline Posture & $\begin{array}{l}\text { Towards the audience, in } \\
\text { an upright position } \\
\text { Sometimes towards the } \\
\text { notes. } \\
\text { Slight rhythmic swaying }\end{array}$ & Close to the audience & $\begin{array}{l}\text { Towards the notes, in a } \\
\text { leaning position. } \\
\text { Sometimes towards the }\end{array}$ \\
\hline Proxemics & Behind the lectern & Alternative uses & $\begin{array}{l}\text { audience. } \\
\text { Slight rhythmic swaying }\end{array}$ \\
\hline Facial expression & No relevant similarities & No relevant similarities & No relevant similarities \\
\hline Paralanguage & No relevant similarities & Used for emphasis & Used for emphasis \\
\hline
\end{tabular}

Table 7.2 Defining uses of semiotic resources across lecturing styles

\subsection{Combining semiotic resources in multimodal ensembles}

In this section, I zoom in on the metadiscursive instances present in the six structuring segments in the sub-corpus and examine the common multimodal ensembles employed by the lecturers, i.e. combinations of semiotic resources co-occurring in these fragments. By doing so, I aim to describe how metadiscourse is co-constructed in different lecturing styles. Thus, the focus of this section is to respond RQ 3.2 and RQ 3.3:

\begin{tabular}{|l|l|}
\hline RQ 3.2 & How do these semiotic resources combine in multimodal ensembles? \\
\hline RQ 3.3 & $\begin{array}{l}\text { Are there any similarities or differences in the non-verbal use of organizational } \\
\text { metadiscourse across lecturing styles? }\end{array}$ \\
\hline
\end{tabular}

In order to provide an answer to these questions, I show a series of examples of the combinations of particular resources in multimodal ensembles and I compare these across lecturing styles. In these ensembles, I comment on the most relevant semiotic resources utilized when conveying metadiscourse. Ultimately, the results show how lecturers employing distinct lecturing styles co-construct meaning differently using the resources 
that are available to them. The availability of these semiotic resources, in turn, seems to be determined by the lecturing style per se and by the degree of attention the lecturers devote to their notes. In order to display the analysis of multimodal ensembles, this section is organized as follows: in Section 7.2.1, I focus on conversational style lecturers and I show three common multimodal ensembles emphasizing the varied use of gestures performed by these lecturers; next, I turn to rhetorical style lecturers in Section 7.2.2 and I discuss two further examples showing the relevance of posture in this lecturing style; after that, in Section 7.2.3, I zoom in on reading style lecturers and describe how metadiscourse may be found in spontaneous fragments or in reading fragments, and how these multimodal ensembles differ; finally, in Section 7.2.4, I conclude the chapter by reflecting upon the ways in which lecturing styles affect the modal density of the multimodal ensembles.

\subsubsection{Multimodal ensembles in conversational style lectures}

As I discussed in the previous section, the multimodal analysis of the dataset demonstrates that different lecturing styles make distinct semiotic choices when elaborating structuring segments. When zooming in on the particular choices co-occurring with metadiscursive instances some trends can be identified not only in the use of semiotic resources, but also in the relevance of notes and the ways in which the audience can be engaged.

Firstly, the most common multimodal ensembles in conversational style lectures are those including organizational metadiscourse accompanied by gestures. Interestingly, the gestures performed by conversational style lecturers that co-occur with organizational metadiscourse are not only beats (the most common type), but also iconic, metaphoric and deictic gestures. In this regard, the combination of organizational metadiscourse with iconic, metaphoric and deictic gestures in conversational style lectures is higher than in other lecturing styles. Out of these, of particular relevance are deictic gestures, which are found especially co-occurring with previewing and reviewing metadiscourse. In addition, although less frequently, conversational style lecturers may also employ wider multimodal ensembles to signal metadiscourse out to the audience. In the following lines, I describe 
three fragments encompassing three multimodal ensembles by conversational style lecturers: a reviewing instance co-occurring with a metaphoric gesture in C1 (Ensemble 1); a reviewing fragment accompanied by a deictic gesture in C2 (Ensemble 2); and a more complex multimodal ensemble displaying previewing metadiscourse in C2 (Ensemble 3).

\section{Ensemble 1}

Figure 7.3 describes an example of gesture co-occurrence in conversational style lectures. In this example, the lecturer in $\mathrm{C} 1$ is performing a metaphoric gesture that co-occurs with the utterance "I was trying to cram a lot of things into the lecture" in a reviewing section. The movement with his hand seems to depict the abstract idea of fitting elements in a particular place -in this case, "the lecture". Although this gesture cannot be understood in isolation without its verbal counterpart, it emphasizes the metadiscursive expression that is directed to the audience. Initially, no relation between the type of metadiscourse and the type of gesture may be established. In this sense, the presence of a metaphoric gesture seems to match the semantic choice of "cramming" things into a place.

Another aspect that may be observed in Figure 7.3 is the importance that notes have for this particular lecturer. As I detail in Section 7.2.4 below, the use of notes -as a choice attached to the lecturing style- seems to constrain the available options in the range of semiotic resources that the lecturers may resort to. In the present example, the lecturer quickly turns his gaze towards the notes at the end of the utterance, even though he is producing a non-note-driven spontaneous -organizational- comment for which notes are not needed. The shift in gaze coincides with the beginning of an introducing topic instance "give me two minutes to talk about the FEPC very quickly". The use of gaze is a typical resource used to engage the audience (Manusov \& Patterson, 2006). In this case, the lecturer constantly shifts from notes to the audience and vice versa in an attempt to connect with the audience.

Finally, from a paralinguistic perspective, it is interesting to remark that the reviewing utterance in this example ("I was trying to cram a lot of things into the lecture") is uttered 
with a short syllabic duration, i.e. it is produced faster than the rest of the speech. When considering the number of syllables per second, this utterance is produced at 7.78 syllables per second (compared with 5.29 as the rate for the second sentence in the example). This appears to indicate a spontaneous use of metadiscourse (see Section 8.2.2).

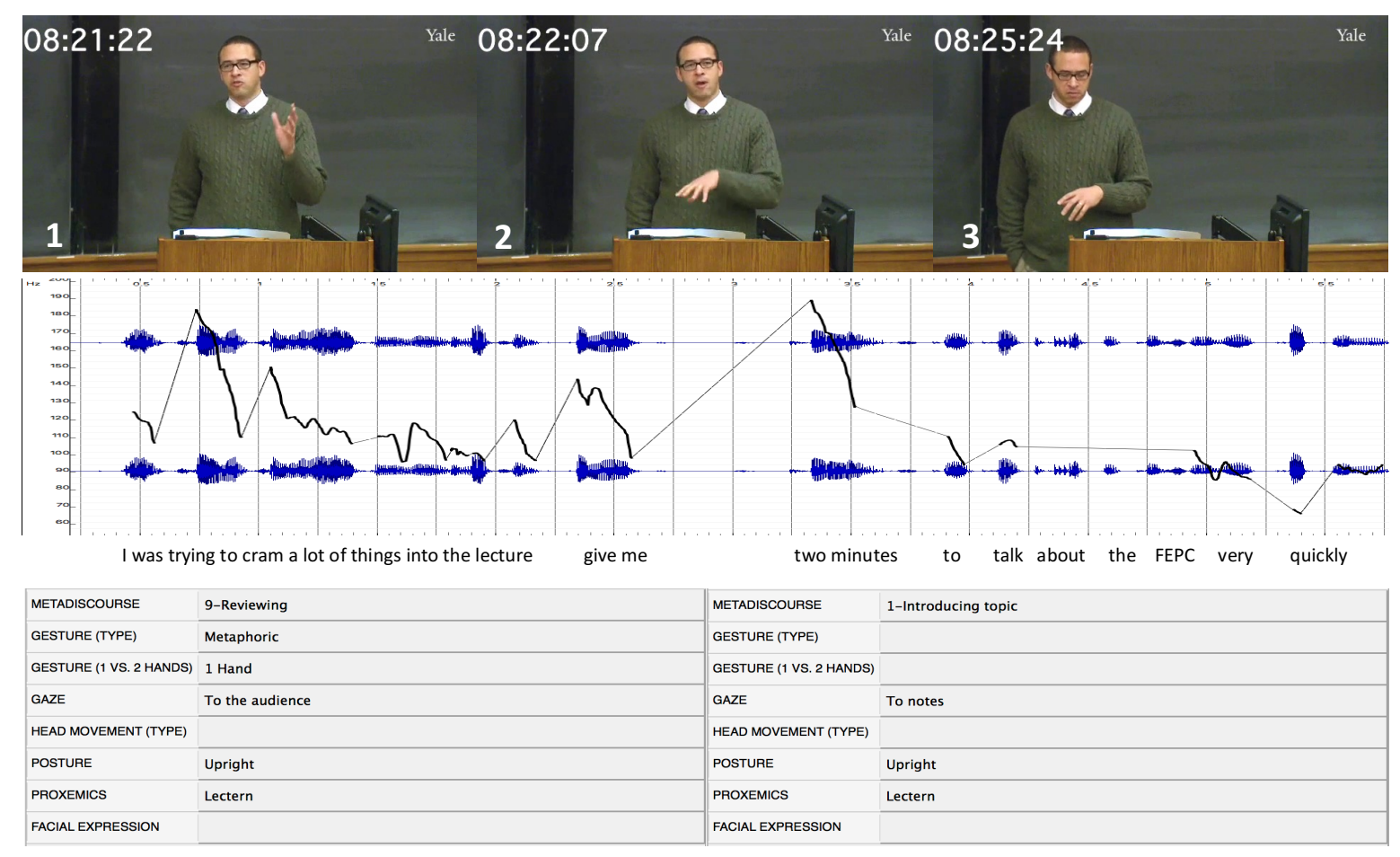

Figure 7.3 Ensemble 1 (Reviewing metadiscourse in C1)

\section{Ensemble 2}

In Figure 7.4, I exemplify a multimodal ensemble in which reviewing metadiscourse cooccurs with a deictic gesture. In line with the results shown in Bernad-Mechó (2015a) and in Bernad-Mechó and Fortanet-Gómez (2017), deictic gestures have been found to cooccur with some previewing and reviewing metadiscursive expressions. In the dataset being analyzed, a number of these instances have been found both in conversational and rhetorical style lectures. Deictic gestures are used to point to concrete or abstract entities. In the case of previewing and reviewing instances, deictic gestures seem to point to the abstract point in the past or in the future to which the metadiscursive instance refers, thus visually reinforcing the connection established verbally. 


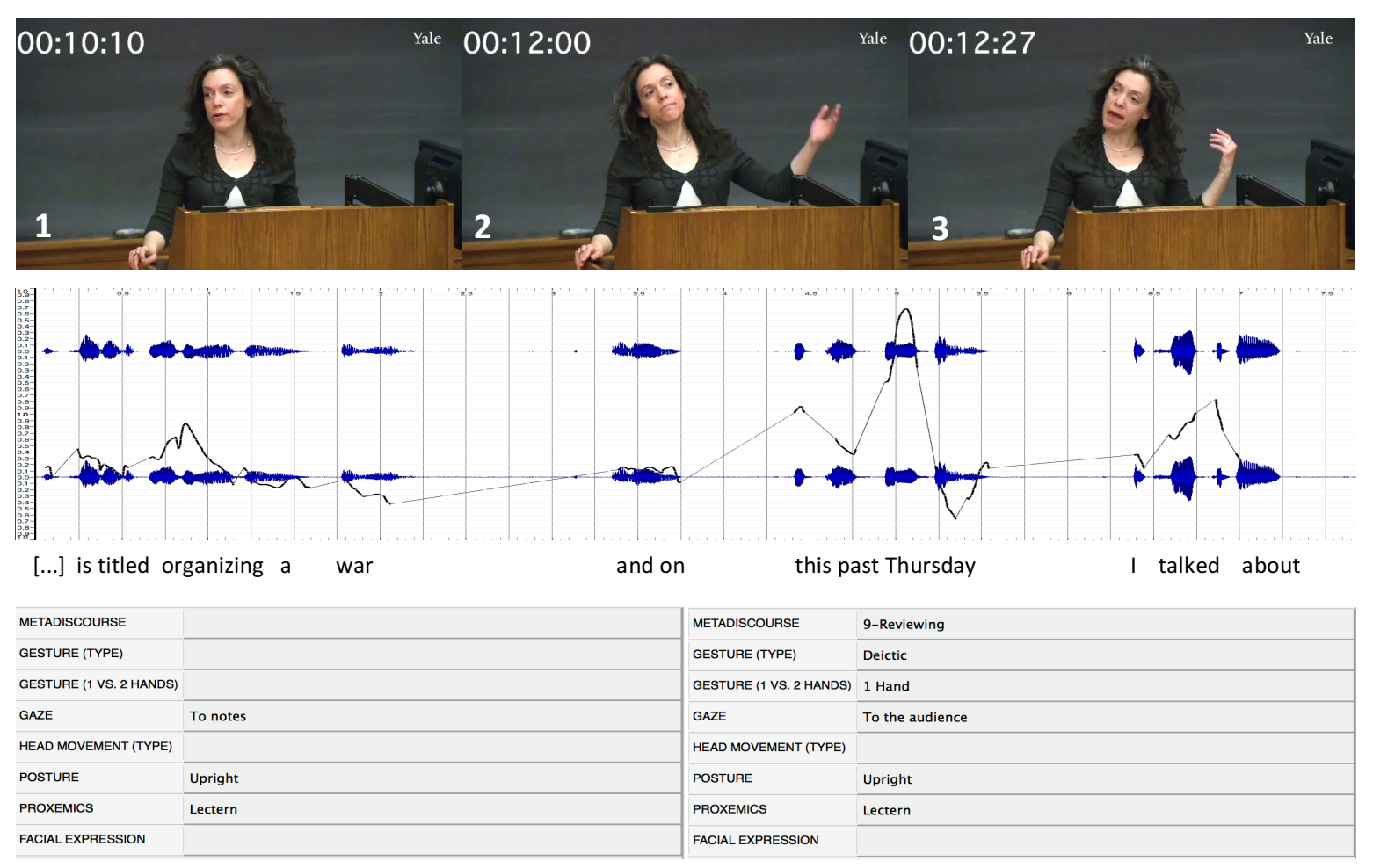

Figure 7.4 Ensemble 2 (Reviewing metadiscourse in C2)

In the present example, the lecturer in $\mathrm{C} 2$ is introducing the lecture. She begins by stating the title of the lecture-Organizing a War-, and then, after a short pause in which she briefly checks her notes, she establishes a connection with the contents of the previous lecture by uttering "and on this past Thursday, I talked about the opening phases...". She does so by directing her gaze towards the audience and performing a deictic gesture in which she raises her hand and moves it backwards towards the board. This gesture co-occurs with the clause "this past Thursday" and makes the connection with the previous lecture more evident in a modally coherent ensemble. By gazing at the audience and performing the deictic gesture, this lecturer engages the audience and makes the organizational signals of the lecture explicit. Unlike the previous example, deictic gestures are frequently found in multimodal ensembles with previewing and reviewing instances (especially in future lecture previewers and past lecture reviewers). 


\section{Ensemble 3}

Finally, in a less common fashion, conversational style lecturers signal out metadiscursive instances to the audience by means of several semiotic resources co-occurring at the same time. In Figure 7.5, the lecturer in $\mathrm{C} 2$ is introducing a previewing instance by uttering "well today, what we're going to be looking at is some of the challenges facing these [...] states". She does so while performing a beat, a slight swaying movement, a head movement and an eyebrow raising that seem to emphasize the previewing function of the organizational metadiscourse while providing a certain sense of rhythm to her speech. In a sense, the use of non-verbal resources in this example seems to perform the function of boosters following Hyland's (2005) terminology. At the same time that the lecturer guides the audience by establishing connections through a gaze shift towards the audience and an upright posture. At a paralinguistic level, a higher intonation is provided the beginning of the reviewing fragment that serves as an emphatic tool (indicated in a red circle in Figure 7.5). Furthermore, a short pause is employed to separate the first part of the metadiscursive instance ("well today"), from the actual information being previewed ("what we're gonna be looking at is some of the challenges..."). This separation, combined with the stress through a rising pitch, seems to stress even more the metadiscursive device. By combining all these semiotic resources the lecturer appears to aim for the audience's attention as she is offering some important guidelines to ease comprehension through the lecture. The combination of several modes to reinforce interactional sections coincides with the results shown in Crawford Camiciottoli $(2015,2016)$.

It seems relevant to remark here that the specific combinations of modes described in the examples above seem to exert a higher influence when the lecturers explicitly utilize verbal metadiscursive instances. Thus, when the lecturers are gazing towards the notes, they rarely use the mode of speech to convey metadiscursive functions nor employ gestures. In other words, verbal metadiscourse in the structuring segments here analyzed rarely stands alone and seems to be explicitly signaled to the audience by showing a high modal density. In these cases, and as I develop in Section 8.2 in the next chapter, metadiscourse receives full attention by the lecturers and plays an active role in the organizational process. 


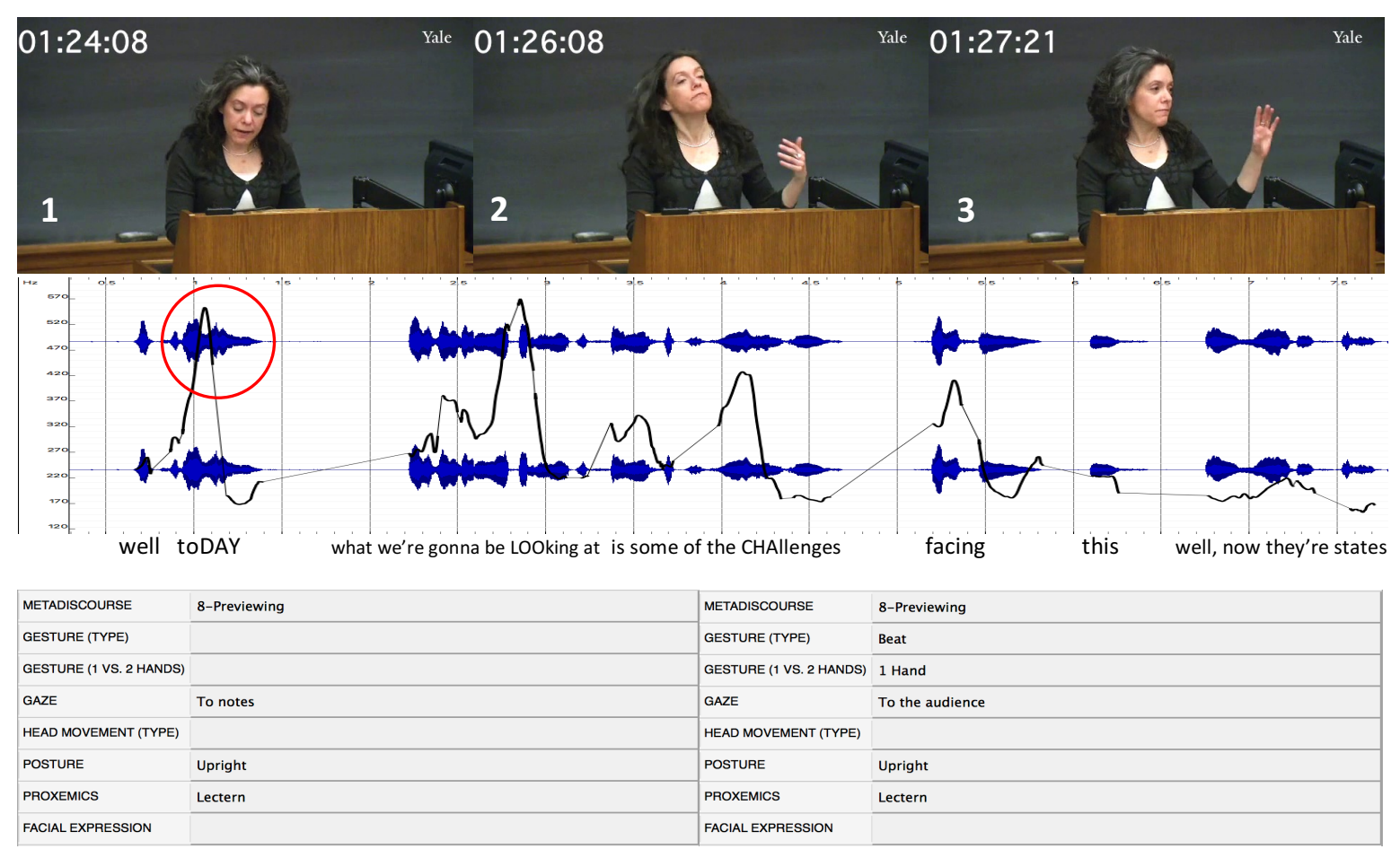

Figure 7.5 Ensemble 3 (Previewing metadiscourse in C2)

\subsubsection{Multimodal ensembles in rhetorical style lectures}

The combination of verbal and non-verbal resources in the conveyance of organizational metadiscourse is also present in rhetorical style lectures, albeit with noteworthy differences when compared to conversational style lectures. In general terms, rhetorical style lecturers expand the range of semiotic resources available at their disposal, including posture and proxemics as two paramount elements to approach and engage the audience. In this section, I show two examples describing these types of multimodal ensembles: an introducing topic fragment in C3 in which no gestures occur but posture plays an important role (Ensemble 4); and a second multimodal ensemble in C3 in which the lecturer produces an introducing topic instance together with a combination of several modes (Ensemble 5). 


\section{Ensemble 4}

Figure 7.6 depicts the lecturer in C3 introducing the topic that he is going to develop in the upcoming part of the class by saying "Still, there are a couple of claims about death that get made frequently enough [...] that I want to focus on". During the utterance of the introduction of the topic, the lecturer does not perform any gesture as he is positioned leaning towards the audience and with both of his hands "holding" the table (Image 1). Interestingly, although he does not perform any gestures, a series of semiotic resources are found in a multimodal ensemble with the verbal conveyance of the metadiscursive function of introducing the topic: he marks the rhythm of the utterance by leaning his posture from one side to the other repeatedly (Images 2 and 3 ) and through the use of paralinguistic emphasis (see red circles in pitch transcription). In addition, the lecturer changes his posture after introducing the topic, which seems to reinforce the boundary between one topic and the next one (Images 4 and 5). In other words, right after having introduced the topic, the lecturer changes his body posture: he moves from a leaning position towards the audience to an upright position, he releases his hands from the table and crosses one leg over the other.

At this point, he begins a content phase in which he starts lecturing on a new topic. This complex multimodal ensemble seems to be successful in engaging the audience, as the modes of gaze and posture are constantly directed to the students. Moreover, the lecturer emphasizes the metadiscursive function of introducing a topic through a wide range of visual and paralinguistic semiotic resources, by changing his posture and providing prosodic stress to the metadiscursive utterance. 

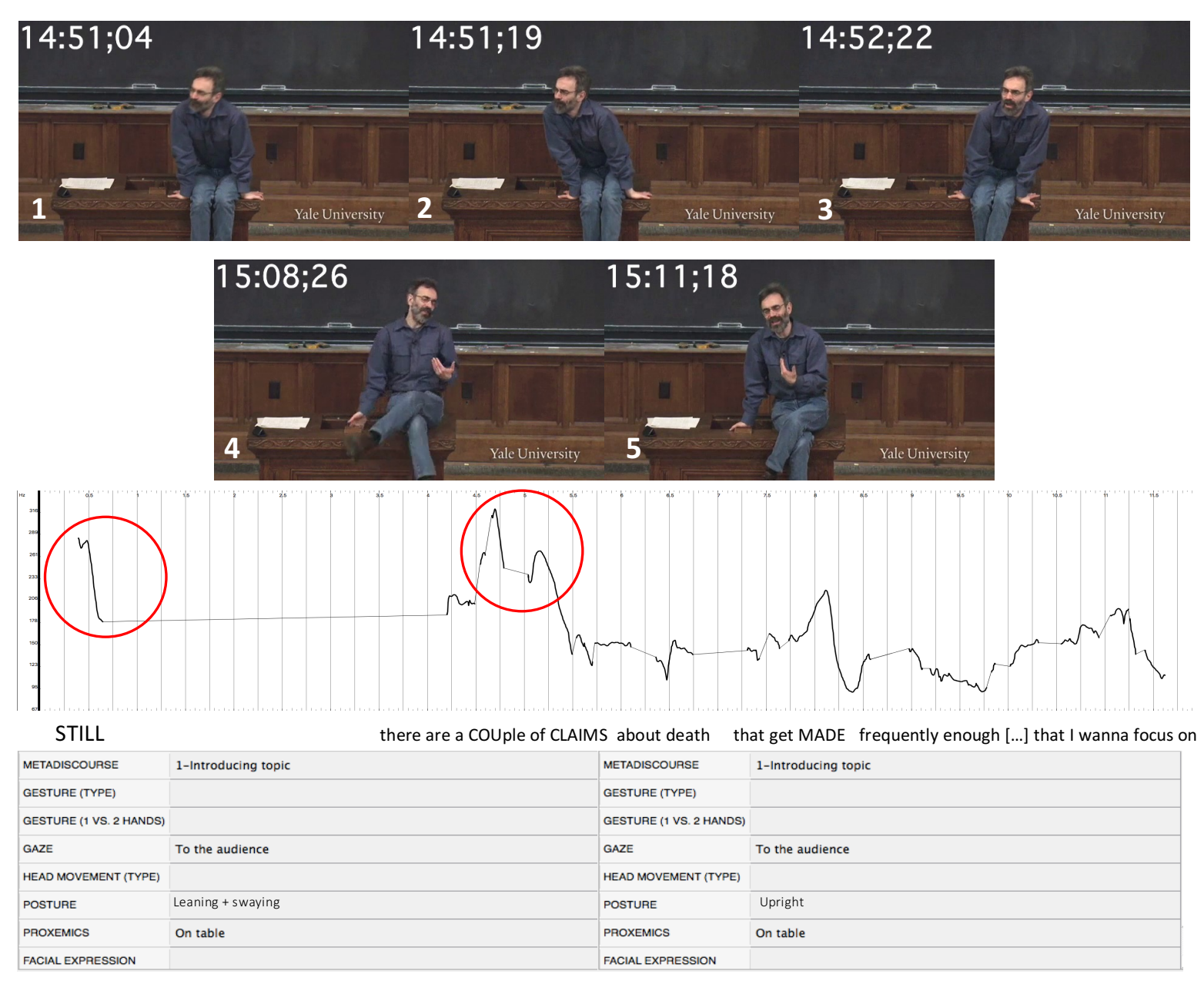

Figure 7.6 Ensemble 4 (Introducing topic in $\mathrm{C} 3)^{13}$

\section{Ensemble 5}

Unlike the example in Ensemble 4 in which gestures are not utilized, rhetorical style lecturers commonly accompany metadiscursive expressions with gestures. However, iconic, metaphorical and deictic gestures are not so common in this lecturing style. Instead, beats are the regular choice. In addition, as rhetorical style lecturers are less constrained by the use of notes or the lectern, gestures are often performed using both hands, showing more emphasis. Regarding the rest of semiotic resources co-occurring with metadiscourse, the use of gaze is undoubtedly relevant in rhetorical style lectures, as lecturers always direct gaze towards the audience. Thus, the lecturer's speech becomes a monolog for

\footnotetext{
${ }^{13}$ Please note that the waveform has been removed in this figure for the sake of clarity.
} 
which the audience engagement is the main focus. Moreover, as I have described above, the position of the lecturers and their posture shifts may serve as indicators of transitions in discourse. Figure 7.7 below is an example of the multiple combinations of modes conducted in an introduction of a topic in C3. While the lecturer is verbally introducing the topic by using introducing topic metadiscourse ("what I want to look at first is the suggestion that [...] nobody really believes they're going to die at all'), he performs a short beat with both hands that co-occurs with the gaze towards the audience, a posture slightly leaning towards the audience, and eyebrow frowning. Form a paralinguistic perspective, the lecturer provides emphasis using two strategies: on the one hand, some words are stressed in the metadiscursive fragment (red circles); and on the other hand, the lecturer performs short pauses at the end of the utterance when stating the new topic, which separate the utterance into smaller fragments ("somehow, at some level, nobody, really, believes, they're going to die, at all'). This particular combination of modes, marked by a high modal density, and the emphatic strategies at a paralinguistic level seem to be used as a booster of the introduction of the topic and as a separator from a previous previewing section.

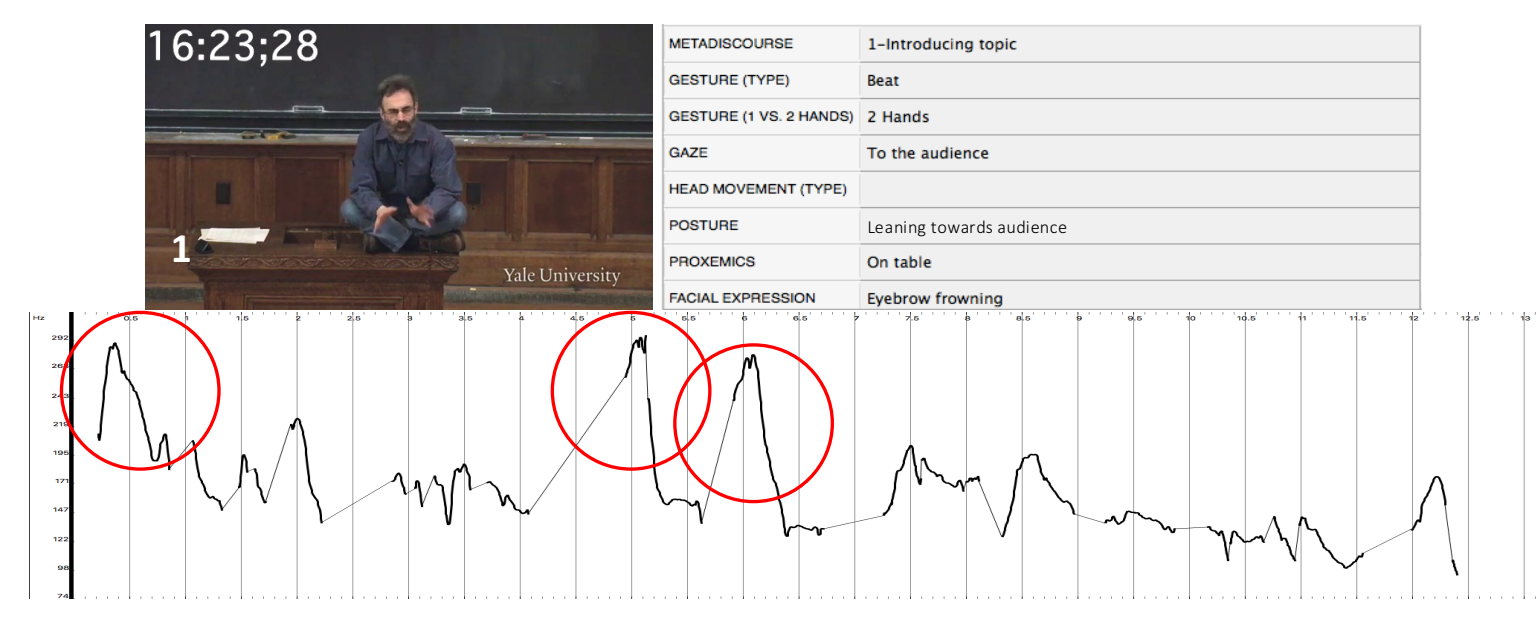

WHAT I wanna look to, look at FIRST is the suggestion that SOMEhow at SOME level NObody REAlly believes they're going to die AT all

Figure 7.7 Ensemble 5 (Introducing topic in C3) ${ }^{14}$

On the whole, rhetorical style lecturers offer a wider range of possible combinations to accompany organizational metadiscourse. In most cases, metadiscourse seems to be separated from the rest of the discourse and is emphasized in one way or another. The role

14 Please, note that the waveform has been removed in this figure for the sake of clarity. 
of posture and proxemics becomes relevant for these lecturers for two main reasons: as tools to show closeness to the audience and, therefore, engage them in the lecture; and as visual modes that reinforce verbal expressions.

\subsubsection{Multimodal ensembles in reading style lectures}

As described throughout Section 7.1, the use of semiotic resources in reading style lectures is more limited than in conversational and rhetorical style lectures. This can be exemplified, for instance, in the use of gestures, as these are rarely used in reading style lectures. In this sense, most metadiscourse occurs with no gesturing concordances. However, two distinct types of multimodal ensembles can be found in these lectures: those encountered in reading actions (where metadiscourse is being read directly from the notes); and those encountered in spontaneous sections in which the lecturer comments on the contents that are being read or makes use of organizational metadiscourse. While the former are rather modally limited, the latter offer the possibility of conveying the message through a wider range of semiotic resources, including some occasional beats. Thus, the use of notes plays an important role in the communication of reading style lecturers as they constrain the ways in which these lecturers can transmit their message and engage with the audience. Therefore, the use of organizational metadiscourse may come about in two manners: as a requirement of the text, since metadiscourse has been previously planned for and added to the notes that are being read; or as part of a spontaneous comment provided by the lecturer which is independent of the text. In this regard, Ensemble 6 shows an instance of introducing topic in $\mathrm{C5}$ in which the lecturer uses metadiscourse spontaneously; and Ensemble 7 describes a previewing expression in $\mathrm{C} 6$ in which metadiscourse is read from the notes. 


\section{Ensemble 6}

Figure 7.8 displays a spontaneous introduction of a topic in C5. In this fragment, the lecturer turns his gaze away from his notes to directly address the audience in a spontaneous manner (Images 1 and 2). This fragment includes the only gesture performed by this lecturer in the structuring fragment considered for these analyses. The lecturer verbally introduces the topic ("and today what l'd like to do is to look at a subset of the bigger problem [...] tropical medicine") and performs an iconic gesture by placing his thumb and index parallel to each other as a non-verbal counterpart of "subset". Moreover, the spontaneous introduction of the topic is separated from the following reading section by a pause and a swallowing (Image 3). However, no relevant emphasis seems to be applied using paralanguage, except for some rhythmic rising pitch lines (marked in red). Although these spontaneous ensembles tend to be more modally complex than those in reading sections, the availability of semiotic resources is rather low, and little effort is made to engage the audience multimodally.

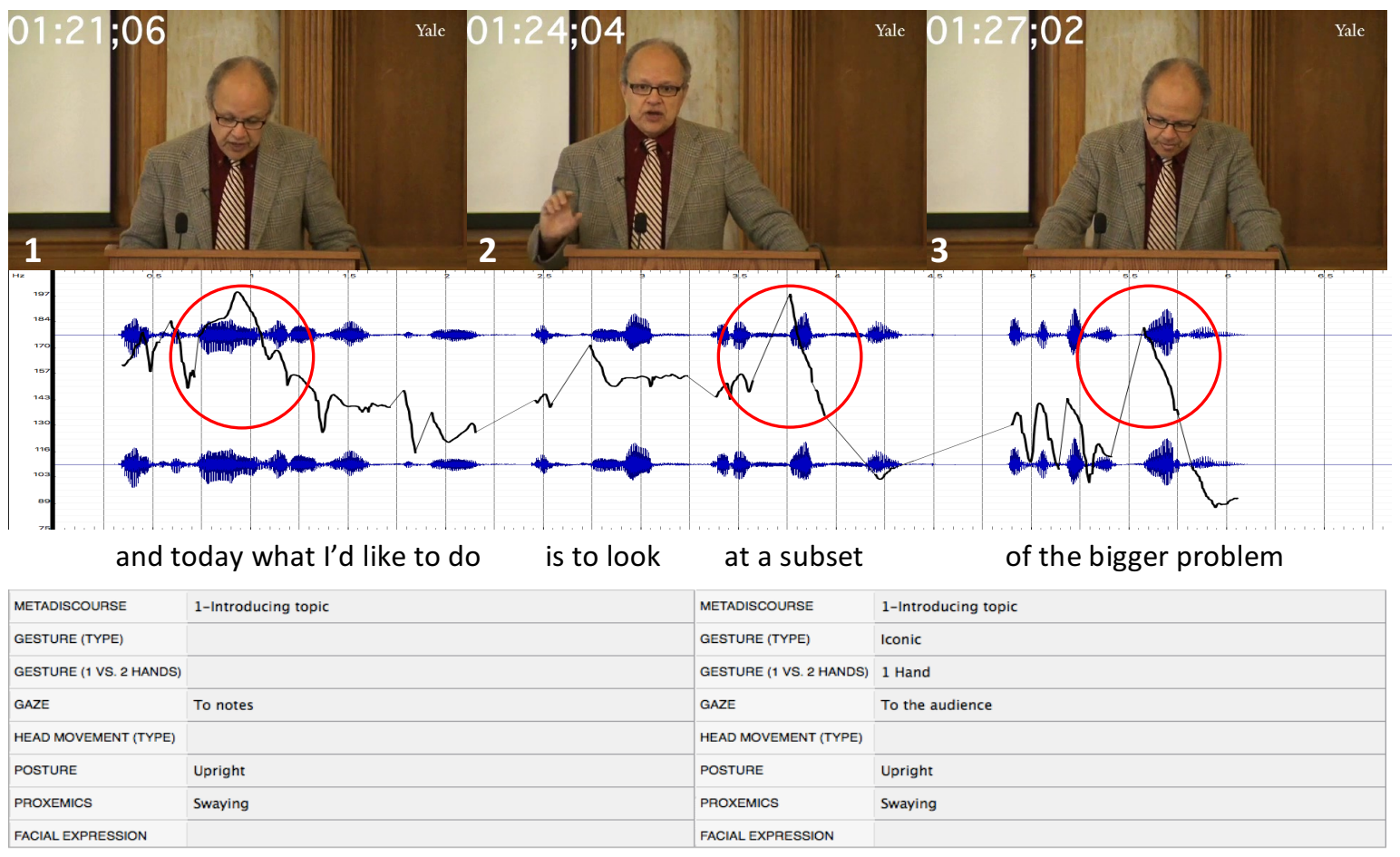

Figure 7.8 Ensemble 6 (Introducing topic in C5)

This example contrasts with those instances in which metadiscourse is used as part of the notes (see Ensemble 7 below). The constant use of notes limits the availability of semiotic 
resources in reading style lectures, as the notes become central in the lecturer's interaction. Figure 7.9 below shows a prototypical position in reading style lecturers. This figure is a screenshot from the State Machine tool in MMA-Video showing all possible combinations of modes considering speech (metadiscourse), gestures, gaze, head movement, posture, proxemics and facial expression. The results indicate that the most frequent combination of modes in $\mathrm{C} 6$ is that in which the lecturer is not using any metadiscourse, gestures, head movements or facial expression, and he is gazing at the notes and leaning towards the lectern. This particular combination adds up to the $21.30 \%$ of the clip. In other words, this particular lecturer is completely focused on the notes during $21.30 \%$ of the time. This highlights the relevance of the notes for reading style lecturers. However, as I detail in the following ensemble, some more elaborate modal combinations may also be singularly relevant in reading sections.

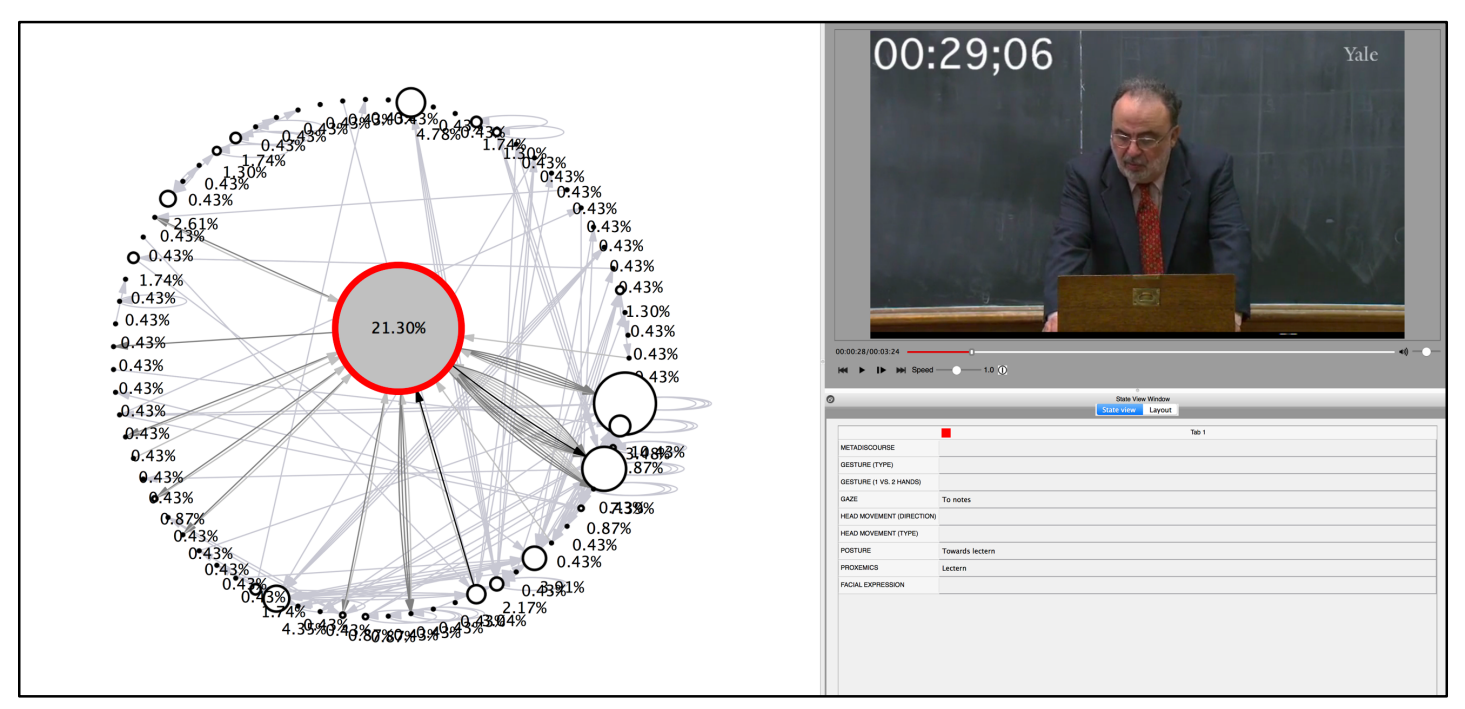

Figure 7.9 Use of notes in reading style lecturers

\section{Ensemble 7}

Although reading sections are generally multimodally monotonous, some engagement with the audience is aimed at, mainly through short glimpses towards the audience, use of intonation and facial expressions. Reading style lecturers seem to be constrained by their notes in their lecturing. They hold onto the lectern during most of their speech and turn 
their bodies and gaze towards the notes. This makes it difficult for them to establish a permanent rapport with the audience or to engage them. Still, some embodied modes are available to these lecturers which may be used to emphasize certain aspects of their speech. An example of this is shown in Figure 7.10. In this fragment, the lecturer in $\mathrm{C} 6$ is previewing some of the information that will be distributed throughout the following lectures. He does so by using verbal metadiscourse "we will be following this development in the episodes that we will be dealing with during the rest of the semester...". This fragment appears to be read directly from the notes as the lecturer's gaze and position are focused on the lectern (Image 1). However, some emphasis is placed on this particular utterance through the use of quick glimpses towards the audience (Image 2), emphatic intonation that marks the rhythm (see red circles in the transcription), and a constant eyebrow raising that stops at the end of the sentence when the lecturer changes his position, turning his focus on the audience (Image 3). All in all, even though the availability of semiotic resources is limited for this lecturer, metadiscourse is emphasized by using the very few resources at his hand.

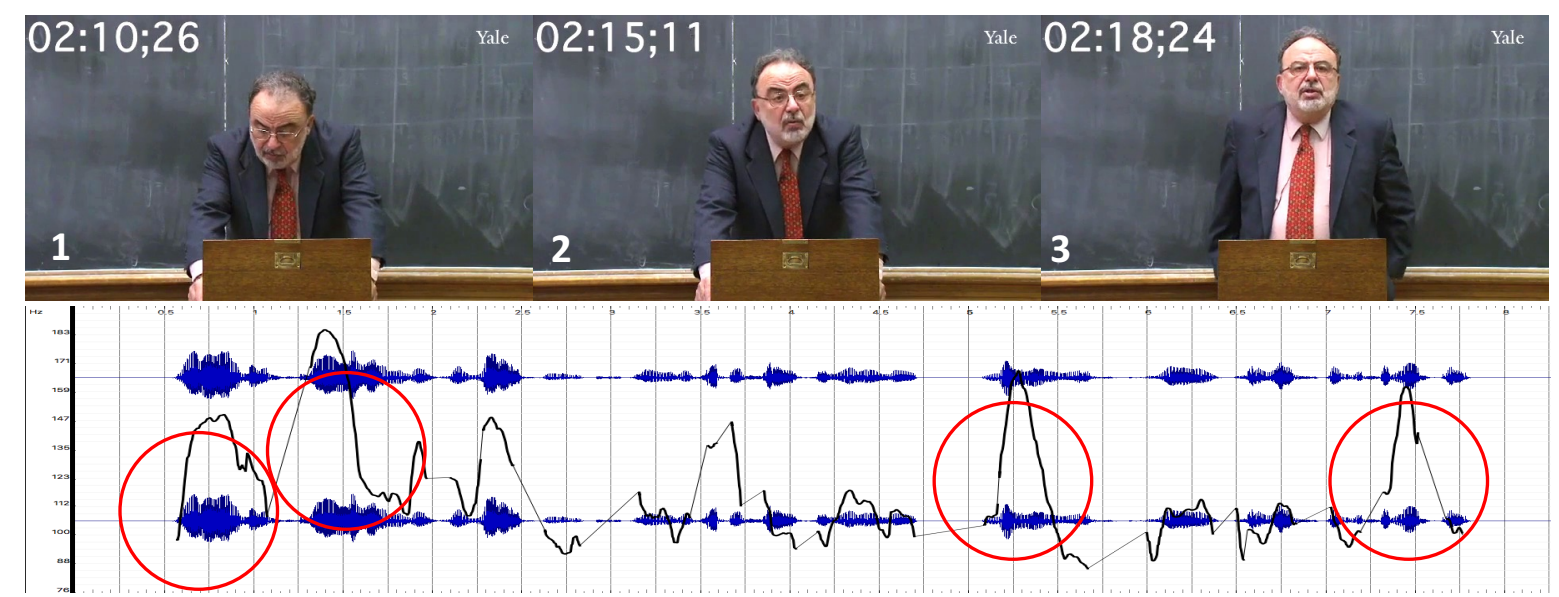

WE will be FOllowing this development in the Episodes that we will be DEAling with during the rest of the seMESter

\begin{tabular}{|l|l|l|l|}
\hline METADISCOURSE & 8-Previewing & METADISCOURSE & 8-Previewing \\
\hline GESTURE (TYPE) & & GESTURE (TYPE) & \\
\hline GESTURE (1 VS. 2 HANDS) & & GESTURE (1 VS. 2 HANDS) \\
\hline GAZE & To notes & GAZE & To the audience \\
\hline HEAD MOVEMENT (TYPE) & & HEAD MOVEMENT (TYPE) & \\
\hline POSTURE & Towards lectern & POSTURE & Upright \\
\hline PROXEMICS & Lectern & PROXEMICS & Lectern \\
\hline FACIAL EXPRESSION & & FACIAL EXPRESSION & Eyebrow frowning \\
\hline
\end{tabular}

Figure 7.10 Ensemble 7 (Previewing in C6) 


\subsubsection{Modal density as constrained by the lecturing styles}

The comparison of the multimodal ensembles in metadiscursive instances raises a series of conclusions. Firstly, the use of gestures and gaze differs considerably from one lecturing style to the other. In general terms, both conversational and rhetorical style lecturers accompany their metadiscursive expressions with gestures, while these are rare in the case of reading style lecturers. Although beats are the most commonly used type of gesture, the use of iconic, metaphoric and deictic gestures is also present and seems to be more regular in conversational style lectures. Rhetorical style lecturers, however, may reinforce their gestures by performing them using both hands. As far as gaze is concerned, this mode is proportionally linked to the use that the lecturers make of their notes and the degree of spontaneity of the metadiscursive utterances. Thus, conversational style lecturers turn their gaze towards the audience when using metadiscourse, although they may go back to their notes quite often; rhetorical style lecturers focus their gaze exclusively on the audience; and reading style lecturers may turn to the audience during spontaneous sections and perform quick glances towards the students during reading sections.

Secondly, all three types of lecturers seem to emphasize the verbal utterances of organizational metadiscourse through a wide variety of combinations of modes. The use of paralinguistic devices such as intonation and intensity, and the presence of facial expression has been found in all lectures. However, it seems more common in rhetorical and reading style lectures. These data expand the results in Bernad-Mechó and FortanetGómez (forthcoming) where facial expression as an emphasizer was also identified in conversational and reading style lectures. As discussed in Ensemble 5, facial expression as a semiotic resource is also found in $C 3$, a rhetorical style course, to provide emphasis to the introduction of a topic. The relevance of these modes, however, seems to be different for different lecturers. The use of intonation and facial expressions becomes of particular importance in note-driven sections in reading style lectures; these sections require the focalization of the lecturer's attention towards the notes, and therefore, are modally constrained. Thus, lecturers may emphasize the message and engage the audience by 
turning to the modes of paralanguage and facial expression, which appear to work independently of other embodied modes in these lecturers.

Finally, the use of posture contributes to the multimodal ensembles accompanying metadiscourse in rhetorical style lectures. As for the use of posture in conversational and reading style lectures, the position of the body helps identify the foci of the lecturers, i.e. whether their attention is centered on the notes or on the audience.

All in all, metadiscursive instances form distinct multimodal ensembles co-occurring with different choices in the non-verbal modes that seem to be determined by constraining elements like the use of notes and the lecturer's use of the classroom space. On the one hand, the presence of notes as a mediational means, limits to a greater or lesser extent the use of modes to convey meaning like gestures, gaze, posture, and proxemics. The extent to which notes become a constraining element depends on the spontaneity of the lecturers. On the other hand, the lecturers' choice of position in space, i.e. whether they stay behind the lectern, on a table, or in front of the audience, also seems to restrict the availability of semiotic resources at hand. Thus, those lecturers who opt for standing behind the lectern may find it more difficult to use their posture to address the audience, or the use of gestures might be less visible. These constraining elements, in turn, may have an effect on the attention of the audience, engaging or disengaging them. Still and all, the use of paralinguistic and facial expressions seems to be unaffected by these constraining elements. In this regard, the more constrained a lecturer is, the more susceptible they are to use these modes.

By considering all these elements, this study corroborates the results in Bernad-Mechó and Fortanet-Gómez (forthcoming) and a continuum of semiotic resources across lecturing styles can be established. Figure 7.11 describes the modal density in the study of the combinations of modes co-occurring with organizational metadiscourse. In short, in a continuum of lecturing styles, the closer lecturers are to the rhetorical style, the more modally complex uses of metadiscourse they perform and, in turn, modally dense uses of metadiscourse may achieve a greater engagement of the audience and enhance the signaling function of metadiscourse in which the lecturers organize their speech and guide 
the students throughout the discourse. On the contrary, reading style lecturers' use of organizational metadiscourse is performed with a low modal density, which may pose problems in the transmission of organizational metadiscourse to the students and keep engagement with the audience to a minimum. A position in between is that of conversational style lecturers, who combine several modes such as speech, gestures, gaze, etc. in the conveyance of metadiscursive meaning. Having said that, lecturers may not fully identify with one style or another. Instead, they may share features from distinct lecturing styles. In this sense, the present chapter has attempted to describe a series of multimodal behaviors that contribute to defining lecturing styles beyond linguistic aspects.

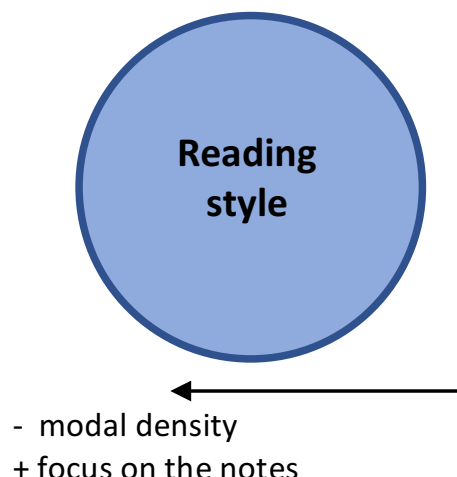

+ focus on the notes

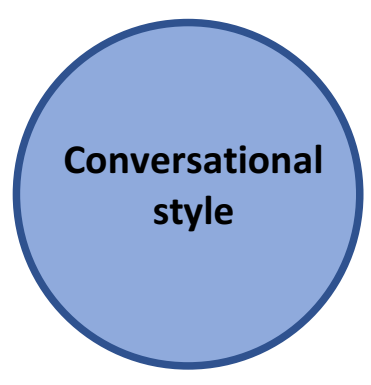

$\sqrt{20}$

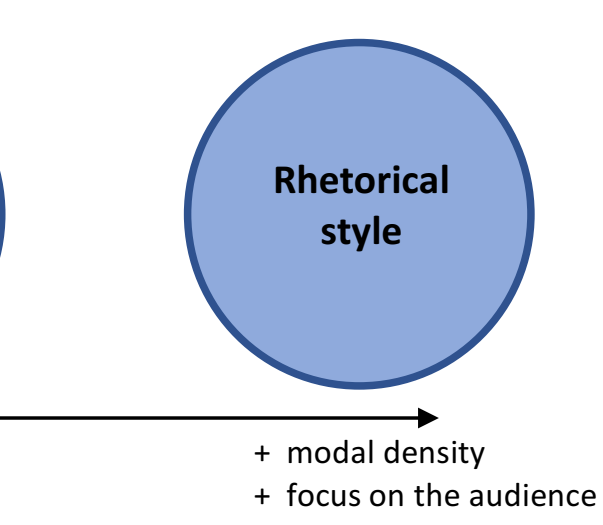

Figure 7.11 Modal density in the use of organizational metadiscourse across lecturing styles. Adapted from Bernad-Mechó and Fortanet-Gómez (forthcoming)

In this chapter, I have explored the multimodal nature of organizational metadiscourse from two perspectives: the recurrent semiotic resources and the multimodal ensembles. In short, I have shown how some semiotic resources are preferred over others in structuring segments. Moreover, I have described the influence of lecturing styles in the lecturers' choices of semiotic resources and in their combinations in multimodal ensembles. In this sense, I have reflected upon some defining traits that are shared between lecturers within the same lecturing style. Finally, I have argued that lecturing styles constrain the availability of semiotic resources for the conveyance of metadiscourse, and I have suggested a continuum of lecturing styles that reflects on the modal density of their ensembles and their foci (whether on the audience or on the notes). In the following chapter, I complete the multimodal analyses in this thesis by tackling the structuring process of lectures from an MIA perspective, looking at structures as sequences of mediated actions. 


\section{CHAPTER 8. MULTIMODAL ANALYSIS: AN MIA APPROACH TO STRUCTURE}

After having examined the use of organizational metadiscourse from a quantitative, a linguistic, and a multimodal perspective, I set out to investigate how lecturers structure their speech in sequences of higher-level actions and how these sequences differ from one another across lecturing styles. This analysis, in turn, will help me discern the role played by verbal metadiscourse in such actions. As I described in Section 4.4.4, I make use of the theoretical and methodological concepts proposed in MIA (Norris, 2004, 2011) in order to obtain a holistic account of how lecturers accommodate metadiscourse within the sets of actions they perform during their lectures (see Section 2.2.3 for an extensive description of MIA).

By employing an MIA approach, I look at the structures of lectures from a novel perspective, i.e. by considering structure as a sequence of actions carried out by the lecturer. In this regard, an MIA approach to the dataset allows for the exploration of how lecturers structure their performances into higher-level actions. Higher-level actions, in turn, may be analyzed in terms of modal density, i.e. taking into account which modes intervene in the production of each action and to which degree. Besides, the analysis of specific modal densities will unveil what actions are given higher or lower attention/awareness in the process of lecture structuring. This attention is indicated in the foreground-background continuum that displays whether an action is given full attention (foreground), little attention (background), or whether it is being considered to a certain extent (midground). Once the higher-level actions are identified, and a level of attention is attached to each of the actions, the role of metadiscourse may be interpreted. For example, if metadiscourse (the verbal mode) occurs in a midgrounded action, it may be interpreted that it is being used with a passive role while another action is receiving full attention by the lecturer. In these cases, the focus of the lecturer is on other actions like organizing notes, or developing content. On the contrary, if metadiscourse is found in a foregrounded action, it may be concluded that it is being used with an active role as it is fully focused on by the lecturer. In this type of instances, metadiscourse seems to be used 
as a tool to guide the students, signal the directions of the lecture, and establish connections.

Thus, the focus of this chapter is on RQ4 and its sub-questions:

\begin{tabular}{|l|l|}
\hline RQ 4 & $\begin{array}{l}\text { How does organizational metadiscourse contribute to the structuring } \\
\text { process of the lectures? }\end{array}$ \\
\hline RQ 4.1 & $\begin{array}{l}\text { What sequences of actions do lecturers perform during the organizational sections of the } \\
\text { lectures? }\end{array}$ \\
\hline RQ 4.2 & $\begin{array}{l}\text { What is the role of organizational metadiscourse in the lecturer's multimodal organization of } \\
\text { lectures? }\end{array}$ \\
\hline RQ 4.3 & $\begin{array}{l}\text { Are there any similarities or differences in the multimodal organization of lectures across } \\
\text { lecturing styles? }\end{array}$ \\
\hline
\end{tabular}

In order to answer these questions, I examine the corpus of six representative lectures described in Section 4.3.2. In particular, I focus on those sections in which organizational metadiscourse occurs: structuring segments with a high concentration of metadiscourse, and spontaneous instances distributed throughout the lectures. Thus, in Section 8.1, I address RQ 4.1 and I examine recurrent sequences of higher-level actions performed by the lecturers in structuring segments. Next, Section 8.2 answers RQ 4.2 and looks into the distinct roles of organizational metadiscourse in structuring segments and in spontaneous actions. As for the influence of lecturing styles (RQ 4.3), I tackle this question in combination with the previous ones. The differences in the structuring patterns of higherlevel actions across lecturing styles are abundant; in other words, lecturers following distinct lecturing styles organize their speech in very different sequences. Therefore, this issue is first tackled in Section 8.1 as I describe how distinct lecturers produce higher-level actions. Then, particular features of specific lecturing styles are also shown in Section 8.2.

\subsection{Addressing higher-level actions. On the structure of lectures}

In this section, I describe the recurrent sequences of higher-level actions performed by the lecturers when using organizational metadiscourse in structuring segments. The study of how lecturers structure their speech into strata of higher-level actions -or scales of actions 
(Norris, 2017)-, and how these higher-level actions succeed each other in the lectures, provides, in the context of this study, an insightful account of the lecturer's organization of lectures beyond the contents of the text. In other words, when higher-level actions are examined from an MIA perspective, underlying structures of foregrounded, midgrounded and backgrounded actions are identified. The identification of specific higher-level actions answers RQ 4.1:

\section{RQ 4.1}

What sequences of actions do lecturers perform during the organizational sections of the lectures?

In the subsequent lines, I define and exemplify prototypical structures of higher-level actions for each of the lecturing styles considered in this thesis. The study of sequences of higher-level actions across lecturing styles has shown very similar patterns within each of the styles. In this regard, Section 8.1 .1 is devoted to examining the prototypical structures of higher-level actions in conversational style lectures; Section 8.1.2 is focused on rhetorical style lectures; and finally, Section 8.1.3 deals with reading style lectures. The exploration of the different structures typical of each lecturing style, in turn, contributes to answering RQ 4.3:

\begin{tabular}{l|l} 
RQ 4.3 & Are there any similarities or differences in the multimodal organization of lectures across
\end{tabular} lecturing styles?

\subsubsection{Prototypical structures in conversational style lectures}

The MIA analysis for conversational style lectures has been carried out on lectures C1_L13 in C1 and C2_L13 in C2. When examining the structure of the lecture beyond the verbal contents, an MIA analysis of the actions reveals the presence of recurrent higher-level actions structured around three main pivotal points: the concept of developing content, the organization of the lecture and the arrangements of notes. Thus, several higher-level actions have been identified for each of these nuclei: when developing content, the lecturers perform actions such as developing content, concluding topic, elaborating on topic, or reading; in the organizational sections the lecturers may perform introducing 
topic, introducing the lecture, reviewing, previewing, contextualizing, or outlining the contents; finally, when utilizing the notes, actions like arranging notes, or reading notes are performed. These higher-level actions, in turn, can interact with each other and be present at the same time in different levels of attention/awareness in the foreground-background continuum. Expressed in a different way, while the lecturer is focusing on one action, they may be producing another, or several ones in the midground and background. For example, at a point in $\mathrm{C1}_{-} 13(28: 36: 05)$ the lecturer is producing the higher-level action of concluding topic while also arranging notes in the midground. The action of arranging notes takes over and becomes the main focus of the lecturer while concluding topic fades out. Next, the higher-level action of introducing topic emerges in the midground and soon moves onto the foreground, and so on and so forth.

After examining the fragments in $\mathrm{C} 1$ and $\mathrm{C} 2$ where the lecturers introduce organizational metadiscourse, a prototypical sequence of higher-level actions may be extracted (see Figure 8.1).

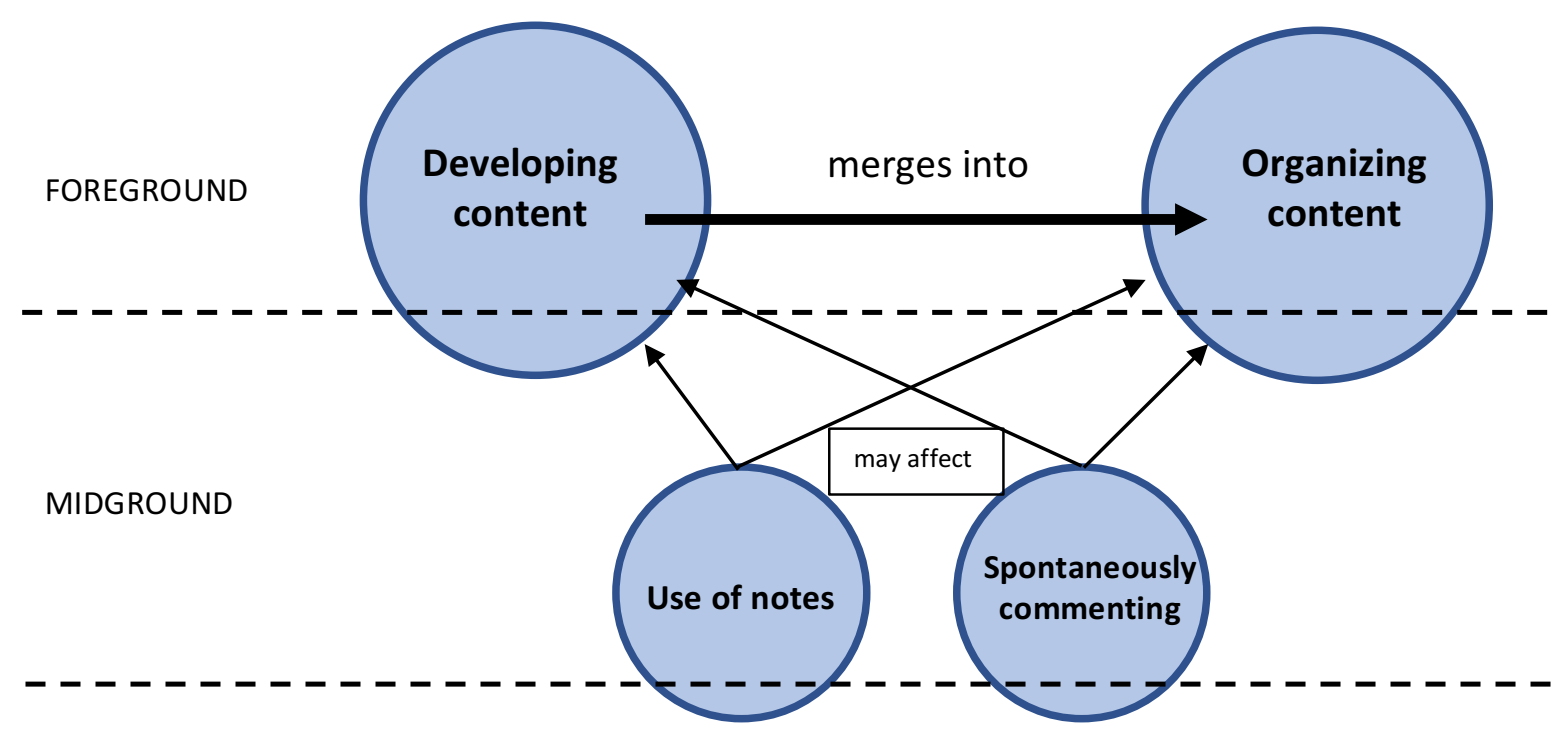

BACKGROUND

Figure 8.1 Prototypical sequence of higher-level actions in conversational style lecturers

As described in the figure, structuring segments performed by conversational style lecturers are built in a two-step process: a higher-level action to develop the content (for instance, developing content, lecturing on topic $X$, or reading from notes) merges into a 
higher-level action that contributes to the organization of the lecture (for example, introducing topic or outlining the contents of the lecture). In other words, conversational style lecturers employ higher-level actions related to content sections and to organizational sections which are organized in a developing content-organizing-developing content pattern, i.e. higher-level actions in which content is developed can be separated from each other by an organizing higher-level action. These actions commonly occur in the foreground, i.e. they receive the highest attention. Moreover, both types of higher-level actions may be influenced to some extent by other higher-level actions in which the lecturer provides spontaneous comments on a given topic or on an organizational manner, or by higher-level actions that are related to the use of notes (for instance, arranging notes, or reading from notes). As I detail in sections 8.2.1.2 and 8.2.2, although these influential actions are commonly found in the midground most of the time, they may become foregrounded by means of modal intensity. For example, a lecturer might be performing the action of developing content on the foreground, and suddenly, they remind the students about information that has already been delivered in the course by means of a short spontaneous comment. In this case, a spontaneous organizational higher-level action receives full attention momentarily.

Although at a general level both lecturers show similar structuring patterns, some minor differences may be identified. In the case of $\mathrm{C} 1$, for instance, and as I demonstrate both in Bernad-Mechó (2017a) and in Section 8.2.1.2, the notes become highly relevant and higher-level actions where notes are being arranged might frequently become foregrounded while other more verbal actions like developing content or structuring discourse are downgraded to the midground. Finally, most structural higher-level actions in $\mathrm{C} 2$ tend to occur in the structuring segments at the beginning of the lecture while structuring segments in $\mathrm{C} 1$ are more dispersed through the lecture. 


\subsubsection{Prototypical structures in rhetorical style lectures}

After examining the lectures C3_L15 for C3 and C4_L13 for C4, a series of recurrent higherlevel actions may be identified. In general terms, these lectures are structured as a succession of independent ideas arranged one after the other that conform to higher-level actions per se, as they are separated by semantic/pragmatic means like posture shifts, or pauses (see discussion on semantic/pragmatic means in Section 2.2.3). These higher-level actions, which I will refer to as developing content on idea $A, B, C$, etc., can be encompassed within a broader of higher-level actions: developing content on topic $A, B, C$, etc., i.e. a higher-level action that is made up of smaller actions. Some other content developing actions, particularly common in $\mathrm{C} 4$, may include actions like reading a fragment, explaining the fragment, or providing a summary. Unlike in conversational style lectures, higher-level actions that develop content in rhetorical style lectures are rarely interrupted by other types of higher-level actions. Still and all, some organizational actions may also be found: recapitulating, reviewing, introducing topic, outlining the contents, contextualizing, etc. These actions are usually found in structuring segments that seem to serve as anchors to turn to in order to avoid long digressions on a topic and usually work in the midground. Having these ideas in mind, a prototypical structure of a sequence of higher-level actions in rhetorical style lectures is provided in Figure 8.2.

As I discussed above, the main structure performed by rhetorical style lecturers is composed of sequences of higher-level actions discussing different independent ideas that fuse one into the other. These actions, in turn, are encompassed within a broader action developing content that constitutes a longer stretch of information. In the case of $\mathrm{C} 4$, the main process of developing ideas may also be interspersed with actions related to the process of reading and commenting on fragments from a book (as C4 is a Literature class). Moreover, rhetorical style lecturers might also perform organizational higher-level actions like introducing topic, or outlining contents. These higher-level actions often occur as a transition between two ideas or two main topics and their degree of attention/awareness will depend on how much the lecturers want to emphasize such transition. 
Higher-level Action of developing content on topic A

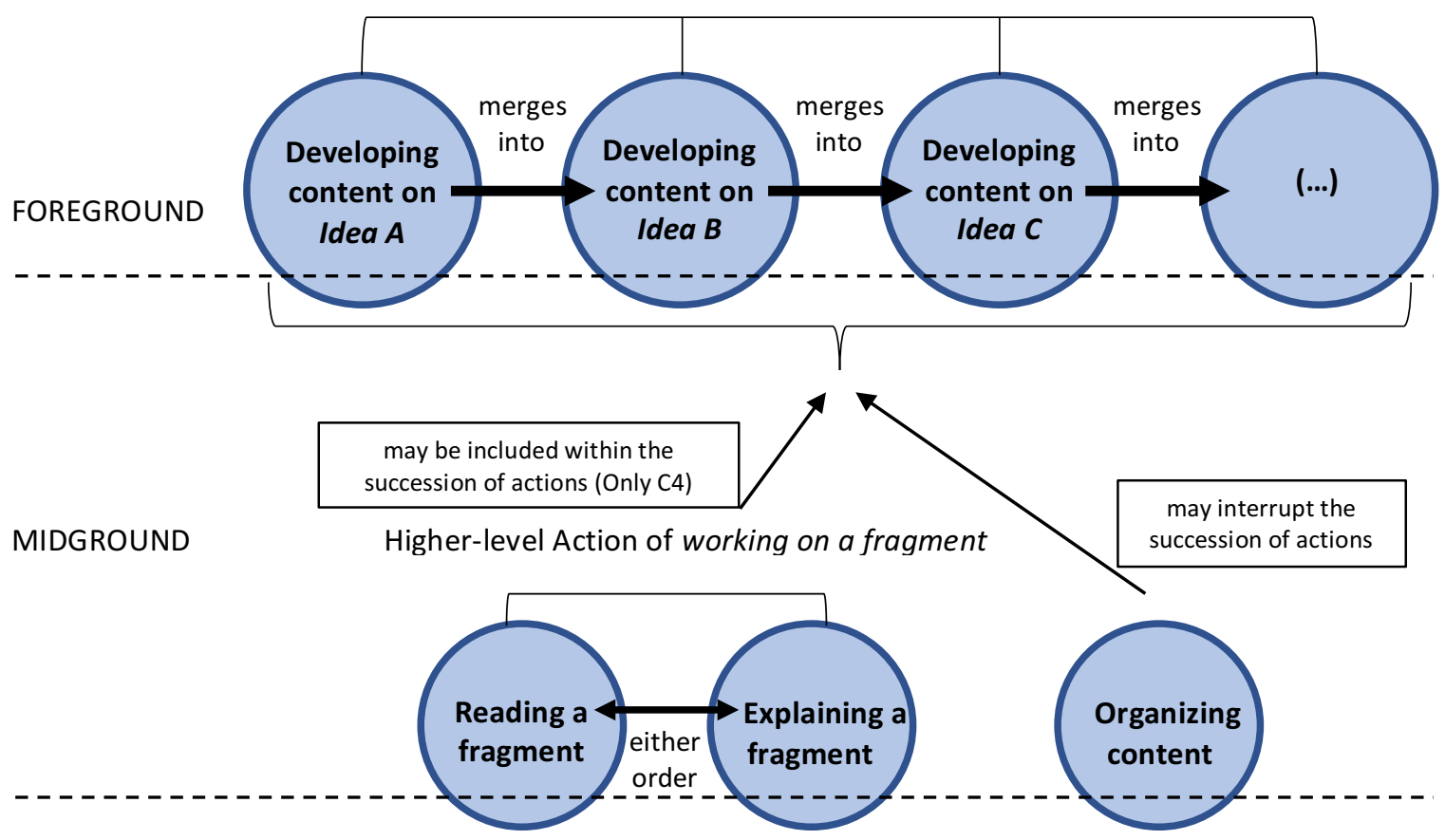

BACKGROUND

Figure 8.2 Prototypical sequence of higher-level actions in rhetorical style lecturers

When comparing the specific structures followed by each rhetorical style lecturer very few differences are encountered. The only relevant one has to do with the use of book fragments as part of the lecture in C4. Although the lecturer in C4 is undoubtedly rhetorical, given the fact that she does not use any notes to deliver her lecture, she does use a book in her sessions. The book serves as a structuring device for the lecturer in the global organization of the lecture as higher-level actions like reading a fragment and explaining $a$ fragment interrupt the normal flow of ideas several times in the lecture. However, the general structure of successions of ideas remains a common feature in rhetorical style lectures that seems to indicate a somehow erratic structure. 


\subsubsection{Prototypical structures in reading style lectures}

The last lectures analyzed were C5_L15 in C5 and C6_15 in C6 corresponding to reading style lecturers. When analyzing the higher-level actions performed by these lecturers, the results show a high presence of reading higher-level actions. These constitute most of the speech as these lecturers read through most parts of the lecture, both when introducing topic-related information and when using metadiscursive expressions. Thus, reading actions may occasionally serve as organizers of discourse. I, therefore, distinguish two broad types of reading higher-level actions: developing content through reading and organizing topic through reading. Moreover, these lecturers also perform spontaneous actions in which they detach from their notes to comment on certain aspects of the lecture. These spontaneous actions are remarkably separated from reading higher-level actions in terms of modal density and may include actions related to both the process of developing content and the organizational one: spontaneously commenting on a topic, introducing topic, outlining the contents, etc. Finally, other infrequent higher-level actions that relate to the interaction of the lecturer with his surroundings can also be found; for instance, arranging notes or using visuals. A prototypical structure of higher-level actions for reading style lecturers is shown in Figure 8.3 below.

The MIA analyses on reading style lectures portray two main distinct types of higher-level actions, namely those that arise from reading higher-level actions and those that are based on spontaneous comments by the lecturer. On the one hand, the most common actions in the data are those that are reading-based. These actions, in turn, may be devoted to either developing the contents of the lecture or to organizing the lecture (metadiscourse would then be written on the notes). On the other hand, these lecturers perform spontaneouslybased actions in which they comment on the contents that are being read or guide the students through the lecture. In this line, reading higher-level actions can also be occasionally influenced by the higher-level action of spontaneously commenting. In these cases, the lecturer momentarily interrupts the main action to offer a short comment and then goes back to reading. In other words, the modal density of spontaneously commenting 
(commonly in the midground) reaches a peak in intensity and moves from the midground to the foreground.

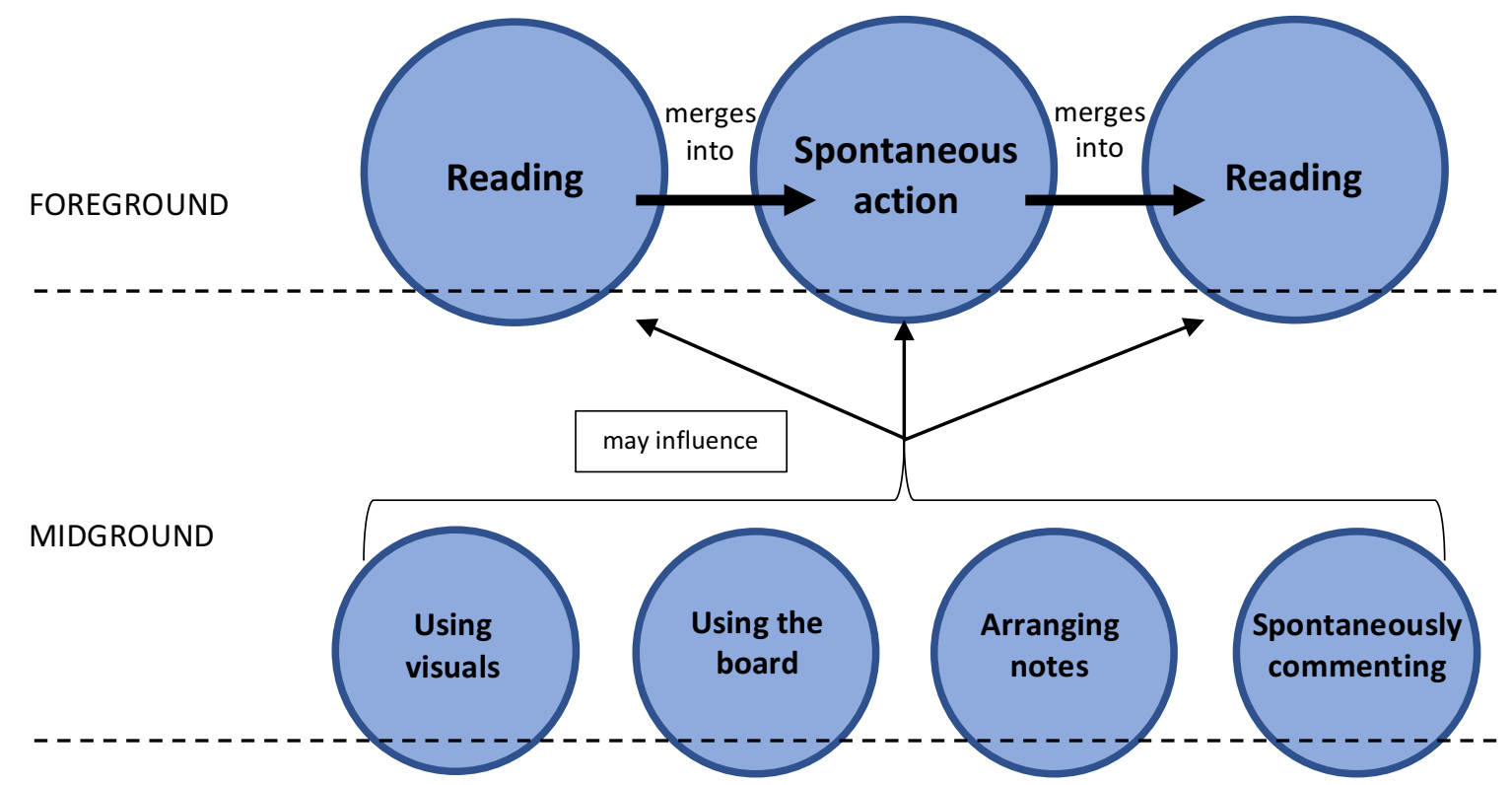

BACKGROUND

Figure 8.3 Prototypical sequence of higher-level actions in reading style lecturers

All things considered, the structuring process of the lecture in reading style courses can occur through reading higher-level actions or through spontaneous higher-level actions in which the lecturer addresses the audience directly. Apart from these, the lecturer may choose to perform other less frequent higher-level actions in which he interacts with either his notes (arranging notes) or the visuals he employs in class (using visuals); in either case, these higher-level actions appear commonly in the midground and the attention received in the foreground is very limited in time.

\subsection{Examining the role of metadiscourse within sequences of actions}

After having shown the recurrent higher-level actions performed by the lecturers and how structuring segments are organized differently across lecturing styles, in this section, I look 
into specific examples demonstrating the distinct roles played by organizational metadiscourse. Thus, in the following lines, I address RQ 4.2:

\begin{tabular}{|l|l|} 
RQ 4.2 & $\begin{array}{l}\text { What is the role of organizational metadiscourse in the lecturer's multimodal organization of } \\
\text { lectures? }\end{array}$
\end{tabular}

As stated in the introduction to the chapter and in Section 4.4, the roles of organizational metadiscourse may be inferred by looking at the modal density determined by the specific modal configurations of the higher-level actions co-occurring during verbal metadiscursive instances. In other words, by describing how higher-level actions co-occur in the foreground-background continuum and how they succeed one another, the analyst can attach a degree of attention/awareness to each of the actions -including those in which metadiscourse is encompassed. In short, by examining the degree of attention attached to metadiscourse different roles seem to arise. In this section, I explore two types of events in which metadiscourse is present: structuring segments in Section 8.2.1 and spontaneous instances of metadiscourse in Section 8.2.2. The MIA analysis reveals that two roles may be attached to metadiscourse occurring in structuring segments (an active and a passive one) and that spontaneous metadiscourse often receives little attention, thus adopting a passive role. Regarding the lecturing styles, no relevant differences are found in the roles played by metadiscourse across the dataset; in other words, all lectures show the presence of both structuring segments and spontaneous metadiscourse, and metadiscourse may be encountered as playing both active and passive roles.

\subsubsection{The role of metadiscourse in structuring segments}

As I have detailed in Section 5.3, organizational metadiscourse tends to concentrate in structuring segments, i.e. short sections within the lecture that show a high concentration of metadiscursive fragments. These segments may be present at the beginning of the lectures (in the introductions to the lecture) and also dispersed throughout the sessions. Structuring segments become influential elements in the lecture as they are used by the 
lecturers to open the session, contextualize the main topic for the lecture and outline the contents of the session, establish connections with previous or forthcoming sessions, or separate long content sections in the lecture. However, despite its undoubted importance, the levels of attention/awareness that these sections receive are not always steady. Thus, two roles may be assigned to the use of metadiscourse: an active role when metadiscourse is purposely used in the foreground to engage the audience, guide the students through the lecture, and create cohesion; and a passive role when metadiscourse is used in the midground as a filler of the verbal mode while the lecturers focus on other actions. These two roles are illustrated through two representative examples in sections 8.2.1.1 and 8.2.1.2 respectively.

\subsubsection{Active role. Metadiscourse in the foreground}

In the following lines, I describe an example in which metadiscourse is employed with an active role. The fragment includes a reviewing instance and is extracted from a structuring segment in C3_L15. Through the multimodal analysis of this segment, I demonstrate the use of reviewing metadiscourse as a tool to recapitulate thoughts and pave the way for the explanation to continue in C3_L15. In the example below, I show the transition between two lecturing sections, and how the use of reviewing metadiscourse becomes useful to facilitate such transition. This excerpt takes place 35 minutes into the lecture. Transcript 8.1 describes the verbal mode in this fragment and Figure 8.4 explores the changes in modal density in the sequence of higher-level actions performed. 


\section{Transcript 8.1}

35:30:09 And I'm observing them from a particular perspective, from a particular STANDpoint (1)

35:36:24 for all that I'm not IN the picture that I'm thinking about. (2)

$[\ldots]$

36:06:01 because this argument, at any rate, seems to me to be unsuccessful. (2)

36:11:10 Now at the start, I distinguished TWO CLAIMS people might have in mind when they say "nobody believes they're going to die

36:18:20 first possibility was the claim was nobody believes that they'll ever cease to exist as a person (.5)

36:24:28 And I've just explained why, at least, the... the... the most FAMILIAR argument for that claim I think doesn't work. (1.5)

36:32:25 The second possible interpretation was this. (1.5)

36:36:17 Nobody beLIEVES their BODY is going to die

\section{$[\ldots]$}

37:11:09 but let's, at least, try to now focus on the SECOND question (.5)

37:15:07 could it be true is there any good reason to believe it is true (1) that (1.5) nobody believes, they're going to undergo, bodily death?

In the example, the lecturer is discussing Freud's argument about death by performing the higher-level action of developing content (Graph 1), which is realized in a particular modal configuration: gaze towards the audience, sitting posture, and verbal mode with peaks of intensity highlighting certain ideas: "And I'm observing them from a particular perspective, from a particular STANDpoint [...]" (Image 1). In 35:42:20, he performs a semantic/pragmatic means which indicates that the higher-level action of developing content is about to end: he changes his posture, pauses, and swallows (Image 2). At this point, he moves on to the higher-level action of concluding (Graph 2) and developing content disappears. In 36:06:01, he accelerates the pace of the verbal mode and employs a falling tone indicating the end of the utterance: "because this argument, at any rate, seems to me to be unsuccessful". Once again, the lecturer pauses, changes his posture and begins a new explanation (Image 3), marking the transition between two higher-level actions: at this point, the higher-level action of concluding is over and a new one, organizing speech is foregrounded in which the lecturer aims to guide the audience through the speech (Graph 3). 

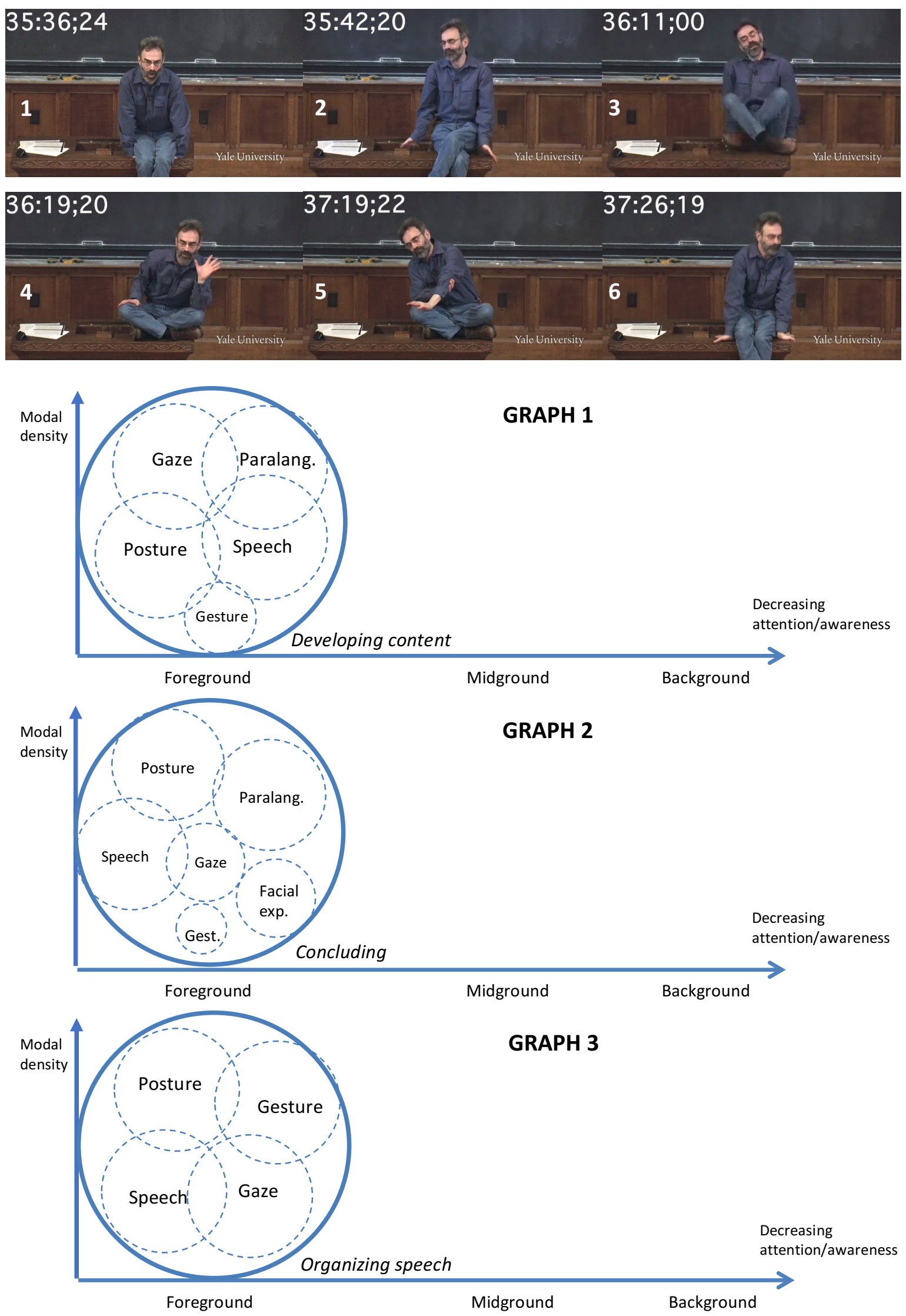

Figure 8.4 Succession of higher-level actions in a structuring segment in C3_L15 

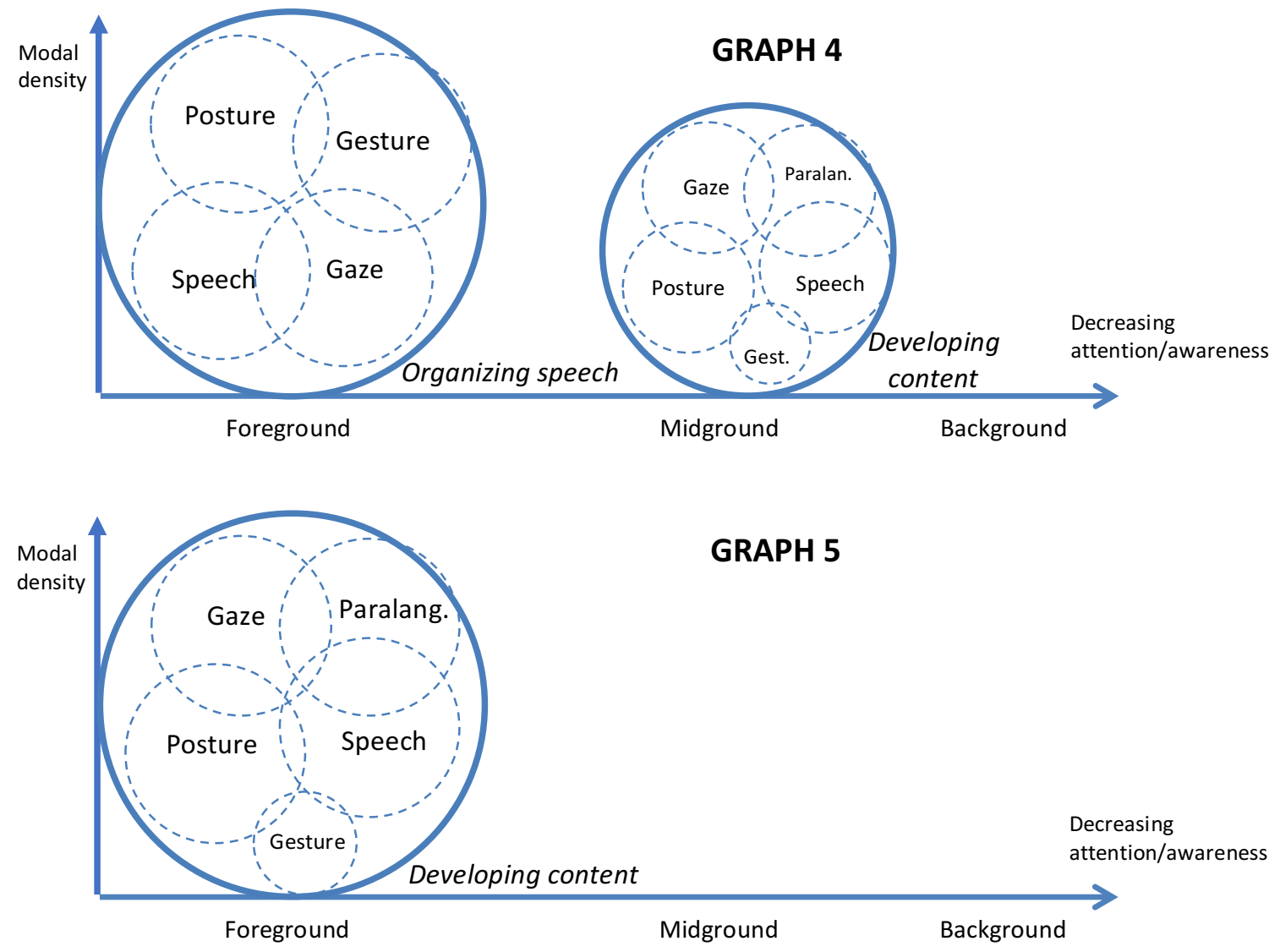

Figure 8.4 (cont.) Succession of higher-level actions in a structuring segment in C3_L15

The higher-level action of organizing speech is performed in order to recapitulate the explanation of the lecturer up to this point. The lecturer does so through the use of the verbal mode -“Now, at the start, I distinguished two claims people might have in mind when they say [...]"-, the emphasis in intonation, the use of beats and metaphorical gestures, and gaze towards the audience (Image 4). During this action, the lecturer also includes a reflection on the explanation that he has performed, which leads him to focus on the second question: "But let's, at least, try to now focus on the second question. Could it be true [...] that nobody believes they're going to undergo bodily death?" As the lecturer is uttering this rhetorical question, he performs yet another semantic/pragmatic means; in 37:19:22 he pulls the sleeve of his shirt up and finishes the sentence (Image 5). This utterance functions as a trigger for the explanation of the lecturer. Expressed in another way, the lecturer poses a rhetorical question to the audience and thus begins a lecturing segment on "the second question". Therefore, the semantic/pragmatic means indicates the presence of the higher-level action developing content in the midground (Graph 4). Finally, the lecturer pauses and changes his posture once again (Image 6) indicating that the new 
higher-level action is now foregrounded (Graph 5). Figure 8.5 below provides a visual interpretation of the transitions and the modal density of the higher-level actions in this fragment.

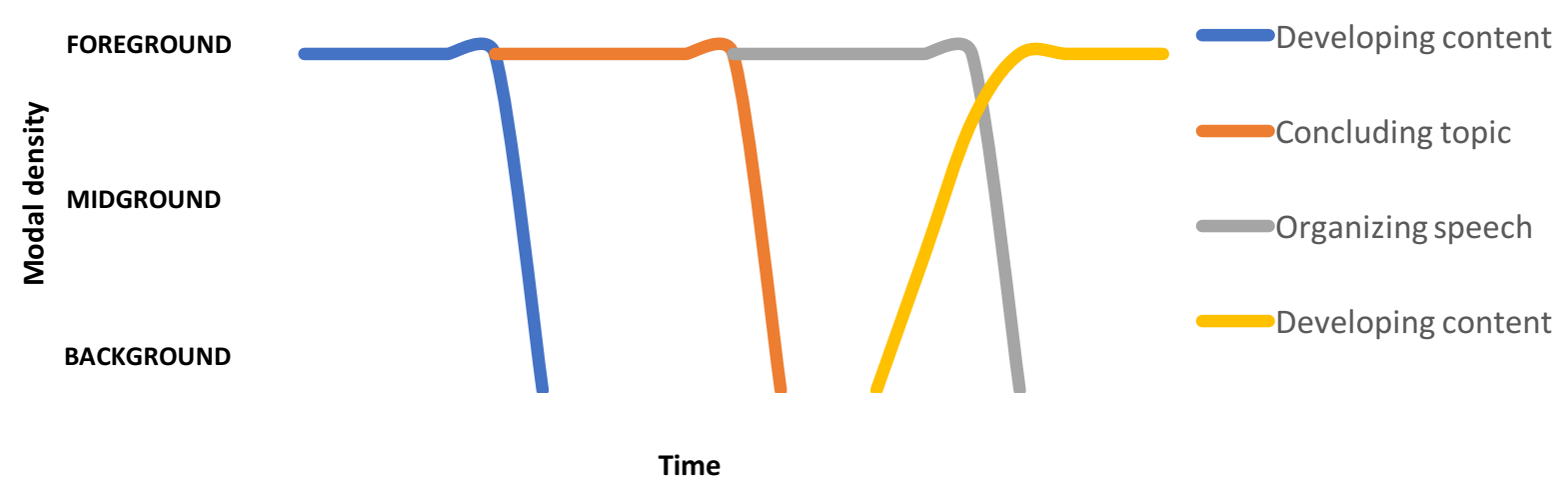

Figure 8.5 Succession of higher-level actions across the foreground-background continuum

In the sequence of higher-level actions analyzed, reviewing metadiscourse is used on several occasions:

- Now, at the start, I distinguished two claims people might have in mind [...] The first possibility was $[\ldots]$

- And I've just explained why at least the most familiar argument for that claim, I think, doesn't work.

- (continuing the first instance) The second possible interpretation was this.

The MIA analysis shows that all these metadiscursive instances occur as part of the verbal mode in the higher-level action of organizing speech. Furthermore, as Figure 8.5 reveals, organizing speech is performed as a foregrounded action during all the time. Thus, metadiscourse becomes highly relevant in this fragment. It is used to recapitulate thoughts in a lecture in which few connections are established and is fully directed to the students, as the multimodal behavior of the lecturer demonstrates. In addition, the structuring segment here analyzed serves as a connection between two longer explanatory discussions: the discussion on "the first question" that has just been concluded, and the 
discussion on "the second question" that is about to start. In this sense, the use of reviewing metadiscourse sets the path for the lecturer to provide a short summary of the concluded discussion, and then connect the summary with the introduction of the new topic. Metadiscourse seems to be employed in order to soften the transition and guide the students throughout the contents of the lecture, coinciding with the purposes established in most traditional definitions of metadiscourse (see Section 3.1). All in all, metadiscourse plays an active role in this fragment as it contributes to the active organization of speech while engaging the audience in the lecture.

\subsubsection{Passive role. Metadiscourse in the midground}

In this section, I focus on an example in which metadiscourse is employed with a passive role. The following excerpt includes an introducing topic instance and is extracted from lecture C4_13. The use of metadiscourse in this fragment is a passive one; the lecturer uses the metadiscursive expression as a verbal filler while she performs the foregrounded action of organizing thoughts. The fragment takes place right at the beginning of the lecture as the lecturer prepares herself to begin the lecturing process. Transcript 8.2 displays the verbal mode in this fragment and Figure 8.6 explores the changes in modal density in the sequence of higher-level actions performed.

\section{Transcript 8.2}

00:01:10 So today, erm.. we will talk about The Bluest Eye. (4.5)

00:08:20 This novel has a lot to do with the questions that John Barth was thinking about, in a very different register, in Lost in the Funhouse. (1)

The lecture begins with the lecturer performing the higher-level action of organizing thoughts. This action is realized through the process of checking her notes on the table, in which she seems to keep a broad structure of the lecture. This can be seen in the modal configuration of the action through her posture towards the notes; the use of proxemics when she moves towards the table; her gaze, which is focused on the notes; and a pause 
in which she appears to be thinking about what to say next (Image 1). During the performance of this action, the lecturer verbally introduces the main topic of the lecture: "So, today we will talk about The Bluest Eye". This verbal introduction is performed in a midgrounded higher-level action-introducing topic- that is realized only through the mode of speech (Graph 1).

In 00:07:20, the lecturer turns her gaze and posture towards the audience in preparation for the next action-contextualizing the novel- in which she will connect the novel with previous contents. At the same time, the lecturer is still performing the higher-level action of organizing thoughts. At this point, the higher-level action of introducing topic has already faded away and two actions are given attention: organizing thoughts in the foreground and contextualizing the novel in the midground (Graph 2). Next, in 00:08:22, the lecturer begins lecturing on the context of the novel (Image 2). In other words, the higher-level action of contextualizing the novel gains importance and is foregrounded. However, the lecturer is still performing the action of organizing thoughts as indicated by the hesitation in the paralanguage as she utters "This novel has a lot to do with the questions that John Barth was thinking about", the gaze directed to the horizon and a holding position of the lecturer's arms which is present since the end of introducing topic (Graph 3). Finally, in 00:10:26, the lecturer lowers her arms and offers a steadier speech ("in a very different register, in Lost in the Funhouse"). Moreover, her gaze is now directed to the audience (Image 3). At this point, the transition between higher-level actions is completed and contextualizing the novel is the only action performed by the lecturer (Graph 4). A visual description of the transitions here described is provided in Figure 8.7.

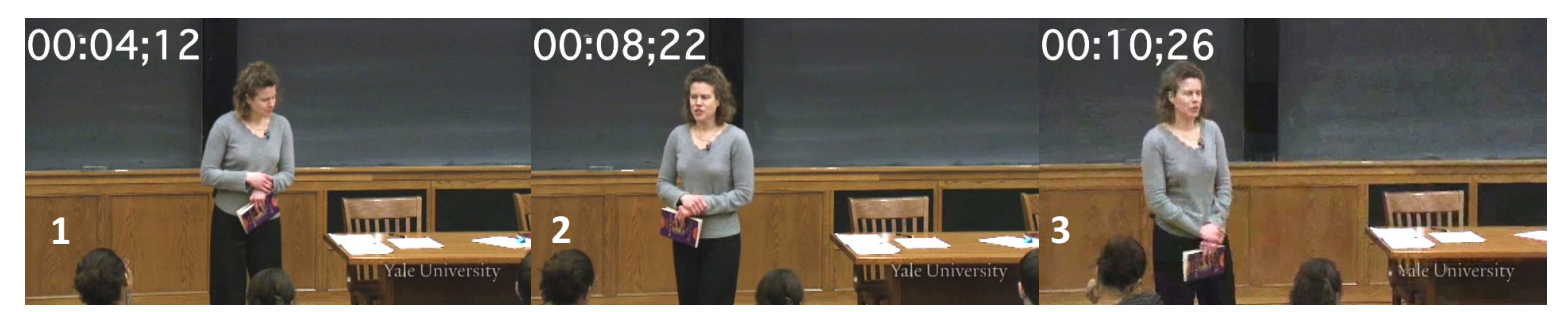

Figure 8.6 Succession of higher-level actions in a structuring segment in C4_L13 

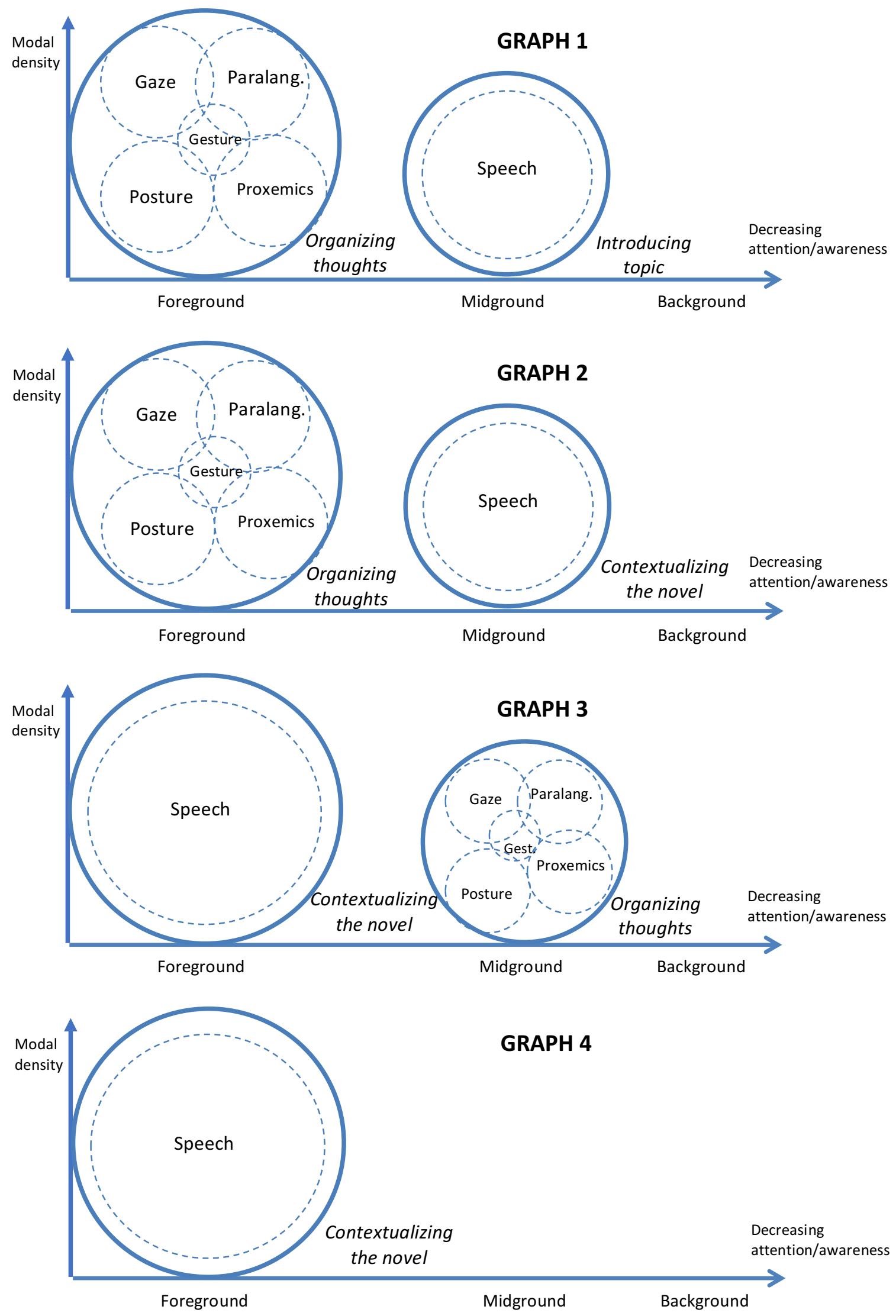

Figure 8.6 (cont.) Succession of higher-level actions in a structuring segment in C4_L13 


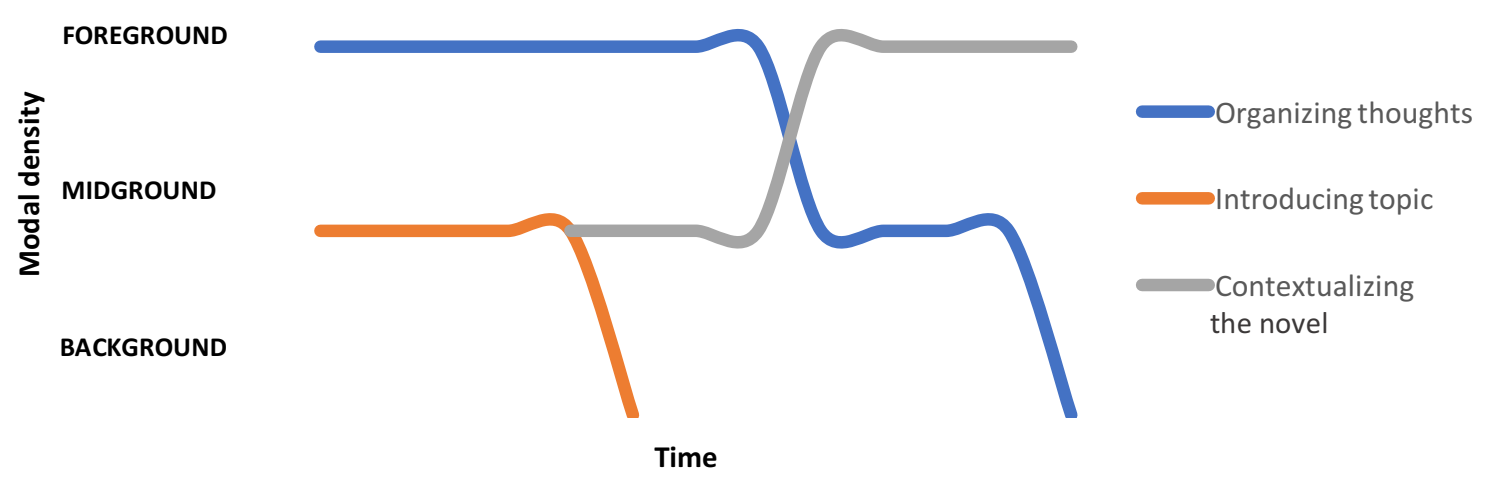

Figure 8.7 Succession of higher-level actions across the foreground-background continuum

In the fragment here analyzed, I have discussed the higher-level actions encompassing the introduction of a topic:

- So, today we will talk about The Bluest Eye.

This instance is employed right at the beginning of the lecture and is encompassed within the higher-level action of introducing topic. This action, however, is receiving medium attention by the lecturer and occurs in the midground, as the multimodal analysis suggests (see Graph 1 in Figure 8.6). The main focus of the lecturer is the organization of her speech, which occurs through the higher-level action of organizing thoughts. This example is characterized by a midgrounded use of metadiscourse. In the fragment, organizational metadiscourse seems to be used as a resource to fill the silence of the higher-level action of organizing thoughts (where no verbal mode is used). This type of action, in turn, is realized through high model complexity by the modes of gaze, posture and proxemics and, as a foregrounded cognitive process, it requires the concentration of the lecturer. Thus, although from a verbal perspective metadiscourse seems to be used as a guide to indicate the direction of the lecture, the multimodal analysis demonstrates that this is not the main intention of the lecturer and metadiscourse seems to "fill" the verbal mode in the multimodal ensemble. In short, metadiscourse plays a passive role in this excerpt. 


\subsubsection{The role of metadiscourse in spontaneous instances}

In this section, I intend to analyze the role of metadiscourse in spontaneous metadiscursive instances. These instances often interrupt the flow of the main utterances to establish connections with previous or future moments. In other words, spontaneous metadiscourse is commonly formed by previewing and reviewing instances. Unlike structuring segments, spontaneous metadiscourse consists of short isolated references which do not work as transitional elements between higher-level actions. Instead, this type of metadiscourse is performed in an unprompted manner and is commonly encompassed within larger nonorganizational higher-level actions. In other words, spontaneous metadiscourse tends to occur in a natural manner within content explanations. Given the little planning and attention received in the modal density compendium, the metadiscursive function of establishing connections between distinct parts of the lecture is very low. Thus, spontaneous metadiscourse seems to be performed in a rather passive manner. Although the ultimate aim of these instances is to connect the present information with other parts of the discourse, little attention is devoted to such connections. Therefore, the only function that can be attached to this type of metadiscourse seems to be that of establishing connections at a low intensity. In the following lines, I show an example of the use of spontaneous metadiscourse.

The following excerpt includes a reviewing instance from C6_15. The use of metadiscourse in this fragment is performed as a midgrounded action that briefly interrupts the lecturing process. The role of metadiscourse is, therefore, a passive one. The fragment takes place 28 minutes into the lecture and a verbal transcription is provided in Transcript 8.3. Moreover, Figure 8.8 describes the succession of higher-level actions in this fragment. 


\section{Transcript 8.3}

28:09:01 This is the end

28:09:28 erm... of... of... of... of... erm... (1)

28:12:15 Spitzer's erm... synthesis erm... his conclusion after this very thorough erm... and brilliant analysis of erm... of the novel. (2)

28:22:20 This is my view

28:23:17 erm... I have been expressing it already (.5)

28:26:00 erm... (1)

28:27:11 this is my view both, view both on erm... on Auerbach and Spitzer, in the glorification of the AUthor, Spitzer does NOT take into account Cervantes' errors. (1.5)

In this fragment, the lecturer goes back to reading after having produced a spontaneous comment on the contents of the lecture. Right at the beginning of the reading process, the lecturer employs reviewing metadiscourse to connect the contents that are being expressed with an unspecified previous moment in the course ("I have been expressing it already"). The action begins with the lecturer performing the higher-level action of spontaneously commenting (Graph 1) in which he states his opinion about a list of quotes that he has previously read. This action is realized through a multiplicity of modes: posture and gaze directed towards the audience; one-handed and two-handed gestures; and some hesitation in the verbal mode (Image 1). The lecturer makes his verbal comment and in 28:20:25 he performs a semantic/pragmatic means right before he finishes the utterance ("[...]after this very thorough and brilliant analysis of the novel"): he lowers his hands towards the lectern, turns his gaze towards the notes and leans his body towards them (Image 2).

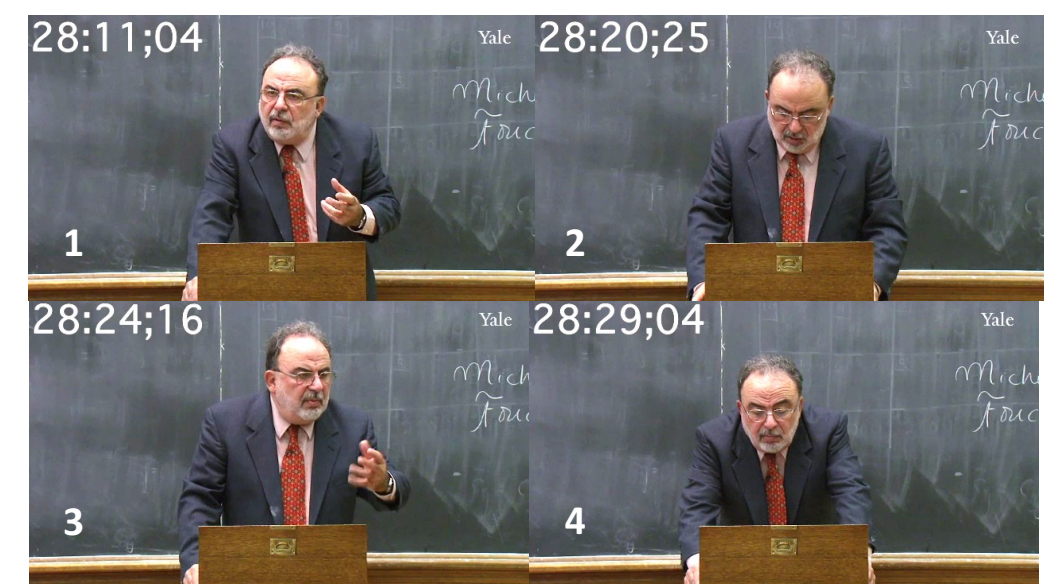

Figure 8.8 Succession of higher-level actions in spontaneous metadiscourse in C6_L15 

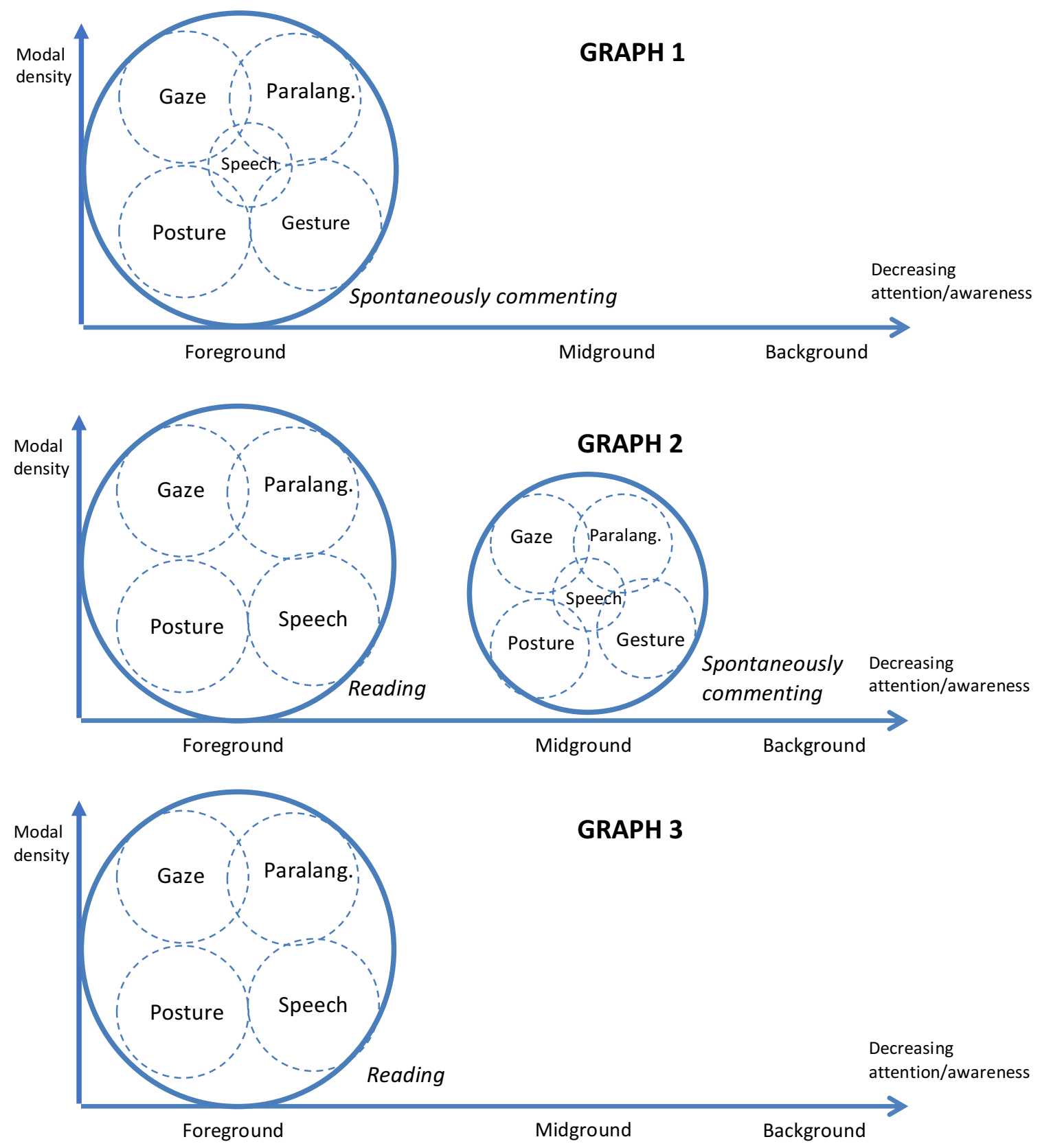

Figure 8.8 (cont.) Succession of higher-level actions in spontaneous metadiscourse in C6_L15

At this point, the action of reading appears in the foreground while spontaneously commenting remains in the background for a while (Graph 2). The lecturer begins reading "This is my view..." but suddenly interrupts his utterance and produces a metadiscursive expression: "I have been expressing it already". By using this spontaneous expression, the lecturer connects what he is about to read with an unspecified moment in the past when he discussed the same topic. This utterance is performed in the midground as part of the higher-level action of spontaneously commenting. The utterance is performed verbally and is accompanied by a beat and a short gaze shift towards the audience (Image 3 ). The main 
focus of the lecturer, however, still seems to be on the notes, as his right hand is placed on the lectern and his posture remains slightly leaned towards it. Next, the higher-level action of spontaneously commenting finalizes and the lecturer continues reading by repeating the beginning of the utterance that he interrupted (Image 4/Graph 3): "this is my view both on Auerbach and Spitzer". Figure 8.9 visually describes the change in modal density in the sequence.

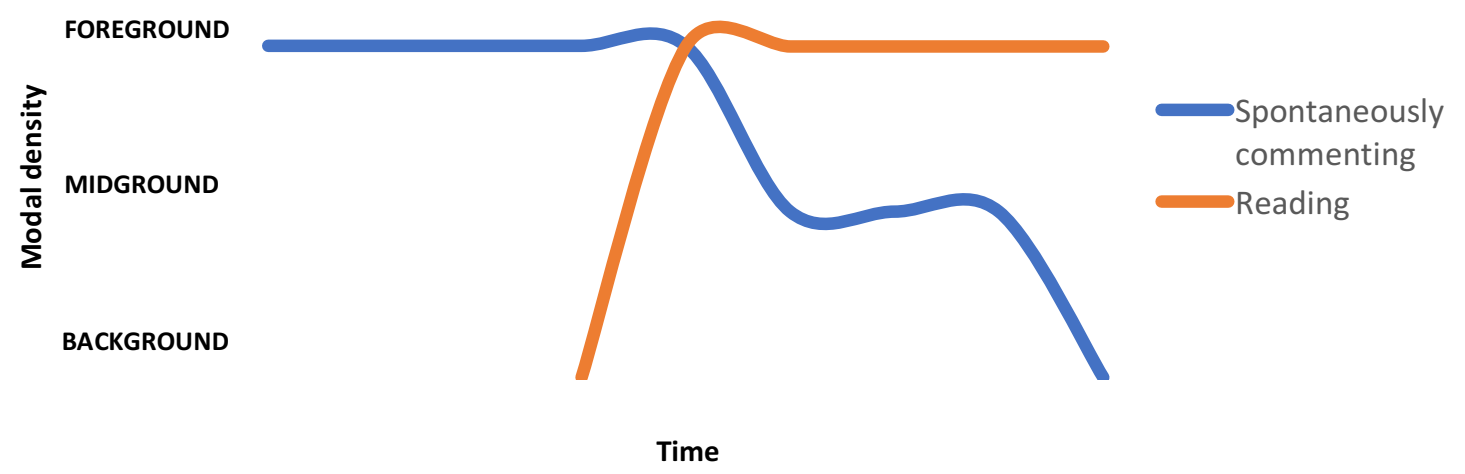

Figure 8.9 Succession of higher-level actions across the foreground-background continuum

In the short fragment here analyzed, the lecturer produces an instance of reviewing metadiscourse:

\section{- I have been expressing it already}

By using this expression, the lecturer in C6 establishes a connection with previous information. The multimodal analysis of the sequence of higher-level actions in this fragment shows that this metadiscursive instance is encompassed within a broader higherlevel action (spontaneously commenting) in which the lecturer provides a spontaneous opinion of a topic. However, metadiscourse occurs at the end of the higher-level action when the action is in a midgrounded position. All these facts seem to indicate that metadiscourse is paid little attention when used spontaneously. The verbalization of the connection with previous information probably occurs as the lecturer realizes that something has been said about the topic already. In conclusion, the uses of metadiscourse in spontaneous fragments seem to differ from those in structuring segments. Thus, although the main function of metadiscourse in spontaneous instances may be that of 
establishing connections with other pieces of information in the discourse (an active role), the attention received by the action in which metadiscourse is encompassed is low (a passive role). This seems to indicate a lower degree of importance in the connection being established as well as little effort to engage the students and guide them through the speech.

In this chapter, I have explored the structure of lectures from an MIA perspective. By conducting this type of analysis, I have shown which are the recurrent organizational sequences of actions performed by the lecturers in each lecturing style. Moreover, I have reflected upon the distinct roles played by metadiscourse in both structuring segments and spontaneous instances. In the following chapter, I wind up the analytical section of this thesis by considering the results as a whole and I offer some concluding remarks. 


\section{CHAPTER 9. CONCLUSIONS}

In this final chapter, I reflect upon the study conducted in this thesis by drawing some conclusions on the results here presented, exploring the pedagogical applications of the study, acknowledging the limitations of the analysis, and suggesting future research lines. Thus, Section 9.1 offers some concluding remarks in which I review the aims and research questions proposed in this thesis in order to discuss the main findings and their implications. Next, in Section 9.2, I suggest some pedagogical applications of the present study. Finally, Section 9.3 concludes this thesis by addressing the limitations of the study and bringing to the fore some proposals for further research in the study of metadiscourse and multimodality.

\subsection{Concluding remarks}

The main objective of this study was to shed new light onto the study of metadiscourse by adopting a novel methodology to explore these instances not only from quantitative and linguistic points of view but also considering the several modes taking part in communication and the structure of lectures as sequences of mediated actions. From my perspective, this thesis offers three main contributions to the field. Firstly, the present study contributes to expanding the knowledge of spoken academic genres by exploring how metadiscourse is used with organizational functions at all levels. In this regard, metadiscourse is a linguistic category that has received much attention in written genres see, for instance, Hyland (2005)-, but only a few studies tackle this issue in spoken genres or from a multimodal perspective (see Section 3.3 in this thesis). Secondly, I consider lecturing styles (see Section 1.3.1.1) as one of the key variables influencing the use of organizational metadiscourse in lectures. Finally, I devise a novel approach for the study of metadiscourse based on the combination of quantitative, linguistic and multimodal methodologies. This is particularly evident in the multimodal approach adopted in this 
thesis, as I combine concepts and tools from three multimodal frameworks (MSS, MDA and MIA) to carry out the analyses of the use of semiotic resources and the structuring process of the lecturers. In this regard, this study has started from the premise that all communication is multimodal. By exploring organizational metadiscourse both at a linguistic level and from a multimodal perspective, I have shown how meaning is coexpressed through a variety of semiotic resources. Moreover, I have described how this meaning is transmitted differently across lecturing styles.

To meet the objective of my study, I have drawn on diverse theoretical frameworks such as discourse analysis -including pragmatics (Austin, 1962; Grice, 1975; Searle, 1969) and SFL (Halliday, 1985, 1994; Halliday \& Matthiessen, 2014)--, Jakobson's functions of language (Jakobson, 1960), mediated discourse analysis (Scollon, 1998, 2001; Scollon \& Scollon, 2004), genre analysis studies (Bhatia, 1993; Fortanet, 2005; Swales, 1990), approaches to the study of lectures (Dudley-Evans, 1994; Young, 1994), and multimodal approaches to discourse -including MSS (Kress, 2000; Kress \& van Leeuwen, 2001; van Leeuwen, 2005), MDA (O'Halloran, 2004a, 2007), and MIA (Norris, 2004, 2011). The combination of these approaches has allowed me to explore metadiscourse from different levels, identifying how metadiscourse is used quantitatively, linguistically, as a combination of semiotic resources, and as an inner element in the lecturers' organization of the lectures in terms of actions. Furthermore, I have been able to discern how these uses vary across lecturing styles. Finally, the lectures used for the analyses in this thesis have been extracted from Yale University's OCW. Although these lectures consist of face-to-face traditional sessions, the fact that they may be obtained from an online corpus has facilitated the compilation and editing process of the data.

As for the study of metadiscourse, I have focused on Ädel's $(2006,2010)$ reflexive model using Ädel's (2010) taxonomy in spoken academic English in order to identify and classify all instances within the category of discourse organization. In the present thesis, Ädel's model has proven to be rather accurate in the study of organizational metadiscourse in lectures, except for minor overlapping issues between the categories of introducing topic and previewing, as described in Section 5.1.2. 
In relation to the multimodal analyses conducted, one of the most novel aspects in this study is the combination of different multimodal approaches to discourse. On the one hand, in order to describe how distinct semiotic resources are employed and combined when conveying metadiscourse, I make use of the tools provided in MSS (Kress, 2000; Kress \& van Leeuwen, 2001; van Leeuwen, 2005) and MDA (O'Halloran, 2004a, 2007), as well as previous literature in the study of the modes being analyzed -gestures (Calbris, 2008; Kendon, 2004; McNeill, 1992), gaze (Goodwin, 1981; Norris, 2004; Tan et al., 2015), head movement (Norris, 2004), posture (Bernad-Mechó, 2017a; Bernad-Mechó \& FortanetGómez, forthcoming), paralanguage (Brazil, 1997), proxemics (Hall, 1966; Norris, 2004), and facial expression (Birdwhistell, 1979; Eibl-Eibesfeldt, 1972; Ekman, 1972; Hwang \& Matsumoto, 2016). On the other hand, an MIA approach (Norris, 2004, 2011) has allowed me to look into the structure of lectures beyond words and in terms of successions of actions.

Lastly, the use of technological tools has been paramount to carry out my research. The use of the multilayer annotation tool MMA-Video has been proven useful to represent interaction as a combination of modes. Moreover, the State Machine tool accessible within MMA-Video has allowed me to obtain quantitative data in the use of semiotic resources, i.e. the percentages of time in which a certain mode is being used. Finally, the use of Sonic Visualiser and the plug-in pYin has contributed to developing my multimodal transcriptions by including objective representations of the mode of paralanguage.

Having this background into account, the research questions that guided my study are:

RQ 1. How is organizational metadiscourse used quantitatively in academic lectures?

RQ 2. How is organizational metadiscourse expressed verbally?

RQ 3. How is organizational metadiscourse expressed non-verbally?

RQ 4. How does organizational metadiscourse contribute to the structuring process of the lectures? 
The first research question has to do with the quantitative use of organizational metadiscourse and aims to narrow down the scope of the study by identifying the most common types of metadiscourse and defining which lectures and which sections may be representative of the use of organizational metadiscourse. The analysis involved the manual identification and classification of all metadiscursive instances in the corpus and a further exploration of the data across disciplines. The findings show that the most recurrently employed types of organizational metadiscourse are endophoric markers, on the one hand, and previewing and reviewing on the other. Endophoric markers are used to refer to materials being used in class (for example, slides, handouts, or books). However, this category has proven to be lecturer-dependent and suffers significant changes depending on the types of materials being used by every lecturer. Therefore, endophoric markers were not further considered in the analysis. As a result, previewing and reviewing have been identified as the most common types of metadiscourse. These categories contribute to the cohesion of the lectures both internally and throughout the course as they are used to establish connections in time. Additionally, the categories of introducing topic and contextualizing have also been identified as recurrent, although in a lower frequency.

The analysis of the distribution of metadiscourse has shown how metadiscourse is more frequent at the beginnings of the lectures and both at the beginnings and endings of courses. Additionally, metadiscourse is commonly distributed in the lectures in two manners: in structuring segments, i.e. sections in the lecture where the lecturers focus on the organization of the session and in which there is a higher presence of metadiscursive instances; and as spontaneous isolated instances distributed throughout the lectures.

Moreover, the quantitative results were compared across lecturing styles. Findings have shown a degree of similarity within each of the styles in terms of the total amount of organizational metadiscourse employed and the metadiscursive categories. These similarities are especially relevant in rhetorical and reading styles. Nonetheless, some differences were also encountered, although these seem to be explained in terms of stylistic or disciplinary reasons. 
All in all, the quantitative analysis has served to narrow down the scope of the forthcoming linguistic and multimodal analyses. This is particularly relevant in the latter, as multimodal analyses entail time-consuming annotation tasks. Thus, only the four most recurrent categories were taken into account for further analyses, and the sub-corpora for the study were completed by selecting six representative lectures and six representative structuring segments within those lectures.

The second research question tackled the verbal aspects of metadiscourse. In this sense, organizational metadiscourse has been explored from a linguistic point of view at two levels: looking at the syntactic structures and analyzing the lexical choices. For this analysis, the corpus of six representative lectures was selected. The syntactic analysis of introducing topic, previewing, reviewing, and contextualizing, revealed that these categories may be encompassed within several syntactic types and subtypes. The main distinction in the choices of syntactic structures has to do with the agency of the utterances -whether the subject of the sentences is the lecturer or the lecturer and the audience, or, on the contrary, whether the subject is the referent of the metadiscursive fragment. In this sense, the thematic choice of the lecturers seems to mark the preference between highlighting the action of previewing, reviewing, etc. or focusing on the contents that are being previewed, reviewed, etc. As for the analysis of lexical choices, communication and mental verbs (Biber et al., 1999) are recurrently used to proclaim metadiscourse. Furthermore, the exploration of the use of personal pronouns has revealed some interesting differences when considering the lecturing styles: conversational and rhetorical style lecturers prefer the use of I over we or you while reading style lecturers generally prefer we. This seems to indicate a tendency of reading style lecturers to include and engage the audience in the lecture. Still and all, few clear-cut differences are found in the linguistic exploration of metadiscourse across lecturing styles. This suggests that metadiscursive categories are accurately defined linguistically, as they are similarly used across lecturing styles.

The third research question looked at the multimodal uses of organizational metadiscourse to describe which semiotic resources are recurrently used and how they are combined in multimodal ensembles. This analysis took the theoretical and methodological tools in MSS (Kress, 2000; Kress \& van Leeuwen, 2001; van Leeuwen, 2005) and MDA (O'Halloran, 
$2004 a, 2007)$ as the point of departure. The study involved the multimodal annotation of the sub-corpus of structuring segments using the software MMA-Video and considering the analytical framework devised in Figure 4.6 under Section 4.3.3. Quantitative and qualitative analyses were carried out using MMA-Video's State Machine (for speech, gesture, gaze, head movement, posture, proxemics and facial expression) and Sonic Visualiser (for paralanguage). In general terms, the findings show a higher recurrence in the use of gestures, gaze, posture, proxemics and paralanguage in structuring segments. Furthermore, the analysis of multimodal ensembles demonstrates that several modes cooccur with speech to convey meaning in lectures, which corroborates previous research (Bernad-Mechó, 2015a; Bernad-Mechó \& Fortanet-Gómez, 2017; Crawford Camiciottoli, 2015, 2016).

When considering the influence of lecturing styles in the choice of semiotic resources and multimodal ensembles, the results seem to point to a constraint of certain lecturing styles over the availability of these resources. This is shown, for example, in the use of gestures: while conversational and rhetorical style lecturers make an abundant use of gestures, reading style lecturers rarely use them. Rhetorical style lectures, in turn, show a higher percentage of two-handed gestures, which indicate emphasis, since these lecturers are not restricted by the use of notes or by the lectern. In this sense, the choices in posture and proxemics in this lecturing style seem to bring the lecturers closer to the audience, thus achieving more engagement. On the contrary, the capacity to engage the audience is restricted in conversational style lecturers and, especially, in reading style lecturers. The use of notes in these lecturers limits the amount of time they can share eye rapport with the addressees and the postures they maintain (often towards the lectern). Reading style lecturers, in particular, seem to resort to alternative modes such the use of intensity and intonation in paralanguage to achieve a connection with the audience.

Overall, relevant differences across lecturing styles are evident. In this regard, a continuum of lecturing styles is proposed (see Figure 7.11 in Section 7.2.4) ranging from those lecturing styles showing low modal density and high focus on the notes (typically reading style lecturers) to lecturing styles showing high modal density and high focus on the audience 
(typically rhetorical style lecturers). This analysis, in turn, has contributed to defining lecturing styles in terms of the use of semiotic resources.

Finally, the fourth question entailed a multimodal analysis of the structures of lectures from a novel multimodal perspective in order to discern how lecturers signal the organization of the session in sequences of actions, and the roles that verbal metadiscourse plays in those sequences. The tools provided by MIA (Norris, 2004, 2011) allowed me to identify the sequences of actions performed by the lecturers. The findings show relevant differences in the ways in which lecturers across lecturing styles construct the sequences of actions when organizing the message. Thus, conversational style lecturers favor structures in which content-developing actions merge into organizational ones that act as separating elements between longer stretches of content-based lecturing; rhetorical style lecturers offer long successions of content-developing actions that may occasionally be interrupted by organizational actions; and reading style lecturers alternate reading and spontaneous actions, and the organizational message may be contained in either.

Moreover, each of the actions performed by the lecturers has been described with a specific modal density that indicates whether the action is performed in the foreground, midground, or background. Finally, by analyzing the actions in which verbal metadiscourse occurs and the attention they receive, I have been able to identify two main roles for metadiscourse that seem to occur across all lecturing styles: an active and a passive one. In this regard, when metadiscourse plays an active role, its main function is that of signaling the direction of the lecture, establishing connections and organizing the discourse. On the other hand, when metadiscourse is used in the midground, it may play a passive role. In these instances, verbal metadiscourse is commonly used as a verbal filler while the lecturers focus on other actions (like organizing their thoughts or checking on the notes).

When considering these findings together, one of the main conclusions that can be reached is that a new layer of meaning is brought to the fore by conducting a combination of multimodal analyses. In this regard, the linguistic category of metadiscourse is identified as being transmitted through a multiplicity of modes. In general terms, the present study complements previous research around two main ideas. On the one hand, this thesis 
expands previous approaches towards metadiscourse by considering how metadiscourse is conveyed through the combination of semiotic resources. On the other hand, the results presented in this thesis contribute to the research on the multimodality of lectures by exploring how lecturers organize their sessions and transmit this organization to the audience.

Furthermore, the study reveals that the connection between the use of organizational metadiscourse and lecturing styles is more evident when these elements are analyzed multimodally. In this sense, no relevant differences in the use of organizational metadiscourse across lecturing styles have been found in the linguistic analysis in Chapter 6 , and only some general trends have been observed at a quantitative level in Chapter 5. On the contrary, the multimodal study in Chapter 7 has shown relevant differences in the semiotic resources available to each lecturer. Finally, the differences across lecturing styles have become even more relevant in the analysis of the structures of actions in Chapter 8. In sum, both multimodal analyses have contributed to defining lecturing styles in multimodal terms. Thus, conversational style lecturers often employ a high amount of metadiscursive instances and combine these instances with a variety of semiotic resources like simple gestures, gaze, and paralanguage to engage the audience. In addition, the structuring sections for these lecturers seem to establish clear-cut boundaries between lecturing and organizational sections. Rhetorical style lecturers, on the other hand, use a lower amount of metadiscursive instances but employ a wider range of semiotic resources to connect with the audience: two-handed gestures, gaze towards the audience, postures, proxemics, paralanguage and facial expression. Their organizational structures, however, are not so clear-cut and their actions are often succeeded as streams of thoughts merging one into another. Finally, reading style lecturers use a moderate amount of metadiscursive instances which are very limited multimodally. In this regard, they may resort to the only few available resources at hand (mainly paralanguage and facial expression) to provide emphasis to metadiscursive elements. As for their organizational structure, although clear boundaries have been found between reading and spontaneous sections, metadiscourse may occur in either and it seems to be used as an embedded element within these actions. 
The last conclusion that I can draw from this study is that the combination of linguistic, quantitative and multimodal methodologies, as well as the combination of distinct multimodal frameworks (MSS, MDA, and MIA), is possible and provides a wider account of the intricacies of communication in academic settings at all levels. I consider this one of the greatest contributions of this thesis, which might have an impact on the ways in which metadiscourse has traditionally been approached, i.e. from a linguistic point of view. Furthermore, the use of the multilayer annotation tool MMA-Video combined with the pitch analysis provided by Sonic Visualiser offers a systematic way of looking into quantitative and qualitative data in multimodal analyses.

\subsection{Pedagogical applications}

Organizing and structuring lectures are crucial issues that new lecturers need to face in their first experiences in higher education (McKeachie \& Svinicki, 2013; Nilson, 2016). As I stated in the introduction to this thesis, as a junior lecturer myself, one of my motivations for conducting this research was to explore the strategies employed by experienced lecturers to organize their sessions and to indicate this organization to the students. Ultimately, the accurate signaling of the directions of the lecture contributes to keeping the audience's interest and smoothing the path for the students to comprehend the new ideas (Palmer Silveira, 2004). Furthermore, English has become the common language of use in academia, especially in conference presentations and written articles. In addition, language policies in European universities tend to foster English as the means of instruction (Fortanet-Gómez, 2013). Within this framework, many lecturers may encounter difficulties when facing the complexity of university lectures and their structuring process. This scenario becomes even more worrisome for young lecturers, especially when English is not their L1.

In this sense, the results of this thesis might be applied in EAP training courses for lecturers or to design teaching materials. It is important to note at this point that the lecturing style 
of a lecturer is a personal choice; I do not argue that one style is better than another. However, as discussed in the previous section, lecturers within distinct lecturing styles make use of different strategies to organize their sessions and signal this organization to the audience. Therefore, these courses should focus on the distinct strategies employed in each lecturing style and how engagement is achieved successfully. The results in Chapter 7, for example, describe the limitations in the use of semiotic resources that seem intrinsic to each lecturing style. Being aware of such constraints may provide (multimodal) tools to better engage the audience in the lecturing process. Additionally, the findings presented in this thesis might contribute to bringing to the fore the importance of metadiscourse to facilitate comprehension by the students and to add cohesion to the lecture. Finally, the multimodal perspective adopted in the study could be a factor to be considered in order to raise awareness on the relevance of non-verbal aspects in communication. From my perspective, these elements have been traditionally neglected in lecturers' training courses.

\subsection{Limitations of the study and suggestions for further research}

The study that I have presented has had some limitations which need to be considered to contextualize its findings. The greatest limitation in the present study has to do with the size of the main corpus and its sub-corpora. In this regard, the size of the corpora was determined by the purposes and the methodology of this thesis. In this sense, all the analyses conducted in this study have been carried out manually. This is particularly relevant when considering the process of multimodal annotation. This process entails the time-consuming task of visualizing and annotating all mode occurrences in each of the clips. Consequently, the sub-corpus of structuring segments had to be manageable enough and was limited to one short clip per lecturer. Furthermore, with the aim of obtaining a manageable sample for the multiple analyses proposed in the methodology, only six lecturers were selected. Having these ideas in mind, as described throughout the analytical chapters, some personal traits seem to shape, to a greater or lesser extent, the ways in 
which metadiscourse is used across lecturing styles. For all these reasons, no broad generalizations can be made on this data; however, the results seem to point towards certain preliminary conclusions and may be used as a reference for similar approaches. Finally, another important limitation in the study has to do with the fact that the data have been extracted from one single source (Yale University's OCW) and that no feedback from either the lecturers or the audience has been taken into account. In this line, the data employed in this thesis come from an Anglo-Saxon university tradition and might or might not coincide with data extracted from other environments. Thus, the present study offers a detailed account of a very culturally-specific type of lectures and contributes to expanding the knowledge on the use of metadiscourse in English as L1 settings. However, the findings presented here cannot be extrapolated to other university contexts.

These ideas bring me to a series of suggestions for further research. Further research lines might be taken in various directions. Although this thesis takes a step forward in the tradition of multimodal analyses by looking at the use of semiotic resources in terms of percentage of use, larger quantitative studies would be needed in order to corroborate these results. In this sense, advances are being made to multimodally analyze big datasets, especially in images (O'Halloran, Tan, Wignell et al., 2016); however, new approaches to the multimodal analysis of large video-corpora are necessary. By expanding the present study to a larger comparative study compiling more lecturers from various sources and backgrounds, the individual factors influencing the use of metadiscourse and semiotic resources could be minimized. In this line, studies comparing lecturers in different languages might also provide a wider view on the multimodality of metadiscourse in lectures. Actually, we conducted elsewhere (Bernad-Mechó \& Fortanet-Gómez, 2017) a preliminary study contemplating this possibility.

From a methodological perspective, the study of modal configurations within higher-level actions in the MIA approach (see Section 8.2) could be expanded to include quantitative data. For practical reasons, only a basic approximation towards modal configurations was taken in this study with the objective of distinguishing the various higher-level actions cooccurring in interaction; however, the tool MMA-Video could also be applied to the study 
of individual higher-level actions in order to obtain a more accurate view of the importance of each semiotic resource within a given action.

Other elements that could be taken into account in further studies are the metapragmatic functions of non-verbal actions. As I briefly describe at the end of Section 3.3, some nonverbal behaviors have been identified as conducting metadiscursive functions (for instance, lip adaptors that serve as indicators of topic shifts). These elements cannot be explained within a theory of metadiscourse as no linguistic reflection is present; nevertheless, metapragmatics seems to be able to explain these particular instances. Such study might further expand the understanding of the ways in which metadiscourse is signaled.

To conclude, the last suggestion for further research has to do with expanding the present study to include not only the analysis of the lecturers, but also that of the audience. By assessing both, the lecturers and the audience, a more reliable picture would be obtained as to how the students react to the signals of the lecturer. In this manner, one could reflect upon which lecturing styles and what particular techniques work better. In this regard, an ethnographic approach including interviews with both lecturers and students might also complement such study. With this aim in mind, the GRAPE (Group for Research on Academic and Professional English) at Universitat Jaume I (Spain) has conducted a pilot study using the electroencephalography neuroheadset Emotiv EPOC+, which registers the brain reactions of students watching online classes (Ruiz-Garrido \& Palmer Silveira, forthcoming). The ultimate aim of this study is, once again, to determine which multimodal strategies work better in each situation.

I hope this thesis and its results can become a relevant contribution to the multimodal discourse analysis field of research. To this end, I intend to disseminate its results and make them known to all researchers in this field. 


\section{REFERENCES}

Abdi, R. (2011). Metadiscourse strategies in research articles: a study of the differences across subsections. Journal of Teaching Language Skills, 3(1), 1-15.

Abdi, R., Rizi, M. T., \& Tavakoli, M. (2010). The cooperative principle in discourse communities and genres: A framework for the use of metadiscourse. Journal of Pragmatics, 42, 1669-1679.

Adami, E. (2015). What's in a click? A social semiotic framework for the multimodal analysis of website interactivity. Visual Communication, 14(2), 133-153.

Adami, E. (2017). Multimodality. In O. García, N. Flores, \& M. Spotti (Eds.), Oxford Handbook of Language and Society (pp. 451-472). New York, NY: Oxford University Press.

Ädel, A. (2005). On the boundaries between evaluation and metadiscourse. In E. TogniniBonelli \& G. Dell Lungo Camiciotti (Eds.), Strategies in Academic Discourse (pp. 153162). Amsterdam/Philadelphia: John Benjamins.

Ädel, A. (2006). Metadiscourse in L1 and L2 English. Amsterdam \& Philadelphia: John Benjamins.

Ädel, A. (2010). Just to give you kind of a map of where we are going: A Taxonomy of Metadiscourse in Spoken and Written Academic English. Nordic Journal of English Studies, 9(2), 69-97.

Ädel, A. (2013). Metadiscourse. In The Encyclopedia of Applied Linguistics (pp. 3663-3669). Hoboken, NJ: Blackwell Publishing Ltd.

Afros, E., \& Schryer, C. (2009). Promotional (meta) discourse in research articles in language and literary studies. English for Specific Purposes, 28, 58-68. 
Aguilar, M. (2008). Metadiscourse in Academic Speech. A Relevance-Theoretic Approach. Bern: Peter Lang.

Aguilar, M., \& Arnó, E. (2002). Metadiscourse in Lecture Comprehension: Does it Really Help Foreign Language Learners? Atlantis, 14, 7-21.

Alias, S. (2004). A semiotic study of Singapore's Orchard Road and Marriott Hotel. In K. O’Halloran (Ed.), Multimodal Discourse Analysis: Systemic functional perspectives (pp. 55-79). London \& New York: Continuum.

Altorfer, A., Jossen, S., Würmle, O., Käsermann, M. L., Foppa, K., \& Zimmermann, H. (2000). Mesurement and meaning of head movements in everyday face to face communicative interaction. Behaviour Research Methods, Instruments and Computers, 32(1), 17-32.

Amiryousefi, M., \& Eslami-Rasekh, A. (2010). Metadiscourse: Definitions, Issues and Its Implications for English Teachers. English Language Teaching, 3(4), 159-167.

Anderson, P. A. (1999). Nonverbal communication: Forms and functions. Mountain View, CA: Mayfield.

Andric, M., \& Small, S. L. (2012). Gesture's Neural Langauge. Frontiers in Psychology, 3(99).

Anwardeen, N. H., Luyee, E. O., Gabriel, J. I., \& Kalajahi, S. A. R. (2013). An Analysis: The Usage of Metadiscourse in Argumentative Writing by Malaysian Tertiary Level of Students. English Language Teaching, 6(9), 83-96.

Archer, A., \& Newfield, D. (2014). Multimodal Approaches to Research and Pedagogy: Recognition, Resources and Access. New York: Routledge.

Archer, D., \& Akert, R. (1977). Words and everything else: verbal and nonverbal cues in social interaction. Journal of Personality and Social Psychology, 35, 443-449.

Argyle, M., \& Cook, M. (1976). Gaze and mutual gaze. Cambridge: Cambridge University Press. 
Argyle, M., Ingham, R., Alkema, F., \& McCallin, M. (1973). The different functions of gaze. Semiotica, 7(1), 19-32.

Artemeva, N., \& Fox, J. (2011). The Writing's on the Board. The Global and the Local in Teaching Undergraduate Mathematics Through Chalk Talk. Written Communication, 28(4), 345-379.

Árvay, A., \& Tankó, G. (2004). A contrastive analysis of English and Hungarian theoretical research article introductins. IRAL - International Review of Applied Linguistics in Language Teaching, 42, 71-100.

Askehave, I. (1999). Communicative purpose as genre determinant. Hermes, Journal of Linguistics, 23, 13-23.

Askehave, I., \& Swales, J. M. (2001). Genre identification and communicative purpose: a problem and a possible solution. Applied Linguistics, 22(2), 195-212.

Austin, J. (1962). How to Do Things with Words. Cambridge, MA: Harvard University Press.

Bäcklund, I. (1998). Metatext in Professional Writing: A Contrastive Study of English, German and Swedish. Texts in European Writing Communities 3. Uppsala: Uppsala Universitet.

Bakhtin, M. M. (1986). The problem of speech genres. In C. Emerson \& M. Holquist (Eds.), Speech Genres and Other Late Essays (pp. 60-102). Austin, TX: The University of Texas Press.

Baldry, A. P. (2000). Multimodality and multimediality in the distance learning age. Campobasso, Italy: Palladino Editore.

Baldry, A. P. (2004). Phase and transition, type and instance: Patterns in media texts as seen through a multimodal concordancer. In K. O'Halloran (Ed.), Multimodal Discourse Analysis (pp. 83-108). London: Continuum.

Baldry, A. P., \& Thibault, P. J. (2006). Multimodal Transcription and Text Analysis: A Multimodal Toolkit and Coursebook with Associated On-line Course. London: Equinox. 
Bateman, J. A., \& Schmidt, K.-H. (2012). Multimodal film analysis: how films mean. London \& New York: Routledge.

Bates, E. (1976). Language and context. New York, NY: Academic Press.

Bavelas, J. B., Chovil, N., Coates, L., \& Roe, L. (1995). Gesture specialized for dialogue. Personality and Social Psychology Bulletin, 21(4), 394-405.

Bavelas, J. B., Chovil, N., Lawrie, D. A., \& Wade, A. (1992). Interactive gestures. Discourse Processes, 15, 469-489.

Bazerman, C. (1988). Shaping Written Knowledge: The Genre and Activity of the Experimental Article in Science. Madison, Wisconsin: University of Wisconsin Press.

Belhiah, H. (2009). Tutoring as an embodied activity: How speech, gaze and body orientation are coordinated to conduct ESL tutorial business. Journal of Pragmatics, $41(4), 829-841$.

Bellés-Fortuño, B. (2006). Discourse markers within the university lecture genre: $A$ contrastive study between Spanish and North-American lectures. Unpublished PhD dissertation. Castelló de la Plana, Spain: Universitat Jaume I.

Benson, M. J. (1994). Lecture listening in an ethnographic perspective. In J. Flowerdew (Ed.), Academic listening: research perspectives. (pp. 181-198). Cambridge: Cambridge University Press.

Bernad-Mechó, E. (2015a). A Multimodal Discourse Analysis of linking metadiscursive elements in two opencourseware lectures (MOOCs). Procedia-Social and Behavioral Sciences, 212, 61-66.

Bernad-Mechó, E. (2015b). OpenCourseWare as part of the new academic discourse in the digital world: Approaching websites and video-lectures. Paper presented at the $1^{\text {st }}$ International Conference: Approaches to Digital Discourse Analysis (ADDA). 19-20 November, 2015. València, Spain. 
Bernad-Mechó, E. (2017a). Metadiscourse and topic introductions in an academic lecture: A multimodal insight. Multimodal Communication, 6(1), 39-60.

Bernad-Mechó, E. (2017b). What does metadiscourse reveal about lecturers? A quantitative approach towards discourse-organizing metadiscourse. Paper presented at the $1^{\text {st }}$ International Conference on Corpus Analysis in Academic Discourse (CAAD), 22-24 November, 2017. València, Spain.

Bernad-Mechó, E. (forthcoming). OpenCourseWare as a hybrid genre: The case of Open Yale Courses.

Bernad-Mechó, E., \& Fortanet-Gómez, I. (2017). Semiotic Modes in the Organization of Lectures in English and in Spanish. In C. Vargas-Sierra (Ed.), Professional and Academic Discourse: an Interdisciplinary Perspective (EPiC Series in Language and Linguistics, Volume 2) (pp. 224-234). Available at https://easychair.org/publications/paper/8mXj Last accessed January $8^{\text {th }} 2018$.

Bernad-Mechó, E., \& Fortanet-Gómez, I. (forthcoming). Organizational metadiscourse across lecturing styles: Engagement beyond language. In C. Sancho-Guinda (Ed.), Engagement in Professional Genres: Deference and Disclosure. Amsterdam \& Philadelphia: John Benjamins.

Berry, M. (1995). Thematic Options and Success in Writing. In M. Ghadessy (Ed.), Thematic Development in English Texts (pp. 55-84). London: Pinter.

Berry, M. (1996). What is Theme? A(nother) personal view. In M. Berry, R. Fawcett, \& G. Huang (Eds.), Meaning and form: systemic functional interpretations (pp. 1-64). Norwood: Ablex Publishing Company.

Bezemer, J. (2014a). Multimodal transcription: A case study. In S. Norris \& C. D. Maier (Eds.), Interactions, images and texts: A reader in multimodality (pp. 155-170). Boston \& Berlin: De Gruyter Mouton.

Bezemer, J. (2014b). The use of gesture in operations. In C. Jewitt (Ed.), The Routledge Handbook of Multimodal Analysis (2nd ed., pp. 354-364). London: Routledge. 
Bezemer, J., \& Kress, G. (2008). Writing in Multimodal Texts: a Social Semiotic Account of Designs for Learning. Written Communication, 25(2), 166-195.

Bezemer, J., \& Kress, G. (2014). Young people, Facebook and pedagogy: Recognizing contemporary forms of multimodal text making. In M. Kontopodis, C. Varvantakis, M. Dafermos, \& C. Wulf (Eds.), Youth, tube, media: Qualitative insights and international perspectives (pp. 22-39). Berlin: Waxmann.

Bhatia, V. K. (1991). A genre-based approach to ESP materials. World Englishes, 10(2), 153166.

Bhatia, V. K. (1993). Analyzing Genre. Language Use in Professional Settings. Essex: Longman.

Bhatia, V. K. (2001). Analysing genre: some conceptual issues. In M. Hewings (Ed.), Academic writing in context. Implications and applications (pp. 79-92). Birmingham: University of Birmingham Press.

Bhatia, V. K. (2002). A generic view of academic discourse. In J. Flowerdew (Ed.), Academic Discourse (pp. 21-39). London: Pearson Education Limited.

Bhatia, V. K. (2004). Worlds of Written Discourse. A Genre-Based View. London \& New York: Continuum.

Biber, D. (1986). Spoken and written textual dimensions in English: Resolving the contradictory findings. Language, 62, 384-414.

Biber, D. (1988). Variation across Speech and Writing. Cambridge: Cambridge University Press.

Biber, D. (2006). Stance in spoken and written university registers. Journal of English for Academic Purposes, 5, 97-116.

Biber, D., Conrad, S., \& Cortés, V. (2004). If you look at...: Lexical bundles in university teaching and textbooks. Applied Linguistics, 25(3), 371-405. 
Biber, D., Johansson, S., Leech, G., Conrad, S., \& Finnegan, E. (1999). Longman Grammar of Spoken and Written English. London: Longman.

Birdwhistell, R. L. (1979). Kinesics and context: Essays on body motion communications. Philadelphia: University of Pensylvania Press.

Blagojevic, S. (2004). Metadiscourse in Academic Prose: a Contrastive Study of Academic Articles Written in English by English and Norwegian Native Speakers. Studies About Languages, 5, 60-67.

Bligh, D. (1972). What's the Use of Lectures? ( $1^{\text {st }}$ ed.). London: Penguin Education.

Bligh, D. (2000). What's the Use of Lectures? ( $2^{\text {nd }}$ ed.). San Francisco: Jossey-Bass.

Boersma, P. (2001). Praat, a system for doing phonetics by computer. Glot International, 5(9), 341-345.

Boersma, P., \& Weenink, D. (2017). Praat: doing phonetics by computer.Retrieved from http://www.fon.hum.uva.nl/praat/ Last accessed January $8^{\text {th }} 2018$.

Bolinger, D. (1986). Intonation and its parts: Melody in spoken English. London: Stanford University Press.

Bondi, M. (2005). Metadiscursive practices in academic discourse: Variation across genres and disciplines. In J. Bamford \& M. Bondi (Eds.), Dialogue within discourse communities: Metadiscursive perspectives on academic genres (pp. 3-30). Tübingen: Max Niemeyer Verlag.

Bondi, M. (2010). Metadiscursive Practices in Introductions: Phraseology and Semantic Sequences across Genres. Nordic Journal of English Studies, 9(2), 99-123.

Brazil, D. (1984). The intonation of sentences read aloud. In D. Gibbon \& H. Richter (Eds.), Intonation, accent and rhythm: Studies in discourse phonology (pp. 46-66). Berlin: Walter de Gruyter. 
Brazil, D. (1997). The communicative value of intonation in English (2nd ed.). Cambridge: Cambridge University Press.

Brazil, D., Coulthard, M., \& Johns, C. (1980). Discourse intonation and language teaching. Harlow: Longman.

Brett, P. (1994). A genre analysis of the results section of sociology articles. English for Specific Purposes, 13(1), 47-59.

Brown, G., \& Yule, G. (1983). Discourse analysis. Cambridge: Cambridge University Press.

Brown, P., \& Levinson, S. (1978). Universals in language usage: politeness phenomena. In E. Goody (Ed.), Questions and Politeness: Strategies in Social Interaction (pp. 56-311). Cambridge: Cambridge University Press.

Bruce, I. (2009). Results sections in sociology and organic chemistry articles: A genre analysis. English for Specific Purposes, 28, 105-124.

Bruti, S. (2015). Teaching learners how to use pragmatic routines through audiovisual material. In B. Crawford Camiciottoli \& I. Fortanet-Gómez (Eds.), Multimodal Analysis in Academic Settings: From Research to Teaching (pp. 213-238). London \& New York: Routledge.

Bu, J. (2014). Towards a pragmatic analysis of metadiscourse in academic lectures: From relevance to adaptation. Discourse Studies, 16(4), 449-472.

Bublitz, W., \& Hübler, A. (2007). Metapragmatics in use. Amsterdam, Netherlands: John Benjamins.

Buck, G. (2001). Assessing Listening. New York: Cambridge University Press.

Bühler, K. (1933). Die Axiomatik der Sprachwissenschaften. Kant-Studien, 38(1-2), 19-90.

Bunton, D. (1999). The Use of Higher Level Metatext in PhD Theses. English for Specific Purposes, 18, 41-56. 
Bunton, D. (2002). Generic moves in PhD thesis introductions. In J. Flowerdew (Ed.), Academic Discourse (pp. 57-75). London: Longman.

Burn, A. (2014). The kineikonic mode: Towards a multimodal approach to moving-image media. In C. Jewitt (Ed.), The Routledge Handbook of Multimodal Analysis (2nd ed., pp. 375-385). London: Routledge.

Burneikaitè, N. (2008). Metadiscourse in Linguistics Master's Theses in English L1 and L2. Kalbotyra, 59(3), 38-47.

Burr, V. (1995). An Introduction to Social Constructionism. London: Routledge.

Caffi, C. (1984). Metapragmatics. Special issue of Journal of Pragmatics. Journal of Pragmatics, 8(4).

Caffi, C. (2006). Metapragmatics. In Encyclopedia of Language and Linguistics (2nd ed., pp. 82-88). Oxford: Pergamon.

Calbris, G. (2008). From left to right...: Coverbal gestures and their symbolic use of space. In A. Cienki \& C. Müller (Eds.), Metaphor and Gesture (pp. 27-54). Amsterdam/Philadelphia: John Benjamins Publishing Company.

Callaghan, J., \& McDonald, E. (2002). Expression, content and meaning in language and music. An integrated semiotic analysis. In P. McKevitt, S. O’Nuallain, \& Mulvihill (Eds.), Language, vision and music. Selected papers from the 8th international workshop on the cognitive science of natural language processing, Galway, Ireland, 1999 (pp. 205220). Amsterdam: John Benjamins.

Cameron, D. (2001). Working with Spoken Discourse. London: Sage.

Cannam, C., Landone, C., \& Sandler, M. (2010). Sonic Visualiser: An Open Source Application for Viewing, Analysing, and Annotating Music Audio Files. In MM '10. Proceedings of the 18th ACM international conference on Multimedia. Firenze, Italy October 25-29, 2010 (pp. 1467-1468). New York, NY, USA: ACM. 
Cao, F., \& Hu, G. (2014). Interactive metadiscourse in research articles: A comparative study of paradigmatic and disciplinary influences. Journal of Pragmatics, 66, 15-31.

Carlson, A. (2005). Using problem based learning to teach thermodynamics: the good, the bad and the ugly. In Paper Number 2005-2092. Submitted to the American Society for Engineering Education Annual Conference. Available at https://peer.asee.org/14819/ Last accessed January $8^{\text {th }} 2018$.

Cauldwell, R. (2002). Streaming speech: listening and pronunciation for advanced learners of English. Birmingham: Speech in Action.

Cauldwell, R. (2013). Phonology for Listening: Teaching the Stream of Speech. Birmingham: Speech in Action.

Chafe, W. (1976). Givenness, contrastiveness, definiteness, subject, topics, and point of view. In C. N. Li (Ed.), Subject and Topic (pp. 25-55). New York: Academic Press.

Chafe, W. (1982). Integration and involvement in speaking, writing, and oral literature. In D. Tannen (Ed.), Spoken and Written Language: Exploring Orality and Literacy. Norwood, NJ: Ablex.

Chafe, W. (1992). Discourse: an overview. In W. Bright (Ed.), International Encyclopedia of Linguistics (pp. 356-358). New York: Oxford University Press.

Chafe, W. (1994). Discourse, Consciousness, and Time: the Flow and Displacement of Conscious Experience in Speaking and Writing. Chicago: University of Chicago Press.

Chan, L. K. (2015). Giving a lecture. In L. K. Chan \& W. Pawlina (Eds.), Teaching Anatomy: A Practical Guide (pp. 61-71). Cham: Springer.

Charles, C., \& Ventola, E. (2002). A multi-semiotic genre: the conference slide show. In E. Ventola, C. Shalom, \& S. E. Thompson (Eds.), The Language of Conferencing (pp. 169209). Frankfurt: Peter Lang.

Chaudron, C. (1982). Vocabulary Elaboration: Teacher's Speech to L2 Learners Research Notes. Studies in Second Language Acquisition, 4, 170-180. 
Chaudron, C., \& Richards, J. (1986). The Effect of Discourse Markers on the Comprehension of Lectures. Applied Linguistics, 7, 113-127.

Cheng, S. W. (2012). "That's it for today": Academic lecture closings and the impact of class size. English for Specific Purposes, 31(4), 234-248.

Cheng, X., \& Steffensen, M. (1996). Metadiscourse: A Technique for Improving Student Writing. Research in the Teaching of English, 30, 149-181.

Chiang, C. S., \& Dunkel, P. (1992). The Effect of Speech Modification, Prior Knowledge, and Listening Proficiency on EFL Lecture Learning. Tesol Quarterly, 26, 345-374.

Chimombo, M., \& Roseberry, R. L. (1998). The Power of Discourse: An Introduction to Discourse Analysis. Mahwah, NJ: Lawrence Erlabaum.

Chun, D. M. (2002). Discourse Intonation in L2: From Theory and Research to Practice. Amsterdam \& Philadelphia: John Benjamins.

Connor, U. (1996). Contrastive Rhetoric. Cross-Cultural Aspects of Second Language Writing. Cambridge: Cambridge University Press.

Cook, R. H. S. (1975). A Communicative Approach to the Analysis of Extended Monologue discourse and its relevance to the development of teaching materials for ESP. Unpublished PhD dissertation. Edimburgh, UK: University of Edinburgh.

Crawford Camiciottoli, B. (2003). Metadiscourse and ESP Reading Comprehension. An Explanatory Study. Reading in a Foreign Language, 15, 28-44.

Crawford Camiciottoli, B. (2004). Interactive discourse structuring in L2 guest lectures: some insights from a comparative corpus-based study. Journal of English for Academic Purposes, 3, 39-54.

Crawford Camiciottoli, B. (2007). The Language of Business Studies Lectures. A CorpusAssisted Analysis. Amsterdam \& Philadelphia: John Benjamins. 
Crawford Camiciottoli, B. (2015). Elaborating Explanations During OpenCourseWare Humanities Lectures: The Interplay of Verbal and Nonverbal Strategies. In B. Crawford Camiciottoli \& I. Fortanet-Gómez (Eds.), Multimodal Analysis in Academic Settings: From Research to Teaching (pp. 144-170). New York: Routledge.

Crawford Camiciottoli, B. (2016). A multimodal Analysis of Interaction in academic lectures: A case study. In V. Bonsignori \& B. Crawford Camiciottoli (Eds.), Multimodality across communicative settings, discourse domains and genres (pp. 65-92). Newcastle upon Tyne, UK: Cambridge Scholars Publishing.

Crawford Camiciottoli, B., \& Fortanet-Gómez, I. (2015). Multimodal Analysis in Academic Settings: From Research to Teaching. New York \& London: Routledge.

Crismore, A. (1982). The Metadiscourse Component: Understanding Writing about Reading Directives. Document ED217374. Washington, DC: ERIC Document Reproduction Service. Available at https://eric.ed.gov/?id=ED217374/ Last accessed January $8^{\text {th }}$ 2018.

Crismore, A. (1989). Talking with Readers: Metadiscourse as Rhetorical Act. New York: Peter Lang.

Crismore, A., Markkanen, R., \& Steffensen, M. (1993). Metadiscourse in persuasive writing: a study of texts written by American and Finnish university students. Written Communication, 10, 39-71.

Crystal, D. (1969). Prosodic systems and intonation in English. Cambridge, UK: Cambridge University Press.

Crystal, D. (1975). Paralinguistics. In J. Benthall \& T. Polhemus (Eds.), The body as a medium of expression (pp. 162-174). London: Institute of Contemporary Arts.

Crystal, D., \& Quirk, R. (1964). Systems of prosodic and paralinguistic features in English. The Hague: Mouton. 
Csomay, E. (2007). Variation in academic lectures: Interactivity and level of instruction. In R. S. Reppen, S. M. Fitmaurice, \& D. Biber (Eds.), Using corpora to explore linguistic variation (pp. 205-224). Amsterdam: John Benjamins.

Cutler, A. (1983). Speakers' Conceptions of the Funcion of Prosody. In A. Cutler \& D. R. Ladd (Eds.), Prosody: models and measurements (pp. 79-91). Berlin \& Heidelberg: SpringerVerlag.

D’Oliveira, C., Carson, S., James, K., \& Lazarus, J. (2010). MIT OpenCourseWare: Unlocking Knowledge, Empowering Minds. Science, 329(5991), 525-526.

Dafouz Milne, E. (2003). Metadiscourse Revisited: A Contrastive Study of Persuasive Writing in Professional Discourse. Estudios Ingleses de La Universidad Complutense, $11,29-52$.

Dafouz Milne, E., \& Núñez Perucha, B. (2010). Metadiscursive devices in university lectures. In C. Dalton-Puffer, T. Nikula, \& U. Smit (Eds.), Language Use and Language Learning in CLIL Classrooms (pp. 213-231). Amsterdam/Philadelphia: John Benjamins Publishing Company.

Dahl, T. (2004). Textual metadiscourse in research articles: A marker of national culture or of academic discipline? Journal of Pragmatics, 36, 1807-1825.

Dalton, C., \& Seidlhofer, B. (1994). Pronunciation. Oxford: Oxford University Press.

Davidsen, J., \& Vanderlinde, R. (2014). Researchers and teachers learning together and from each other using video-based multimodal analysis. British Journal of Educational Technology, 45(3), 451-460.

Davies, F. (1997). Marked Theme as a heuristic for analysing text-type, text and genre. In J. Piqué \& D. Viera (Eds.), Applied Languages: Theory and Practice in ESP (pp. 45-71). València: Servei de Publicacions Universitat de València. 
de Cheveigné, A., \& Kawahara, H. (2002). YIN, a fundamental frequency estimator for speech and music. The Journal of the Acoustical Society of America, 111(4), 19171930.

de Jong, N. H., \& Wempe, T. (2007). Automatic measurement of speech rate in spoken Dutch. ACLC Working Papers, 2(2), 51-60.

DeCarrico, J., \& Nattinger, J. R. (1988). Lexical phases for the comprehension of academic lectures. English for Specific Purposes, 7, 91-102.

Deppermann, A. (2013). Conversation Analytic Studies of Multimodal Interaction. Journal of Pragmatics (Special Issue), 46.

Deroey, K. L. B. (2012). What they highlight is...: The discourse functions of basic wh-clefts in lectures. Journal of English for Academic Purposes, 11(2), 112-124.

Deroey, K. L. B., \& Taverniers, M. (2011). A corpus-based study of lecture functions. Moderna Språk, 105(2), 1-22.

Deroey, K. L. B., \& Taverniers, M. (2012). Just remember this: Lexicogrammatical relevance markers in lectures. English for Specific Purposes, 31(4), 221-233.

Diani, G. (2015). Visual Communication in Applied Linguistics Conference Presentations. In B. Crawford Camiciottoli \& I. Fortanet-Gómez (Eds.), Multimodal Analysis in Academic Settings: From Research to Teaching (pp. 83-107). New York: Routledge.

DiPiro, J. T. (2009). Why do we still lecture? American Journal of Pharmaceutical Education, 73(8), Article 137.

Dittmann, A. (1972). The body movement-speech rhythm relationship as a cue to speech encoding. In A. W. Siegman \& B. Pope (Eds.), Studies in dyadic communication (pp. 135-151). Elmsford: Pergamon Press.

Domingo, M. (2014). Transnational language flows in digital platforms: A study of urban youth and their multimodal text making. Pedagogies: An International Journal, 9(1), 7-25. 
Domingo, Kress, G., M., Jewitt, C., Adami, E., O’Conell, R., Elliott, H., \& Squire, C. (2015). Development of methodologies for researching online communication: the case of food blogs. Report on a Collaborative Project for the NCRM Nodes MODE and NOVELLA. Document 11/14. NCRM working paper. Available at http://eprints.ncrm.ac.uk/3704/ Last accessed January $8^{\text {th }} 2018$.

Dubois, B. L. (1981). The management of pity in biomedical speeches. In J. E. Copeland \& P. W. Davis (Eds.), The seventh LACUS forum 1980 (pp. 249-257). Columbia: Hornbea.

Dudley-Evans, T. (1986). Genre analysis: an investigation of the introduction and discussion sections of MSc dissertations. In M. Coulthard (Ed.), Talking about Text. Discourse Analysis Monograph No. 13 (pp. 128-145). Birmingham: English Language Research, University of Birmingham.

Dudley-Evans, T. (1987). Introduction to genre analysis and ESP. English Language Research Journal, 1, 27-39.

Dudley-Evans, T. (1994). Variations in the discourse patterns favoured by different disciplines and their pedagogical implications. In J. Flowerdew (Ed.), Academic listening: research perspectives (pp. 146-158). Cambridge: Cambridge University Press.

Dudley-Evans, T., \& Johns, T. F. (1981). A team teaching approach to lecture comprehension for overseas students. In T. Dudley-Evans \& T. F. Johns (Eds.), The teaching of listening comprehension (pp. 30-46). London: British Council.

Duncan, S. (1972). Some signals and rules for taking speaking turns in conversations. Journal of Personality and Social Psychology, 23, 283-292.

Duncan, S., \& Niederehe, G. (1974). On signalling that it's your turn to speak. Journal of Experimental Social Psychology, 10(3), 234-247.

Duszak, A., \& Lewkowicz, J. (2008). Publishing Academic Texts in English: A Polish Perspective. Journal of English for Academic Purposes, 7(2), 108-120. 
Edmundo Tovar, A. D., \& Nelson Piedra, J. C. (2013). OCW-S: enablers for building sustainable Open Education. Evolving OCW and MOOC. In IEEE Global Engineering Education Conference (EDUCON). March 13-15 2013 (pp. 1262-1271). Technische Universität Berlin, Berlin, Germany.

Efron, D. (1941). Gesture and environment. Morningside Heights: King's Crow Press.

Eibl-Eibesfeldt, I. (1972). Similarities and differences between cultures in expressive movements. In M. von Cranach \& I. Vine (Eds.), Nonverbal communication (pp. 297312). Cambridge, England: Cambridge University Press.

Ekman, P. (1965). Differential communication of affect by head and body cues. Journal of Personality and Social Psychology, 2(5), 726-735.

Ekman, P. (1972). Universals and cultural differences between cultures in expressive movement. In J. Cole (Ed.), Nebraska symposium on motivation. 1971 (pp. 207-283). Lincoln: University of Nebraska Press.

Ekman, P. (1985). Telling lies: clues to deceit in the marketplace, marriage, and politics. New York: W. W. Norton.

Ekman, P. (2007). Emotions revealed. Recognizing faces and feelings to improve communication and emotional life (2nd ed.). New York: Owl Books.

Ekman, P., \& Friesen, W. V. (1967). Head and body cues in the judgement of emotion: A reformulation. Perceptual and Motor Skills, 24, 711-724.

Ekman, P., \& Friesen, W. V. (1969). The repertoire of nonverbal behavioral categories: origins, usage, and coding. Semiotica, 1, 49-98.

Ekman, P., \& Friesen, W. V. (1978). The facial action coding system: a technique for the measurament of facial movement. Palo Alto, CA: Consulting Psychology Press.

Ekman, P., Friesen, W. V, O’Sullivan, M., Chan, A., Diacoyanni-Tarlatzis, I., Heider, K., ... Tzavaras, A. (1987). Universals and cultural differences in the judgments of facial expressions of emotion. Journal of Personality and Social Psychology, 53(4), 712-717. 
Fa-gen, L. (2012). Identification and Functions of Metadiscourse. US-China Foreign Language, 10(1), 864-854.

Fairclough, N. (2001). Language and power (2nd ed.). Harlow: Longman.

Fairclough, N. (2003). Analyzing Discourse: Textual Analysis for Social Research. London: Routledge.

Fang, L. (2012). Genre analysis of American presidential inaugural speech. Theory and Practice in Language Studies, 2(11), 2407-2411.

Fernández Polo, F. J. (2014). Native and Non-Native Speaker Interpersonal Skills at Conferences: Managing Self-Mentions and Humour. In A. Lyda \& K. Warchal (Eds.), Occupying Niches: Interculturality, Cross-culturality and Acculturality in Academic Research (pp. 163-178). Heidelberg: Springer.

Field, T. (1981). Infant gaze aversion and heart rate during face-to-face interactions. Infant Behavior and Development, 4, 307-315.

Flewitt, R., Hampel, R., Hauck, M., \& Lancaster, L. (2014). What are multimodal data and transcription? In C. Jewitt (Ed.), The Routledge Handbook of Multimodal Analysis (pp. 44-59). London: Routledge.

Flewitt, R., Messer, D., \& Kucirkova, N. (2014). New directions for early literacy in a digital age: The iPad. Journal of Early Childhood Literacy, 15(3), 289-310.

Fløttum, K., Kinn, T., \& Dahl, T. (2006). "We now report on..." versus "Let us now see how...": Author roles and interaction with readers in research articles. In K. Hyland \& M. Bondi (Eds.), Academic Discourse Across Disciplines (pp. 203-224). New York: Peter Lang.

Flowerdew, J. (1990). Problems of speech act theory from an applied perspective. Language Learning, 40, 79-105.

Flowerdew, J. (1994). Academic listening: research perspectives. Cambridge: Cambridge University Press. 
Flowerdew, J., \& Miller, L. (1992). Students perceptions, problems and strategies in L2 lectures. RELC Journal, 23(12), 60-80.

Flowerdew, J., \& Tauroza, S. (1995). The effect of discourse markers on second language lecture comprehension. Studies in Second Language Acquisition, 17, 435-458.

Forceville, C. J., \& Urios-Aparisi, E. (2009). Multimodal Metaphor. Berlin and New York: Mouton de Gruyter.

Forey, G. (2002). Aspects of theme and their role in workplace texts. Unpublished PhD dissertation. Glasgow, UK: University of Glasgow.

Fortanet-Gómez, I. (2004a). The Use of "we" in University Lectures: Reference and Function. Journal of English for Specific Purposes, 23, 45-66.

Fortanet-Gómez, I. (2004b). "I think": opinion, uncertainty or politeness in academic spoken English. RAEL: Revista Electrónica de Lingüística Aplicada, 3, 63-84.

Fortanet-Gómez, I. (2005). Honoris Causa speeches: an approach to structure. Discourse Studies, 7(1), 31-51.

Fortanet-Gómez, I. (2013). CLIL in Higher Education: Towards a Multilingual Language Policy. Bristol: Multilingual Matters.

Fortanet-Gómez, I., \& Belles, B. (2005). Spoken academic discourse : An approach to research on lectures. Revista Española de Lingüística Aplicada (RESLA). Volumen Monográfico, (25), 161-178.

Fortanet-Gómez, I., \& Crawford Camiciottoli, B. (2015). Introduction. In B. Crawford Camiciottoli \& I. Fortanet-Gómez (Eds.), Multimodal Analysis in Academic Settings: From Research to Teaching (pp. 1-14). New York \& London: Routledge.

Fortanet-Gómez, I., Posteguillo, S., Palmer, J. C., \& Coll, J. F. (1998). Genre studies in English for academic purposes. Castelló de la Plana: Publicacions de la Universitat Jaume I. 
Fortanet-Gómez, I., \& Ruiz-Madrid, M. N. (2014). Multimodality for comprehensive communication in the classroom: questions in guest lectures. Ibérica, 28, 203-224.

Fortanet-Gómez, I., \& Ruiz-Madrid, M. N. (2015). Multimodal humour in plenary lectures in English and in Spanish. In B. Crawford Camiciottoli \& I. Fortanet-Gómez (Eds.), Multimodal Analysis in Academic Settings: From Research to Teaching (pp. 39-60). New York: Routledge.

Fortanet-Gómez, I., \& Ruiz-Madrid, M. N. (2016). Multimodal Humor in Plenary Lectures in English and in Spanish. Multimodal Communication, 5(1), 55-69.

Fox, J., \& Artemeva, N. (2013). The cinematic art of teaching university mathematics: chalk talk as embodied practice. Multimodal Communication, 1(1), 83-103.

Freddi, M. (2005). From corpus to register: the construcion of evaluation and argumentation in linguistics textbooks. In E. Tognini Bonilli \& G. Del Lungo Camiciotti (Eds.), Strategies in Academic Discourse (pp. 133-154). Amsterdam \& Philadelphia: John Benjamins.

Freedman, A., \& Medway, P. (1994). Genre and the new rhetoric. London \& Bristol: Taylor \& Francis.

Freedman, N. (1972). The analysis of movement behaviour during clinical interviews. In A. W. Siegman \& B. Pope (Eds.), Studies in dyadic communication (pp. 152-172). Elmsford: Pergamon Press.

Freedman, N., \& Hoffman, S. P. (1967). Kinesic behaviour in altered clinical states: approach to objective analysis of motor behaviour during clinical interviews. Perceptual and Motor Skills, 24, 527-539.

Frege, G. (1930/1980). On sense and reference. In P. Geach \& M. Black (Eds.), Translations from the Philosophical Writings of Gottlob Frege (3rd ed., pp. 56-78). Oxford: Blackwell. 
French, A., Greenhalgh, C., Crabtree, A., Wright, M., Brundell, P., Hampshire, A., \& Rodden, T. (2006). Software replay tools for time-base Social Science data. Paper presented at the 2nd annual international e-Social Science conference. June 2016, University of Manchester, Manchester, UK.

Fu, X. (2012). The use of interactional metadiscourse in job postings. Discourse Studies, 14(4), 399-417.

Fuentes-Olivera, P. A., Velasco-Sacristan, M., Arribas-Bano, A., \& Samaniego-Fernandez, E. (2001). Persuasion and adversising English: Metadiscourse in slogans and headlines. Journal of Pragmatics, 33, 1291-1307.

Fukuhara, Y. (2008). Current status of OCW in Japan. In Distance Learning and the Internet Conference, Session 8 Misc. 19-22 November 2008 (pp. 221-223). Waseda University, Tokyo Japan.

Fung, L., \& Carter, R. (2007). Discourse Markers and Spoken English: Native and Learner Use in Pedagogic Settings. Applied Linguistics, 28(3), 410-439.

Galloway, C. M. (1972). An analysis of theories and research in nonverbal communication. Document ED059988. Washington, D.C: ERIC Document Reproduction Service. Available at https://eric.ed.gov/?id=ED059988/ Last accessed January $8^{\text {th }} 2018$.

Gee, J. P., \& Handford, M. (2012). The Routledge handbook of discourse analysis. Abingdon, Oxon : Routledge.

Geoffrey, W. B. (1981). Sequential temporal patterns of speech and gaze in dialogue. In A. Kendon (Ed.), Nonverbal communication, interaction and gesture (pp. 297-320). The Hague: Mouton.

Gibson, J. J. (1977). The theory of affordances. In R. E. Shaw \& J. Bransford (Eds.), Perceiving, Acting, and Knowing (pp. 127-143). Hillsdale, NJ: Lawrence Erlabaum Associates.

Gibson, J. J. (1979). The Ecological Approach to Visual Perception. Hillsdale, NJ: Lawrence Erlabaum Associates. 
Giménez, R. (2000). La repetición lingüística en el género de la clase magistral: el inglés académico oral en el ámbito de las ciencias sociales. PhD dissertation. València, Spain: Publicacions de la Universitat de València.

Givón, T. (1979). Discourse and Syntax. New York: Academic Press.

Givón, T. (1983). Topic Continuity in Discourse. Amsterdam: John Benjamins.

Givón, T. (1990). Syntax: A Functional-Typological Introduction. Amsterdam: John Benjamins.

Goffman, E. (1959). The presentation of self in everyday life. New York, NY: Doubleday.

Goffman, E. (1963). Behavior in public places: notes on social organization of gatherings. New York, NY: Free Press.

Goffman, E. (1974). Frame analysis. New York, NY: Harper \& Row.

Goffman, E. (1981). The lecture. In E. Goffman (Ed.), Forms of Talk (pp. 162-195). Philadelphia, PA: University of Philadelphia Press.

Goldin-Meadow, S. (2003). Hearing gesture: How our hands help us think. Cambridge, MA: Harvard University Press.

Goodwin, C. (1979). The interactive construction of a sentence in natural conversation. In G. Psathas (Ed.), Everyday language: studies in ethnomethodology (pp. 97-121). New York: Irvington.

Goodwin, C. (1981). Conversational organization: interaction between speakers and hearers. New York: Academic Press.

Goodwin, C. (1984). Notes on story structure and the organization of participation. In J. M. Atkinson \& J. Heritage (Eds.), Structures of social action: studies in conversation analysis (pp. 225-246). Cambridge: Cambridge University Press.

Granger, S., \& Tyson, S. (1996). Connector Usage in the English Essay Writing of Native and Non-native EFL Speakers of English. World Englishes, 15, 17-27. 
Green, G. (1989). Pragmatics and Natural Language Understanding. Hillsdale: Lawrence Erlabaum Associates.

Gregory, M. (1983). Towards communication linguistics: a framework. In J. D. Benson \& W. S. Greaves (Eds.), Systemic perspectives on discoruse. Volume 1 (pp. 119-134). Norwood, NJ: Ablex.

Grice, H. P. (1975). Logic and conversation. In P. Cole \& J. L. Morgan (Eds.), Syntax and Semantics, vol. 3 (pp. 41-58). New York: Academic Press.

Gumperz, J. (1982). Discourse strategies. Cambridge, England: Cambridge University Press.

Gunel, M., Hand, B., \& Gunduz, S. (2006). Comparing student understanding of quantum physics when embedding multimodal representations into two different writing formats: Presentation format versus summary report format. Science Education, 90(6), 1092-1112.

Haas, C., \& Flowers, L. (1988). Rhetorical Reading Strategies and the Construction of Meaning. College Composition and Communication, 139, 167-183.

Hadar, U., Steiner, T. J., Grand, E. C., \& Rose, F. C. (1983). Head movement correlates of juncture and stress at sentence level. Language and Speech, 26, 117-129.

Hadar, U., Steiner, T. J., Grand, E. C., \& Rose, F. C. (1984a). The relationship between head movements and speech dysfluencies. Language and Speech, 27, 333-342.

Hadar, U., Steiner, T. J., Grand, E. C., \& Rose, F. C. (1984b). The timing of shifts of head postures during conversation. Human Movements Science, 3, 237-245.

Hall, E. T. (1959). The Silent Language. New York: Doubleday.

Hall, E. T. (1966). The Hidden Dimension. New York: Doubleday.

Halliday, M. A. K. (1973). Explorations in the Functions of Language. New York: Elsevier North-Holland, Inc. 
Halliday, M. A. K. (1978). Language as a Social Semiotic: The Social Interpretation of Language and Meaning. Baltimore, PA: University Park Press.

Halliday, M. A. K. (1985). An Introduction to Functional Grammar. London: Edward Arnold.

Halliday, M. A. K. (1989). Spoken and Written Language. Oxford: Oxford University Press.

Halliday, M. A. K. (1994). Introduction to Functional Grammar (2nd ed.). London: Edward Arnold.

Halliday, M. A. K., \& Greaves, S. (2008). Intonation in the Grammar of English. London: Equinox.

Halliday, M. A. K., \& Hasan, R. (1976). Cohesion in English. London: Longman.

Halliday, M. A. K., \& Hasan, R. (1985). Language, Context and Text: Aspects of Language in a Social-Semiotic Perspective. Waurn Ponds, Victoria: Deakin University Press.

Halliday, M. A. K., \& Matthiessen, C. M. I. M. (2014). Halliday's Introduction to Functional Grammar (4th ed.). London \& New York: Routledge.

Harklau, L. (2005). Ethnography and Ethnographic Research on Second Language Teaching and Learning. In E. Hinkel (Ed.), Handbook of Research in Second Language Teaching and Learning (pp. 179-194). Mahwah, NJ: Lawrence Erlabaum.

Harris, Z. (1952). Discourse analysis. Language, 28, 1-30.

Hasselgård, H. (2016). Discourse-Organizing Metadiscourse in Novice Academic English. In M. J. López-Couso, B. Méndez-Naya, P. Núñez-Pertejo, \& I. M. Palacios-Martínez (Eds.), Corpus Linguistics on the Move (pp. 106-131). Leiden \& Boston: Brill Rodopi.

Heath, C. (1984). Talk and recipiency: sequential organization in speech and body movement. In J. M. Atkinson \& J. Heritage (Eds.), Structures of social action: studies in conversation analysis (pp. 247-265). Cambridge: Cambridge University Press. 
Heino, A., Tervonen, E., \& Tommola, J. (2002). Metadiscourse in Academic Conference Presentations. In E. Ventola, C. Shalom, \& S. Thompson (Eds.), The Language of Conferencing (pp. 127-146). Frankfurt: Peter Lang.

Helal, F. (2013). Discourse and Intercultural Academic Rhetoric. Open Journal of Modern Linguistics 3(2), 149-156.

Heng, C. S., \& Tan, H. (2010). Extracting and comparing the intricacies of metadiscourse of two written persuasive corpora. International Journal of Education and Development Using Information and Communication Technology (IJEDICT), 6(3), 124-146.

Hinkel, E. (2002). Second Language Writer's Text. Mahwah, NJ: Lawrence Erlabaum.

Hirano, E. (2009). Research article introductions in English for specific purposes: a comparison between Brazilian Portuguese and English. English for Specific Purposes, $28,240-250$.

Hodge, R., \& Kress, G. (1988). Social semiotics. Cambridge, England: Polity.

Hodgson, V. E. (2005). Lectures and the experience of relevance. In F. Marton, D. Hounsell, \& N. Entwistle (Eds.), The experience of learning: implications for teaching and studying in higher education (3rd ed., pp. 159-171). Edinburgh: University of Edinburgh, Centre for Teaching, Learning and Assessment.

Holmes, R. (1997). Genre analysis and the social sciences: an investigation of the structure of research article discussion sections in three disciplines. English for Specific Purposes, 16(4), 321-337.

Holsanova, J. (2010). Myter och sanningar om läsning. Om samspelet mellan språk och bild i olika medier. Stockholm: Norstedts.

Holsanova, J. (2014). Reception of multimodality: Applying eye-tracking methodology in multimodal research. In C. Jewitt (Ed.), The Routledge Handbook of Multimodal Analysis (2nd ed., pp. 287-298). London: Routledge. 
Holsanova, J., Holmberg, N., \& Holmqvist, K. (2009). Reading information graphics: The role of spatial contiguity and dual attentional guidance. Applied Cognitive Psycology, 23, 1215-1226.

Hood, S. (2011). Body language in face-to-face teaching: a focus on textual and interpersonal meaning. In S. Dreyfus, S. Hood, \& M. Stenglin (Eds.), Semiotic margins: Meaning in multimodalitites (pp. 31-52). London \& New York: Continuum.

Hood, S., \& Forey, G. (2005). Introducing a Conference Paper: Getting Interpersonal with Your Audience. Journal of English for Academic Purposes, 4(4), 291-306.

Hsu, A. Y. (2006). Metadiscourse Instruction in EAP Courses: Feasibility and Acceptability. Unpublished PhD dissertation. Hsinchu, China: National Tsing Hua University.

Hu, G., \& Cao, F. (2015). Disciplinary and paradigmatic influences on interactional metadiscourse in research articles. English for Specific Purposes, 39, 12-25.

Hübler, A. (2007). On the metapragmatics of gestures. In W. Bublitz \& A. Hübler (Eds.), Metapragmatics in use (pp. 107-128). Amsterdam, Netherlands: John Benjamins.

Hwang, H. C., \& Matsumoto, D. (2016). Facial Expressions. In D. Matsumoto, H. C. Hwang, \& M. G. Frank (Eds.), APA Handbook of Nonverbal Communication (pp. 257-288). Washington, D.C.: American Psychological Association.

Hyland, K. (1992). Genre analysis: just another fad? Forum, 30(2), 1-17.

Hyland, K. (1994). Hedging in academic textbooks and EAP. English for Specific Purposes, 3(3), 239-256.

Hyland, K. (1996a). Talking to the academy: Forms of hedging in science research articles. Written Communication, 13, 251-281.

Hyland, K. (1996b). Writing without conviction? Hedging in science research articles. Applied Linguistics, 17, 433-454.

Hyland, K. (1998). Hedging in Scientific Research Articles. Amsterdam: John Benjamins. 
Hyland, K. (1999a). Academic attribution: citation and the construction of disciplinary knowledge. Applied Linguistics, 20(3), 341-367.

Hyland, K. (1999b). Disciplinary discourses: writer stance in research articles. In C. Candlin \& K. Hyland (Eds.), Writing: Texts, Processes and Practices (pp. 99-121). London: Longman.

Hyland, K. (1999c). Talking to students: Metadiscourse in introductory course books. English for Specific Purposes, 18(1), 3-26.

Hyland, K. (2000). Disciplinary Discourses: Social Interactions in Academic Writing. London: Longman.

Hyland, K. (2001a). Bringing in the reader: addresse features in academic articles. Written Communication, 18(4), 549-574.

Hyland, K. (2001b). Humble servants of the discipline? Self-mention in research articles. English for Specific Purposes, 20(3), 207-226.

Hyland, K. (2002a). Academic Argument: Induction or Interaction? Revista Canaria de Estudios Ingleses, 44, 29-45.

Hyland, K. (2002b). Authority and invisibility: authorial identity in academic writing. Journal of Pragmatics, 34(8), 1091-1112.

Hyland, K. (2004a). Disciplinary interactions: metadiscourse in L2 postgraduate writing. Journal of Second Language Writing, 13, 133-151.

Hyland, K. (2004b). Graduates' gratitude: The generic structure of dissertation acknowledgements. English for Specific Purposes, 23(3), 303-324.

Hyland, K. (2005). Metadiscourse: Exploring interaction in writing. London, England: Continuum.

Hyland, K. (2009). Academic discourse: English in a global context. London: Continuum. 
Hyland, K. (2010). Metadiscourse: Mapping Interactions in Academic Writing. Nordic Journal of English Studies, 9(2), 125-143.

Hyland, K., \& Tse, P. (2004). Metadiscourse in academic writing: a reappraisal. Applied Linguistics, 6(2), 156-177.

Hyland, K., \& Tse, P. (2005). Hooking the reader: a corpus study of evaluative that in abstracts. English for Specific Purposes, 24(2), 123-139.

Hymes, D. (1972). Models of the interaction of language and social life. In J. Gumperz \& D. Hymes (Eds.), Directions in sociolinguistics: the ethnography of communication (pp. 35-57). New York: Rhinehart and Winston.

Hyon, S. (1996). Genre in three traditions: implications for ESL. Tesol Quarterly, 30(4), 693722.

ledema, R. (2001). Resemiotization. Semiotica, 1(4), 23-39.

ledema, R. (2003). Multimodality, resemiotization: extending the analysis of discourse as multi-semiotic practice. Visual Communication, 2(1), 29-57.

ledema, R. (2004). Analysing film and television: A social semiotic account of hospital: An unhealthy business. In T. van Leeuwen \& C. Jewitt (Eds.), The Handbook of Visual Analysis (pp. 183-204). London: Sage.

Ifantidou, E. (2005). The Semantics and Pragmatics of Metadiscourse. Journal of Pragmatics, 37, 1325-1353.

Intaraprawat, P., \& Steffensen, M. S. (1995). The Use of Metadiscourse in Good and Poor ESL Essays. Journal of Second Language Writing, 4, 253-272.

Jakobson, R. (1960). Closing Statement: Linguistics and Poetics. In T. A. Sebeok (Ed.), Style in language (pp. 350-377). Cambridge, Mass: M.I.T. Press.

Jakobson, R. (1972). LInguistics and Poetics. In R. DeGeorge \& F. DeGeorge (Eds.), The Structuralists: from Marx to Levi-strauss. Garden City, NY: Doubleday. 
Jakobson, R. (1998). On language: Roman Jakobson. (L. R. Waugh \& M. Monville-Burston, Eds.). Cambridge, MA: Harvard University Press.

Jewitt, C. (2008a). Multimodality and literacy in school classrooms. Review of Research in Education, 32, 241-267.

Jewitt, C. (2008b). Technology, literacy, learning: A multimodality approach. London: Routledge.

Jewitt, C. (2009a). An Introduction to Multimodality. In The Routledge Handbook of Multimodal Analysis (1st ed., pp. 14-27). London \& New York: Routledge.

Jewitt, C. (2009b). The Routledge handbook of multimodal analysis. (1 ${ }^{\text {st }}$ ed.). London, England: Routledge.

Jewitt, C. (2011). The changing pedagogic landscape of subject English in UK classrooms. In K. O'Halloran \& B. A. Smith (Eds.), Multimodal studies: Exploring issues and domains (pp. 184-201). London: Routledge.

Jewitt, C. (2012). An introduction to Using Video for Research. Document 03/2012. NCRM working paper. Available at http://eprints.ncrm.ac.uk/2259/ Last accessed January $8^{\text {th }}$ 2018.

Jewitt, C. (2013). Multimodal methods for researching digital technologies. In S. Price, C. Jewitt, \& B. Brown (Eds.), The SAGE handbook of digital technology research (pp. 250265). London: Sage.

Jewitt, C. (2014). Different approaches to multimodality. In C. Jewitt (Ed.), The Routledge Handbook of Multimodal Analysis ( $2^{\text {nd }}$ ed., pp. 28-39). London: Routledge.

Johanna, T. (1994). Guiding the Reader: The Use of Metatext in Master's Theses Written in English. Helsinki: Helsinki School of Economics and Business Administration.

Johns, A. M. (1997). Text, role and context: Developing academic literacies. Cambridge: Cambridge University Press. 
Johnstone, B. (2002). Discourse Analysis. Oxford: Blackwell.

Jones, R. H. (2014). Mediated discourse analysis. In S. Norris (Ed.), Interactions, images and texts: A reader in multimodality (pp. 39-51). Berlin: De Gruyter Mouton.

Jones, R. H. (2016). Spoken Discourse. London \& New York: Bloomsbury Academic.

Jones, S. E. (2007). Reflections on the lecture: Outmoded medium or instrument of inspiration? Journal of Further and Higher Education, 31(4), 397-406.

Kadmon, N. (2001). Formal Pragmatics: Semantics, Pragmatics, Presupposition, and Focus. Malden, MA \& Oxford, UK: Blackwell Publishers.

Kanoksilapatham, B. (2005). Rhetorical structure of biochemistry research articles. English for Specific Purposes, 24, 269-292.

Keenan, E. (1971). Two kinds of presupposition in natural language. In C. Fillmore \& D. T. Langendoen (Eds.), Studies in Linguistic Semantics (pp. 45-54). New York: Holt, Reinhart and Winston.

Keller, E. (1979). Gambits: Conversational strategy signals. Journal of Pragmatics, 3, 219238.

Kendon, A. (1967). Some functions of gaze direction in social interaction. Acta Psychologica, 26, 22-63.

Kendon, A. (1972). Some relationships between body motion and speech. In A. W. Siegman \& B. Pope (Eds.), Studies in dyadic communication (pp. 177-210). Elmsford: Pergamon Press.

Kendon, A. (1978). Differential perception and attentional frame in face-to face interaction: Two problems for investigation. Semiotica, 24(3), 305-315.

Kendon, A. (1980). Gesticulation and speech: two aspects of the process of utterance. In M. Key (Ed.), The relationship of verbal and non-verbal communication (pp. 207-227). The Hague: Mouton. 
Kendon, A. (1987). On gesture: its complementary relationship with speech. In A. W. Siegman \& S. Feldstein (Eds.), Nonverbal behaviour and the nonverbal communication (2nd ed., pp. 65-97). Hillsdale: Lawrence Erlabaum.

Kendon, A. (1988). How gestures can become like words. In F. Poyatos (Ed.), Crosscultural perspectives in nonverbal communication (pp. 131-141). Toronto: Hogrefe.

Kendon, A. (1990a). Conducting interaction: patterns of behaviour in focused encounters. Cambridge: Cambridge University Press.

Kendon, A. (1990b). Some functions of the face in a kissing round. In A. Kendon (Ed.), Conducting interaction: patterns of behaviour in focused encounters (pp. 117-152). Cambridge: Cambridge University Press.

Kendon, A. (2002). Some uses of head shake. Gesture, 2, 147-183.

Kendon, A. (2004). Gesture: Visible action as utterance. Cambridge: Cambridge University Press.

Keshavarz, M. H., \& Kheirich, Z. (2011). Metadiscourse elements in English research articles written by native English and non-native Iranian writers in Applied Linguistics and Civil Engineering. Journal of English Linguistics, 1(3), 3-15.

Khedri, M., Heng, C. S., \& Ebrahimi, S. F. (2013). An exploration of interactive metadiscourse markers in academic research article abstracts in two disciplines. Discourse Studies, 15(3), 319-331.

Kimble, C. E., \& Olszewski, D. A. (1980). Gaze and emotional expression: The effects of message positivity-negativity and emotional intensity. Journal of Research in Personality, 14(1), 60-69.

King, P. (1994). Visual and verbal messages in the engineering lecture: notetaking by postgraduate L2 students. In J. Flowerdew (Ed.), Academic listening: research perspectives. (pp. 219-238). Cambridge: Cambridge University Press.

Kini, R. (2011). Internet courses v classroom courses. Yale Economic Review, 7(1), 5. 
Kita, S. (1990). The temporal relationship between gesture and speech: a study of JapaneseEnglish bilinguals. University of Chicago.

Knox, J. S. (2009). Multimodal discourse on online newspaper home pages. A social semiotic perspective. Unpublished PhD dissertation. Sydney, Australia: University of Sydney.

Knox, J. S. (2014). Online newspapers: structure and layout. In C. Jewitt (Ed.), The Routledge Handbook of Multimodal Analysis (2nd ed., pp. 440-449). London \& New York: Routledge.

Kress, G. (1989). Linguistic processes in sociocultural practice. Oxford, UK: Oxford University Press.

Kress, G. (1993). Agains arbitrariness: The social production of the sign as a foundational issue in critical discourse analysis. Discourse and Society, 4(2), 169-191.

Kress, G. (2000). Multimodality. In B. Cope \& M. Kalanzis (Eds.), Multiliteracies: Literacy learning and the design of social futures (pp. 182-202). London: Routledge.

Kress, G. (2003). Literacy in the new media age. London: Routledge.

Kress, G. (2010). Multimodality: A Social Semiotic Approach to Contemporary Communication. London: Routledge.

Kress, G. (2012). Multimodal Discourse Analysis. In J. P. Gee \& M. Handford (Eds.), The Routledge Handbook of Discourse Analysis (pp. 35-50). London \& New York: Routledge.

Kress, G. (2014). What is mode? In C. Jewitt (Ed.), The Routledge Handbook of Multimodal Analysis (2nd ed., pp. 60-75). New York: Routledge.

Kress, G., Jewitt, C., Bourne, J., Franks, A., Hardcastle, J., Jones, K., \& Reid, E. (2004). English in urban classrooms: Multimodal perspectives in teaching and learning. London: Routledge Falmer. 
Kress, G., Jewitt, C., Ogborn, J., \& Tsatsarelis, C. (2001). Multimodal teaching and learning: The rhetorics of the science classroom. London: Continuum.

Kress, G., \& van Leeuwen, T. (1996). Reading images: The grammar of visual design. London, England: Routledge.

Kress, G., \& van Leeuwen, T. (2001). Multimodal discourse: The modes and media of contemporary communication. London: Edward Arnold.

Krystallidou, D. (2014). Gaze and body orientation as an apparatus for patient inclusion into/exclusion from a patient-centred framework of communication. The Interpreter and Translator Trainer, 8(3), 399-417.

Kuo, C.-H. (1998). The Use of Personal Pronouns: Role Relationships in Scientific Journal Articles. English for Specific Purposes, 18(2), 121-138.

Kwan, B. S. C. (2006). The schematic structure of literature reviews in doctoral theses of applied linguistics. English for Specific Purposes, 25, 30-55.

Lanham, R. (2001). What next for text? Education, Communication, and Information, 1(1), $59-74$.

Lautamatti, L. (1978). Observations on the development of the topic in simplified discourse. In V. Kohonen \& N. E. Enkvist (Eds.), Text Linguistics, Cognitive Learning, and Language Teaching (pp. 71-104). Turku: University of Turku Publications.

Laver, J. (1980). The phonetic description of voice quality. Cambridge: Cambridge University Press.

Le, E. (2004). Active Participation within Written Argumentation: Metadiscourse and Editorialist's Authority. Journal of Pragmatics, 36, 687-714.

Lebauer, R. S. (1984). Using lecture transcripts in EAP comprehension courses. Tesol Quarterly, 18(1), 41-53. 
Lee, J. J. (2009). Size matters: an exploratory comparison of small- and large-class university lecture introductions. English for Specific Purposes, 28(1), 42-57.

Lee, J. J., \& Casal, J. E. (2014). Metadiscourse in results and discussion chapters: A crosslinguistic analysis of English and Spanish thesis writers in engineering. System, 46, 3954.

Lee, J. J., \& Subtirelu, N. C. (2015). Metadiscourse in the classroom: A comparative analysis of EAP lessons and university lectures. English for Specific Purposes, 37, 52-62.

Leonard, T., \& Cummins, F. (2011). The temporal relation between beat gestures and speech. Language and Cognitive Processes, 26, 1457-1471.

Letsoela, P. 'M. (2013). Inappropriate Use of Transitions by National University of Lesotho Students. International Journal of English Language Education, 2(1), 100-112.

Levinson, S. C. (2000). Presumptive Meanings: The Theory of Generalized Conversational Implicature. Cambridge, MA: MIT Press.

Lhommet, M., \& Marsella, S. (2015). Expressing emotion through posture and gesture. In R. Calvo, S. D'Mello, J. Gratch, \& A. Kappas (Eds.), The Oxford handbook of affective computing (pp. 273-285). Oxford: Oxford University Press.

Lim, F. V., O'Halloran, K., \& Podlasov, A. (2012). Spatial pedagogy: mapping meanings in the use of classroom space. Cambridge Journal of Education, 42(2), 235-251.

Lin, C.-Y. (2010). “... that"s actually sort of you know trying to get consultants in...': Functions and multifuntionality of modifiers in academic lectures. Journal of Pragmatics, 42, 1173-1183.

Longo, B. (1994). The Role of Metadiscourse in Persuation. Technical Communication, 41, $341-352$.

Lucy, J. A. (1993). Reflexive language and the human disciplines. In J. A. Lucy (Ed.), Reflexive language (pp. 9-32). Cambridge, England: Cambridge University Press. 
Luukka, M.-R. (1994). Metadiscourse in Academic Texts. In B.-L. Gunnarsson, P. Linell, \& B. Nordberg (Eds.), Text and Talk in Professional Contexts. Selected papers from the International Conference "Discourse and the Professions," Uppsala, 26-29 August, 1992 (pp. 26-29). Uppsala: ASLA, The Swedish Association of Applied Linguistics.

Lynch, T. (1994). Training lectures for international audiences. In J. Flowerdew (Ed.), Academic listening: research perspectives. (pp. 269-289). Cambridge: Cambridge University Press.

Lyons, J. (1977). Semantics. Vol. 1. Cambridge: Cambridge University Press.

MacDonald, M., Badger, R., \& White, G. (2000). The real thing?: authenticity and academic listening. English for Specific Purposes, 19, 253-267.

Machin, D. (2004). Building the world's visual language. Visual Communication, 3(2), 316336.

Machin, D. (2014). What is multimodal critical discourse studies? Critical Discourse Studies, 10(4), 347-355.

Machin, D., \& Mayr, A. (2012). How to Do Critical Discourse Analysis. London: Sage.

Machotka, P. (1965). Body movement as communication. Dialogues: Behavioral Science Research, 2, 33-65.

Malavska, V. (2016). Genre of an Academic Lecture. LLCE, 3(2), 56-84.

Manusov, V., \& Patterson, M. L. (2006). The SAGE Handbook of Nonverbal Communication. London: Sage.

Mao, L. M. (1993). "I conclude not": Toward a pragmatic account of metadiscourse. Rhetoric Review, 11(2), 265-289.

Mar Dueñas, M. P. (2003). Analising stance in American and Spanish business management RAs: the case sentence-initial "retrospective labels." Journal of English Studies, 4, 137154. 
Mar Dueñas, M. P. (2007). "I/we focus only": a cross-cultural analysis of self-mentions in business management research articles. Journal of English for Academic Purposes, 6, $143-162$.

Mar Dueñas, M. P. (2011). An intercultural analysis of metadiscourse features in research articles written in English and in Spanish. Journal of Pragmatics, 43, 3068-3079.

Markkanen, R., Steffensen, M., \& Crismore, A. (1993). Quantitative Contrastive Study of Metadiscourse: Problems in Design and Analysis of Data. Papers and Studies in Contrastive Linguistics, 28, 137-152.

Martín-Monje, E., Bárcena, E., \& Read, T. (2014). Peer-to-peer interaction and linguistic feedback in foreign language MOOCs. Profesorado, Revista de Currículum Y Formación de Profesorado, 18(1), 167-183.

Martin, J. R. (1984). Language, register and genre. In F. Christie (Ed.), Children Writing: Reader (pp. 21-29). Geelong, Vic: Deakin University Press.

Martin, J. R. (2000a). Beyond Exchange. Appraisal Systems in English. In S. Hunston \& G. Thompson (Eds.), Evaluation in text: authorial stance and the construction of discourse (pp. 142-175). Oxford: Oxford University Press.

Martin, J. R. (2000b). Grammar meets Genre - Reflections on the "Sydney School." Arts: The Journal of the Sydney University Arts Association, 22, 47-95.

Martin, J. R. (2006). Metadiscourse: Designing Interaction in Genre-based Literacy Programs. In R. Whittaker, M. O’Donnell, \& A. McCabe (Eds.), Language and Literacy: Functional Approaches (pp. 95-122). London: Continuum.

Martin, J. R., \& Rose, D. (2005). Designing Literacy Pedagogy: Scaffolding Asymmetries. In R. Hasan, C. M. I. M. Matthiessen, \& J. Webster (Eds.), Continuing Discoruse on Language (pp. 251-280). London: Equinox.

Martin, J. R., \& White, P. (2005). The Language of Evaluation: Appraisal in English. London: Palgrave Macmillan. 
Mauch, M., Cannam, C., Bittner, R., Fazekas, G., Salamon, J., Dai, J., ... Dixon, S. (2015). Computer-aided Melody Note Transcription Using the Tony Software: Accuracy and Efficiency. In Proceedings of the 1st International Conference on Technologies for Music Notation and Representation (TENOR 2015) (pp. 25-30).

Mauch, M., \& Dixon, S. (2014). pYin: A fundamental frequency estimator using probabilistic threshold distributions. In 2014 IEEE International Conference on Acoustics, Speech and Signal Processing (ICASSP). May 4-9 Florence, Italy (pp. 659-663).

Mauranen, A. (1993a). Contrastive ESP rhetoric: Metatext in Finnish-English economics text. English for Specific Purposes, 12, 3-22.

Mauranen, A. (1993b). Cultural Differences in Academic Rhetoric: A Textlinguistic Study. Frankfurt am Main: Peter Lang.

Mauranen, A. (2001). Reflexive Academic Talk: Observations from MICASE. In R. C. Simpson \& J. M. Swales (Eds.), Corpus Linguistics in North America: Selections from the 1999 Symposium (pp. 165-178). Ann Arbor, MI: The University of Michigan Press.

Mauranen, A. (2002). "A good question”. Expressing evaluation in academic speech. In G. Cortese \& P. Riley (Eds.), Domain-specific English: Textual Practices across Communities and Classrooms (pp. 115-140). Frankfurt: Peter Lang.

Mavers, D. (2012). Transcribing video. Document 05/12. NCRM working paper. Available at http://eprints.ncrm.ac.uk/2877/4/NCRM_working_paper0512.pdf/ Last accessed January $8^{\text {th }} 2018$.

Mavers, D. (2014). Image in the multimodal ensemble: Children's drawing. In C. Jewitt (Ed.), The Routledge Handbook of Multimodal Analysis (2nd ed., pp. 431-439). London: Routledge.

Maynard, S. (1987). Interactional functions of a nonverbal sigh: head movement in Japanes dyadic casual conversation. Journal of Pragmatics, 11, 589-606.

McCarthy, M. (2001). Issues in Applied Linguistics. Oxford: Oxford University Press. 
McClave. (2000). Linguistic functions of head movements in the context of speech. Journal of Pragmatics, 101, 72-87.

McKeachie, W., \& Svinicki, M. (2013). Teaching Tips: Strategies, Research, and Theory for College and University Teachers (14th ed.). Boston: Cengage Learning.

McKinlay, A., \& Potter, J. (1987). Modal discourse: Interpretive repertoires in scientists' conference talk. Social Studies of Science, 17, 443-463.

McNeill, D. (1985). So do you think that gestures are not verbal? Psychological Review, 92, 350-371.

McNeill, D. (1992). Hand and mind: what gestures reveal about thought. Chicago \& London: The University of Chicago Press.

McNeill, D. (2000). Language and gesture. (D. McNeill, Ed.). Cambridge: Cambridge University Press.

McNeill, D. (2005). Gesture and Thought. Chicago: University of Chicago Press.

McNeill, D., \& Levy, E. T. (1982). Conceptual representations in language activity and gesture. In R. Jarvella \& W. Klein (Eds.), Speech, place and action (pp. 271-295). Chichester: Wiley \& Sons.

Mead, R. A. (2016). Situated Proxemics and Multimodal Communication: Space, Speech, and Gesture in Human-Robot Interaction. Unpublished PhD dissertation. Los Angeles, USA: University of Southern California.

Meyer, B. J. F., Brandt, D. M., \& Bluth, G. J. (1980). Use of Top-level Structure in Text: Key for Reading Comprehension of Ninth-grade Students. Reading Research Quarterly, 16, 72-103.

Miller, C. R. (1984). Genre as social action. Quarterly Journal of Speech, 70(2), 151-167. 
Mirshamsi, A., \& Allami, H. (2013). Metadiscourse Markers in the Discussion/Conclusion Section of Persian and English Master's Theses. The Journal of Teaching Language Skills (JTLS), 5(3), 23-40.

Morell, T. (2002). La interacción en la clase magistral: rasgos lingüísticos del discurso interactivo en inglés. Unpublished PhD dissertation. Alacant, Spain: Universitat d'Alacant.

Morell, T. (2004). Interactive lecture discourse for university EFL students. English for Specific Purposes, 23, 325-338.

Morell, T. (2007). What enhances EFL students' participation in lecture discourse? Student, lecturer and discourse perspectives. Journal of English for Academic Purposes, 6, 222237.

Morell, T. (2013). Communicating research at international conferences: A multimodal analysis of an intercultural or a disciplinary specific genre. In A. Lyda \& K. Warchał (Eds.), Occupying Niches: Interculturality, Cross-culturality and Acculturality in Academic Research (pp. 153-162). Switzerland: Springer International Publishing.

Morell, T. (2015). International conference paper presentations: A multimodal analysis to determine effectiveness. English for Specific Purposes, 37, 137-150.

Moreno, A. I. (1997). Genre Constraints Across Languages: Casual Metatext in Spanish and English Ras. English for Specific Purposes, 16(3), 161-179.

Morrison, J. W. (1974). An investigation of problems in listening-comprehension encountered by overseas students in the first year of postgraduate studies in the University of Newcastle upon Tyne and the implications for teaching. Unpublished M.Ed. dissertation. Newcastle upon Tyne, UK: University of Newcastle upon Tyne.

Müller, C. (2009). Gesture and language. In K. Malmkjaer (Ed.), Routledge's Linguistics Encyclopedia (pp. 214-217). London: Routledge. 
Müller, C., \& Cienki, A. (2009). Words, gestures, and beyond: Forms of multimodal metaphor in the use of spoken language. In C. J. Forceville \& E. Urios-Aparisi (Eds.), Multimodal Metaphor (pp. 297-328). Berlin and New York: Mouton de Gruyter.

Muntigl, P. (2004). Modelling multiple semiotic systems: the case of gesture and speech. In E. Ventola, C. Cassily, \& M. Kaltenbacher (Eds.), Perspectives on multimodality (pp. 3150). Amsterdam: John Benjamins.

Murillo, S. (2012). The use of reformulation markers in Business Management research articles: an intercultural analysis. International Journal of Corpus Linguistics, 17(1), 6490.

Myers, G. (1989). The pragmatics of politeness in scientific articles. Applied Linguistics, 10, $1-35$.

Myers, G. (1992). Texts books and the sociology of scientific knowledge. English for Specific Purposes, 11(1), 3-17.

Nesi, H., \& Basturkmen, H. (2006). Lexical bundles and discourse signalling in academic lectures. International Journal of Corpus Linguistics, 11, 283-304.

Nichols, K. A., \& Champness, B. G. (1971). Eye gaze and the GSR. Journal of Experimental Social Psychology, 7(6), 623-626.

Nilson, L. B. (2016). Teaching at Its Best: A Research-Based Resource for College Instructors (4th ed.). New York: Jossey-Bass.

Noble, W. (2010). Understanding Metadiscoursal Use: Lesons from a "Local" Corpus of Learner Academic Writing. Nordic Journal of English Studies, 9(2), 145-169.

Norman, D. A. (1988). The Psychology of Everyday Things. New York: Doubleday.

Norris, S. (2004). Analyzing Multimodal Interaction. A methodological framework. New York: Routledge. 
Norris, S. (2006). Multiparty interaction: A multimodal perspective on relevance. Discourse Studies, 8(3), 101-115.

Norris, S. (2011). Indentity in (Inter)action. Introducing Multimodal Interaction Analysis. Göttingen: De Gruyter Mouton.

Norris, S. (2013). What is a mode? Smell, olfactory perception, and the notion of mode in multimodal mediated theory. Multimodal Communication, 2(2), 155-169.

Norris, S. (2014). Modal Density and Modal Configurations. In C. Jewitt (Ed.), The Routledge Handbook of Multimodal Analysis (2nd ed., pp. 86-99). New York: Routledge.

Norris, S. (2015a). Multimodal Interaction - Language and Modal Configurations. In N.-M. Klug \& H. Stöckl (Eds.), Handbuch Sprache im multimodalen Kontext (pp. 121-142). Berlin \& Boston: De Gruyter Mouton.

Norris, S. (2015b). Multimodality. Critical Concepts in Linguistics. London \& New York: Routledge.

Norris, S. (2016). Concepts in multimodal discourse analysis with examples from video conferencing. Yearbook of the Poznań Linguistic Meeting, 2, 141-165.

Norris, S. (2017). Scales of action: An example of driving and car talk in Germany and North America. Text and Talk, 37(1), 117-139.

Norris, S., \& Jones, R. H. (2005a). Discourse in action: Introducing mediated discourse analysis. New York: Routledge.

Norris, S., \& Jones, R. H. (2005b). Introducing mediated action. In S. Norris \& R. H. Jones (Eds.), Discourse in Action: Introducing Mediated Discourse Analysis (pp. 15-19). London: Routledge.

Norris, S., \& Makboon, B. (2015). Objects, Frozen Actions, and Identity: A Multimodal (Inter)action Analysis. Multimodal Communication, 4(1), 43-59. 
Norte Fernández-Pacheco, N. (2016a). Multimodal digital tools and EFL audio-visual comprehension: Student's attitudes towards vodcasts. Language Value Journal, 8(1), 49-76.

Norte Fernández-Pacheco, N. (2016b). The orchestration of modes and EFL audio-visual comprehension: A multimodal discourse analysis of vodcasts. Unpublished PhD dissertation. Alacant, Spain: Universitat d'Alacant.

Northedge, A., \& McArthur, J. (2009). Guiding students into a discipline. The significance of the teacher. In C. Kreber (Ed.), Teaching and Learning Within and Beyond Disciplinary Boundaries (pp. 108-118). New York, New York, USA: Routledge.

Nursyuhada, Z., Nursuhaila, I., Noor, H. R., Maisarah, N., Norhartini, A., \& Nurul, N. R. (2014). ESL Writing Strategies across Disciplines among Diploma Students. International Journal of Technical Research and Applications, 10, 57-60.

O'Connor, J. D., \& Arnold, G. F. (1973). Introduction of colloquial English. Bristol: Longman Group Ltd.

O'Halloran, K. (1998). Classroom discourse in mathematics: A multisemiotic analysis. Linguistics and Education, 19(3), 359-388.

O'Halloran, K. (2003). Intersimiosis in mathematics and science. Grammatical metaphor and semiotic metaphor. In A. Simon-Vandenbergen, M. Taverniers, \& L. J. Ravelli (Eds.), Grammatical Metaphor: Views from systemic functional linguistics (pp. 337365). Amsterdam \& Philadelphia: John Benjamins.

O'Halloran, K. (2004a). Multimodal discourse analysis: Systemic functional perspectives. London: Continuum.

O'Halloran, K. (2004b). Visual semiosis in film. In K. O'Halloran (Ed.), Multimodal Discourse Analysis: Systemic functional perspectives (pp. 109-130). London \& New York: Continuum. 
O'Halloran, K. (2005). Mathematical discourse: Language, symbolism and visual images. London: Continuum.

O'Halloran, K. (2007). Systemic Functional Multimodal Discourse Analysis (SF-MDA) approach to mathematics, grammar and literacy. In A. McCabe, M. O’Donnell, \& R. Whittaker (Eds.), Advances in Language and Education (pp. 75-100). London: Continuum.

O'Halloran, K. (2008). Systemic functional-multimodal discourse analysis (SF-MDA): Constructing ideational meaning using language and Visual Imagery. Visual Communication, 7(4), 443-475.

O'Halloran, K. (2011). Multimodal discourse analysis. In K. Hyland \& B. Paltridge (Eds.), Companion to Discourse (pp. 120-137). London: Continuum.

O'Halloran, K., Podlasov, A., Chua, A., \& E, M. K. L. (2012). Interactive software for multimodal analysis. Visual Communication, 11(3), 363-381.

O’Halloran, K., Tan, S., \& E, M. K. L. (2017). Multimodal analysis for critical thinking. Learning, Media and Technology, 42(2), 147-170.

O'Halloran, K., Tan, S., \& Smith, B. A. (2016). Multimodal approaches to English for Academic Purposes. In K. Hyland \& P. Shaw (Eds.), The Routledge Handbook of English for Academic Purposes (pp. 256-269). London \& New York: Routledge.

O’Halloran, K., Tan, S., Wignell, P., Bateman, J. A., Pham, D.-S., Grossman, M., \& Vande Moere, A. (2016). Interpreting text and image relations in violent extremist discourse: A mixed methods approach for big data analytics. Terrorism and Political Violence, 121. doi:10.1080/09546553.2016.1233871

O’Malley, J. M., Chamot, A. U., \& Cüpper, L. (1989). Listening Comprehension Strategies in Second Language Acquisition. Applied Linguistics, 10, 418-437. 
O’Rourke, J., Main, S., \& Cooper, M. (2014). Student perceptions of online interactive versus traditional lectures; or how I managed not to fall asleep with my eyes open. MERLOT Journal of Online Learning and Teaching, 10(3), 405-418.

O'Toole, M. (1994). The Language of Displayed Art (1st ed.). London: Leicester University Press.

O'Toole, M. (2004). Opera Ludentes: The Sydney Opera House at work and play. In K. O’Halloran (Ed.), Multimodal Discourse Analysis (pp. 11-27). London \& New York: Continuum.

O'Toole, M. (2011). The Language of Displayed Art (2nd ed.). London \& New York: Routledge.

Ozturk, I. (2007). The textual organization of research article introductions in applied linguistics: Variability within a single discipline. English for Specific Purposes, 26, 2538.

Palmer Silveira, J. C. (2002). Defining structure in business presentations: linguistic features. In M. C. Campoy \& M. P. Safont (Eds.), Proposals and Resources for the Development of Oral Communication Skills (pp. 185-202). Castelló de la Plana: Universitat Jaume I.

Palmer Silveira, J. C. (2004). Delivery Strategies in Classroom Lectures: Organising the Message. In P. Garcés Conejos, R. Gómez Morón, L. Fernández Amaya, \& M. Padilla Cruz (Eds.), Current Trends in Intercultural, Cognitive and Social Pragmatics (pp. 97114). Sevilla: Editorial Kronos.

Paltridge, B. (1997). Genres, Frames and Writing in Research Settings. Amsterdam/Philadelphia: John Benjamins.

Paltridge, B. (2005). Discourse analysis: An Introduction. London \& New York: Continuum. 
Paltridge, B. (2013). Genre and English for specific purposes. In B. Paltridge \& S. Starfield (Eds.), The handbook of English for Specific Purposes (pp. 347-366). New York: WileyBlackwell.

Pang, K. M. A. (2004). Making histori in "From Colony to Nation": A multimodal analysis of a museum exhibition in Singapore. In K. O'Halloran (Ed.), Multimodal Discourse Analysis (pp. 28-54). London \& New York: Continuum.

Pérez-Llantada, C. (2007). Native and Non-native English Scholars Publishing Research Internationally: a Small-scale Study on Authorial (In)visibility. Journal of Applied Linguistics, 4(2), 217-238.

Pérez-Llantada, C. (2010). The Discourse Functions of Metadiscourse in Published Academic Writing: Issues of Culture and Language. Nordic Journal of English Studies, 9(2), 4168.

Pérez-Llantada, C., \& Ferguson, G. (2006). English as a glocalization phenomenon: Observations from a linguistic microcosm. València: Universitat de València.

Pirini, J. (2013). Analysing business coaching: Using modal density as a methodological tool. Multimodal Communication, 2(2), 195-215.

Pirini, J. (2014). Producing Shared Attention/Awareness in High School Tutoring. Multimodal Communication, 3(2), 163-179.

Pirini, J. (2015). Research into Tutoring: Exploring Agency and Intersubjectivity. Unpublished PhD dissertation. Auckland, New Zealand: Auckland University of Technology.

Pisanski Peterlin, A. (2008). Translating metadiscourse in research articles. Across Languages and Cultures, 9(2), 205-218.

Pisanski Peterlin, A. (2010). Hedging devices in Slovene-English Translation: A Corpus-Based Study. Nordic Journal of English Studies, 9(2), 171-193. 
Poos, D., \& Simpson, R. (2002). Cross-disciplinary comparisons of hedging: some findings from the Michigan Corpus of Academic Spoken English. In R. Reppen, S. M. Fitzmaurice, \& D. Biber (Eds.), Using corpora to explore linguistic variation (pp. 3-23). Amsterdam: John Benjamins.

Poppi, F. (2004). Boosters and hedges: two sides of the same coin? A case study of a small corpus of economics textbooks. In L. Anderson \& J. Bamford (Eds.), Evaluation in oral and written academic discourse (pp. 137-150). Rome: Office Edizioni.

Potts, C. (2015). Presupposition and implicature. In S. Lappin \& C. Fox (Eds.), The handbook of Contemporary Semantic Theory (2nd ed., pp. 168-202). Oxford: Wiley-Blackwell.

Poyatos, F. (2002). Nonverbal communication across disciplines. Volume II. Paralanguage, kinesics, silence, personal and environmental interaction. Amsterdam: John Benjamins.

Psathas, G. (1990). The organization of talk, gaze, and activity in a medical interview. In G. Psathas (Ed.), Interaction competence. Studies in ethnomethodology (pp. 205-230). Washington: International Institute for ethnomethodology and Conversation Analysis \& University Press of America.

Querol-Julián, M. (2010). Multimodality in discussion sessions: corpus compilation and pedagogical use. Language Value Journal, 2(1), 1-26.

Querol-Julián, M. (2011a). Discussion sessions in specialised conference paper presentations. A multimodal approach to analyse evaluation. Unpublished PhD dissertation. Castelló de la Plana, Spain: Universitat Jaume I.

Querol-Julián, M. (2011b). Evaluation in discussion sessions of conference paper presentations: A multimodal approach. Saarbrücken: LAP Lambert Academic Publishing.

Querol-Julián, M., \& Fortanet-Gómez, I. (2012). Multimodal evaluation in academic discussion sessions: How do presenters act and react? English for Specific Purposes, $31,271-283$. 
Rabe-Hemp, C., Woollen, S., \& Humiston, G. S. (2009). A comparative analysis of student engagement, learning, and satisfaction in lecture hall and online learning settings. Quarterly Review of Distance Education, 10(2), 207-218.

Race, P. (1993). Never Mind the Teaching Feel the Learning. Birmingham: SEDA.

Race, P. (2001). Using Feedback to Help Students Learn. New York: Higher Education Academy.

Räisänen, C. (1999). The conference forum as a system of genres: a sociocultural study of academic conference practices in automotive crash-safety engineering. Göteborg, Sweden: Acta Universitatis Gothoburgensis.

Ravelli, L. J., \& Stenglin, M. (2008). Feeling space: interpersonal communicationa and spatial semiotics. In G. Antos \& E. Ventola (Eds.), Interpersonal communication handbook of applied linguistics: volume 2 (pp. 355-396). Berlin: Mouton de Gruyter.

Revell, A., \& Wainwright, E. (2009). What Makes Lectures "Unmissable"? Insights into Teaching Excellence and Active Learning. Journal of Geography in Higher Education, 33(2), 209-223.

Richards, J. C. (1983). Listening comprehension: approach, design, procedure. Tesol Quarterly, 17(29), 219-240.

Richmond, V., \& McCroskey, J. (2000). Nonverbal behavior in interpersonal relations (4th ed.). Needham Heights, MA: Allyn \& Bacon.

Roach, P., Stibbard, R., Osborne, J., Arnfield, S., \& Setter, J. (1998). Transcription of prosodic and paralinguistic features of emotional speech. Journal of the International Phonetic Association, 28, 83-94.

Rohlfing, K., Loehr, D., Duncan, S., Brown, A., Franklin, A., Kimbarra, I., ... Wellinghoff, S. (2006). Comparison of multimodal annotation tools: Workshop report. OnlineZeitschrift Zur Verbalen Interaktion, 7, 99-123.

Rost, M. (2002). Teaching and researching listening. London: Longman. 
Rounds, P. (1987). Characterizing successful classroom discourse for NNS teaching assistant training. Tesol Quarterly, 21(4), 643-669.

Rowley-Jolivet, E., \& Carter-Thomas, S. (2005). The rhetoric of conference presentation introductions: context, argument and interaction. IJAL, 15, 45-70.

Ruiz-Garrido, M. F. (2015). Intensifying Adverbs in Academic Spoken Discourse: A Contrastive Study Between English and Spanish. In B. Crawford Camiciottoli \& I. Fortanet-Gómez (Eds.), Multimodal Analysis in Academic Settings: From Research to Teaching (pp. 61-82). New York, New York, USA: Routledge.

Ruiz-Garrido, M. F., \& Fortanet-Gómez, I. (2008). El Lenguaje de Las Comunicaciones. In I. Fortanet-Gómez (Ed.), Hablar inglés en la universidad: Docencia e investigación (pp. 125-157). Oviedo: Septem ediciones.

Ruiz-Garrido, M. F., \& Palmer Silveira, J. C. (forthcoming). Assessing audience's impressions using Emotiv EPOC+.

Ruiz-Madrid, M. N., \& Fortanet-Gómez, I. (2016). A model for a multimodal analysis of asides in conference plenary lectures. E-Aes/a, 2, 157-168.

Ryan, A., Cohn, J. F., Lucey, S., Saragih, J., Lucey, P., De la Torre, F., \& Rossi, A. (2009). Automated Facial Expression Recognition System. In 43rd Annual 2009 International Carnahan Conference on Security Technology; 5-8 Oct. (pp. 172-177). Zurich, Switzerland.

Sacks, H., Schegloff, E. A., \& Jefferson, G. (1974). A Simplest Systematics for the Organization of Turn-Taking for Conversation. Language, 50(4), 696-735.

Salas, M. D. (2015). Reflexive metadiscourse in research articles in Spanish: Variation across three disciplines (Linguistics, Economics and Medicine). Journal of Pragmatics, 77, 2040. 
Salas Valdebenito, M. (2015). Una propuesta de taxonomía de marcadores metadiscursivos para el discurso académico-científico escrito en español. A taxonomy of metadiscourse in written scientific Spanish. Revista Signos. Estudios de Lingüística, 48(87), 95-120.

Samraj, B. (2002). Introductions in research articles: Variations across disciplines. English for Specific Purposes, 21, 1-17.

Scheflen, A. E. (1964). The significance of posture in communication systems. Psychiatry, 27, 316-331.

Schiffrin, D. (1980). Meta-Talk: Organizational and evaluative brackets in discourse. Sociological Inquiry: Language and Social Interaction, 50, 199-236.

Schiffrin, D., Tannen, D., \& Hamilton, H. (2001). The Handbook of Discourse Analysis. Malden, MA: Blackwell.

Schleef, E. (2008). The "lecturer's OK" revisited: changing discourse conventions and the influence of academic division. American Speech, 83, 62-84.

Schleppegrell, M. J. (2012). Systemic functional linguistics. In J. P. Gee \& M. Handford (Eds.), The Routledge Handbook of Discourse Analysis (pp. 21-34). London \& New York: Routledge.

Schmitt, R. (2007). Koordination: Analysen zur multimodalen Interaktion. Tübingen, Germany: Narr.

Schultze-Mosgau, S., Zielinski, T., \& Lochne, J. (2004). Interactive, web-based e-lectures with a multimedia online examination. Medical Education, 38, 1184.

Scollon, R. (1998). Mediated Discourse as Social Interaction. London; New York: Longman.

Scollon, R. (2001). Mediated discourse: the nexus of practice. London; New York: Longman.

Scollon, R., \& Scollon, S. (2003). Discourse in place: Language in the material world. New York: Routledge. 
Scollon, R., \& Scollon, S. (2004). Nexus Analysis: Discourse and the Emerging Internet. London: Routledge.

Scollon, S. (2005). Agency distributed through time, space and tools: Bentham, Babbage and the census. In S. Norris \& R. H. Jones (Eds.), Discourse in Action: Introducing Mediated Discourse Analysis (pp. 172-182). London \& New York: Routledge.

Searle, J. (1969). Speech acts. Cambridge: Cambridge University Press.

Searle, J. (1976). The classification of illocutionary acts. Language in Society, 5(1), 1-24.

Shepherd, M., \& Watters, C. (1998). The Evolution of Cybergenres. In Proceeding HICSS '98. Proceedings of the Thirty-First Annual Hawaii International Conference on System Sciences - Volume 2. January 6-9, 1998. (pp. 97-109).

Silverstein, M. (1976). Shifters, linguistic categories, and cultural description. In K. Basso \& H. Selby (Eds.), Meaning in anthropology (pp. 11-55). Albuquerque: University of New Mexico Press.

Silverstein, M. (1993). Metapragmatic discourse and metapragmatic function. In J. A. Lucy (Ed.), Reflexive language (pp. 33-58). Cambridge, England: Cambridge University Press.

Simpson, R. (2006). Academic speech across disciplines: lexical and phraseological distinctions. In K. Hyland \& M. Bondi (Eds.), Academic Discourse Across Disciplines (pp. 295-316). Bern: Peter Lang.

Simpson, R. L. (1988). Essentials of Symbolic Logic. Canada: Broadview Press.

Sinclair, J. (1981). Planes of discourse. In S. Rizvi (Ed.), The Two-fold Voice: Essays in Honour of Ramesh Mohan (pp. 70-89). Salzburg: Salzburg University Press.

Sinclair, J. (2005). Language as a string of beads: Discourse and the M-word. In E. TogniniBonelli \& G. Del Lungo Camiciotti (Eds.), Strategiesin academic discourse (pp. 163168). Amsterdam: John Benjamins. 
Sloetjes, H., \& Wittenburg, P. (2008). Annotation by category - ELAN and ISO DCR. In Proceedings of the 6th International Conference on Language Resources and Evaluation (LREC 2008). (pp. 816-820).

Smith, M. S. (2009). Opening education. Science, 323, 89-93.

Stenglin, M. (2009). Space odyssey: Towards a social semiotic model of 3D space. Visual Communication, 8(1), 35-64.

Stenglin, M. (2011). Spaced out: An evolving cartography of a visceral semiotic. In S. Dreyfus, S. Hood, \& M. Stenglin (Eds.), Semiotic margins: Meaning in multimodalitites (pp. 73-100). London: Continuum.

Stenglin, M. (2014). Space and communication in exhibitions: unravelling the nexus. In C. Jewitt (Ed.), The Routledge Handbook of Multimodal Analysis (2nd ed., pp. 431-439). London \& New York: Routledge.

Stöckl, H. (2014). Semiotic paradigms and multimodality. In C. Jewitt (Ed.), The Routledge Handbook of Multimodal Analysis (pp. 274-286). London: Routledge.

Strodt-López, B. (1991). Tying it all in: Asides in university lectures. Applied Linguistics, 12(2), 117-140.

Strongman, K. T., \& Champness, B. G. (1969). Dominance hierarchies and conflict in eye contact. Acta Psychologica, 28, 376-386.

Stubbs, M. (1983). Discourse Analysis: The Sociolinguistic Analysis of Natural Language. Chicago, IL: University of Chicago Press.

Sun, Y. C., \& Yang, H. C. (2012). Do language proficiency and lecture comprehension matter? OpenCourseWare lectures for vocabulary learning. CALICO Journal, 29(4), 663-678.

Swales, J. M. (1981). Aspects of article introductions. Aston ESP Research Reports 1. Birmingham: University of Aston, Language Studies Unit. 
Swales, J. M. (1983). Developing materials for writing scholarly introductions. In R. R. Jordan (Ed.), Case Studies in ELT (pp. 188-200). London: Collins ELT.

Swales, J. M. (1984). Research into the structure of introductions to journal articles and its application to the teaching of academic writing. In R. Williams, J. M. Swales, \& J. Kirkman (Eds.), Common Ground: Shared Interests in ESP and Communication Studies. ELT Documents 117 (pp. 77-86). Oxford: Pergamon.

Swales, J. M. (1990). Genre Analysis: English in Academic and Research Settings. Cambridge: Cambridge University Press.

Swales, J. M. (1996). Occluded genres in the academy: The case of the submission letter. In E. Ventola \& A. Mauranen (Eds.), Academic Writing: Intercultural and Textual Issues (pp. 45-58). Amsterdam/Philadelphia: John Benjamins.

Swales, J. M. (2001). Metatalk in American academic talk: The cases of point and thing. Journal of English Linguistics, 29, 34-54.

Swales, J. M. (2004). Research Genres: Exploration and Applications. Cambridge: Cambridge University Press.

Swales, J. M., \& Burke, A. (2003). "It's really fascinating work": differences in evaluative adjectives across academic registers. In P. Leistyna \& C. F. Meyer (Eds.), Corpus Analysis: language structure and language use (pp. 1-18). Amsterdam: Rodopi.

Tan, H. (2012). A Proposed Metadiscourse Framework for Lay ESL writers. World Applied Sciences Journal, 20(1), 1-5.

Tan, S. (2009). A systemic functional framework for the analysis of corporate television advertisments. In E. Ventola \& A. J. M. Guijarro (Eds.), The world told and the world shown: Multisemiotic issues (pp. 157-182). Hampshire: Palgrave Macmillan.

Tan, S. (2010). Modelling engagement in a web-based advertising campaing. Visual Communication, 9(1), 91-115. 
Tan, S., O'Halloran, K., \& Wignell, P. (2016). Multimodal Research: Addressing the Complexity of Multimodal Environments and the Challenges for CALL. ReCALL, 28(3), 253-273.

Tan, S., Smith, B. A., \& O'Halloran, K. (2015). Online leadership discourse in higher education: A digital multimodal discourse perspective. Discourse and Communication, 9(5), 559-584.

Tannen, D. (1982). Spoken and Written Language: Exploring Orality and Literacy. Norwood, NJ: Ablex.

Tannen, D. (1984). Conversational style: Analyzing talk among friends. Norwood, NJ: Ablex.

Taylor, S. (2013). What is discourse analysis? London \& New York: Bloomsbury Academic.

Tench, P. (1996). The intonation systems of English. London: Cassell.

Thesen, L. (2016). The Past in the Present: Modes, Gaze and Changing Communicative Practices in Lectures. In A. Archer \& E. O. Breuer (Eds.), Multimodality in Higher Education (pp. 31-52). Leiden, The Netherlands: Koninklijke Brill NV.

Thibault, P. J. (1991). Social semiotics as praxis: Text, social meaning making, and Nabokov's Ada. Minneapolis: University of Minnesota Press.

Thomas, S., \& Hawes, T. (1994). Reporting verbs in medical journal articles. English for Specific Purposes, 13, 129-148.

Thompson, G. (2001). Interaction in Academic Writing: Learning to Argue with the Reader. Applied Linguistics, 22, 58-78.

Thompson, G., \& Muntigl, P. (2008). Systemic Functional Linguistics: An Interpersonal Perspective. In G. Antos \& E. Ventola (Eds.), Handbook of Interpersonal Communication (pp. 107-132). Berlin: Mouton de Gruyter.

Thompson, G., \& Thetela, P. (1995). The sound of one hand clapping: the management of interaction in written discourse. TEXT, 15(1), 103-127. 
Thompson, J. (1992). The Concept of Culture. London: Polity Press.

Thompson, S. (1994). Frameworks and contexts: a genre-based approach to analysing lecture introductions. English for Specific Purposes, 13(2), 171-187.

Thompson, S. (2002). "As the Story Unfolds": The Uses of Narrative in Research Presentations. In E. Ventola, C. Shalom, \& S. Thompson (Eds.), The Language of Conferencing (pp. 147-167). Frankfurt am Main: Peter Lang.

Thompson, S. E. (2003). Text-structuring metadiscourse, intonation and the signaling of organization in academic lectures. Journal of English for Academic Purposes, 2, 5-20.

Toumi, N. (2009). A Model for the Investigation of Reflexive Metadiscourse in Research Articles. Language Studies Working Papers, 1, 64-73.

Trager, G. L. (1958). Paralanguage: a first approximation. Studies in Linguistics, 13, 1-12.

Tseng, C. (2008). Coherence and cohesive harmony in filmic text. In L. Unsworth (Ed.), Multimodal Semiotics: Functional analysis in contexts of education (pp. 87-104). London: Continuum.

Tseng, C., \& Bateman, J. A. (2010). Chain and choice in filmic narrative: An analysis of multimodal narrative construction in "The Fountain." In C. R. Hoffman (Ed.), Narrative revisited: Telling a story in the age of new media (pp. 213-244). Amsterdam: John Benjamins.

Twigg, C. A. (1999). Improving Learning and Reducing Costs: Redesigning Large-Enrollment Courses. Troy, NY.

Tyler, A. (1992). Discourse Structure and the Perception of Incoherence in the International Teaching Assistants' Spoken Discourse. Tesol Quarterly, 26, 713-729.

UNESCO, \& Commonwealth of Learning. (2015). Guidelines for Open Educational Resources (OER) in Higher Education. Paris \& Vancouver: UNESCO \& Commonwealth of Learning. 
Unsworth, L. (2006). Towards a metalanguage for multiliteracies education: Describing the meaning-making resources of language-image interaction. English Teaching: Practice and Critique, 5(1), 55-76.

Urios-Aparisi, E. (2009). Interaction of multimodal metaphor and metonymy in TV commercials: Four case studies. In C. J. Forceville \& E. Urios-Aparisi (Eds.), Multimodal Metaphor (pp. 95-118). Berlin and New York: Mouton de Gruyter.

Valeiras-Jurado, J. (2017). A Multimodal Approach to Persuasion in Oral Presentations. The case of conference presentations, research dissemination talks and product pitches. Unpublished PhD dissertation. Castelló de la Plana, Spain \& Ghent, Belgium: Universitat Jaume I \& Ghent University.

Valero-Garcés, C. (1996). Contrastive rhetoric: Metatext in Spanish-English economics texts. English for Specific Purposes, 15, 279-294.

van der Merwe, L. J., van Zyl, G. J., Nel, M. M., \& Joubert, G. (2014). How we see "Y": South African health sciences students' and lecturers' perceptions of Generation Y students. AJHPE, 6(1), 10-16.

van Dijk, T. A. (1977). Pragmatic macrostructures in discourse and cognition. In M. de Mey, R. Pinxten, M. Poriau, \& F. Vandamm (Eds.), The cognitive viewpoint. Communication and cognition (pp. 99-113). Ghent: University of Ghent.

van Dijk, T. A. (1980). Macrostructures. Hillsdale, NJ: Lawrence Erlabaum.

van Dijk, T. A. (1996). Discourse, power and access. In R. C. Caldas-Coulthard \& M. Coulthard (Eds.), Texts and practices: readings in critical discourse analysis (pp. 84104). London: Routledge \& Kegan Paul.

van Leeuwen, T. (1999). Speech, Music, Sound. London: Macmillan.

van Leeuwen, T. (2005). Introducing Social Semiotics. London: Routledge.

van Leeuwen, T. (2008). Discourse and Practice: New Tools for Critical Discourse Analysis. Oxford: Oxford University Press. 
van Leeuwen, T. (2010). The Language of Colour: An introduction. London: Routledge.

van Leeuwen, T. (2012). Multimodality and multimodal research. In E. Margolis \& L. Pauwels (Eds.), The Sage Handbook of Visual Research Methods (pp. 549-569). London: Sage.

van Leeuwen, T. (2013). Critical Analysis of Multimodal Discourse. In C. A. Chapelle (Ed.), The Encyclopedia of Applied Linguistics (pp. 1416-1421). Hoboken, NJ: Blackwell Publishing Ltd.

van Leeuwen, T. (2014). Colour: code, mode, modality. The case of film and video. In C. Jewitt (Ed.), The Routledge Handbook of Multimodal Analysis (2nd ed., pp. 397-409). London: Routledge.

van Valin, R. D., \& LaPolla, R. J. (1997). Syntax: Structure, Meaning and Function. Cambridge: Cambridge University Press.

Vande Kopple, W. J. (1985). Some Exploratory Discourse on Metadiscourse. College Composition and Communication, 36(1), 82-93.

Vande Kopple, W. J. (2002). Metadiscourse, discourse, and issues in composition and rhetoric. In E. Bartion \& G. Stygall (Eds.), Discourse studies in composition (pp. 91113). Creeskill, New Jersey: Hampton Press.

Vande Kopple, W. J. (2012). The importance of studying metadiscourse. Applied Research in English, 1(2), 37-44.

Varó Alcaraz, E. (2000). El inglés profesional y académico. Madrid: Alianza Editorial.

Vassileva, I. (1998). Who am I/who are we in academic writing?: A contrastive analysis of authorial presence in English, German, French, Russian and Bulgarian. Journal of Applied Linguistics, 8(2), 163-185.

Vassileva, I. (2000). Who is the Author? A Contrastive Analysis of Authorial Presence in English, German, French, Russian and Bulgarian Academic Discourse. Sankt Augustin: Asgard Verlag. 
Ventola, E., Charles, C., \& Kaltenbacher, M. (2004). Perspectives on multimodality. Amsterdam: John Benjamins.

Villanueva, M. L., Luzón, M. J., \& Ruiz-Madrid, M. N. (2008). Understanding digital genres as semiotic artefacts: meaning and cognition beyond standardised genres. Computers and Composition, Online, (Spring Issue). Retrieved from http://cconlinejournal.org/DigitalGenres/

Vygotsky, L. S. (1978). Mind in Society. Cambridge, MA: Harvard University Press.

Vygotsky, L. S. (1986). Feminist Practice and Poststructuralist Theory. Oxford: Blackwell.

Waggoner, M. (1984). The new technologies versus the lecture tradition in higher education: is change possible? Educational Technology, 24(3), 7-12.

Watts, R. J. (1989). Taking the Pitcher to the "Well": Native Speakers' Perception of their Use of Discourse Markers in Conversation. Journal of Pragmatics, 13, 203-237.

Waugh, G. H., \& Waugh, R. F. (1999). The new technologies versus the lecture tradition in higher education: is change possible? Australian Journal of Teacher Education, 24(1), $35-51$.

Weinberg, A., Fukawa-Connelly, T., \& Wiesner, E. (2013). Instructor gestures in proof-based mathematics lectures. In M. Martínez \& A. Castro Superfine (Eds.), Proceedings of the 35th Annual Meeting of the North American Chapter of the International Group for the Psychology of Mathematics Education (p. 1119). Chicago: The University of Chicago Press.

Wells, J. (2006). English Intonation. Cambridge: Cambridge University Press.

Wertsch, J. V. (1991). Voices of the Mind. Cambridge, MA: Harvard University Press.

Wertsch, J. V. (1994). The primacy of mediated action in sociocultural studies. Mind, Culture and Activity, 1(4), 202-208.

Wertsch, J. V. (1998). Mind as action. New York: Oxford University Press. 
Wertsch, J. V, Tulviste, P., \& Hagstrom, F. (1993). A sociocultural approach to agency. In E. A. Forman, N. Minick, \& C. A. Stone (Eds.), Contexts for Learning: Sociocultural Dynamics in Children's Development (pp. 336-356). New York: Oxford University Press.

West, T. (2009). Music and designed sound. In C. Jewitt (Ed.), The Routledge Handbook of Multimodal Analysis (pp. 284-292). London: Routledge.

Wichman, A. (2000). Intonation in text and discourse: Begginings, middles and ends. London: Longman.

Widdowson, H. G. (1995). Discourse analysis: a critical view. Language and Literature, 4(3), 157-172.

Williams, A., Birch, E., \& Hancock, P. (2012). The impact of online lecture recordings on student performance. Australian Journal of Educational Technology, 28(2), 199-213.

Williams, J. M. (1981). Style: Ten Lessons in Clarity \& Grace. Glenview, IL: Scott, Foresman and Company.

Wittenburg, P., Brugman, H., Russel, A., Klassmann, A., \& Sloetjes, H. (2006). ELAN: a professional framework for multimodality research. In Proceedings of LREC 2006, Fifth International Conference on Language Resources and Evaluation. (pp. 1556-1559).

Wulff, S., Swales, J. M., \& Keller, K. (2009). "We have seven minutes for questions": the discussion sessions from a specialized conference. English for Specific Purposes, 28, 79-92.

Yakhontova, T. (2006). Cultural and Disciplinary Variation in Academic Discourse: The Issue of Influencing Factors. Journal of English for Academic Purposes, 5(2), $153-167$.

Yale University. (2018). Open Yale Courses. Available at http://oyc.yale.edu/ Last accessed January $8^{\text {th }}, 2018$. 
Yang, H. C., \& Sun, Y. C. (2013). It is more than knowledge seeking: examining the effects of OpenCourseWare lectures on vocabulary acquisition in English as a foreign language (EFL) context. Computer Assisted Language Learning, 26(1), 1-20.

Yates, J., \& Orlikowski, W. J. (1992). Genres of organisational communication: a structurational approach to studying communication and media. Academy of Management Review, 17(2), 299-326.

Young, L. (1990). Language as behaviour, language as code. A study of academic English. Amsterdam/Philadelphia: John Benjamins.

Young, L. (1994). University lectures - macro-structure and micro-features. In J. Flowerdew (Ed.), Academic listening: research perspectives. (pp. 159-176). Cambridge: Cambridge University Press.

Yu, N. (2009). Nonverbal and multimodal manifestation of metaphors and metonymies: A case study. In C. J. Forceville \& E. Urios-Aparisi (Eds.), Multimodal Metaphor (pp. 119143). Berlin and New York: Mouton de Gruyter.

Yule, G. (1980). Speakers' topics and major paratones. Lingua, 52, 33-47.

Yus, F. (2009). Visual metaphor versus verbal metaphor: A unified account. In C. J. Forceville \& E. Urios-Aparisi (Eds.), Multimodal Metaphor (pp. 147-172). Berlin and New York: Mouton de Gruyter.

Zhang, Z. (2015). Disagreements in Plenary Addresses as Multimodal Action. In B. Crawford Camiciottoli \& I. Fortanet-Gómez (Eds.), Multimodal Analysis in Academic Settings: From Research to Teaching (pp. 17-38). London: Routledge. 


\section{APPENDICES}

\section{APPENDIX A: CORPUS OF LECTURES}

The appendices to the thesis describe the main corpus and the two sub-corpora employed in my study. Appendix A is made up of the transcriptions of the lectures in the main corpus; it is organized in courses and includes 152 entries for the analyses in Chapter 5 (see description of the main corpus in Section 4.3.2 in the thesis). The transcriptions have been obtained directly from Yale University's OCW1 and are originally organized internally into chapters, which is roughly an organization into topics.

The corpus of lectures may be accessed in the DVD attached. Alternatively, they may be downloaded in the following link ${ }^{15}$ :

https://goo.gl/B5VFqF

15 Last accessed January 8th 2018. 



\section{APPENDIX B: CORPUS OF REPRESENTATIVE LECTURES}

Appendix B consists of six video files corresponding to the sub-corpus of representative lectures for the analyses in chapters 6 and 8 (see Section 4.3.2):

LECTURE 1: C1_L13 (Course 1, Lecture 13)

LECTURE 2: C2_L13 (Course 2, Lecture 13)

LECTURE 3: C3_L15 (Course 3, Lecture 15)

LECTURE 4: C4_L13 (Course 4, Lecture 13)

LECTURE 5: C5_L15 (Course 5, Lecture 15)

LECTURE 6: C6_L15 (Course 6, Lecture 15)

The video files may be accessed in the DVD attached. Alternatively, they may be downloaded in the following link ${ }^{16}$ :

\section{https://goo.gl/mNih1Y}

For the transcriptions of these lectures, please see these lectures in Appendix A.

${ }^{16}$ Last accessed January 8th 2018. 



\section{APPENDIX C: CORPUS OF STRUCTURING SEGMENTS}

Appendix $\mathrm{C}$ is made up of six short video clips that constitute the sub-corpus of structuring segments selected for the analyses in Chapter 7 (see Section 4.3.2):

SEGMENT 1: SS_C1_L13 (Extracted from Course 1, Lecture 13)

SEGMENT 2: SS_C2_L13 (Extracted from Course 2, Lecture 13)

SEGMENT 3: SS_C3_L15 (Extracted from Course 3, Lecture 15)

SEGMENT 4: SS_C4_L13 (Extracted from Course 4, Lecture 13)

SEGMENT 5: SS_C5_L15 (Extracted from Course 5, Lecture 15)

SEGMENT 6: SS_C6_L15 (Extracted from Course 6, Lecture 15)

The corpus of structuring segments may be accessed in the DVD attached. Alternatively, they may be downloaded in the following $\operatorname{link}^{17}$ :

\section{https://goo.gl/ag2mAE}

For the transcriptions of these lectures, please see the lectures from which the segments have been extracted in Appendix A.

17 Last accessed January 8th 2018. 


